\title{
WestVirginiaUniversity
}

THE RESEARCH REPOSITORY @ WVU

Graduate Theses, Dissertations, and Problem Reports

2005

\section{The organ music of Robert Hebble (b.1934)}

John Paul Cappa

West Virginia University

Follow this and additional works at: https://researchrepository.wvu.edu/etd

\section{Recommended Citation}

Cappa, John Paul, "The organ music of Robert Hebble (b.1934)" (2005). Graduate Theses, Dissertations, and Problem Reports. 4137.

https://researchrepository.wvu.edu/etd/4137

This Dissertation is protected by copyright and/or related rights. It has been brought to you by the The Research Repository @ WVU with permission from the rights-holder(s). You are free to use this Dissertation in any way that is permitted by the copyright and related rights legislation that applies to your use. For other uses you must obtain permission from the rights-holder(s) directly, unless additional rights are indicated by a Creative Commons license in the record and/ or on the work itself. This Dissertation has been accepted for inclusion in WVU Graduate Theses, Dissertations, and Problem Reports collection by an authorized administrator of The Research Repository @ WVU.

For more information, please contact researchrepository@mail.wvu.edu. 


\title{
The Organ Music of Robert Hebble (b.1934)
}

\author{
John Paul Cappa
}

\author{
Research Project submitted to \\ The College of the Creative Arts \\ at West Virginia University \\ in partial fulfillment of the requirements \\ for the degree of
}

Doctor of Musical Arts

in

Organ Performance

Dr. William Haller, Chair

Dr. Keith Jackson

Dr. James Miltenberger

Mr. James Held

Morgantown, West Virginia

2005

Keywords: Organ Music; Robert Hebble; Virgil Fox; American Music; Eclecticism;

Jazz Elements

Copyright 2005 John Paul Cappa 


\title{
ABSTRACT \\ THE ORGAN MUSIC OF ROBERT HEBBLE (b. 1934)
}

\author{
John Paul Cappa
}

The purpose of this research project is to provide a stylistic and quasi-theoretical study of Robert Hebble's compositions for organ as a performer's guide. Hebble presently resides in Lake Worth, Florida. He is still composing, accepting commissions, writing articles, playing recitals, and giving workshops.

The organ music of Robert Hebble is a significant contribution to twentiethcentury American organ literature. He has composed in various genres, from simple church service music to solo concert pieces. His organ compositions span his entire career and make use of a wide variety of techniques and styles.

Part I provides information about the composer's life. It discusses his background, education, and professional positions.

Part II discusses Hebble's use of the organ in his writing, particularly his use of the American Classic Organ. This section looks at his approach to registrations, use of pedal, improvisation, pianistic devices, and development of his compositional style. It also explores effects idiomatic to the organ of American designers and builders of the mid- to late twentieth century.

Part III presents an overview of Hebble's organ compositions, grouping his organ works into two categories: chorales and free works. Only published works from 1958 to 1999 will be discussed, not unpublished works or arrangements. The circumstances under which each work or collection was written are discussed. His treatment of hymntunes and use of accompanimental material is examined. The free works and ensemble pieces demonstrate his formal design and the important structural, motivic, and unifying devices that are used. This study will explore Hebble's use of melodic material, motivic treatment, development, tonality, harmony, contrapuntal procedures, rhythm, and form. There are many charts and musical examples.

Part IV, the conclusion, is a summation of the conclusions of each chapter. These are gathered and extended. It essentially discusses Hebble's approach to organ music and puts him into the context of American organ music in the late twentieth century.

The Appendices include lists of Hebble's complete compositional output, both published and unpublished works. There is a discography of recorded organ works to date. Finally, there are specifications for two representative American organs (ACO) for his organ works. 


\section{ACKNOWLEDGMENTS}

The completion of this project would not have been possible without the assistance of several people. First of all, sincere gratitude is expressed to Mr. Robert Hebble, who generously contributed many hours in taped interviews, phone calls and letters, and loaned many of his manuscripts. His cooperation and enthusiasm have made it possible to undertake and complete this project. Appreciation is also expressed to Dr. William Haller for his direction of this project. He has been a source of information, advice, and encouragement throughout this project, giving his time to assist with analyses. Thanks is extended to Professor James Held and Mr. Jack P. Held for assisting previously with grammar and style.

It is also important to express gratitude to Mrs. Jacqueline Free (Murrysville, PA) for her helpful comments and reviews. My gratitude also goes to Dr.Christopher Wilkinson for guiding me to the Internal Review Board and helping me to develop the oral history. My thanks is extended to The Riverside Church of New York City for allowing me time to play and examine the console of the organ, and Frederick Swann for submitting to an interview of Hebble's organ compositions and explaining and examining the console of the Crystal Cathedral organ, the former of which led to Hebble's career.

Thanks is also extended to Mr. Mark Indorf of Capital University in Columbus, Ohio for assisting me with the musical examples. Also I am grateful to Warner Brothers Publications for their kind permission to copy musical examples for this research project, and to Erma Mac Pherson for technical support. 


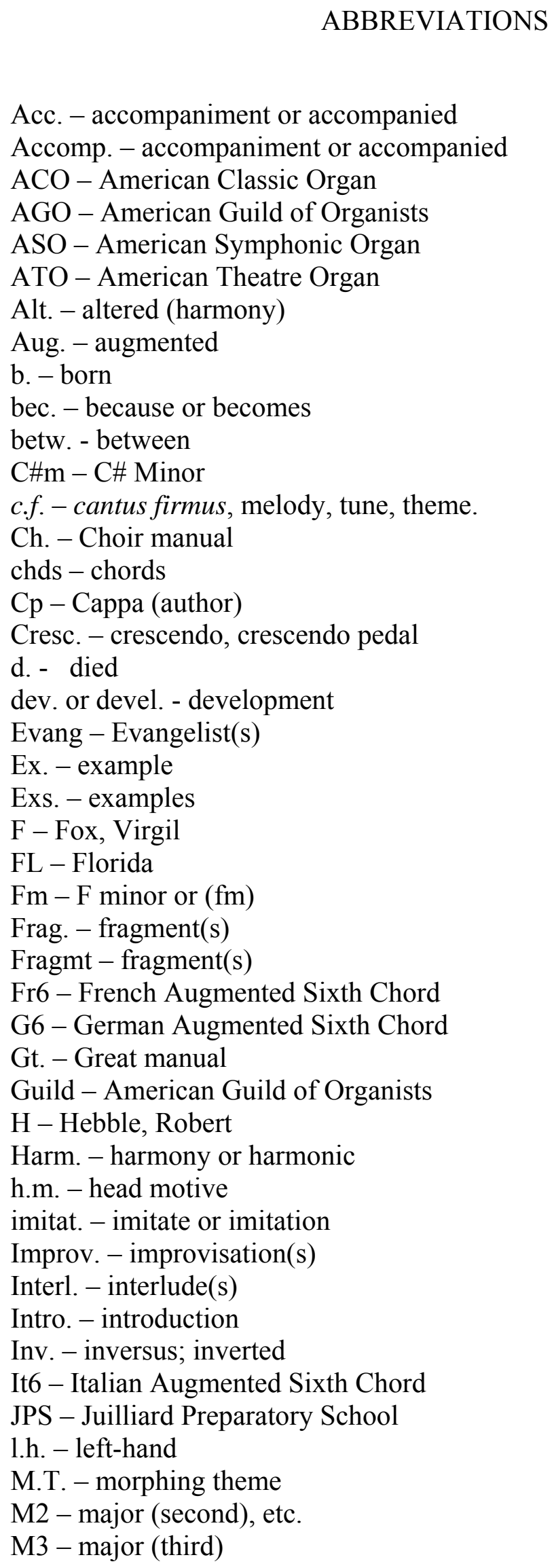

Acc. - accompaniment or accompanied Accomp. - accompaniment or accompanied ACO - American Classic Organ 


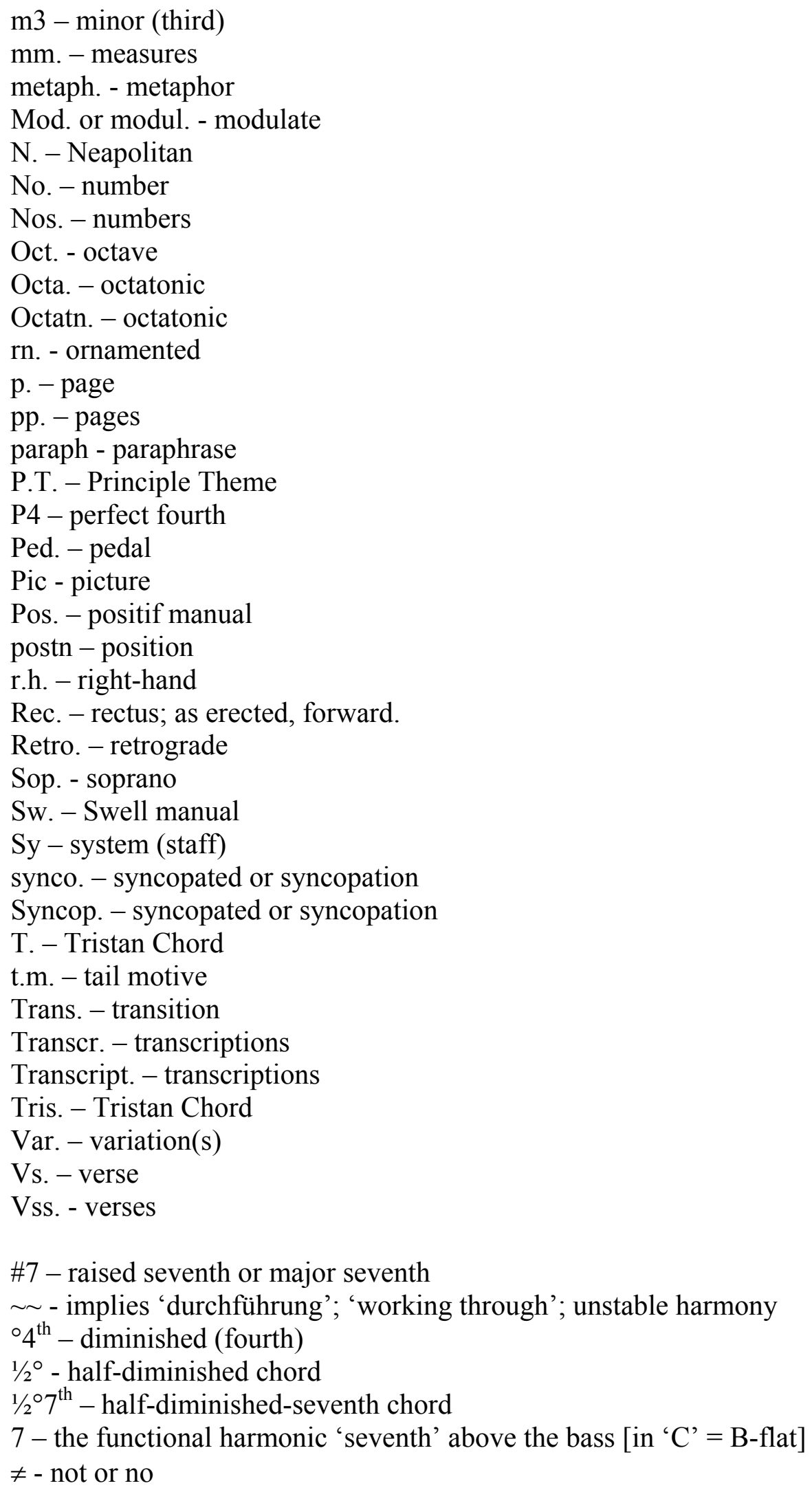




\section{TABLE OF CONTENTS}

Abstract

p. ii

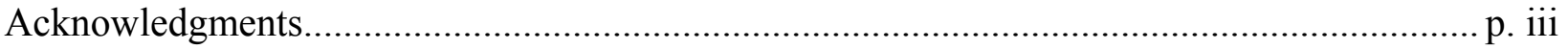

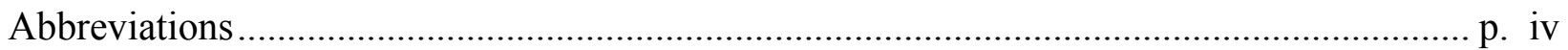

Part I: Biography

Chapter $1 \quad$ Early Childhood ...........................................................................p. 1

Chapter 2 The "Burning Bush Experience" ....................................................p. 8

Chapter 3 Professional Career .......................................................................... 15

Part II: Approach to the Organ

Chapter 4 The American Classic Organ ..........................................................p. 24

Chapter 5 Hebble's Use of the Organ............................................................... 35

Part One .................................................................... 35

Part Two ..................................................................... 42

Part Three................................................................... 57

Chapter 6 Development With Hebble's Compositional Style...........................p. 67

Part III: Analyses (A Descriptive Catalogue)

Chapter 7 A General Overview ..................................................................... 74

Chapter $8 \quad$ The Chorales ................................................................................. 91

Chapter 9 The Free Works...........................................................................p. 205

Part IV: Conclusions

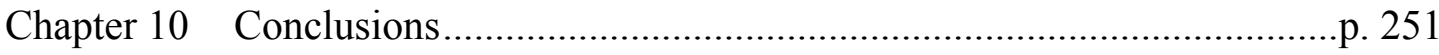

Appendices A $\quad$ List of Complete Works........................................................ 262

B List of Unpublished Works................................................ 270

C Discography …………………....................................... 272

D Specification of The Riverside Church Organ.................... 274

E Specification of the Crystal Cathedral Organ .....................p. 276

F $\quad$ Music Examples............................................................... 281

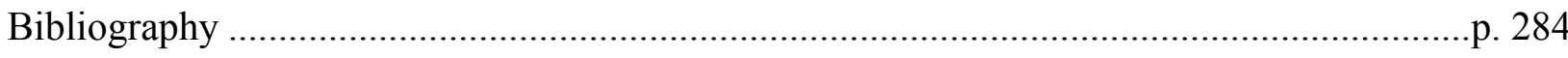




\title{
PART I Biography
}

\author{
The Organ Music of Robert Hebble
}

\section{CHAPTER 1}

\section{Early Childhood}

"I could not imagine selling cars the rest of my life!" - Robert Hebble

Robert Christian Hebble was born February 14, 1934 in Orange, New Jersey. The son of Christian Bartholomew (1902-1985) and Ethel Elizabeth Edwards (1905-1990), Hebble's only sibling was a younger brother named Alan Sherman (b.1940). Neither his father nor his younger brother was musical; in fact, Hebble's father did not like to hear music when he was home. However, Hebble's mother and maternal grandmother were organists. They each worked in local churches, but it was Nellie Edwards (1881-1949), his grandmother, who played in the silent movie theatres. She was a local church organist and organist at the Paramount Theatre in Newark, New Jersey. ${ }^{1}$

Hebble began to play the piano at such an early age that he could not see over the top of the keyboard and, at first, did not know that there were "black notes." He began to play chords right away and used to mark with crayons (on the front of the keys) where his favorite notes (chords) were. Hebble guesses that he was one to one and a half years old at that time. ${ }^{2}$ The piano was his first instrument and his grandmother Edwards was his first teacher. She taught him his first lessons of easy piano works and Hanon exercises

\footnotetext{
${ }^{1}$ Taped interview with Robert Hebble: June 17, 2001, Canton, Ohio by the author: tape one, side 'A'. ${ }^{2}$ Ibid.
} 
used to teach the basics of music. When he was five years old his grandmother took him to her church one Saturday afternoon so that she could practice for Sunday morning services. There was a large Aeolian-Skinner organ at the church, the First Church of Christ Scientist in Orange, New Jersey. Edwards let Hebble sit on the bench at the organ console. Afterwards, she began to show him a little about the organ. He could not reach the pedals, but remembers seeing the various stops and hearing the "beautiful sounds she made." He remembers that she was a "fiery player" and used the trumpets and various organ registrations. This increased his appreciation of the organ. During the hymns, she would play fanfares and interludes and "did exciting things with the hymns." Hebble felt that this was all very interesting to him. ${ }^{3}$

Hebble also maintains that it was legendary Ethel Smith who really "turned him on to the organ" when he was nine years old. Her movies were popular at the box office, and he would go to the theatre all Saturday afternoon to hear Smith's movies, attending them over again several times just to hear the organ portions. Hebble never thought about the organ as much as the piano until that point. When he heard Ethel Smith, the organ became "exciting, rhythmic and colorful;" he felt it was "breath-taking." When he went home, he talked his mother into getting a Hammond organ like Smith's so he could play like her. ${ }^{4}$ According to Hebble, her appeal was her "excitement and enthusiasm for the organ"; and he also said that she was a "personality" for the organ. Even today her movies are enduring "Americana" for the organ. ${ }^{5}$ Hebble eventually studied with Ethel

\footnotetext{
${ }^{3}$ Ibid.

${ }^{4}$ Forty years later, Hebble presented Ethel Smith in concert at his church, First Congregational, in Lake Worth, Florida in 1995. It was the last concert Smith played. It also featured "clips" of Smith's movies. Hebble later found that virtually everyone his age attending the concert, including members of the American Guild of Organists, admitted that Smith was the one who initially influenced their interest in the organ.

${ }^{5}$ Hebble claims not to have purchased any of her editions for the organ, which were published in 1949.
} 
Smith's arranger, Milton Page, who was the organist at the Roxy Theatre in New York City and was a good arranger and theatre organist. Hebble had wanted to learn some of Smith's techniques and ideas. Page died young, therefore Hebble's study with him only lasted a few months.

Although Hebble was learning basic piano and organ repertoire during his childhood, he began to compose some of his own works by the age of twelve. He wrote "Concert Grandiose Ballad" for piano and orchestra. The orchestra part was written as a second piano part with indications as to which instruments were to play those notes. According to Hebble, it was "too big to deal with" and so he abandoned it. These sojourns into composition eventually led him to improvisation.

As Hebble's piano skills improved, his father would occasionally enjoy exploiting his talents. He would travel with his parents to "Pal's Cabin" a popular restaurant in the 1940s, when he was ten or twelve years old. Hebble's father would have "Bobby" go and play a piece on the piano on stage before Lee Liberace came out to play. This was just as Liberace was becoming famous. Everyone would applaud "Bobby" and Lee Liberace would come out on stage and "make a big deal out of it." "I've had a very fabulous life!"6

At the age of twelve, Hebble went to the Juilliard Preparatory School, because by that time, according to Hebble, he had surpassed all his local teachers. New York City was only forty-five minutes away and his teachers all encouraged him to go. Even during these formative years at the Juilliard Preparatory School, Hebble would put aside his assigned pieces, which he prepared for his lessons, and begin to improvise. He

\footnotetext{
${ }^{6}$ Hebble, Los Angeles, CA interview, July 5, 2004
} 
remembers his mother in the kitchen telling him to "return to his scales and lessons." Improvising would eventually become his life's work because, as Hebble states, "composition is frozen improvisation." Improvisation was something that was "in him that needed to come out." ${ }^{, 7}$ When he was twelve years old he began playing for church. He did not know very much about the organ, or being an organist, at that time and it took two buses to get there. He was frightened to play for congregational singing, which requires a different style of performing than being a soloist, and the organ was a horrible sounding electronic. He does not remember what kind.

Hebble's father was the owner of a Buick Automotive Agency in East Orange, New Jersey. It was, for forty years, the third largest in the greater New York City area. Mr. Hebble wanted to give the successful Buick Agency to Robert because he was the oldest son. Hebble's father expected him to take over the business. Hebble responded that he "could not imagine selling cars for the rest of his life." ${ }^{8}$ His father was never disappointed. Even though he would have liked to give the business to his son, he continued to encourage Hebble's interest in music by buying him a Steinway grand piano and paying for his Juilliard education at the Preparatory School.

Hebble played the piano in high school for practically everything, including the orchestra and chorus. As his schooling progressed, he went to West Orange High School during the week and JPS on the weekends, where he was a piano major and a theory minor. There he studied the rudiments of music from $9^{\text {th }}$ through $12^{\text {th }}$ grades. Arnold Fish was his composer and theory teacher. Edgar Roberts taught Hebble piano. He is still

\footnotetext{
${ }^{7}$ Taped interview with the composer, No. 1, side 'A'.

${ }^{8}$ Hebble later jokes that he was sorry he never took over the business "because the men who now own it are multi-millionaires several times over;' tape 1, side 'B'.
} 
there, and he also taught Marvin Hamlisch, who is a current jazz arranger and conductor. Roberts was a good piano teacher for technique, musicality, and repertoire. He taught Hebble to "make every finger count." Hebble did not take improvisation class as they did not offer the course, but instead wrote his own harmonizations.

During his teenage years there were a number of pianists and organists who visited the Hebble household. Hebble was fortunate that many of these people were aware of the work he was doing. He was already studying with faculty at the JPS, his mother and grandmother were organists in the area churches and theatres, his father was a very sociable person for business purposes, and studying with Page brought many people to the Hebble's Steinway grand piano. Although most of these people were minor figures in the musical scene, they encouraged his talents.

Hebble recalls an annual music contest in high school sponsored by The New York Times and WQRX-NY in which ten final contestants played for Vladimir Horowitz. Each school submitted the names of two of their best pianists and although Hebble had attended the JPS only on weekends at that point and only fifteen at the time, he represented West Orange High School. Hebble was chosen as one of the ten finalists out of approximately 300 high schools in the New York area. He won third place and a piano lesson with Horowitz in his New York studio.

His young life was totally musical. As a teenager Hebble was not involved in sports. His father, although he provided the Steinway grand piano, hated to hear it. However, when his father's golfing companions came to the house, his father would go to the piano, lift the lid and announce "and now my son will play for you." His father was very proud of him. Although Hebble felt his father's actions were quite peculiar, it was 
an "unwritten rule" that there was to be no music when his father was home. Hebble recalls that his father was never mean about it.

In 1949 Hebble's grandmother Nellie Edwards, his first teacher and mentor, died. She had been the one to take "Bobby" each week on Saturday afternoons to places in New York City ${ }^{9}$ such as the Metropolitan Opera, the Roxy Theatre and other places, including The Riverside Church. She used to take Hebble to The Riverside Church to "bask in the glory of their music." She was enthralled with Virgil Fox (1916-1980), then the church's famed organist. Once, when they were there on a Saturday afternoon while the organ was being tuned, Fox happened to walk through the narthex and she screamed, "There's Virgil Fox!"10 His grandmother wanted Hebble to soak in all the musical events The Riverside Church offered. After she died, Hebble went there himself to hear what it was that this great artist, Fox, was doing with the organ.

In high school, Hebble's piano repertoire included all the standards. At that point, Hebble played no organ repertoire, but was familiar with it. What he liked primarily about the organ were the colors Fox created with the Riverside organ and the opportunity for his own improvising. Hebble loved the harmonies and colors of Debussy and Ravel. Hebble emphasizes the importance of spacing of the harmony vertically. Colorful harmony became an important feature of Hebble's music throughout his life. This will be discussed in more detail in Section III. He says that jazz was not an influence on him, that he did not listen to it much and that he was not an aficionado.

\footnotetext{
${ }^{9}$ They would travel on a Fifth Avenue, double-decker bus.

${ }^{10}$ At the time, this meant little to Hebble, as he did not know Virgil Fox.
} 
Hebble would listen to Fox improvise on Sunday mornings (usually occurring between the verses of hymns). He would also go up to the Riverside organ console after services:

There were always so many people around Virgil Fox and the console at Riverside that no one noticed me leaning over the console to memorize the over 200 stops and controls. One time, after everyone had left the church, Fox had left the organ on, so I tried out and found the hymn registrations. I would try out Virgil's presets to figure out what Fox must have used during the service. ${ }^{11}$

Fox had two formulas he would use and Hebble "caught on" since he had perfect pitch. Hebble would listen to Fox on Sundays, then go home immediately to his Hammond organ, remembering what he had heard, and recreate what Fox had done. Hebble would also add his own harmonies, which often included major seconds, an added fourth, minor sixths and major or minor sevenths. Hebble maintains that although Fox was a great organist when it came to repertoire, he was not talented at harmony. Hebble states that:

Fox had a square, scholarly understanding of harmony and he loved beautiful chords and the way they moved together in a harmonic progression, but had no clue about how to find them himself. ${ }^{12}$

\footnotetext{
${ }^{11}$ There were twenty generals on the console at that time. According to Hebble numbers 4, 5, 6, 7 and 8 were the hymn generals which never changed.

${ }^{12}$ Tape 2, side B.
} 


\section{CHAPTER 2}

\section{The "Burning Bush Experience"}

“And now, we've got to hear from our youngest!" - Virgil Fox (1950)

In 1950, at age 16, Hebble read that Fox was giving a five-day workshop in New York City at The Riverside Church, and Hebble enrolled as an observer. The other people in the class were much older and were famous organists from all around the country, New York City and Columbia University. During the master class, those enrolled played organ repertoire or hymns for Fox and he would critique, giving them helpful suggestions. All week Hebble sat on the far side and took notes, never thought of playing, and loved being there and hearing what Fox had to say. The other organists, who were there to play for Fox, sheepishly approached the large console and shook with terror. They did not know where the stops were, but Fox would say "you just play, honey, and I'll run the organ."13

On the last day, as Fox was concluding the class and saying his farewells, he suddenly turned and said, "oh, and now we have got to hear from our youngest," and he pointed to Hebble. ${ }^{14}$ Hebble walked over to the console, unnerved, sat down and pressed "general 6" (scores of stops were activated) and did the only thing he knew how to do, which was to play a big hymn in Fox/Hebble style. Hebble remembers that the hymn had five verses and that he modulated after each verse, re-harmonizing some of the stanzas.

\footnotetext{
${ }^{13}$ At the master class, Fox "had to listen to each person poorly grind out all the standard repertoire. Fox instead loved exciting people and exciting music," according to Hebble; and when Fox heard Hebble improvise there was an immediate bond.

${ }^{14}$ Hebble said he initially felt that Fox chose him because Fox figured that Hebble's mother contributed $\$ 50$ for the master class and he wanted Hebble to be able to go home and say that he got to play a few chords.
} 
He also used the Celestial Reeds, which were difficult to activate since they went through the coupling system, and the organ roared. He continued to change pistons with each verse and added interludes. Fox was jumping up and down in the background, had tears in his eyes, and was ecstatic. He threw his arms around Hebble and screamed "yes, yes, yes!" Years later Fox would retort that "Bobby played the organ louder that day than I ever did!" which was, of course, hyperbole.

Later that day (Friday) Fox had to go to the airport to leave for Europe, where he stayed for two months on his regular sabbatical. The following Tuesday he called Hebble from Hamburg, Germany and pleaded with his mother saying "I have to have your son with me at the Riverside console every time I walk in the building." This thrilled Mrs. Hebble. Fox wanted to tap into Hebble's creativity and said that their collaboration would give Hebble the equivalent of a $\$ 50,000$ education. Thus, Hebble became Fox's console assistant, and Hebble worked by composing hymn arrangements and organ interludes for Fox. Fox taught Hebble everything about the organ, particularly the ACO. At that time in 1950, the Riverside organ was a 1936 Hook and Hastings. It was large, but it wasn't until 1955 that the renowned Skinner ACO was installed. Hebble was a witness to this transformation. ${ }^{15}$

During their initial collaboration in the early 1950s, Hebble wrote out all of Fox's modulations and interludes, spicing up the music with his own harmonizations. ${ }^{16}$ When he was with Fox, he "would enter Fox's world and recreate it and embellish it in his own way," which he did for thirty years. Hebble also helped Fox arrange some of Fox's "old

\footnotetext{
${ }^{15}$ Torrence, Richard. Virgil Fox “The Dish”. Circles International Publishing, New York, 2000, p. 176.

${ }^{16}$ Hebble and Fox often called these harmonies "\$50 chords". Once, when Hebble played a particularly lavish harmony, bystanders commented that "that one was worth $\$ 250$ !"
} 
pieces" for RCA Victor Records, but Hebble maintains they were nothing significant. ${ }^{17}$ Fox would ask Hebble in the middle of an improvisation "which harmony do I use next?" Fox loved beautiful and unexpected chords and he encouraged Hebble to keep writing them. Hebble feels that Fox added so much to his life musically and hopes that his writing for Fox "added to Fox's musical life."18 Fox called Hebble his "first born," and Hebble was with Fox when he died in Palm Beach, Florida on October 25, 1980. ${ }^{19}$ Hebble says that he was not the best student in high school because he was so interested in music. After high school and JPS he went to Yale University in New Haven, Connecticut from 1953-1956. He had also auditioned at Eastman, but his father wanted Hebble to attend an Ivy League school such as Harvard, Princeton, or Yale. Hebble's high school grades were not good; however, he was such a good student at JPS that he entered Yale University as a sophomore, skipping his first year. He studied piano and composition at Yale, beginning composition lessons with Paul Hindemith (18951963). ${ }^{20}$ He was then assigned to study with Quincy Porter (1897-1966) and Bruce Simmons. Hindemith, according to Hebble, definitely came from a more Germanic tradition with its "emphasis on counterpoint and heavy-duty architecture and was less interested in altered harmony."21 The other teachers in composition at Yale were students of Nadia Boulanger. Hebble composed each week. At his lessons the teacher would play Hebble's composition and critique it. At first he was chastised to balance the proportions of sections and "fix what didn't work." His teachers at Yale would be hard

\footnotetext{
${ }^{17}$ Hebble often referred to these recordings as "slush albums."

${ }^{18}$ Hebble, FL interview.

${ }^{19}$ Torrence, p. 116 and p. 388.

${ }^{20}$ Hindemith had taken ill earlier and left Yale for convalescence, but later died in 1963.

${ }^{21}$ Hebble interview.
} 
on him for correct spelling of notes (e.g. an F\# should have been a $\mathrm{G}^{\text {b}}$, etc.). Hebble felt that his teachers' corrections were merely superficial and that he otherwise did well.

Before leaving Yale Hebble took time off to study with Boulanger in Paris for eleven months from (1955-56). He had three lessons with her every two weeks. She did not prop up his scores on the music rack and play them, as did his teachers at Yale. Instead, she kept them in her lap and read them intensely. She often would not speak for ten or fifteen minutes as she pondered them. ${ }^{22}$ When she finally began to speak she explained to Hebble "what was in the music from the instant it appeared in his mind to how the thought process evolved." Hebble said he had no idea that there was "that much" in the music itself which she found and explained to him. Forty-five minutes later she would comment on proportions or correct an $F \#$ to $\mathrm{G}^{\mathrm{b}}$. He said she did not quibble over the smaller compositional matters. ${ }^{23}$

Hebble felt that Boulanger imparted to him "the actual creation of music and the way it was shaped in the mind of the composer." 24 That which Hebble was not aware he was doing she, in fact, knew, and this was her great gift as a teacher. She had the reputation of being the greatest teacher of composition of the twentieth century, because she could look into the compositions of each student and pull ideas out of the music from the beginning to the end regarding how motives, harmonies, or melodies evolved within it as a work of art. Hebble always felt her comments were beyond anything he had ever dreamed existed in the music, and then realized that behind the "pretty chords" 25 there

\footnotetext{
${ }^{22}$ Hebble stated that it was as if she were in a trance.

${ }^{23}$ Tape 1 , side 'B'.

${ }^{24}$ Ibid.

${ }^{25}$ Hebble, FL interview.
} 
was shape and great creativity involved. Of all his teachers she was the only one to explain this to Hebble.

They had a great rapport, and she was so fond of Hebble that she scheduled him at the end of her lesson day so that the lesson would be open-ended - going on well past the allotted hour to two or three hours. Hebble felt she was always disappointed when he would leave, and he thought this was wonderful. He felt he did good work for Boulanger, writing some serious pieces, but (like ten years earlier) also did some arranging and improvisations.

Hebble remembers his last lesson with Boulanger. She was in a good mood and he thought to ask her to listen to one of his arrangements of a Gershwin piece, and she agreed. Hebble felt with its altered harmonies it best expressed his style and Boulanger loved it. Her comments are quoted as:

I don't get to hear this kind of music very often. Your arrangements have great style and creativity. Always remember, Bobby, there are two kinds of music: not popular music and classical music, but good music and bad music. What you did was good. In fact, it's very good. $^{26}$

Hebble had a number of other experiences in Paris, mostly of compositional interest involving classes with Boulanger and meeting other famous musicians. At Fountainebleu Chateau, outside of Paris, Boulanger would give enormous master classes in the auditorium of the American Conservatory or out on the lawn where hundreds of people came (all claiming to be her pupils). Hebble had wanted to study with Boulanger more, but his father's money was running out and so he went back to Yale after his year in Paris.

\footnotetext{
${ }^{26}$ Tape 1 , side 'B'.
} 
While he was in Paris studying with Boulanger, Hebble enjoyed the great food and went to museums. Fox had arranged for Hebble to meet Doda Conrad, Boulanger's assistant and a baritone in the Paris Opera. They became good friends and Conrad knew everyone in Paris. When Hebble arrived in Paris, they would go out each night after composing. Conrad would arrive at Hebble's pied a terre (apartment), would take Hebble on his Vespa (motorcycle), and would "go sailing" ${ }^{27}$ through the streets of Paris. They would always end up at Cafe d'Flore on the Left Bank the café where, throughout history, all the important musicians and writers frequented. Hebble states that three nights per week he would sit at a table with Pierre Bernac (a French singer), Francis Poulenc (Bernac's partner), and Ned Rorem. ${ }^{28}$ They would all sit, talk, drink and joke. Hebble said that he saw Francis Poulenc and laughed so often with him that he did not realize how important Poulenc was until much later. Poulenc liked to drink Pernod. They occasionally talked of musical matters together with Rorem, but above all were more friends than colleagues.

After returning to the States, Hebble began working for Virgil Fox at Riverside once again. During this time Hebble began studies for his Masters degree at the Juilliard School in New York City with Vittorio Gianinni (1903-1966) until his death. Roger Sessions (1896-1974) was then appointed his teacher and Hebble felt he was "a lovely man and a very grandfatherly person to the students." Hebble states that Sessions taught him about form and helped in "clarifying" ${ }^{29}$ what he was doing. As he continued the pursuit of his own voice, Hebble wanted Sessions' input regarding his own creativity.

\footnotetext{
${ }^{27}$ Hebble, FL interview.

${ }^{28}$ Rorem later wrote of these exact times in his book "The Paris Diary."

${ }^{29}$ Hebble, FL interview.
} 
Thus, Hebble improved his style by "tightening up his harmonic concepts." process reminded him of the master class given by Ralph Vaughan Williams at Yale in composition when he said not to feel bad if you change composition teachers, because "no one teacher has all the secrets." ${ }^{31}$ Sessions gave Hebble some new perspectives and helped in clarifying his ideas. However, Hebble feels these new ideas were so minor compared to Boulanger's ideas that he finds them hard to recall specifically.

Hebble always returns to Virgil Fox when talking about learning "musicality" and "phrasing," or "shaping the line" and "expressiveness." ${ }^{32}$ Hebble was with Fox every time he was at The Riverside Church or in concert in New York City, and Hebble learned from him. Fox was happy to stop everything that he was doing to show Hebble how he was getting certain effects in the music. Fox was the most important influence on Hebble. Their musical bond was so deep that Hebble instinctively knew when to change stops before Fox made his choices known. Hebble felt that they were on the same "spiritual level." "33

\footnotetext{
${ }^{30}$ Ibid.

${ }^{31}$ Ibid.

${ }^{32}$ Ibid.

${ }^{33}$ Ibid.
} 


\section{CHAPTER 3}

\section{Professional Career}

"We make a living out of what we get, we make a life out of what we give." ${ }^{34}$

How Hebble came to publishing his first piece for the organ is an amalgamation of three interesting stories. It is important to begin by noting that for four years, when he was working for Fox, he composed minor pieces for the organ. These were essentially for Fox's use as modulations, interludes and arrangements. ${ }^{35}$ Hebble's first solo piece for organ was Nave Cp1 composed in 1958. The first story begins with Christmas Eve in 1957. The Riverside Church was about to begin its renowned "Candlelight Service" and Fox was running late in the robing room downstairs. Hebble was close behind Fox as they ran up the stone staircase that led to the curtain just behind the organ console.

Hebble states:

Virgil was tearing up the back stairs like a fire engine, with me in close pursuit. He stopped at the bottom of the staircase and announced "Oh, I forgot to mention that the American Guild of Organists asked me to play the opening concert for their convention next summer in Phoenix". I said, "Well, Virgil, that's wonderful!", and we kept running up the stairs. Suddenly, Virgil stopped again in the middle of the staircase and said, "....and the Guild wants me to play the premiere of a new American work for the organ." Again, I said, "why Virgil, that's great," and we finished flying up the stairs. Just as we got to the curtain, right before Virgil was to emerge to play the organ prelude before thousands of people who had come from near and far, Virgil turned to me and said, "And, YOU'RE going to write it!" and he flew from out behind the curtain and onto the organ bench to a roar of applause. ${ }^{36}$

\footnotetext{
${ }^{34}$ Winston Churchill.

${ }^{35}$ Some can be found in Hebble's Collection called The Hymnal Companion; see Appendix A.

${ }^{36}$ Torrence, pp. 343-344.
} 
Hebble states, "Can you imagine how I felt? I was shocked that one of the greatest living organists and performers in the world asked me to write for the organ: to premiere a new work." Hebble was only twenty-three and did not know what to write. He pondered it for some time.

The second story begins somewhere before New Year's Eve in 1957. Fox, Hebble and Ernest White (1901-1980) ${ }^{37}$ were going out to dinner in New York City. It was a snowy night and they ate at a restaurant just off Times Square when White asked Hebble how the commission was coming. Hebble later found out that Fox had planted White at dinner because he knew Hebble was having trouble coming up with ideas for the piece. Hebble responded that he had no ideas so far. White looked Hebble right in the eyes and said, "I think that you're going to write that piece tonight," and he insisted on bringing Hebble to his church, the Church of St. Mary the Virgin. After dinner, Fox went off in his car and Hebble and White went to the church balcony. It was very dark inside and one light lit the organ's music rack. White gave Hebble pencil and manuscript paper, showed Hebble where the bathroom and the exit were, and left him to compose.

It was gloomy and spooky in there. As Hebble's eyes adjusted to the dark, he got up and leaned on the balcony rail and looked out into the dark church. In the darkness all that could be seen were the many little red votive candles flashing in the distance. They made the stone pillars, which were up near the front altar, undulate and move in the candlelight. Then Hebble suddenly started to hear chords and music. They were not what he had originally thought the music would be. He turned to the organ, quickly

\footnotetext{
37 - - - - . The Organists Book of Days, American Guild of Organists Headquarters, Riverside Drive, New York, 1994, no page numbers. White was a famous organist who played at the Church of St. Mary the Virgin on West $46^{\text {th }}$ Street in NYC.
} 
began to play, and to write down what he was hearing. The procedure began the genesis of this piece. About one hour later, Hebble heard monks singing in his imagination. They were singing Divinum Mysterium, a melody which he quoted in the composition. The next day, Hebble wrote out the music neatly in ink and brought it to Fox that night. Fox stopped everything he was doing and said "let's hear it." Hebble played it for Fox who absolutely adored it. They spent the rest of the night until $4 \mathrm{am}$ or later playing through Nave Cp1 and setting the registration for it on the Riverside organ. The registration was set that night and is still the same.

Fox premiered the piece the following summer at the opening of the American Guild of Organists' convention in Phoenix, Arizona, 1958. The concert featured Fox and Hebble's new music Nave Cp1. H.W. Gray immediately wanted it for publication. It was Hebble's first commissioned piece and his first published piece. It has become his most famous piece. "Nave" is the Gothic term for the interior of a church where people sit, much like the one in the Church of St. Mary the Virgin on West $46^{\text {th }}$ street in NYC. It was well received at the convention and the publishers began coming to Hebble for more works. Fox had called this technique for writing Nave Cp1, "perfuming the air", because "it just floats and sets the mood." Since Hebble received so much attention at the convention, publishers wanted more. ${ }^{38}$

Story three starts with Hebble's decision to notate some of Fox's famous transcriptions and arrangements for organ. Fox had played Now Thank We All Our God (BWV 687) by J.S. Bach as an encore for seventy concerts a year for over fifty seasons. Finally, Hebble insisted that Fox write it down, because everyone wanted it. But Fox

\footnotetext{
${ }^{38}$ Hebble, FL interview.
} 
said, "If I have to so much as take a pencil in my hand, I won't do it!” Hebble responded, "Well, damn it, then let me write it down." After choir rehearsal Hebble told Fox to play it extremely slowly and Hebble would capture it in manuscript. Fox said, "Well, I'm not so sure you could do that" and Hebble persisted, "Yes, I can!" Hebble got on a chair and while standing behind Fox's head, looked down at the manuals, the registration and Fox's hands, and wrote it down the first time in his own "shorthand" for composing which he used when ideas were coming fast. When they were finished, Fox put his head in his hands and said, "How many more times will I have to play this?" Hebble responded, “That's it, I got it." Fox said, "Oh, come on." It had taken fifteen minutes and Hebble went home and wrote it out correctly and neatly for Fox to proofread - it was correct. Hebble sent it off to H.W. Gray who was delighted to have it and then sent the proofs to Fox. It was perfect in every way, even down to the Riverside organ's manuals and registration. ${ }^{39}$ Fox never again questioned Hebble nor asked him again to see proofs of Fox's future transcriptions. Fox insisted on was putting Hebble's name at the bottom of the first page of Now Thank We All Our God and also insisted that Hebble should receive fifty-percent of the royalties. Gray said it was usually five or ten percent that was given to copyists/arrangers, but Fox said he would not submit it unless Hebble got fifty-percent. This, at long last, began Hebble's career composing for the organ. ${ }^{40}$

When Virgil Fox retired from The Riverside Church, Hebble, who remained in New York City, had to find other work. This work consisted of his continuing experiences in his jazz background, based in the theatre organ, coupled with his classic

\footnotetext{
${ }^{39}$ These registrations, like Nave, were precedent setting because the Riverside organ was one of the premiere models of ACO building and Fox's use of the organ in this arrangement exploited the vast tonal possibilities of the ACO, which Hebble captured to score.

${ }^{40}$ All quotations here, tape 1 , side B.
} 
organ experiences with Fox. Hebble was the rehearsal pianist for hundreds of Broadway novices and students. He was a pianist for Broadway in several studios from 1955 to about 1965. One of these rehearsal studios was in Washington Square Village in an apartment at $13^{\text {th }}$ Street and $7^{\text {th }}$ Avenue. He was the initial pianist for the show My Fair Lady one year before it opened and became famous. He had dozens of clients most of whom are now deceased, but who had leading roles such as Robert Morre who played in How To Succeed in Business, and Gwen Verdon, who was in Sweet Charity and Red Head. He also played the piano for Anthony Quinn, which "had to be private" 41 because he was not a singer. He also had a studio at Harlequin Studios in Newark, New Jersey "when it was beautiful" 42 in the Colonnade Apartments.

Further jazz experiences involved him as the pianist "for thousands" of records and solo concerts of popular piano and vocal music while in NYC at this time, only some of which credit him. He accompanied such singers as Mickey Rooney for a television show "in either the 1960s or 1970s."43 Hebble also accompanied Noree Boyd, a singer, in St. Louis, Missouri and in Florida.

Robert Hebble frequently traveled with the Rogers Organ Company. He performed concerts on their new organ installations all over the country. He also presented workshops concerts for Rogers organs in Australia, the Far East, Singapore and Korea, the latter of which conferred on him the "Governor's Episcopal Award of Recognition.",44

\footnotetext{
${ }^{41}$ Hebble, Los Angeles, CA interview, July 5, 2004, during the AGO National Convention.

${ }^{42}$ Ibid.

${ }^{43} \mathrm{Ibid}$.

${ }^{44}$ Ibid.
} 
Hebble's professional career blossomed further with several teaching positions. From 1957 to 1975 Hebble taught music full-time at Red Bank High School in Red Bank, New Jersey, eventually becoming Chair of their music department. Red Bank H.S. did a major Broadway show every year with the help of several assistants, such as Anthony Polistina. For the high school choruses Hebble composed his famous Mass of Unity, published by the Gregorian Institute of America, as well as many other choral compositions, many of which are listed in Appendix A. Hebble's Mass of Unity has been disseminated globally and has been translated into many different languages and scored for orchestra.

From 1968 to 1979 Hebble taught part-time at the Stevens Institute of Technology in Hoboken, New Jersey. He was an "Assistant in Music" for college-aged students, and feels this was his most unusual musical position. Here one had to teach music "not as an art but as a science": sound waves, decibels, diagrams and pitch relationships. "To them music was a series of diagrams and charts," which was a revelation to Hebble. He says he taught them to "listen" to music, and they responded that they "never thought of doing that." In return the students, who "talked about music all the time," helped Hebble appreciate music as a science as well. When the author asked Hebble how this affected his own music and composing, Hebble responds that when he had to devise "tests" for evaluatory and grading purposes for his classes, that this was when he was most influenced by music as a science. He said when he had to go the "extra mile" to think of music in their terms and teach it in this manner, he learned from his students. It resulted in "more exactitude in my music.",45

${ }^{45}$ Ibid. 
Hebble's career continued with teaching upon his move from NYC to Florida in 1980. From 1982 to 1997 Hebble taught music as an adjunct faculty member at the Palm Beach Atlantic College. There he was an Assistant Professor of Organ and Composition and is still a guest lecturer. He had private organ and composition students and taught composition classes. Stan Doyle, who was the Chair of the music department at the time, had the students trace a "musical lineage of teachers" from Franz Liszt to Hebble: Liszt had taught Debussy, who had taught Fauré, who had taught Boulanger, who had taught Hebble. ${ }^{46}$ Stewart Wayne Foster was one of Hebble's most promising young organ students from this period. Foster is now a concert organist and winner of several prestigious organ competitions and prizes.

Other events in the 1980s include the following: 1.) Hebble's first published collection consisting entirely of his own works was Hymn-Tunes, Preludes and Improvisations by Bradley Publishing in 1981. 2.) Hebble, who was unofficially a "Composer in Residence" at Riverside Church, functioned as such at his own church in Lake Worth, Florida. 3.) He was appointed the newest "Steinway Artist" (as recently as 1994). 4.) He has played or been present for a number of his own premieres, including the premiere of Heraldings at the Crystal Cathedral in Los Angeles, California in 1982 when Fred Swann played. 5.) Hebble is presently composing the second commissioned piece for that great organ, which is a synthesis of two great ACO organs: The old Lincoln Center Skinner organ of 1956 of NYC and the old Ruffati organ 1972 of the Garden

\footnotetext{
${ }^{46}$ Ibid.
} 
Grove Community Church in Los Angeles, California. ${ }^{47}$ He is also presently working on a commission for the John Wannamaker organ called Cathedral of Commerce and another called Litany for the Denver AGO chapter in memory of Virgil Fox.

Robert Hebble is still accepting commissions. He is often invited to speak at American Guild of Organists chapter meetings all around the United States, Canada and abroad. Occasionally, he performs recitals of his own works and supplements the programs with selections from the standard organ repertoire. He is invited from time to time to serve as adjunct faculty to music departments and schools such as his alma maters the Juilliard School and Yale University, where he discusses composing, the American organ scene, the life of Virgil Fox, or his own compositions. He still speaks at clinics and offers workshops on composing for both choral and organ works, including his own works and recently released compositions. Various publishing companies as well as the Chorister's Guild or the American Guild of Organists sponsor workshops in various locations around the country.

Unfortunately, Mr. Hebble suffered a mild stroke in the autumn of 2002. This occurred after speaking at a Virgil Fox Society convention in Atlanta, Georgia. Hebble had spoken of Fox's “registrations as similar to the controversy surrounding Bach's organ registrations in his own time," as he quoted from the Bach Reader. The convention celebrated the restoration of the Theatre Organ "Mighty Mo" at the renowned Fox Theatre in Atlanta, an historical building, which had also been restored. Virgil Fox had given a legendary concert there in 1978. This concert was the catalyst for the decision not to demolish the building and organ, but to restore them. Both the instrument and the

\footnotetext{
${ }^{47}$ See Appendix E for the specification of the Crystal Cathedral organ.
} 
building are important landmarks for the American organ scene of the early twentieth century. Hebble has since slowly recovered, but has retired from his church position and has taken a sabbatical from recitals and workshops until a fuller recovery is made. 


\section{PART II: Approach to the Organ}

\section{CHAPTER 4}

\section{The American Classic Organ: A Brief History}

It is important to look at the instrument that Hebble had in mind when he composed for the organ. This instrument, the American Classic Organ (ACO), is unique in the world and only came to the fore in the $1930 \mathrm{~s} .{ }^{48}$ Concurrently, with the rise of the ACO, was the rise of the organ reform movement. It is on the one hand a simple, but on the other hand a complex synthesis of concepts which evolved through the early twentieth century in time and in practice from the late 1920s to the present.

The ACO is a product of a notion that an organ is capable of playing most, if not all, of the organ's centuries long history of repertoire, which is from approximately 1325 A.D. ${ }^{49}$ to the present. This instrument had a greater ability to properly register various classic repertoire within a legitimate range of acceptable performance practices for a particular repertoire. The stop list of the organ as well as the location of the pipes played a crucial role in the ACO's development. John Fesperman in his Two Essays on Organ Design says it this way:

Facts to be learned from the dispositions of early organs are that 1) the resources of the organ and the requirements of the repertoire are matched; 2) the instrument itself has coherent form. Reciprocally, the composer or performer takes for granted an instrument with predictable form and limitations. For the most part, French music was played in Paris and not in Rome or London, and there was small reason to be concerned about an eclectic repertoire, which simply

\footnotetext{
${ }^{48}$ Whitney, Craig. All the Stops; The Glorious Pipe Organ and Its American Masters. Public Affairs, New York (2003), p. 50.

${ }^{49}$ The Robertsbridge Codex is the first written music for the organ.
} 
was not available before the days of easy, inexpensive reproduction of printed music. ${ }^{50}$

The ACO was a departure from the American symphonic organ of the early twentiethcentury. The latter was an instrument loosely described as one with many sounds that replicate orchestral sounds, many stops of similar pitch or tone quality: what Fesperman has called a "mindless eclectic conglomeration not appropriate for making music in any style." ${ }^{51}$ The ACO is a combination of several concepts over two or three decades. The development of the $\mathrm{ACO}$ is concurrent with the lifetime and compositional output of Robert Hebble.

The earlier American organ (c.1775-1900) was subjected to irresponsible enterprising and unsympathetic tampering so that the concept of 'organ' was blurred from its classic identity. ${ }^{52}$ Besides this development, the visits to the United States of organists Alexander Guillmant, Marcel Dupré, Joseph Bonnet brought the classic organ repertoire to America. Organ builders began to see the significance of European organ repertoire once again. Most American organs at the turn of the twentieth century were not sufficiently disposed to legitimately recreate either the music of Bach or the music of the French romantic organ, and were closer in disposition to the American symphonic organ.

European editions of early music for the organ became more widely available after WWII. But it was also the interest of American students who had studied abroad that made possible after the war the rediscovery of the organ ideal to Americans, particularly to American organ builders. What is this ideal? In short, the ideal is a

\footnotetext{
${ }^{50}$ Fesperman, John. Two Essays on Organ Design. Raleigh, NC, Sunbury Press, (1975), p. 10.

${ }^{51}$ Ibid.

${ }^{52}$ Ibid., p. 11.
} 
classic organ design ensemble combined with additional stops for more orchestral coloring. ${ }^{53}$ The final catalyst, which encouraged American organ builders to take the remaining steps towards more "classic" designs (the ACO), was the growing number of imported organs ${ }^{54}$ and the appointments of European musicians (organists) to important American posts. These organists demanded better instruments for European-based repertoire and universities and churches were interested.

The following is a brief summary of the genesis of the ACO, which began mainly in Boston and New York. Up to roughly 1950, when importing organs began in earnest, the most important influences on American ideas about organ building were instruments which Walter Holtkamp (1894-1962) and G. Donald Harrison (1889-1956) of the Aeolian Skinner Organ Company had built for educational institutions, churches and museums, which were accessible to a wide public. ${ }^{55}$ Among Harrison's most influential instruments were the organ of Harvard University's Germanic Museum built in 1934 and The Riverside Church organ of 1955. Virgil Fox (1912-1980) from The Riverside Church in NYC made many recordings of its 1955 Aeolian Skinner organ which were played over radio stations. The Riverside ACO disposition is in Appendix C. The disposition of the Harvard organ is as follows: ${ }^{56}$

\footnotetext{
${ }^{53}$ This would be the use of orchestral stops like the English Horn, the Basset Horn, the French Horn, the Hecklephone, the Flute Celeste or the Flauto Mirabilis, etc., which are unique to ASO. Although there are European organs with "English Horns", etc., in their dispositions, this was clearly due to the later influence of American builders.

${ }^{54}$ Pape, p. 2.

${ }^{55}$ Ibid.

${ }^{56}$ Ibid., p. 10.
} 
Hauptwerk 21/2" wind

$\begin{array}{ll}\text { Quintade } & 16^{\prime} \\ \text { Montre } & 8^{\prime} \\ \text { Spitzflöte } & 8^{\prime} \\ \text { Principal } & 4^{\prime} \\ \text { Rohrflöte } & 4^{\prime} \\ \text { Quinte } & 2{ }^{2 / 3^{\prime}} \\ \text { Super Octave } & 2^{\prime} \\ \text { Furniture IV } & \end{array}$

Positiv 21/2" wind

Koppelflöte $\quad 8^{\prime}$

Nachthorn 4'

Nasat 2/3'

Blockflöte $\quad 2^{\prime}$

Terz

Sifflöte1'

Zimbel III

Krummhorn $8^{\prime}$
Pedal 3" wind

$\begin{array}{ll}\text { Bourdon } & 16^{\prime} \\ \text { Quintaton } & 16^{\prime} \\ \text { Gedeckt } & 8^{\prime} \\ \text { Principal } & 8^{\prime} \\ \text { Nachthorn } & 4^{\prime} \\ \text { Fourniture III } & \\ \text { Posaune } & 16^{\prime} \\ \text { Trompete } & 8^{\prime}\end{array}$

In 1933 Walter Holtkamp's building of the Positiv division for the organ of the Cleveland Museum of Art marked the start of a revolution in American organ design. With Harrison's organ at Harvard, the "organ reform" movement began in America, for the building of an unenclosed division was a daring step for both of them.

What affected the development of the ACO is that it happened to coincide with the popularity of the theater organ c. $1915^{57}$ and the development of the electronic organ c.1930s. The former exerted a considerable influence since some of the players were popular performers of the day, such as Fats Waller in Cincinnati playing the famous "Moon River" program over the radio and Jesse Crawford playing at New York's "Roxy Theater." Both of them represented a "dazzling popular style, now almost totally lost.",58 Formerly, experiments in producing sounds electronically took place even before the twentieth century, but came to the fore when the Hammond Organ Company promoted and managed to produce with unusual skill the electronic sound keyboard. ${ }^{59}$ The cheap cost $(\$ 1250)$ versus that of the pipe organ had the Hammond Organ in 567 churches by

\footnotetext{
${ }^{57}$ This instrument also lent the ACO some of its orchestral coloring.

${ }^{58}$ Fesperman, pp. 47 and 48.

${ }^{59}$ Ranger, Richard. "Electric Music as New Supplement to Tone of Organ Pipes", The Diapason. Vol. 23, No. 12, November (1932), p. 25.
} 
1936. ${ }^{60}$ William Minters' 1960 'Survey of Church Music in Baptist Churches in the San Francisco Bay Area" documented the popularity of electronic organs in small churches: seven out of nine churches (with memberships of 300-600) used electronic organs. ${ }^{61}$ The Hammond Organ was so popular that Walt Disney Studio used the then renowned "Hammond Organist" Ethel Smith (1908-1990) in its 1948 production called "Movie Magic.” Ethel Smith, (see Part I), was Robert Hebble's first organ idol when he was 12 years old and throughout his life. Despite the Hammond organ's and the theater organ's popularity, the builders of the ACO still had their eyes towards historic organs and performance practices, which became a more enduring side-movement to the Early Music movement. The ACO, thus, grew out of an appreciation for outstanding European organs. ${ }^{62}$

As the ACO continued to develop it took as its models the English organs of Henry Willis (1821-1901), the French organs of Cavaillé-Coll, ${ }^{63}$ and the German organs of Arp Schnitger (1648-1719) and Gottfried Silbermann (1683-1753). ${ }^{64}$ The organ of Notre Dame by Cavaillé-Coll (1868) had modifications unknown to French organs of the time,${ }^{65}$ nor to other European organs, and it came to greatly affect the ACO in these ways: 1) couplers for each manual to the pedal 2) couplers from each upper manual to the Great 3) ventils to control reed choruses placed on separate wind chests 4) the Great sub-coupler 5) Swell to Choir coupler 6) levers for tremolos (as opposed to 'stops') and

\footnotetext{
${ }^{60}$ Ochse, p. 371.

${ }^{61}$ Minter, William John. "Church Music in the American Baptist Union of the San Francisco Bay Cities", thesis, Union Theological Seminary, (1960), 54.

${ }^{62}$ Ochse, pp. 377 and 379.

${ }^{63}$ Whitney, pp. 52, 57, 89 and 162.

${ }^{64}$ Harrison, F.L., "Gottfried Silberman", New College Encyclopedia of Music. W.W. Norton Company, New York, (1976), p. 502.

${ }^{65}$ Kasouf, Edward J. Louis Vierne and His Six Organ Symphonies. PhD Dissertation, Catholic University of America, (1970), p. 5.
} 
7) extension of the manual keyboards. ${ }^{66} 67$ These devices were built to be controlled by the feet, freeing the hands to play the manuals. ${ }^{68}$

The English organs of Henry Willis also contributed to the ACO concept. They were well engineered, had well balanced principal choruses, powerful chorus reeds, and have been described in the twentieth century as having the "most typically English organ sound." ${ }^{99}$ The Schnitger organs emphasized narrow-scaled principals, wide-scaled flutes, and more upper-work, while Silbermann organs put more emphasis on individual ranks of 8 ' pitch, and both made more balanced pedal-to-manual specifications as well as colorful solo reeds. In the 1950s the true ingredients of these organs were just slowly coming to be understood. Basically, the ACO has, among several possibilities, a French Swell, a German Great and Positiv with balanced pedal and possibly an English Swell or Choir division. G. D. Harrison combined these three styles in the late 1930s when he took over the Skinner Company. An evaluation of Harrison's style is best summarized by the late Lawrence Phelps:

Motivated by strong artistic convictions, he chose to limit his basic tonal concepts to ideals he thought were best set forth in the work of Gottfried Silbermann, who was really the first of the great Romantic builders, and in the work of Cavaillé-Coll, the last and greatest Romantic builder. Harrison's goal was to produce an instrument on which all of the organ's literature could be interestingly, and thus for him satisfactorily, performed regardless of the tonal environment or the school that produced it...his instruments were really only fine Romantic instruments even though the stop lists indicated more classic aspirations. ${ }^{70}$

\footnotetext{
${ }^{66}$ Goode, Jack. Pipe Organ Registration. p. 82.

${ }^{67}$ The pedals were already extended in previous organs by Cavaillé-Coll.

${ }^{68}$ Widor, Charles-Marie. L'Orgue Moderne, Leduc, Paris, (1932), p. 11

${ }^{69}$ Owen, Barbara and Williams, Peter. The Organ: The New Groves Musical Instrument Series. London: W. W. Norton, (1988), p. 395.

${ }^{70}$ Phelps, Lawrence. “A Short History of the Organ Revival”, Church Music, no. 1 (1967), p. 29.
} 
Here is the stop-list of a representative ACO from this period. It is the Groton

School organ of St. John's Chapel, Groton, Massachusetts. It was built by Aeolian

Skinner in 1935 and designed by G. Donald Harrison.

\begin{tabular}{|c|c|c|c|}
\hline Great Division & Choir Division & \multicolumn{2}{|c|}{ Pedal Division } \\
\hline Sub Principal 16 & Quintaton 16 & \multicolumn{2}{|c|}{ Contrebass (open) 32} \\
\hline Principal 8 & Viola 8 & \multicolumn{2}{|c|}{ Principal 16} \\
\hline Diapason 8 & Dulciana 8 & \multicolumn{2}{|l|}{ Contrebass 16} \\
\hline Gemshorn 8 & Unda Maris 8 & \multicolumn{2}{|l|}{ Bourdon 16} \\
\hline Rohr Bordun 8 & Orchestral Flute 8 & \multicolumn{2}{|c|}{ Quintaton 16 (choir) } \\
\hline Grosse Quinte 5 1/3 & Nachthorn 4 & \multicolumn{2}{|c|}{ Flûte Conique 16 (swell) } \\
\hline Principal 4 & Zauberflöte 4 & \multicolumn{2}{|c|}{ Grosse Quinte 10 2/3 } \\
\hline Octave 4 & English Horn 16 & \multicolumn{2}{|l|}{ Octave 8} \\
\hline Flûte Couverte 4 & Trompette Harm. 8 & \multicolumn{2}{|c|}{ Flûte Ouverte 8} \\
\hline Quinte 2 2/3 & Bombarde 8 (Gt) & \multicolumn{2}{|c|}{ Cello (extension) } \\
\hline Super Octave 2 & Clarinet 8 & \multicolumn{2}{|c|}{ Gedeckt (swell) } \\
\hline Blockflöte 2 & Rohr Schalmei 4 & \multicolumn{2}{|l|}{ Quinte $51 / 3$} \\
\hline Fourniture IV & Tremulant & \multicolumn{2}{|c|}{ Super Octave 4} \\
\hline Scharf III & & \multicolumn{2}{|l|}{ Hohlflöte 4} \\
\hline Sesquialtera IV & Swell Division & \multicolumn{2}{|c|}{$\begin{array}{l}\text { Klein Gedeckt } 4 \text { (swell) } \\
\text { Waldflöte } 2\end{array}$} \\
\hline Bombarde 8 & & \multicolumn{2}{|c|}{ Waldflöte 2} \\
\hline & Flûte Conique 16 & \multicolumn{2}{|l|}{ Mixture III } \\
\hline Positif Division & Geigen 8 & \multicolumn{2}{|l|}{ Fourniture III } \\
\hline & Viole de Gambe 8 & \multicolumn{2}{|l|}{ Bombarde 16} \\
\hline Lieblich Gedeckt 8 & Viole Celeste 8 & \multicolumn{2}{|c|}{ English Horn 16 (choir) } \\
\hline Principal 4 & Flûte Conique 8 & \multicolumn{2}{|l|}{ Trompette 8} \\
\hline Koppelflöte 4 & Flûte Celeste 8 & \multirow{2}{*}{\multicolumn{2}{|c|}{ Clairon 4}} \\
\hline Nazard 2 2/3 & Gedeckt 8 & & \\
\hline Principal 2 & Octave Geigen 4 & \multirow{2}{*}{\multicolumn{2}{|c|}{ Couplers }} \\
\hline Tierce $13 / 5$ & Fugara 4 & & \\
\hline Larigot $11 / 3$ & Flûte Octaviante 4 & G-P & S-P 8,4 \\
\hline \multirow{11}{*}{ Cymbel IV } & Nazard $22 / 3$ & Pos-P & C-P 8,4 \\
\hline & Flageolet 2 & S-G $16,8,4$ & C-G $16,8,4$ \\
\hline & Tierce $13 / 5$ & S-C $16,8,4$ & Pos-G 16, 8 \\
\hline & Mixture III & S 16,4 & C 16,4 \\
\hline & Plein Jeu IV & \multicolumn{2}{|l|}{ S unison off } \\
\hline & Bombarde 16 & \multicolumn{2}{|l|}{ Pos unison off } \\
\hline & Trompette 8 & \multicolumn{2}{|l|}{$\mathrm{C}$ unison off } \\
\hline & Hautbois 8 & & \\
\hline & Vox Humana 8 & & \\
\hline & Clairon 4 & & \\
\hline & Tremulant & & \\
\hline
\end{tabular}


It is easy to see in this example the influence of the English, German and French schools of organ building reflected in the stop names. Further, one can observe the influence of orchestral coloring, hear "ensemble" in the principal choruses and their subsequent balance between the divisions. Finally, the organist was given the correct scaling (balance) between divisions and the opportunity to play compositions within the organ repertoire in their rightful historical style.

In 1957 Robert Hebble was commissioned by Virgil Fox to write a new piece of organ music for the opening of the American Guild of Organists convention in Phoenix, Arizona in 1958. Fox would be the performer, Hebble the composer and his first piece was entitled Nave Cp1. ${ }^{71}$ This composition not only demonstrated Hebble's compositional prowess and introduced him to the organ world of America at the time, but also demonstrated the ACO. This piece, although composed with the Riverside organ in mind, ${ }^{72}$ set a new trend for organ composition: composing idiomatically for this new kind of organ. The ACO, and compositions for it, had become the uniquely American contribution to the organ world, and Hebble had been a part of that.

Even with the renewed interest in "neo-Baroque" historical organs, the ACO continued to flourish in part due to radio and recordings. Fox recorded the famed Riverside organ frequently through the 1950s and 1960s. ${ }^{73}$ These recordings were increasingly available for purchase and played over the radio both nationally and

\footnotetext{
${ }^{71}$ Torrence, Richard. Virgil Fox, The Dish. Circles International, 2001, p. 117.

${ }^{72}$ Hebble's composition emphasized the panoply of divisions and tonal resources of the Riverside organ in particular since it was new in 1955, as not many organs have an English Horn as the pedal solo.

${ }^{73}$ Fox received five Honorary Doctorates in addition to numerous Repertoire and Performing certificates. He made eleven recordings on this organ from 1955 to 1958 alone.
} 
internationally. ${ }^{74}$ Aeolian Skinner was besieged with orders during this time and all other organ builders copied Skinner's building plans.

G.D. Harrison is quoted as saying that "as a result of the organ's transformation into a symphonic orchestra, it lost its original character". ${ }^{75}$ What is significant about this statement is that he then designed the ACO to play the standard repertoire. This is the resumption of organ building in "classic" or "historic" European organ style coupled with orchestral stops. This was enough to justify composing in a new style for a new instrument. This is exactly what Robert Hebble did with his compositions.

Thus, the ACO of the mid-twentieth century blended the style of organ sound and building concepts evolved into an eclectic instrument built to play a variety of repertoire. $^{76}$ With the radio playing recordings of performances of E. Power Biggs (1911-1977) and Fox of music by Dunstable through Bach to contemporary, and at a time when the phonograph was increasingly available to the consuming public, an organ was needed that could play it all. ${ }^{77}$

This eclectic design was epitomized in the Riverside organ of 1955, where Hebble's career started. The capabilities of this instrument are characterized by the following elements. These not only influenced future ACO design, but they also influenced how American organ composers thought about composing for this new instrument. These characteristics are paralleled in Hebble's compositional style. They are

\footnotetext{
${ }^{74}$ Fesperman, p. 44.

${ }^{75}$ Barnes, William Harrison. The Contemporary American Organ. Glen Rock, NJ: J. Fischer, (1971), p. 166. Harrison was referring to the earlier American organ and justifying his ideas with the ACO.

${ }^{76}$ Sumner, William Leslie. The Organ: Its Evolution, Principles of Construction and Use. MacDonald and Company, $3^{\text {rd }}$ edition, London, (1962), p. 89.

${ }^{77}$ Fesperman, p. 82.
} 
1) the use of antiphonal effects between two or even three divisions

2) the use of polyphonic textures which demand several separate 'voci' of equal clarity

3) the use of 'solo and accompaniment' requiring a variety of both reed and flue sounds

4) having the basic tonal resources such as (a) principal chorus consisting of 8' 4' 2 ' and mixture on at least two keyboards plus and comparable pedal specification (b) a chorus for 'forte' polyphonic music and support for congregational singing and (c) for French "Grands Jeux" having an 8' trumpet, $16^{\prime}$ bourdon and a tierce in the Great plus an $8^{\prime}$ trumpet in the pedal

5) possessing as many combinations for the playing of trios in two keyboards and uncoupled pedal as possible and for French Classic music a Cornet versus an $8^{\prime}$ Cromhorne with an $8^{\prime}$ bass in the pedal

6) having a variety of reed and flue sounds for plain or ornamented solo lines on keyboards and pedal. For Northern European Chorale "cantus" playing a 4' in the pedal is necessary as is an 8 ' trumpet for French plainsong 'cantus' lines

7) an adjustable tremulant is desirable for some American repertoire and is essential for French music ${ }^{78}$

In the end, it has been stated that too much versatility can destroy the sense of 'instrument' in an organ because it becomes unmanageable unless acoustics and

${ }^{78}$ Fesperman, p. 84. 
placement of the divisions are taken into account. ${ }^{79}$ Hebble uses all of the resources of the ACO and makes them work in his organ music. He uses the large organ well and knows how to make even small organs speak their best by composing with them in mind. The next chapter will explore how Hebble uses this new ACO in his organ compositions, now into the twenty-first century.

${ }^{79}$ Ibid., p. 83. 


\section{CHAPTER 5}

\section{Hebble's Use of the Organ}

"His use of the organ stops struck fear in the hearts of other organists" - C. P. E. Bach ${ }^{80}$

This section of the project examines how Robert Hebble uses the organ in his compositions: for example, which stops, which manuals or divisions, and which controls of the organ reveal the timbres and textures Hebble has in mind to articulate his music. It is divided into three parts: Part One discusses John Fesperman's concept of the "classic organ;" Part Two provides three charts which graph Hebble's organ registrations; and Part Three reveals the six recurrent or unique characteristics of Hebble's organ registration.

\section{Part One: the Classic Organ}

It should be noted that Fesperman's list from the previous chapter (see page 32) defines the ACO's ability to "legitimately play 'classic' repertoire", and that each item he postulates does not necessarily correspond to a representative organ work composed by Hebble. Yet his essay constitutes a landmark writing about the classic organ movement, and his ideas prove helpful to compare with Hebble's use of the organ. Part One shows how Hebble's use of the organ parallels the Fesperman "classic organ" list.

Fesperman's organ characteristic 1 is the use of "antiphonal effects" between two or even three divisions. Hebble's Heraldings Cp58 is a prime example of this. Hebble has trumpet stops from one end of the building sound a phrase of music, then has a

\footnotetext{
${ }^{80}$ C.P.E. Bach, in a necrology to Forkel 1774, recounting how his father, J.S. Bach, used organ stops.
} 
trumpet stop from the other end of the building respond: two antiphonal divisions. $\mathrm{He}$ then summons a third division in yet another area of the building by having the main organ enter with the principal theme after the series of opening fanfares. Some chorales that indicate an echo or antiphonal division are Bread of Life Cp32 and Nicea Cp52. Also, Nave $\mathrm{Cp} 1$ is not restricted to Flute Celestes from the main organ. One could employ Ethereal Strings from the antiphonal division to begin the piece and then at measure 17, when the double pedal enters, the organist could change manuals to include the required Celeste of the main organ. ${ }^{81}$ Also, Haec Dies Resurgam Cp37 contrasts the main organ in the front of the church against a "fff solo reed" which is mounted on the back wall of the church. Aside from antiphonal divisions are the echo effects created by playing various stops in alternation such as in O Saving Victim, Open Wide Cp112a, Symphony of Light Cp169 (1 ${ }^{\text {st }}$ and $4^{\text {th }}$ movements) and Good King Wenceslas Cp23. Finally, there is antiphonal phrasing, or echoes, such as in At the Cross Her Station Keeping Cp106 and Hail Holy Queen Enthroned Above Cp110. In these cases there are a series of written-out echoes, or repeats of the end of a phrase, which are each played on a different keyboard, rendering an antiphonal effect or echo.

Characteristic 2 of Fesperman's ACO characteristics requires "several separate 'voci' of equal clarity for polyphonic textures." ${ }^{\prime 2}$ Strict polyphony does not occur in the organ music of Robert Hebble. Although some of his textures are imitative or may state multiple themes concurrently, his textures approaching polyphony are often between contrasting stops on separate manuals and are not usually 'voci' within a single timbre.

\footnotetext{
${ }^{81}$ Tape 3 interview with the composer, April 21, 2002, Boca Raton Florida, side A.

${ }^{82}$ Fesperman, p. 84. He is referring, presumably, to one stop (or a few stops) which can clearly render separate voices because of the stop's evenness: not too much weight in the bass range or too much thinness or presence in the upper range. Its purpose would be to legitimately play a Bach organ fugue.
} 
There are two concurrent c.f. in Come, Holy Ghost, Creator Blest Cp108 (mm. 18-29, 33-37, 41-48) and Amazing Grace Cp31 on the same timbre.

The third characteristic of the classic organ espoused by Fesperman and employed by Hebble is "the use of 'solo and accompaniment' requiring a variety of both reed and flue sounds." 83 This is found in abundance in Hebble's organ music. In his first work for organ, Nave Cp1, Hebble accompanies with the Flute Celeste while a solo flute plays a tune. Later, in this same work, the strings in the manuals accompany the solo English Horn in the pedal. In his first collection, Ted Alan Worth in Concert, the only original work by Hebble ${ }^{84}$ is Londonderry Air Cp6, where the solo theme appears in the pedal while the manuals accompany on flutes and celestés. In his eleventh collection, Designs for Organ, Hebble indicates foundations as an accompaniment against a loud solo reed in The Majestic Trumpet Cp134 and in Trumpet Tune Cp135. Reeds are not the only solo stops Hebble uses, as the ACO has the panoply of flute sounds. In his Symphony of Light Cp169b the solo is a bourdon 8. And in his chorales such as Abide With Me Cp91 and Fairest Lord, Jesus Cp97, there are codas that conclude the work with a solo flute. There is also "Crepèscule” Cp70 from his Seven Palette Sketches, for solo flute with accompaniment. Other flutes serving as solos would be in his At Your Service collection, where the unspecified solo could be the principal 8 against an accompaniment of flutes. ${ }^{85}$ Further examples would be Praise to the Lord Cp125, Most Perfect Is the Law of God Cp124, Holy God, We Praise Thy Name Cp120 and Thee We Adore Cp126.

The fourth Fesperman classic organ characteristic is "having the basic tonal

\footnotetext{
${ }^{83}$ Ibid.

${ }^{84}$ The other pieces in the collection are arrangements he created and are not covered here.

${ }^{85}$ Hindemith, Hebble's teacher at Yale, also does not include specific registrations, only dynamic markings.
} 
resources such as (a) principal choruses consisting of $8,4,2$ and mixture on at least two keyboards plus a comparable pedal specification (b) a chorus for forte polyphonic music and support for congregational singing and (c) for French grands jeux having a trumpet 8 , bourdon 16 and a Tierce $(13 / 5)$ in the manual plus a trumpet 8 in the pedal. ${ }^{86}$ Regarding part (a), Hebble writes a number of works with this characteristic feature of the ACO (without reeds) using manual echoes: Toccata Brevis Cp42, Festive Piece on 'A Mighty Fortress' Cp98, Celebration Cp56, Exultate Deo Cp50, Toccata on 'Old Hundredth' Cp72, Schematics Cp63, Haec Dies Resurgam Cp37, Toccatino con Rico Tino Cp103, Symphony of Light Cp169a and Cp169d, Cwm Rhondda Cp36, Where Christmas Dwells Cp43, Postlude on 'Nicea' Cp52, Come, Holy Ghost Cp108, Hail, Holy Queen Cp110, Partita on Lobe Den Herren Cp171c "Finale", Variation on an American Hymn Cp170g "Toccata", and Variations on a Medieval Carol Cp104g. Each uses several principal choruses with a comparable pedal specification. The two different principal choruses serve to offer contrast and changes in dynamics. He also uses them coupled. Regarding part (b) "a chorus for forte polyphonic music and support for congregational singing," there are no sufficient examples of polyphony in Hebble's music. ${ }^{87}$ However, the entire seventh collection, The Hymnal Companion, is intended for use with congregational singing. There are few representative examples of French classic style registration in Hebble's organ music, let alone registration for (c) "for French grands jeux having a trumpet 8 , bourdon 16 and a Tierce $(13 / 5)$ in the manual plus a trumpet 8 in the pedal." However, the use of the manual chorus reeds and the 16'manual flue stop in addition to

\footnotetext{
${ }^{86}$ Ibid. Again, Fesperman's list acknowledges the ACO's ability to "legitimately play 'classic' repertoire", as Hebble never indicates a pure 'French Classic' organ registration. (See p. 84).

${ }^{87}$ There are several 'moments' of polyphony in Hebble's organ music (see Simms, p. 356). However, they encompass only a phrase or two and use a varied registration from Fesperman's.
} 
the pedal 8'reed does appear in his music. Representative examples of Hebble's organ music containing this specification are within such organ compositions as Variations on an American Hymn Cp172e, Toccata Brevis Cp42, Exultate Deo Cp50 and Toccatino con Rico Tino Cp103, Toccata on 'Old Hundredth’ Cp72, Jesus Shall Reign Cp121, Symphony of Light Cp169a and 169d, Haec Dies Resurgam Cp37, American Declaration Cp136, Variation on a Medieval Carol Cp104g “Toccata," Variations on an American Hymn Cp170g “Toccata," and Partita on Lobe Den Herren Cp171c "Finale."

The fifth ACO characteristic is that the organ should "possess as many combinations for the playing of trios on two keyboards and uncoupled pedal as possible and for French classic music a Cornet versus a Cromhorne 8 is mandatory with a bass 8 in the pedal." 88 Trio-like writing occurs rarely in the organ music of Hebble, and it is not always strict polyphony, ${ }^{89}$ such as in the Fugetta of Cwm Rhondda Cp36, O Saving Victim Open Wide Cp112a, Most Perfect Is the Law Cp124, and Divertimento Cp129. Hebble is fond of the Cromhorne 8 stop and uses it frequently as can be seen in Charts 1 and 2 in Part Two; however, he does not use it strictly in the French classic manner, which is in juxtaposition with the Cornet. The Cromhorne is indicated in these representative works as a solo against flutes, strings or mutations (e.g. 2 2/3, 1 1/3 with a flute 8), the latter of which are similar to a Cornet decomposé: Amazing Grace Cp31, Herzliebster Jesu Cp38, Simple Gifts Cp20, Divertimento Cp129, Variations on an American Hymn var5, Cp172f, Partita on 'Lobe Den Herren' Cp169b, Pastel Cp61, Diptych Cp57, Symphony of Light Cp169c, and I Wonder As I Wander Cp59.

\footnotetext{
${ }^{88}$ Fesperman, p. 84.

${ }^{89}$ Meaning it does not occur as a trio so titled with two differing treble voices accompanied by a bass voice, but are momentary phrases within an improvisational texture with two or three different timbres between the hands and pedal.
} 
The sixth organ characteristic is "having a variety of reed and flue sounds for plain or ornamented solo lines on keyboard and pedal." 90 Both reeds and flues are used plentifully as solos in Hebble's organ chorales. Use of the pedal reed solo includes Nave Cp1, and manual solos in Amazing Grace Cp31, My Shepherd Will Supply Cp60, Simple Gifts Cp20; and use of the flutes as solos include Fairest Lord, Jesus Cp97, Abide With Me Cp91, and Bread of Life Cp32. While most of these are single presentations of the c.f., there are a few that are ornamented (e.g. Abide with Me Cp91, Symphony of Light Cp169b, Haec Dies Resurgam Cp37). The entire tenth collection At Your Service marks the solo as $\boldsymbol{f}$ and stops are unspecified by Hebble; thus the choice of reed or flute solo is made by the performer.

The other part of Fesperman's sixth characteristic is "a 4 in the pedal is necessary as is a trumpet 8 for French plainsong 'cantus' lines." ${ }^{\text {,91 }}$ The use of the pedal stop 4, or a manual stop coupled to the pedal at 4, is common in Hebble's chorales. Representative works would be Nave Cp1, I Wonder As I Wander Cp59, O Little Town of Bethlehem Cp28, Where Christmas Dwells Cp43, Romanza Cp7, Londonderry Air Cp6, and Simple Gifts Cp20.

Finally, Fesperman states that "an adjustable tremulant is desirable for some American repertoire and is essential for French music." ${ }^{92}$ Indications for the use of the tremulant in Hebble's organ music are found in these representative examples: Seven Palette Sketches, “Rue des Saints-Pères” Cp64, “L’église Saint-Séverin” Cp66, “L’église Boissy-Saint-Antoine” Cp 68, Soft Stillness and the Night Cp 71, Pastel Cp 61, Psalm

\footnotetext{
${ }^{90} \mathrm{Ibid}$.

${ }^{91}$ Ibid.

${ }^{92}$ Ibid.
} 
Prelude Cp 62, Partita on Lobe Den Herren Cp 169b, Herzliebster Jesu Cp 38, Bread of Life Cp 32, Beatitudo Cp 33, Amazing Grace Cp 31, Londonderry Air Cp 6, O Saving Victim Open Wide Cp 112b, and Improvisation on "Veni Creator" Cp 115.

This concludes part one of this chapter. As seen above, Hebble's organ music is squarely ensconced within the traditional paradigm of the classic organ. Part two begins with a chart detailing Hebble's use of stops through 172 of his published organ works, including organ arrangements, which are essential to an understanding of his approach. Although a longer response follows the chart, a short explanation of the colors and categories here will provide clarification. The colors in Chart 1 from left to right begin with two dark blues to signify the early stages of organ stops (thirteenth through sixteenth centuries). The next lighter blues and greens to the right signify the capabilities of the organs of this period and additions made to them during the seventeenth and eighteenth centuries. These organs had less-used stops, which are delineated in the middle gray areas. The yellow and red areas show the developments and stop usage of organs in the nineteenth and twentieth centuries. The colors from left to right show the growth of the organ from 1300 to the present. The stops and capabilities of the ACO encompass the entire Chart 1. 


\section{Part Two}

Hebble's Use of Stops (Registration): Chart 1

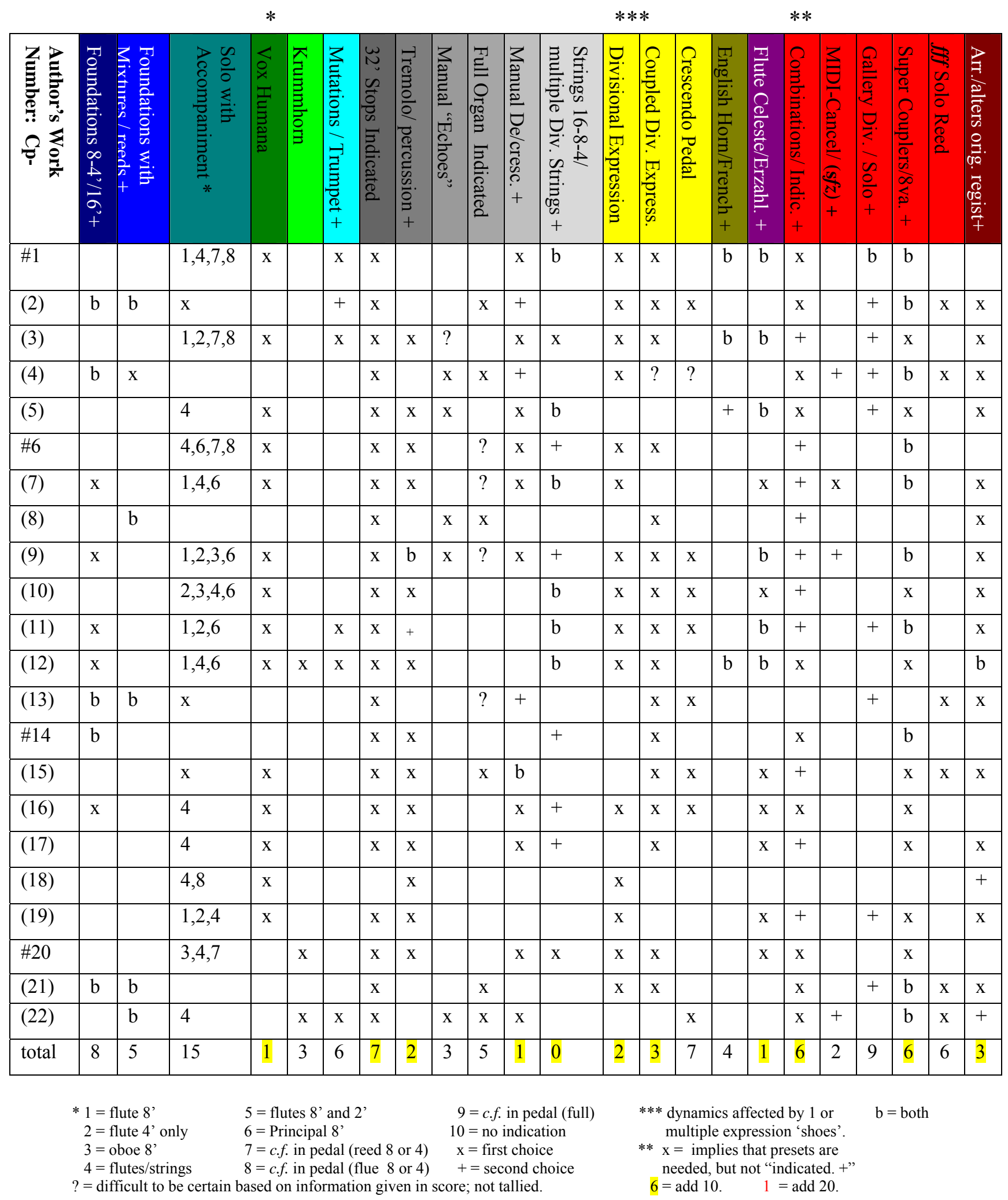




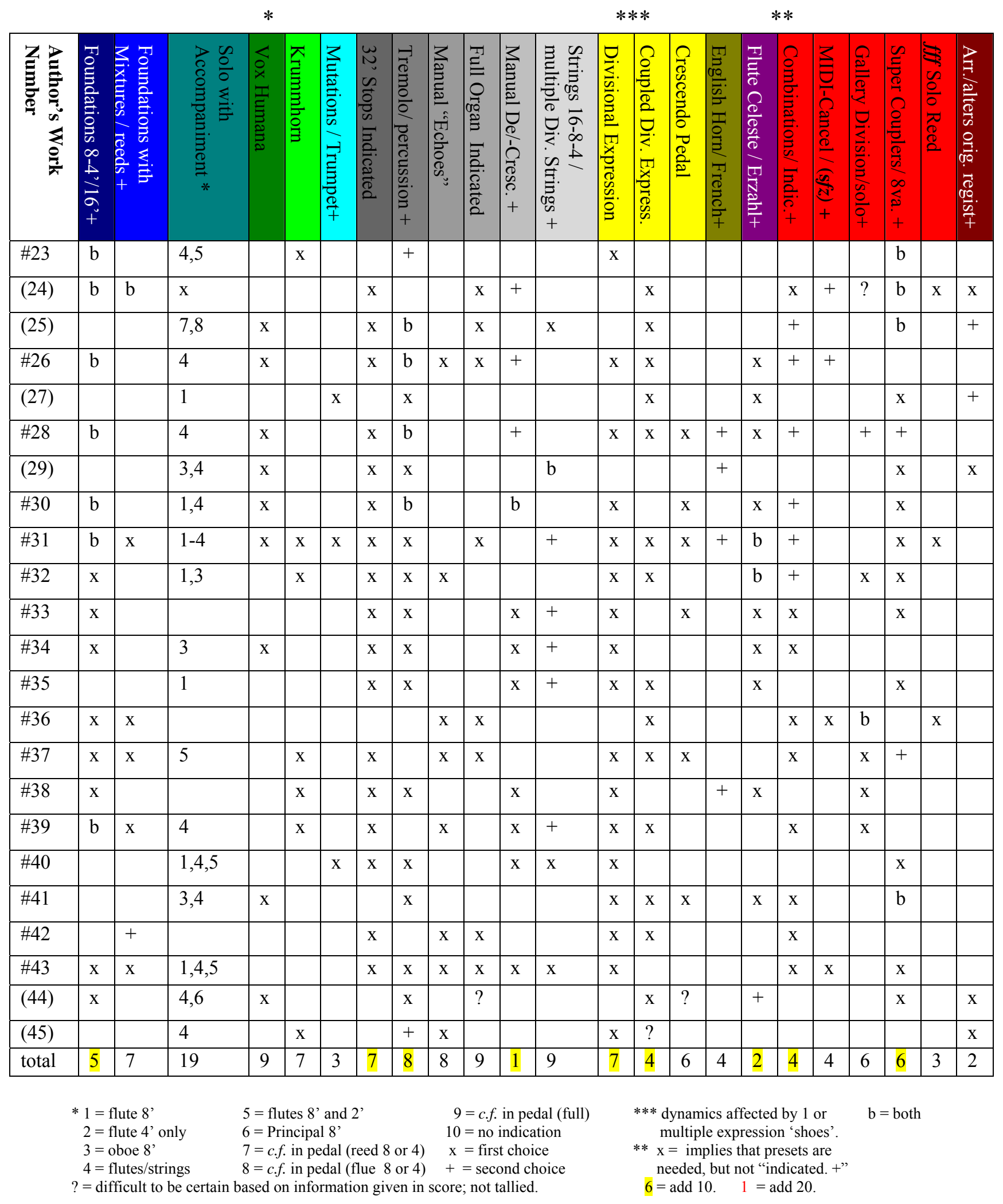




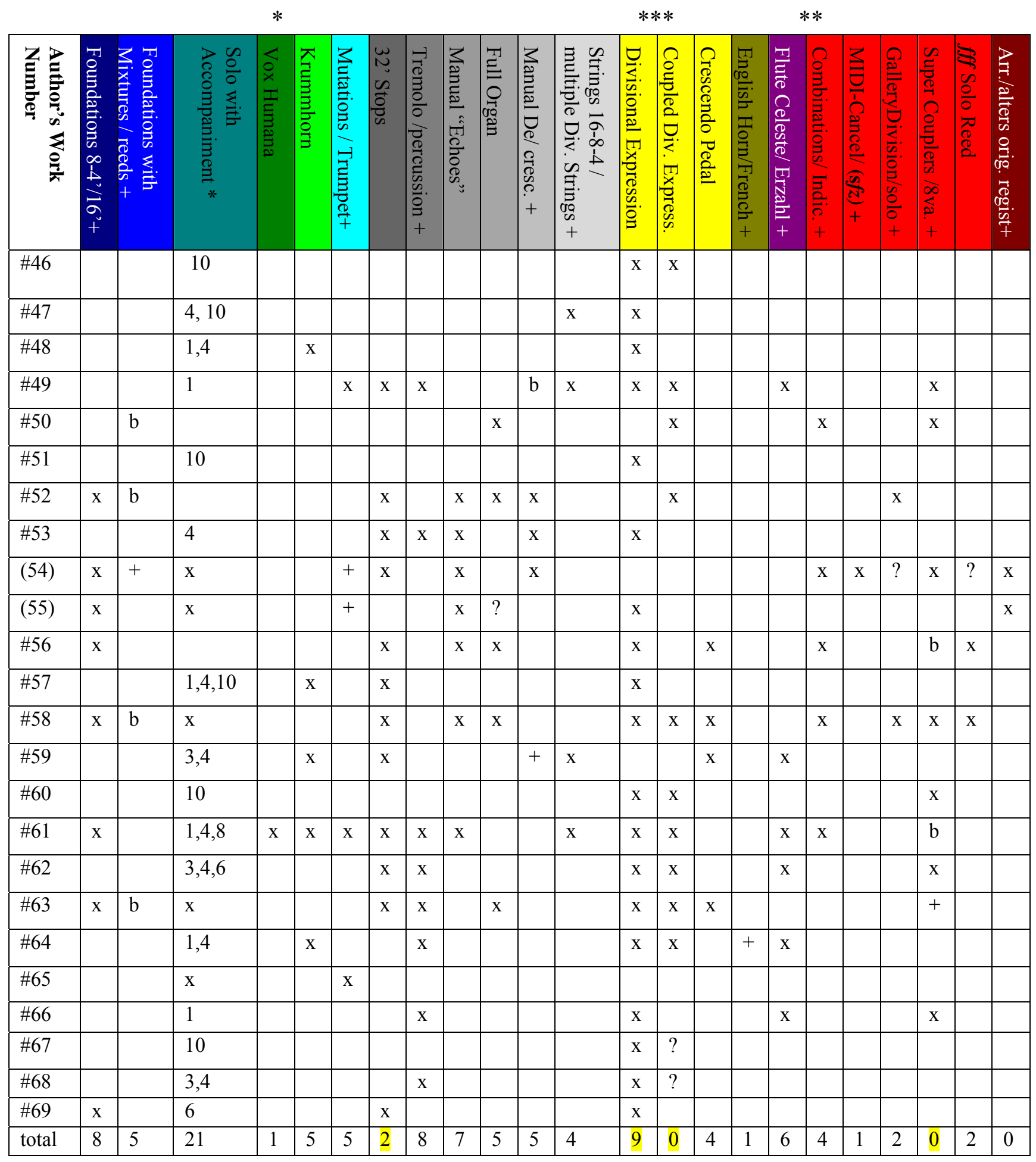

$* 1=$ flute $8 *$

2 = flute 4 ' only

$3=$ oboe 8 ,

$5=$ flutes $8^{\prime}$ and $2^{\prime}$

$6=$ Principal 8

$7=$ c.f. in pedal (reed 8 or 4$)$

$9=$ c.f. in pedal (full)

$10=$ no indication

$4=$ flutes/strings

$8=$ c.f. in pedal (flue 8 or 4 ) $\quad+=$ second choice

$?=$ difficult to be certain based on information given in score; not tallied.

\footnotetext{
*** dynamics affected by 1 or $\quad b=$ both multiple expression 'shoes'.

** $\mathrm{x}=$ implies that presets are needed, but not "indicated. + "

$6=$ add $10 . \quad 1=$ add 20.
} 


\begin{tabular}{|c|c|c|c|c|c|c|c|c|c|c|c|c|c|c|c|c|c|c|c|c|c|c|c|}
\hline & & & & $*$ & & & & & & & & & & $* *$ & & & & $*$ & & & & & \\
\hline 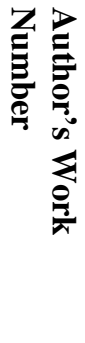 & 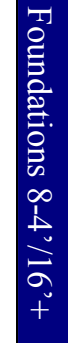 & 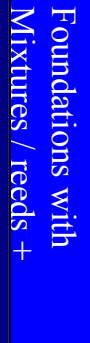 & 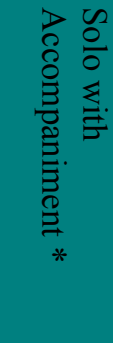 & 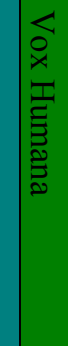 & 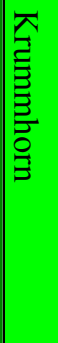 & 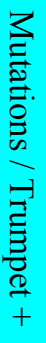 & 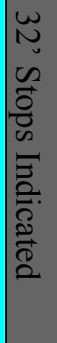 & $\begin{array}{l}=1 \\
0 \\
0 \\
0 \\
0 \\
0 \\
0 \\
0 \\
0 \\
0 \\
\tilde{0} \\
\tilde{0} \\
0 . \\
0 \\
= \\
+\end{array}$ & 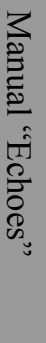 & 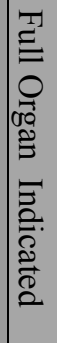 & 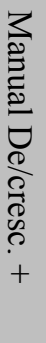 & 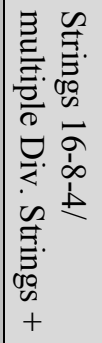 & 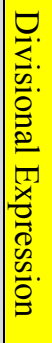 & 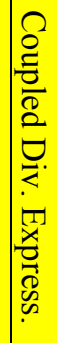 & 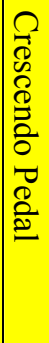 & 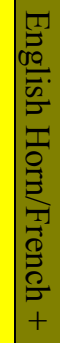 & 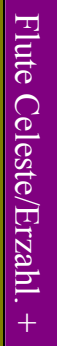 & 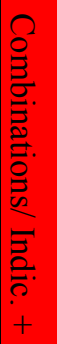 & 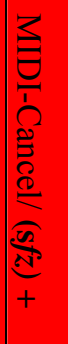 & 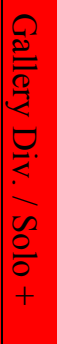 & 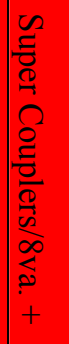 & 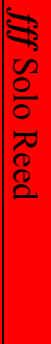 & 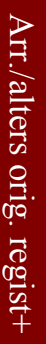 \\
\hline$\# 70$ & $\mathrm{x}$ & & 1,4 & & & & $\mathrm{x}$ & & & & $\mathrm{x}$ & & $\mathrm{x}$ & $?$ & & & $\mathrm{x}$ & & & & $\mathrm{x}$ & & \\
\hline$\# 71$ & $\mathrm{x}$ & & $2,4,8$ & $\mathrm{x}$ & $\mathrm{x}$ & & $\mathrm{X}$ & $x$ & & & & + & $\mathrm{x}$ & $\mathrm{x}$ & & & $\mathrm{X}$ & $\mathrm{X}$ & & & $\mathrm{x}$ & & \\
\hline$\# 72$ & $X$ & & 9 & & & & $\mathrm{X}$ & & $\mathrm{X}$ & $\mathrm{X}$ & & & $x$ & $?$ & & & & $x$ & & & & $\mathrm{X}$ & \\
\hline$\# 73$ & $\mathrm{X}$ & & & & & & & & & & $?$ & & $?$ & $?$ & $?$ & & & & & & & & \\
\hline$\# 74$ & $\mathrm{X}$ & $\mathrm{x}$ & & & & & & & & & & & & & & & & & & & & & \\
\hline$\# 75$ & $\mathrm{x}$ & $\mathrm{b}$ & 4 & & & & & & & & & & & & & & & & & & & & \\
\hline$\# 76$ & $\mathrm{X}$ & $\mathrm{x}$ & & & & & & & & & & & & & & & & & & & & & \\
\hline$\# 77$ & $\mathrm{x}$ & $\mathrm{X}$ & & & & & & & & & & & & & & & & & & & & & \\
\hline$\# 78$ & $\mathrm{x}$ & $\mathrm{x}$ & & & & & & & & & & & & & & & & & & & & & \\
\hline$\# 79$ & $X$ & $\mathrm{~b}$ & & & & & & & & & & & & & & & & & & & & & \\
\hline$\# 80$ & $\mathrm{X}$ & $\mathrm{x}$ & & & & & & & & & & & & & & & & & & & & & \\
\hline$\# 81$ & $\mathrm{x}$ & $\mathrm{x}$ & & & & & & & & & & & & & & & & & & & & & \\
\hline$\# 82$ & $\mathrm{X}$ & $\mathrm{x}$ & & & & & & & & & & & & & & & & & & & & & \\
\hline$\# 83$ & $\mathrm{x}$ & $\mathrm{x}$ & & & & & & & & & & & & & & & & & & & & & \\
\hline$\# 84$ & $\mathrm{x}$ & $\mathrm{b}$ & & & & & & & $\mathrm{x}$ & & & & & & & & & & & + & & & \\
\hline$\# 85$ & $\mathrm{x}$ & $\mathrm{x}$ & & & & & & & $\mathrm{x}$ & & & & & & & & & & & + & $\mathrm{x}$ & $\mathrm{x}$ & \\
\hline$\# 86$ & $\mathrm{x}$ & $\mathrm{b}$ & & & & & & & & & & & & & & & & & & & & & \\
\hline$\# 87$ & $\mathrm{X}$ & $\mathrm{X}$ & & & & & & & & & & & & & & & & & & & & & \\
\hline$\# 88$ & $\mathrm{x}$ & $\mathrm{x}$ & & & & & & & & & & & & & & & & & & & & & \\
\hline \#89 & $\mathrm{x}$ & $\mathrm{x}$ & & & & & & & & & & & & & & & & & & & $\mathrm{x}$ & & \\
\hline$\# 90$ & $\mathrm{X}$ & $\mathrm{b}$ & & & & & & & & & & & & & & & & & & & & & \\
\hline \#91 & $\mathrm{x}$ & & 1,3 & $\mathrm{x}$ & & $\mathrm{X}$ & $\mathrm{x}$ & $\mathrm{x}$ & & & $\mathrm{x}$ & & $\mathrm{x}$ & $\mathrm{x}$ & $\mathrm{x}$ & & $\mathrm{x}$ & $x$ & & & & & \\
\hline$\# 92$ & $\mathrm{x}$ & $\mathrm{x}$ & & & & & $\mathrm{x}$ & & $\mathrm{x}$ & $\mathrm{x}$ & & & $\mathrm{x}$ & $\mathrm{x}$ & & & $\mathrm{x}$ & $\mathrm{x}$ & & $\mathrm{x}$ & & $\mathrm{x}$ & \\
\hline total & 1 & 18 & 5 & 2 & 1 & 1 & 5 & 2 & 4 & 2 & 2 & 1 & 5 & 3 & 1 & 0 & 4 & 4 & 0 & 3 & 4 & 3 & 0 \\
\hline \multicolumn{4}{|c|}{$\begin{aligned} * 1 & =\text { flute } 8 \\
2 & =\text { flute } 4 \\
3 & =\text { oboe } 8 \\
4 & =\text { flutes/string } \\
?= & \text { difficult to be }\end{aligned}$} & $\begin{array}{l}5=\mathrm{fl} \\
6=\mathrm{P} \\
7=c . \\
8=c .\end{array}$ & $\begin{array}{l}\text { ites } 8 \\
\text { incip } \\
\text { f. in p } \\
\text { fin } \mathrm{p}\end{array}$ & & $\begin{array}{l}\text { reed } \\
\text { flue }\end{array}$ & $\begin{array}{l}\text { or 4) } \\
\text { or 4) }\end{array}$ & & $\begin{array}{l}=c . \\
=\text { no } \\
=\text { fir } \\
=\mathrm{se}\end{array}$ & $\begin{array}{l}\mathrm{np} \\
\text { adic } \\
\text { cho } \\
\text { nd }\end{array}$ & $\begin{array}{l}\text { dal (full) } \\
\text { ation } \\
\text { ice } \\
\text { hoice }\end{array}$ & & \multicolumn{6}{|c|}{ 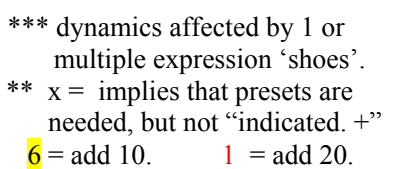 } & \multicolumn{2}{|c|}{$\mathrm{b}=$ both } & & \\
\hline
\end{tabular}




\begin{tabular}{|c|c|c|c|c|c|c|c|c|c|c|c|c|c|c|c|c|c|c|c|c|c|c|c|}
\hline & & & & $*$ & & & & & & & & & $*$ & & & & & $* *$ & & & & & \\
\hline 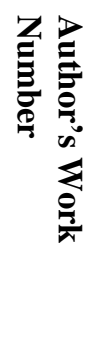 & 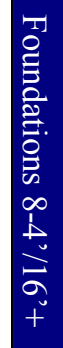 & 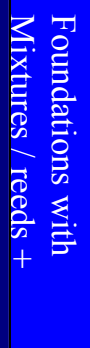 & 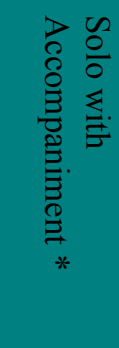 & 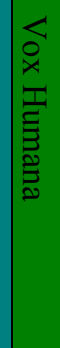 & 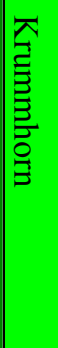 & 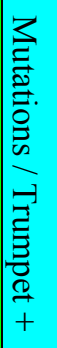 & 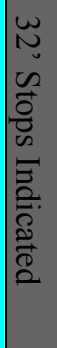 & $\begin{array}{l}\exists \\
\overrightarrow{0} \\
3 \\
0 \\
0 \\
0 \\
0 \\
0 \\
0 \\
0 \\
0 \\
0 \\
0 . \\
0 \\
0 \\
+\end{array}$ & 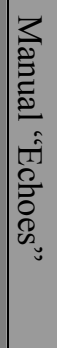 & 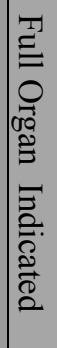 & 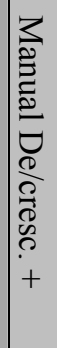 & 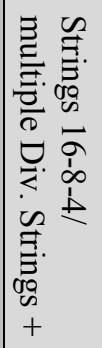 & 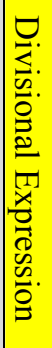 & 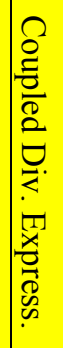 & $\begin{array}{l}\Omega \\
0 \\
0 \\
0 \\
0 \\
2 \\
0 \\
0 \\
0 \\
0 \\
2\end{array}$ & 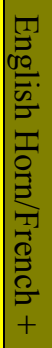 & 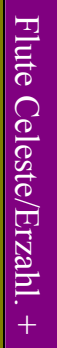 & 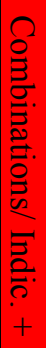 & 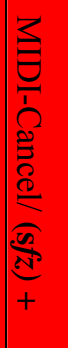 & 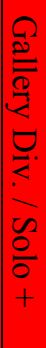 & 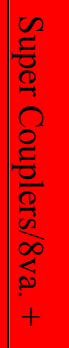 & 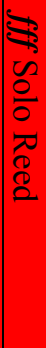 & 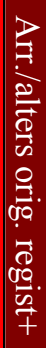 \\
\hline$\# 93$ & & & 5 & & & & & & $\mathrm{x}$ & & & & & & $\mathrm{x}$ & & & & & & $\mathrm{x}$ & & \\
\hline$\# 94$ & & & 4,9 & & & & & & & & & & $\mathrm{X}$ & $\mathrm{x}$ & & & & & & & & & \\
\hline$\# 95$ & $\mathrm{x}$ & & 1,3 & & & & $\mathrm{x}$ & $\mathrm{x}$ & & & $\mathrm{X}$ & & $\mathrm{X}$ & $\mathrm{x}$ & $\mathrm{x}$ & & & $\mathrm{X}$ & & & $\mathrm{X}$ & & \\
\hline$\# 96$ & & & 10 & & & & & $\mathrm{x}$ & & & & & $\mathrm{x}$ & & & & & & & & & & \\
\hline$\# 97$ & & & 1 & & & & $\mathrm{x}$ & $\mathrm{x}$ & & & & & $\mathrm{x}$ & & & & $\mathrm{x}$ & & & & & & \\
\hline \#98 & $\mathrm{b}$ & $\mathrm{b}$ & 4 & & & & $\mathrm{x}$ & $\mathrm{x}$ & $\mathrm{x}$ & $\mathrm{x}$ & & & $\mathrm{x}$ & $\mathrm{x}$ & & & & $\mathrm{x}$ & & & $\mathrm{x}$ & $\mathrm{x}$ & \\
\hline \#99 & & & 1 & & $\mathrm{x}$ & $\mathrm{x}$ & $\mathrm{X}$ & $\mathrm{x}$ & & & & & $\mathrm{X}$ & $\mathrm{x}$ & & & $\mathrm{X}$ & & & & & & \\
\hline$\# 100$ & & & 1,4 & & & $\mathrm{x}$ & & $\mathrm{x}$ & & & & $\mathrm{x}$ & $\mathrm{X}$ & & & & $\mathrm{x}$ & & & & $\mathrm{x}$ & & \\
\hline \#101 & $\mathrm{x}$ & $\mathrm{b}$ & & & & $\mathrm{x}$ & $\mathrm{x}$ & & & & $\mathrm{X}$ & & $\mathrm{X}$ & & & & & & & & + & $\mathrm{x}$ & \\
\hline \#102 & & & 7 & & & $\mathrm{x}$ & & & & & & & & & & & & & & & & & \\
\hline$\# 103$ & & $\mathrm{x}$ & 9 & & & & $\mathrm{X}$ & & & $\mathrm{x}$ & & & & $\mathrm{x}$ & & & & & & & $\mathrm{x}$ & $\mathrm{x}$ & \\
\hline$\# 104$ & $\mathrm{~b}$ & $\mathrm{~b}$ & all & $\mathrm{x}$ & $\mathrm{x}$ & $\mathrm{b}$ & $\mathrm{x}$ & $\mathrm{x}$ & $\mathrm{x}$ & $\mathrm{x}$ & $\mathrm{b}$ & $\mathrm{b}$ & $\mathrm{x}$ & $\mathrm{x}$ & $\mathrm{x}$ & & $\mathrm{x}$ & $\mathrm{x}$ & + & $b$ & $\mathrm{~b}$ & $\mathrm{x}$ & \\
\hline$\# 105$ & $\mathrm{x}$ & & 1,4 & & $\mathrm{x}$ & $\mathrm{x}$ & $\mathrm{x}$ & & & & & & $\mathrm{X}$ & & & & $\mathrm{X}$ & & & & & & \\
\hline \#106 & $\mathrm{x}$ & $\mathrm{x}$ & & & & & & & $\mathrm{x}$ & & & & & $\mathrm{x}$ & & & $\mathrm{x}$ & & & $\mathrm{x}$ & & & \\
\hline \#107 & $\mathrm{X}$ & & 4 & & & & & & & & & & & $\mathrm{x}$ & & & & & & & & & \\
\hline \#108 & & $\mathrm{x}$ & 9 & & & & & & $\mathrm{x}$ & $\mathrm{x}$ & & & & & & & & & & + & $\mathrm{x}$ & $\mathrm{x}$ & \\
\hline$\# 109$ & & $\mathrm{x}$ & & & & & & & & $\mathrm{x}$ & & & & $\mathrm{x}$ & & & & & & + & $\mathrm{x}$ & $\mathrm{x}$ & \\
\hline$\# 110$ & $\mathrm{x}$ & $\mathrm{x}$ & 5 & & & & & & $\mathrm{x}$ & & & & $\mathrm{x}$ & & & & $\mathrm{x}$ & $\mathrm{x}$ & & $\mathrm{x}$ & & & \\
\hline \#111 & & & $1,4,10$ & & & & & & & & & & $\mathrm{x}$ & & & & $\mathrm{x}$ & & & & & & \\
\hline $\begin{array}{l}\# 112 \\
\mathrm{a}\end{array}$ & & & & & & $\mathrm{x}$ & & & & & & & $\mathrm{x}$ & & & & $\mathrm{x}$ & & & & & & \\
\hline $\begin{array}{l}\# 112 \\
b\end{array}$ & & & 4 & $\mathrm{x}$ & & & $\mathrm{x}$ & $\mathrm{X}$ & $\mathrm{x}$ & & & & $\mathrm{X}$ & & & & & & & & $\mathrm{x}$ & & \\
\hline$\# 113$ & & & $1,3,4$ & & & & & & & & & & & & & & $\mathrm{x}$ & & & & & & \\
\hline$\# 114$ & & & $1,3,4$ & & $\mathrm{x}$ & $\mathrm{x}$ & $\mathrm{x}$ & & $\mathrm{x}$ & & & & $\mathrm{x}$ & $\mathrm{x}$ & & & $\mathrm{x}$ & & & & & & \\
\hline total & 7 & 8 & 19 & 2 & 4 & 8 & 0 & 8 & 7 & 5 & 3 & 2 & 5 & 0 & 3 & 0 & 1 & 4 & 1 & 5 & 0 & 6 & 0 \\
\hline \multicolumn{4}{|c|}{$\begin{aligned} & * 1=\text { flute } 8 \\
& 2=\text { flute } 4 \\
& 3=\text { oboe } 8 \\
& 4=\text { flutes } \\
& \text { /strings } \\
& ?=\text { difficult to be c }\end{aligned}$} & $\begin{array}{l}5=\mathrm{fl} \\
6=\mathrm{P} \\
7=c . \\
8=c .\end{array}$ & $\begin{array}{l}\text { es } 8 \\
\text { ncip. } \\
\text { in } p \\
\text { in } p \\
\text { info }\end{array}$ & $\begin{array}{l}\text { and } \\
18 \text {, } \\
\text { edal } \\
\text { edal } \\
\text { rmati }\end{array}$ & $\begin{array}{l}\text { reed } \\
\text { flue } \\
\text { on gi }\end{array}$ & $\begin{array}{l}\text { or 4) } \\
\text { or } 4) \\
\text { en in }\end{array}$ & ) & $\begin{array}{l}=c . \\
=\text { no } \\
=\text { fir } \\
=\text { se }\end{array}$ & $\begin{array}{l}\text { in p } \\
\text { indic } \\
\text { st cho } \\
\text { cond }\end{array}$ & $\begin{array}{l}\text { dal (full) } \\
\text { ation } \\
\text { ice } \\
\text { hoice }\end{array}$ & & \multicolumn{6}{|c|}{ 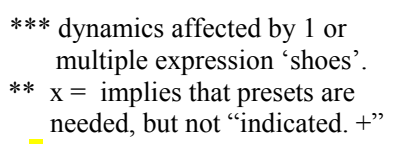 } & \multicolumn{2}{|c|}{$\mathrm{b}=$ both } & & \\
\hline
\end{tabular}




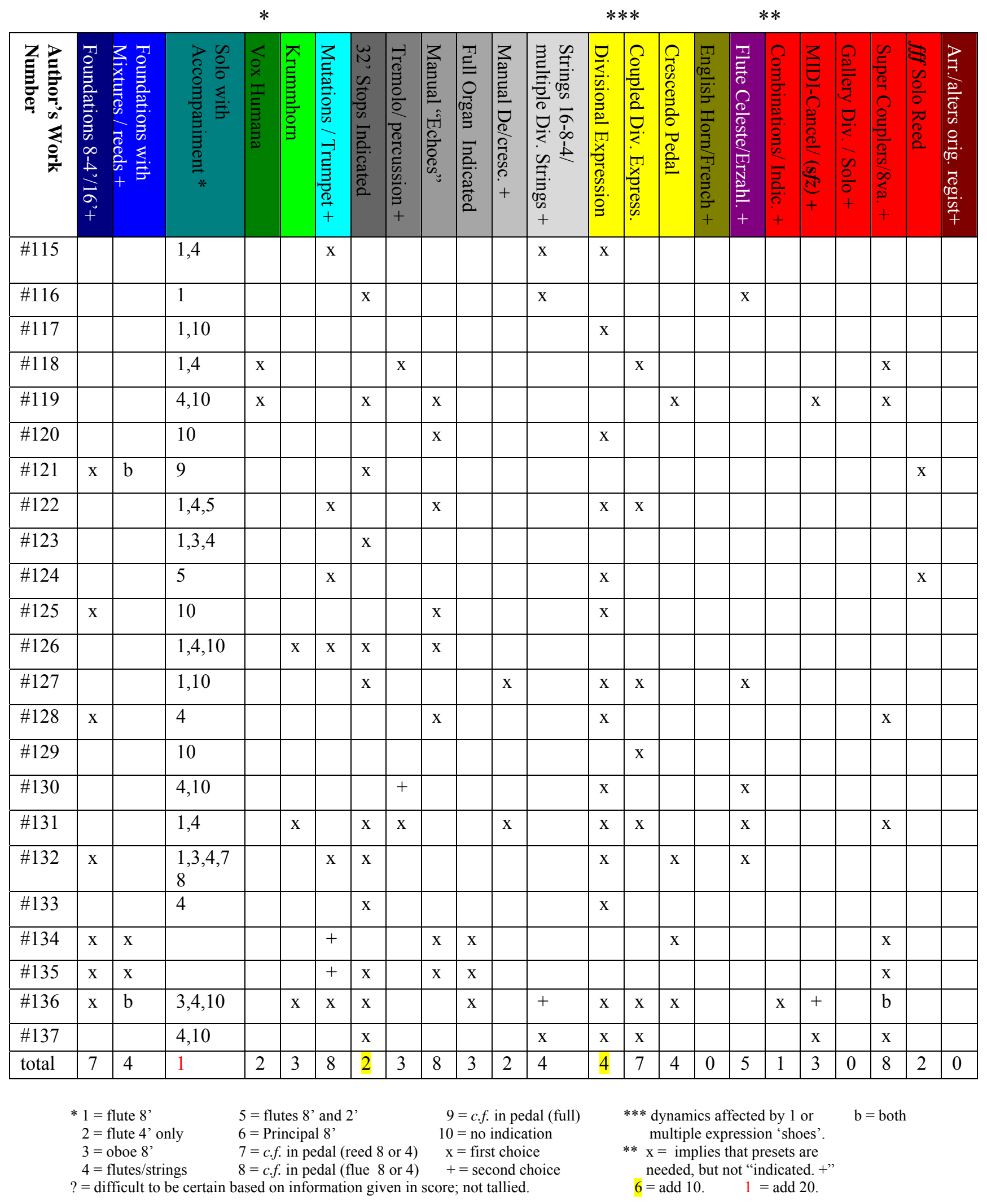




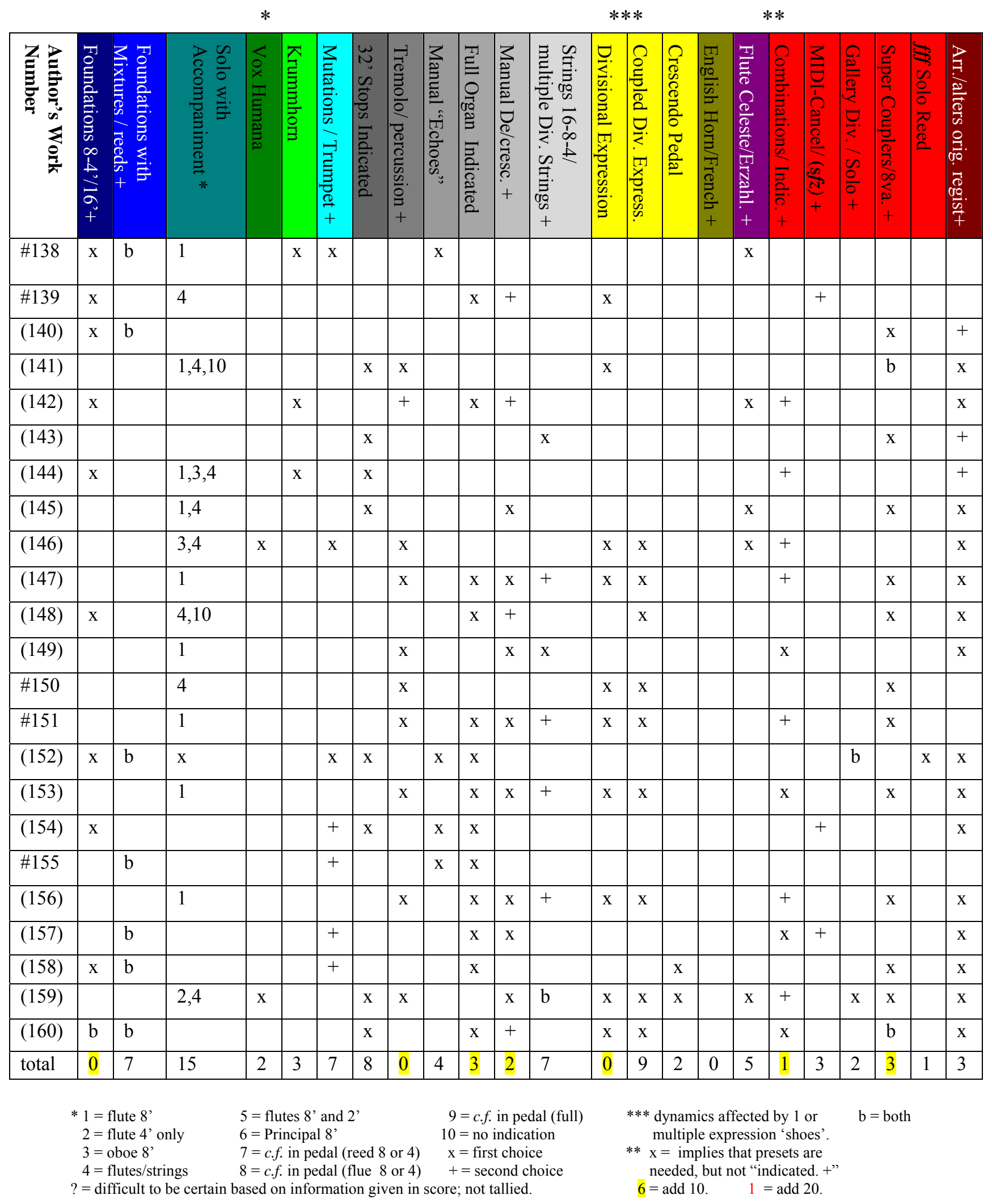




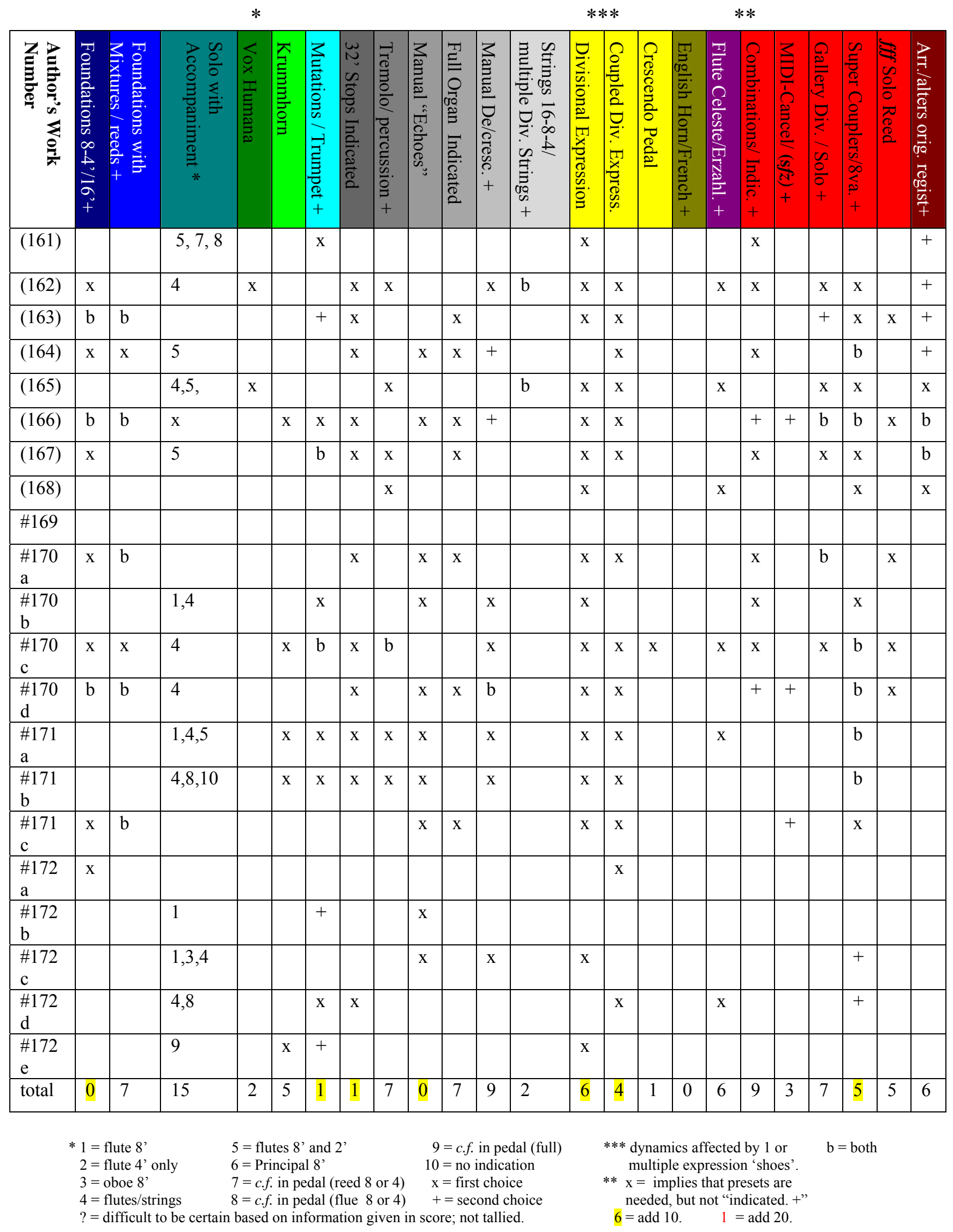




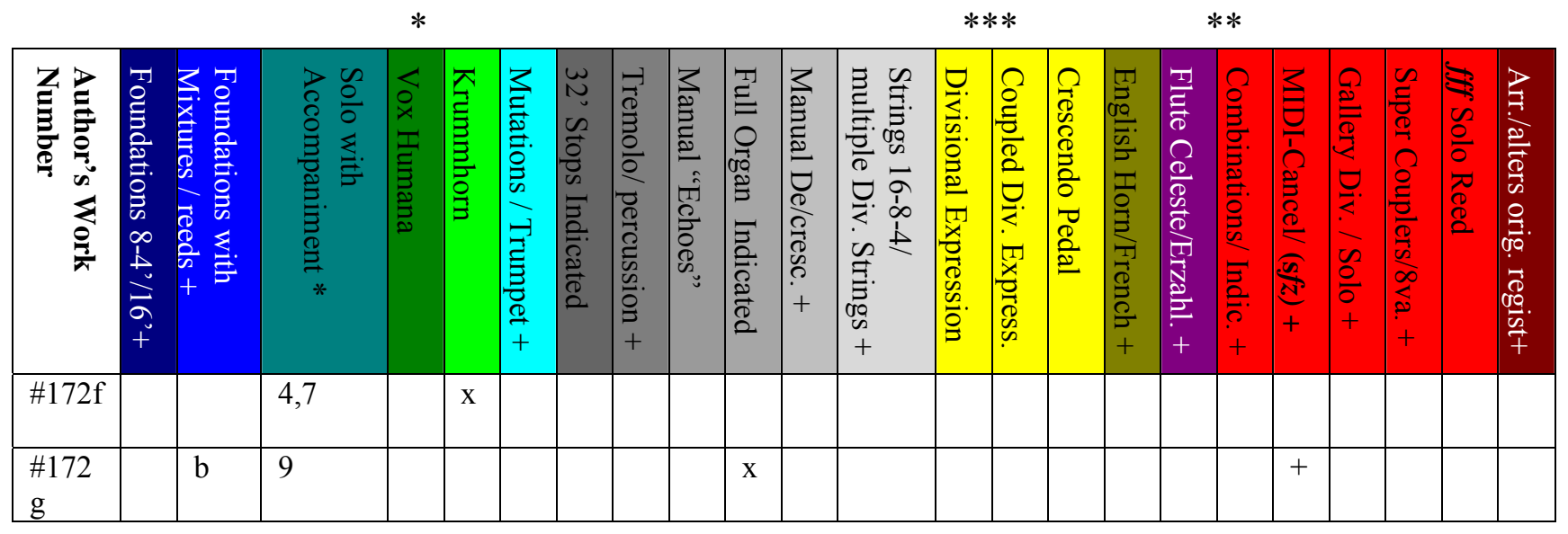

TOTALS:

\begin{tabular}{|c|c|c|}
\hline $\begin{array}{l}\text { Foundations 8'-4' } \\
\text { (with 16') } \\
\text { only } 16^{\prime}\end{array}$ & $\begin{array}{l}=88 \\
=18 \\
=0\end{array}$ & $\begin{array}{c}\text { English Horn indicated } \\
\text { (French Horn) } \\
\text { both stops }\end{array}$ \\
\hline $\begin{array}{r}\text { Foundations with } \mathrm{M} \\
\text { (and reeds) } \\
\text { foundations with onl }\end{array}$ & $\begin{array}{r}\mathrm{s}=62 \\
=32 \\
\mathrm{ds}=2\end{array}$ & $\begin{array}{c}\text { Flute Celeste indicated } \\
\text { (Erzãhlers) } \\
\text { both stops }\end{array}$ \\
\hline
\end{tabular}

Use of a solo manual against [see separate graph below for this category] accompaniment manual $=\mathbf{1} / 52 ; \mathbf{2} / 9 ; \mathbf{3} / 20 ; \mathbf{4} / 76 ; \mathbf{5} / 12 ; \mathbf{6} / 10 ; \mathbf{7} / 10 ; \mathbf{8} / 11 ; \mathbf{9} / 6 ; \mathbf{1 0} / 22$.

\begin{tabular}{|c|c|c|c|}
\hline Vox Humana & $=34$ & $\begin{array}{c}\text { Combinations needed } \\
\text { (indicated) }\end{array}$ & $\begin{array}{l}=44 \\
=25\end{array}$ \\
\hline Krummhorn & $=32$ & & \\
\hline $\begin{array}{l}\text { Mutations } \\
\text { (chorus trumpet) }\end{array}$ & $\begin{array}{l}=49 \\
=12\end{array}$ & $\begin{array}{c}\text { Use of MIDI or "Cancel" } \\
\text { (sfz indicated })\end{array}$ & $\begin{array}{l}=5 \\
=14\end{array}$ \\
\hline $\begin{array}{l}\text { (chorus trumpet) } \\
\text { both stops }\end{array}$ & $\begin{array}{l}=12 \\
=3\end{array}$ & $\begin{array}{c}\text { Use of a Gallery Division } \\
\text { (Solo Division) }\end{array}$ & $\begin{array}{l}=20 \\
=20\end{array}$ \\
\hline 32 ' stops indicated & $=96$ & both divisions & $=6$ \\
\hline $\begin{array}{l}\text { Use of Tremulant } \\
\text { (percussion) } \\
\text { both stops }\end{array}$ & $\begin{array}{l}=71 \\
=11 \\
=6\end{array}$ & $\begin{array}{c}\text { Use of Super Couplers 4' } \\
\text { (8va. indicated) } \\
\text { both uses }\end{array}$ & $\begin{array}{l}=89 \\
=31 \\
=26\end{array}$ \\
\hline Use of manual "echoes" & $=54$ & Use of $f f f$ solo reed & $=26$ \\
\hline Indicates "Full Organ" & $=53$ & $\begin{array}{l}\text { Is an arrangement } \\
\text { (alters original registration) }\end{array}$ & $\begin{array}{l}=40 \\
1)=14\end{array}$ \\
\hline $\begin{array}{l}\text { Uses a manual decrescendo } \\
\text { (crescendo) } \\
\text { both uses }\end{array}$ & $\begin{array}{l}o=58 \\
=18 \\
=10\end{array}$ & [regarding organ works] & \\
\hline $\begin{array}{l}\text { Use of Strings } 16^{\prime}-8^{\prime}-4^{\prime} \\
\text { (coupled strings) } \\
\text { both uses }\end{array}$ & $\begin{array}{l}=[\text { intramanual }] 26 \\
=[\text { intermanual }] 27 \\
=10\end{array}$ & $\begin{array}{l}\text { Divisional expression } \\
\text { Coupled Div. Expression }\end{array}$ & $\begin{array}{l}=111 \\
=83\end{array}$ \\
\hline Use of Crescendo Pedal & $=29$ & END OF CHART 1 & \\
\hline
\end{tabular}




\section{Chart 2: "Solo and Accompaniment" Organ Registration of Hebble}

\begin{tabular}{|c|c|c|c|c|c|c|c|c|c|c|}
\hline & 53 & 9 & 20 & 76 & 12 & 10 & 10 & 11 & 6 & 22 \\
\hline 70 & & & & & & & & & & \\
\hline 65 & & & & & & & & & & \\
\hline 60 & & & & & & & & & & \\
\hline 55 & & & & & & & & & & \\
\hline 50 & & & & & & & & & & \\
\hline 45 & & & & & & & & & & \\
\hline 40 & & & & & & & & & & \\
\hline 35 & & & & & & & & & & \\
\hline 30 & & & & & & & & & & \\
\hline 25 & & & & & & & & & & \\
\hline 20 & & & & & & & & & & \\
\hline 15 & & & & & & & & & & \\
\hline 10 & & & & & & & & & & \\
\hline 5 & & & & & & & & & & \\
\hline & 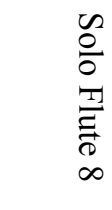 & $\begin{array}{l}n \\
0 \\
0 \\
\stackrel{\overrightarrow{0}}{\overrightarrow{0}} \\
\overrightarrow{0} \\
\vec{D}\end{array}$ & $\begin{array}{l}\mathscr{W} \\
0 \\
0 \\
0 \\
\varnothing \\
\infty \\
\infty\end{array}$ & 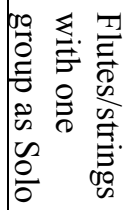 & 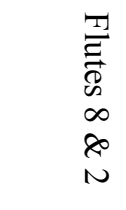 & 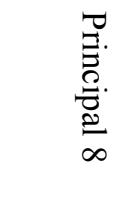 & 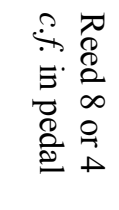 & 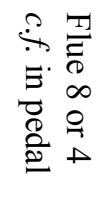 & 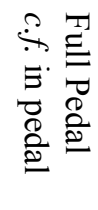 & 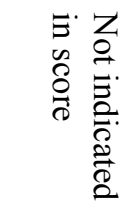 \\
\hline
\end{tabular}

Solo Groups

Overall Hebble Organ Registration: Chart 3

(Compilation of Charts 1 and 2)

\begin{tabular}{lllllllllll}
10 & 20 & 30 & 40 & 50 & 60 & 70 & 80 & 90 & 100 & 110 \\
\hline
\end{tabular}

Foundations 8'-4'.

$\left(\right.$ with $\left.16^{\prime}\right)=\ldots \ldots . . \mid 18$

Foundations with Mixtures $=$

$($ and reeds $)=\ldots \ldots \ldots \ldots \ldots \ldots . \mid 32$
Foundations with only reeds $=2$

Use of a solo manual against

accompaniment manual $=\mathbf{1}$

$2 \ldots \ldots \ldots . \mid 9$

3 ................ 20

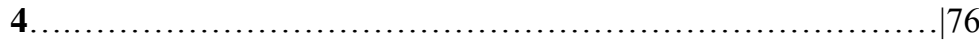




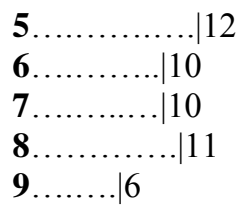

$10 \ldots \ldots \ldots \ldots \ldots \ldots \ldots .22$

Vox Humana .....................34

Krummhorn .................... 32

Mutations .49

(chorus trumpet) $=12$

both stops $=3$

32' stops indicated

Use of Tremulant |96

$($ percussion $)=11$

both stops $=6$

Use of manual "echoes" .154

Indicates "Full Organ". ..53

(alters original registration) $=14$

Uses a manual Decrescendo .158

$($ Crescendo $)=18$

both uses $=10$

Use of Strings 16' -8 ' -4 ' = 26

(coupled strings) $=27$

both uses $=10$

Use of Crescendo Pedal......|29

English Horn indicated $=3$

$($ French Horn $)=9$

both stops $=3$

Flute Celeste indicated. 62

$($ Erzãhlers $)=10$

both stops $=8$

Combinations needed.

$($ indicated $)=\ldots \ldots \ldots . \mid 25$

$(\boldsymbol{s f z}$ indicated $)=14$

Use of MIDI or "Cancel" $=5$

Use of a Gallery Division $=20$

(Solo Division)....|20

both divisions $=6$

Use of Super Couplers 4'

(8va. indicated)................ 31

both uses ................. 26

Use of fff solo reed....... 26

Is an arrangement.................... 40

Divisional expression.....

Coupled Div. Expression.

.


"Foundations 8 and 4". When Hebble indicated that the performer should add the pedal Posaune 16 and Choir Petite Trompette 8, and Positiv Terzzymbel III this author created the next general category called "Foundations with Mixtures/reeds", etc. One should be able to ascertain the basic registration of each organ work by perusing Chart 1 . The registrations suggested in the published editions are (sometimes) generalized to be useful for any church organ. While Part Three discusses the six (6) highlights of Hebble's organ registrations, the remainder of this section explains the details of the remaining categories from Chart 1 .

First, "Solo with Accompaniment" is not unique to Hebble as it is common throughout organ literature. What is special with him is which stop he has designated for the solo. There are ten subgroupings in Chart 1. Therefore, although Hebble may have indicated a Harmonic Flute 8 or a Bourdon 8 or Flute Octavante 4, the author simply generalized them into a "1" or a "2". Similarly, rather than detail which reeds were used in a pedal c.f. specification, such as those in groups "7" or "9", the corresponding number was used instead for brevity. One need only examine the score for clarity, as Hebble is usually specific about which stops he wants.

Further, more than $25 \%$ of "solo and accompaniment" in Chart 2 show "no indication." Like his teacher at Yale, Paul Hindemith, Hebble scores some works marked only with $\boldsymbol{m} \boldsymbol{p}$ or $\boldsymbol{f}$. Hebble's response to this regards ease in publishing certain collections. In other words smaller organs have fewer resources available and could not provide larger specific registrations. On the other hand, more capable organists (with a larger pipe organ) can purchase these collections and be creative, as Hebble encourages them in the Preface to these collections, to choose "colorful and engaging registrations." 
Second, the Krummhorn (Cromhorne) occurs with such regularity in Hebble's registration of the organ, that it was assigned its own category in Chart 1. Obtaining a rating of 32/100 (in Chart 3), this stop is indicated a third of the time. Though he is inspired by the neo-Baroque organ movement of the mid-twentieth century, Hebble says that he is "enthralled with this stop and its piquant tones." ${ }^{\text {"93 }}$ Similar is his fascination with certain mutation combinations.

Third, Hebble's registration of mutations registers a 49 out of 100 in Chart 3 and he almost never uses a strict cornet. ${ }^{94}$ Instead, Hebble judiciously incorporates smaller amounts of mutations together, favoring such combinations as 8,4 , and $11 / 3$, or 8 and 2 2/3. These lesser cornets, called cornet decomposé, are assembled from the full cornet as listed in the previous footnote. This is also a "pretty sound" 95 borrowed from the organ reform movement.

Fourth, not all of Hebble's trumpet pieces call for a fff reed. Occasionally, he wants a bright chorus reed without the breadth and power of a Bombarde 8 or Enchamade 8. This species of stop is called for in his Trumpet Tune Cp135 and in Majestic Trumpet Cp134. Most often a chorus reed is used in Hebble's arrangements: see The Heavens Declare the Glory of God (Cp54) and Trumpet Tune (Cp55). He also requests it in variations: see Variations on an American Hymn Cp172b and 172e.

Fifth, the gray areas of Chart 1 indicate rarer usages of seventeenth and eighteenth century organs that are available on the ACO. Since 32-foot stops will be discussed in

\footnotetext{
${ }^{93}$ Hebble, FL interview.

${ }^{94}$ Usually a flute 8 coupled with those of $4,22 / 3,2$, and $13 / 5$.

${ }^{95}$ Hebble, FL interview.
} 
Part Three, it is noted here that Hebble's notation of tremolo, manual echoes, full organ and manual decrescendo/crescendo is rooted in the orchestral tradition but still forms a large part of his use of and writing for the ACO. These "rarer effects" are so named because one generally uses the basics of organ registration first (principals, flutes), then may augment these fundamentals with those in the gray category. For example, an organist never draws only the tremolo or changes manuals. Although some of these rarer effects were available to organists in former centuries, they were secondary to drawing a registration. Yet Hebble still incorporates these early features in his modern compositions.

Sixth, "full organ" needs to be understood not as $s f z$, a pre-set combination that engages virtually all the stops. "Full organ" is as full a sound as is needed to fulfill the demands of the music, it does not mean to engage all the stops. Most organists, when asked to manually draw "full organ", do not draw all of the stops and couple together every division. ${ }^{96}$ Usually, the least amount of stops is drawn to create a full sound without incurring sag or compromising the integrity of ensemble. ${ }^{97} \mathbf{S f z}$, on the other hand, a feature of the ACO which was not available in most pre-1900s historic European or American organs, is a thumb or toe activated button that draws "full organ" as defined above, and also adds more stops and more divisions along with super- and sub-couplers. This is the difference. Hebble is careful to indicate which one he wants, and sometimes asks for "full organ" in a cadential area, only to later indicate $s f z$ near the very end of the

\footnotetext{
${ }^{96}$ Williams, v3, p. 167.

${ }^{97}$ Owens, Barbara. The Registration of Baroque Organ Music. Indiana University Press, Bloomington, (1997), p. 167.
} 
work: see Heraldings Cp58. Hebble is quite aware of the difference between the two and uses the $\boldsymbol{s f z} \mathbf{z}$ to "create a sense of crisis." 98 The $\boldsymbol{s f z}$ is a stronger sound than "full organ."

Seventh, although the ACO is equipped with many preset controls ranging from "General Presets" to "Divisional Presets" and "Reversable Toe-studs," Hebble still prefers the concept of gradually building up or diminishing a registration manually. Throughout the score, Hebble indicates which manual and which stop to add or change and when. The organist is directed to press a preset combination and then, proceeding to the end of the work, gradually eliminates stops manually until the music ends softly. This type of sweeping effect is symphonically inspired. Manual adjustment of the stops is also a pianistic effect from a touch-sensitive and dynamic perspective, by creating a sense of fade or dynamic diminishment on the organ. Hebble also wanted to achieve pianistic effects out from the organ: going from loud, pounding $f f$ sounds to very quiet dulcimer-like tones as did the piano composers who were his models. The influence of the piano and the orchestra must not be underestimated in Hebble's life and organ music.

Lastly, much of the remaining registration classifications [divisional expression, coupled divisions expression, crescendo pedal, English and French horns, flute celestes, combinations, MIDI, cancel, solo divisions or gallery divisions, super-couplers, $8 \mathrm{va}$, the fff solo reed and arrangements] are designed to conjure up images of orchestral music. Hebble uses these judiciously and with aplomb. Few times in his organ music are there no indications to use the expression pedals. Hebble's use of the expression pedals in virtually every organ composition is patterned after the "sense of symphonic surge and of [music] that has direction". ${ }^{99}$ This is used frequently in his organ music as Chart 1 and 3

\footnotetext{
${ }^{98}$ Hebble, FL interview.

${ }^{99}$ Hebble, FL interview.
} 
can attest, with Chart 3 reaching beyond the 100-point range, the largest category. His indications to use " $8 \mathrm{va}$," which is virtually unnecessary in organ registration, is evidence of the piano's influence. ${ }^{100}$ Additionally " $8 \mathrm{va"} \mathrm{or} \mathrm{super-couplers} \mathrm{serve} \mathrm{to} \mathrm{obtain} \mathrm{high}$ searing string sounds or to give brilliant sparkle to flue stops not normally heard in these ambits. It changes their color. This is similar to the effects rendered on the upper end of the piano keyboard. These pianistic and orchestral effects are at the root of the characteristics that constitute the next part of this chapter.

In the end it should be stated that the ACO, (not the ASO), is best suited for the organ music of Robert Hebble. The ASO is essentially disqualified for two basic reasons: 1) Hebble composes organ music almost entirely for church use and these instruments are rarely, if ever, found in churches, 2) Hebble registrations clearly show a preference for upper-work (bright mixtures and mutations, see Chart 3) to add brilliance and depth to his toccatas, power to his full organ indications and accompanimental support for his plentiful use of the solo fff reed.

Part Three: Hebble's Unique Recurrent Registrations

There are six final characteristics in Hebble's organ music which have become a signature of his registration of the organ. Each of these is subsequently discussed in detail, respectively.

1) consistent use of the solo fff reed 8

2) prevalent use of the Vox Humana 8 with strings and tremolo

3) recurrent use of inter-manual and intra-manual strings 8 (16 and 4)

4) liberal use of pedal stops 32 '

${ }^{100}$ Most organs already have companion stops of 4 and 2, etc. So, there is usually no need to play 8 va. 
5) persistant use of console devices, percussion and unique stops

6) use of MIDI (Musical Instrument Digital Interface)

The ACO made the powerful fff solo reed a standard member of the stop list in large organs. When Hebble was 16 years old in 1950 and assisting Virgil Fox at the console of The Riverside Church, the then 1936 Hook and Hastings organ had a similar series of stops called Tuba Mirabilis 8, Trompette Harmonique 8, Hooded Bombarde 8, and Celestial Reeds 16, 8 and $4 .{ }^{101}$ In 1955 many of these stops were retained and improved upon by the Skinner Company. In 1980 at the bequest of Anthony Buffano, the tremendous fff solo reed, Trompetta Majestatis 8, was installed in The Riverside Church organ in memory of his mother. It is undoubtedly one of the loudest organ stops in the world. Once it was established that stops such as this began to be installed in large ACO and its heirs, Hebble made it a point to compose for this stop and feature it. It can be found in these representative works: Symphony of Light Cp169a, 167c and 169d, Haec Dies Resurgam Cp 37, Heraldings Cp 58, Festive Piece on 'A Mighty Fortress Is Our God' Cp 98, Toccata on 'Old Hundredth' Cp 72, Toccata Brevis Cp 42, and Toccatino con Rico Tino Cp 103 as well as, possibly, any organ work by Hebble with 'trumpet' in the title.

Hebble's custom of employing the Vox Humana 8 is another trait of his organ music and a standard stop in the ACO. What is unique about the use of the Vox Humana in Hebble's music is his call for this stop in conjunction with strings 8 and tremolos in a style similar to that of the theater organ. Hebble regularly uses this registration in his

\footnotetext{
${ }^{101}$ Pamphlet: The Organs and Organists of The Riverside Church - a History, (1978), 120 Riverside Drive, New York, New York, p. 4.
} 
improvising and as a background to solos. As a solo it is usually found in the baritone ambit. To consider merging a theatre organ registration with classic organ registrations is attributable to the influence of Virgil Fox and Hebble's mother and grandmother who were theater organists. It is an innovation to the more traditional registrations, and a testament to his liberal education at Juilliard and Yale. Fox, who was also well educated, was a proponent of this registration, especially when making arrangements of orchestral based repertoire for organ. Hebble continued to make arrangements using this registration. Some representative works of Hebble's which feature the Vox Humana in this manner are Londonderry Air Cp6, Amazing Grace Cp31, Londonderry Air Cp40, Lead, Kindly Light Cp34, and O Saving Victim Open Wide Cp112b.

The third unique characteristic of organ registration that Hebble exploits is his use of Strings 8 combinations. He accomplishes this by layering several stops-sets of Strings 8 together (e.g. Flute Celeste 8 with Erzähler Celeste 8 or the Unda Maris 8 and Dulciana 8 with the Voix Celeste 8 and Salicional 8, etc.). He also uses the intradivisional coupled Strings at 16 and 4 pitches in his organ works. The latter was not possible in organs of the world before the ACO. It had the proper relays and electronic switching necessary to provide the same stop at 16 and 4 . Some representative works by Hebble using this or similar registrations are Londonderry Air Cp6, Night Communion Cp131, Amazing Grace Cp31, Beatitudo Cp33, Bread of Life Cp32, Herzliebster Jesu Cp38, Lead, Kindly Light Cp34, Chorale on 'Spohr' Cp35, O Saving Victim Cp112b, Improvisation on Veni Creator Cp115, Psalm Prelude Cp62, Pastel Cp61, Soft Stillness and the Night Cp71, Nave Cp1, and L'église Saint-Séverin Cp66. Hebble is also careful to indicate which strings he feels work best as each is unique. There are Erzähler 
Celestes indicated in Amazing Grace Cp31, Beatitudo Cp33, and Lead, Kindly Light Cp34. Flute Celestes are specified in Nave Cp1, Antiphonia Cp92, Medieval Carol Cp104v5, In the Cross of Christ I Glory Cp100, Paraphrase on 'Jesus Loves Me' Cp99, Spohr Cp35, Day Star Cp49. The Voix Celestes are employed in Bread of Life Cp32, St. Columba Cp94, Land of Rest Cp48, Symphony of Light 169c. Gambe Celestes serve in Nave Cp1 and King of Love Cp94. The Unda Maris and Dulciana are used in Crépescule Cp64, L'Eglise St. Severin Cp65, L'Eglise Boissy St. Antoinne Cp68, and Londonderry Air Cp6. Each stop-set is unique and Hebble is a master in orchestrating the ACO.

The fourth unique registration characteristic that Hebble exploits with aplomb are the 32 ' stops. These stops are available as reeds and flues in various dynamic levels and timbres. Hebble makes use of virtually all of them. For the reeds there are Contrafagott 32 and ContreBombarde 32 (the former is softer and gritty, the latter louder, coarser, and most commanding). For the flues there are Untersatz 32, Bourdon 32, Subbass 32, Contraviolone 32, Principal Bass 32, and the Contrabass 32 (each one is progressively louder and more present than the previous). Each stop requires large pipes with large wind requirements and results in a big sound. Fox was famous for wanting these sounds in his electronic touring organ and the influence on Hebble is unmistakable. The $32^{\prime}$ can be found in much of Hebble's music for organ, but his use of it is decidedly artful. Some representative works by Hebble that use 32' stops, which are indicated in the score, are Nave Cp1, Londonderry Air Cp6, Psalm Prelude Cp62, Pastel Cp61, Diptych Cp57, Soft Stillness and the Night Cp71, Toccata on 'Old Hundredth' Cp72, I Wonder As I Wander Cp59, L'église Saint-Séverin Cp66, La chapelle de Beaulieu Cp69, Crépescule Cp70, Celebration Cp56, Cp31-40 and Cp42, Cp170-var3 and 6, Abide with Me Cp91, Fairest 
Lord, Jesus Cp97, Paraphrase on 'Jesus Loves Me’ Cp99, Festive Piece on 'A Mighty Fortress' Cp98, Symphony of Light Cp169a,b,c,d, Partita on 'Lobe Den Herren Cp169a,b,c, Trumpet Tune Cp135, Supplication Cp133, Cantilene Cp127, and Prelude on an American Folk Melody Cp132.

The fifth unique category of organ registration that Hebble exploits is that of unique solo stops, console devices, percussion stops (Chimes, Zimblestern, Harp, Celesta) and the use of the Crescendo Pedal, Cancel and Toe-studs. Although these specialty stops/devices are included in large ACOs, the following are not usually found in the average church organ, for example: French Horn 8, English Horn 8, Millennial Trumpet 8, Cor de Schuller 4, Gambe Celestes 8, etc. Yet Hebble makes use of such stops and indicates them in the registration of his organ works. Many of these unique solo stops have been re-registered in his published works to indicate more commonly used stops. He is careful to note in the scores what other stops may substitute for these stops should they not be available. Hebble has done this since his first published piece. In Nave Cp1, Hebble begins his career with an indication in the score for the English Horn, and not in the manual but, uniquely, in the pedal at 4. From the Seven Palette Sketches, Hebble specifies a French Horn on the Solo Manual for Rue des Saints-Pères $\mathrm{Cp}$ 64. The use of these unique stops, particularly the use of the following percussion stops, comes from his theater organ experiences,.

The Chimes and the Zimblestern are indicated in his organ music. His directions are not new, as this practice occurred in German and Spanish Baroque organ music, ${ }^{102}$ but are again drawn from his theater organ background. Hebble's Litany of the Bells Cp130 
indicates Chimes as does almost the entire third collection Virgil Fox - The Christmas Album. Hebble makes considerate use of Chimes throughout the chorales, employing the stop for only a phrase or on the last note or two in a coda. The Zimbelstern is indicated in his arrangement of Delius' Winter Night (Cp9), where he also indicates "Sleigh Bells" in the organ score. Regarding the Crescendo Pedal, Hebble makes significant specifications in his organ music for this console device. It adds sound, stop by stop, in a gradual, sometimes programmable fashion until most or all of the organ's stops are drawn. Several representative works where Hebble uses the crescendo pedal are Abide With Me Cp91, Amazing Grace Cp31, Chorale on Beatitudo Cp33, Schematics Cp63, American Declaration Cp136 and I Wonder as I Wander, Cp61.

The last group is Hebble's use of MIDI (Musical Instrument Digital Interface) ${ }^{103}$ and other console devices such as Cancel, divisional cancel, toe-studs, super-couplers and preset combinations indicated in the organ score. His use of these devices represents highlights in his Registration Chart 1, while MIDI (used in Blessed Assurance Cp 119) and Cancel (used plentifully when he is improvising live) is anomalous in his registration of the organ in the published works and merits closer examination. MIDI is a synthetic computer generated sound or series of sounds that may be incorporated into the registration electronically, and is currently in vogue. His use of it is limited, but it is indicated in, for example, Blessed Assurance Cp 119. MIDI works as the electronic medium to connect the organ manuals with an electronic keyboard or computer. A performer can then choose sounds on either instrument. One keyboard is usually designated the master keyboard (organ). MIDI makes no sound itself, but connects sound

\footnotetext{
${ }^{102}$ Owens, pp. 231 and 251.
} 
sources together in tandem. Cancel is used in his second Blessed Assurance Cp137, a duet for piano and organ. The reason it is indicated is that there had been so many registration changes (perhaps using all the "generals"104), that the next change is more easily accomplished by "canceling" the organ and manually resetting the new smaller registration. Hebble also uses a "divisional cancel” on Romanza $\mathrm{Cp}(7)$, which cancels stops on only one division (manual) of the organ. As well is the specification of a "toestud" in Sinfonia to Cantata XXIX Cp(8) and Now Thank We All Our God Cp2, which, in this case, affects the pedal division by reducing (or adding) some of the stops. Toe-studs can be wired to be "general" presets or "reversables" for the pedal division that may engage or disengage, for example, the ContreBombarde 32 or affect all divisions as a reversable $\boldsymbol{s f z}$ button. It is used to facilitate registration changes without compromising musical integrity by permitting the hands to be free.

Hebble uses supercouplers and subcouplers to 1) achieve a new tessitura, timbre or new combination of pitches pre-established with a certain stop (e.g., Swell Flute 4 coupled to Choir at 16 and 4, or English Horn 8 coupled to pedal at 4), 2) to make "walls of sound" out of comparatively light-sounding stops (e.g., light strings at 16, 8 and 4), 3) to create consorts of sounds from reeds, such as the "smothered reeds" effect (e.g., Swell reeds 16,8 , and 4 with the expression box closed) ${ }^{105}$ and 4) to create surges of sound by coupling most or all divisions together registered full at 8 and 4 (sometimes at 16). Hebble specifies overall changes of registration which are facilitated by these devices.

\footnotetext{
${ }^{103}$ Although most ACOs of the 1950s had many of these console controls, MIDI was a later addition to these instruments c.1990s.

104 "Generals" are presets that can combine all stops and couplers in all divisions of the organ at once.

${ }^{105}$ Virgil Fox used to call it the "smothered rage," Torrence, p. 191.
} 
Specified settings or combination pistons (presets) are probably the most remarkable aspect about Hebble's registration of the organ because he is one of the few composers for organ of the twentieth century who provides this information in the score. While organ scholars have pined for centuries to understand what stops J. S. Bach had in mind for his organ plenum or in his various chorales, Hebble has taken the time to specify exactly what stops he wants and to ingeniously preset which stop combinations would best recreate his music. These are indicated at the beginning of the work. This practice not only facilitates playing his organ works, but also ensures that the exact selection of stops on a large console will engage at precisely the desired time. It is a virtual necessity for Hebble's organ music and is often a deciding factor when programming a recital that includes his music: questions such as "does this organ have presets?"; "can the organist play a particular work by Hebble with this organ?"; "what compromises can one make with little or no presets?", will need to be addressed. Combination presets thus become part of the fabric of the music with Hebble's use of the organ so as not to interrupt the flow of the music.

These characteristics of Hebble's registrations have been pointed out in order to determine his intentions so that his works will be legitimately performed and recreated on a suitable organ. Hebble has found his voice: his sound. This has been characterized in this chapter. It is a uniquely American organ sound, which is the result of his creating registrations on the ACO in combination with his spacing of "voices" and use of jazz harmonic progressions.

Additionally, Hebble enjoys extremes. If one examines the registrations of the complete works in Chart 1, one sees his wide registrational palette encompassing the 
chart. Each composition strives to demonstrate the palette of the ACO. This instrument could be louder, softer and produce more variety of timbre than any other pipe organ in history, and Hebble exploits this in almost every work. In Amazing Grace Cp31 there are 52 different timbre changes to note. In Abide with Me Cp91 or I Wonder As I Wander Cp59, again within these single compositions, Hebble indicated stop changes dozens of times from ppp to fff. Further examples of his extremes range from his writing for ethereal strings in Nave Cp1 (which seems to emanate from below a whisper) to his 'trumpet pieces', which feature the loudest stops. He enjoys a great variety in registration from both the flues and the reeds, often indicating exactly what type of 'string' or 'flute' or 'reed' to use. He is interested and prefers the lowest extremes of pitch with his frequent use of 32' stops combined with the highest pitches. He enjoys a wide gamut of registrations from the standard foundations and early music stops (e.g., the Krummhorn) to the non-standard use of the Vox Humana with celestes and tremolos as well as coupled strings at 16,8 and 4. Each of these is more associated with simulating the sounds of orchestral music and the American theater organ, yet his registrations are also heavily based on registrations of the past.

Finally, Hebble enjoys using a tremendous variety of registrations to articulate the form and style of his organ works. Hebble relies on improvisation as the basis for his composing, which he calls "written-out improvisations." 106 Some modern organists have been critical of his organ registration, either because of his association with Fox, who was unfortunately dismissed as a showman, ${ }^{107}$ or because of Hebble's own use of "theatrical"

\footnotetext{
${ }^{106}$ Hebble, Atlanta interview, 2002.

${ }^{107}$ Craig Whitney said in his book All the Stops that "Too many people were offended by a showman when they should have been dazzled by a genius," p. 214. He was quoting Richard Torrence.
} 
combinations. One could even say about Hebble what they had said about J. S. Bach so many centuries before in the necrology by C.P.E. Bach about his father in a letter to Forkel:

Oft erschraken die Organisten, wenn er auf ihren Orgeln spieln wollte, u nach seiner Art die Register anzog, indem die glauben es könnte unmöglich so, wie er wollte, gut klingen, hörten hernach aber hernach einen Effeckt, worüber sie erstaunten.

Often organists were terrified when he [Bach] wished to play on their organs and drew the stops in his manner, since they believed it could not possibly sound well in the way he wanted; but little by little they heard an effect that amazed them. ${ }^{108}$

and

This kind of registering peculiar to him was a consequence of his exact knowledge of organ-building and similarly of all single stops. Early on he had become used to giving each stop a melody suited to its nature, and this led him towards new combinations of these stops which he would otherwise never have hit upon. ${ }^{109}$

\footnotetext{
${ }^{108}$ Williams, Peter. The Organ Music of J. S. Bach, (III Background), Cambridge University Press, Cambridge, (1984), p. 155. The words of C.P.E. Bach about his father, J.S. Bach, 1774.

${ }^{109}$ Ibid. (in Forkel's own words about J.S. Bach).
} 


\section{CHAPTER 6}

Development of Hebble's Compositional Style for the Organ

It would be difficult to establish early, middle or late periods with any composer without sufficient knowledge of a compositional chronology: discerning which works were early and which ones were later. An explanation of the author's numbering system of Hebble's organ works requires a clarification in order to establish a clearer chronology. Even with Hebble's assistance it is difficult for him to remember which specific composition came before another many years ago. The numbering of Hebble's organ works in Appendix A for this project is in chronological published order, not composed order. Therefore, the following chart outlines a more accurate general composed order of the collections.

Collections in Composed Order by No.

\begin{tabular}{|l|l|l|l|l|l|l|l|l|}
\hline VII & II & Single & III & I & V & IV & VI & VIII, \\
early & later & works & early & early & middle & later & early & etc. \\
$1950 \mathrm{~s}$ & $1950 \mathrm{~s}$ & $(1-5)$ & $1960 \mathrm{~s}$ & 1971 & $1970 \mathrm{~s}$ & $1970 \mathrm{~s}$ & $1980 \mathrm{~s}$ & $(1984)$ \\
\hline
\end{tabular}

The actual published order of the collections is presented below for a comparison, which coordinates with Appendix A.

Collections in Published Order by No.

\begin{tabular}{|l|l|l|l|l|l|l|l|l|}
\hline Single & I & II & III & IV & V & VI & VII & VIII, \\
Works & $(1971)$ & $(1980)$ & $(1980)$ & $(1981)$ & $(1982)$ & $(1982)$ & $(1983)$ & etc. \\
$1-5$ & from & from & from & from & from & from & from & $(1984)$ \\
& early & the late & early & later & middle & early & early & from \\
& $1970 \mathrm{~s}$ & $1950 \mathrm{~s}$ & $1960 \mathrm{~s}$ & $1970 \mathrm{~s}$ & $1970 \mathrm{~s}$ & $1980 \mathrm{~s}$ & $1950 \mathrm{~s}$ & $1984 \ldots$ \\
\hline
\end{tabular}


Once Hebble's compositional chronology is in order, and after a perusal of the compositions has been performed, one practical a priori characteristic becomes apparent before one can approach a development in compositional style: Hebble's early awkward technique of playing the organ. Of particular note is his early slow proficiency at coordinating manuals to pedal.

Hebble began as a pianist. He loved the music of Debussy, Ravel, and Gershwin. Recall from Part I that Hebble only played the organ in church occasionally for his mother and grandmother Edwards. He did not play the theater organ, ${ }^{110}$ but could imitate its style on the piano. He was not originally trained on the organ. His use of the manuals was sufficient and his use of the organ (registration) was good, but the pedals proved to be an early, albeit brief, challenge for Hebble. When he began composing hymn reharmonizations for Virgil Fox, Hebble's technical organ skills required only basic coordination. Hebble's easily observed early technical deficiencies, along with his corroborating narrative, provide a notion for dividing his organ compositions into three chronological groups based on style: an Early Period (1950-1958), a Middle Period (1959-1979) and a Late Period (1980-1999).

A comparison of these periods shows the emergence of some interesting parallels. His Early Period (1950-1958) required only a small amount of organ technique and this is reflected in his compositions from this time. This early period is characterized by 1) homophony and homogenous musical movement between the manuals and the pedal and by 2) stasis in the manuals versus activity in the pedals (and visa versa). This coordinates with his early organ experiences. Church hymns were technically the easiest

\footnotetext{
${ }^{110}$ He did play just for "fun".
} 
works for him to play. They were the compositions for organ with which he was already familiar, not major organ repertoire, and they coordinate with the time in his life when his mother and grandmother played the organ for church. They also parallel his work with Virgil Fox, which was mostly steeped in hymn arrangements and free-accompaniments. Thus, Hebble composed mostly hymn arrangements during this time. Most of the organ compositions of this early period are those in Collection VII The Hymnal Companion (1983). Other early organ works are the "arrangements" he created for the Fox Collections, Nos. II and III (1980), which were hymn based and strophic in structure: Simple Gifts Cp20, In Dulci Jubilo Cp14, Londonderry Air Cp6, Silent Night Cp30 are examples. Even Nave Cp1 is a hymn-based work, and its sojourn into the character piece style ends this early period in 1958 as his first published organ composition.

Emerging parallels of his Middle Period (1959-79) coordinate with his accruing organ technique, and his continued correspondence with the career of Virgil Fox. This middle period is typified by 1) greater pedal dexterity during manual activity and 2) multiple levels of simultaneous musical activity resulting in greater virtuosity. Such representative works from the middle period include greater use of forms and genres are (Toccata Brevis Cp42, I Wonder As I Wander Cp59 and Toccata on “Old Hundredth” Cp72), short occurances of polyphonic writing ${ }^{111}$ (Amazing Grace Cp31, and Cwm Rhonnda Cp36) and less reliance on homorhythmic musical movement (Heraldings Cp58, Meditation on “My Shepherd Will Supply” Cp60, and Schematics Cp63). During this time Hebble transcribed for organ many of Fox's organ arrangements of orchestral

${ }^{111}$ Meaning multiple melodies (voices) occurring simultaneously. 
works. These would be Now Thank We All Our God (Cp2) [Bach], Ye Sweet Retreat (Cp3) [Boyce], Rigaudon (Cp4) [Campra], ${ }^{112}$ etc. Also included are such arrangements as Fanfares, from "Parsifal" (Cp13) [Wagner], Liebestöde [Wagner], Nocturne from Shylock (Cp16) [Fauré] and Wedding Day (Cp156) [Grieg]. Transcribing these works for organ not only acquainted Hebble with orchestral coloring on the organ (registration), but showed him how other composers thought about form and arranged their musical ideas. His organ technique improved. It also revealed to him how Fox rendered orchestral music on the organ. ${ }^{113}$ This led to a period of compositional experimentation in Hebble's organ music.

Such musical experiments were the leitmotifs found in Haec Dies Resurgam Cp37 and atonality in Soft Stillness and the Night Cp71. In these works he was influenced by the improvisational style of Marcel Dupré and Pierre Cochereau, which coincided with an improvement in Hebble's organ facility. This improvisational style is noted in Hebble's variations on Amazing Grace Cp31. Experiments in spacial relationships and thematic transformation are found in Heraldings Cp58. As his organ playing skills increased, so did his ease in incorporating elements of jazz harmonies and rhythms into his organ compositions. Noted also are his deftness at melodic extention and ornamentation. Many of Hebble's most challenging organ works from this period are unpublished and are noted in Appendix B.

Hebble's Late Period (1980-1999) also shows coordinating musical characteristics between his life and compositional output. In 1980, when Fox passed away, Hebble was

\footnotetext{
${ }^{112}$ Refer to Appendix A regarding numbering.

${ }^{113}$ Fox felt one could not just transfer the notes to the organ then register the right stops, but one had to know how to "make it properly sing on the organ". This meant lightening thick textures, using particular divisions as well as the expression pedals. - Hebble, FL interview.
} 
asked by various publishers to create "editions" of Fox's performances of major repertoire for posterity. By this time Hebble's organ facility reached its peak, and he was able to pursue his own voice. His prior period of experimentation was an epiphany that had revealed to him what he really enjoyed: composing chorale-preludes in a jazzimprovised style, working with classic compositional forms, employing theater organ/orchestral compositional colors, and memorializing Fox. Although Hebble readily admits that even though his organ skills have reached a zenith for him, he has never developed a concert organist's technique and rarely plays major organ repertoire in public. $^{114}$

His organ skills came from his style of improvising on the organ. Representative works from his late period are Abide with Me $\mathrm{Cp} 91$, which contains ostinato, improvisation, and text painting. Also The Majestic Trumpet Cp134 and Collections Nos. IX and X shows Hebble's comfort with miniatures in this late period and his sharpened ability to "say what I mean and mean what I say" musically. ${ }^{115}$ The "Improvisations" in Collection IX also demonstrate this. He is comfortable with his voice, with forms, such as rondo (The Majestic Trumpet Cp134 and Trumpet Tune 135) and ritornello (Antiphonia on Aberstwyth Cp92 and Praise to the Lord Cp125), and procedures like ostinato (Abide with Me Cp91, Sing of Mary Cp113 and Praise to the Lord Cp125), parody (Blessed Assurance Cp119 and Variations on an American Hymn Cp172d), and canon ${ }^{116}$ (Variations on a Medieval Carol Cp104b, Come, Holy Ghost Cp108, Let All Mortal

\footnotetext{
${ }^{114}$ Hebble; FL interview, 2001.

${ }^{115}$ Ibid.

${ }^{116}$ These are rare instances in his opera omnia and only exist for a phrase or verse within a larger work.
} 
Flesh Keep Silent Cp122, Lo! He Comes with Clouds Descending Cp123 and Thee We Adore Cp126) juxtaposed with jazz elements and improvisation.

This late period is characterized by the dexterity of Hebble's coordinated manual and pedal independence (Variations on a Medieval Carol Cp104e, O Saving Victim Cp112a, Most Perfect Is the Law Cp124, and Divertimento Cp129), improvisation in ABA form (Immaculate Mary Cp111, Sing of Mary Cp113, Salve Regina Cp114, and Jesus Shall Reign Cp121, ) and facility in both miniature (Attende Domine Cp105, Salve Regina Cp114, Veni Creator Cp115, Victimae Paschali Laudes Cp117 and Cps118-126) and larger forms (sonata Symphony of Light Cp169 and variation/partita Variations on a Medieval Carol Cp104, Partita on Lob Den Herren Cp171, Variations on an American Hymn Cp172). The following chart ${ }^{117}$ provides a summary of the previous discussion.

\begin{tabular}{|l|l|l|}
\hline \multicolumn{1}{|c|}{ Early Period } & \multicolumn{1}{|c|}{ Middle Period } & \multicolumn{1}{c|}{ Late Period } \\
\hline Time: 1950-1958 & 1959-1979 & 1980-1999 \\
\hline $\begin{array}{l}\text { Organ skills:1 to 2/out of } \\
\text { 10* hands and pedal move } \\
\text { either concurrently or one } \\
\text { group at a time }\end{array}$ & $\begin{array}{l}\text { 3 to 5/ out of 10* } \\
\text { more pedal dexterity during } \\
\text { manual activity, structured- } \\
\text { freer use of hands and feet }\end{array}$ & $\begin{array}{l}\text { 6 to 8/ out of 10* } \\
\text { great organ facility, manual } \\
\text { and pedal independence, } \\
\text { (mastery of registration) }\end{array}$ \\
\hline $\begin{array}{l}\text { People: mother, E. Smith, } \\
\text { grandmother, Fox, Paige }\end{array}$ & $\begin{array}{l}\text { Fox, Boulanger, Dupré, } \\
\text { Hindemith, Sessions, Porter }\end{array}$ & Pierre Cochereau \\
\hline $\begin{array}{l}\text { Types: free-accompmnts., } \\
\text { modulations, interludes for } \\
\text { hymns, reharmonizations }\end{array}$ & $\begin{array}{l}\text { Transcriptions, chorales, } \\
\text { free-works (miniatures?) }\end{array}$ & $\begin{array}{l}\text { Editions, transcriptions, } \\
\text { improvisations, miniatures, } \\
\text { chorales, free-works, duets, } \\
\text { symphony }\end{array}$ \\
\hline $\begin{array}{l}\text { Forms: hymns, strophic } \\
\text { Through-composed, } \\
\text { strophic variations, ternary, } \\
\text { ABA, toccatas, scherzos, } \\
\text { mild counterpoint }\end{array}$ & $\begin{array}{l}\text { Improvisation in ABA and } \\
\text { rondo, ritornello, (toccatas) }\end{array}$ \\
\hline $\begin{array}{l}\text { Works: } \text { homophonic, stasis } \\
\text { versus activity, } \\
\text { homogenous movement, no }\end{array}$ & $\begin{array}{l}\text { Multiple musical ideas, } \\
\text { greater use of musical } \\
\text { structures, neoclassicism, }\end{array}$ & $\begin{array}{l}\text { Facility with compact style, } \\
\text { denser musical interest, } \\
\text { parody, experimentation }\end{array}$ \\
\hline
\end{tabular}

${ }^{117}$ Refer to Table of Abbreviations. 
musical speculation, rare passing tones, risky chromaticism, many works with $c . f$. in the pedal atonality, jazz, morphing, octatonic, motifs, palindromes, program music, ostinatos, musical objects, hermeneutics with partial scales, jazz, canon, imitation, short trio, palindromes, ostinatos, hermeneutics, eclecticism, musical objects

* - Based on an arbitrary scale of ten (10).

In summary, Hebble's early works display an interest in that which was already familiar to him: the strophic hymn form. His middle period was a time of compositional trial and arrangements/transcriptions of other composers' music. Hebble's late period was his most productive. The late period, from 1980 to the present, represents the majority of Hebble's compositional output for the organ. This late period began slowly for him as a composer: his first published collections were Virgil Fox's editions/arrangements of hymns and repertoire, with one or two of Hebble's works being interjected. As demand for Fox's arrangements rose, and Hebble's own music, which was interspersed in these collections, became more known, Hebble published his first collection containing solely his own organ works, Hymn Tunes, Preludes and Improvisations (1981). 


\section{PART III The Organ Collection}

\section{CHAPTER 7}

\section{A General Overview of the Organ Collection}

Hebble's first compositions for the organ predate his first published piece, Nave Cp1 in 1958; however, Hebble's early works for the organ before this time are lost. These first compositions were personal improvisations used in church services that were sketched but never scored. Some of these were created for organist Virgil Fox for his personal use as interludes, modulations, or altered harmonies in the hymns and service music at The Riverside Church during Hebble's days as Fox's console assistant from 1950 to 1965 . These latter works, once belonging to Fox, are also now lost. ${ }^{118}$ There are a few early extant organ compositions that have survived only in Hebble's personal collection (which have not been published and are sketches from Hebble's Riverside days). Some of these early compositions have been reworked and published in his early out-of-print editions. ${ }^{119}$

The focus of this chapter is on the various collections of Hebble's organ music which were published between 1958 and 1999. Only a cursory discussion of the style and forms presented in each collection are included. This chapter does not discuss organ works published after 1999 nor the unpublished works. Also, this project does not explore Hebble's many arrangements of pre-existing classic music. These

\footnotetext{
118 Tape 2; interview with the composer, June 17, 2001, Canton, Ohio, side one.

119 Some of these early pieces were in the published collection from 1981 called Hymn Tunes and Improvisations and The Hymnal Companion, both of which are now permanently out of print.
} 
arrangements are listed in Appendices A and B. A "Complete Works List" of both organ music (including the unpublished organ works) and other genres and music by Hebble is available in the Appendices. The sixteen published collections of organ music from 1980 to 1999 and nine individual pieces of organ music published from 1958 to 1999 are the focus of this chapter. They are listed below and detail the number of individual works within the collection, the date published, and include publisher information:

Collection: Year $\quad$ Title Publisher/No.

I. 1971 Ted Alan Worth in Concert (4) [1=Hebble] Sacred Music Press KK246

II. 1980 Virgil Fox - The Organist (12) [1=Hebble] Bradley Publications 24M21

III. 1980 Virgil Fox - The Christmas Album (9) [4=Hebble] Bradley Publications 24M20

IV. 1981 Hymn Tunes, Preludes and Improvisations (13) - Bradley Publications 24M22

V. 1982 The Robert Hebble Collection (12) Bradley Publications B22M24

VI. 1982 The Crystal Cathedral Collection (18) - Warner Brothers Publications, Inc. EL9508

VII. 1983 The Hymnal Companion - Free-Accompaniments (18), Bradley Publications B23M27

VIII.1984 Rejoice (14) Improvisations on Hymn Melodies; Bradley Publications B23M28

IX. 1989 For the Masses (12) - Sacred Music Press/Lorenz KK430

X. 1989 At Your Service (9) - Sacred Music Press/Lorenz KK427

XI. 1992 Designs for Organ (10) - Sacred Music Press/Lorenz KK517

XII. 1994 The Hebble Duet Collection (9) -- Warner Brothers Publications, Inc. EL03966

XIII. 1995 Wedding Music for Organists (19) [3=Hebble] -- Belwin Mills GB9503

XIV. 1995 Festive Hymns and Pieces (7) - Warner Brothers Publications, Inc. GB9502

XV. 1995 Favorite Hymns for Organ (15) - Warner Brothers Publications, Inc. BHS9501

XVI. 1999 The Virgil Fox Legacy (9) Bradley Publications KK276

Single Works:

11958 Nave (single) - (H. W. Gray/St. Cecilia Series \#859) (in collection \#15)

21980 Haec Dies Resurgam (single) Dreena Music (in collection \#4)

31986 A Symphony of Light (in 4 movements) - (Hinshaw Music HMO150)

41986 Partita on "Lobe den Herren" Hinshaw Music HMO1986

51997 Variations on an American Hymn (6 variations) - (Warner Bros., BHS9703)

61980 Amazing Grace (single) from Collection \#4, Bradley Publishing

(7) ${ }^{120} 2002$ Cathedral Tapestry - Crystal Cathedral (commission 2002 by the Crystal Cathedral)

(8) 2002 Litany AGO Denver; Virgil Fox memorial commission 5/2002

(9) 2004 Cathedral of Commerce (2004 commission for Wannamaker Organ, Philadelphia)

\footnotetext{
${ }^{120}$ Parenthesis here indicates that these works have been recently composed after 1999, are not published and are not included in this study. They are listed here for the reader's information.
} 
Within these collections are 172 individual works published by Hebble. A closer examination of these collections reveals that there are twenty-three organ works which were re-released (duplicated) in later collections. They are listed below in alphabetical order along with the corresponding original collections from which they were published:

\begin{tabular}{|r|l|l|l|l|}
\hline & Organ Work & First Pub/Collect & Second Pub/Collect & Third Pub/Collect \\
\hline 1 & Abide with Me & Rejoice & Favorite Hymns & \\
\hline 2 & Amazing Grace & Hymnal Companion & Hymn Tunes, Pre. & At Your Service \\
\hline 3 & Be Thou My Vision & Rejoice & Favorite Hymns & \\
\hline 4 & Celebration & Wedding Music ... & Crystal Cathedral & \\
\hline 5 & Chorale “Beatitudo” & Hymn Tunes, Pre. & Hymnal Companion & \\
\hline 6 & Chorale “Spohr” & Hymn Tunes, Pre. & Favorite Hymns & \\
\hline 7 & Cwm Rhondda & Hymn Tunes, Pre. & Hymnal Companion & \\
\hline 8 & Chorale on 'Ellers' & RH Collection & Hymnal Companion & \\
\hline 9 & Fairest Lord, Jesus & Favorite Hymns & Rejoice & \\
\hline 10 & Haec Dies Resurgam & single piece & Hymn Tunes, Pre. & \\
\hline 11 & Herzliebster Jesu & Favorite Hymns & Hymnal Companion & \\
\hline 12 & Land of Rest & RH Collection & Favorite Humns & \\
\hline 13 & Lead, Kindly Light & Favorite Hymns & Hymn Tunes, Pre. & \\
\hline 14 & Londonderry Air & Hymn Tunes... & Ted Alan in Con. & \\
\hline 15 & Nave & single piece & Crystal Cathedral... & \\
\hline 16 & Now Thank We... & single piece & VF-Legacy & \\
\hline 17 & Postlude on Holy Holy & Favorite Hymns & Hymnal Companion & R.H. Collect. \\
\hline 18 & Romanza & Ted in Concert & Designs for Organ & \\
\hline 19 & Scherzo on Joyful & Rejoice & Favorite Humns & \\
\hline 20 & Simple Gifts & VF-The Organist & Favorite Hymns & \\
\hline 21 & Stretch Forth Thy... & RH Collection & Favorite Hymns & \\
\hline 22 & The King of Love & Rejoice & Favorite Hymns & \\
\hline 23 & Var. Medieval Carol & Rejoice & Favorite Hymns & \\
\hline & & & \\
\hline
\end{tabular}

There are also five collections in which Hebble composed only a few original works. Most of the works in these collections are arrangements of other composer's organ music or are transcriptions for the organ by Hebble. Of the fifty-two works in these collections, only thirteen are original compositions by Hebble. They are listed below: 


\begin{tabular}{|c|l|c|c|l|}
\hline \multicolumn{1}{|c|}{$\begin{array}{c}\text { The } \\
\text { Collection }\end{array}$} & $\begin{array}{c}\text { Total Works } \\
\text { Within } \\
\text { Collection }\end{array}$ & $\begin{array}{c}\text { Works } \\
\text { Composed } \\
\text { by Hebble }\end{array}$ & \multicolumn{1}{|c|}{$\begin{array}{c}\text { The Title of } \\
\text { Hebble's Organ Works }\end{array}$} \\
\hline 1 & Wedding Music for Organists & $(19)$ & 2 & $\begin{array}{l}\text { Celebration } \\
\text { The Wedding of Cana }\end{array}$ \\
\hline 2 & The Hebble Duet Collection & $(8)$ & 4 & $\begin{array}{l}\text { American Declaration } \\
\text { Blessed Assurance } \\
\text { Chrysalis } \\
\text { Finlandia }\end{array}$ \\
\hline 3 & Ted Alan Worth in Concert & $(4)$ & 1 & Londondonderry Air \\
\hline 5 & Virgil Fox- The Organist & $(12)$ & 1 & Simple Gifts \\
\hline 5 & Virgil Fox-The Christmas Album & $(9)$ & 5 & $\begin{array}{l}\text { Good Kind Wenceslaus } \\
\text { Joy to the World } \\
\text { In Dulci Jubilo } \\
\text { O Little Town of Bethlehem } \\
\text { Silent Night }\end{array}$ \\
\hline
\end{tabular}

This brings the total amount of original organ works in each collection, again excluding duplications and arrangements of classic repertory, to approximately 172.

This amount of published organ music makes Hebble one of the most prolific American composers for the organ in the twentieth century. Although For the Masses and At Your Service are temporarily out of print, and Hymn Tunes Prelude and Improvisations and the Hymnal Companion are permanently out of print, Hebble remained one of the most popular composers for the organ at the end of the twentieth century. ${ }^{121}$ It can be noted in Walter Frankel's Organ Music in Print, 1997 Master Index that of all the popular ${ }^{122}$ composers for the organ of the twentieth century, living or deceased, who are listed by Frankel, Robert Hebble had as many publications in print (six) as William Bolcom. Robert Powell had nineteen listings, and the next grouping

\footnotetext{
${ }^{121}$ Frankel, Walter. Organ Music in Print, 1997 Master Index, p. 52.

${ }^{122}$ Defined as other living composers whose music is still in demand and currently in print.
} 
(those with five or less compositions or collections in print) includes such composers as William Albright, Jan Bender, James Biery, E. Power Biggs, Diane Bish, Charles Callahan, Clarence Dickinson, Emma Lou Diemer, Marcel Dupré, Maurice Duruflé John Ferguson, Calvin Hampton, Gerre Hancock, Libby Larson, Dan Locklair, Jane Lorenz, Austin Lovelace, Gilbert Martin, Olivier Messiaen, and John Weaver.

A general overview of the organ works now begins with a discussion of each collection in chronological published order according to the list in Appendix A. Then each work will be considered in alphabetical order within each collection according to the numbering system provided by the author.

Nave Cp1 is Hebble's first published piece (1958). For the sake of clarity and brevity, refer to Chapter 3 in lieu of repeating information here. The next four single organ works (Cps 2-5) are arrangements, which will not be discussed in this paper. They were arranged for organ by Virgil Fox but scored by Hebble. Fox created these some years before 1958, and exact dates are unknown separate from publication year. H.W.

Gray published them all. Fox refused to write out these arrangements himself, so Hebble, serving as Fox's console assistant at The Riverside Church, wrote these out for Fox beginning in the late 1950s up to 1971.

\section{Collection I}

Ted Alan Worth in Concert

(1971)
Sacred Music Press

KK246

4 compositions [3 are arrangements]

Ted Alan Worth was a protégé of Virgil Fox and concertized widely. Organists wanted Worth's organ arrangements, which were composed by Hebble, so the collection was published. It contains four pieces, three of which are Hebble's arrangements of preexisting Classical works from orchestral repertoire and transcribed for organ. They are 
Romanza $\mathrm{Cp}(7)$ (Grieg), Sinfonia $\mathrm{Cp}(8)$ (Bach) and Winter Night $\mathrm{Cp}(9)$ (Delius). The fourth is his chorale-prelude on Londonderry Air Cp6. Hebble's arrangements for the organ remain very faithful to the original notes, spacing, keys, orchestral timbres (registration), dynamics, and general style at their composition.

\section{Collection II Bradley Publications \\ Virgil Fox - The Organist 24M20 \\ 12 compositions [11 are arrangements]}

The second collection contains mainly Hebble's arrangements of pre-existing classical music, which Virgil Fox used in concert and at The Riverside Church. It includes one original chorale by Hebble - Simple Gifts Cp20. The collection was published because Fox passed away in 1980 and many organists wanted Fox's arrangements. It was also a means of memorializing Fox.

Collection III Virgil Fox - The Christmas Album (1980)
Bradley Publications 24M21

[9 compositions; 4 arrangements]

This collection contains nine carols, four of which are arrangements of pre-existing classical music associated with Christmas and five that are purely Hebble's arrangements of the Christmas carols: Good King Wenceslas Cp23, In Dulci Jubilo Cp25, Joy To the World Cp26, O Little Town of Bethlehem Cp28 and Silent Night Cp30. Hebble is the "ghost writer" for the chorale arrangements and is not credited in this collection. One can see the influence of Fox in Hebble's writing by the concerted nature of the carols, requiring significant pedaling technique and console geography for the required registration changes. Also remarkable is Hebble's faithful preservation of Fox's performing style in these works: manuals, phrasing, extra notes, and registration. 
Collection IV

Hymn Tunes, Preludes and Improvisations (1981)
Bradley Publications

24M 22

[12 chorales; 1 free work]

This is Hebble's first published collection of all original organ works. The idea behind this collection in Hebble's words is as follows:

Richard Bradley is a good organist, wonderful musician, in the NewYork City area who was more in the theater vein. He owned a publishing company which was very successful because they owned Billy Joel and all his stuff. Richard Bradley came to The Riverside Church with Richard Torrence and heard me playing. He was so impressed that he wanted to get a hold of me and look through my scores, and wanted them immediately. He put all I had that day into a collection, which became my first published collection completely of my own music. ${ }^{123}$

Most of the compositions in Hymn Tunes, Preludes and Improvisations were composed before 1981 and "had been sitting around since the 1960s and 1970s." "124 In this collection Fredrick Swann commissioned Haec Dies Resurgam Cp37 in 1978 for the Riverside organ's new stop, the Trompeta Majestatis 8, and premiered it there on Easter Sunday in 1979. It was also played at the memorial service for Virgil Fox at The Riverside Church in November of 1980 and uses the chorale O Quanta Qualia. Another featured piece in this collection is Toccata Brevis Cp42, which uses "St. Denio" as a cantus firmus in the pedal. It has rapid manual figurations, changing meters, canon between pedal and "fff reed" in the right hand and imitation between the manuals and pedal, which require rapid piston and manual changes in a very concert-like Foxian style.

${ }^{123}$ Florida tape 1, side A, April 22, 2002, Hebble speaking.

${ }^{124}$ Ibid. 
Hebble also notes that this collection demonstrates the variety of his style, and that he is not a "formula composer."

Many people have a procedure or a formula, a preconceived frame on which you hang new notes. Each work is different in this collection. It's what fits best in the situation. ${ }^{125}$

\section{Collection V}

The Robert Hebble Collection

(1982)
Bradley Publications

B22M24

[12 compositions; 4 arrangements]

There are four arrangements of pre-existing classical pieces: five original free-works and three chorales. It is subtitled Organ Music for the Church Service. Hebble felt that he needed to make these arrangements because, although other organ arrangements existed, ${ }^{126}$ "they lacked something; they needed a little sparkle and [I] wrote them in my own way, which was [in] the counterpoint, the texture." Hebble set out to create arrangements that were different from standard transcriptions. Of note is The Heavens Declare the Glory of God (Marcello) Cp(54) for example, where Hebble slightly alters the standard arrangement organists have come to know by creating more interesting voice leading at the cadences or on the repeats of the main theme.

Collection VI The Crystal Cathedral Collection (1982/[second edition 1995])
Warner Brothers Publishing EL9508 [6 chorales; 6 free works]

The sixth collection contains 12 pieces with Nave being repeated in it from earlier publication. The chorales are all Long Form. This collection received its title because

\footnotetext{
${ }^{125}$ Florida tape 1, side A, April 22, 2002, Hebble speaking.

${ }^{126}$ G. Schirmer Publishing Company had made many organ transcription/arrangements in the early twentieth century of standard Classical or orchestral works as did Albert E. Weir in Symphonic Pieces for Organ, New York, New York, Harcourt, Brace and Company, 1935.
} 
the first work in the collection, Heraldings Cp58, was commissioned for the Crystal Cathedral organ dedication in 1982. Also, many of the new works in the collection were being written for and performed by the cathedral organist, Fredrick Swann, who had succeeded Virgil Fox as organist at The Riverside Church.

\section{Collection VII The Hymnal Companion (1983)

\author{
Bradley Publications \\ B23M27 \\ [18 hymn reharmonizations]
}

The seventh collection contains eighteen reharmonizations of standard hymnody. Written during the 1950s for Virgil Fox's use at The Riverside Church, they essentially follow a similar procedure used by J.S. Bach, who also reharmonized many chorales (371) for congregational singing. The hymn is stated on the first page as it traditionally appears in modern hymnals, then Hebble presents his embellishment, which is intended to be played on the last verse of the hymn. The reharmonizations are in the same key as the hymn, but several contain modulations before the final verse. Fred Swann said that when Fox used these reharmonizations, "it was like attending a concert just to sing the hymns." ${ }^{127}$ Although this collection was not published until 1983, it contains much of the hymn music used at The Riverside Church during the Fox/Hebble/Weagley ${ }^{128}$ era.

$\begin{array}{ll}\text { Collection VIII } & \text { Bradley Publications } \\ \text { Rejoice } & \text { B23M28 } \\ \text { (1984) } & \text { [12 chorales; 2 free works }]\end{array}$

The chorales in the Rejoice collection are evenly split between Short Form and Long Form chorales. Some are quite involved concert pieces like Festive Piece on A Mighty

\footnotetext{
${ }^{127}$ Fred Swann, et al; taped interview in Pittsburgh, PA, May 15, 2002, tape 1, side B. Fred Swann is currently the president of the American Guild of Organists, 2004, and is organist emeritus at Riverside and the Crystal Cathedral.

${ }^{128}$ Richard Weagley was the Choirmaster of The Riverside Church during the tenure of Fox.
} 
Fortress $\mathrm{Cp} 98$, in the style of a chorale-fantasia, that have introduction, extended interludes and codas. Others are less challenging. Some of his most interesting writing is in this collection: unexpected Neapolitan harmonies, use of Tristan harmonies and enriching theological symbolism in the text painting and subjective expression. These are particularly evident in Abide with Me Cp91, Fairest Lord, Jesus Cp97, Be Thou My Vision (Slane) Cp96 and the Scherzo Cp102. ${ }^{129}$ Hebble felt that his writing had improved because he had lived more and had more ideas. ${ }^{130}$ The Scherzo on Joyful, Joyful Cp102 has a jocularity that stays firmly with the traditional scherzo ABACA architecture. The Toccatino con Rico Tino Cp103 has an interesting story. It is composed almost entirely on the "black notes" of the manuals with pedal obbligato.

Well, the collection had to be in New York City in two days, for some reason I can't remember, and the toccatino took only one and a half days to write. Just as I finished it, Ethel Smith stopped by the house to visit and I said, Ethel, you're just in time to hear my latest piece, tell me what you think, you'll be the first to hear it. Well, she just loved it, but hated the name 'toccatino'. She said, "everyone writes toccatinos, can't you call it something else? It needs more words." I said, "like what"; and she spun around and said, "I know! Call it 'Toccatino con Rico Tino'!" And I said, "well, what does that mean?" And she said, "I don't know, but it sounds better." And so that's how it got its name. I don't know any Spanish, it could mean something naughty or just be gibberish for all I know! ${ }^{131}$

\footnotetext{
${ }^{129}$ See Chapter 8 for the discussion of individual works.

${ }^{130}$ Florida, tape two, side A.

${ }^{131}$ Ibid.
} 
Collection IX

For the Masses

(1989)
Sacred Music Press

KK430

[12 chorales; 4 "improvisations"]

These compositions are based on Catholic chants and eight other vernacular hymns frequently used in early post-Vatican II Catholic Masses. The title of the collection has a double meaning: organ music for everyone (the "masses") and music specifically for the Catholic church liturgies (Masses). Since most of Hebble's previous collections had used "Hebble" in the title, he wanted a different title. This is true for the following two collections as well. The chorales in this collection are all Short Form. The four improvisations are thus called because "they do not follow a compositional procedure; they don't stay in one key for very long, the chant is quoted irregularly, and they are basically just short thoughts." 132 Hebble had been giving seminars at the National Association of Pastoral Musicians conventions and the people asked for some new Catholic music by him. The formation of these chorales "creates an atmosphere" or fills in a space in the Mass. Most of the melodies Hebble had not heard before or had forgotten, so he considered it a challenge to add some new color in Hebble's life and in Catholic organ music. ${ }^{133}$

Collection X

At Your Service (1989)
Sacred Music Press

KK427

[10 chorales]

At Your Service is the companion collection to For the Masses. At Your Service was subsequently made mainly for the Protestant church. The organ pieces of this chorales-

${ }^{132}$ Hebble, Florida tape one, side B.
${ }^{133}$ Ibid. 
only collection are also mostly Short Form, but there are a few longer fantasias. There are also four chorales based on chant (or hymns) used frequently in the Catholic church: Adore Te Devote Cp126, Tantum Ergo Cp123, Picardy Cp122 and Grosser Gott Cp120. All the pieces have short introductions and codas. Blessed Assurance Cp119 substantially paraphrases J.S. Bach's Jesu, Joy of Man's Desiring (Cantata 147) while incorporating the modern chorale of Blessed Assurance in place of Bach's original chorale. Frederick Swann says this is Hebble's most frequently discussed piece for organ. ${ }^{134}$

Collection XI Designs For Organ (1992)
Sacred Music Press

KK517

[8 free works; 1 arrangement; 1 chorale]

The Romanza $\mathrm{Cp}(7)^{* 135}$ is here republished from his first collection . The composer states,

I was just sick of hymn arrangements that year - just sick of them! I was told that if I were a painter and my paintings were in Hong Kong and people could tell they were mine, then that was a great achievement. It just happens though; if it agrees with you then that's what you go with. And, musically, that's what I was trying to do.

The compositions in Designs For Organ are based on original melodies by Hebble, except for Prelude on an American Folk Melody Cp132 (There Is A Balm), which is a Short Form chorale-prelude. The various works in this collection are designed to demonstrate the panoply of registrations associated with the American Classic Organ and

\footnotetext{
${ }^{134}$ Swann, Pittsburgh interview, May, 2002.

135 Parenthesis and an asterisk means an arrangement has been republished from previous collection. See subtitles of Appendix A.
} 
are more concert-like in nature. This is unlike the premise of his chorale-based collections, which were primarily for church services. Thus, there is use of pianissimo string celestès, solo flutes, and Baroque reeds as well as louder reed solos with full organ and a variety of principal choruses.

\section{Collection XII Belwin Mills \\ The Hebble Duet Collection EL03966 (1993) \\ [2 chorales; 1 free work; \\ 6 arrangements]}

The twelfth collection contains eight pieces for piano and organ duet. Most of the chorales and classical arrangements in this collection can be used in church and in recital. Finlandia Cp139 and Blessed Assurance Cp137 are the two chorales (Long Form). Finlandia quotes portions of the Sibelius Symphony, but concentrates mainly on an arrangement of the hymn-tune. Blessed Assurance Cp137 is a setting well beyond the Bach paraphrase from his earlier arrangement, Cp119. American Declaration Cp136 and Chrysalis Cp138 are the two free-works in the collection: American Declaration Cp136 is a medley of "America the Beautiful", "Battle Hymn of the Republic," and "When Johnny Comes Marching Home". It includes bravura virtuoso writing for the piano with $32^{\text {nd }}$-note passages, rapid double-note four-octave descending scales and colorful harmonic changes in a jazzy style which "brings the house down."136 The remaining four pieces are arrangements of classic pieces for piano and organ as duets: In

\footnotetext{
${ }^{136}$ Swann interview, tape one, side two.
} 
Thee Is Joy $\mathrm{Cp}(140)^{137}$ (J.S. Bach) chorale, Parlez-Moi d'Amore Cp(141) (Lenoir), The

Sunken Cathedral Cp(142) (Debussy), and Take Us, Lord, Into Thy Keeping Cp(143)

(Bach) chorale. The story associated with this collection is that Hebble's home church acquired a new Baldwin Grand Piano and he wanted something "good" for piano and organ together. The composer states:

There were other duet arrangements out there, but they were too musically unsatisfying. They tended to be too ticky-tacky, too commercial and very obvious. I wanted to put a higher level of composing into duets for piano and organ. I feel they are my finest effort and are highly creative. It was one of my most successful collections and I'm working on another one. ${ }^{138}$

In Chrysalis Cp138, Hebble experiments with thematic transformation.

Collection XIII Wedding Music for Organists (1995)
Belwin Mills

GB9503

[1 chorale; 3 free works; 15 arrangements]

Collection thirteen contains nineteen works. O Perfect Love Cp150 is treated as a chorale-prelude (Short Form) and is the only chorale. There are three free works by Hebble: Celebration Cp56*139, which is re-published from The Crystal Cathedral Collection, Reverie Cp151 and The Wedding at Cana Cp155. The latter is a small tonepoem. The remaining works are arrangements of classic pieces. The composer comments

There were other collections on the market, but, again, they were too ticky-tacky or were merely the standard Schirmer arrangements with added registrations only. Those aren't arrangements. Many of them were unplayable on the organ. Virgil Fox taught me a lot of music

\footnotetext{
${ }^{137}$ Parenthesis indicates an 'arrangement'. See subtitles on Appendix A.

${ }^{138}$ Florida tape two, side A.

${ }^{139}$ Asterisks refer to the work being re-published from an earlier collection. See subtitles in Appendix A.
} 
for weddings, so I had made many of these arrangements years before. Virgil found the repertoire, we created fabulous registrations together and made the standards better; plus, I added some lovely new things. The publishers were elated to have this and it has done well. The Stanley was redone from scratch and the Bell Symphony uses real chimes; and it was not done in print before at all. ${ }^{140}$

Collection XIV

Festive Hymns and Pieces (1994)
Warner Brothers Publications

GB 9502

[5 chorales; 3 free works;

2 arrangements; re-released]

The fourteenth collection of Hebble's organ music contains ten works: three Long Form chorales, one Short Form chorale, two arrangements and three free-works. Everything in this collection was reprinted from earlier publications into this new collection, which emphasize festivity. Warner Brothers bought the old publishers and wanted to make their own book of Hebble pieces with the new publisher's name on the collection. ${ }^{141}$

Collection XV

Favorite Hymns for Organ (1995)
Warner Brothers Publishing

BHS 9501

[15 chorales, re-released]

It was published for the same reasons as the previous collection, except that this one contains only chorales. These works were published from various earlier collections and are evenly divided between Short Form and Long Form chorales. ${ }^{142}$

\footnotetext{
${ }^{140}$ Florida tape one, side B.

141 Ibid.

142 Ibid.
} 


\section{Collection XVI The Virgil Fox Legacy (1999) \\ Sacred Music Press \\ KK276 \\ [9 arrangements]}

This last organ collection by Hebble contains nine arrangements of music by J. S. Bach that Virgil Fox played and that had never been scored and edited. Most of these were dictated to Hebble by Fox from his deathbed to include information about how Fox performed these works: including stop changes, manuals, fingering, pedaling, and phrasing that he used, etc. There are three transcriptions: Air on G String $\mathrm{Cp}(159)$, Chorale from Cantata XXII Cp(160) and Jesu, Joy of Man's Desiring Cp(165); and six arrangements of Bach organ works which Fox edited. This collection came about because of the renewed interest in Virgil Fox in recent years ${ }^{143}$ and the demand that more of Fox's performance practices be made available to organists.

Since 1999 there are five compositions, (Cp168, 169, 170, 31 and 37), which were published, or re-published, as single works. These were later incorporated into the collections, except for Lamentation on “Were You There?”Cp170, and Symphony of Light Cp169. They are We Thank Thee, God Cp(168) [Bach], Amazing Grace Cp31, and Haec Dies Resurgam Cp37. $\mathrm{Cp}(168)$ is an organ arrangement of the famous orchestral opening of Bach Cantata 22, the others are Short Form chorales, except for Haec Dies which is a Long Form chorale. These single works were originally published between 1972 and 1997. The Symphony of Light is unique in this category because of its epic length, scope and virtuosity. It is dedicated to the memory of Virgil Fox and is in four movements. Movement No. 2 is a large Long Form chorale fantasia on "How Brightly

\footnotetext{
${ }^{143}$ Mardirosian, Haig. "Reviews", The American Organist, March (2002) volume 36, no. 3, pp. 88-89.
} 
Shines the Morning Star." The Symphony is in the spirit of a Widor or Vierne organ symphony and is Hebble's most ambitious composition for organ to date. ${ }^{144}$

There is a final series of variations by Hebble that make up the last category of the organ collection. Chronologically, the Diptych or Variations on "Orientus Partibus"Cp57* was composed in 1982 and first appeared in The Crystal Cathedral Collection. It has three variations: Ostinato, Moderato and Ritornello. In 1984 the Rejoice collection contained his Variations on a Medieval Carol Cp104*, which contains six variations and an opening section. Hebble's Partita on Lob Den Herren Cp171 (1986, Hinshaw Music Incorporated HMO-154) is in the form of chorale-variations. It contains three variations that are composed as three movements entitled Praeludium, Sicilienne and Finale. Finally, in 1997 Hebble composed his last work in this project Variations on an American Hymn, Cp172 (1997, Warner Brothers Publishing BHS9703). There are six variations, which constitute a Long Form chorale partita. The variations all display a wide range of styles and levels of difficulty.

\footnotetext{
${ }^{144}$ Hettinger, Sharon L. American Organ Music of the $20^{\text {th }}$ Century: An Annotated Bibliography of Composers, Harmonie Park Press, Warren Michigan, (1997), p. 30.
} 


\title{
CHAPTER 8
}

\section{The Chorales}

\begin{abstract}
"When composing, I don't have a pre-conceived frame on which to hang new notes. Each composition is new each time." - Robert Hebble
\end{abstract}

This study will divide Hebble's organ music into two categories: chorale-preludes (Chapter 8) and free-works (Chapter 9). According to the Harvard Dictionary of Music, the definition of a chorale is a "congregational song or hymn of the...church."145 For the purpose of this study, the word "chorale" refers to the body of organ music that Hebble composed based on a cantus prius factus (a hymn-tune or chant), and not on an original melody of his own. Hebble, like other composers of organ music, including Bach, uses the chorale melody as the principal theme of the composition, referred to as the cantus firmus (c.f.).

As each collection is subsequently discussed, it will be presented in chronological published order, then in alphabetical order within each collection according to the author's numbering system created in Appendix A. Each work will receive a cursory analysis only but will be perused in as much detail as necessary to reveal its general form and style, highlighting the treatment of melody, harmony and any anomalies. They will be categorized according to the chart below, based on standard chorale forms.

Commentary on each work will cite the number of the work assigned in Appendix A. Entries will include the title of the work (that given by the composer, the name of the collection, date and publishing number) as well as describe the requirements of the organ

\footnotetext{
${ }^{145}$ Randel, Don Michael. "Chorale", The Harvard Dictionary of Music, Harvard University Press, Cambridge, Massachusetts, (1986, Eighth printing, 1996), p.158.
} 
(e.g. whether the work is designed for three manuals and pedal, etc.). Commentary will also contain keys, meter, number of measures and give a brief account of the treatment of the cantus firmus (c.f.). Entries will occasionally supply the hermeneutic reasoning within the composition based on the subjective expression of the hymn's theology. Only the chorale's basic associations will be discussed in order to point out the composer's creative method in general (e.g., what style he is adopting). Commentary on each work will occasionally provide the source-material for the chorale, if any, in order to supply evidence for the piece as it stands (e.g., Bach's chorales, Debussy's piano music, the improvisational models of Dupré or Cochereau, American Cinema (Theater) organs or jazz), to approach what is the background for the work. Finally, most compositions will have a chart diagramming the work's construction, and some of these will include Roman numeral analysis. The following chart offers clarification of the chorale types:

\section{Short Form Chorales ${ }^{146}$} Short Melody Chorale - (e.g., J. S. Bach Orgelbüchlien) - the c.f. appears as a continuous melody in the soprano with no interludes, may contain an intro. or coda. (e.g., Ich ruff' zu dir BWV639) Short Ornamental Chorale - the c.f. is presented without interludes and is highly embellished, may contain an intro. or coda. (e.g., O Mensch bewein' BWV622) Short Chorale Canon - the c.f. is set in canon without interludes against an accompaniment. (e.g., In Dulci Jubilo BWV608)

Short Chorale Fantasia - throughcomposition of $c$.f. in fragments with very short interludes whose music penetrates and is adopted by the tune itself, or motifs

\section{Long Form Chorales}

Long Melody (c.f.) Chorale - the c.f. appears as a continuous melody but separated with interludes, usually contains an introduction and coda. (e.g., Nun danket BWV657)

Long Ornamental Chorale - the c.f. is presented highly embellished with interludes, usually contains intro. and coda. (e.g., Nun komm', BWV659) Long Chorale Canon - the c.f. is set in canon with interludes against an accompaniment.

\section{Long Chorale Fantasia - emerged as a} virtuosic display-piece (toccata); throughcomposition of multiple full quotes of $c$.f. with interludes whose music penetrates and

\footnotetext{
${ }^{146}$ May, Ernest; Stauffer, George, editors. J.S. Bach As Organist. Bloomington, Indiana University Press, (1986), pp. 83-100.
} 


\begin{tabular}{|c|c|}
\hline $\begin{array}{l}\text { drawn from c.f.; contains very short } \\
\text { introductions or codettas. (e.g., In Dir Ist } \\
\text { Freude BWV615) }\end{array}$ & $\begin{array}{l}\text { is adopted by the tune itself, or motifs } \\
\text { drawn from c.f.; extended introductions and } \\
\text { codas. (e.g., Ein' feste burg BWV720) }\end{array}$ \\
\hline $\begin{array}{l}\text { Chorale Motet - imitates the vocal motets } \\
\text { of the early seventeenth century, presents } \\
\text { motifs of each strophe in imitation creating } \\
\text { a series of entries in 'fore-imitation' based } \\
\text { on each strophe in succession. (e.g., Vor } \\
\text { deinen thron BWV668) }\end{array}$ & $\begin{array}{l}\text { Chorale Fughetta - brief fugues occur } \\
\text { sectionally based on each strophe of the c.f. } \\
\text { presented in succession. (e.g., Wir glauben } \\
\text { all' an einen Gott BWV681) [not } \\
\text { necessarily the expansion of the chorale } \\
\text { motet, but similar] }\end{array}$ \\
\hline $\begin{array}{l}\text { Short Chorale Prelude }- \text { independent } \\
\text { structure in the chorale-free voices. } \\
\text { Accompaniment contains no interludes to } \\
\text { contrast the areas of } c . f . .\end{array}$ & $\begin{array}{l}\text { Long Chorale Prelude -independent } \\
\text { structure in the chorale-free voices. } \\
\text { Accompaniment contains interludes that } \\
\text { contrast those of the } c . f . \text { strengthening the } \\
\text { identity of the accompaniment (e.g., } \\
\text { Schübler Chorales) }\end{array}$ \\
\hline $\begin{array}{l}\text { Short Trio Chorale }- \text { c.f. is presented in a } \\
\text { three-voice texture without interludes, or an } \\
\text { extremely short introduction or coda. (e.g., } \\
\text { Herr Jesu Christ BWV655a); [similar to a } \\
\text { chorale-motet] }\end{array}$ & $\begin{array}{l}\text { Long Trio Chorale }- \text { c.f. is presented in a } \\
\text { three-voice texture with interludes and } \\
\text { introduction and coda. (e.g., Wachet auf } \\
\text { BWV656); [similar to a chorale-motet] }\end{array}$ \\
\hline $\begin{array}{l}\text { By virtue of the "ritornello", which can act } \\
\text { as an intro, interlude and coda, there is no } \\
\text { short form comparative. }\end{array}$ & $\begin{array}{l}\text { Ritornello Chorale - a recurring episode } \\
\text { presented as interludes between c.f. } \\
\text { sections: } c . f . \text { is usually unadorned (e.g., Aus } \\
\text { Tiefer Not BWV686) or ornamented (e.g., } \\
\text { Schücke dich BWV654a) }\end{array}$ \\
\hline No short form cc & $\begin{array}{l}\text { Chorale Variations/Partita - the verses of } \\
\text { the chorale are treated individually in } \\
\text { succession; designed to present the } c . f . \text { by } \\
\text { many diverse musical treatments such as } \\
\text { those previously mentioned. (e.g., Sei } \\
\text { gegrüsset, Jesus gütig BWV768; O Gott, } \\
\text { du frommer Gott BWV681) }\end{array}$ \\
\hline No short form comparative & $\begin{array}{l}\text { Combination Chorale Form - similar to, } \\
\text { but beyond the fantasia form by combining } \\
\text { two or more chorale forms within one } \\
\text { work: (e.g., a ritornello form in which one } \\
\text { episode is treated fugally, or the work } \\
\text { contains an extended introduction or coda } \\
\text { in fantasia style framing an interior } \\
\text { ritornello form) or a concluding toccata. }\end{array}$ \\
\hline
\end{tabular}

Chorale Cp1 Nave

H. W. Gray \#859
Single work (1958)

Four Manuals/Pedal 
Long Chorale Fantasia $\quad 61 \mathrm{~mm}$

A major; 4/4

This is Hebble's first published work. It was commissioned by Virgil Fox in December of 1957 for the summer AGO convention in Phoenix, Arizona in 1958. Fox premiered it at the convention. The story of its creation is covered in Chapter 3. The work is divided into three "pictures", as Hebble calls them, and is in the style of a character piece. As such, the work is not titled after the chorale, but is instead titled according to the images conjured by the music: a church's "nave". Each "picture" contains three phrases, alluding to the trinity, except for the third picture, which contains 7 phrases, alluding to perfection. The first picture's phrases, see Ex. 8-1, sy1, are made up of two separate octatonic scales moving from "cool harmonies" of $\mathrm{F}$ minor and $\mathrm{E}^{\mathrm{b}}$ minor to the "warm harmonies" of the second picture of $\mathrm{G}$ major and $\mathrm{D}^{\mathrm{b}}$ major. Via a common-tone modulation (an enharmonic $\mathrm{c} \#$ ) the harmonies move to the tonic A major in the third picture. This latter section contains the area of c.f. treatment (based on Divinum Mysterium), played on an English Horn 4 in the pedal, see Ex. 8-1, sy2. In the coda, there is stretto (mm. 53-55, 58-59, 60-61) which extrapolates upon the associated text "evermore".

\begin{tabular}{|c|c|c|c|}
\hline Picture 1 & Picture 2 & Picture 3 & Coda \\
\hline $\begin{array}{l}3 \text { phrases (solo } \\
\text { versus tutti-pp), no } \\
\text { pedal, } 2 \text { octatonic } \\
\text { scales }\end{array}$ & $\begin{array}{l}3 \text { phrases (duet } \\
\text { versus 'tutti'), } \\
\text { double-pedal, } \\
\text { polytonality, c.f. } \\
\text { fragments }\end{array}$ & $\begin{array}{l}\text { Area of } c . f . \\
\text { treatment in pedal, } 4 \\
\text { phrases of } 2 \text { bars, } \\
\text { then } 3 \text { phrases of } 4 \\
\text { bars for } 7 \text { phrases }\end{array}$ & $\begin{array}{l}\text { Repeat final strophe } \\
\text { of } c . f \text {. repeated in } \\
\text { pedal, three } \\
\text { occurrences of } \\
\text { stretto (balance intr) }\end{array}$ \\
\hline mm 1-16 & $17-32$ & $33-55$ & $56-61$ \\
\hline
\end{tabular}




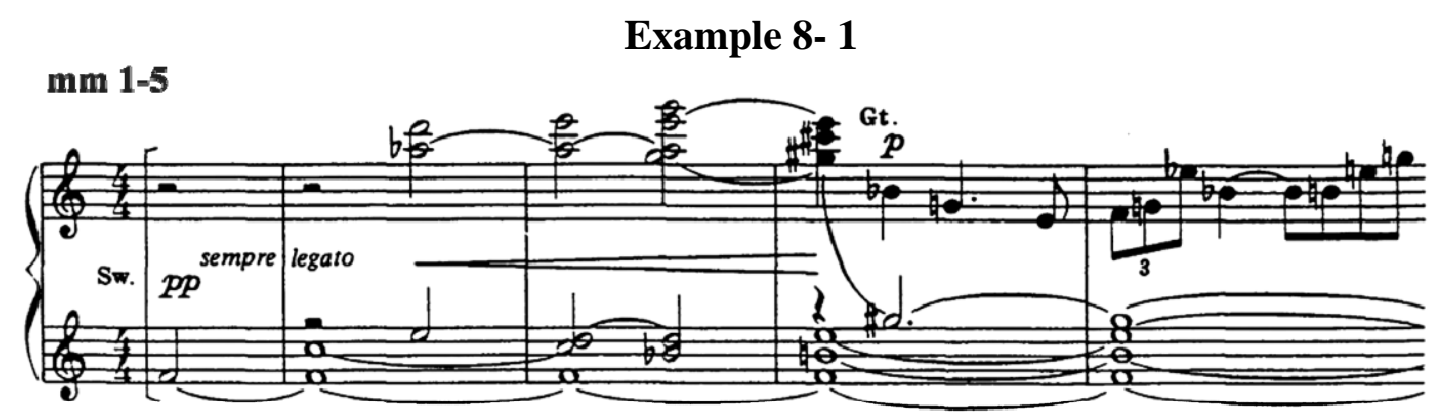

\section{mm 31-33}

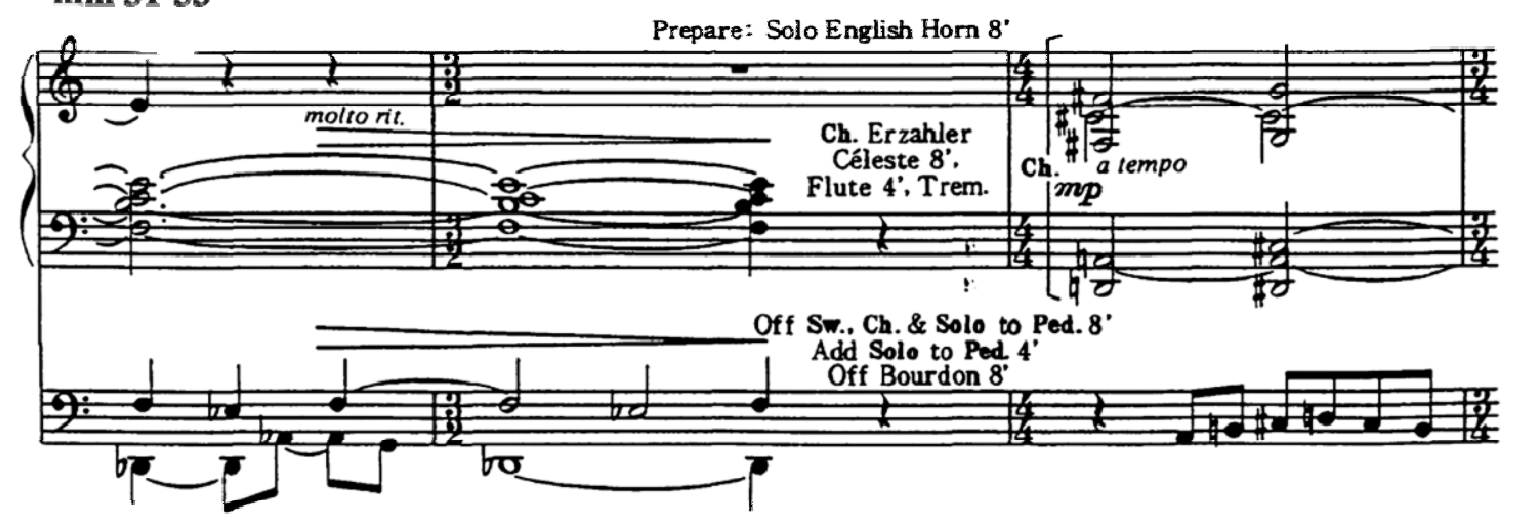

Chorale Cp6 Londonderry Air

Sacred Music Press KK246

Long Chorale Fantasia

C major; $4 / 4$
Collection I; (1/1[4]) $)^{147}$

Ted Alan Worth in Concert (1971)

Three Manuals/Pedal

$45 \mathrm{~mm}$

Composed in 1962 it varies from his later version of the same title $C p 40$, the latter of which is from Collection IV. Cp6 treats two verses of the tune, has an introduction, an extended coda and an interlude between the verses, qualifying it as a long form. The $c . f$. appears mostly in the pedal, see Ex. 8-2, although it transfers briefly to the manuals in the chorus of the second verse (mm. 28-36) where there is a sixteenth-note counter-melody. Hebble provides specific registration changes throughout the work. It requires three

\footnotetext{
${ }^{147}$ This refers to the first chorale out of one chorale in a collection of $\underline{4}$ pieces. The last number refers to number of works in the collection, the middle number refers to the number of a particular 'species' (chorales) in the collection, and the first number is from the alphabetical ordering.
} 
organ preset combinations. ${ }^{148}$ The texture is 5 voices, contrapuntal in brief moments (imitating the motivic contour of the c.f., not polyphonic), and is infused with blues harmony and added note chords.

\section{Example 8- 2}
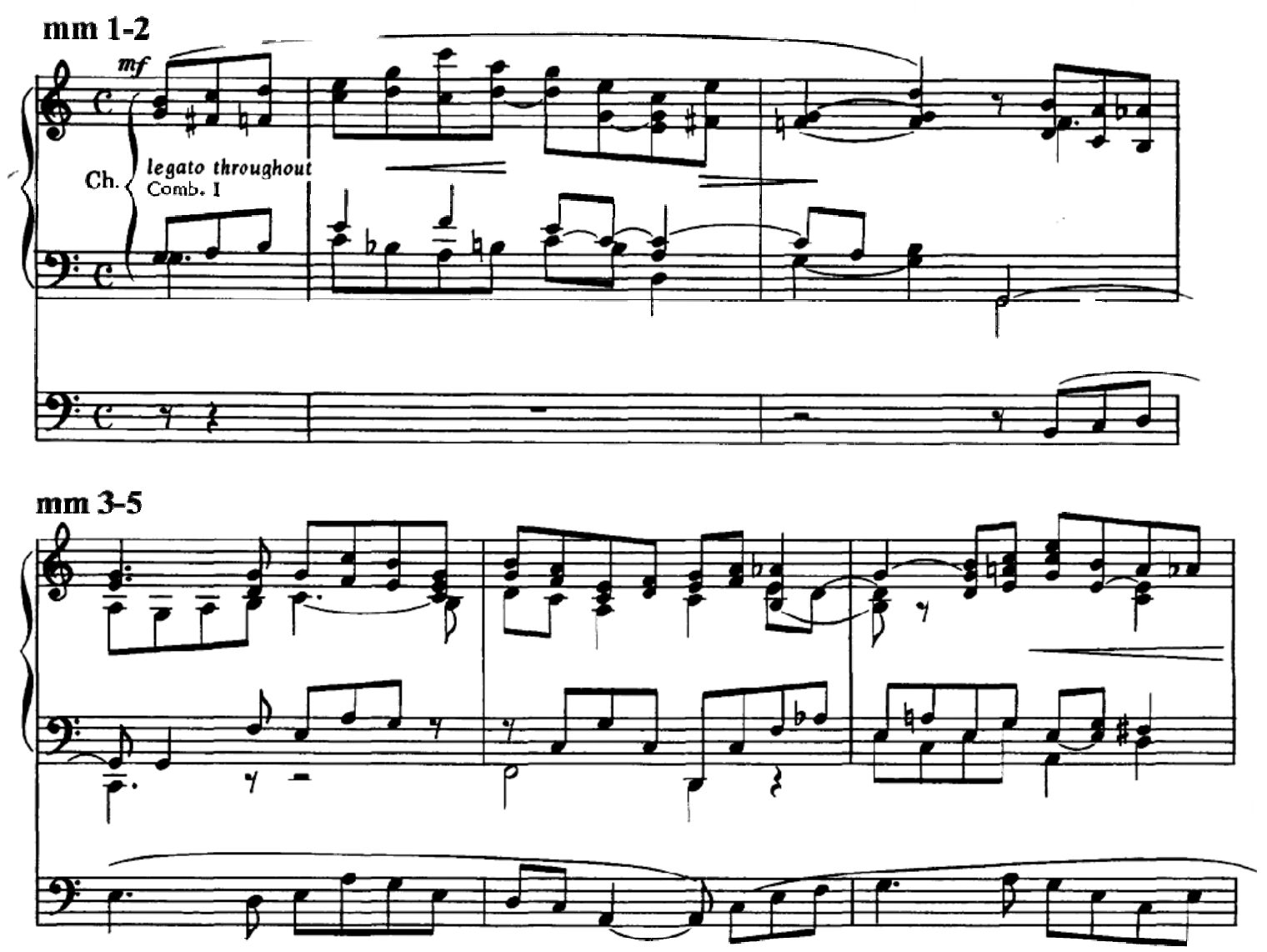

Chorale Cp20 Simple Gifts

Bradley Publications 24M21

Long Chorale Fantasia

F major; $4 / 4$
Collection II (1/1[12])

Virgil Fox - The Organist (1980)

3 Manuals/Pedal

$41 \mathrm{~mm}$

The work was commissioned by Contemporary Keyboard magazine for the $80^{\text {th }}$ birthday of Aaron Copland (1900-1992). It precedes Cp41 of the same name. It is a long form

\footnotetext{
148 "Pre-sets" are buttons on the organ console that permit the pre-selection of needed stops that are programmed ahead of performances. Rather than arrest musical action to re-set the registration, pre-sets instantly facilitate this process and permit the use of a wider range of timbres and colors.
} 
because of the interludes as well as introduction and coda. After the introduction, the c.f. appears in the pedal while the manuals accompany on blues-like chords, see Ex. 8-3.

After a short interlude, a second treatment of the c.f. emerges, stating only fragments of the refrain in the manuals, part of which is without pedal. There are alterations to the organ registration throughout the work, which are marked.

\begin{tabular}{|c|c|c|c|c|c|c|}
\hline tro. & c.f. & interlude 1 & c.f. frag. & interlude 2 & c.f. frag. & coda \\
\hline no pedal & all verse 1 & no pedal & strophe 3 & no pedal & strophe 4 & elided \\
\hline mm. 1-8 & $12-24$ & $24-27$ & $28-31$ & $31-33$ & $4-39$ & $3 \xi$ \\
\hline
\end{tabular}

\section{Example 8- 3}
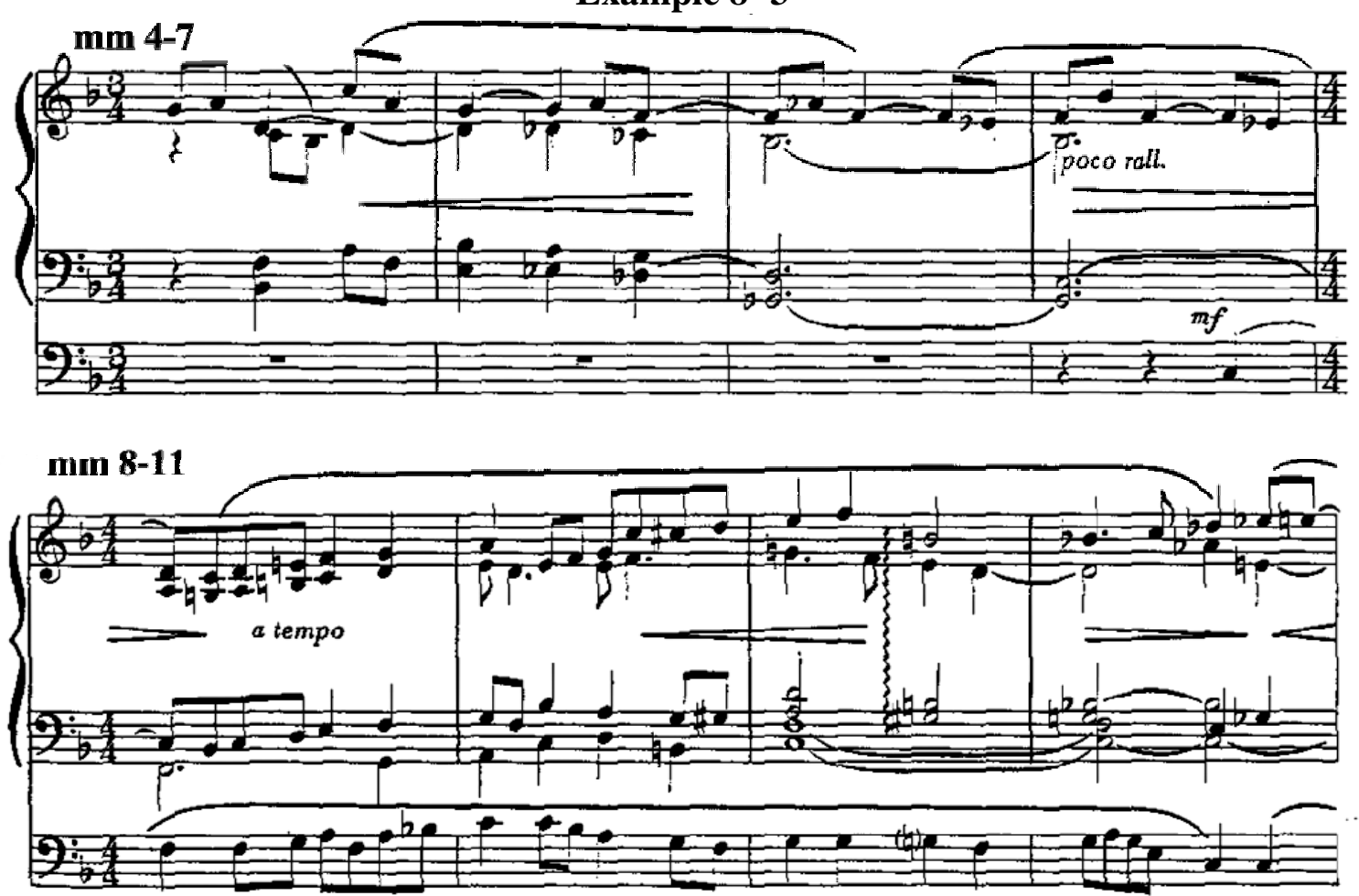
Chorale Cp23 Good King Wenceslas Collection III; (1/4/[9])

Bradley Publications 24M20

Short Melody Chorale

$\mathrm{A}^{\mathrm{b}}$ major; cut time

Virgil Fox - The Christmas Album (1980)

Three Manuals/Pedal

$47 \mathrm{~mm}$

The work contains a short introduction and coda plus two successive verses, see Ex. 8-4,

sy1. Its unique registration is worth noting: Flutes 8 and 2 in the top octave against a

Krummhorn 8 and Flute 4, the latter of which contains the c.f. in the baritone range, see

Ex. 8-4, sy2. At the beginning of verse two, a reed 16 is added to enhance the already

amusing quality of the Krummhorn sound which is further humored by the

reharmonization of the last verse.

\begin{tabular}{|c|c|c|c|}
\hline introduction & variation one & variation two & coda \\
\hline 2 phrases; high flutes & Krummhorn has c.f. & $\begin{array}{l}\text { Reharmonized } 2^{\text {nd }} \text { half } \\
\text { of strophes in c.f. }\end{array}$ & $\begin{array}{l}\text { Interlude; } 4 \text { octave } \\
\text { run; pizzicato pedal }\end{array}$ \\
\hline Measures 1-4 & $5-21$ & $22-37$ & $38-44 ; 45-47$ \\
\hline
\end{tabular}

Example 8- 4
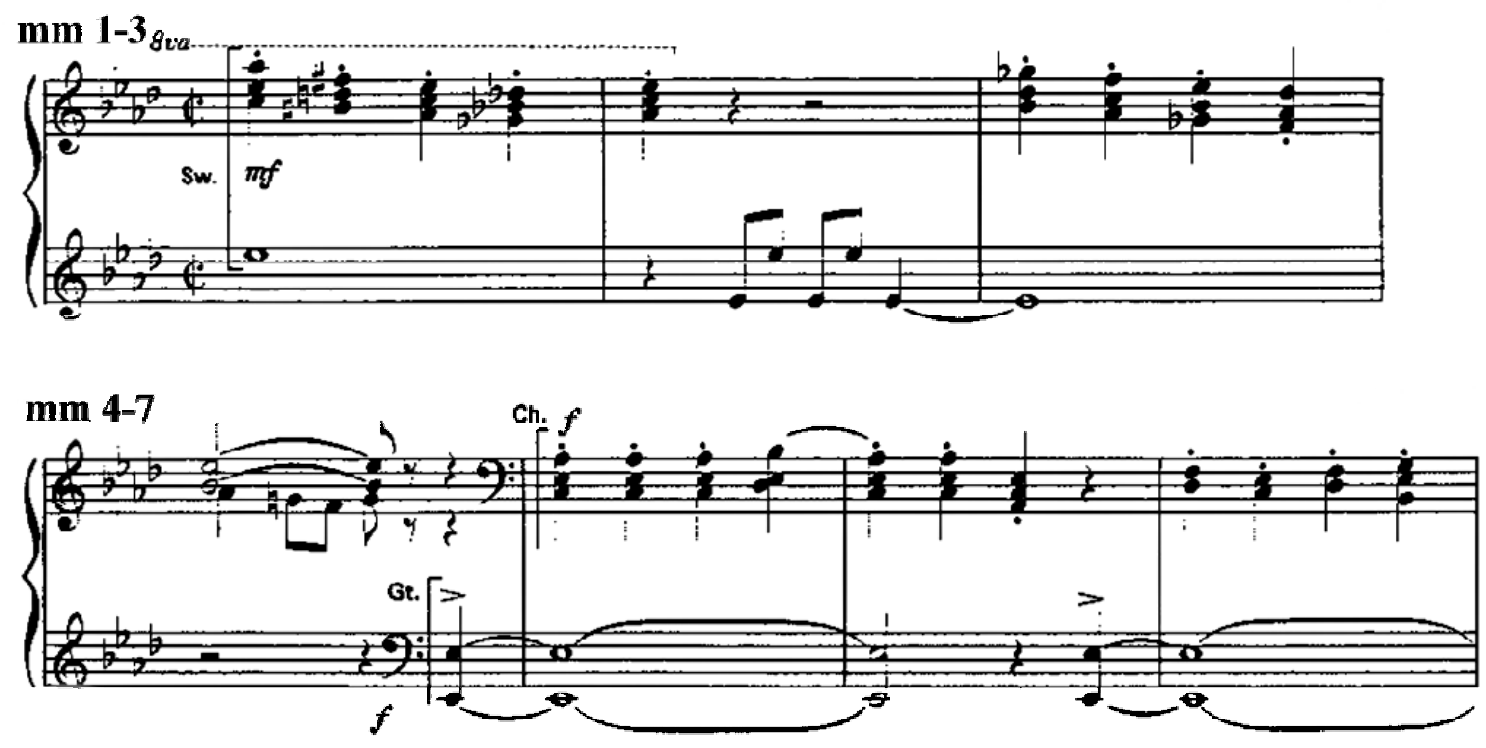
Chorale Cp26 Joy To the World

Bradley Publications 24M20

Long Melody Chorale

$\mathrm{C}$ to $\mathrm{E}^{\mathrm{b}}$ major; cut time
Collection III, (2/4[9])

Virgil Fox - The Christmas Album (1980)

Four Manuals/Pedal

$99 \mathrm{~mm}$

This is a hymn-like work that treats four verses of the Handel tune. It has four successive keys $\left(\mathrm{C}, \mathrm{D}^{\mathrm{b}}, \mathrm{D}\right.$ and $\left.\mathrm{E}^{\mathrm{b}}\right)$. There is a five-measure introduction on full organ. On a separate manual there is a Chimes sequence (intended to be played by a separate player), which acts as an interlude between each verse, see Ex. 8-5, sy3. Generally, Hebble embellishes the work with his own counterpoint, thickens the texture with the addition of descants and maintains traditional harmony. The modulations are direct, with no composed progression, see Ex. 8-5, sy3 and 4. Although the chorale could be played for recitals, it is more of a free-accompaniment for congregational singing. Note also the quasi-canon of the interlude (an introduction in some editions), see Ex. 8-5, sy1. 
Slower $(d=80)$

\section{Example 8- 5}
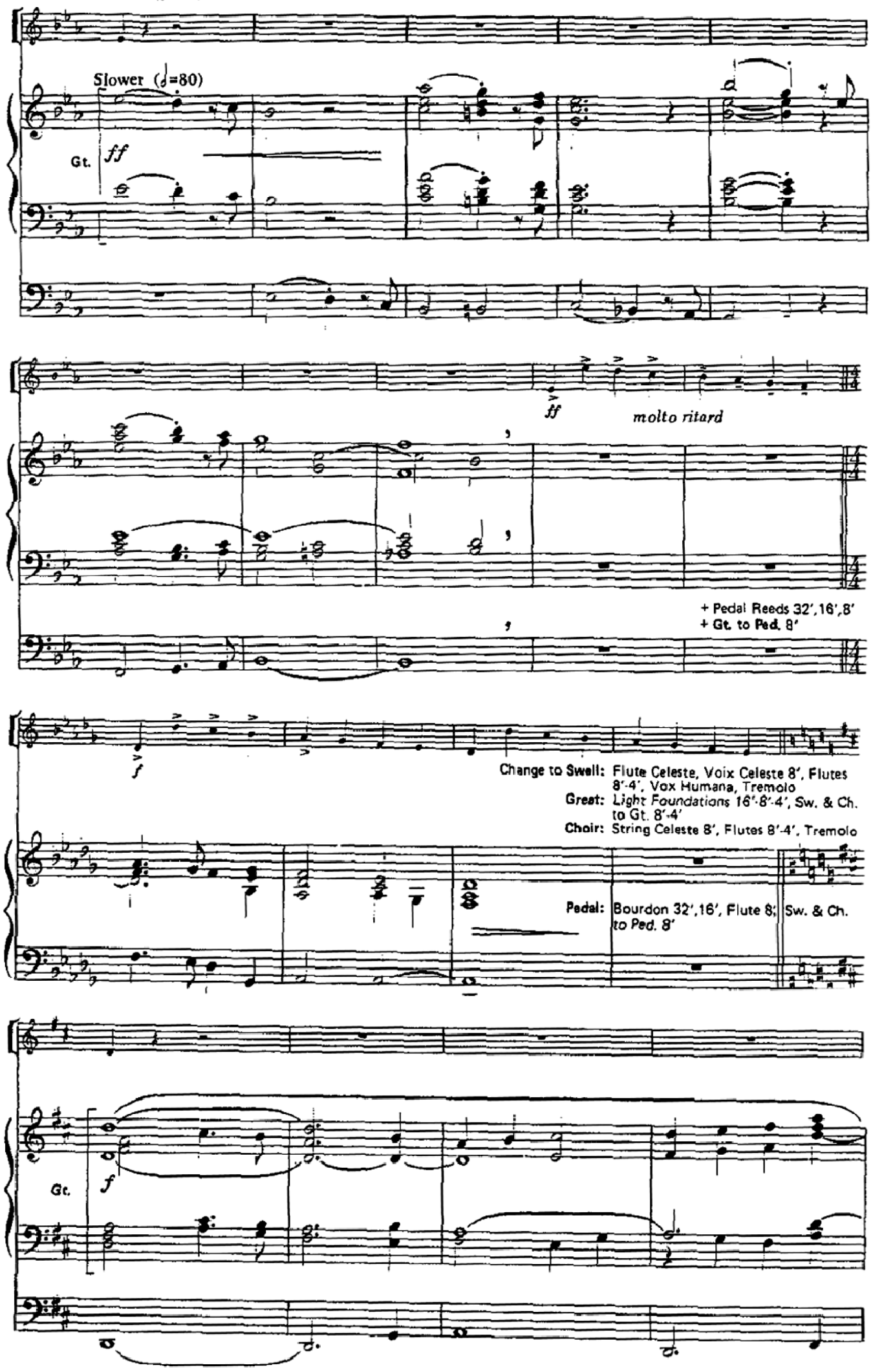


$\begin{array}{lc}\text { Chorale Cp28 O Little Town of Bethlehem } & \text { Collection III; (3/4[9]) } \\ \text { Bradley Publications 24M20 } & \text { Virgil Fox }- \text { The Christmas Album (1980) } \\ \text { Chorale Variations } & \text { Two Manuals/Pedal } \\ \text { F major; 4/4 } & 76 \mathrm{~mm}\end{array}$

It is a set of three variations with interludes and Chimes. The work is recaptured from Hebble's memory of how he arranged it for Fox to perform at The Riverside Church. The last strophe of the verse is adapted as the introduction on the Chimes, which is played by a separate person. See Ex. 8-6, sy1. The first variation of the c.f. uses the French Horn $8^{149}$ in the tenor range while the right-hand and pedal are obbligato in a temporary Short Melody Chorale form, see Ex. 8-6, sy2. There is an interlude (mm. 2124) which establishes a toccata-like figuration in variation two, with the c.f. in augmentation in the pedal in a Short Chorale fantasia form, see Ex. 8-6, sy3. There is an interlude, which brings the second verse to a close before the third verse, where the $c . f$. is in the soprano along with a melismatic chimes sequence. The harmonies retain most of the traditional progressions associated with this carol, with only the occasional incorporation of non-harmonic tones.

\begin{tabular}{l|l|l|c|c|c|}
\multicolumn{1}{l}{ Introduction } & \multicolumn{1}{c}{ var. 1 } & \multicolumn{1}{c}{ interlude } & \multicolumn{1}{c}{ var. 2} & \multicolumn{1}{c}{ interlude } & \multicolumn{1}{c}{ var. 3} \\
\hline Solo chimes & c.f. in tenor & Figura estab. & c.f. in pedal & Senza Figura & c.f. in soprano \\
\hline mm. 1-4 & $5-20$ & $21-24$ & $25-56$ & $57-60$ & $61-76$
\end{tabular}

149 This is the Symphonic Organ's (ASO) contribution to the American Classic organ from the early 1900s. 


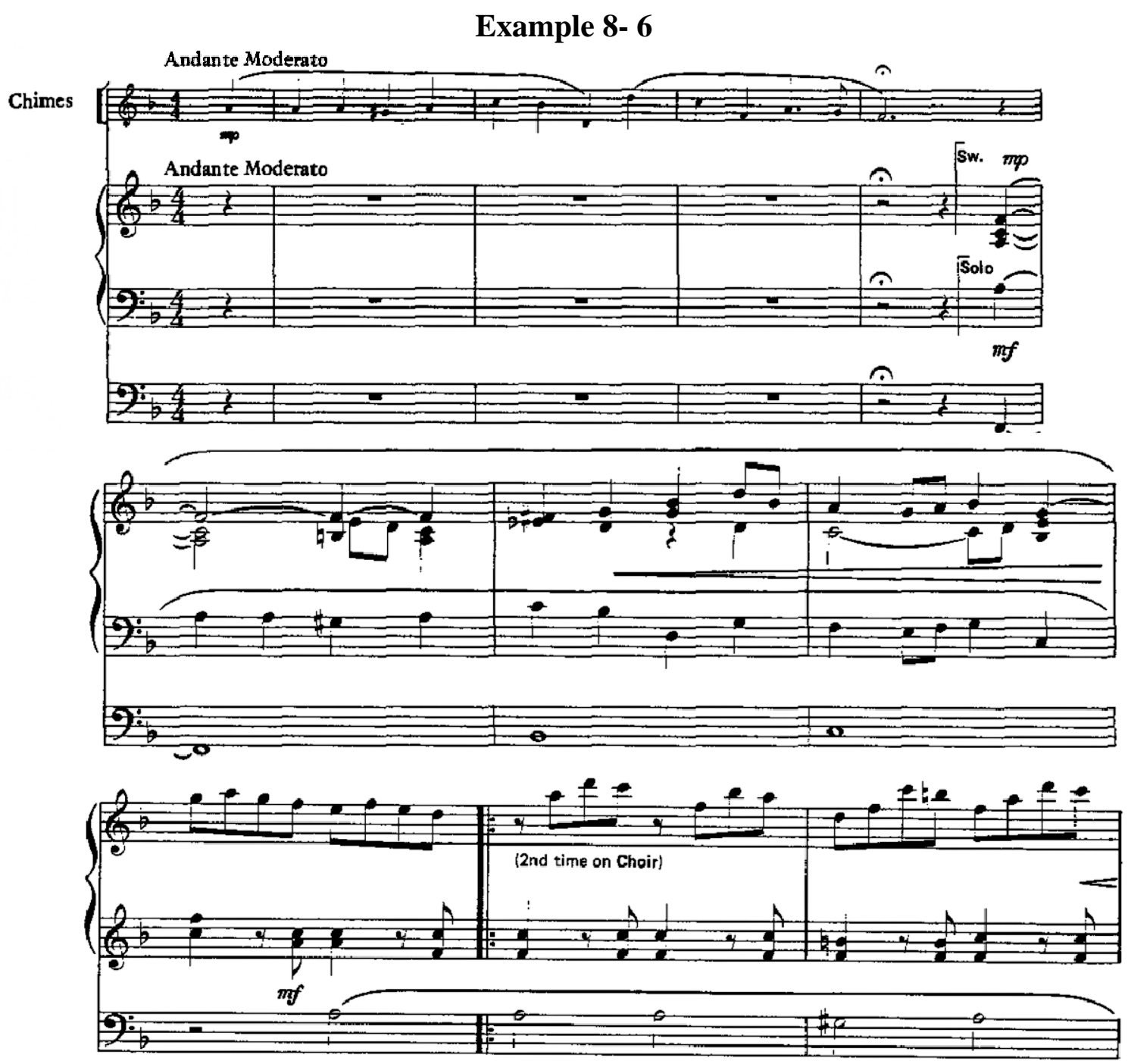

Chorale Cp30 Silent Night

Bradley Publications 24M20

Chorale Variations

$\mathrm{B}^{b}$ major; $3 / 4$ (two modulations)
Collection III; (4/4[9])

Virgil Fox - The Christmas Album (1980)

Two Manuals/Pedal

$76 \mathrm{~mm}$

This is the arrangement Hebble wrote for Fox to use at The Riverside Church during the

1950s. It had never been written down, but Hebble remembers how Fox played it and registered it with Chimes ${ }^{150}$ (played by a separate player), see Ex. 8-7. Treating three variations with traditional harmonies, Hebble avoids the dominant-seventh chord directly

\footnotetext{
${ }^{150}$ E-mail: teemark@aol.com, July 20, 2002, regarding Christmas arrangements Fox played by Hebble.
} 
by composing the dominant pedal a measure or more before the tonic chord. Since Fox liked the traditional harmony (with the V7s), Hebble only adds the $7^{\text {th }}$ of the $\mathrm{V}$ on the last beat before the tonic chords (mm. 25, 49 and 73). There is a climactic arrival on a Tristan harmony related to the text underlay at measure 72 on the word "born", implying that, according to Christian theology, Jesus' life began 'unresolved' in birth; that His coming was ultimately for human salvation at Easter.

\begin{tabular}{|c|c|c|c|}
\hline Introduction & var. one & var. two & var. three \\
\hline Solo Chimes & c.f. solo flutes in $\mathrm{B}^{b}$ & c.f. soprano (echo) $\mathrm{E}^{b}$ & c.f. tenor (echo) $\mathrm{A}^{b}$ \\
\hline mm. 1-4 & $5-28$ & $29-52$ & $53-76$ \\
\hline I & $\mathrm{V} / \mathrm{I}$ & $\mathrm{V} / \mathrm{I}$ & "T" I \\
\hline
\end{tabular}

\section{Example 8- 7}
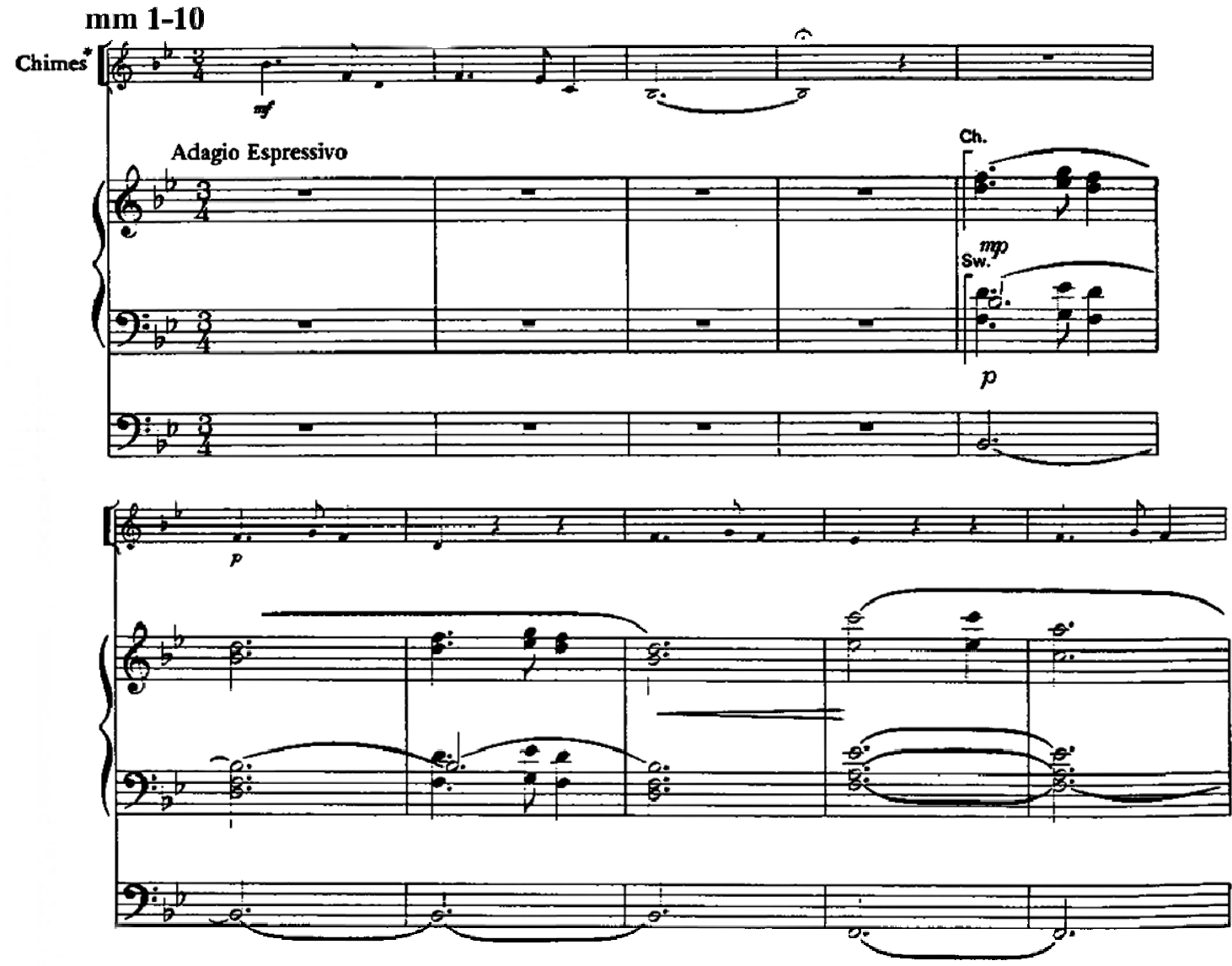
Chorale Cp31 Amazing Grace

Bradley Publications 24M22

Chorale Variations

$\mathrm{B}^{\mathrm{b}}$ Major; $3 / 4$ time
Collection IV; (1/12[13])

Hymn Tunes, Preludes and Improvisations (1981)

Three Manuals/Pedal

$119 \mathrm{~mm}$

This is a set of five variations in multiple keys with an introduction, interludes and coda.

There are also five different pre-set registrations prescribed, which contribute to the music's unique color. With a two measure introduction, an ostinato on open 5 ths in $\mathrm{B}^{\text {b }}$ evokes the sound of bagpipes, and begins variation one, see Ex. 8-8, sy1. The c.f. is in the soprano, and contains an accompaniment of non-harmonic tones over a tonic pedal $\mathrm{B}^{b}$. The second variation has an altered harmonization of an ornamented c.f. (mm. 31-32) while the pedal adds a concurrent new c.f. called How Firm a Foundation (mm. 18-34), see Ex. 8-8, sy2 and 3. There is an interlude (mm. 34-37), see Ex. 8-8, sy4, and a modulation to d-minor for verse three, which is without pedal. During variation three the c.f. is accompanied by a recurring motif in the left-hand, see Ex. 8-8, sy5. There is another interlude (mm. 54-66) during which the music is highly extemporized in a French Paraphrase style. ${ }^{151}$ Variation four modulates to F major (m.67) and the c.f. is in the soprano with imitation in the pedal in $\mathrm{f}$-minor (m. 68) amidst a blues harmonization, see Ex. 8-8, sy6. An interlude (mm. 85-89) leads to the final variation of the c.f., with a $\mathrm{G}^{\text {b }}$ chord (via a Neapolitan, m. 89), and is composed in an (mm. 89-107) ornate and intensely jazz influenced improvisation. Hebble describes it as "bebop and scat for the organ." ${ }^{152}$ The coda (mm. 108-119) employs the Neapolitan, the ${ }^{\mathrm{b}} 3^{\text {rd }}$ and two voices of imitation in stretto and augmentation in the pedal (mm. 112-115).

\footnotetext{
${ }^{151}$ This term is defined in Part IV, Conclusions, Chapter 10, p. 256.

${ }^{152}$ Florida interview, 2001, Hebble.
} 


\section{Example 8- 8}

mm 1-3
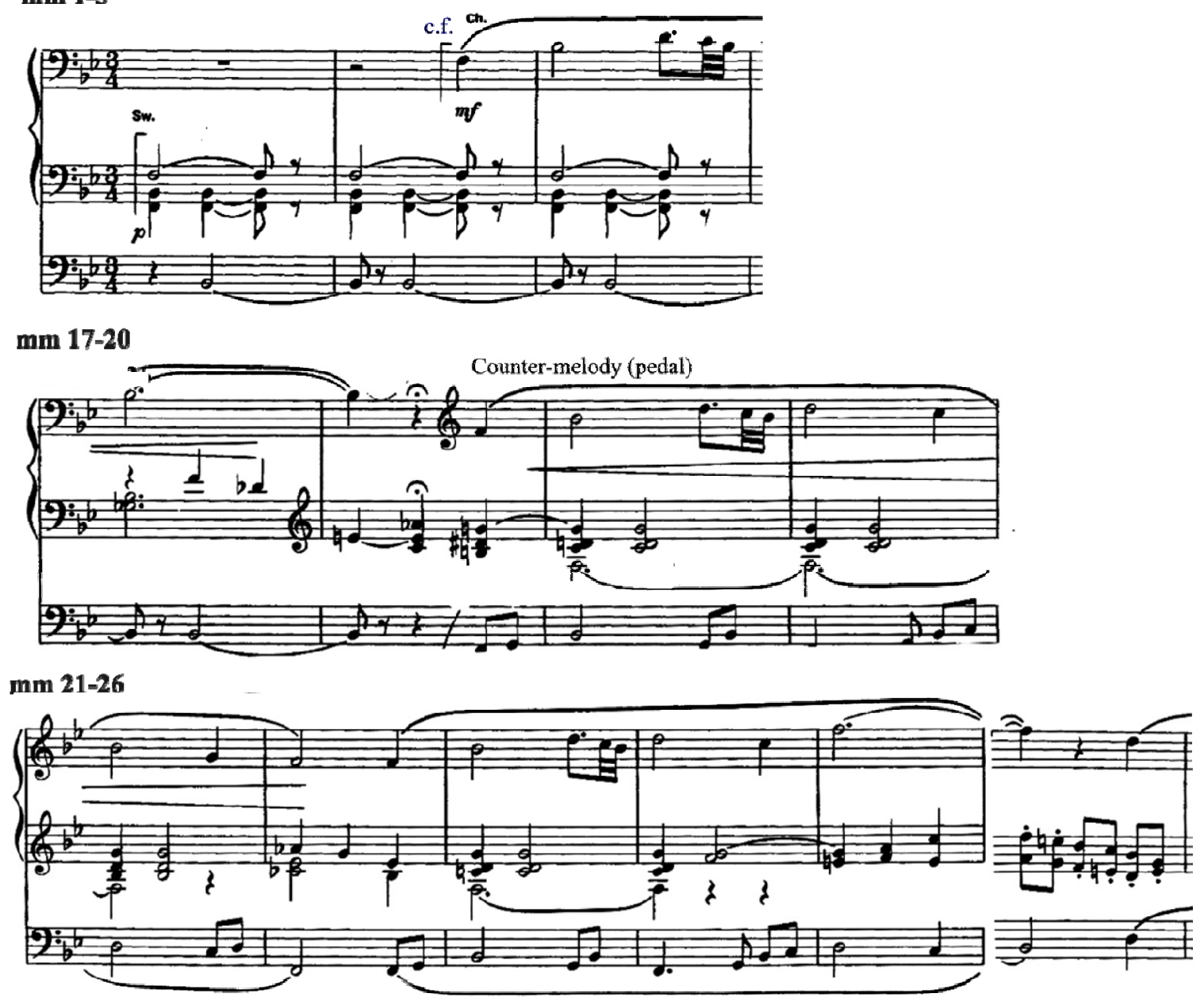

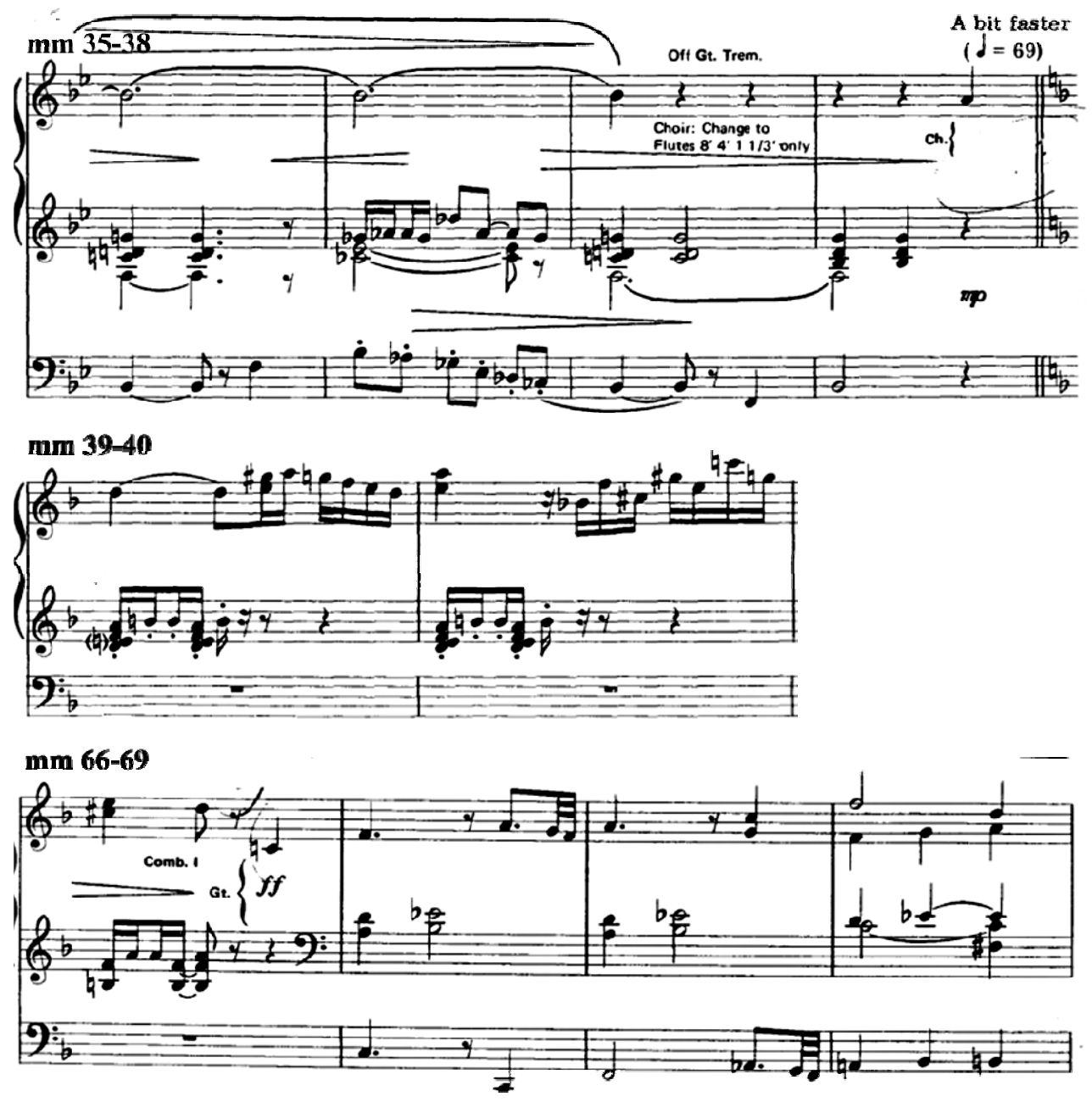

Chorale Cp32 Bread of Life

Bradley Publications 24M22

Chorale Motet

$E^{b}$ major; 4/4 time
Collection IV; $(2 / 12[13])$

Hymn Tunes, Preludes and Improvisations (1981)

Four Manuals/Pedal

$64 \mathrm{~mm}$

The c.f. is divided into sections by strophes and is a chorale-motet. There is a sustained subdominant chord $\left(\mathrm{A}^{b}, \mathrm{~mm} .3-11\right)$ that pivots back and forth between its Neapolitan (m.5) and the Neapolitan of the tonic (m. 9) for five phrases before the c.f. enters. The tenor c.f. is augmented and syncopated (m. 12-) while the accompaniment contains blues and altered harmony, see Ex. 8-9, sy2. There are small interludes before strophe three (mm. 28-35) and four (mm. 44-47) which motivically anticipate the next c.f. entrance in 
fore-imitation. ${ }^{153}$ See Ex. 8-9, sy1. These interludes attempt to depart from the key by suspended chromatic passing tones and altered harmonies. Palindromically, it ends as it began. It requires two preset-combinations.

\begin{tabular}{|c|c|c|c|c|c|}
\hline Introduction & strophe one & strophe two & strophe three & strophe four & coda \\
\hline $\begin{array}{l}\text { Fragments } \\
\text { of various } \\
\text { strophes }\end{array}$ & $\begin{array}{l}\text { c.f. in the } \\
\text { tenor; } \\
\text { ornamented }\end{array}$ & $\begin{array}{l}\text { c.f. in the } \\
\text { tenor; ornamt. }\end{array}$ & $\begin{array}{l}\text { Small } \\
\text { interlude, c.f. } \\
\text { tenor, ornamt. }\end{array}$ & $\begin{array}{l}\text { Interlude, c.f. } \\
\text { in soprano } \\
\text { augmentation }\end{array}$ & $\begin{array}{l}\text { Cyclic of } \\
\text { introduction } \\
\text { backwards }\end{array}$ \\
\hline Mm 1-11 & $12-19$ & $20-27$ & $28-43$ & $44-54$ & $55-64$ \\
\hline
\end{tabular}

\section{Example 8- 9}
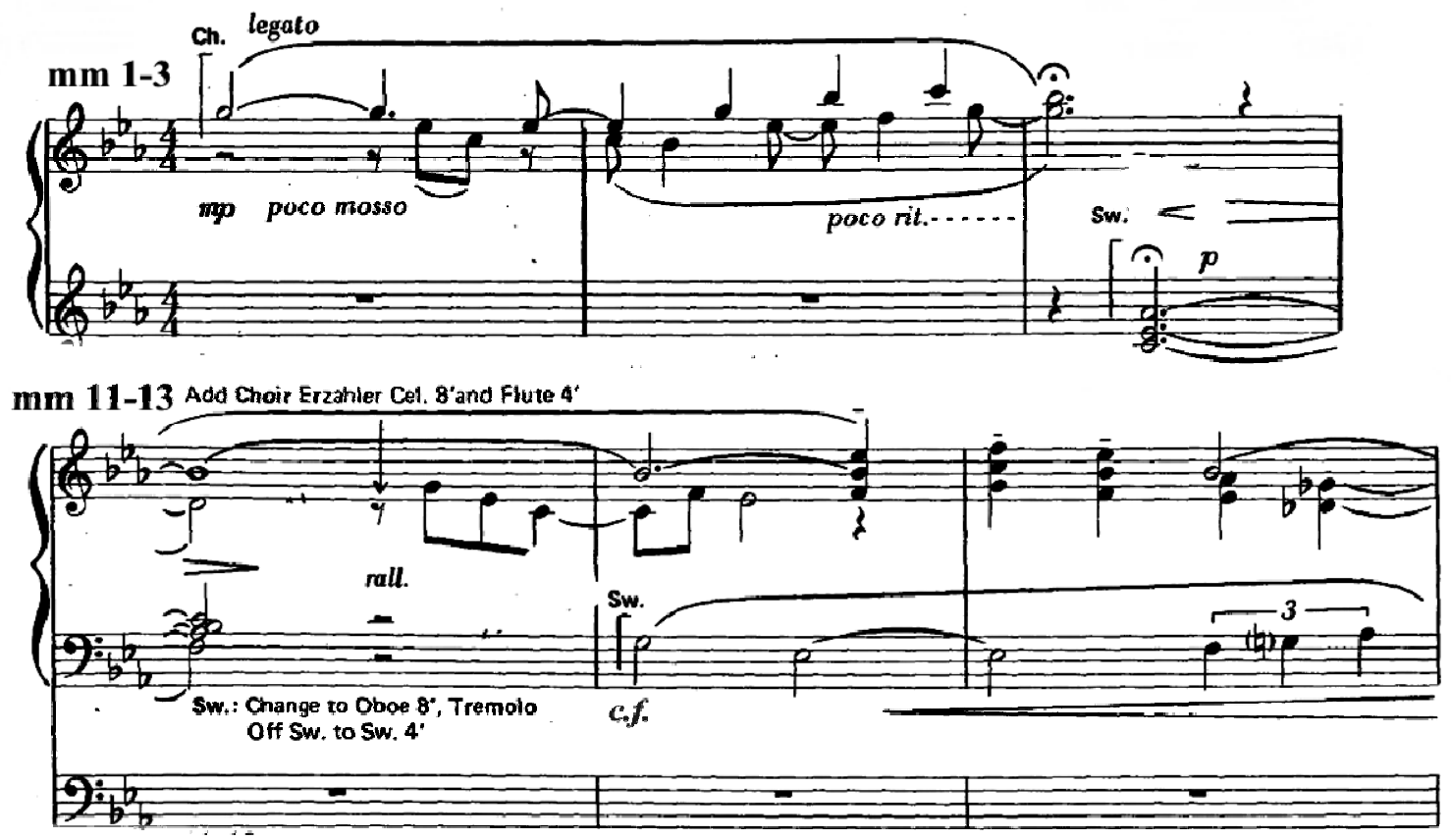

${ }^{153}$ Schalk, Carl. Key Words in Church Music. St Louis, Missouri, Concordia Publishing House (1978), p. 293. Fore-imitation is Schalk's translation of the German vorimitation. 
Chorale Cp33 Beatitudo

Bradley Publications 24M22

Type 1 Chorale Motet

$\mathrm{A}^{\mathrm{b}}$ major; $4 / 4$ time
Collection IV; (3/12[13])

Hymn Tunes, Preludes and Improvisations (1981)

Three Manuals/Pedal

$74 \mathrm{~mm}$

The strophes are treated in motivic fore-imitations and sectionally in this chorale-motet. It is dedicated to Dr. Thomas Richner, who was the organist at the First Church of Christ Scientist, Boston, Massachusetts, where there is a large Skinner ACO much like the one at The Riverside Church in New York City. The introduction is 25 measures long (about a third of the composition) and contains three elided phrases of 8 measures each, see Ex. 8-10, sy1. The c.f. is in the tenor (beginning at $\mathrm{m}$. 26) with blues and altered harmonies occurring above in the right-hand, see Ex. 8-10, sy2. There is an interlude that incorporates melodic material from the preceding strophe (mm. 41-44), then the second strophe (mm. 45-48) then the third strophe (mm. 49-56) in fore-imitation and employing the crescendo pedal to great effect. As the c.f. on the remaining strophe occurs in the soprano, an ostinato peals in the pedal (mm. 57-60), see Ex. 8-10, sy3. The coda repeats the phrases of the introduction and contains an objectified Neapolitan harmony ${ }^{154}$ before the final tonic (m. 73), completely avoiding the dominant-seventh chord. It requires two preset-combinations.

\footnotetext{
${ }^{154}$ The Neapolitan tingeing is not spelled correctly, but there is no mistake in hearing it.
} 


\section{Example 8- 10}
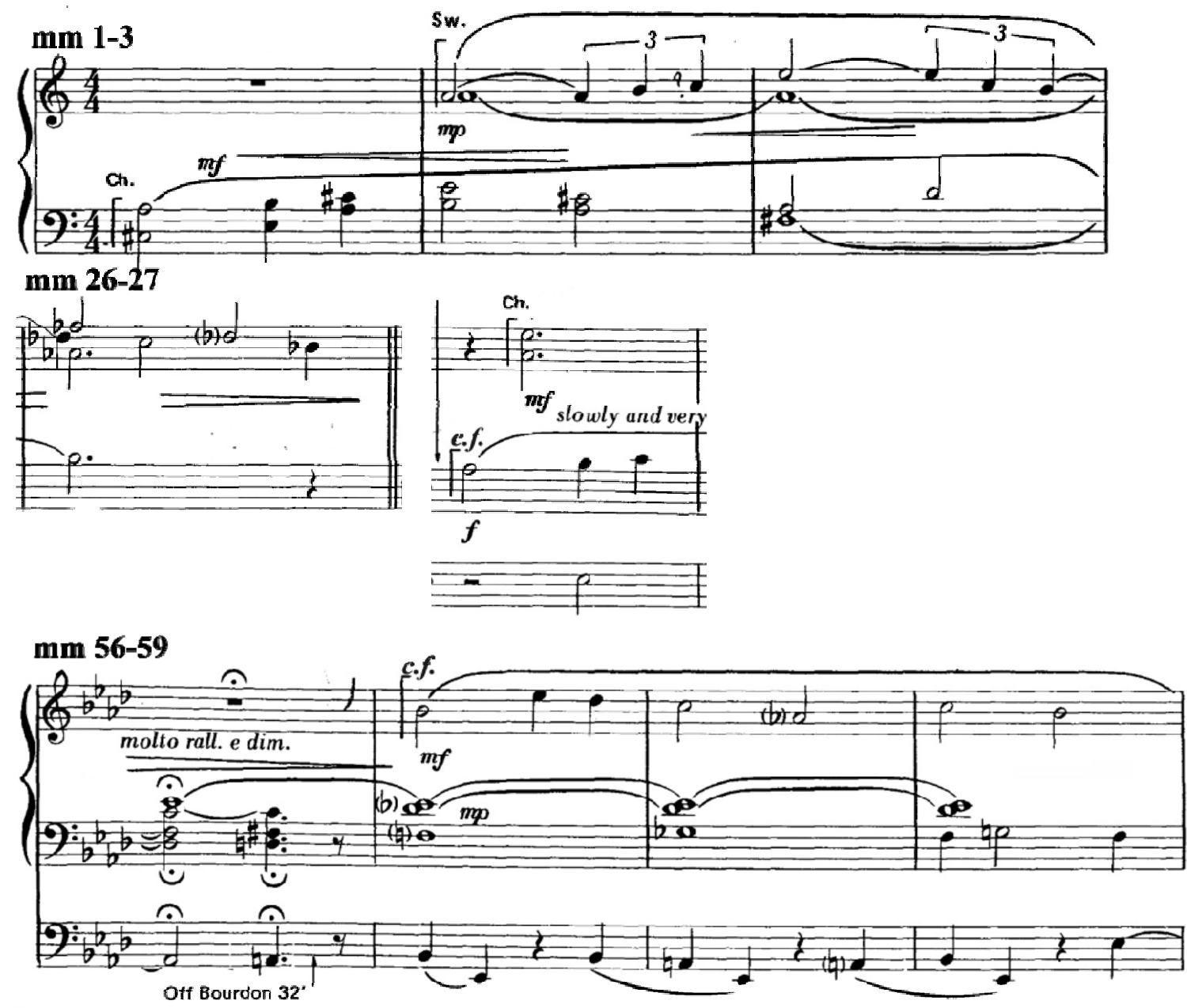

Chorale Cp34 Lead, Kindly Light Collection IV; (4/12[13])

Bradley Publications 24M22 Hymn Tunes, Preludes and Improvisations (1981) Chorale Motet
$A^{b}$ Major; $4 / 4$ time
$49 \mathrm{~mm}$

Three manuals/Pedal

It is treated in a twentieth century French organ paraphrase style and is highly

improvisatory. The harmonies include non-harmonic tones and blues, see Ex. 8-11, sy1.

The strophes are treated in successive sections as in a chorale motet and the treatment of the c.f. in strophe one and two is obvious in this regard, see Ex. 8-11, sy2. The c.f. in 
strophe three is disguised among imitation (mm. 26-27, 30-31), reharmonized repetitions and altered harmonies; and, appropriately, the associated text for strophe three is "...I do not ask to see the distant scene." At the fourth strophe Hebble preserves some of the altered harmonic treatment of the previous strophe as an accompaniment to the fourth strophe (mm. 38-41). The concluding melody of the c.f. purposefully misses its steps to the tonic $\mathrm{A}^{b}$ and is drawn from the text “...one step enough for me.” The coda begins as a repeat of the introduction (m. 45), but ends with open fifths and an added-second to the chord contributing to the sense of openness with the associated text "lead Thou me on." It requires two preset-combinations.

Introduction
\begin{tabular}{|l|l|l|l|l|}
\hline $\begin{array}{l}\text { Cthereal, high } \\
\text { soft strings, frags }\end{array}$ & $\begin{array}{l}\text { Strophes 1 and 2 } \\
\text { c.f. in tenor }\end{array}$ & $\begin{array}{l}\text { Disguised } \\
\text { strophe 3 }\end{array}$ & $\begin{array}{l}\text { Strophe 4, c.f. in } \\
\text { soprano }\end{array}$ & $\begin{array}{l}\text { Like intro, cyclic } \\
\text { fragments, open }\end{array}$ \\
\hline mm. 1-16 & $17-25$ & $26-37$ & $38-44$ & $44-49$
\end{tabular}

\section{Example 8- 11}
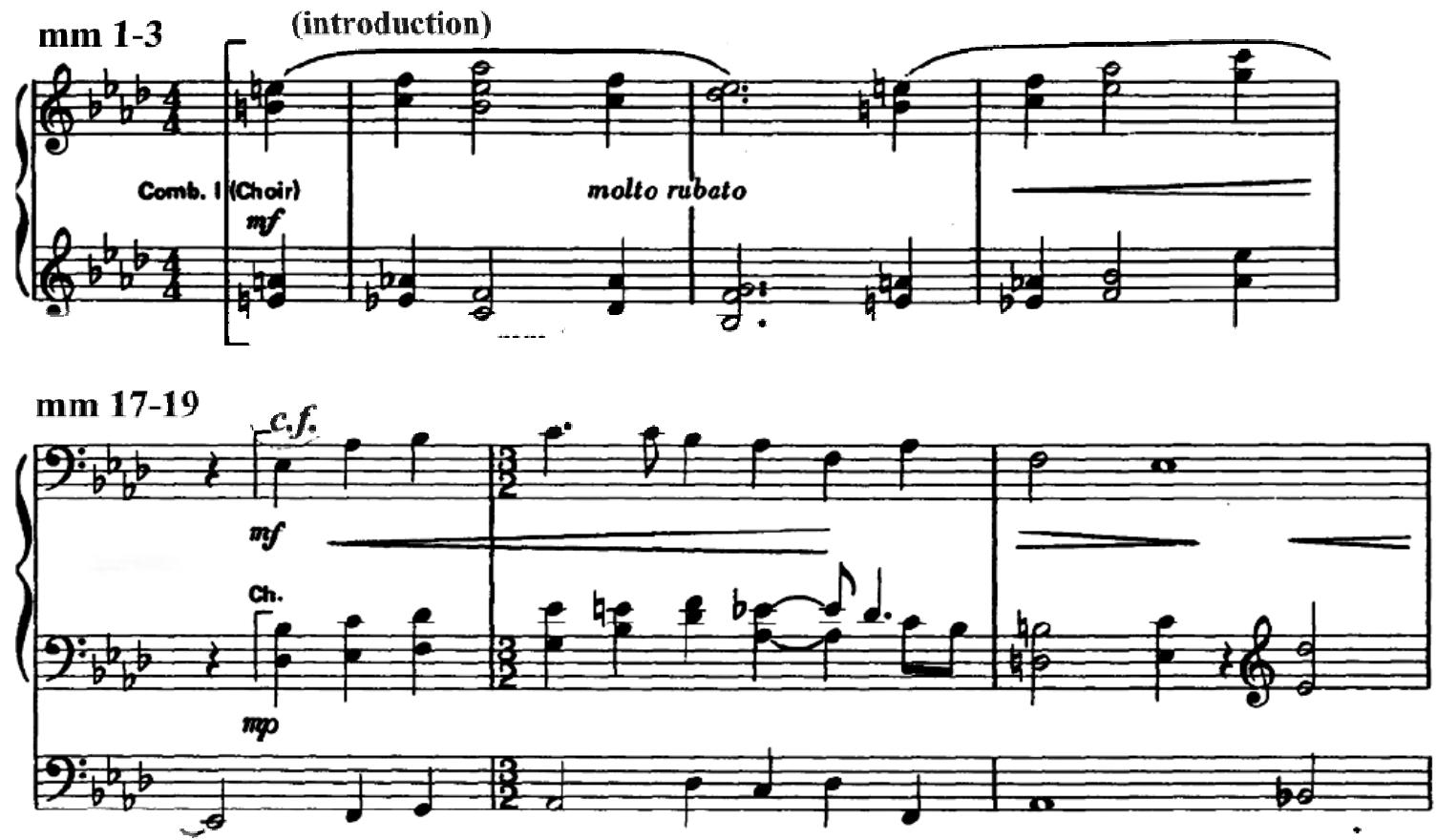
Chorale Cp35 Spohr

Bradley Publications 24M22

Chorale Motet

D major; $3 / 4$ time
Collection IV; (5/12[13])

Hymn Tunes, Preludes and Improvisations (1981)

Three manuals/Pedal

$64 \mathrm{~mm}$

This chorale is also associated with the hymn Gerald. It begins with an introduction, pastorale, with an upper pedal on the V scale degree, while there is imitative treatment of the opening motive of the hymn tune in diminution in fore-imitations, see Ex. 8-12, syl. The altered harmony and the influence of jazz is apparent in the harmony and syncopated rhythms. The c.f. (m.11) is in augmentation and is marked Adagio with a syncopated left-hand and pedal accompaniment. The first verse depicts "wandering mind" of the associated text versus stability. There is an interlude, which continues the ideas stated in the previous accompaniment, see Ex. 8-12, sy2. The third strophe has the c.f. in the tenor (mm. 34-41), and repeats the accompaniment from the previous phrase, with greater harmonic freedom (mm. 43-51). In the final strophe the c.f. is stated in the soprano with altered harmony (mm. 52-57) and ends on the Neapolitan. ${ }^{155}$ The coda begins like the introduction in paraphrase and ends as it began on the manual upper pedal V scale degree. The work requires two preset-combinations. Although the accompaniment motivically anticipates the $c . f$. with each successive strophe, it eventually derives its own shape independent of the c.f., lending the work to the short chorale-prelude category as well.

\begin{tabular}{|c|c|c|c|c|c|c|}
\hline Introduction & strophe 1 & interlude & strophe 3 & interlude & strophe 4 & coda \\
\hline $\begin{array}{l}\text { Upper } \\
\text { pedal V, } \\
\text { imitative } \\
\text { fragmts c.f. }\end{array}$ & $\begin{array}{l}\text { c.f. in } \\
\text { soprano, } \\
\text { syncopated } \\
\text { accomp. }\end{array}$ & $\begin{array}{l}\text { Accomp. } \\
\text { Expanded, } \\
\text { then } \\
\text { strophe } 2\end{array}$ & $\begin{array}{l}\text { Begins on } \\
\text { upper pedal } \\
\mathrm{V}, \text { c.f. in } \\
\text { tenor }\end{array}$ & $\begin{array}{l}\text { Repeats } \\
\text { strophe } 3, \\
\text { tenor, alter } \\
\text { tune paraph }\end{array}$ & $\begin{array}{l}\text { c.f. in } \\
\text { soprano, } \\
\text { altered } \\
\text { harmonies }\end{array}$ & $\begin{array}{l}\text { Cyclic to } \\
\text { introduct. } \\
\text { upper pedal } \\
\text { V }\end{array}$ \\
\hline mm. 1-11 & $12-19$ & $20-32$ & $33-41$ & $42-51$ & $51-57$ & $8-64$ \\
\hline
\end{tabular}

155 This Neapolitan is spelled correctly and is in the correct inversion (m. 57). 


\section{Example 8- 12}

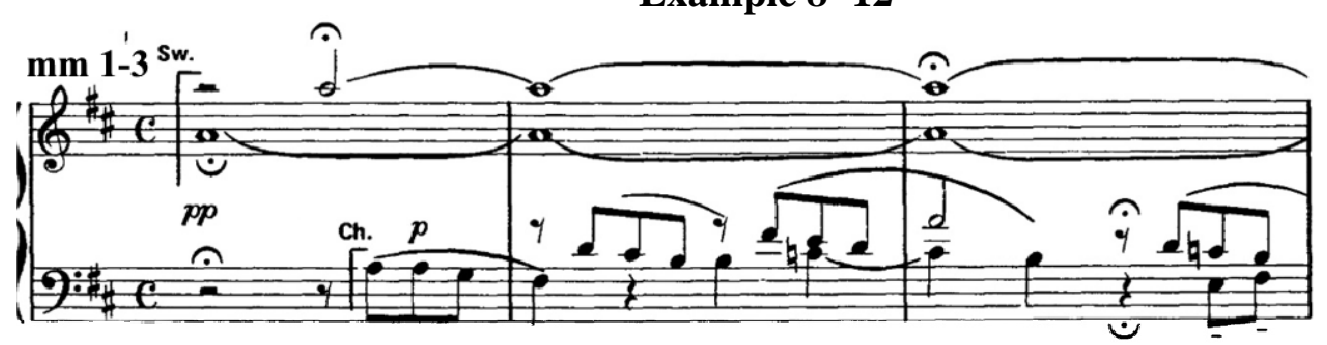

mm 10-12
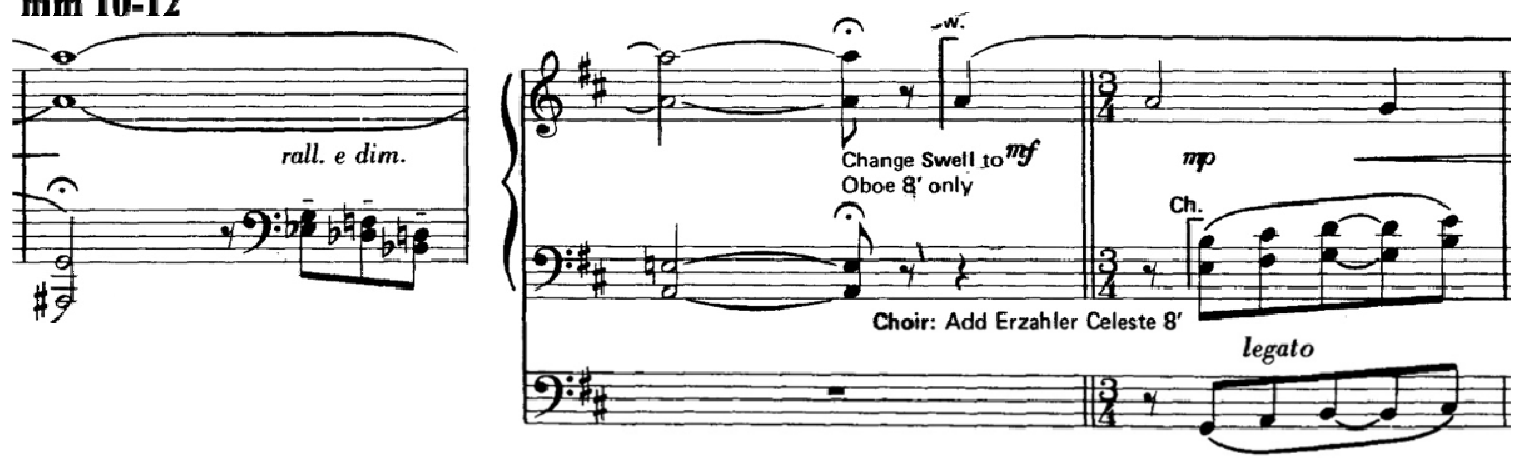

Chorale Cp36 Cwm Rhondda

Bradley Publications 24M22

Long Chorale Fantasia

from $\mathrm{B}^{\text {b }}$ to $\mathrm{G}$ major; $4 / 4$ time

Collection IV; (6/12[13])

Hymn Tunes, Preludes and Improvisations (1981)

Three manuals/Pedal

$62 \mathrm{~mm}$

A notable feature of this work is that Hebble begins with improvisation on fragments of

c.f. and then gradually develops it into a French romantic style toccata, ending with the

c.f. in the pedal (mm. 43-51), see Ex. 8-13, sy3 and 4. As per the chart below, the

introduction begins in the soprano with the second phrase of the first strophe, which is imitated in syncopation in the alto over a dominant pedal, see Ex. 8-13, sy1. After eight measures, a quasi-fughetta in trio ensues (mm. 12-30) in imitation of the full first strophe on three separate reed stops: r.h. Krummhorn 8 , 1.h. Oboe 8 and a Reed 8 in the pedal, forming a reed consort, see Ex. 8-13, sy2. From this quasi-fughetta is derived the musical foreshadowing of the pending toccata figuration (e.g., mm. 9-11 versus mm. 4344). The interlude (mm. 31-42) juxtaposes together two varying and normally separate 
strophes of the c.f. and modulates from $\mathrm{B}^{b}$ major to $\mathrm{G}$ major. The toccata is a free manual treatment over the c.f. presentation in the ff pedal in stretto. The toccata section quotes the entire c.f., not just fragments, and ends with a temporary transition of the tune from the pedal to the manual (mm. 52-55) and concluding back in the pedal before the bravura of the coda. The coda improvises upon fragments of the final strophe of the c.f. over a tonic pedal at $\mathbf{s f z}$ while the very commanding Bombarde 32 coupled to the Solo fff Reed is summoned for the dramatic conclusion, see Ex. 8-13, sy4. The variety of fughettas, independence of the chorale-free voices leading to a long chorale prelude form, trio chorale form, the extended ornamentation of the c.f., and the concluding toccata lends this work towards the combination chorale category, including variations form.

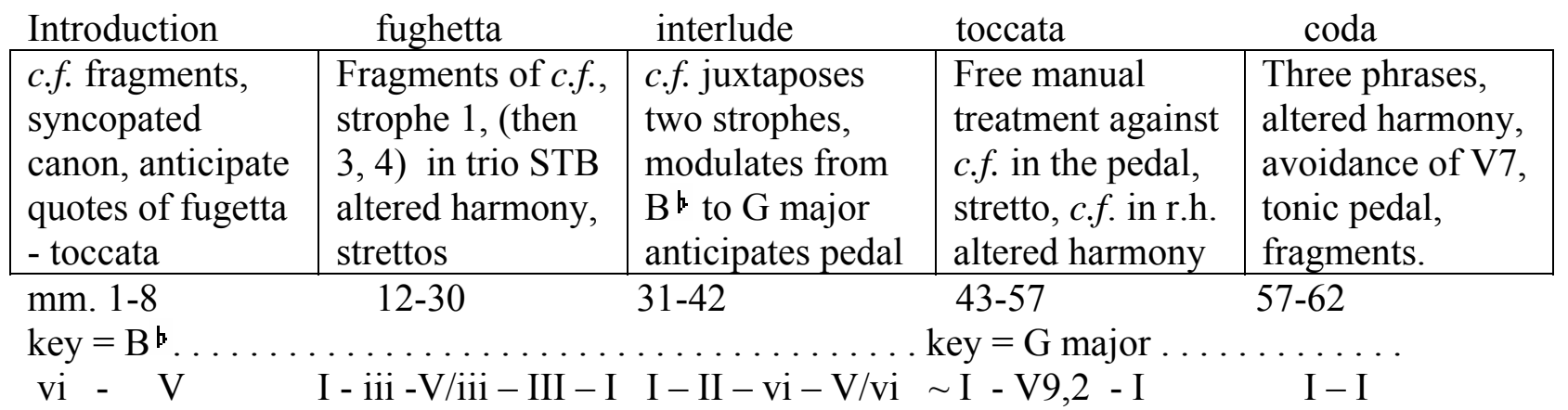




\section{Example 8- 13}
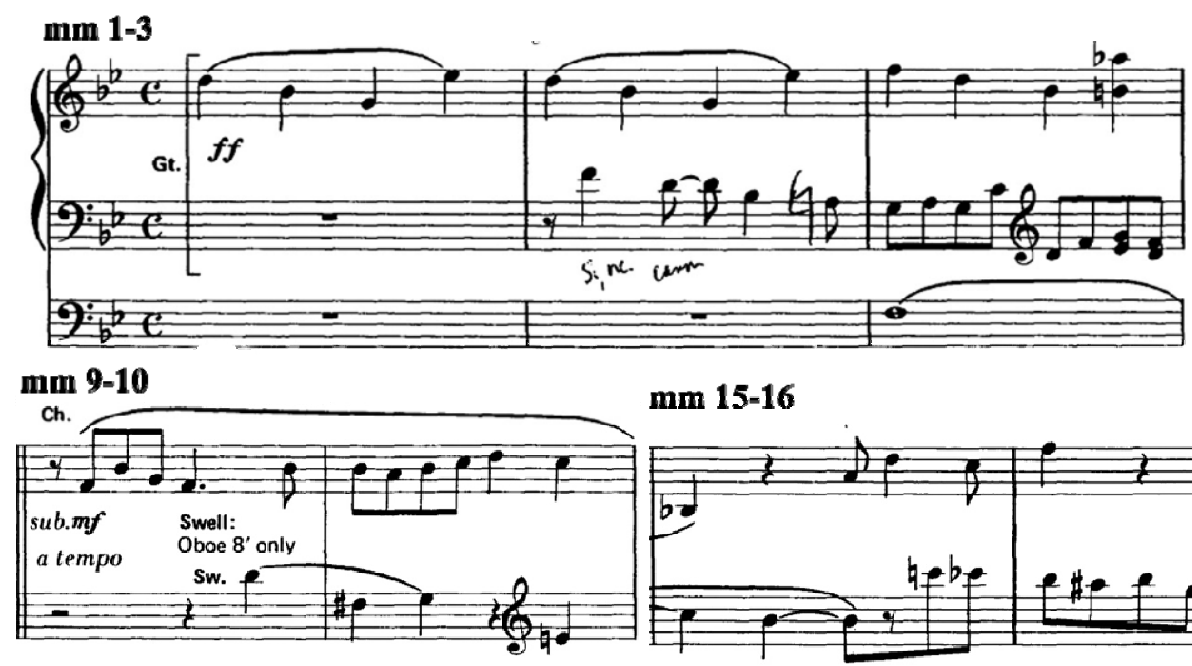

mm 15-16
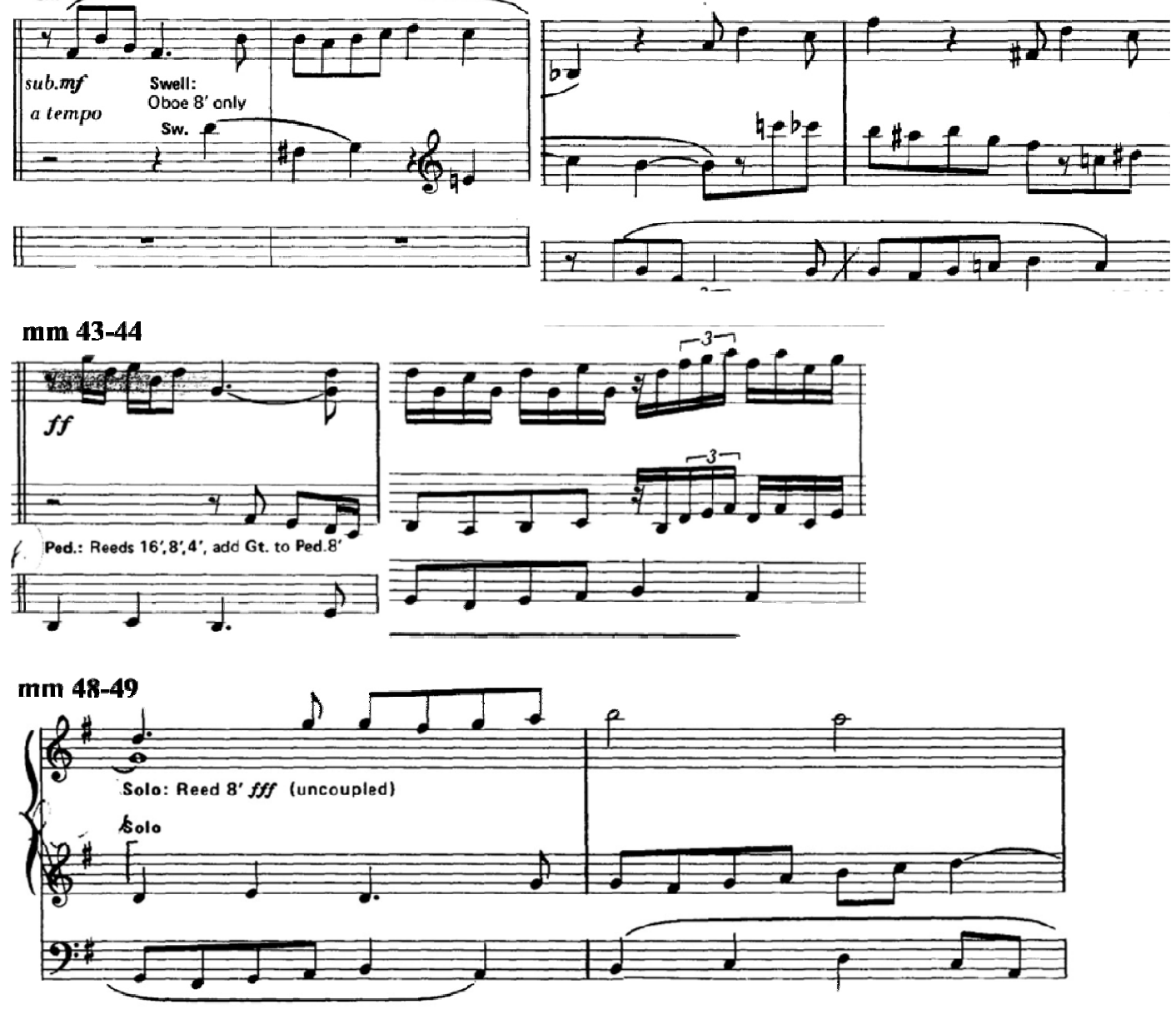
Chorale Cp37 Haec Dies Resurgam Collection IV; (7/12[13]) B Bradley Publications 24M22 Hymn Tunes, Preludes and Improvisations (1981) Long Chorale Fantasia

G major; $3 / 4$ time Four Manuals/Pedal $207 \mathrm{~mm}$

It was commissioned by Frederick Swann for the new organ stop called Trompeta Majestatis 8', built for The Riverside Church organ in 1980. Swann premiered the composition at Riverside on Easter Sunday, April 6, 1980, and also at Westminster Abbey, London, on August 14, 1980. A through-composed chorale fantasia, it is one of Hebble's most virtuosic works and is based on the chorale O Quanta Qualia, which does not appear until measure 70 on the new featured trompetta stop, see Ex. 8-14, sy2. The piece begins in e-minor but does not have a tonic chord until the c.f. enters with the trompetta stop at measure 70 in G major, see Ex. 8-14, sy1. As a rhapsodic fantasy piece, it is similar to the Liszt Ad Nos and the Reubke Sonata on the $94^{\text {th }}$ Psalm and is programmatic music, telling a story. The story depicts Fox leaving Riverside, becoming ill with cancer, and Swann coming to Riverside, reconditioning the organ and adding this new stop. Like a Wagner opera, there are leitmotifs assigned to the various characters, the church, and the organ. Virgil Fox is represented by the rapid pedal octaves, see Ex. 8-14, sy3, and resurrection (or Fox's place in heaven) is represented in the r.h. and by the proper key of the hymn-tune, see Ex. 8-14, sy4. 


\section{Example 8- 14}

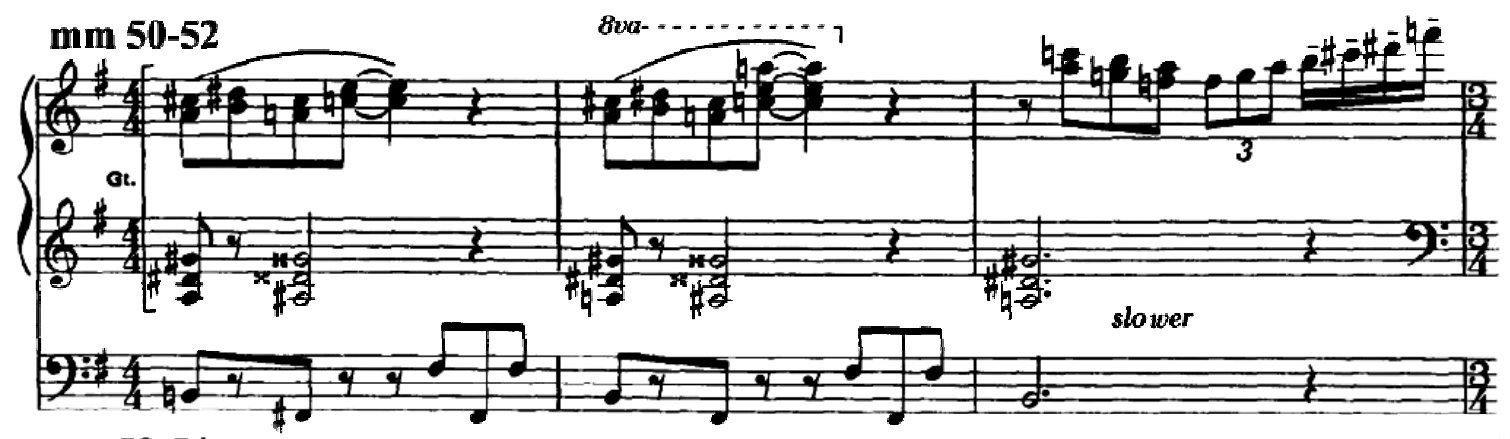

mm 53-54

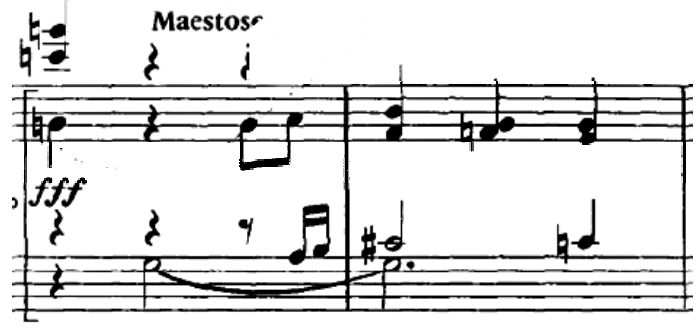

$$
\text { (Hymn tune "O Quanta Qualia") }
$$

mm 144-145
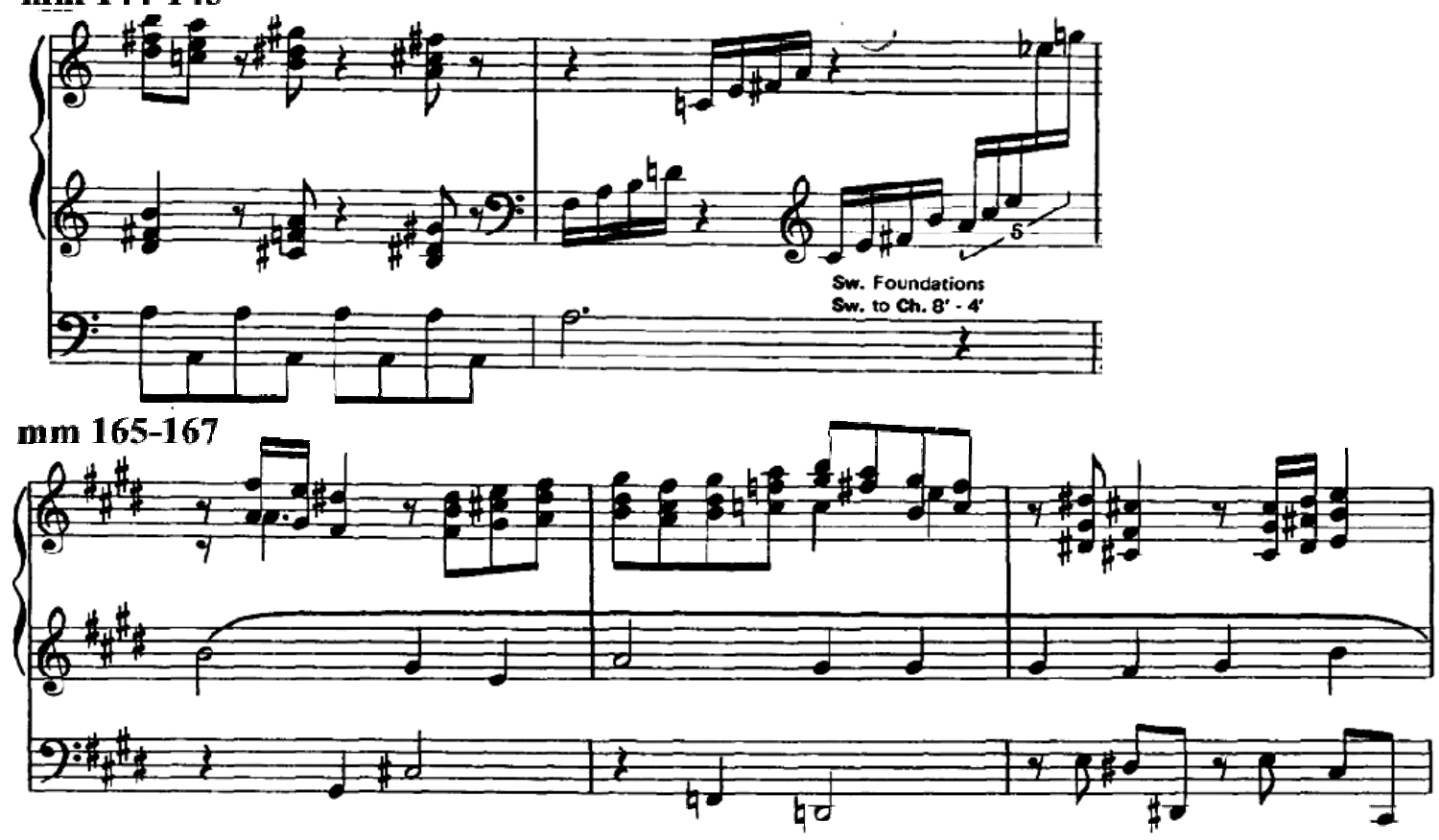
Chorale Cp38 Herzliebster Jesu Collection IV; (8/12[13])

Bradley Publications 24M22

Long Chorale Fantasia

Multiple keys; 4/4 time

Hymn Tunes, Preludes and Improvisations (1981)

Three manuals/Pedal

$78 \mathrm{~mm}$

It contains three variations of the $c . f$. based on the chorale Ah, Holy Jesus with an introduction, coda and interludes, making it a fantasia form. Its successive treatments of the chorale verses make it susceptible to the combination chorale form. Hebble depicts the text of each variation in the spirit of Baroque text-painting. In verse one the "holiness of Jesus" is represented in high pitched Flute Celestes of the organ registration (mm. 911) and "offended" (m. 6) is treated as a banal tonic harmony at the point of the normally expected dominant harmony. In variation two a serpentine motif (mm. 22-37) portrays "guilt", "treason" and "undoing" taken from the associated text, see Ex. 8-15, sy2. The Tristan harmony depicts non-resolution of the associated text "since I cannot pay Thee" (mm. 47-50) of the interlude, see Ex. 8-15, sy3. The blues treatment of the final variation juxtaposes the major $\left(\mathrm{A}^{\mathrm{b}}\right)$ with minor $(\mathrm{Fm})$ in conjuction with its associated text "mortal sorrow," "death of anguish," and "bitter passion" (mm. 58-61). There is whole tone writing during the interlude (mm. 38-47) and in the coda (mm. 44-45, 69-72). The tripart coda replays fragments of the associated text "not my deserving" from the c.f., which is supplemented with whole tone writing (showing the listener what the guilty "deserve"), resolving in the calm of C major (showing the "unswerving love" of Jesus).

\begin{tabular}{|c|c|c|c|c|c|c|}
\hline Intro/var. 1 & var. 2 & interlude & var. 3 & coda 1 & coda 2 & da 3 \\
\hline $\begin{array}{l}\text { Tonic (Em) } \\
\text { manual } \\
\text { pedal, c.f. } \\
\text { altered } \\
\text { harmony, } \\
\text { no pedals }\end{array}$ & $\begin{array}{l}\text { c.f. C\#m, } \\
\text { serpentine } \\
\text { 1.h. motif, } \\
\text { no pedals }\end{array}$ & $\begin{array}{l}\text { c.f. } \\
\text { fragments, } \\
\text { modulation } \\
\text { to f-minor, } \\
\text { uses tristan } \\
\text { chords }\end{array}$ & $\begin{array}{l}\text { Fm, c.f. in } \\
\text { the soprano } \\
\text { uses tristan } \\
\text { harmony, } \\
\text { juxtaposes } \\
\text { major acc. }\end{array}$ & $\begin{array}{l}\text { Elided with } \\
\text { final phrase } \\
\text { of } c . f . \text { in fm } \\
\text { repeats } \\
\text { final } \\
\text { phrases } c . f \text {. }\end{array}$ & $\begin{array}{l}\text { Modulates } \\
\text { to C major } \\
\text { Quotes } \\
\text { fragments } \\
\text { of } c . f . \text { pedal } \\
\text { C. }\end{array}$ & $\begin{array}{l}\text { Ends as it } \\
\text { began with } \\
\text { manual } \\
\text { pedal on } \\
\text { tonic. }\end{array}$ \\
\hline mm. $1-20$ & $21-37$ & $38-47$ & $48-61$ & $62-65$ & $66-73$ & -78 \\
\hline
\end{tabular}




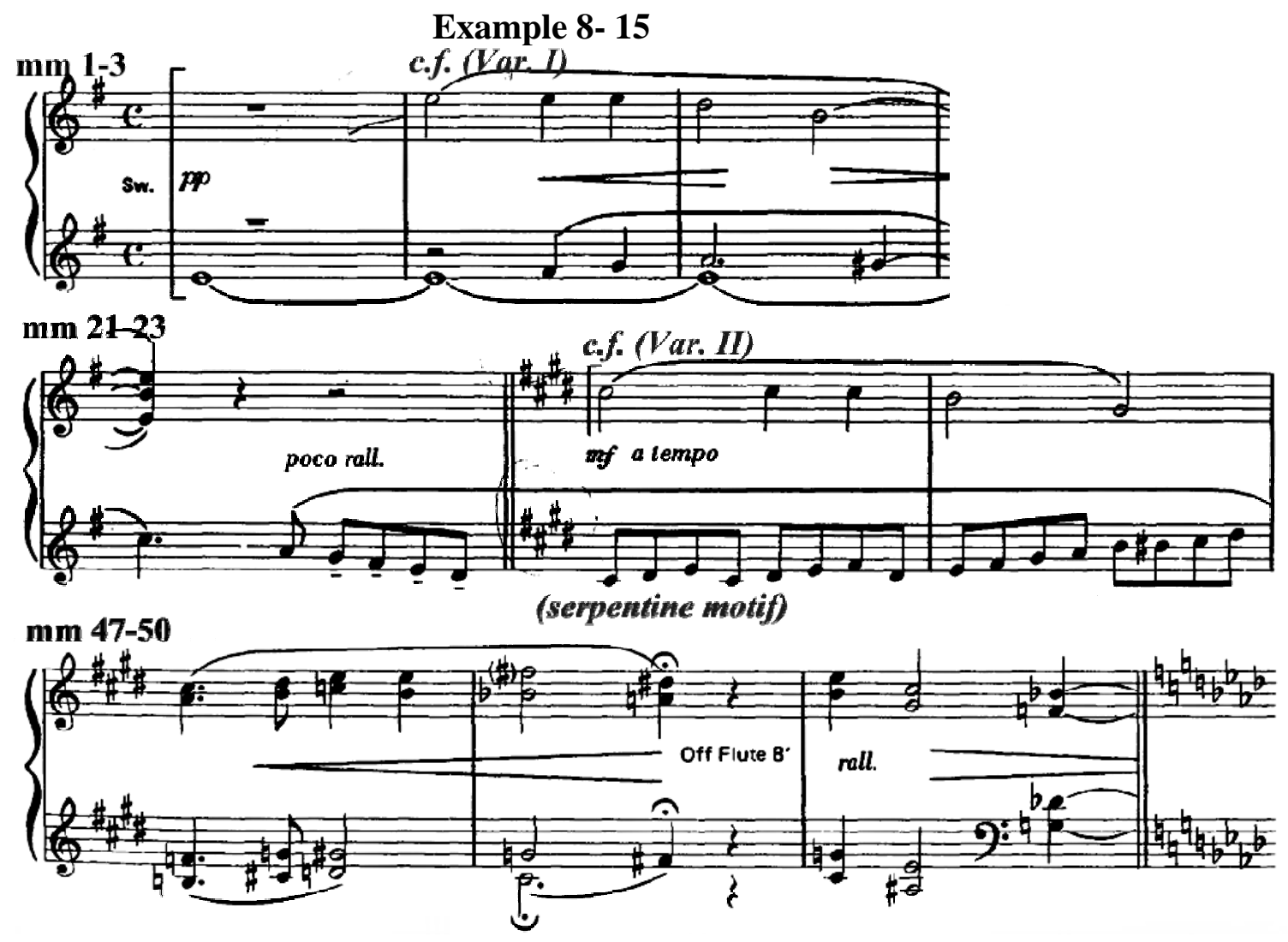

Chorale Cp39 Hyfrydol

Bradley Publications 24M22

Long Chorale Fantasia

$\mathrm{B}^{b}$ major; $3 / 4$ time
Collection IV; $(9 / 12[13])$

Hymn Tunes, Preludes and Improvisations (1981)

Three manuals/Pedal

$80 \mathrm{~mm}$

It is a highly improvised piece in the French paraphrase style ${ }^{156}$ coupled with an adapted ritornello chorale form, where the c.f. is quoted sectionally strophe by strophe, see Ex. 816, sy1. The c.f. is interrupted with ritornellos that evolve and each re-entrance becomes less recognizable. As in many of his chorales, when the appearance of the c.f. is unclear its reappearances become very apparent in other areas of the work. Thus the ritornello form becomes a suspending agent for his plethora of musical ideas as well as areas of

\footnotetext{
156 That is, in the Dupré, Tournemiere, Cochereau tradition.
} 
fore-imitations of c.f. treatments, see Ex. 8-16, sy2. He is then able to be as free as he dares, while still keeping the composition proportionally balanced. It qualifies as a long fantasia form because of the introduction, coda and extended ritornello interludes, and as such could possibly be another combination form chorale.

\begin{tabular}{|c|c|c|c|c|c|c|c|c|}
\hline Intro/rit & str. 1 & rit. 2 & str. 2 & rit. 3 & str. 4 & rit. 4 & str. 5 & \\
\hline $\begin{array}{l}\text { Syncop/ } \\
\text { Pedal } \\
\text { ostinato } \\
\text { mm. 1-4 }\end{array}$ & $\begin{array}{l}\begin{array}{l}\text { c.f. in } \\
\text { soprano }\end{array} \\
5-12\end{array}$ & $\begin{array}{l}\text { Syncop/ } \\
\text { departs } \\
\text { key } \\
13-15\end{array}$ & $\begin{array}{l}\text { c.f. in } \\
\text { soprano } \\
\mathrm{G}^{b} \\
16-24\end{array}$ & \begin{tabular}{|l} 
Interl. \\
improv \\
fragmts \\
$25-50$
\end{tabular} & $\begin{array}{l}\text { new } \\
\text { motif } \\
\text { syncop } \\
51-58\end{array}$ & $\begin{array}{l}\text { Improv } \\
\text { fragmts } \\
512-67\end{array}$ & $\begin{array}{l}c . f . \text { in } \\
\text { soprano } \\
\text { fragmts } \\
68-69\end{array}$ & $\begin{array}{l}\text { Fragmts } \\
\text { pedal } \\
\text { cadenza } \\
70-80\end{array}$ \\
\hline
\end{tabular}

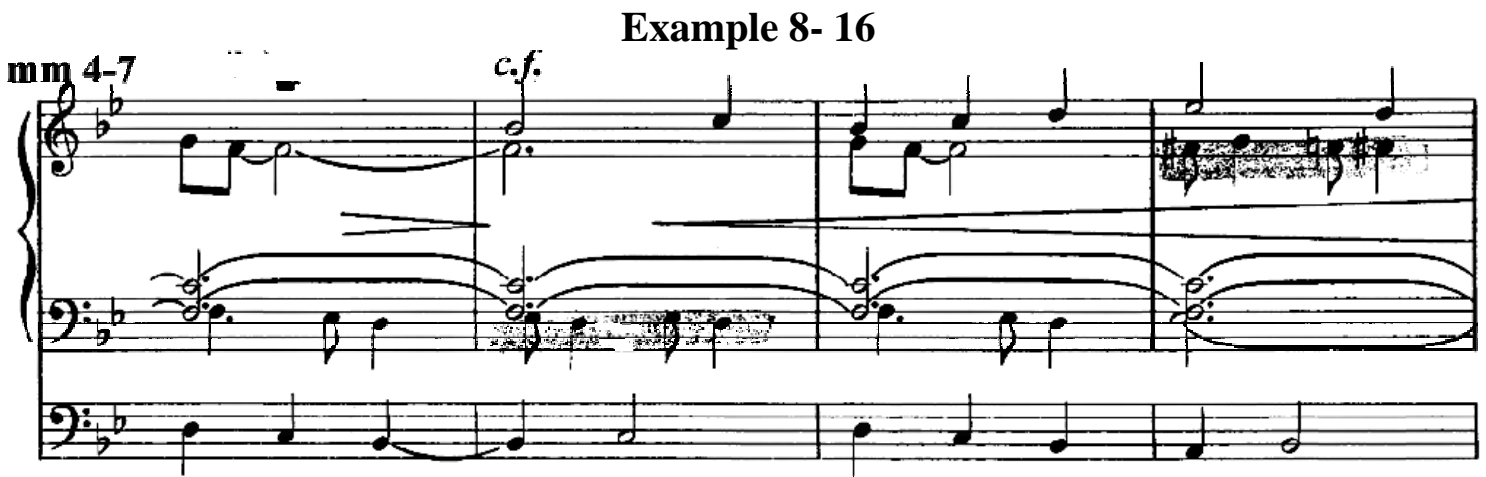

mm 51-52

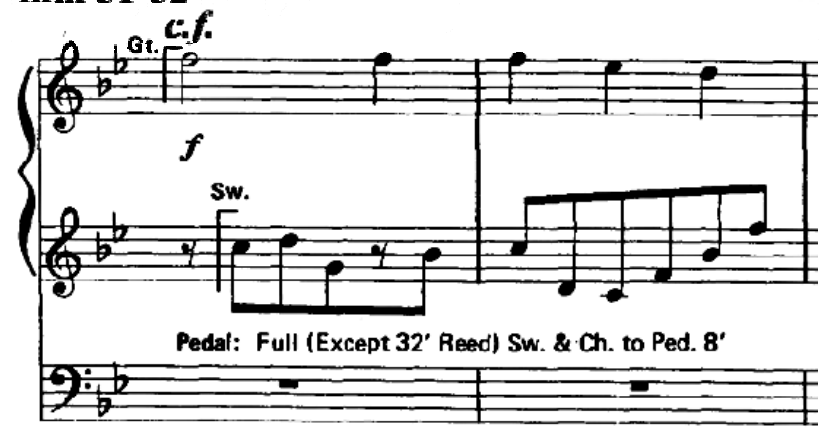

Chorale Cp40 Londonderry Air $\quad$ Collection IV; (10/12[13])

Bradley Publications 24M22 Hymn Tunes, Preludes and Improvisations (1981)

Long Chorale Fantasia

Three manuals/Pedal

D major; $4 / 4$ time

$50 \mathrm{~mm}$

It is dedicated to Richard Bradley who admired Hebble's organ compositions and, being of Irish descent, was fond of Londonderry Air. He was also Hebble's publisher for many 
years before selling the copyrights to Warner Brothers in 1995. After the introduction, the $c . f$. is set in the tenor, see Ex. 8-17, sy1 and 2. Occasionally the $c . f$. is disguised in the French paraphrase style of improvisation, but Hebble keeps a balance of recognition present. This qualifies the work as a long form due to the improvisations pushing the chorale-free voices of the accompaniment sections into the realm of interludes, see Ex. 817, sy3. He oscillates from blues and altered harmonies to the more strident French paraphrase harmony with aplomb. The $c . f$. is heavily ornamented in the refrain portion. The coda improvises upon fragments of the c.f. in a highly embellished jazz style.

\begin{tabular}{|c|c|c|}
\hline Introduction & c.f. treatment & coda \\
\hline 2 long, ornamented phrases & strophes treated successively & 3 long phrases, c.f. fragments \\
\hline
\end{tabular}




\section{Example 8- 17}
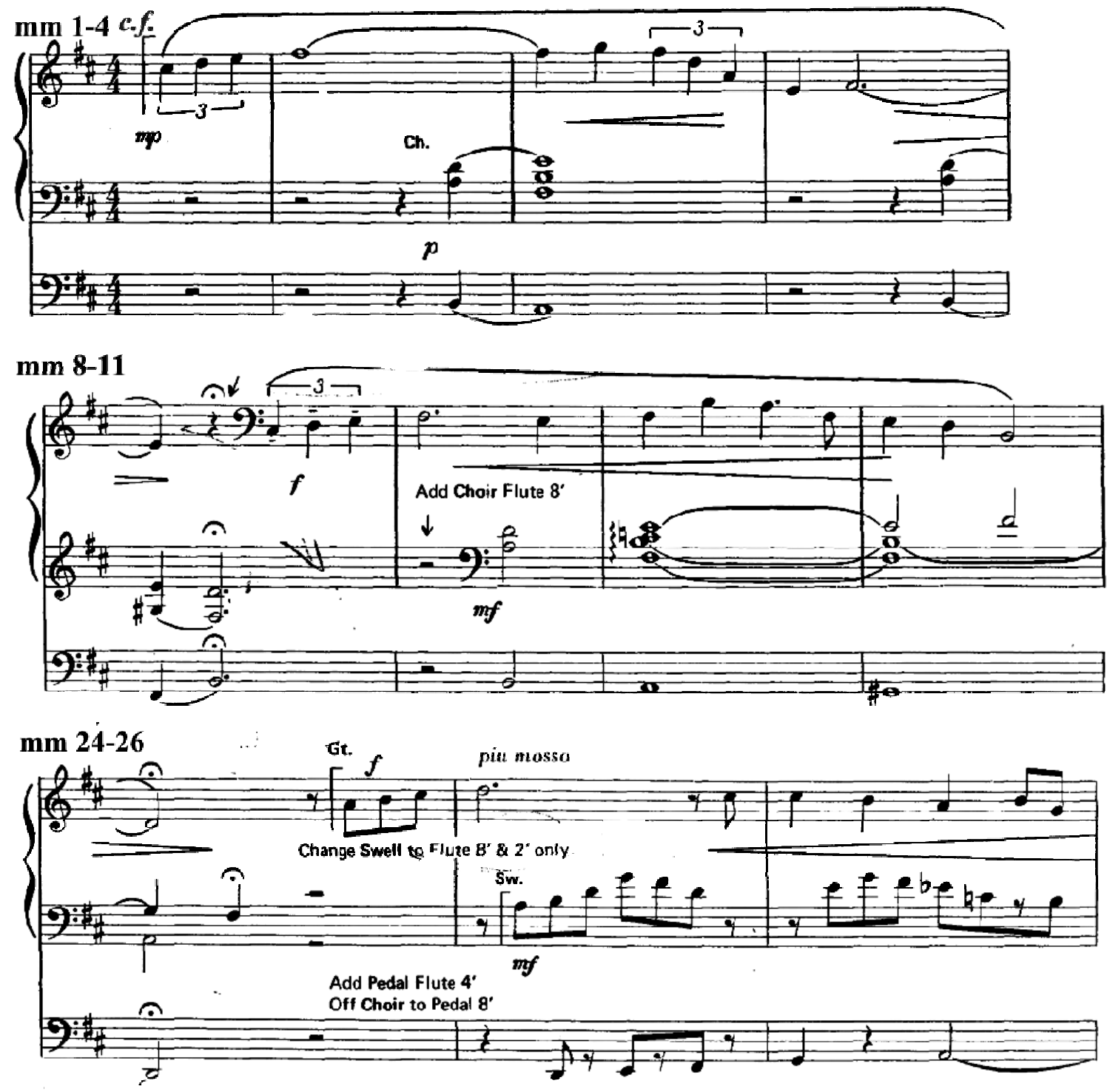

Chorale Cp41 Simple Gifts

Collection IV; (11/12[13])

Bradley Publications 24M22 Hymn Tunes, Preludes and Improvisations (1981)

Long Melody Chorale

F major; $4 / 4$ time

Three manuals/Pedal

$36 \mathrm{~mm}$

Just 5 measures shorter than Hebble's earlier treatment of this chorale $C p 20, C p 41$ begins promptly with the theme at measure one, see Ex. 8-18. Although there is no introduction, the work qualifies as a long form due to the extended inner improvisation and coda. The 
c.f. is presented in four phrases of four measures each in the soprano with harmonic

parallelisms in the accompaniment, mostly sixths, and occasional blues harmony. ${ }^{157}$ See

Ex. 8-18. Hebble writes an extended coda/improvisation (mm. 17-36), the divisions of

which are blurred. While there is a brief canon at the fourth in the right hand solo in this improvisation, the left hand pivots between minor sixth chords, and minor seventh chords as a background on quieter stops in three four-bar phrases (mm. 17-20, 21-24, 25-29).

Between the phrases are breaks concluding with fragments of the $c . f$. in octave displacement from m. 25 to the end. Tristan ${ }^{158}$ harmonies are featured (mm. 22, 32, 3435), but measure 32 is the actual Tristan chord, spelled with flats, while the last two are half-diminished-seventh chords accompanying the "Tis the Gift to Be Simple" melody. This juxtaposition of ideas is Hebble's notion of making theological references to the elusiveness of spiritual "simplicity" as Tristan depicts the elusiveness of love. ${ }^{159}$

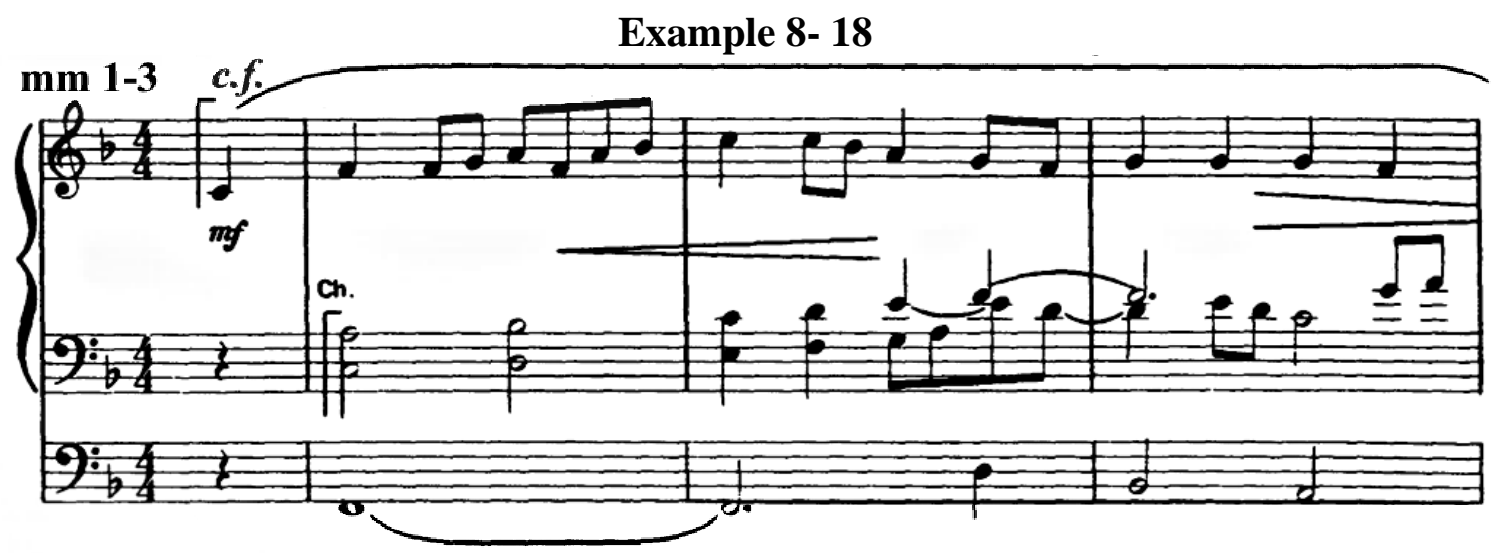

\footnotetext{
${ }^{157}$ Westerup, J.A. and Harrison, F.L. The New College Encyclopedia of Music. New York, W.W. Norton, 1981, p. 76; blue notes being lowered thirds or sevenths (mm. 5-7), and featuring a solo voice (here, an organ reed).

${ }^{158}$ Burkhart, Charles. Anthology for Musical Analysis. New York: Holt, Rinehart and Winston, Inc. 1972, p. 385, m. 2: f, b, d\#, a\#; The Tristan Chord.

${ }^{159}$ Although it is a misconception to think of the blues as sad, Tristan and Isolde sought each other's love through great trials, and 'blues' grew out of the trials symbolized in African-American Spirituals.
} 
Chorale Cp42 Toccata Brevis Collection IV; (12/12[13])

Bradley Publications 24M22 Hymn Tunes, Preludes and Improvisations (1981)

Long Chorale Fantasia

$\mathrm{B}^{b}$ major; $3 / 4$ time Three manuals/Pedal

$51 \mathrm{~mm}$

Although he seems to project instability in his toccata writing, this work is built on a four-square tune. It changes meter frequently, it is built upon the tune St. Denio, which appears first in the pedal in a twentieth century French toccata form, see Ex. 8-19. After four measures of introduction, the c.f. appears in the pedal on $\boldsymbol{f f}$, but before the phrase ends there is stretto between pedal and the manuals (mm. 7-9). A dovetail into the next phrase (m. 10) led by the formidable pedal ornaments the c.f. line (mm. 10-13). An interlude appears before the c.f. reemerges and gains energy from the syncopated manual rhythm (mm. 16-21) which quotes motifs from the c.f. with altered harmonization. The c.f. occurs in the manuals (mm. 22-25), repeats the last strophe (mm. 25-28), and is then embellished into a "splendid"160 display of syncopation and virtuosity (mm. 30-40). It becomes so highly embellished melodically, harmonically, and rhythmically (mm. 40-51) that it is difficult to distinguish the final strophe of the c.f. or to determine where the coda begins. This coordinates with the associated text of the final strophe, "'tis only the splendor of light hideth thee."

${ }^{160}$ The text of the last strophe is "All praise we would render; O help us to see 'tis only the splendor of light hideth Thee!" Thus, the last strophe is engulfed in 'splendor'. 


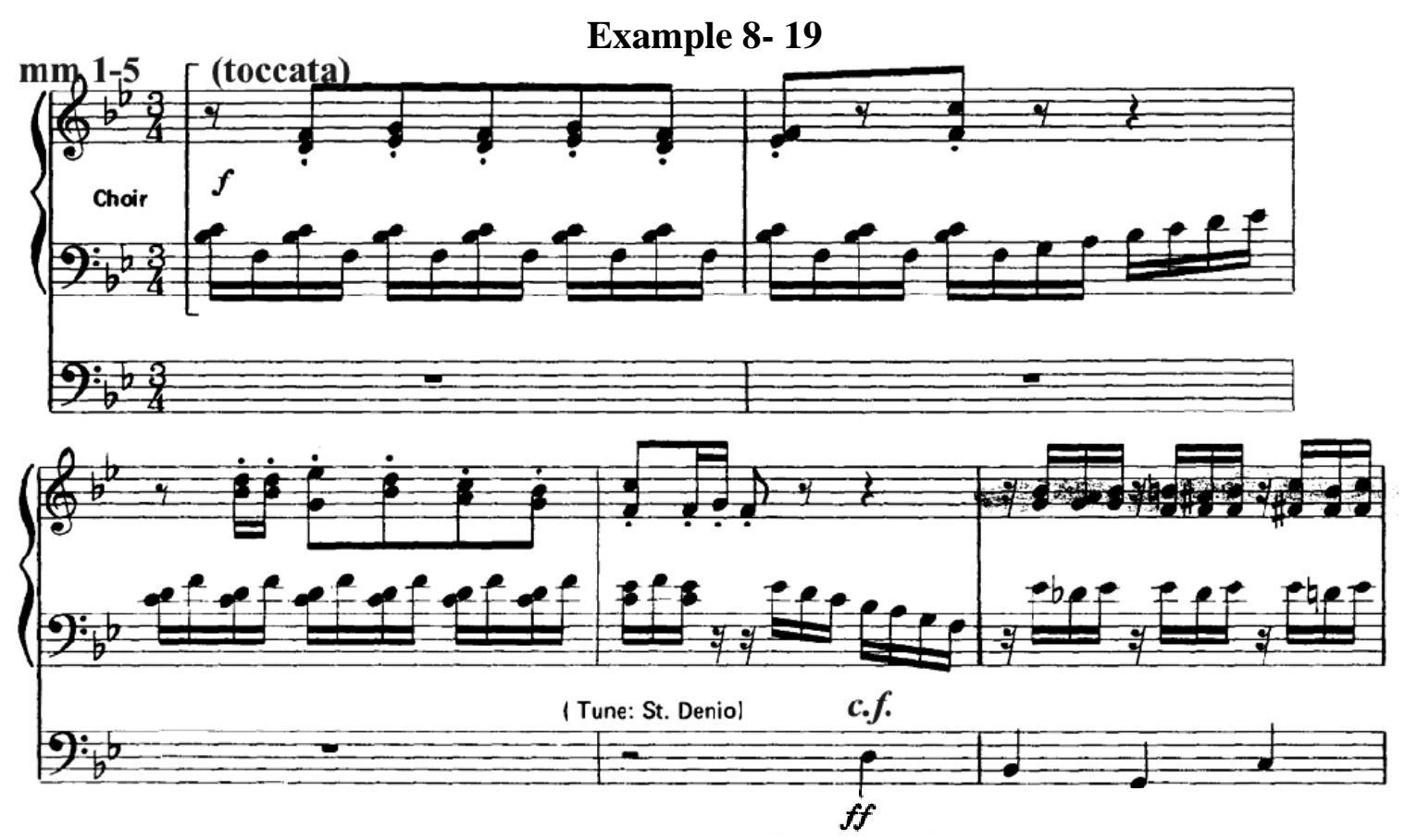

Freework Cp43 Where Christmas Dwells Collection IV; (1/1/[13])

Bradley Publications 24M22

A major; $6 / 8$ time

$112 \mathrm{~mm}$; variations chorale

Hymn Tunes, Preludes

and Improvisations (1981)

Four Manuals/Pedal

This work is a written out improvisation, and is drawn from a cantus prius factus based on the fifteenth century carol "This Endris Night". Here the c.f. is treated in such an improvisatory fashion as to compell the composer himself to categorize it as a free work. It most resembles a sonata with a series of inner variations that develop the motivic and rhythmic structures of the c.f. , (B), which are framed by an introduction and recapitulation/cadencial area that are alike, (A). The first section (mm. 1-27) is marked Andante and pianissimo with the theme entering in the pedal on a 4 ' stop (m. 9). The second section (mm. 28-58) is marked Faster and changes meter between 2/4, 3/4, 5/8, $4 / 4,3 / 8$. The c.f. is outlined harmonically and is not directly quoted. Halfway through the B section (mm. 59-72), a toccata figura ensues which quotes the theme tangentially in the 
soprano with chord octaves, see Ex. 8-20, sy1 and 2. The third section has the theme is in the pedal marked ff while a canon occurs with the fourth manual fff reed (mm. 73-76). The toccata becomes more rhythmically complex (mm. 82-88) until the full organ (m. 85 ) is reached and the term cancel organ (m. 88) appears, where the organist is directed to "cancel" all stops. In an unusual step, Hebble manually resets the organ, rather than create another preset combination; however, the final section is marked Slowly and this allowance makes the stop changes possible, see Ex. 8-20, sy3.

Introduction

$\mathrm{V}$ manual pedal mixolydian mode
A

B

Exposition

Theme in

pedal A major

Development

Changing meters
theme fragments
A

Recapitulation Coda

Toccata figure Introductory
theme in pedal material, 9ths

10-27

$73-99$ mm. 1-9 
mm 66-72

Example 8- 20
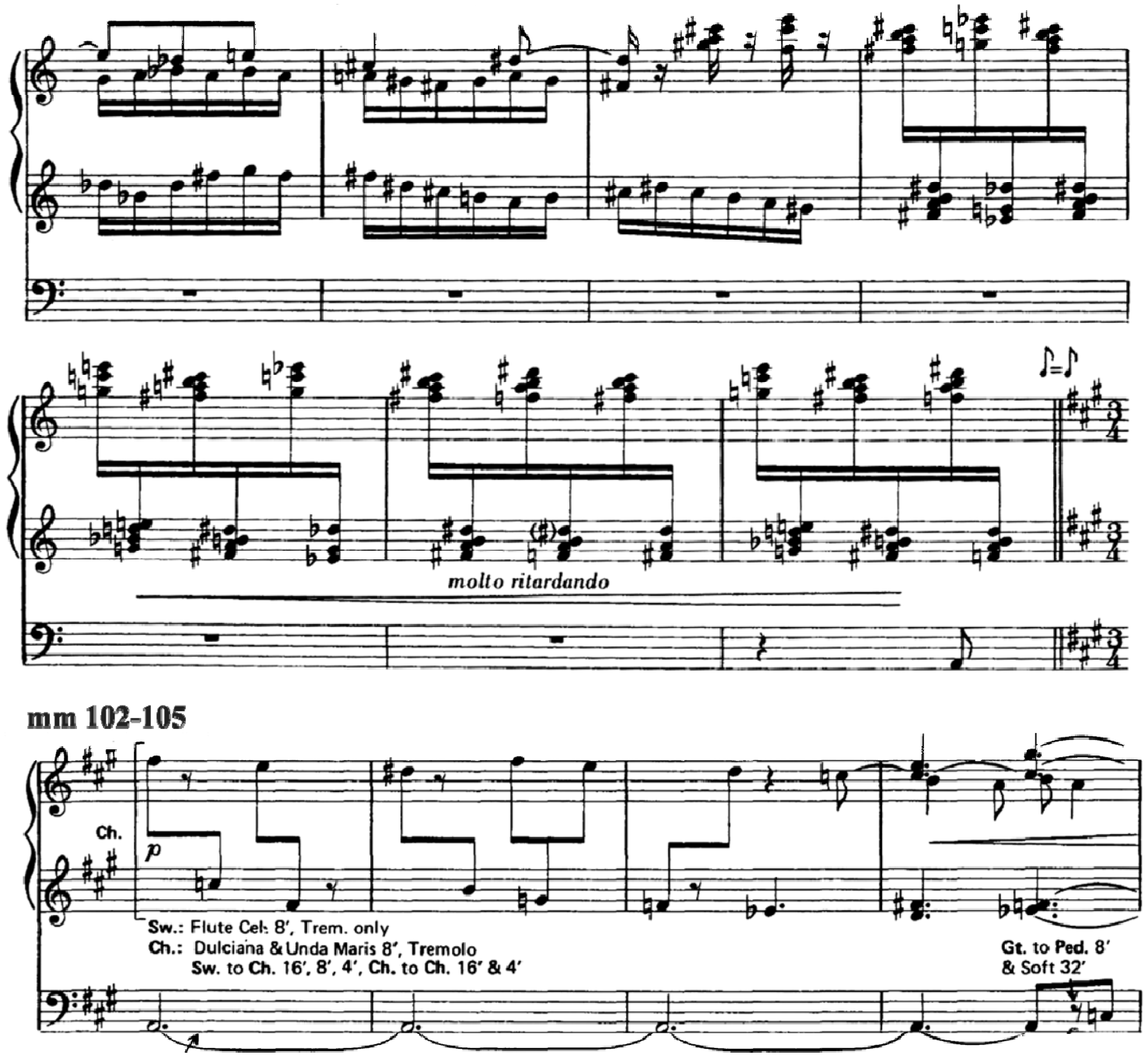

Chorale Cp47 Ellers

Bradley Publications B22M24

Long Melody Chorale

$A^{b}$ major; $4 / 4$
Collection V; (1/3[12])

The Robert Hebble Collection (1982)

Two manuals/Pedal

$42 \mathrm{~mm}$

The tune is most often associated with the hymn "Savior Again to Thy Dear Name". It combines two imaginative ideas: the associated text and a reverie. There is a two bar introduction which paraphrases the Debussy Reverie (1898) for piano. It serves as an ostinato-based accompaniment presented irregularly throughout the work, see Ex. 8-20. 
There is frequent employment of jazz harmonies and non-harmonic tones added to the treatment of the c.f., which is in the soprano. The c.f. is stated in its entirety, then Hebble improvises upon it for the second half of the work in a combination of melody chorale and chorale fantasy forms. The coda returns to the introductory material.

Introduction
\begin{tabular}{|l|l|l|l|}
\hline $\begin{array}{l}\text { Ostinato established } \\
\text { from the Debussy } \\
\text { Reverie }(1898)\end{array}$ & $\begin{array}{l}\text { Entire } \text { c.f. in soprano, } \\
\text { altered harmonies }\end{array}$ & $\begin{array}{l}\text { Fragments of } \text { c.f., } \\
\text { altered harmony } \\
\text { Ostinato fragment }\end{array}$ & $\begin{array}{l}\text { Cyclic to introduction } \\
\text { with slight adaptation } \\
\text { Ostinato fragments }\end{array}$ \\
\hline mm. 1-2 & $3-24$ & $24-37$ & $38-42$
\end{tabular}

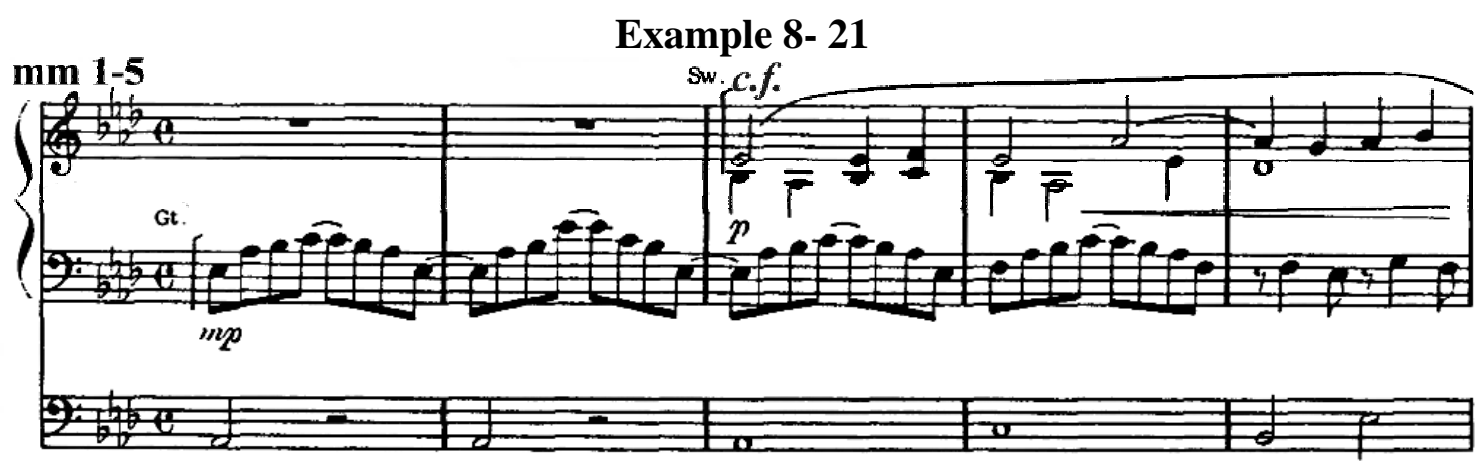

Chorale Cp48 Land of Rest

Bradley Publications B22M24

Long Melody Chorale

G major; $3 / 4$ time
Collection V (2/3[12]) called

The Robert Hebble Collection (1982)

Three manuals/Pedal

$47 \mathrm{~mm}$

The introduction begins on a solo line derived from the c.f. and leads to a series of chords that give the impression of bell harmonies (mm. 5-8, 13-16, 37-40) and alludes to church bells, see Ex. 8-21. These chords also act as interludes between the treatments of the strophes of the $c . f .$. The central section of $c . f$. treatment contains an accompaniment of mostly thirds, sixths, pedals, and parallel motion, see Ex. 8-21. The bell harmonies imply that the church is a "land of rest" or of heaven. 


Introduction
\begin{tabular}{|l|c|c|}
\hline Solos versus chord groups & Entire c.f. in the soprano & coda \\
\hline mm. 1-16 & $16-32$ & $32-47$
\end{tabular}

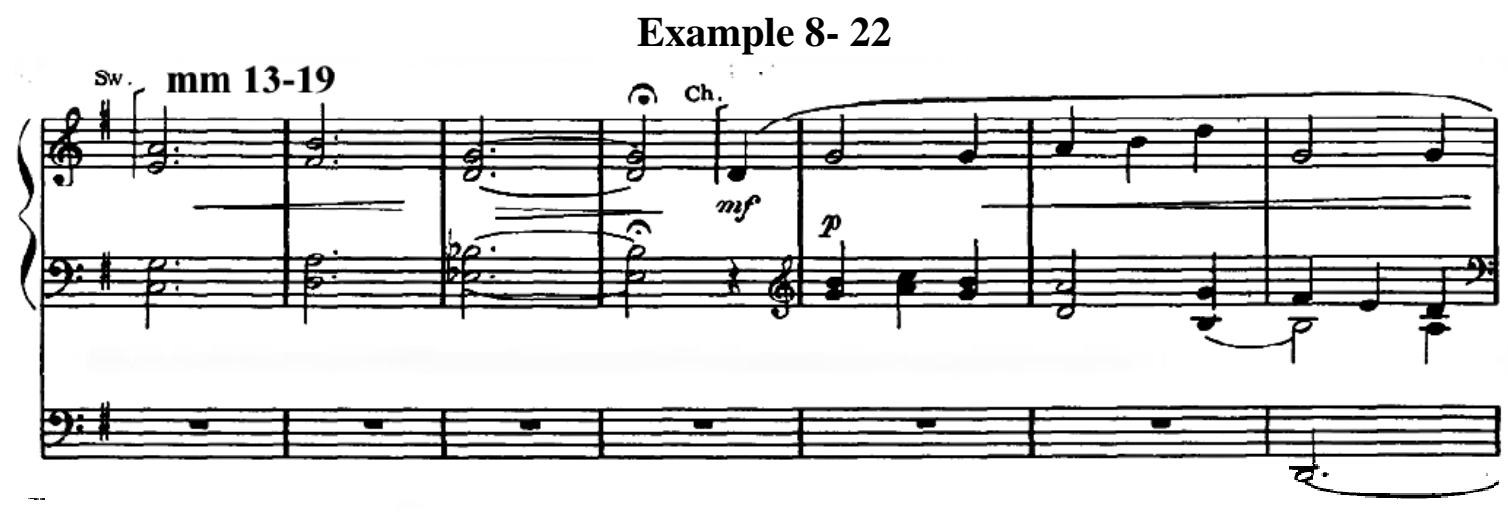

Chorale Cp52 Postlude on 'Nicea' Collection V; (3/3[12])

Bradley Publications B22M24 The Robert Hebble Collection (1982)

Ritornello Chorale $\quad$ Three $(+)^{161}$ Manuals/Pedal

$\mathrm{E}^{\mathrm{b}}$ major; $4 / 4$ time $\quad 47 \mathrm{~mm}$

This chorale is based on the ritornello form. The ritornellos contain usually two voices in syncopation, but up to four and six voices, suspending pedal activity, see Ex. 8-22, sy1 and 3. The episodes contain the treatment of the c.f., see Ex. 8-23, sy2. In a combinationchorale form, the episodes offer a variety of c.f. treatments including imitation and pedal c.f..

\begin{tabular}{|l|l|l|l|l|}
\multicolumn{1}{|l}{ Ritornello } & \multicolumn{1}{c}{ Episode 1 } & \multicolumn{1}{c}{ Ritornello } & \multicolumn{1}{c}{ Episode 2 } & Ritornello \\
\hline 2 voci & $\begin{array}{l}\text { c.f. } \text { soprano } \\
\text { Strophe 1 }\end{array}$ & imitation & $\begin{array}{l}\text { I7, } \text { ' III } \\
\text { Strophe 2 }\end{array}$ & 4 voci \\
\hline mm. 1-6 & $7-10$ & $11-14$ & $15-18$ & $18-23$ \\
\hline
\end{tabular}

\begin{tabular}{|l|l|l|l|c|}
\multicolumn{1}{l}{ Episode 3 } & Ritornello & \multicolumn{1}{l}{ Episode 4 } & Ritornello & \multicolumn{1}{c}{ Coda } \\
\hline $\begin{array}{l}\text { Altered harm. } \\
\text { Strophe 3 }\end{array}$ & 6 voci & $\begin{array}{l}\text { Syncopation } \\
\text { Strophe 4 }\end{array}$ & 3 rds & c.f. pedal \\
\hline mm. 24-26 & $27-32$ & $33-36$ & $37-40$ & $41-47$ \\
\hline
\end{tabular}

\footnotetext{
${ }^{161}$ More manuals could be used depending on the instrument.
} 
mm 1-5

\section{Example 8- 23}
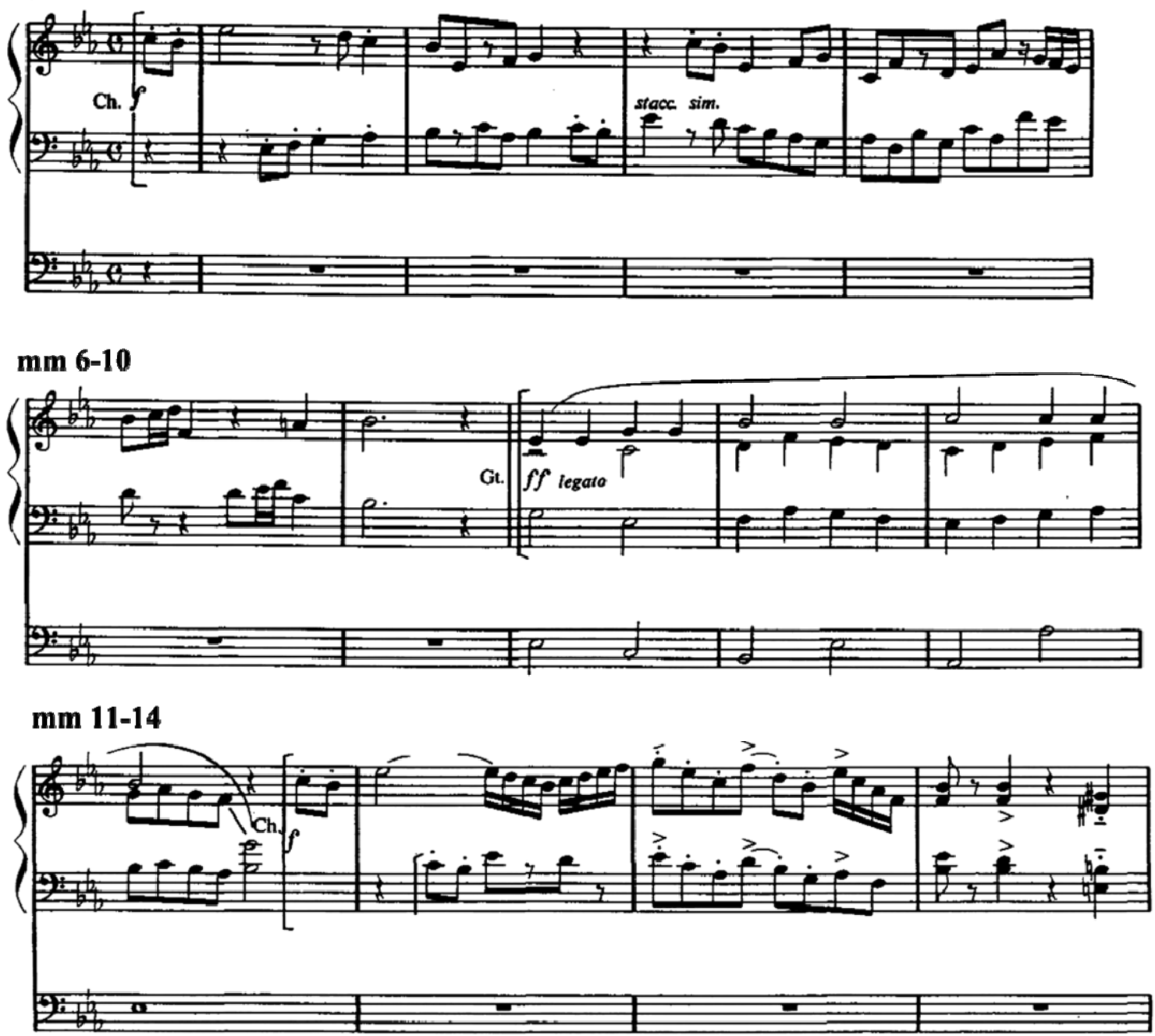

Chorale Cp57 Diptych on “Orientus Partibus” Collection VI; (1/6[12]) Warner Brothers Publishing EL9508 The Crystal Cathedral Collection (1982/1995) Chorale Variations Three Manuals/Pedal G major; $3 / 4$ time $54 \mathrm{~mm}$

The word diptych means two-parts or two sections. Here, Hebble treats two variations of the c.f. plus a small introduction and coda, which, again, blurs the line between variations and fantasia forms towards a possible combination chorale form. The introduction begins with a right-hand solo ostinato, which continues to play along with the $c$.f. and adjusts 
harmonically and intervalically until the conclusion of the variation (mm. 5-22), see Ex.

8-24. Concurrently, the c.f. appears and there is no pedal. The first variation repeats. The second variation begins in the parallel minor $(\mathrm{G})$ with altered harmony, but then returns to major. The pedal is added at the second strophe. After a brief interlude, where the ostinato returns (mm. 41-44), the first strophe of the c.f. is stated in the style of the second variation (as an incomplete third variation), but in $\mathrm{G}$ major. The coda contains the ostinato and the piece ends as it began.

\begin{tabular}{|c|c|c|c|c|c|}
\hline Introduction & variation 1 & variation 2 & interlude & (variation 3 ) & coda \\
\hline $\begin{array}{l}\text { r.h. solo } \\
\text { ostinato } \\
\text { pattern } \\
\text { created }\end{array}$ & $\begin{array}{l}\text { c.f. in alto, } \\
\text { altered } \\
\text { ostinato, no } \\
\text { pedal }\end{array}$ & $\begin{array}{l}\text { In G minor, } \\
\text { homophonic } \\
\text { altered } \\
\text { harmony }\end{array}$ & $\begin{array}{l}\text { Return of } \\
\text { ostinato with } \\
\text { l.h. accomp. } \\
\text { Add pedal }\end{array}$ & $\begin{array}{l}\text { G major } \\
\text { homophonic } \\
\text { in style of } \\
\text { variation } 2\end{array}$ & $\begin{array}{l}\text { Return of } \\
\text { the ostinato }\end{array}$ \\
\hline mm. 1-4 & $5-22$ & $23-40$ & $41-44$ & $45-49$ & $50-54$ \\
\hline
\end{tabular}

\section{Example 8- 24}

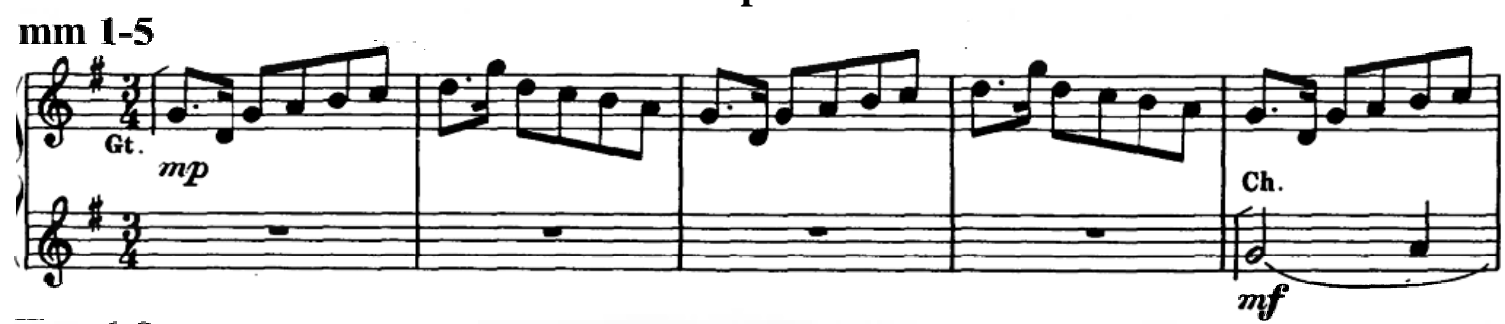

\section{mm 6-8}

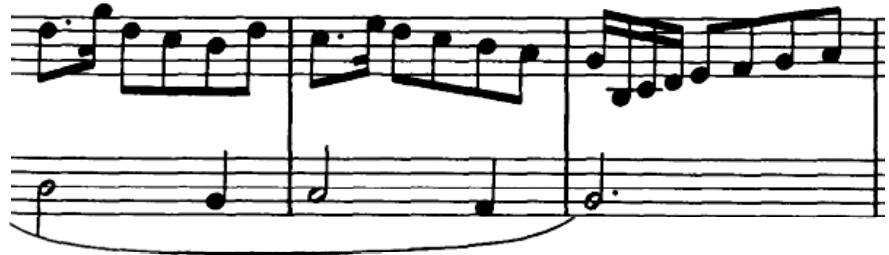


Chorale Cp59 I Wonder as I Wander

Warner Brothers Publishing EL9508

Long Chorale Fantasia/Variations

E minor; $6 / 8$ time
Collection VI; (2/6[12])

The Crystal Cathedral Collection (1982)

Three manuals/Pedal

$56 \mathrm{~mm}$

The composition qualifies as a combination chorale form due to the successive treatment of the verses, like a variation form, plus the addition of interludes, an introduction and a coda, like a fantasia form. After the nine measures of introduction over a tonic pedal with altered harmony and fore-imitation drawn from c.f., the work is reminiscent of the otherworldly character of Herbert Howells' organ preludes, see Ex. 8-25, sy1 and 2. The first variation is composed with the c.f. in the right-hand as a solo with an offbeat accompaniment (mm. 10-18). An interlude (mm. 19-21) introduces the more rapid accompaniment for the next variation (mm. 22-23) in which the c.f. is found in the pedal while flights of sixteenth notes circle high above with altered harmony in the style of a Long Form Cantus Firmus chorale, see Ex. 8-25, sy3. Hebble depicts angels and the "night sky" (mm. 24-25) with an expansive Ravelian modal harmony in a high ambit. There are interludes between the strophes (mm. 24-25, 28 and 31) in a twentieth century French organ improvisational style. Verse three is a French paraphrase improvisation on the c.f., which is disguised in the top voice on full organ, and uses a broken chord accompaniment, see Ex. 8-25, sy4. The coda has two sections: the first (mm. 46-50) is inspired by the introduction, the second ( $\mathrm{mm} .50-56)$ is drawn from the c.f. chorale section (m. 22-25). Then there is a complete "wandering" away from that which has been musically established, thus creating more imagery in the music. It requires three pre-set combinations. 


\begin{tabular}{|c|c|c|c|c|c|}
\hline Intro. & var. 1 & var. 2 & interlude & var. 3 & coda \\
\hline $\begin{array}{l}\text { Dovetailing, } \\
\text { terraced } \\
\text { dynamics, } \\
\text { motifs, } \\
\text { developed } \\
\text { altered } \\
\text { harmony }\end{array}$ & $\begin{array}{l}\text { c.f. in } \\
\text { soprano off- } \\
\text { beat } \\
\text { accomp. } \\
\text { tonic pedal } \\
\text { interlude }\end{array}$ & $\begin{array}{l}\text { c.f. in pedal, } \\
\text { 'circling' } \\
\text { upper } \\
\text { accomp. } \\
\text { manual } \\
\text { melodic } \\
\text { assistance }\end{array}$ & $\begin{array}{l}\text { Culminates } \\
\text { accomp. } \\
\text { material }\end{array}$ & $\begin{array}{l}\text { Broken } \\
\text { melodic and } \\
\text { accomp. } \\
\text { fragments } \\
\text { only }\end{array}$ & \begin{tabular}{|l} 
Two \\
sections, $1^{\text {st }}$ \\
$=$ similar to \\
intro., $2^{\text {nd }}=$ \\
altered
\end{tabular} \\
\hline mm.1-9 & $10-18(19-21)$ & $22-33$ & $34-35$ & $36-45$ & $6-56$ \\
\hline
\end{tabular}




\section{Example 8- 25}

mm 5-8

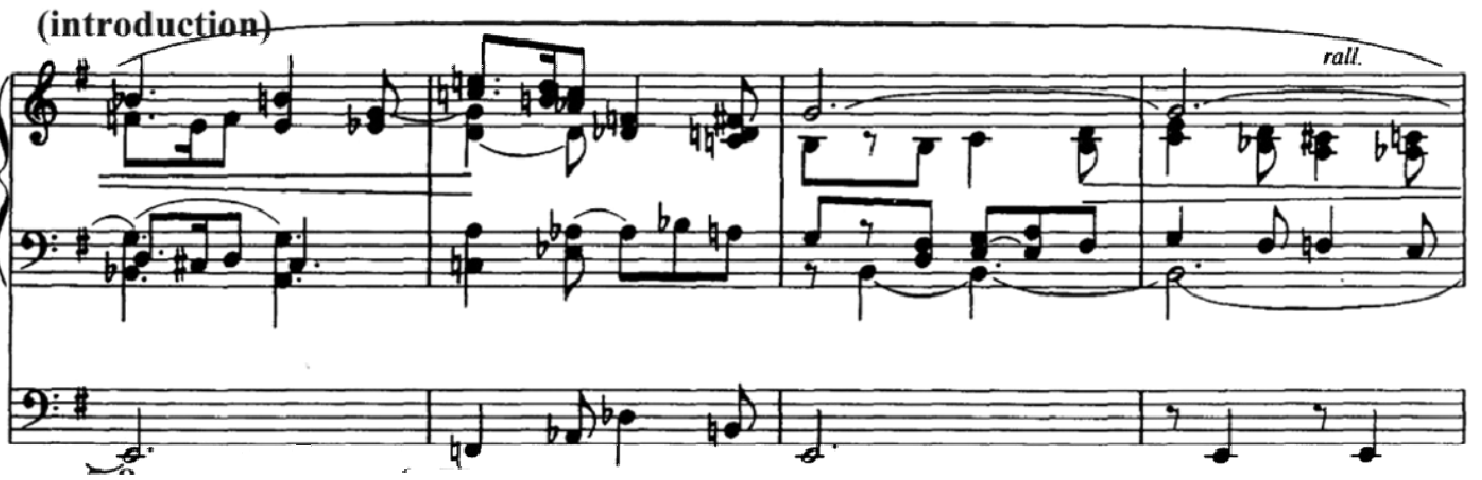

mm 9-12

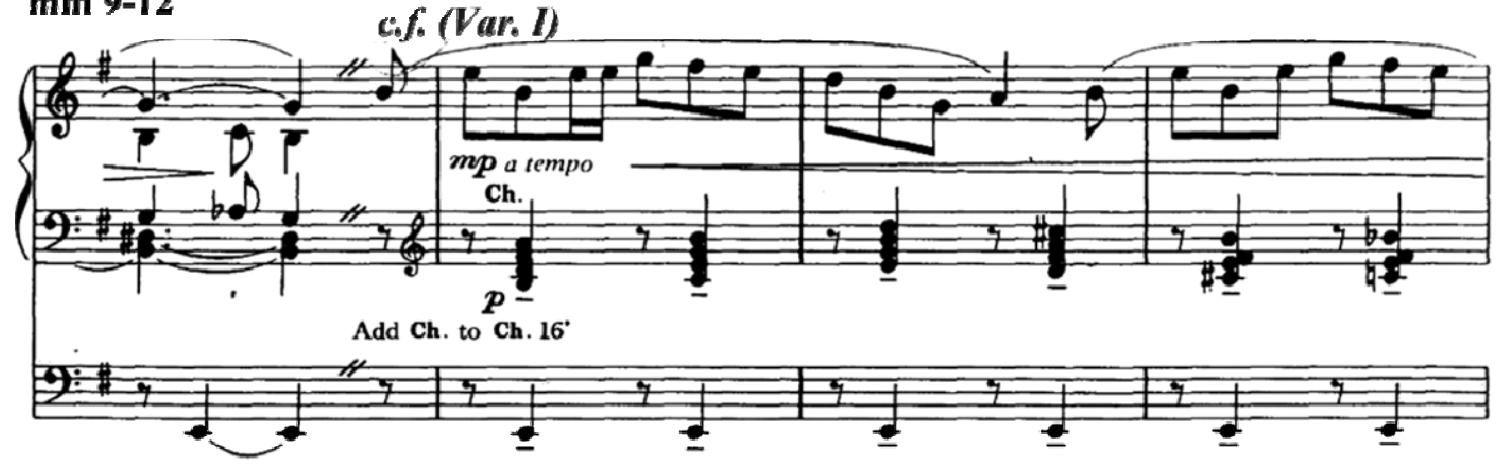

mm 20-22

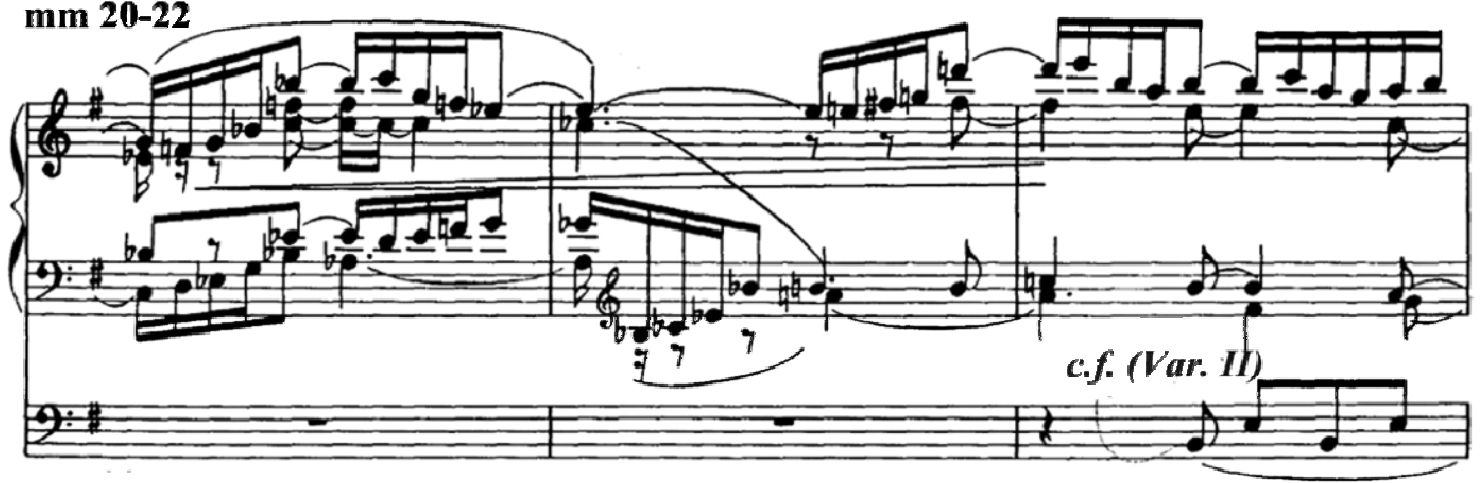

mm 36-39

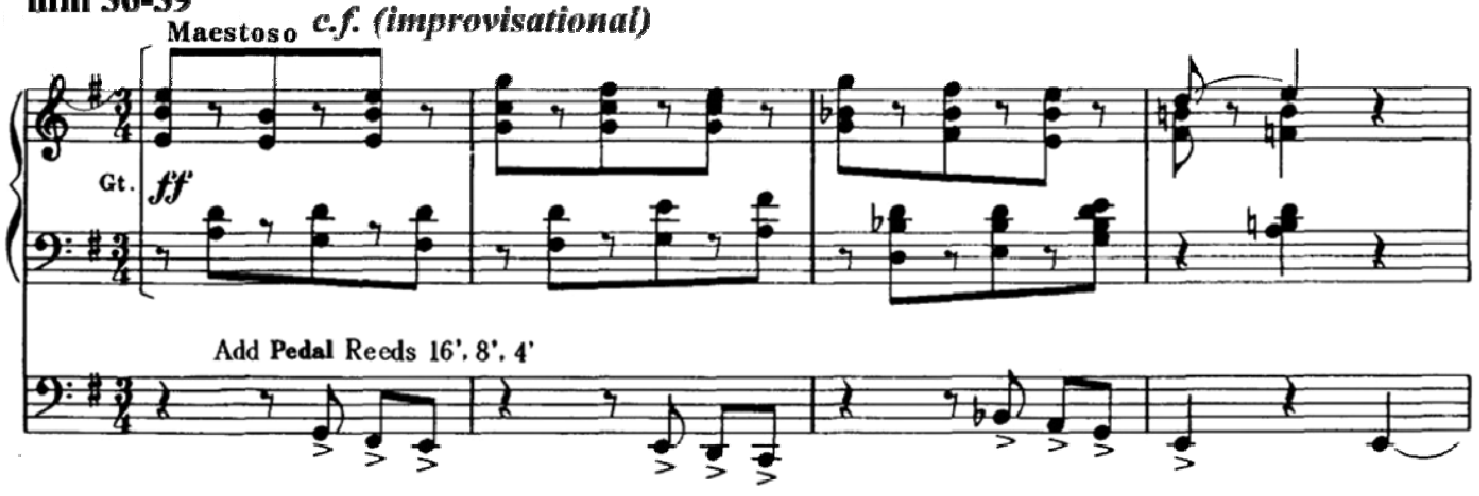


Chorale Cp60 My Shepherd Will Supply My Need Collection VI; (3/6[12])

Warner Brothers Publishing EL9508 The Crystal Cathedral Collection (1982)

Short Melody Chorale

D major; $3 / 4$ time

Two manuals/Pedal

$43 \mathrm{~mm}$

The text is based on Psalm 23 "The Lord Is my Shepherd" and set to the tune

"Resignation". The work is dedicated to Dr. Jack Jones, a personal friend of Hebble's, and is a Short Form Melody chorale. After a brief introduction containing an ostinato in the pedal and a developing motif in the accompaniment (eventually becoming motivic transformation), the c.f. appears in the soprano on a solo stop and continues uninterrupted to the coda, see Ex. 8-26. The accompanying motif develops. While the harmony generally pivots from the subdominant (IV) to the submediant (vi), the work is infused with blues harmony, such as the lowered seventh (mm. 2, see Ex. 8-26, [mm13, 27, 31, $38])$ and the lowered third (mm. 15, 22, 31, 38) and lowered sixths (mm. 18, 27, 28, 31, 38). The short coda begins on a Neapolitan harmony (m. 37), which is treated as a musical object. ${ }^{162}$ He resolves chromatically through the ascension of block chords to the tonic. The pedal remains pizzicato throughout the work, except where marked. The introduction and the coda are four and five measures long, respectively; thus maintaining balance, see Ex. 8-26. The introduction commences the motivic development while the coda gradually suspends it. Factors that affect this composition's classification as a possible combination chorale form, including the short chorale prelude, involve the complete independence of the chorale-free voices, as well as the fantasia-like additions of an introduction and coda. The composer's comments are interesting.

\footnotetext{
${ }^{162}$ Explained in Chapter 13.
} 
I just couldn't write this piece fast enough! This was one of the most pleasurable pieces to write. It's lovely, it works and it has received many comments from other organists and people from the congregation. The thoughts were coming so fast, they just leapt from my pen. The piece just wanted to be born. ${ }^{163}$

Introduction
\begin{tabular}{|l|l|l|}
\hline $\begin{array}{l}\text { Pedal ostinato, motivic } \\
\text { development for accomp. }\end{array}$ & $\begin{array}{l}\text { o.f. in soprano on solo stop, } \\
\text { straight and uninterrupted }\end{array}$ & $\begin{array}{l}\text { Begins on Neapolitan } \\
\text { chord, contrary motion }\end{array}$ \\
\hline mm. 1-4 & $4-36$ & $36-41$
\end{tabular}

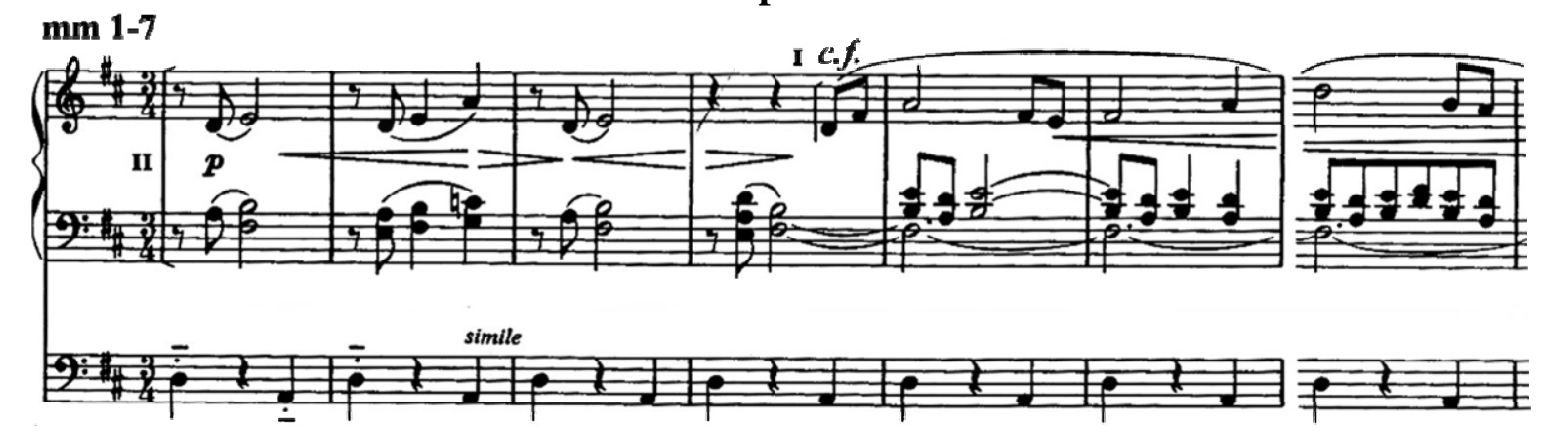

\section{Example 8- 26}

Chorale Cp63 Schematics

Warner Brothers Publishing EL9508

Long Chorale Fantasia

F minor; $4 / 4$
Collection $(5 / 6[12])^{164}$

The Crystal Cathedral Collection (1982)

Three manuals/Pedal

$72 \mathrm{~mm}$

After a ten measure introduction, Hebble treats two verses of the c.f., although each treatment is partial. It is an written-out improvisation, see Ex. 8-26, based on fragments of the tune "Ebenezer", also known as "Ton y Botel". Hebble called the work Schematics based on the 'plans' drawn up by organ builders which show the layout of the pipework and electronic relays in an organ console and pipe chamber. "This piece", says Hebble, "features how the tune is laid out within this improvisation. The scheme, like an organ schematic, is not always apparent, but those who know how to listen [read the

\footnotetext{
${ }^{163}$ Hebble, FL interview.

${ }^{164}$ This numbering skips Nave Cp1 (4/6/[12]), which is a republished work in Collection VI.
} 
schematic] can follow the scheme in this hard-to-hear-melody improvisation." ${ }^{\prime 65}$ The c.f. is uniquely disguised in an occasional hocket style of writing, see Ex. 8-26, sy1. It can be found syncopated and thematically transformed, see Ex. 8-26, sy4. Regarding the latter, the $c . f$. is transformed in reverse: it begins complete and whole and then is taken apart, essentially “decomposed," see Ex. 8-27, sy5. Hebble explains,

It decomposes towards something we don't recognize anymore; just like a schematic to the average person. Did you ever see a schematic of an organ? Believe me, it doesn't look anything like an organ! And this piece does not sound like "Ebenezer", unless you follow schematics. ${ }^{166}$

\begin{tabular}{|c|c|c|c|}
\hline Introduction & verse one & verse two & coda \\
\hline $\begin{array}{l}\text { Manual and pedal } \\
\text { on tonic and } \\
\text { dominant, hocket } \\
\text { fragments of } c . f \text {. } \\
\text { between pedal and } \\
\text { manual, altered } \\
\text { harmony in } \\
\text { homophonic section }\end{array}$ & $\begin{array}{l}\text { First-half no pedal, } \\
\text { c.f. in soprano, l.h. } \\
\text { ostinato accomp., } \\
\text { ostinato moves to } \\
\text { pedal, two voices in } \\
\text { manual break-up c.f. } \\
\text { in hocket in F major }\end{array}$ & $\begin{array}{l}\text { New ostinato in the } \\
\text { pedal, c.f. in } \\
\text { soprano, temporary } \\
\text { toccata figure in } \\
\text { hemiola in 1.h. } \\
\text { moves to A minor, } \\
\text { c.f. in hocket and } \\
\text { 'telescoped'. }\end{array}$ & $\begin{array}{l}\text { Syncopated toccata } \\
\text { figure, back to F } \\
\text { minor, c.f. heavily } \\
\text { disguised in l.h. and } \\
\text { r.h. of toccata, only } \\
\text { harmonic } \\
\text { suggestion, then } \\
\text { only rhythmic }\end{array}$ \\
\hline $1-12$ & $13-28$ & $29-60$ & $61-72$ \\
\hline
\end{tabular}

${ }^{165}$ Hebble, Atlanta, Georgia. Interview: August 30, 2002.

${ }^{166}$ Ibid. 
Example 8- 27

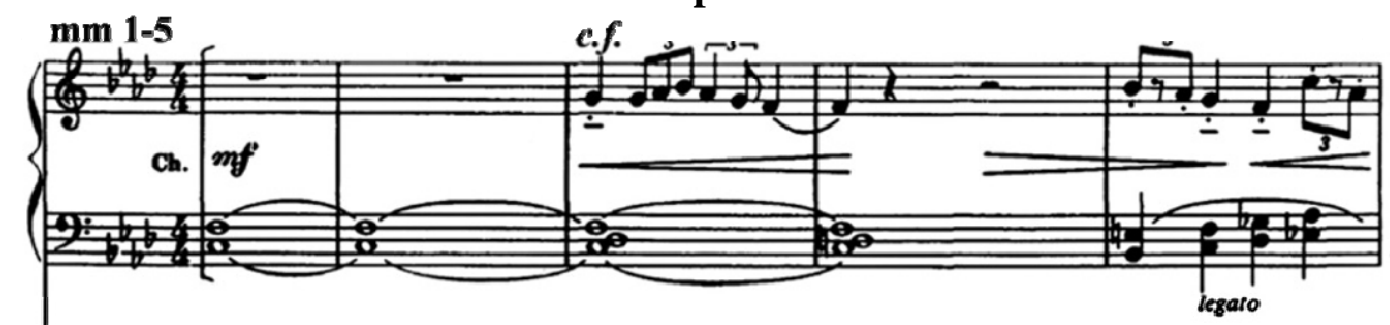

2010
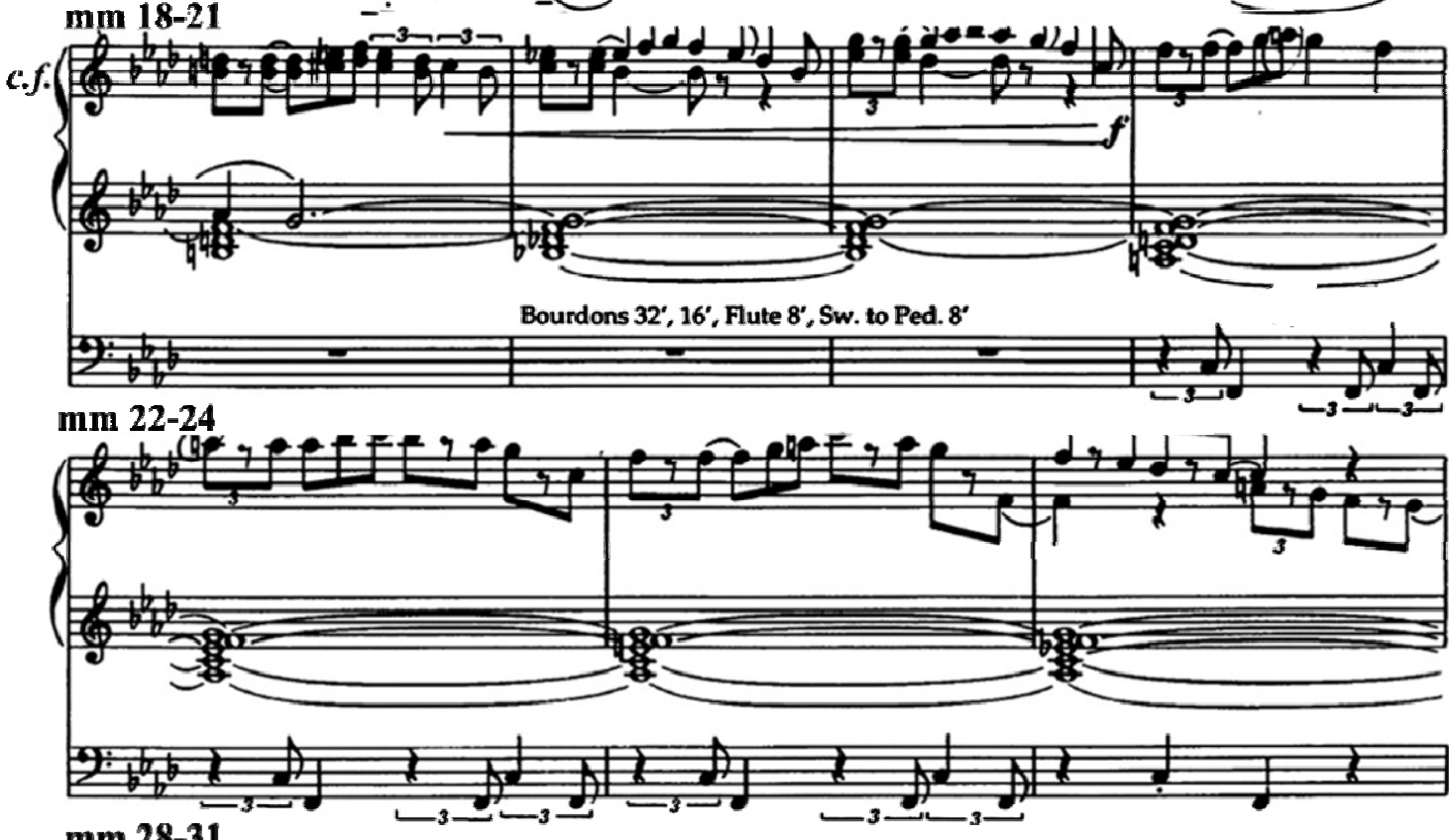
mm 28-31

(3)

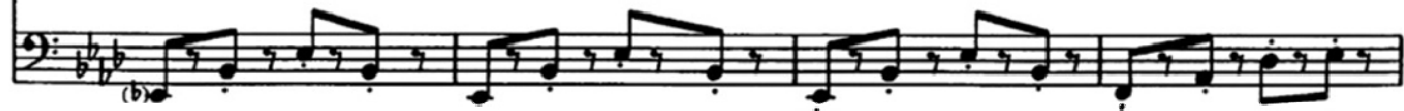

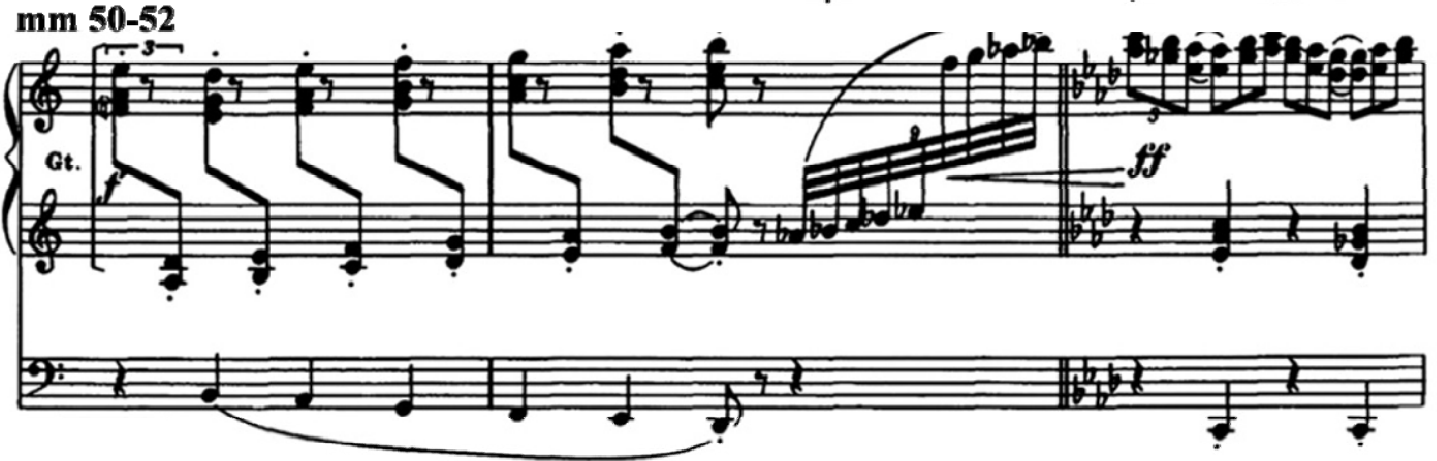


Chorale Cp72 Toccata on "Old Hundredth" Collection VI; (6/6/[12])

Warner Brothers Publishing EL9508 The Crystal Cathedral Collection (1982)

Long Chorale Fantasia/Variations Three manuals/Pedal

A major; cut time

$141 \mathrm{~mm}$

Similar to both variation-chorale form and chorale-fantasia, it was commissioned by St.

Paul Lutheran Church, Orlando, Florida and dedicated to Keith E. Bailey. It is similar in style to a $17^{\text {th }}$ century Italian organ toccata ${ }^{167}$ in that it is sectional and contains a rhythmic accelerando. ${ }^{168}$ Hebble's treatment has five large sections, which correspond to the four variations he treats plus the coda. Additionally, there are short interludes of one to two measures, and a short introduction. The interludes act as "connector pieces"169 (e.g., m. 37) supplying new motivic material (fore-imitation) in the transitions ahead of each variation. Hebble employs motivic transformation, which follows the melodic contour of the c.f.. This motif is slightly transformed each time it appears (e.g., mm. 10, $12,37,38,60,86)$. It adjusts intervalically during the toccata pattern over new harmonic progressions, see Ex. 8-28, sy4. Of harmonic interest is the interlude at mm. 37-38 incorporating some whole-tone writing. There is c.f. ornamentation in mm. 63-64, 69-70, 76-77, based in a planing motion. A modulation in the third variation moves from A major to $\mathrm{D}^{b}$ major via a common-tone $\mathrm{c} \#$, which is enharmonic to both keys. There are offbeat thirteenth-chords in the fourth variation, which are similar to the Dupré Prelude in G Minor, see Ex. 8-28, sy5. The hermeneutics of the work are based on the associated text of the first strophe of the c.f., drawn from the Psalms, and which permeates the work: "Praise God from whom all blessings flow". Based on the text of Psalm 150, it states "let

\footnotetext{
${ }^{167}$ Similar architecturally to the organ toccatas of Girolamo Frescobaldi, Claudio Merulo or Dietrick Buxtehude: sectional, sometimes with a rhythmic crescendo.

${ }^{168}$ The composition gradually increases in speed from quarter-notes to eighth-notes to sixteenth-notes.

${ }^{169}$ Hebble, FL interview.
} 
everything praise the Lord", thus Hebble writes out an improvisation whereby the melody of this text motivically pervades the entire work. The motives are found in the toccata pattern, see Ex. 8-28, sy3 (ascending); the pedal, the areas of syncopation, see Ex. 8-27, sy2; the c.f. solos, the interludes and the pedal cadenza, see Ex. 8-28, sy7 --symbolizing that everything is praising God.

\begin{tabular}{|c|c|c|c|c|c|}
\hline Introduction & var. one & var. two & var. three & four & coda \\
\hline $\begin{array}{l}\text { 1.h. tonic } \\
\text { pedal, } \\
\text { Aeolian } \\
\text { mode, } c . f \text {. } \\
\text { fragment in } \\
\text { pedal }\end{array}$ & $\begin{array}{l}\text { Modal } \\
\text { quartal } \\
\text { accomp., c.f. } \\
\text { in } 2 \text { part } \\
\text { soprano, } \\
\text { syncopated }\end{array}$ & $\begin{array}{l}\text { After } \\
\text { interlude, } \\
\text { motivic } \\
\text { toccata } \\
\text { pattern, c.f. } \\
\text { in tenor, no }\end{array}$ & $\begin{array}{l}\text { Tocata in } \\
\text { tenor, c.f. in } \\
\text { quartal in } \\
\text { soprano and } \\
\text { 'telescoped', } \\
\text { pedal in } \\
\text { ostinato }\end{array}$ & $\begin{array}{l}\text { Interlude, } \\
\text { c.f. in pedal, } \\
\text { meter } \\
\text { changes, off- } \\
\text { beat } 13^{\text {th }} \\
\text { chords }\end{array}$ & $\begin{array}{l}\text { Toccata } \\
\text { pattern } \\
\text { returns, c.f. } \\
\text { fragments in } \\
\text { tenor, pedal } \\
\text { cadenza }\end{array}$ \\
\hline & 0) & $41-59$ & $60-85(86-95)$ & $5-119$ & 41 \\
\hline
\end{tabular}


Example 8- 28
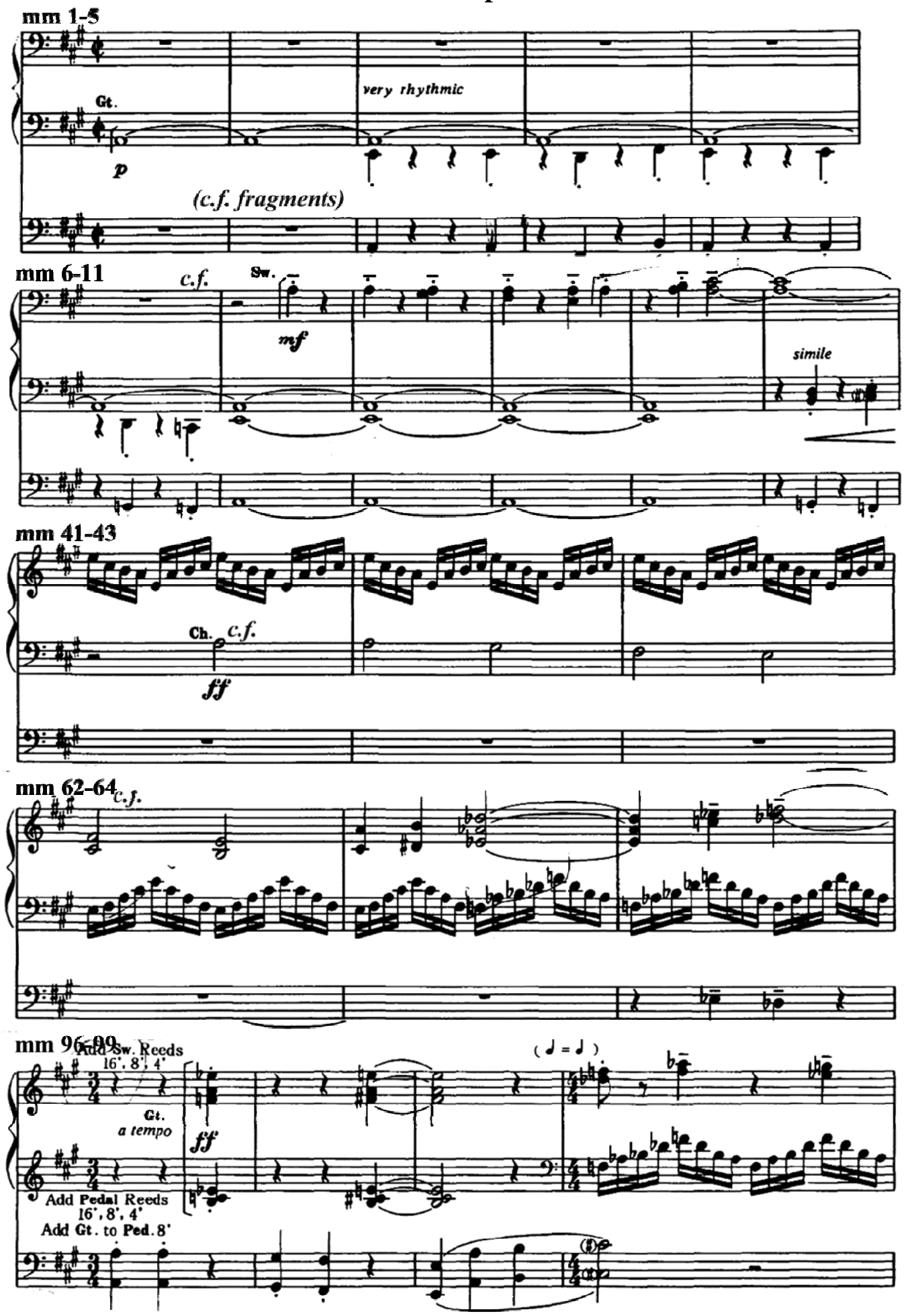

c. $f$. 
mm 134-141
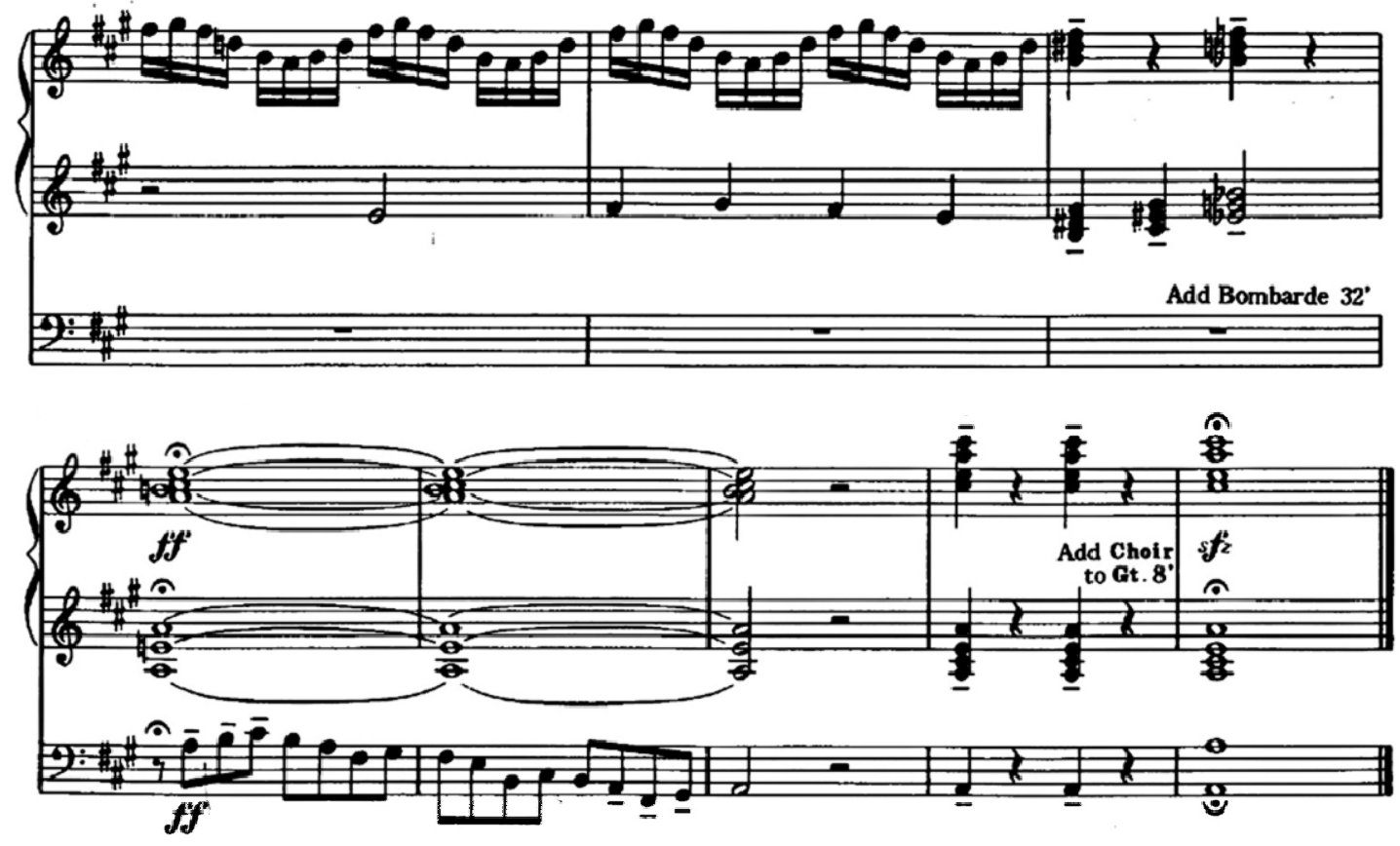

Chorale Cp91 Abide with Me

Bradley Publications B23M28

Long Chorale Fantasia

A major; $4 / 4$ time
Collection VIII; (1/14[14])

Rejoice (1984)

Three manuals/Pedal

$73 \mathrm{~mm}$

This is in a combination-chorale form. It has two large sections: $\mathrm{mm} .1-35$ and $\mathrm{mm}$. 42-

73. There is an introduction and a coda contributing to the overall palindrome structure of the work in the chart below. The introduction begins with an ostinato in the choralefree voices of the accompaniment, see Ex. 8-29. The third strophe of the c.f. is ornamented (mm. 21-27) coordinating with the text "when other helpers fail and comfort flees," depicting that "comfort" (the c.f.) has been abandoned. The second variation begins as an improvisation which summons the crescendo pedal to full organ. ${ }^{170}$ It repeats the melody "O abide with me" three times, (Trinity) then returns to the original

\footnotetext{
${ }^{170}$ This effect, coupled with its gripping text and compelling dissonance, implies "concern" if not "hell" because its results are encompassing, captivating and prevailing. The effect on the worshipper does not fail to grab the ear with a ferocious snap to attention.
} 
ostinato, creating a "bell-motif" that plays ten times, paralleling the "Ten

Commandments". ${ }^{171}$ This occurs over a series of unresolved harmonies, including

Tristan harmonies as metaphors for endless "abidance".

\begin{tabular}{|l|l|l|l|}
\multicolumn{1}{l}{ Introduction } & Section A & \multicolumn{1}{c}{ Section B } & \multicolumn{1}{c}{ Coda } \\
\hline ostinato & Ostinato with c.f. & c.f. paraphrased & New ostinato \\
\hline mm. $1-4$ & $5-35$ & $36-59$ & $60-73$ \\
I away from tonic & & vi7 & towards tonic - I
\end{tabular}

\section{Example 8- 29}

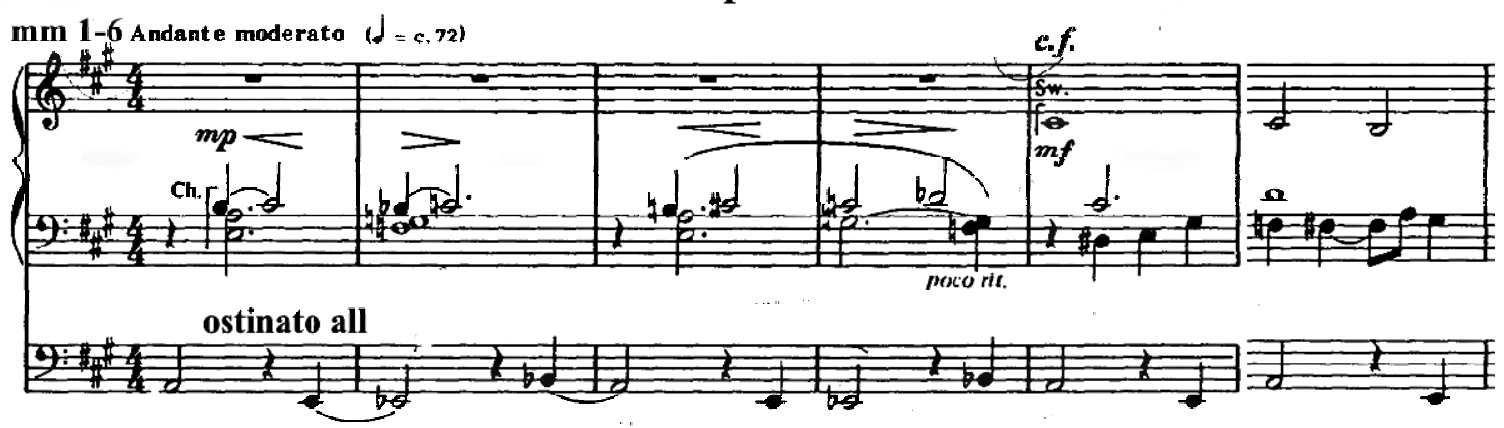

Chorale Cp92 Antiphonia

BradleyPublications B23M28

Ritornello Chorale

E minor; $4 / 4$ time
Collection VIII; (2/14[14])

Rejoice (1984)

Three manuals/Pedal

$76 \mathrm{~mm}$

The work is built on a fanfare-ritornello, see Ex. 8-30, sy1, which uses the Trompette-EnChamade stop for the voice of Jesus. It is based on the text "Jesus, Lover of My Soul" (the same text associated with an alternate tune at $\mathrm{Cp} 93$ ) on the tune Aberystwyth. It is most easily analyzed by its strophic structure:

${ }^{171}$ This implies that the faithful must adhere to the 'law' (10) in order to 'abide' with God. 
TEXT

Jesus, lover of my soul, Let me to Thy bosom fly,

While there nearer waters roll, while the tempest still is high:

Hide me, O my Savior, hide, Till the storm of life is past;

Safe into the haven guide; O receive my soul at last!
MELODIC STRUCTURE

A,B

A,C

$\mathrm{D}, \mathrm{D}$ '

E,A

The c.f. appears in various voices and with various organ registrations from the previously mentioned trompette to foundations to flute celestes. Hebble uses the these registrations to articulate the architecture and his multiple treatments of the c.f.: the trompette is used in the fanfare-ritornellos, the foundations are used in syncopated/ornamented passages, see Ex. 8-30, sy2 near the end, and the celestes are for homophonic treatments of the $c . f$. with altered harmony. Note that in the following graph, partial-strophes B and C are not used.

\begin{tabular}{|c|c|c|c|c|}
\hline $\begin{array}{l}\text { Fanfare- } \\
\text { ritornello } \\
\end{array}$ & c.f. area 1 & $\begin{array}{l}\text { Fanfare- } \\
\text { ritornello } \\
\end{array}$ & c.f. area 2 & $\begin{array}{l}\text { Fanfare- } \\
\text { ritornello } \\
\end{array}$ \\
\hline$\overline{\text { trompette }}$ & foundations & $\overline{\text { trompette }}$ & foundations & $\overline{\text { Trompette and }}$ \\
\hline E minor (i) & $\mathrm{A}, \mathrm{A}^{\prime}, \mathrm{D}^{\prime}$, & $\mathrm{B}$ minor $(\mathrm{v})$ & $\mathrm{D}, \mathrm{D}^{\prime}, \mathrm{A}$, & foundations \\
\hline & $\mathrm{A}$ & & $\mathrm{E}, \mathrm{A}, \mathrm{E}$ & E minor (i) \\
\hline
\end{tabular}
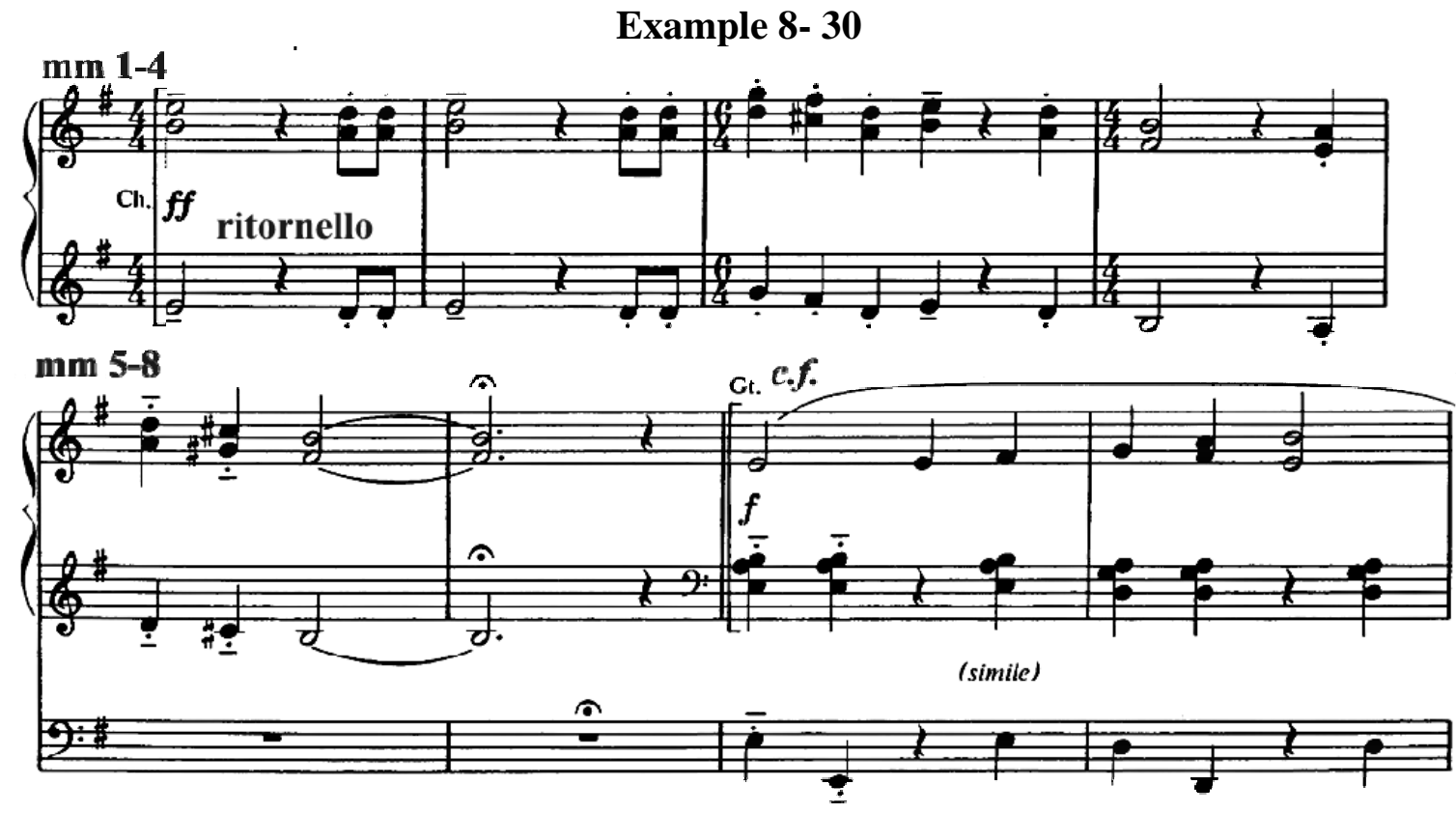
Chorale Cp93 Balocco on Martyn

Bradley Publications B23M28

Chorale Variations

F major in 6/8 time
Collection VIII; (3/14[14])

Rejoice (1984)

Two manuals/Pedal

$103 \mathrm{~mm}$

A 'balocco' is an Italian word for "plaything" or "toy" and the work is marked jovial and the chorale treatment is a combination-chorale of variations and fantasia. In variation one, the c.f. appears first in the soprano with short phrases of interlude, see Ex. 8-31, sy1. It is then rhythmically augmented (mm. 21-24) before finishing the last strophe. The second variation incorporates the motivic material from the interlude into the c.f., which itself becomes a main part of this verse (mm. 46-48, see Ex. 8-31, sy2 [37-40, 54]). Moments of bi-tonality constitute the third variation (mm. 81-82, 84-86) which never states the c.f. completely, but rather 'hides' ${ }^{172}$ it amidst great improvisation. The coda continues with material from the interludes with harmony altered to the end, see Ex. 8-30, sy3. Hebble continues to repeat the associated c.f. text "O receive my soul at last" five times throughout the coda (mm. 99-103, see Ex. 8-1, sy3 [83-84, 85-86, 86-88, 89-90]). The c.f. is in the soprano. It resembles a Vierne scherzo for organ.

\begin{tabular}{|c|c|c|c|c|}
\hline Var. one & var. two & interlude & var. three & coda \\
\hline $\begin{array}{l}\text { Short intro, } \\
\text { interludes betw } \\
\text { each strophe } 1\end{array}$ & $\begin{array}{l}\text { Preceding interl } \\
\text { interludes betw } \\
\text { each strophe } 2\end{array}$ & $\begin{array}{l}\text { Departure from } \\
\text { key quotes } \\
\text { fragments }\end{array}$ & $\begin{array}{l}\text { Mostly an } \\
\text { improvisation }\end{array}$ & $\begin{array}{l}\text { Return of interl. } \\
\text { Material, repeats } \\
\text { final strophe } 5 x\end{array}$ \\
\hline mm. 1-31 & $32-66$ & $67-80$ & $81-90$ & $91-103$ \\
\hline
\end{tabular}

\footnotetext{
${ }^{172}$ This is drawn from the text "Let me hide myself in Thee".
} 


\section{Example 8- 31}

mm 1-5

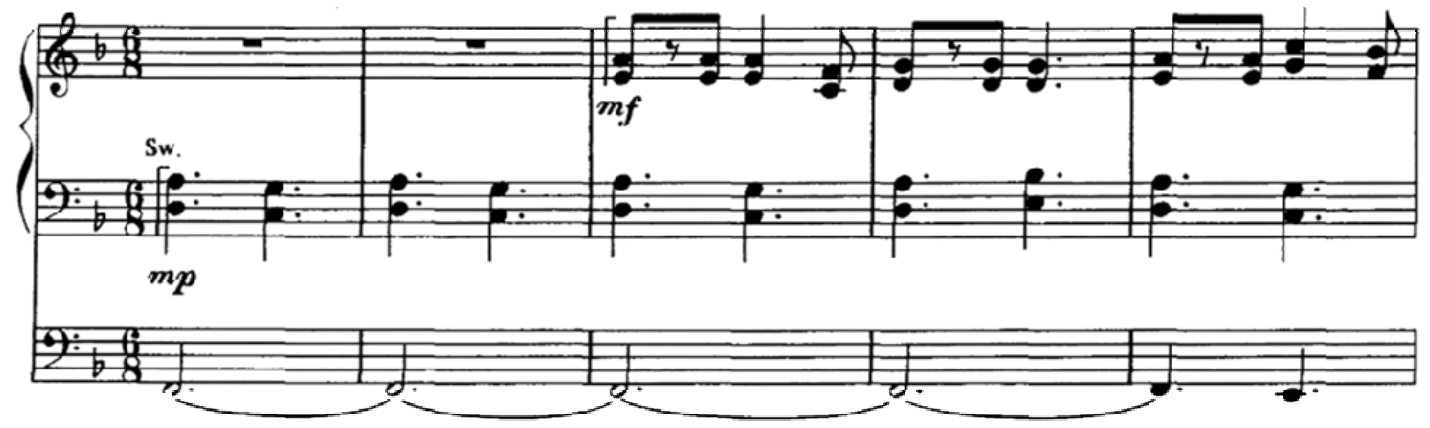

mm 46-50
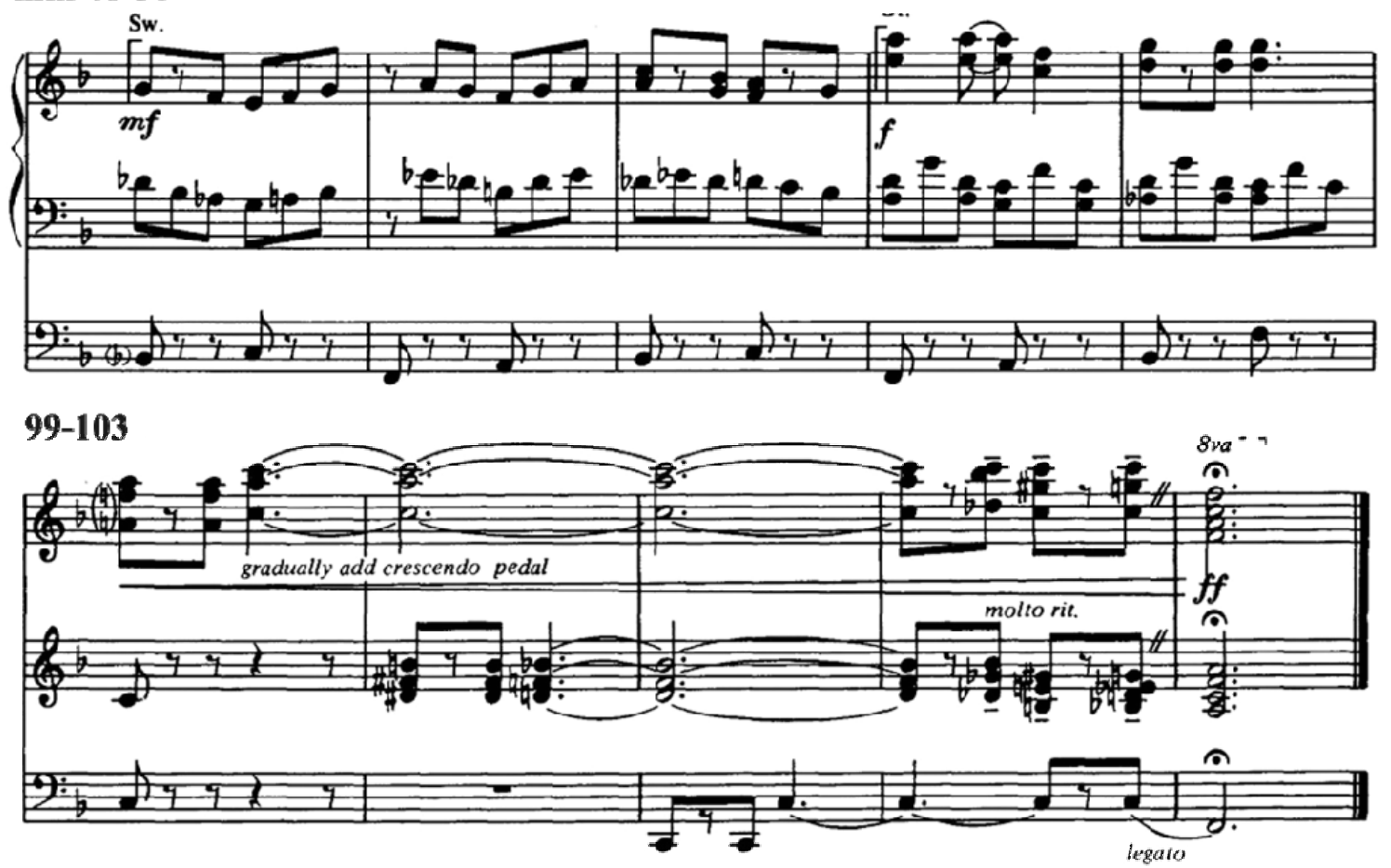

Chorale Cp94 St. Columba

Bradley Publications B23M28

Long Chorale Canon

F major; $3 / 4$ time
Collection (4/14[14])

Rejoice (1984)

Two Manuals/Pedal

$32 \mathrm{~mm}$

It is most often associated with the hymn "The King of Love, My Shepherd Is". Non-

harmonic tones (e.g. m. 32) and blues harmony (mm. 3-5, see Ex. 8-32, [6-10, 15, 18-19, 27-29]) imbue the composition within a chorale canon, a long form due to the inclusion 
of an introduction and coda. The middle section contains the canon between the manual and pedal that alludes hermeneutically to its text "confused and foolish oft' I've strayed." The final longa on the last note of the c.f. refers to the words "and He is mine forever" which is the last word of the verse. In the coda Hebble has roving progressions, like Mahler, that leave the work sounding endless.

Introduction
\begin{tabular}{|l|l|l|}
\hline $\begin{array}{l}\text { Two long phrases of first } \\
\text { strophe, altered harmonies }\end{array}$ & $\begin{array}{l}\text { c.f. } \text { in the soprano, canon at } \\
\text { the octave in the pedal }\end{array}$ & $\begin{array}{l}\text { Holds final note of } c . f . \text { while } \\
\text { chords progress "endlessly" }\end{array}$ \\
\hline mm. 1-11 & $12-26$ & $27-32$
\end{tabular}

\section{Example 8- 32}

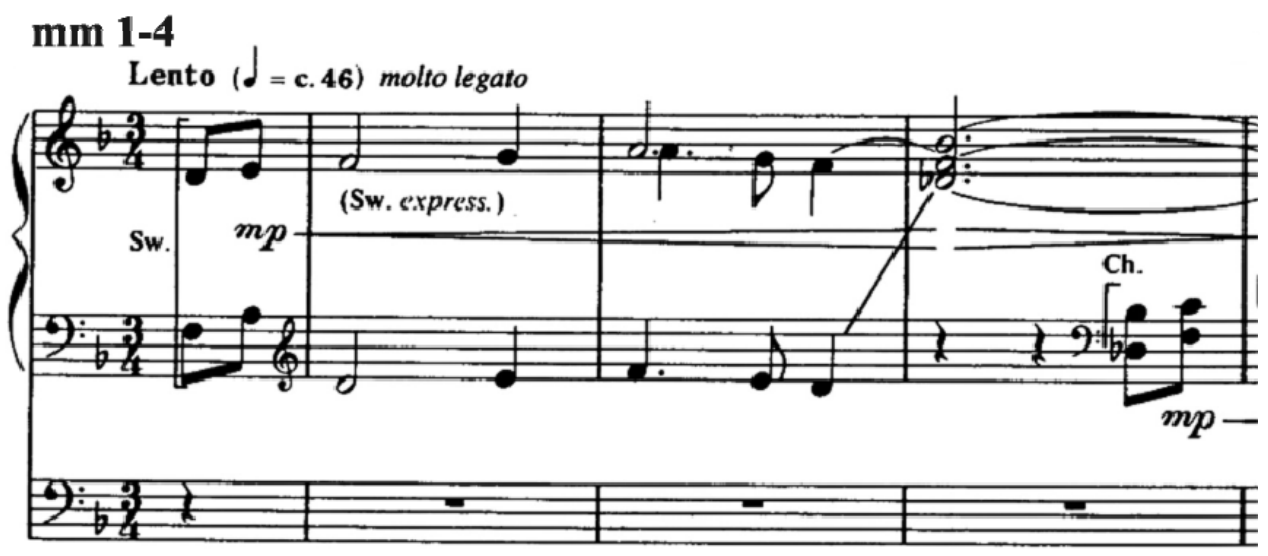

Chorale Cp95 St. Margaret

Bradley Publications B23M28

Long Chorale Fantasia

$\mathrm{F}$ to $\mathrm{G}$ major; cut time
Collection VIII; $(5 / 14 /[14])$

Rejoice (1984)

Three Manuals/Pedal

$83 \mathrm{~mm}$

The tune is associated with the hymn O Love That Will Not Let Me Go. The introduction quotes fragments of the tune in $\mathrm{C}$ major, the $\mathrm{V}$ for the eventual $\mathrm{F}$ major, see Ex. 8-33, sy1. In verse one the c.f. is in the soprano while a toccata figuration plays in the left-hand over a staccato pedal, see Ex. 8-33, sy2. The middle section (mm. 37-38) contains a brief modulation to $G^{b}$, then pivots to $G$ major where the c.f. is in the soprano (mm. 39-72), 
but at the end of the verse the work dissolves into an improvisational style (mm. 68-72).

There are fragments of the c.f. as well as rhythmic borrowings in this section, but the tune does not finish. The reason is that both the first and the second verses end with "I give back the life I owe, that in Thine ocean depths its flow may fuller, richer be"; and also, "I yield my flickering torch to Thee, ... that in Thy sunshine's blaze its day may brighter, fairer be". Thus, hermeneutically, by receding into improvisation Hebble depicts "giving back the life (melody) I owe" by removing the melody, then the texture becomes "richer, fuller" to the end. When the tune is associated with Jesus, Lover of My Soul the verse reads "hide me, and receive my soul at last!" the improvisation disguises the c.f. and 'hides' it. ${ }^{173}$ The fifths in the coda also suggests "will not let me go". The following chart shows the harmonic progression.

Improvisation

\begin{tabular}{|c|c|c|c|}
\hline Introduction & Verse 1 & Modulation & Verse 2 incomplete - coda \\
\hline $\mathrm{C}$ (c.f.) & $\mathrm{F}$ toccata & $\mathrm{G}^{\mathrm{b}}$ & $\mathrm{G}$
\end{tabular}

\section{Example 8- 33}
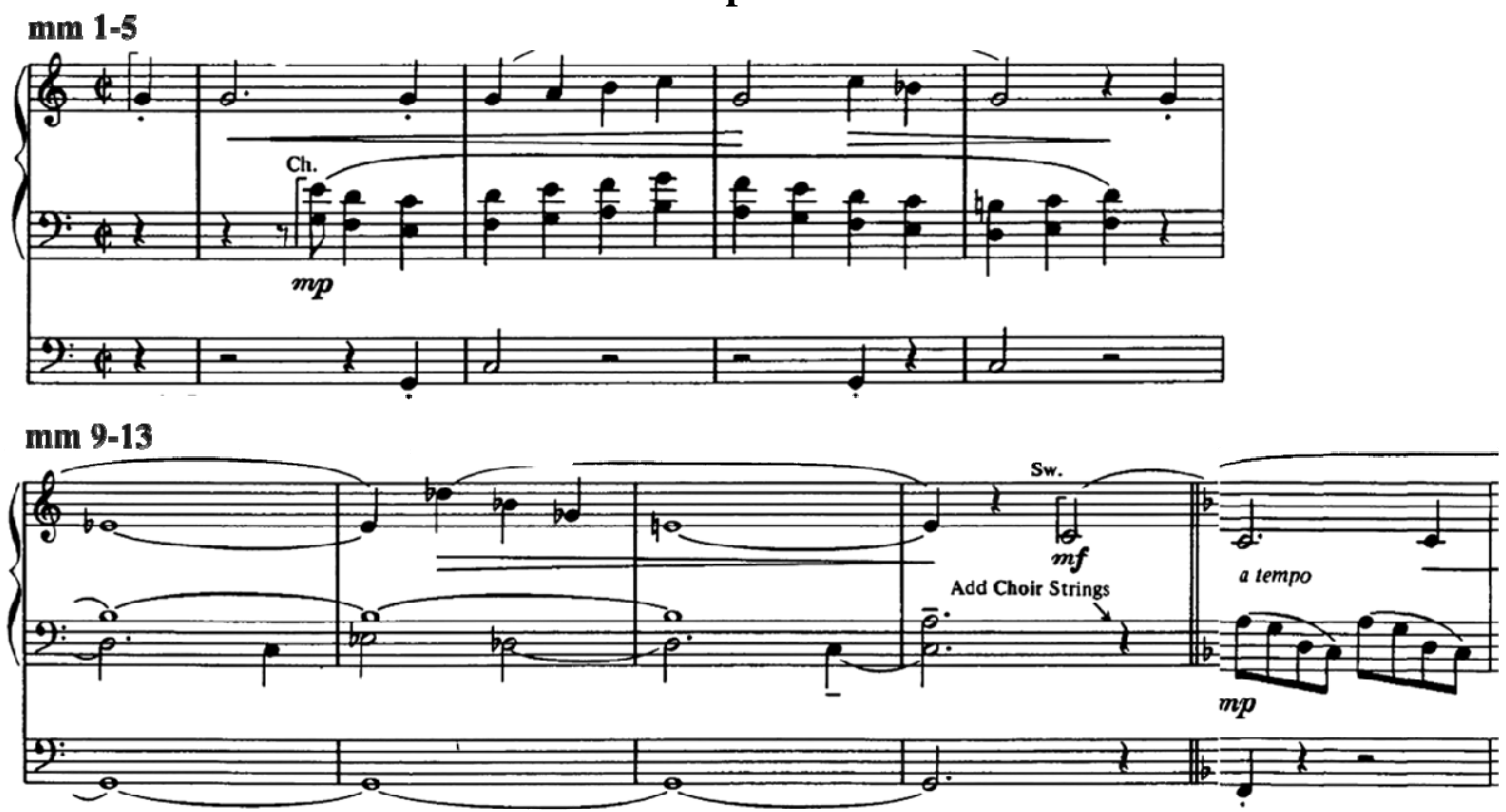

${ }^{173}$ Hebble, Canton tape two, side two. 
Chorale Cp96 Chorale on Slane

Bradley Publications B23M28

Long Chorale Fantasia

$\mathrm{E}^{b}$ major; $3 / 4$ time
Collection VIII; (6/14/[14])

Rejoice (1984)

Two manuals/Pedal

$40 \mathrm{~mm}$

With an introduction in mm. 1-8 the work paraphrases the Erik Satie Gymnopedie No.1.

It begins with an ostinato in the accompaniment and pedal (evoking the image of meditation or a vision) ${ }^{174}$ and an ambiguous first-inversion relative-minor harmony moving to a ${ }^{b}$ VII. This suggests a person 'being lost' and in need of a 'vision' in order to proceed, coordinating with the associated text Be Thou My Vision. The c.f. is then presented in its entirety (mm. 12-28) with an accompaniment of parallelisms in ascending block chords (elevating the idea of a 'vision'), and an interrupting interlude between the third and fourth phrase of the c.f. (mm. 21-24) when a moment of the original ostinato returns. The c.f. resumes (measure 25) with the fourth phrase and ends on a deceptive lowered VI-9 chord at measure 28. The coda ${ }^{175}(\mathrm{~mm} .29-40)$ maintains proportion between the c.f. treatment area (16 measures) and the interlude/coda areas (16 measures). The tonic finally appears on the last chord on the word, "prayer", alluding to its importance. The final phrase contains a tonic 'upper pedal' in the soprano, a resumption of the original ostinato in the alto and tenor, and the return of parallelisms in the left hand, which descend, to create a correlative opposite with the previous ascending chords. The last four bars contain hemiola.

\begin{tabular}{|c|c|c|}
\hline Introduction & c.f. treatment & coda \\
\hline "Satie" ostinato & $\begin{array}{l}\text { c.f. in soprano (interlude } \\
\mathrm{mm} .21-24 \text { ) }\end{array}$ & Upper pedal tonic, ostinato \\
\hline
\end{tabular}

\footnotetext{
${ }^{174}$ This coordinates with the text of the second strophe of the first verse: "nothing matters, but that Thou art."

${ }^{175}$ This coda is stylistically very similar to the codas of "Nun komm der Heiden Heiland BWV 659" of J. S. Bach and Louis Vierne's Adagio (4th) movement of Symphonie III, last ten measures. [Fox played and knew these works, which may have influenced Hebble.]
} 
Chorale Cp97 Fairest Lord Jesus

Bradley Publications B23M28

Ritornello Chorale

$E^{b}$ major; 4/4 time
Collection VIII; (7/14/[14])

Rejoice (1984)

Two Manuals/Pedal

$50 \mathrm{~mm}$

Hebble creates a ritornello form from which he creates two phrases in the introduction, see Ex. 8-34, sy1, (mm. 1-4 and 5-11 with extentions), two phrases in the coda (mm. 4146 and 47-50), and one phrase in augmentation during the playing of the c.f. (mm. 12-19), see Ex. 8-34, sy2. The c.f. is also augmented. Coupled with its andante cantabile tempo, Tristan, Neapolitan and extended chord harmonies, the introduction gives the impression of a beatific vision. This coordinates with the associated text, "...Jesus is fairer than sunshine...moonlight...the springtime, brighter, purer than all the angels heaven can boast". A Neapolitan chord at measure 18 is reminiscent of J.S. Bach's surprising use of it in his Orgelbüchlein chorale O Mensch, bewein dein Sünde Groß BWV 622. The coda is ten (10) measures long, balancing with the introduction, and includes the final appearance of the ritornello (m. 47). Hebble incorporates the Tristan harmony in measures 9, 27, 36 and 37 as a metaphor to suggest that the 'fairness' of Jesus is elusive (as the fabled love of Tristan and Isolde) and defies explanation or resolution. 


\section{Example 8- 34}

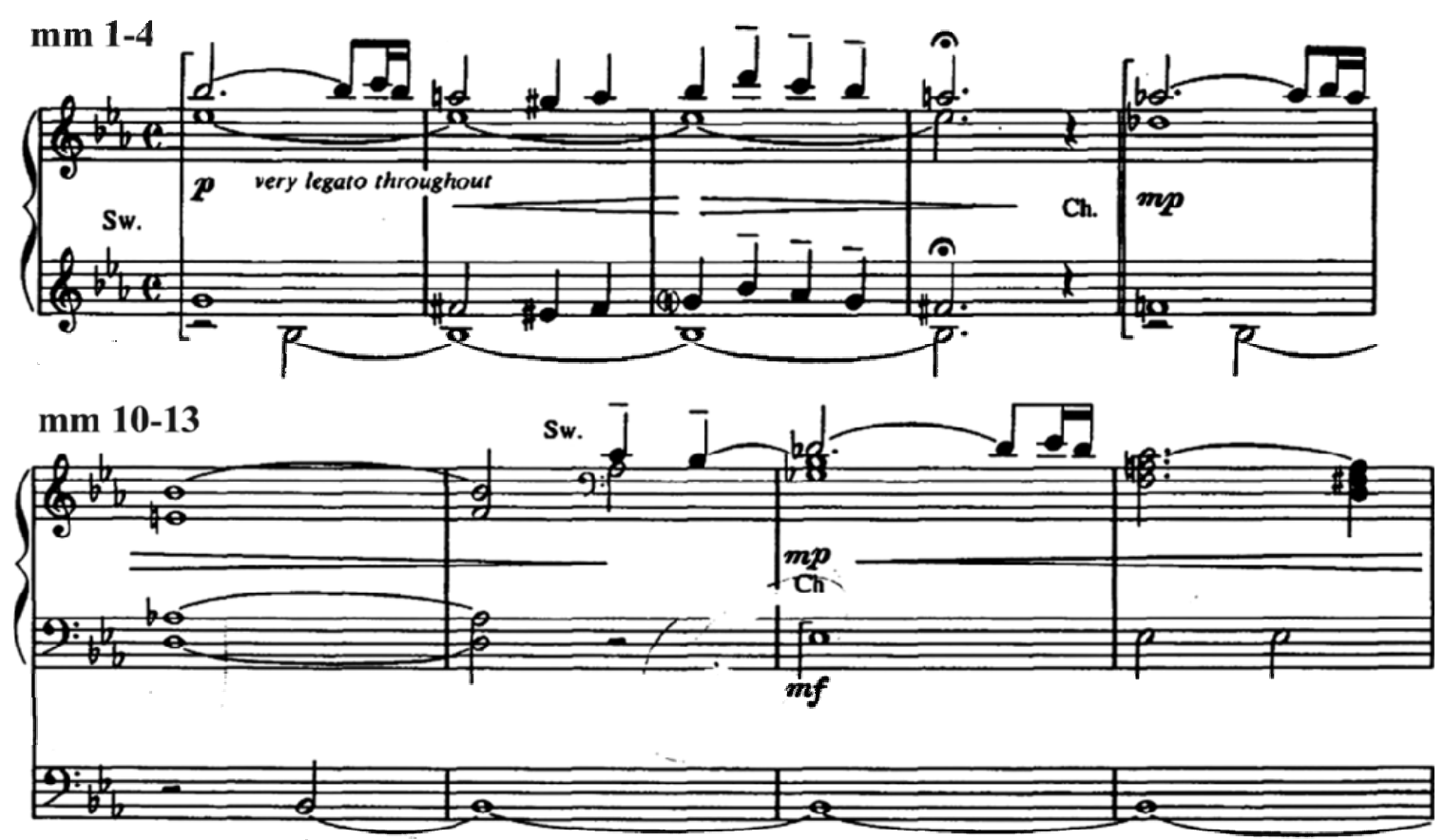

Chorale Cp98 Festive Piece on “A Mighty Fortress” Collection VIII; (8/14/[14]) Bradley Publications B23M28 Rejoice (1984)

Long Chorale Fantasia

C major: modulates; multiple meters Three Manuals/Pedal $136 \mathrm{~mm}$

This piece is an improvisation that has been notated. Similar to a chorale-motet, it paraphrases successive strophes of the c.f. in a toccata form, see Ex. 8-35, sy1. Many of the improvised c.f. phrases are ornamented (mm. 14-15), harmonically altered (mm. 1718), include metrical changes (mm. 10-26, see Ex. 8-35, sy2) or elongation (mm. 26-32). A central section (mm. 44-63) treats the c.f. in the dominant key $(\mathrm{G})$ after which another central-like section (mm. 64-88) treats the c.f. in E minor. Jazz elements and nonharmonic chord tones permeate the work, especially as the c.f. returns to $\mathrm{C}$ major (mm. 112 to end) on "full organ". The motet portion is contained with the larger fantasia treatment of this known Lutheran chorale, which pays homage to Reinken and Bach. 


\begin{tabular}{|c|c|c|c|c|c|c|c|c|}
\hline e & f. $\operatorname{str} 1$ & str2 & str3 & c.f. $s \operatorname{str}$ & free & $f . \operatorname{str} 1$ & free & free \\
\hline $\begin{array}{l}\text { c.f. } \\
\text { frag in } \\
\text { pedal, } \\
\text { toccata }\end{array}$ & $\begin{array}{l}\text { c.f. in } \\
\text { soprano, } \\
\text { changes } \\
\text { meter }\end{array}$ & $\begin{array}{l}\text { c.f. in } \\
\text { soprano, } \\
\text { Solo ff, } \\
\text { syncop }\end{array}$ & $\begin{array}{l}\text { c.f. in } \\
\text { tenor, } \\
\text { toccata } \\
\text { frags }\end{array}$ & $\begin{array}{l}\text { c.f. } \\
\text { hocket } \\
\text { manuals, } \\
\text { improvs }\end{array}$ & $\begin{array}{l}\text { Frags } \\
\text { last } \\
\text { strophe }\end{array}$ & $\begin{array}{l}\text { Full } \\
\text { organ } \\
\text { altered } \\
\text { harmony }\end{array}$ & $\begin{array}{l}\text { Cyclic } \\
\text { of } \\
\mathrm{m} .10 \\
\text { frags }\end{array}$ & $\begin{array}{l}\text { fff reed, } \\
\text { frags, } \\
\text { blind } \\
\text { octaves }\end{array}$ \\
\hline & & & & & & & & \\
\hline
\end{tabular}

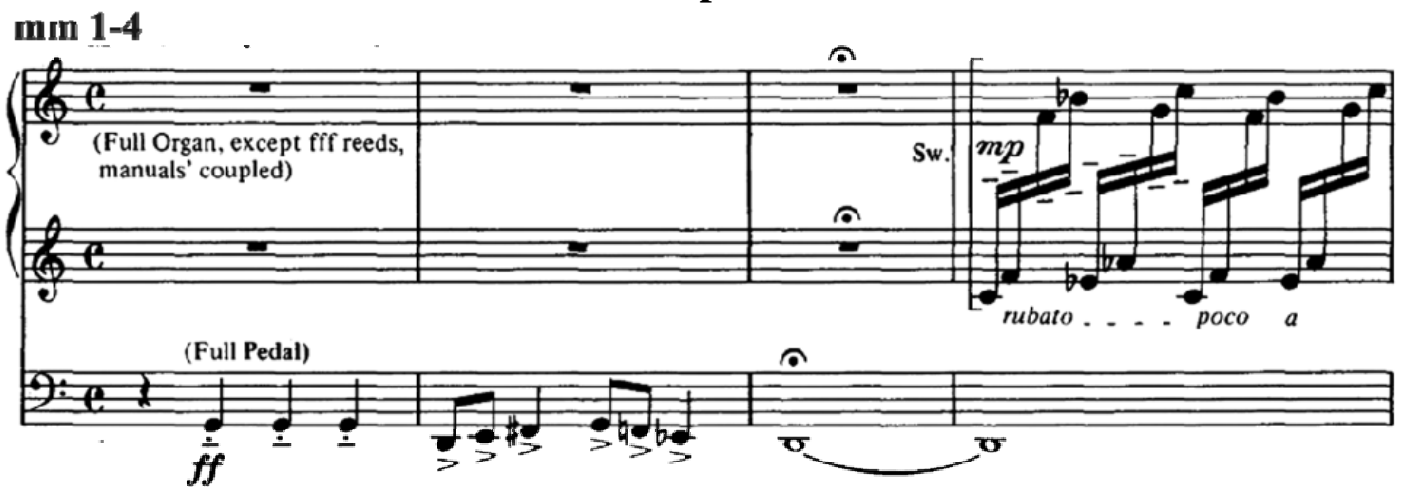

\section{Example 8- 35}
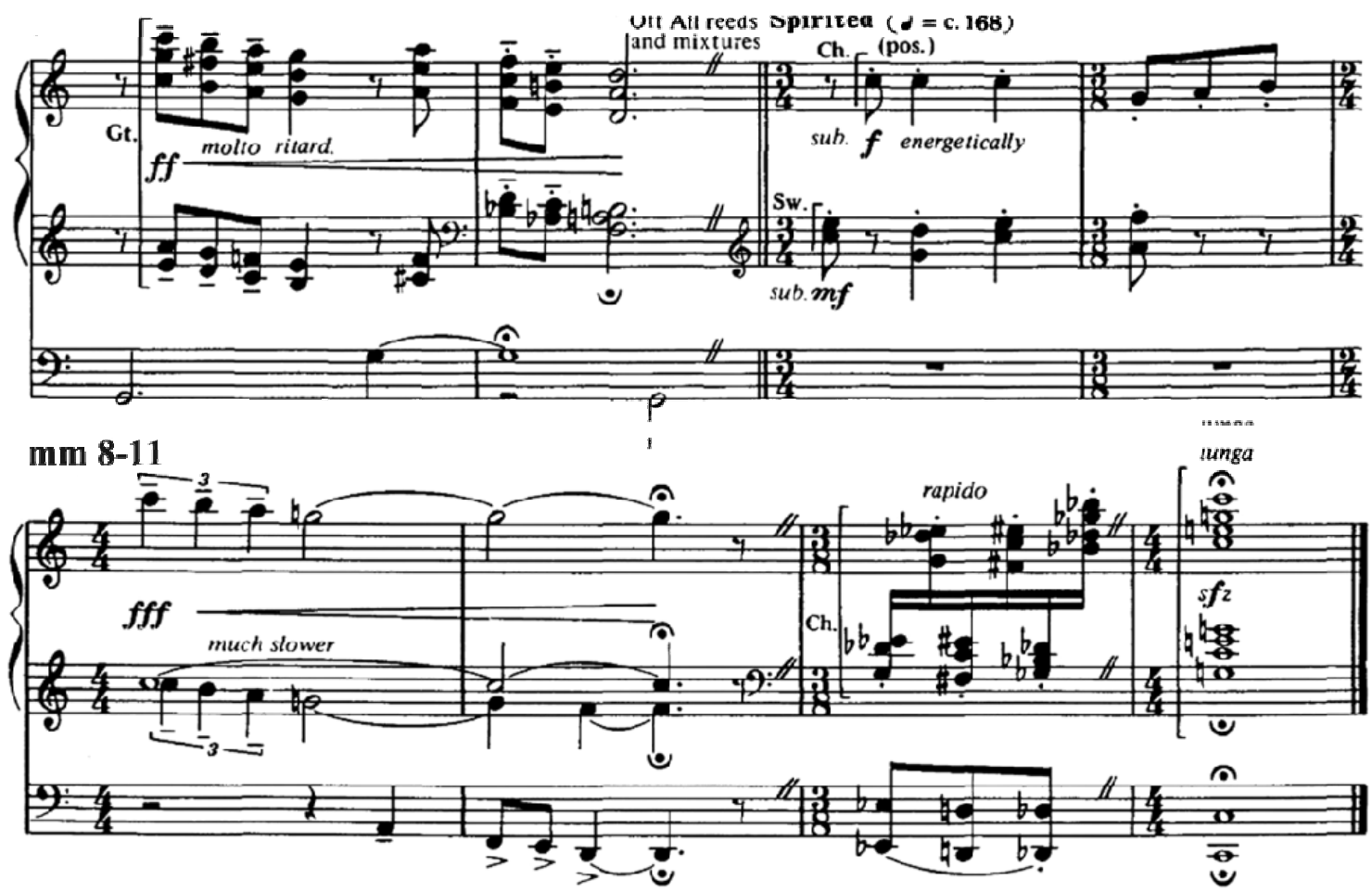
Chorale Cp99 Paraphrase on “Jesus Loves Me” Bradley Publications B23M28

Long Chorale Fantasia

$\mathrm{E}^{\text {b }}$ major; common time
Collection VIII; $(9 / 14 /[14])$

Rejoice (1984)

Three manuals/Pedal

$35 \mathrm{~mm}$

Beginning on a manual pedal on $\mathrm{V}$, the introductory area is on a "flute celeste and flute 8 with tremolo" and concludes with augmentation and extention of strophe four, see Ex. 8-36, sy1. The c.f. is presented on the "Krummhorn 8, cantabile" in the soprano based on the first four strophes, see Ex. 8-36, sy2. The work is influenced by Gershwinesque harmonies and jazz-like embellishments during the interlude. Half-dimished- $7^{\text {th }}$ chords are part of the harmonic palette, see Ex. 8-36, sy2, last measure. The coda has the $c . f$ in the pedal in augmentation and altered harmonically, see Ex. 8-36, sy3.

Introduction
\begin{tabular}{|l|l|l|l|l|} 
Manual Pedal on & \multicolumn{1}{l}{ c.f. } & c.f. in soprano \\
$\begin{array}{l}\text { V ; altered } \\
\text { harmonies }\end{array}$ & $\begin{array}{l}\text { simple altered } \\
\text { harmony accom. }\end{array}$ & $\begin{array}{l}\text { 2 phrases in } \\
\text { extempore jazz } \\
\text { ends on V7 }\end{array}$ & $\begin{array}{l}\text { Final refrain of } \\
\text { c.f.; ends on II9 }\end{array}$ & $\begin{array}{l}\text { Elided with last } \\
\text { note of } \text { c.f. }\end{array}$ \\
\hline mm. 1-12 & $13-20$ & $21-26$ & $27-32$ & $33-35$ \\
\hline
\end{tabular}


Example 8- 36

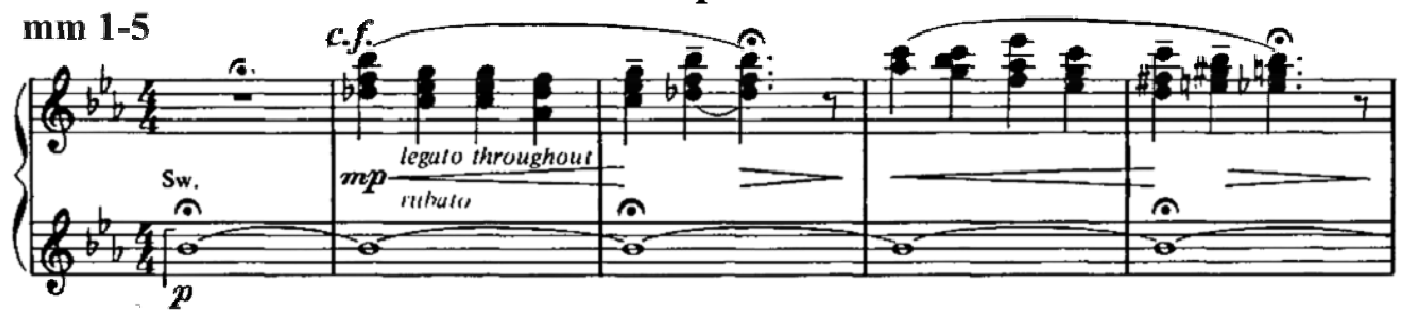

mm 11-15
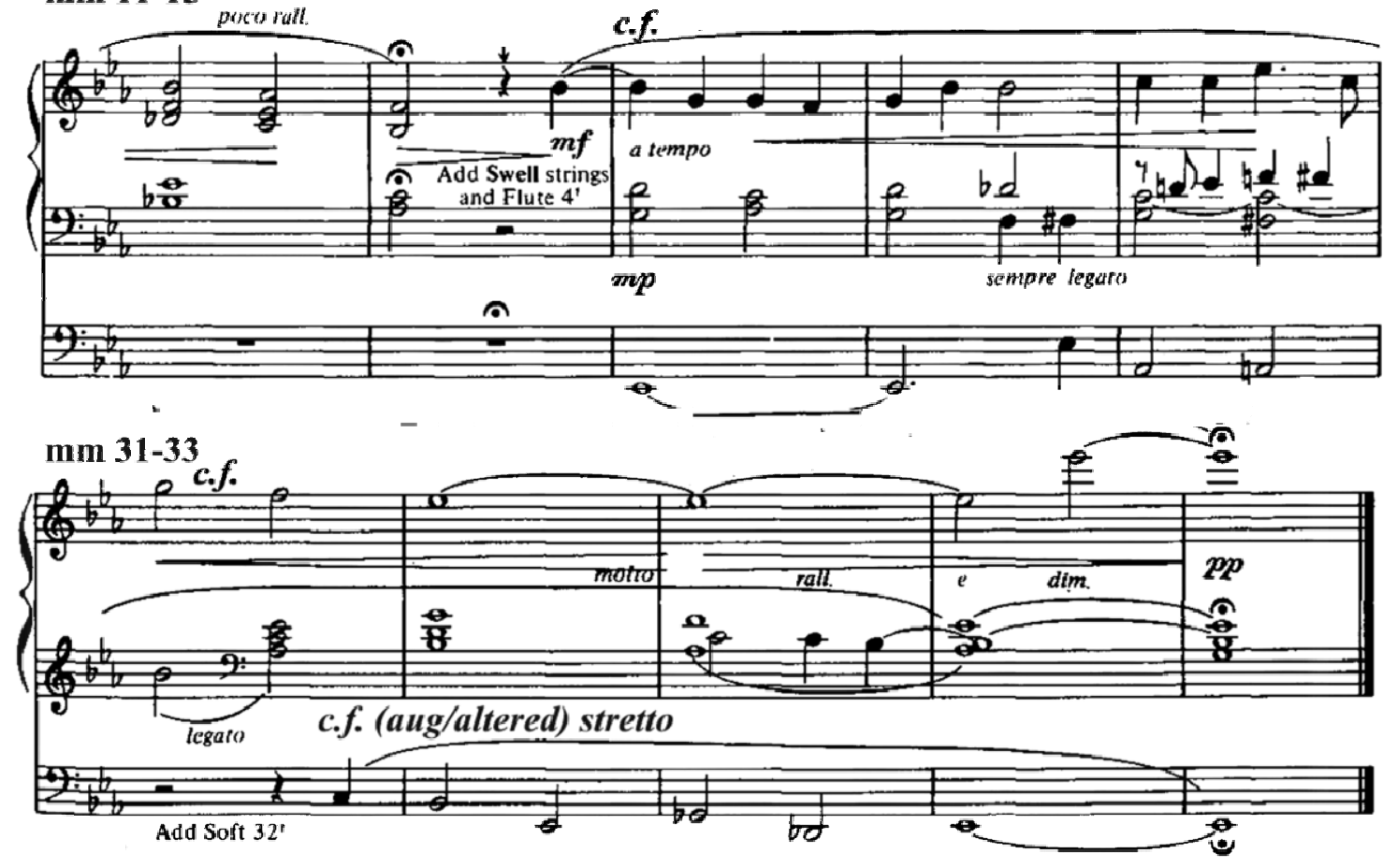

Chorale Cp100 Reflections on "In the Cross of Christ I Glory" Collection VIII; Bradley Publications B23M28 Rejoice (1984); (10/14/[14]) Short Melody Chorale $\mathrm{C \# -minor} \mathrm{in} 3 / 4$ time Two Manuals (no pedal) $33 \mathrm{~mm}$

It is through-composed, strophic and contains "cross" imagery. The introduction contains an ostinato, which permeates the work, much like Flor Peeters' Aria for Organ or Eric Satie's Gymnopedie for piano, see Ex. 8-37. The c.f. is in the soprano in minor and ends modally, the second phrase of which is up a half step. The ostinato is accompanied by a manual pedal, which creates suspense and portrays looking up from 
below. The Adagio indication with the ostinato and pedal create allusions to 'panting', 'breathing', 'trudging', and 'heartbeat'. ${ }^{176}$ - all images associated with the cross.

\section{Example 8- 37}

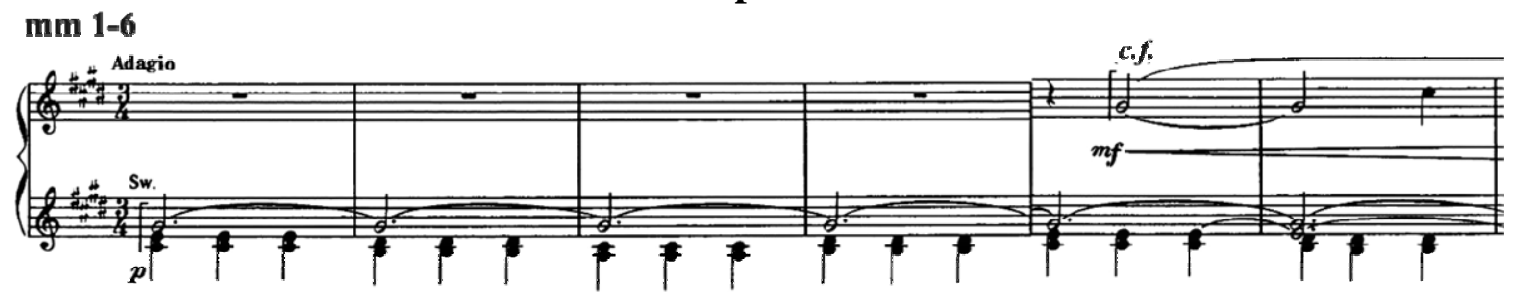

Chorale Cp101 Ring Out Wild Bells

Bradley Publications B23M28

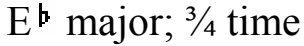

Chorale Fantasia
Collection VIII; $(1 / 1 /[14])$

Rejoice (1984)

Three Manuals/Pedal

$127 \mathrm{~mm}$

The text "Ring Out the Old, Ring in the New" is by Alfred Tennyson (1849). This composition is based on the tune "Deus Tuorum Militum". The idea behind this work is the "bell-motif," see Ex. 8-38a (mm 1-4), and heightened by rhythmic activity. The c.f. appears in the tenor (mm. 19-29) then moves to the soprano (mm. 30-40). After a series of "bell-motifs" (mm. 47-58) a new key area of B major is established. This area saturates the tonic with a rhythmic "bell-motif" (mm. 59-84) in the lefthand where, at m. 85, a common-tone ${ }^{177}$ modulation pivots the listener back to $\mathrm{E}^{\mathrm{b}}$ major, see Ex. 8-38a. The theme returns with the full power of the pedal (mm. 85 to the end) while double trills on the dominant soar above (mm. 85-91) for two strophes. A triple canon ensues $(\mathrm{mm}$. 95-104), but it is short and not strict. While the right hand alone plays a flourish (mm. 104-107) the left-hand prepares the 32' pedal reed, which plays various quotes of the opening strophe "Ring out the old" (mm. 108-110, 112-114) before a pedal cadenza in

${ }^{176}$ Hebble, Canton tape two, side two.
${ }^{177}$ Ribble, p. 438. 
hemiola. Meanwhile, in another canon, the manuals play the same quote a tritone away from the pedal entrance exactly two bars later (mm. 110-112, 114-116).

\begin{tabular}{|c|c|c|c|c|}
\hline Introduction & Section A & Section B & Section A & Coda \\
\hline $\begin{array}{l}\text { "bell-motif", } \\
\text { quartal } \\
\text { harmonies }\end{array}$ & $\begin{array}{l}\text { Theme in tenor, } \\
\text { then sop. Quartal } \\
\text { accompaniment }\end{array}$ & $\begin{array}{l}\text { Theme fragments } \\
\text { dorian mode } \\
\text { rhythmic pedal }\end{array}$ & $\begin{array}{l}\text { Theme in pedal, } \\
\text { trills on V, } 3 \text { part } \\
\text { canon, flourish }\end{array}$ & $\begin{array}{l}\text { Theme fragments } \\
\text { in pedal, canon at } \\
\text { tri-tone, hemiola }\end{array}$ \\
\hline
\end{tabular}

\section{Example 8-38a}

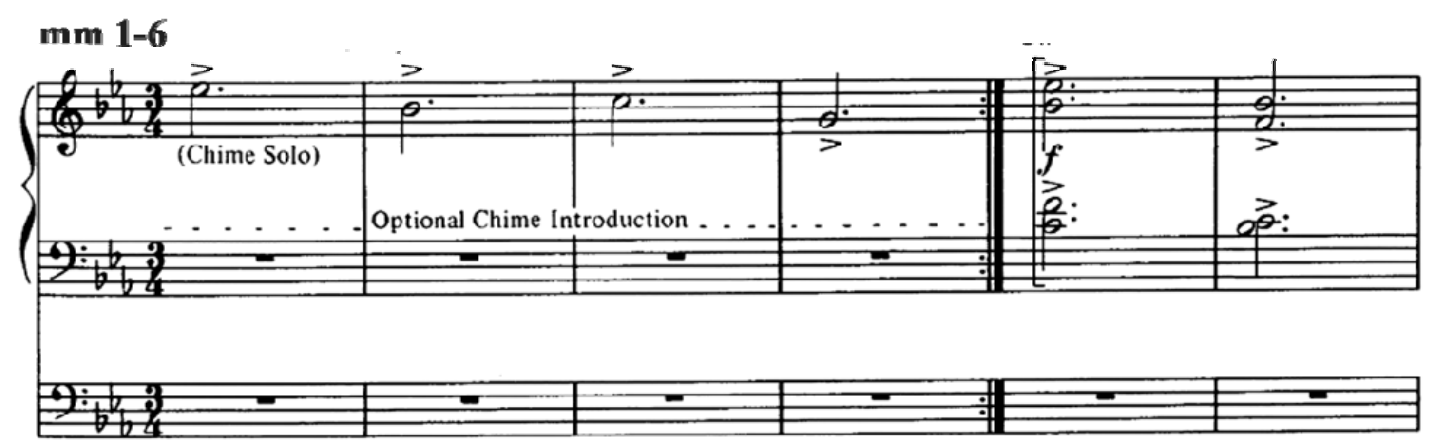

\section{mm 84-88}

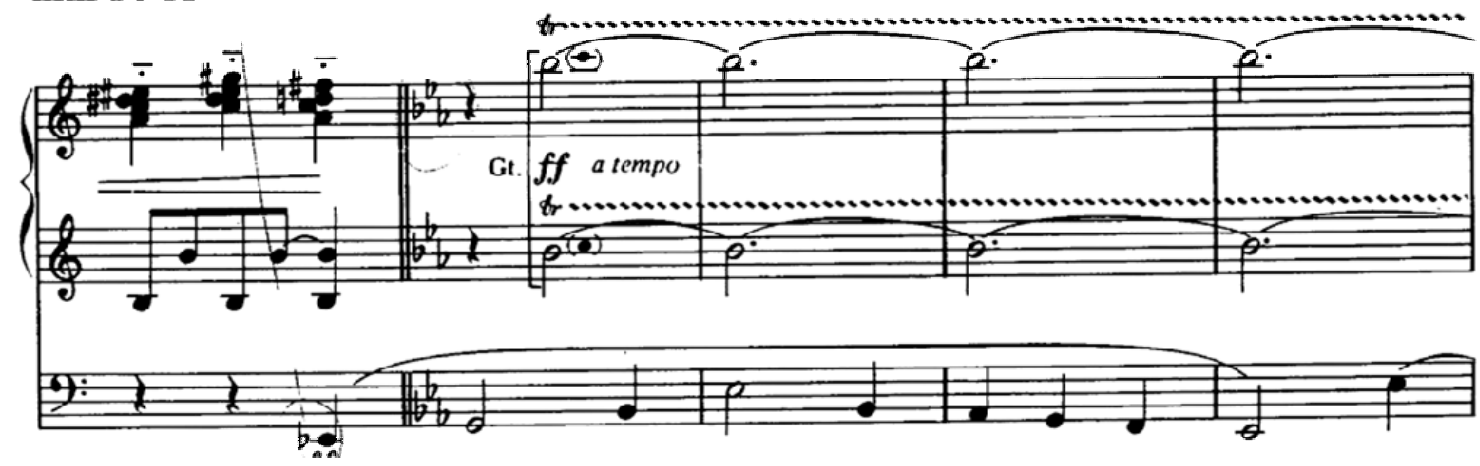

Chorale Cp102 Scherzo on "Joyful, Joyful”

Bradley Publications B23M28

Long Chorale Fantasia

$\mathrm{B}^{b}$ major; 6/8
Collection VIII; (12/14/[14])

Rejoice (1984)

Two Manuals/Pedal

$48 \mathrm{~mm}$

This tune is associated with Samuel Wesley's hymn "Praise the Lord, You Heavens

Adore Him", although it maintains the 87.87 meter of the "Joyful, Joyful" text. The speed of the composition is thus drawn from the ebullient nature of the latter text, making 
the "scherzo" title plausible. The composition is in a toccata-like style that closely resembles Louis Vierne's Scherzo from his Second Symphony for Organ, Opus 20, a work that Fox championed. It is similar in three respects: 1) it is in (6/8) time with rapid triplet-figures in the manuals, 2) the harmonies are infused with augmented and Neapolitan sonorities which do not resolve in the orthodox manner, and 3) the theme is in the pedal, see Ex. 8-38b. The registrations are also similar: high-pitched mutations in the manuals. There is a short interlude at measure 17 and augmented chords at the end of the first phrase on the dominant at measure 18. The second phrase explores whole tone writing (m. 11-12) culminating in a Neapolitan of the V (m.12, beat 2) which escapes (m.12, beat 3 ) to the $\mathrm{V} 7$ of $\mathrm{V}(\mathrm{m} .12$, beat 4$)$ and leads back to the V. While a manual 'pedal' is sustained here, there are a series of parallelisms of fourths, to sixths then sevenths (mm.16-17). This interlude also contains a convolution (joke) of "B-A-C-H", spelled here "C-H, B-A" in measure $17 .{ }^{178}$ The third phrase is intensified through a dominant trill in the manuals (mm. 18-21) and includes a Neapolitan to the subdominant (m. 24, beats 2 to 3). There is also a Neapolitan of the major III (m. 24, beat 4 to m. 25) with the $\mathrm{A}$ in the pedal as an anticipatory tone. ${ }^{179}$ The final phrase finishes a series of three two-bar sequences (mm. 26-27, 28-29, 30-31) with the sequences coming in diminution of three phrases in two measures (mm. 33-34), ending much like Bach's Toccata, Adagio and Fugue in C Major, BWV 564.

\footnotetext{
${ }^{178}$ It is also in the correct key (B): beat 1 alto is $\mathrm{C}$, beat 2 alto is $\mathrm{H}$, beat 3 is $\mathrm{B}$, beat 4 is $\mathrm{A}$.

${ }^{179}$ This also results in a 'common tone' modulation.
} 


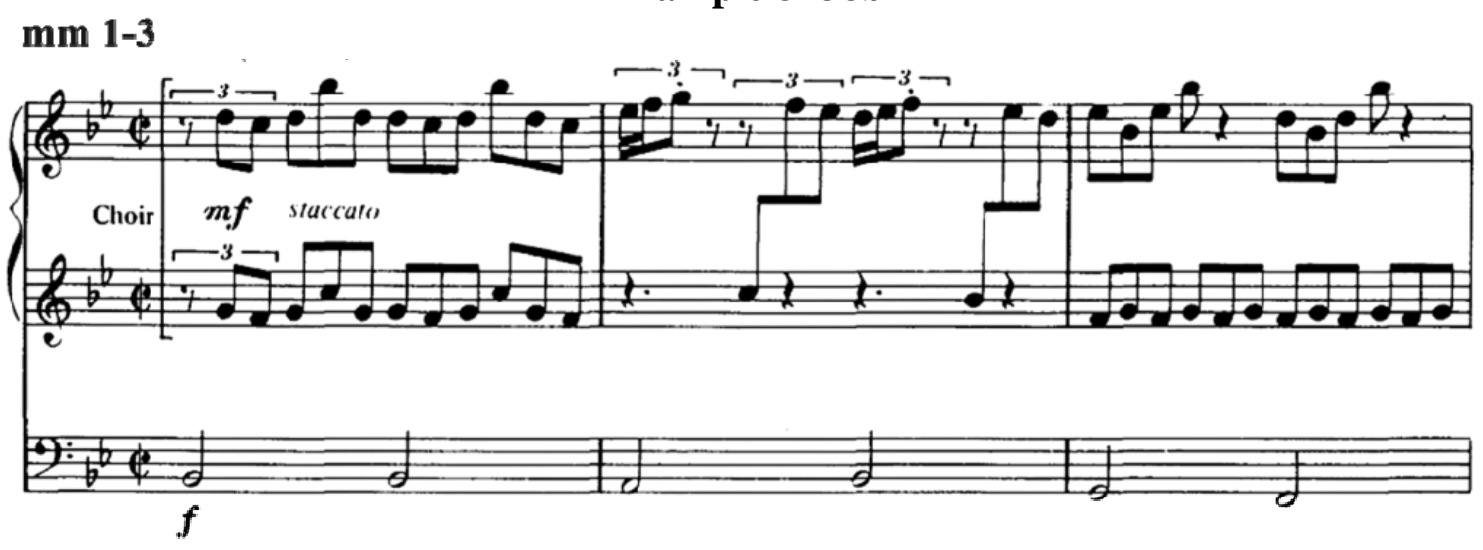

Chorale Cp103 Toccatino con Rico Tino

Bradley Publications B23M28

Long Chorale Fantasia

$\mathrm{G}^{\text {b }}$ to A major; cut time
Collection VIII; (13/14/[14])

Rejoice (1984)

Three manuals/Pedal

$130 \mathrm{~mm}$

This toccata uses Festal Song as its c.f. in the pedal, see Ex. 8-39, sy1. The piece opens with manual figurations in the manner of a French toccata (similar to Vierne's Carillon de Westminster, mid-section, or Joseph Jongen's Symphonie Concertante, Finale): it breaks away from the c.f.. then resumes with the same figuration inverted in the manuals). There is an enharmonic modulation from $\mathrm{G}^{b}$ to A major (mm. 21-25). At the end of verse two the pedal oscillates from "do" to "ti" nine times (Trinity three times equals nine) (mm. 36-45), see Ex. 8-39, sy2. The interlude continues in a modulation back to $\mathrm{G}^{\text {b }}$. The final verse has a canon in augmentation between the manual and pedal (mm. 80-92), see Ex. 8-39, sy3. The extended coda is in three sections, appearing reluctant to end and features groups of 9 and tri-tones, see Ex. 8-39, sy4.

Hermeneutically, this alludes to the title Rise Up, O Men of God, which occurs repeatedly throughout the hymn. Hebble also states that "people enjoyed singing this hymn so much, and it was so short, that they always hated to put the hymnal down afterwards; so 
when I wrote my arrangement I made it go on and on and on". ${ }^{180}$ This is the work that Ethel Smith suggested entitling "Rico Tino". The story is covered in Chapter 7 under Collection VIII.

\begin{tabular}{|c|c|c|c|c|}
\hline Ver & c.f. verse two & interlude & c.f. verse three & codas \\
\hline $\begin{array}{l}\text { Toccata figure } \\
\text { also inverted, c.f. } \\
\text { in pedal in } \mathrm{G}^{b}\end{array}$ & $\begin{array}{l}\text { Toccata figure } \\
\text { Modulates to A } \\
\text { c.f. in pedal/man }\end{array}$ & $\begin{array}{l}\text { Unique "do-ti" } \\
\text { Pedal, \& c.f. } \\
\text { rhythm, toccata }\end{array}$ & $\begin{array}{l}\text { Canon betw. } \\
\text { Manual and } \\
\text { pedal toccata }\end{array}$ & $\begin{array}{l}\text { Block chords } \\
\text { toccata and c.f. } \\
\text { fragments }\end{array}$ \\
\hline mm. $1-20$ & $21-36$ & $37-75$ & $76-99$ & $00-130$ \\
\hline
\end{tabular}

${ }^{180}$ Hebble, Canton tape two, side one. 


\section{Example 8- 39}
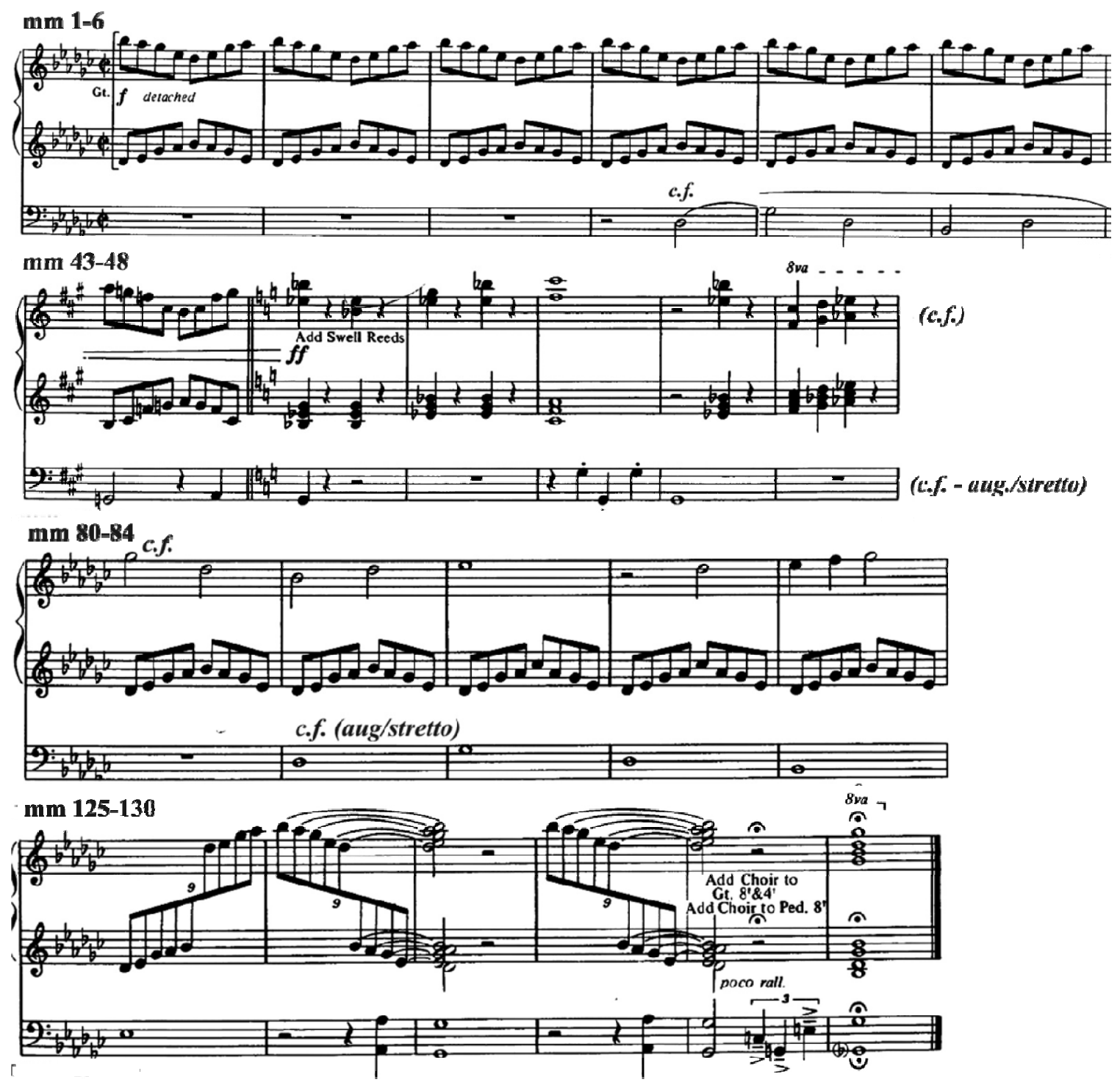
Chorale Cp104 Variations on a Medieval Carol

Bradley Publications B23M28

Chorale Variations

D Major; $3 / 4$ time
Collection VIII; (14/14/[14])

Rejoice (1984)

Three Manuals/Pedal

$103 \mathrm{~mm}$

There are six variations each of which may be played separately as a short form chorale.

The tune is Puer Nobis Nascitur (c.1582). An introduction presents the c.f., and the chorale-free voices accompany with fifths, see Ex. 8-40, sy1. The first variation is for two voices in canon, with some altered harmony (the b 7 th), see Ex. 8-40, sy2. The second variation paraphrases the c.f. rhythmically and intervalically, see Ex. 8-40, sy3, but outlines its general direction. This is improvisation like that of Cochereau, including the registration (mutations), which can often be heard in his recordings. Variation three is quite chromatic in altered harmony; the c.f. is in the soprano, see Ex. 8-40, sy4. Variation four changes the meter and the melody is treated to hocket writing. This is presented over a staccato pedal and has two repetitions of the verse, with the second one more extemporized in style than the first, see Ex. 8-40, sy5. The variation five puts the c.f. at 4' in the pedal with chromaticism and substitute chords in the manuals, see Ex. 8-40, sy6. The final variation is energized some by a dominant pedal, a pervasive quarter-note motif in the left-hand and an ornamented c.f. in hemiola in the soprano on a $f f$ trumpet stop, see Ex. 8-40, sy7. 


\section{Example 8- 40}
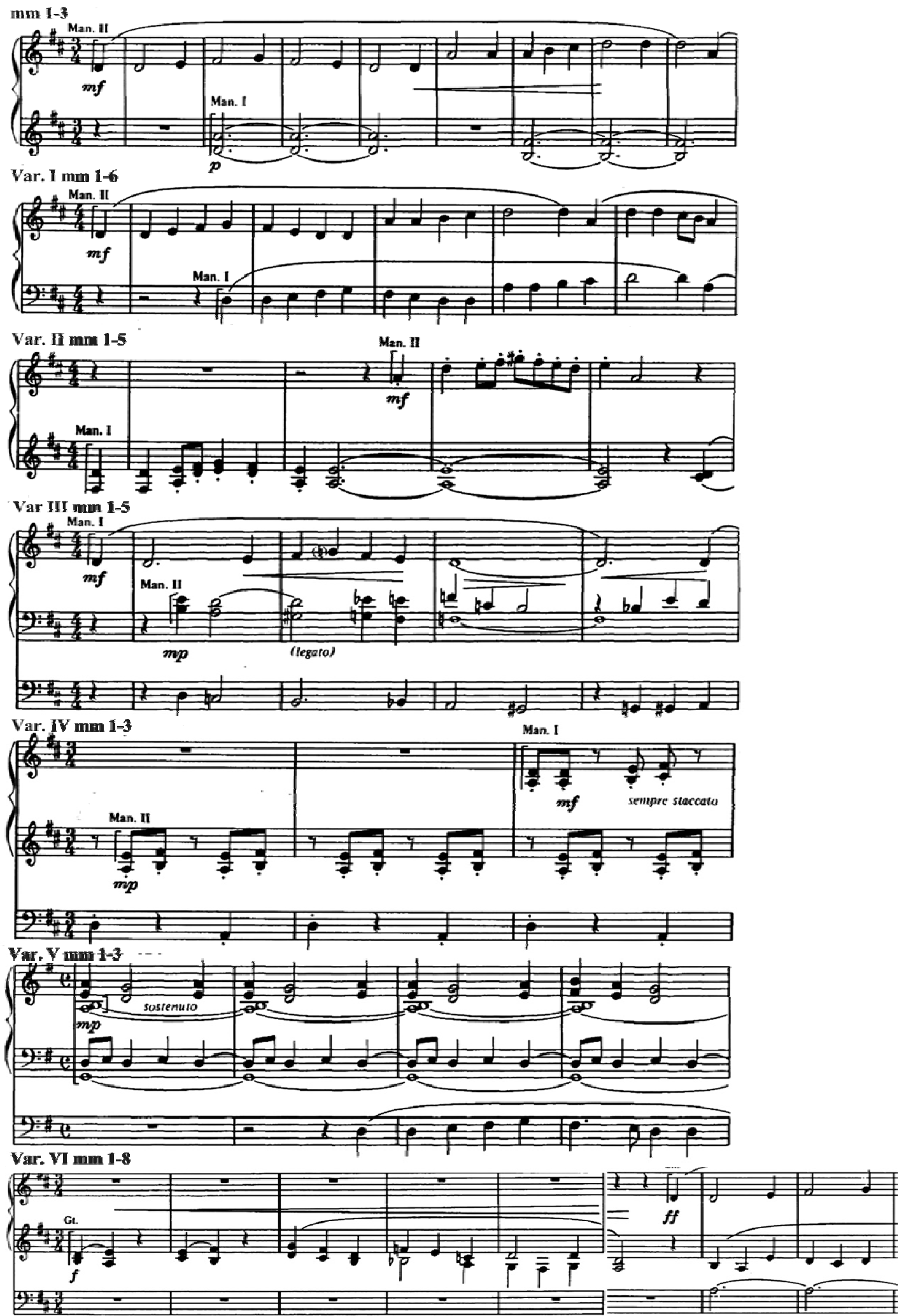
Chorale Cp105 Improvisation on Attende Domine Collection IX; (1/12[12])

Sacred Music Press KK430

For the Masses (1989)

Ritornello Chorale

Three Manuals/Pedal

C major; $9 / 8$ time

$36 \mathrm{~mm}$

This improvisation follows an ABA form and uses only paraphrases the melismatic chant c.f., see Ex. 8-41, sy1 and 3. There is an introduction and coda framing the ABA.

Originally a responsory in which a refrain is repeated, thus ABA, Section A quotes the refrain as the c.f.. The B Section contains fragments of the c.f. drawn from the versicle and is instead a development of the introduction and coda in remote keys, see Ex. 8-41, sy2. The repetition of material from the introduction and coda in the middle section give this composition the characteristics of a Ritornello Chorale.

Introduction A B A Coda

\begin{tabular}{|l|l|l|l|l|}
\hline $\begin{array}{l}\text { Quasi-ritornello, } \\
\text { added } 6^{\text {th }}, 9^{\text {th }} \\
\text { rhythmically } \\
\text { outlines c.f. }\end{array}$ & $\begin{array}{l}\text { Opening 'refrain' } \\
\text { of Attende c.f. } 9^{\text {th }} \\
\text { chords and } \\
\text { parallelisms. }\end{array}$ & $\begin{array}{l}\text { Quasi-ritornello, } \\
\text { 'versicle' } \\
\text { developed, } \\
\text { altered harmony }\end{array}$ & $\begin{array}{l}\text { Opening phrase } \\
\text { of c.f. returns in } \\
\text { tenor }\end{array}$ & $\begin{array}{l}\text { Quasi-ritornello, } \\
\text { added } 6^{\text {th }}, 9^{\text {th }} \\
\text { imitation in pedal } \\
\text { of c.f. fragments }\end{array}$ \\
\hline mm. 1-8 & $12-16$ & $16-25$ & $26-31$ & $32-36$
\end{tabular}




\section{Example 8- 41}
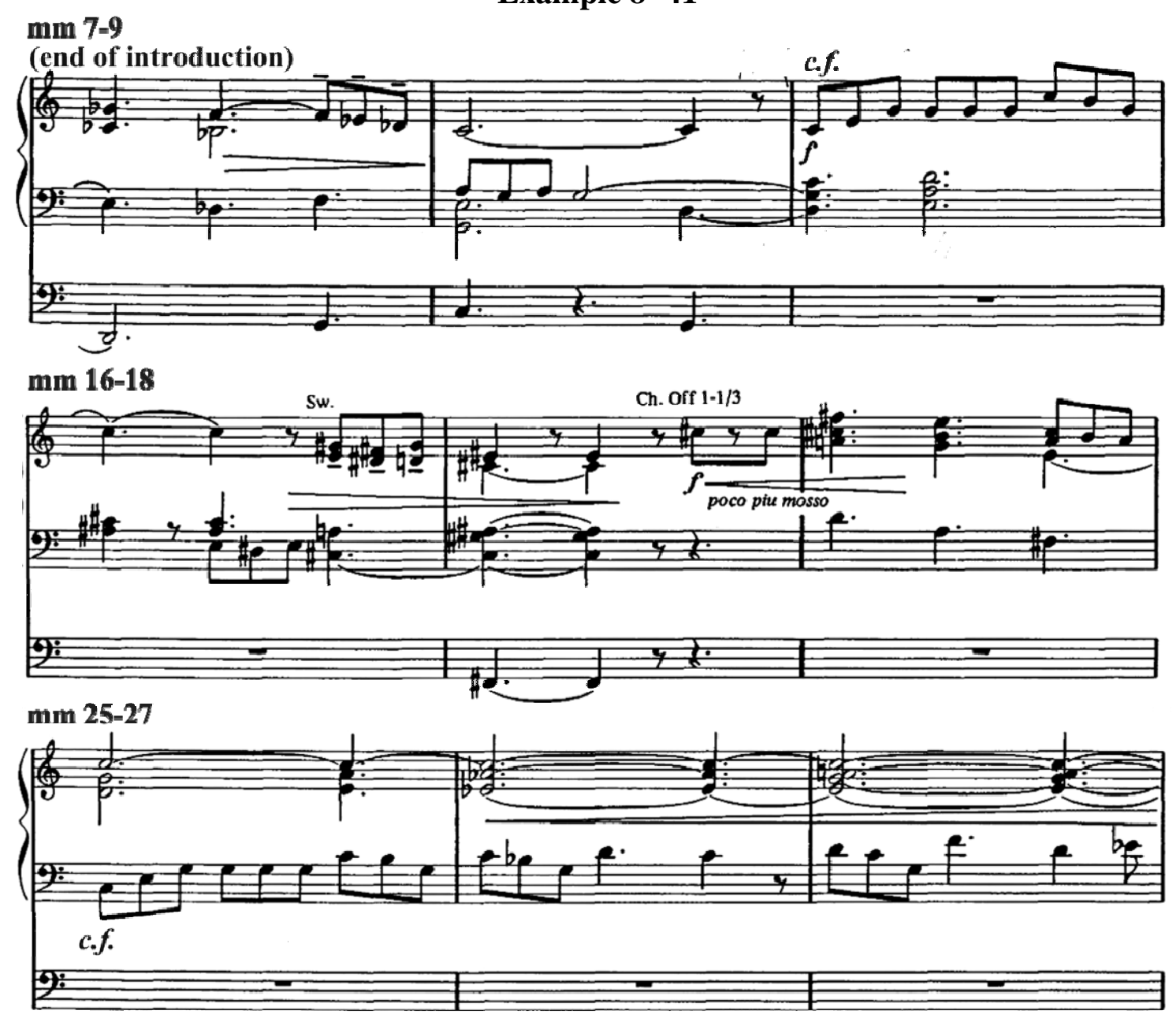

Chorale Cp106 At the Cross Her Station Keeping Collection IX; (2/12/[12])

Sacred Music Press KK430

For the Masses (1989)

Short Chorale Motet

Three manuals/Pedal

$A^{b}$ major; 2/4 time

$36 \mathrm{~mm}$

This is like Brahms' treatment of the chorale "O World I Now Must Leave Thee" for

organ. Hebble's treatment is homophonic and hymn-like (strophic) with the c.f. in the

soprano, see Ex. 8-42. It is a chorale motet in reverse: instead of 'fore-imitation' (motifs

occurring before the entrance of the c.f. that intervalically anticipate it), this chorale has

'post-imitation' (motifs occurring after the c.f. that intervalically echo it). Thus, after 
each strophe is a small, two-phrase interlude of four measures, each phrase of which echoes the last three notes of the c.f., see Ex. 8-42. The last interlude extends into the coda. This 'post-imitation' structure makes the chorale an exception to the long form. Hermeneutically, Hebble makes ample use of Tristan harmony, which is used metaphorically (mm. 5, 10, 26 and 35). The first strophe begins in the relative minor and uses passing dissonances to depict the stresses of Mary, Mother of Jesus. The Tristan harmony implies that tension remains unresolved (m. 10) ${ }^{181}$. The Neapolitan harmony lends weight to the associated text "weeping" (m. 15) and its shocking arrival conveys the grief in the text. There is a deceptive cadence on an E major-seventh ${ }^{182}$ (m. 20) at the end of the phrase "close to Jesus to the last", which alludes to Mary's endurance until the end, the resolution of which is far away (m. 31/36). This lack of resolution is further alluded to by the injection of an interlude (mm. 21-26) before the coda where there is a complete departure from the tonic to parallel seventh chords in F\# minor. Hebble has the organ crescendo to 'reeds', punctuating the stress, before a manual descresendo. The coda is a repeat of the last strophe of c.f. with unstable harmony (mm. 27-34), but concluding with a firm cadence (m. 31). A non-dominant treatment of the resolution (m. 35-36), where Hebble replaces $V$ with a $G^{b} 9^{\text {th }}$ chord, resolves to the $A^{b}$ key signature.

\begin{tabular}{|c|c|c|c|c|c|c|}
\hline C.F. $\mathbf{s t}$ & & Iopn & entile & stroph & interlude & coda \\
\hline $\begin{array}{l}\text { Homo- } \\
\text { Phonic, c.f. } \\
\text { in soprano, } \\
\text { begins in } \\
\text { minor }\end{array}$ & $\begin{array}{l}\text { Two small } \\
\text { phrases, c.f. } \\
\text { last } 3 \text { notes } \\
\text { Tristan } \\
\text { chord }\end{array}$ & $\begin{array}{l}\text { Homo- } \\
\text { Phonic, c.f. } \\
\text { in soprano, } \\
\text { Tristan } \\
\text { harmonies }\end{array}$ & \begin{tabular}{|l|} 
Two small \\
phrases, c.f. \\
last 3 notes \\
Neapolitan \\
chord
\end{tabular} & $\begin{array}{l}\text { Homo- } \\
\text { Phonic, c.f. } \\
\text { in soprano, } \\
\text { much } \\
\text { chromatics }\end{array}$ & $\begin{array}{l}\text { Departure } \\
\text { from tonic, } \\
\text { augmented } \\
\text { dom. pedal, } \\
\text { Tristan }\end{array}$ & $\begin{array}{l}\text { Sigh } \\
\text { motifs, } \\
\text { chromatics, } \\
\text { Tristan } \\
\text { ending }\end{array}$ \\
\hline mm. 1-4 & 5-8 & $12-12$ & 13-16 & $17-20$ & $21-26$ & $7-36$ \\
\hline
\end{tabular}

\footnotetext{
${ }^{181}$ Here, the Tristan chord is the actual Wagnerian chord: F, B, E- ${ }^{b}(\mathrm{D} \#)$ and $\mathrm{A}^{\mathrm{b}}(\mathrm{G} \#)$.

${ }^{182}$ The G-\# is enharmonic to the $A^{b}$ key, but moves back to $A^{b}$.
} 


\section{Example 8- 42}

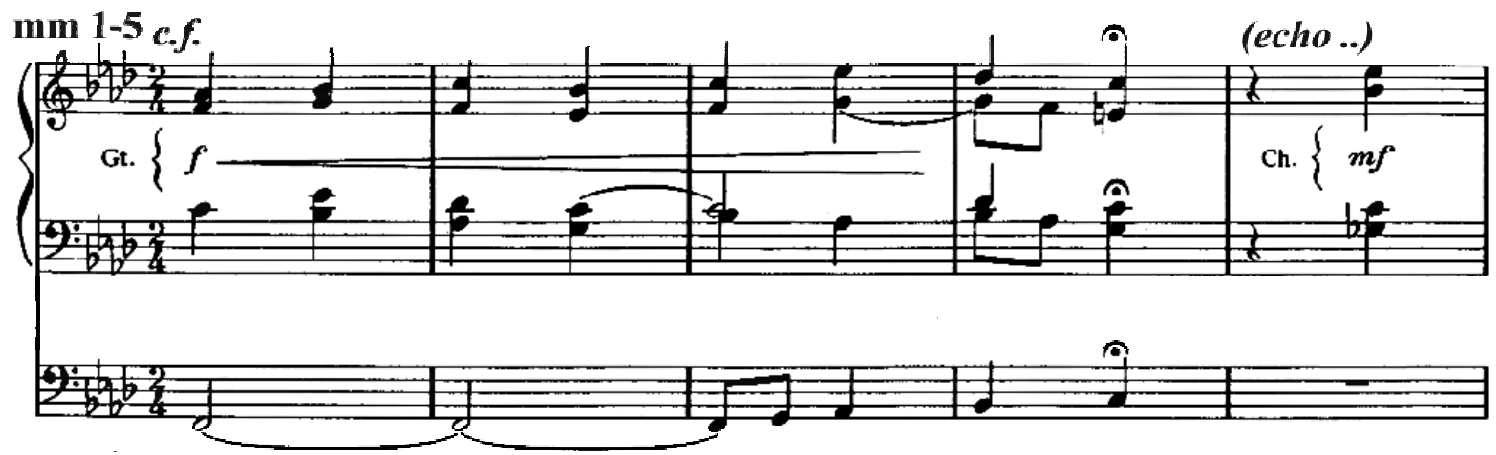

Chorale Cp107 Cleanse Me from Sin, O Lord Sacred Music Press KK430

Short Chorale Fantasia

F\# Minor; common time
Collection IX; (3/12/[12])

For the Masses (1989)

One manual/Pedal

$23 \mathrm{~mm}$

This work contains multiple repetitions of the first six notes of the $c . f$. and is improvisatory. It resembles the Benoit Elevations for organ. The form may also be seen as $\mathrm{ABA}$ because of a central section of harmonic and melodic departure. In section $\mathrm{B}$ are various imitations of the original melodic cell, ranging from different brief key areas (mm. 11-12) to parallelism (mm. 9 and 17) to embellishment (mm.13-14). The constant repetition of only the single phrase of c.f., similar to the talea of isorythmic Mass technique, the lack of any development coupled with its almost harsh dissonances lead to an exploration of the original Latin text: Asperges Me: "cleanse me, purify me". The entire work pleads on behalf of the congregant repetitively (litany) for God's purification and "cleansing." 183 The composition explores this pleading motif derived from the c.f., see Ex. 8-43. The following chart graphs these fragments of c.f. permutations.

\footnotetext{
${ }^{183}$ Florida tape two, side one.
} 


\begin{tabular}{|c|c|c|}
\hline A & $A$ & \\
\hline \begin{tabular}{lllll} 
Sop - c.f. & c.f. & \multicolumn{1}{c}{ c.f. } & & \\
Alto & & c.f. & & \\
Tenor & & & c.f. & c.f. \\
Bass & & & & \\
\end{tabular} & 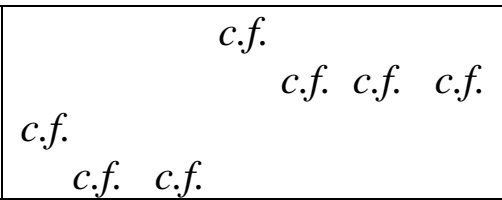 & \begin{tabular}{|ll} 
c.f. & \\
& c.f.
\end{tabular} \\
\hline $\begin{array}{lcccccc}\mathrm{Mm} & 1 & 3 & 4 & 5 & 7 & 8 \\
\text { F\#minor (i) } & & & & \end{array}$ & 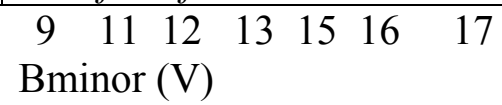 & $\begin{array}{ll}18 & 19 \\
\text { F\#minor (i) }\end{array}$ \\
\hline
\end{tabular}

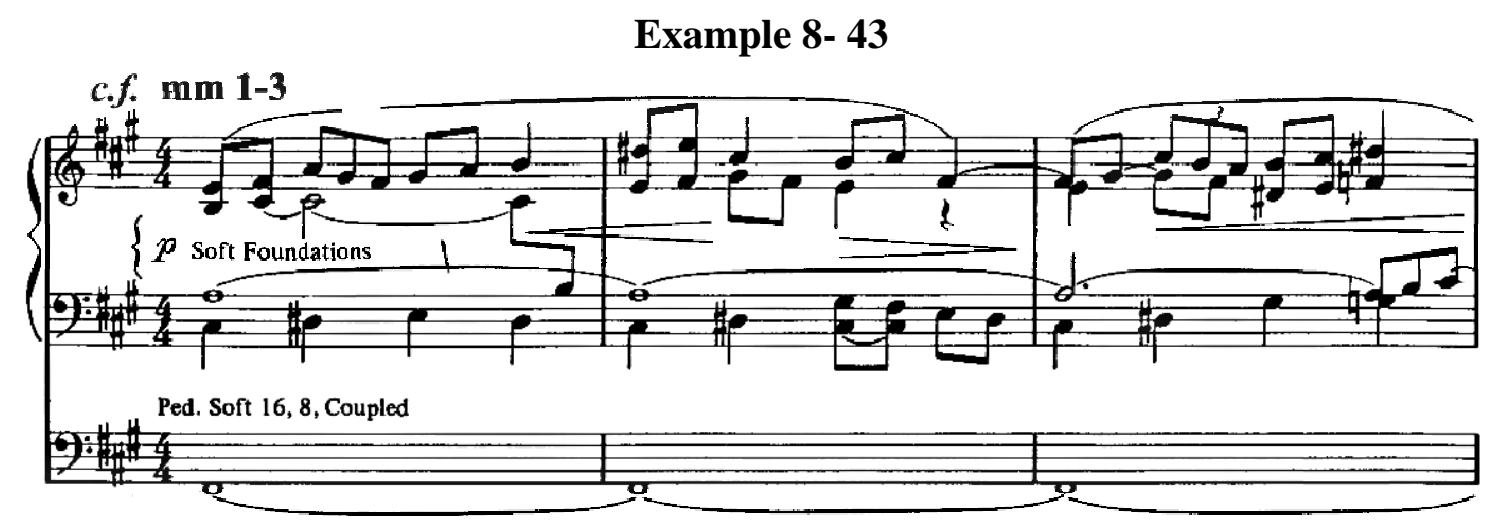

Chorale Cp108 Come, Holy Ghost

Sacred Music Press KK430

Ritornello Chorale

F major to G major; $3 / 4$ time
Collection IX; (4/12/[12])

For the Masses (1989)

Two manuals/Pedal

$60 \mathrm{~mm}$

This exuberant composition is a combination of a toccata within a ritornello with a modulation in the middle of this longer form treatment. The nine measure introduction establishes the motif for both the toccata figuration of the left-hand and the rising motif (mm. 2-4) which then descends (m. 5) in the right-hand alluding to the ascension of Christ and the descent of the 'dove' or the Holy Ghost, see Ex. 8-44, syland 2. The staccato pedal is repeated in patterns of three, which represents Trinity, and contains the first three notes of the c.f., see Ex. 8-44, sy1and 2. The static movement of the bass establishes a dominant pedal from which the c.f. takes flight (m.10). The c.f. is played on the solo fff trumpet while the toccata figuration is on "full organ" (mm. 10-17), see 
Ex. 8-43, sy1 and 2. The interludes maintain the toccata figuration while the same strophe of the c.f. is repeated in augmentation in the soprano concurrent with a motif 'descent of the Holy Spirit' in the pedal (mm. 18-28). These elements are used to propel the modulation to G major (m. 29). After a short 're-introduction' (mm. 29-32), the c.f. reappears in the pedal while an augmented version of fragments of the original Latin chant Veni Creator Spiritus is paraphrased in the soprano (mm. 33-48), see Ex. 8-44, sy3 and 4. Another "descent of the Holy Spirit" motif (mm. 41-43) is portrayed in the soprano by three measures of descending quarter-notes, which outline a ninth symbolizing the "Trinity times three". The Coda begins in hemiola. The work concludes with the introductory material and the dominant pedal, adds altered harmony and ninth chords (m. 59), and avoids the dominant-seventh chord.

Introduction
\begin{tabular}{|l|l|l|l|l|l|}
\hline $\begin{array}{l}\text { c.f. } \\
\begin{array}{l}\text { Dominant } \\
\text { pedal, kernels } \\
\text { toccata figure }\end{array}\end{array}$ & $\begin{array}{l}\text { In soprano, F } \\
\text { major }\end{array}$ & $\begin{array}{l}\text { Toccata } \\
\text { figure, } \boldsymbol{c . f .} \\
\text { augmented }\end{array}$ & $\begin{array}{l}\text { Toccata } \\
\text { kernels G } \\
\text { major }\end{array}$ & $\begin{array}{l}\text { c.f. in pedal, } \\
\text { veni creator } \\
\text { in soprano }\end{array}$ & $\begin{array}{l}\text { Introductory } \\
\text { material, } \\
\text { hemiola }\end{array}$ \\
\hline mm. 1-9 & $10-17$ & $18-28$ & $29-32$ & $33-48$ & $49-60$ \\
\hline
\end{tabular}



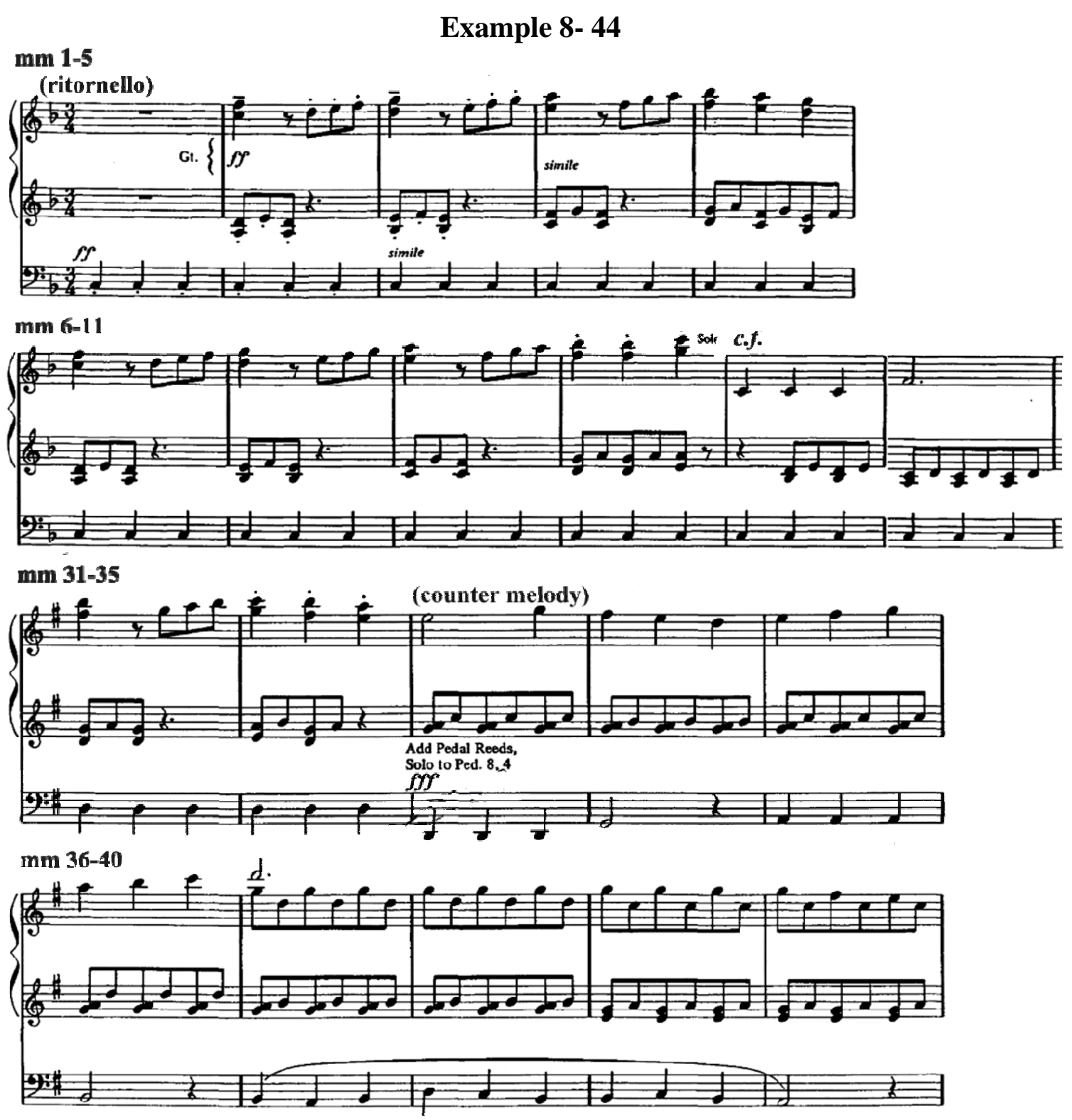

Chorale Cp109 Dear Maker of the Starry Skies

Sacred Music Press KK430

Long Chorale Fantasia

D major; $4 / 4$ time
Collection IX; (5/12/[12])

For the Masses (1989)

Three manuals/Pedal

$50 \mathrm{~mm}$

This work resembles ABA because of the key change in section B and apparent

'development' of the c.f.. The c.f. chant, Conditor Alme Siderum, is not completely

quoted, but paraphrased. Basically, the first strophe of the tune is freely improvised, with 
occasional insertions of the second strophe (mm. 14-17). The motivic outline of the first seven notes of the c.f. is embellished intervalically and chromatically throughout the composition, see Ex. 8-45, sy1. Seven is the number of perfection. Modally tinged harmonies are present, see Ex. 8-44, sy2. Pedal points are employed, including the mediant (mm. 21-22). Secondary-dominance (mm. 34-37) as well as the Tristan harmony (m. 35) occur as metaphors regarding the "endlessness of the stars" and nonresolution. There are also thirteenth and ninth chords $(\mathrm{mm} .8-9)$ as well as altered chords throughout. Associated with the words "everlasting light", Hebble creates a sequence from the c.f. (mm.14-17) concurrent with a descending chromatic scale in the pedal alluding, once again, to a sense of "endlessness". ${ }^{184}$

A $\quad$ B $\quad A^{\prime}$

Opening 5ths, c.f. fragment in $\quad$ D minor, scales in $\mathrm{B}^{\mathrm{b}}$ Lydian; soprano; D major; tonic pedal; bi-tonality, whole-tone scale, altered chords, chromatic sequence, repeats of opening motiv of c.f. seven notes mm. 1-21 ostinato in 1.h., secondary dominance
$\mathrm{A}^{\prime}$ D major; dominant pedal, altered chords, Phrygian mode, syncopation, c.f. fragment in the pedal. seven notes

${ }^{184}$ Hebble, phone conversation July 7, 2002. 
Example 8- 45
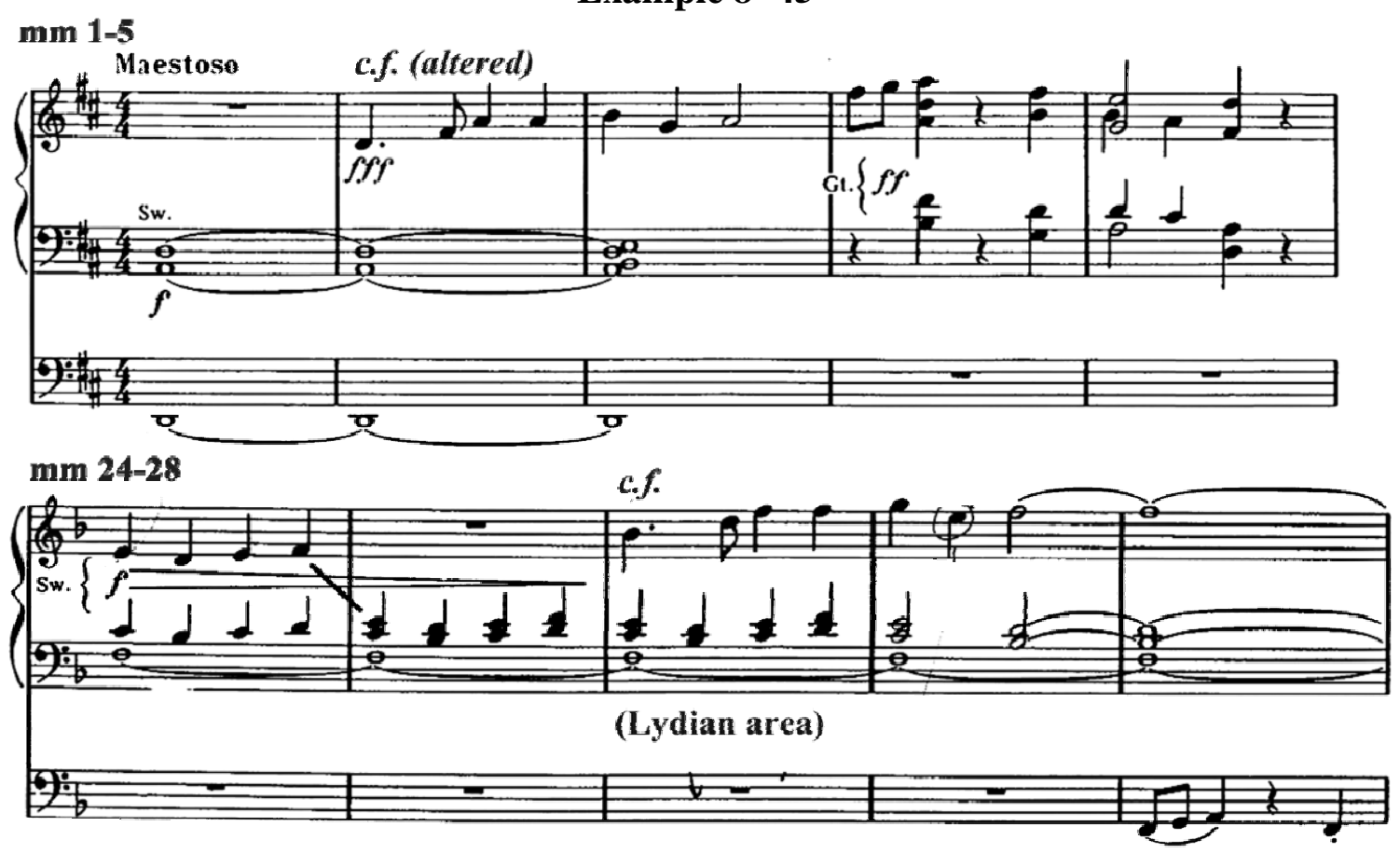

Chorale Cp110 Hail, Holy Queen Enthroned Above Collection IX; (6/12/[12])

Sacred Music Press KK430

For the Masses (1989)

Long Melody Chorale

$\mathrm{B}^{\mathrm{b}}$ major; $4 / 4$ time

Three manuals/Pedal

$31 \mathrm{~mm}$

While the treatment of the c.f. is hymn-like/strophic, Hebble makes leaping manual changes, and composes in an improvisational style in the echo passages, see Ex. 8-46.

For example, halfway through the first strophe (m. 3) there is a manual change from loud to soft and then another (m. 5) to an even softer echo division on the last two notes of the c.f.. The same occurs with the second strophe, but the third, fourth and fifth strophes are presented without echoes. Before the sixth strophe, Hebble inserts an interlude (mm. 1719) which depicts the associated text "heaven and earth resound the hymn". Hebble returns to the c.f. and repeats the procedure of inserting an improvisation after the final 
strophe associated with its text "salve regina". The coda repeats the final phrase of the c.f. and crescendos to full-organ with increased harmonic abandon (mm. 28-31).

\begin{tabular}{|c|c|c|c|c|c|c|c|}
\hline c.f. str. 1 & str. 2 & str. 3 & str. 4 & str. 5 & interlude & str. 6 & oda \\
\hline $\begin{array}{l}\text { Homoph, } \\
\text { two echo } \\
\text { manual } \\
\text { changes }\end{array}$ & $\begin{array}{l}\text { Homoph, } \\
\text { two echo } \\
\text { manual } \\
\text { changes }\end{array}$ & $\begin{array}{l}\text { Homoph, } \\
\text { Running } \\
\text { counterpt, } \\
\text { pedal }\end{array}$ & $\begin{array}{l}\text { Homoph, } \\
\text { chromatic } \\
\text { altered } \\
\text { harmony }\end{array}$ & $\begin{array}{l}\text { Homoph, } \\
\text { altered } \\
\text { harmony }\end{array}$ & $\begin{array}{l}\text { Interprets, } \\
\text { improvi- } \\
\text { sation }\end{array}$ & $\begin{array}{l}\text { Homoph, } \\
\text { c.f. in } \\
\text { soprano }\end{array}$ & $\begin{array}{l}\text { Improvi- } \\
\text { sation, } \\
\text { altered } \\
\text { harmony }\end{array}$ \\
\hline mm. 1-5 & $6-10$ & $1-12$ & -14 & $5-16$ & $7-19$ & $0-23$ & -31 \\
\hline
\end{tabular}

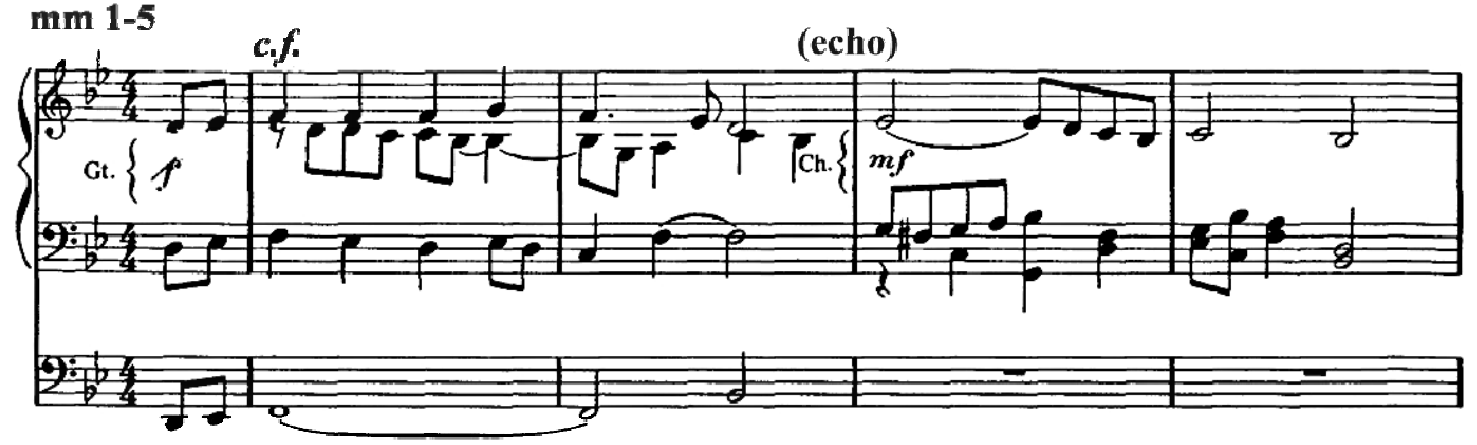

Chorale Cp111 Immaculate Mary

Sacred Music Press KK430

Chorale Motet

$\mathrm{C}$ major to $\mathrm{F}$ major; $3 / 4$ time
Collection IX; (7/12/[12])

For the Masses (1989)

Three Manuals/Pedal

$51 \mathrm{~mm}$

The introduction incorporates the last phrase of the $c . f$. with imitative entrances of the opening motif (mm. 3-5) in C, see Ex. 8-47, sy1. A tonic pedal in the manuals brings in the solo c.f. in the soprano on the first two strophes, see Ex. 8-47, sy2. The refrain of the c.f. has a tonic pedal on strophe three and part of strophe four to the interlude. The tonic becomes the dominant for the new key: F major (m. 32). The second verse is treated with altered harmony and the refrain (mm. 41-47) contains an offbeat ostinato on the dominant. Fragments of the c.f. make up the brief coda (mm. 47-51). 


\begin{tabular}{l|l|l|l|c|}
\multicolumn{1}{l}{ Introduction } & \multicolumn{1}{c}{ c.f. verse 1 } & \multicolumn{1}{l}{ interlude } & \multicolumn{1}{c}{ c.f. verse 2 } & coda \\
\hline $\begin{array}{l}\text { Imitation on } \\
\text { opening motif. }\end{array}$ & $\begin{array}{l}\text { Solo } \text { c.f. with } \\
\text { accompaniment }\end{array}$ & $\begin{array}{l}\text { Altered harmony } \\
\text { modulation to F }\end{array}$ & $\begin{array}{l}\text { Homophonic, } \\
\text { altered harmony }\end{array}$ & c.f. fragments d \\
\hline mm. 1-11 & $12-27$ & $28-32$ & $33-48$ & $48-51$ \\
\hline
\end{tabular}

\section{mm 1-6}

Example 8- 47
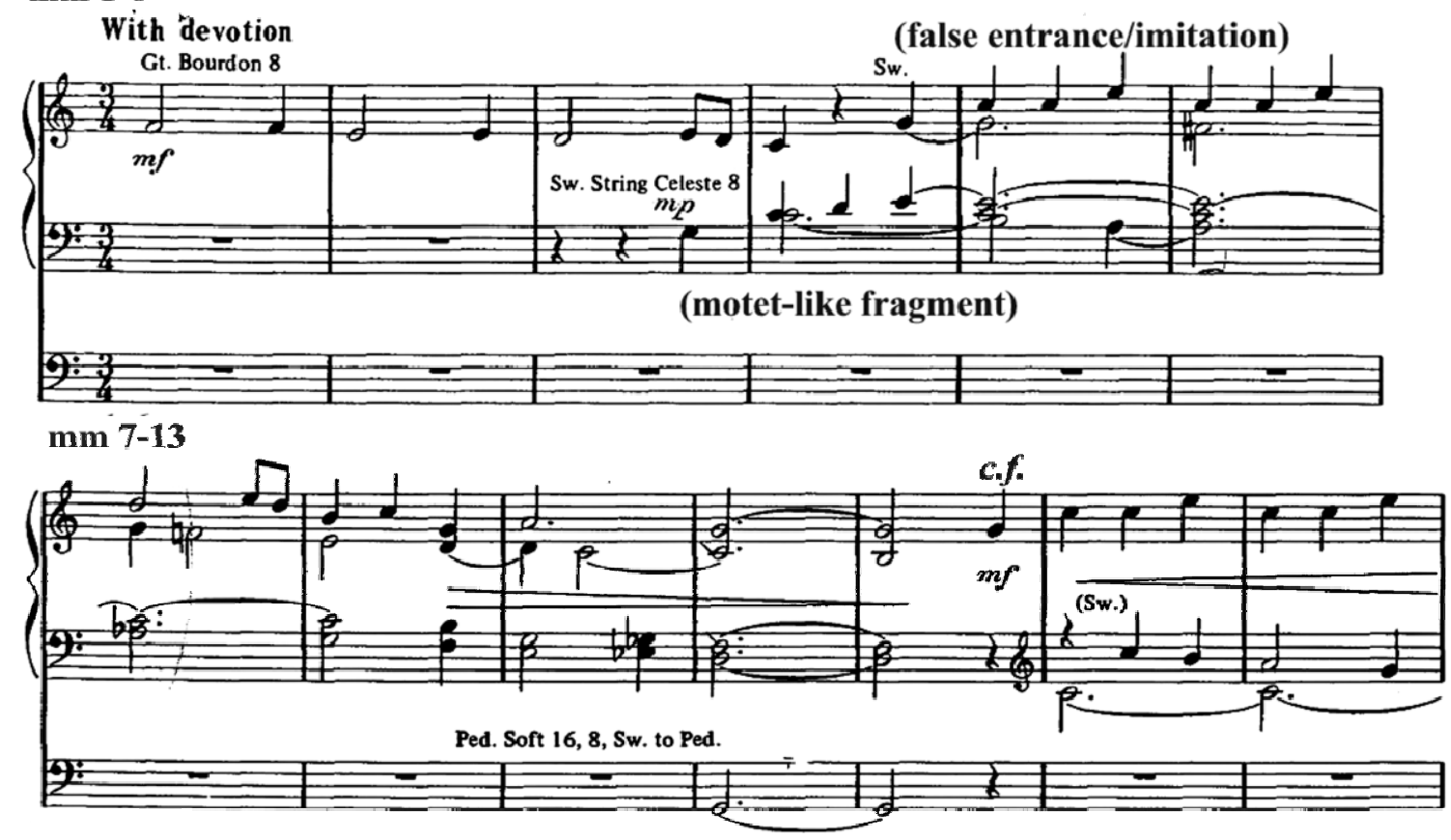

Chorale Cp112a O Saving Victim, Open Wide

Sacred Music Press KK430

Short Trio Chorale

$\mathrm{E}^{\mathrm{b}}$ major; $6 / 8$ time
Collection IX; (8a/12/[12])

For the Masses (1989)

Three manuals/Pedal

$38 \mathrm{~mm}$

With only a flute 8 as the tonic pedal, his manual registration directs the player to draw

two contrasting flute combinations ( 8 and $1-1 / 3^{185}$ versus 8 and 2 ) in imitation of the

French Classic ${ }^{186}$ style of registration. The $c . f$. appears in the right-hand and is

rhythmically altered. The left-hand imitates the c.f. at the fifth in an altered harmony to

${ }^{185}$ Called Larigot in French. It plays a gentle fifth over the tonic two octaves higher.

${ }^{186}$ A school of organ composition in Paris in the early eighteenth century. 
the right-hand and in incomplete statements, see Ex. 8-48. The left-hand dramatizes the melodic gestures of the c.f. in a rhetorical dialogue reminiscent of French Classicism in organ music (mm. 14-20). The coda provides a moment of contrast with a new texture from the Swell division: second-inversion chords (mm. 28-32) and a small pedal cadenza (mm. 34-36).

\begin{tabular}{|l|l|l|}
\hline c.f. treatment & improvisational interlude & \multicolumn{1}{c}{ coda } \\
\hline $\begin{array}{l}\text { Duet between contrasting } \\
\text { flutes, canon at the fifth, } \\
\text { irregular (French Classic) }\end{array}$ & $\begin{array}{l}\text { Duet takes on a rhetorical } \\
\text { gesture of dramatic dialogue } \\
\text { (French Romantic Scherzo) }\end{array}$ & $\begin{array}{l}\text { Manual changes, imitation, } \\
\text { small pedal cadenza, altered } \\
\text { harmony }\end{array}$ \\
\hline mm. 1-12 & $13-27$ & $28-38$
\end{tabular}

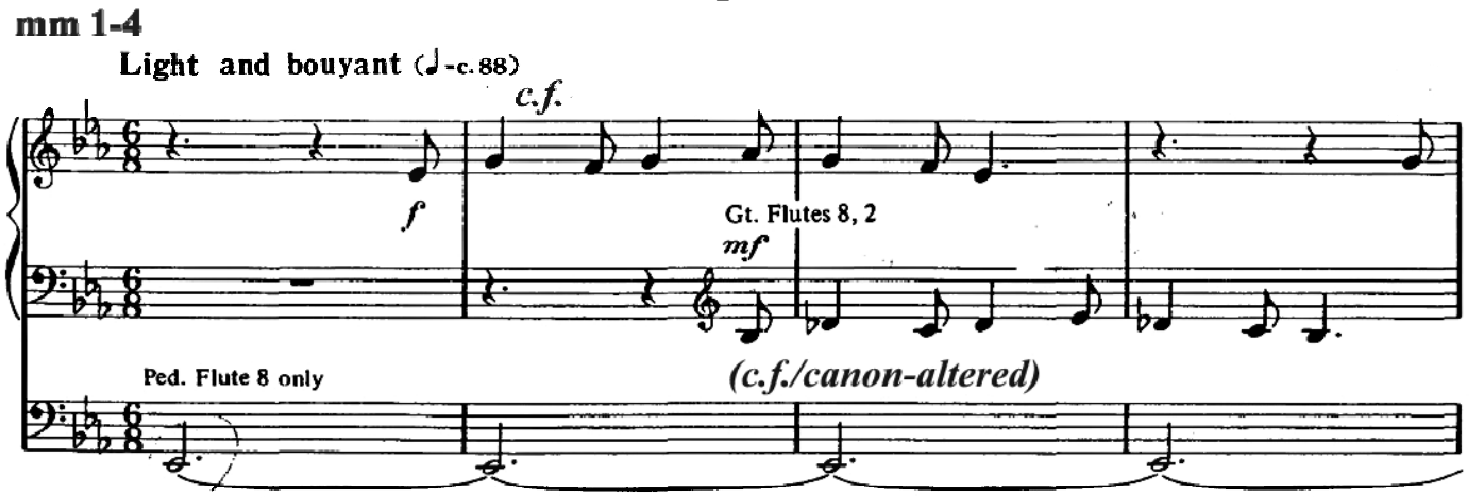

Chorale Cp112b O Saving Victim, Open Wide

Sacred Music Press KK430

Chorale Motet

$\mathrm{E}^{\mathrm{b}}$ major; $3 / 4$ time
Collection IV $(8 \mathrm{~b} / 12 /[12])$

For the Masses (1989)

Two manuals/Pedal

$46 \mathrm{~mm}$

To the tune written by Anthony Werner, Hebble composes a chorale motet in reverse:

the 'fore-imitation' comes after each strophe rather than before, see Ex. 8-49. The c.f. is presented on a flute 8 (with tremolo in 8va range) then repeated in fragments as an echo on a warmer registration of strings, flutes and vox humana. Each successive strophe is treated this way with the final strophe repeated and extended into a larger interlude ( $\mathrm{mm}$. 
25-32). There is no introduction, but there is a coda (mm. 33-47). In the latter the pedal plays a final fragment of the $c . f$. in augmentation.

\begin{tabular}{|c|c|c|c|c|}
\hline Strophe one & strophe two & strophe three & strophe four & coda \\
\hline $\begin{array}{l}\text { c.f. in soprano, } \\
\text { homophonic, } \\
\text { imitative } \\
\text { interlude }\end{array}$ & $\begin{array}{l}\text { c.f. in soprano, } \\
\text { homophonic, } \\
\text { imitative } \\
\text { interlude }\end{array}$ & $\begin{array}{l}\text { c.f. in soprano, } \\
\text { homophonic, } \\
\text { imitative } \\
\text { interlude }\end{array}$ & $\begin{array}{l}\text { c.f. in soprano, } \\
\text { homophonic, } \\
\text { imitative larger } \\
\text { interlude }\end{array}$ & $\begin{array}{l}\text { Fragments of } c . f . \text {, } \\
\text { augmentation of } \\
\text { c.f. in the pedal }\end{array}$ \\
\hline mm. 1-7 & $8-14$ & $15-21$ & $22-32$ & $33-47$ \\
\hline
\end{tabular}
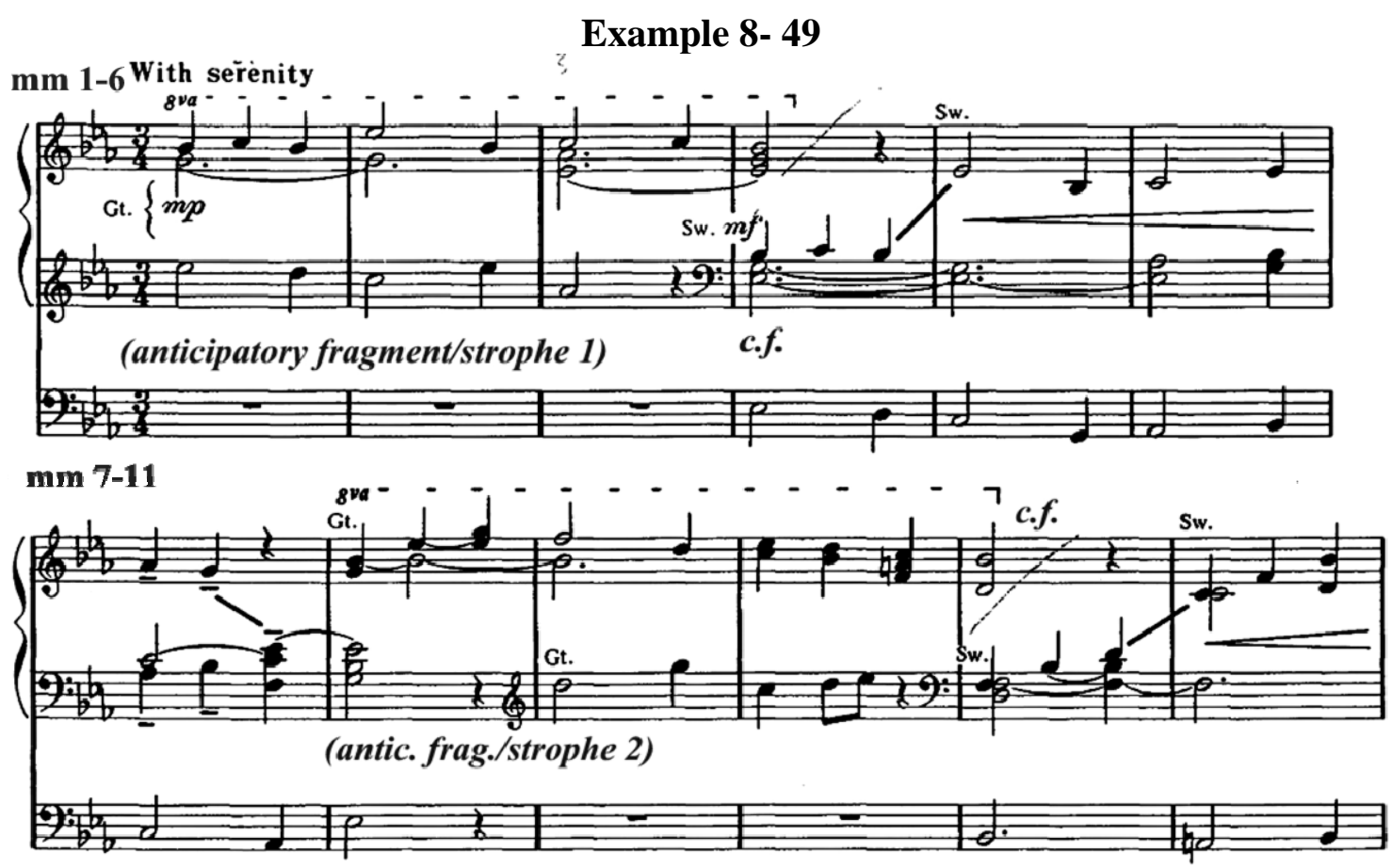

Chorale Cp113 Sing of Mary

Sacred Music Press KK430

Chorale Variations

F major; common time
Collection (9/12[12])

For the Masses (1989)

Three manuals/Pedal

$57 \mathrm{~mm}$

This composition is a series of three continuous variations. After a two bar introduction exposing an accompaniment mostly unrelated to the c.f., see Ex. 8-50, variation one (mm.

3-18) treats the c.f. as a short melody chorale while planing parallel sixths accompany 
over a tonic pedal. There is altered harmony on the last strophe. Without interlude, the second variation (mm. 19-34) is in the relative minor with the c.f. in the soprano for the first and third strophe (m. 19 and 27) and in the tenor for the second and fourth strophe (m. 23 and 31) in a hocket-like style. Variation three $(\mathrm{mm} .35-53)$ treats the c.f. as a short chorale prelude with a syncopated accompaniment in the chorale-free voices. Before the conclusion of the third variation, Hebble inserts a brief interlude (mm. 47-49, which adorns a fragment of the c.f. at the beginning of the last strophe) then resumes with the remaining c.f. of the final strophe. The coda incorporates one rhythmically diminished fragment of c.f. (m. 54) and then an augmented fragment (mm. 55-56).

\begin{tabular}{|l|l|l|l|l|l|}
\multicolumn{1}{l}{ Introduction } & \multicolumn{1}{l}{ var. one } & \multicolumn{1}{l}{ var. two } & \multicolumn{1}{l}{ var. three } & \multicolumn{1}{l}{ interlude } & \multicolumn{1}{c|}{ coda } \\
\hline $\begin{array}{l}\text { Short, } \\
\text { oscillating } \\
\text { parallel 6ths }\end{array}$ & $\begin{array}{l}\text { c.f. in soprano } \\
\text { over 6ths, } \\
\text { pastorale }\end{array}$ & $\begin{array}{l}\text { C.f. in soprano } \\
\text { in relative } \\
\text { minor key }\end{array}$ & $\begin{array}{l}\text { c.f. in soprano } \\
\text { syncopated } \\
\text { accompanimt }\end{array}$ & $\begin{array}{l}\text { Extemporized } \\
\text { c.f., altered } \\
\text { harmonies }\end{array}$ & $\begin{array}{l}\text { Fragments of } \\
\text { c.f., } \\
\text { augmentation }\end{array}$ \\
\hline mm. 1-2 & $3-18$ & $112-34$ & $35-53$ & $47-49$ & $54-57$
\end{tabular}

\section{mm 1-5}

Example 8- 50

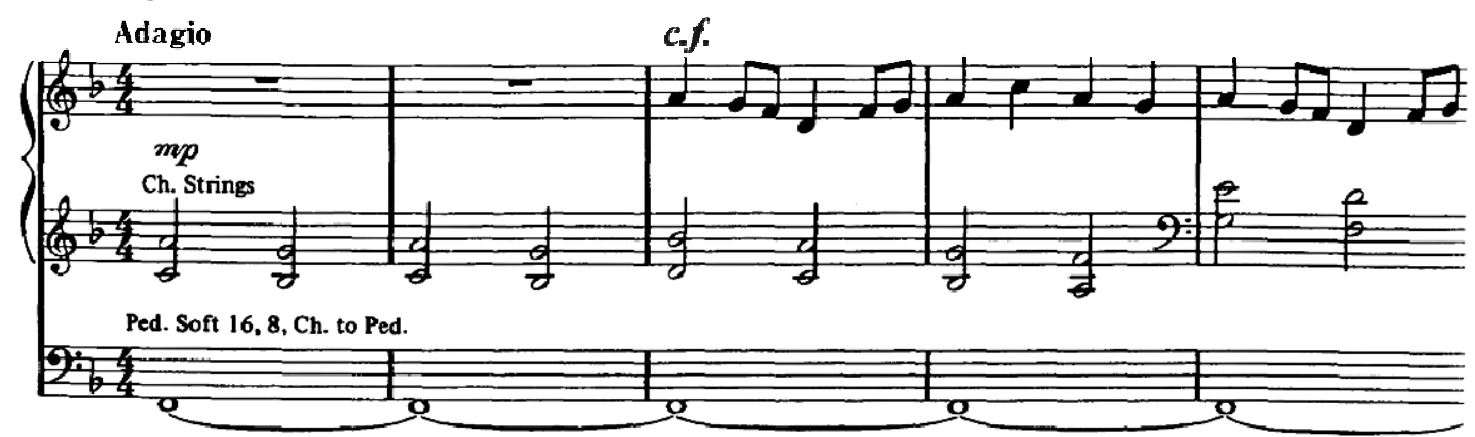


Chorale Cp114 Improvisation on Salve Regina Collection IX; (10/12[12])

Sacred Music Press KK430

Long Chorale Fantasia

F major; 4/4
For the Masses (1989)

Three manuals/Pedal

$57 \mathrm{~mm}$

With an introductory section in the relative minor and a tonic pedal under undulating parallelisms (mm. 1-12), this improvisation outlines ABA structure, whereby B is an extended improvisation. These improvisations in the French paraphrase style untilize only fragments of the $c . f$. with additional motivic material related to the $c . f .$. The tune is altered rhythmically (mm. 1, see Ex. 8-51, [13, 15-16, 17-19]). Section A maintains the tonic pedal while the $c . f$. is ornamented in the soprano. The chorale-free voices contain parallel sixths, which ascend (then descend) in groups of seven, representing "perfection" which is the goal of the associated text: "Hail Queen of heaven, our life, our sweetness and our hope...". Section B, in A minor, develops a rhythmic motif derived from the rhythmically altered c.f.. The return of section A in F major includes the new rhythm of section B in the pedal and includes a short coda.

\begin{tabular}{|c|c|c|}
\hline $\mathrm{A}$ & B & $A^{\prime}$ \\
\hline $\begin{array}{l}\text { D minor solo fragment of c.f., } \\
\text { pedal on tonic }(\mathrm{F}), \text { c.f. in } \\
\text { soprano solo; ascending acc. }\end{array}$ & $\begin{array}{l}\text { A minor/D major bi-tonality, } \\
\text { c.f. fragments, altered chords, }\end{array}$ & $\begin{array}{l}\text { Return to } \mathrm{F} \text { major, echoes in } \\
\text { pedal of } c . f \text {. fragment, end on } \\
\text { tonic added } 9^{\text {th }} \text { and } 13^{\text {th }}\end{array}$ \\
\hline
\end{tabular}

\section{Example 8- 51}

\section{mm 1-5}

Slowly' 'and expressively

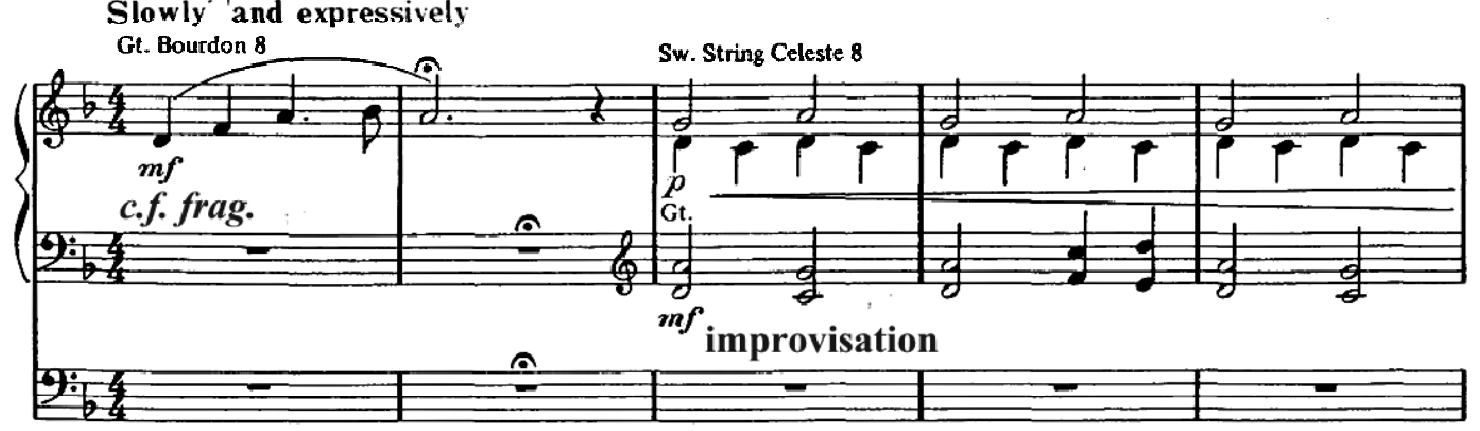


Chorale Cp115 Veni Creator Spiritus

Sacred Music Press KK430

Short Chorale Fantasia

C major; 4/4 time
Collection IX; (11/12[12])

For the Masses (1989)

Three Manuals/Pedal

$24 \mathrm{~mm}$

Originally entitled Improvisation on Veni Creator Spiritus, it is a through-composed improvisation. There are five measures of chromatically ascending chords, then the c.f. enters, which is a fragment of the opening phrase, accompanied by inversions of seventh and ninth chords, see Ex. 8-52. The c.f. continues to be paraphrased, not quoted directly, while the interludes an extemporization based on the general melodic contour (mm. 1011, 12-14, 20-23) and rhythmically (mm. 14, 17, 18-19). The interludes are supported by eleventh and thirteenth chords (mm. 9, 14-16, 19-20) and compound rhythms (mm. 17, 21). Notable is the spare quotation of $c . f$. material and sparse texture that is hard to distinguish from the chorale-free voices of the interludes

\section{Example 8- 52}

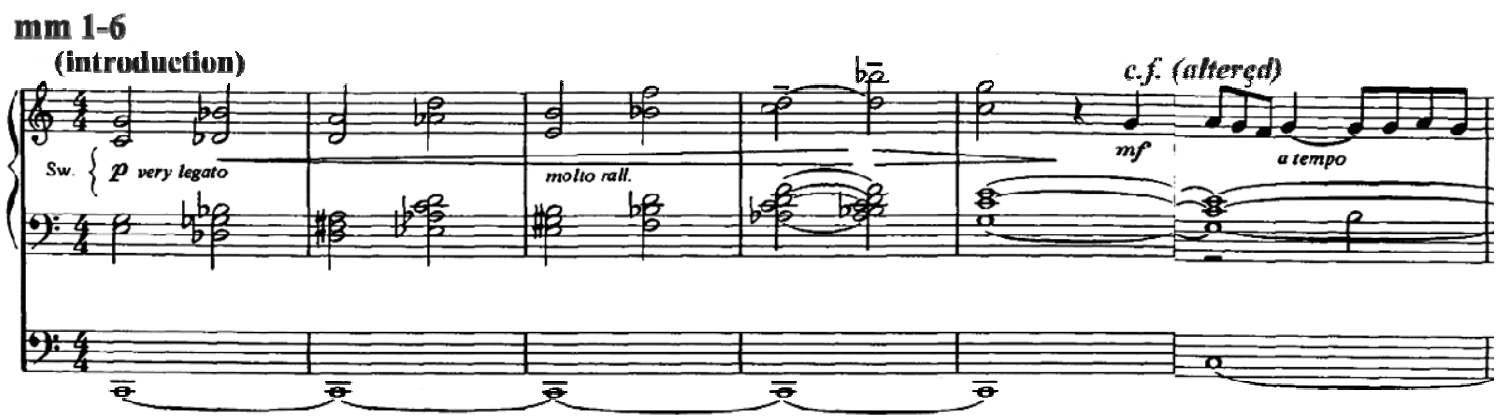


Chorale Cp116 Victimae Paschali Laudes

Sacred Music Press KK430

Short Chorale Fantasia

mostly in C Lydian (uses a raised fourth) $2 / 2$ time
Collection IX; (12/12[12])

For the Masses (1989)

Two manuals/Pedal

$36 \mathrm{~mm}$

This composition is through-composed and contains no suggestion of ABA. There are five fragments of the c.f. in this "written out improvisation". ${ }^{187}$ The entire work is performed on manuals alone until the final chord when the pedal is added. It contains open spacing on fourths and fifths in Lydian mode with fragments of the opening phrase of c.f., which is drawn from the Sequence for Easter Sunday, and appears five times (mm. 4, see Ex. 8-53, [10, 16-17, 23, 29]). The supporting harmonies are subsequently altered and supplemented with sevenths and ninths, whose only symbolism is that those particular numbers indicate both highest perfections (7) and levels of angels (9). The associated text from Easter Day follows. The c.f. is fragmented and paraphrased in style. ${ }^{188}$

Christians praise the Paschal Victim, Honor God, the sacrifice. Christ the Lamb has saved the sheep, Christ, who only is sinless, Reconciling sinners to the Father.

\begin{tabular}{|c|c|c|}
\hline Intro/ opening & Middle Section & Closing / Coda \\
\hline $\begin{array}{l}\text { Open position } 4^{\text {ths }} \text { and } 5 \text { ths, } \\
\text { c.f. in soprano }=\text { first phrase, } \mathrm{E} \\
\text { minor }\end{array}$ & $\begin{array}{l}\text { Open position chords, altered } \\
\text { harmony, c.f. stretto, } \mathrm{E}^{b} \text { minor } \\
\text { and F minor bi-tonal }\end{array}$ & $\begin{array}{l}\text { Open position } 4 \text { ths and } 5^{\text {th }} \mathrm{s} \\
\text { Second strophe of } c \text {.f. in } \\
\text { soprano f\# minor and } \mathrm{e}^{b} \mathrm{~m}\end{array}$ \\
\hline $\begin{array}{l}\mathrm{mm} .1-3, \quad 4-12 \\
\text { victimae paschali laudes }\end{array}$ & 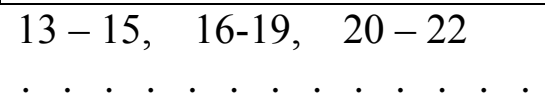 & $\begin{array}{c}23-31, \quad 32-36 \\
\text { immolent christiani, }\end{array}$ \\
\hline
\end{tabular}

\footnotetext{
${ }^{187}$ Hebble, FL interview, tape two.

${ }^{188}$ Hebble, Florida tape two, side one.
} 
mm 1-5

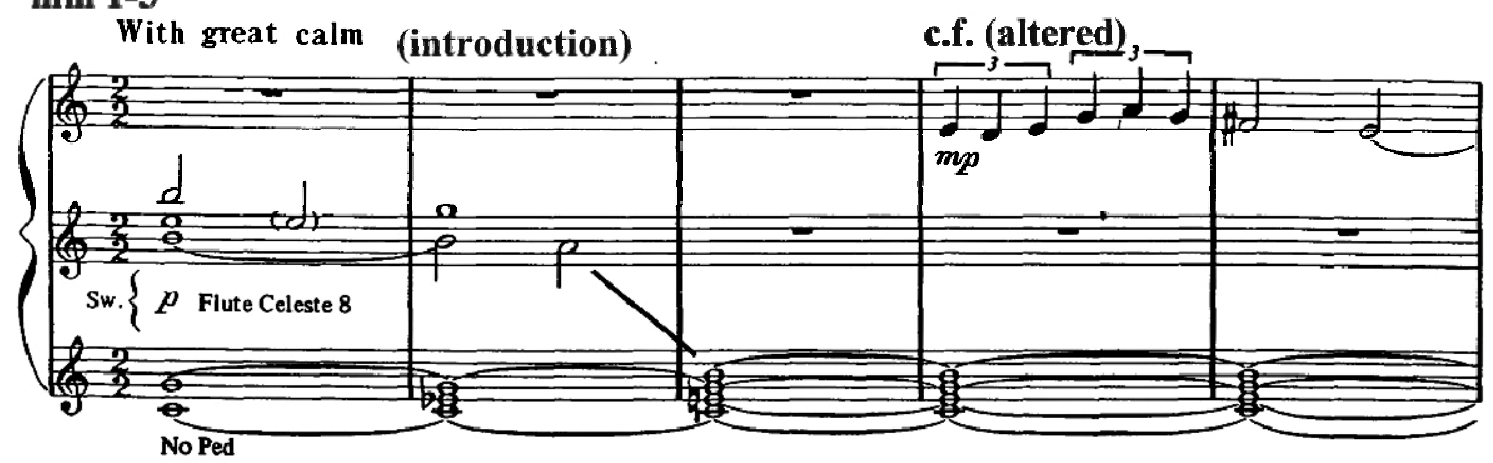

Chorale Cp117 Amazing Grace

Sacred Music Press KK427

Short Melody Chorale

G major; $3 / 4$

\section{Example 8- 53}


this piece depicts a very hot summer's day in the South; (it's) not sure what to do, escape up or (oscillate) down or to suspend or to anticipate a harmony. I hate the dominant-seventh chord: too cliché, too obvious. ${ }^{189}$

Introduction
\begin{tabular}{|l|l|l|}
\hline $\begin{array}{l}\text { Tertian harmonies: G, bm, } \mathrm{E}^{b} \\
\text { em, (no V7: traditional use) }\end{array}$ & $\begin{array}{l}\text { one verse of c.f.: solo right- } \\
\text { hand against accompaniment }\end{array}$ & $\begin{array}{l}\text { Similar to introduction, but } \\
\text { extended }\end{array}$ \\
\hline Measures 1-8 & $9-24$ & $25-39$
\end{tabular}
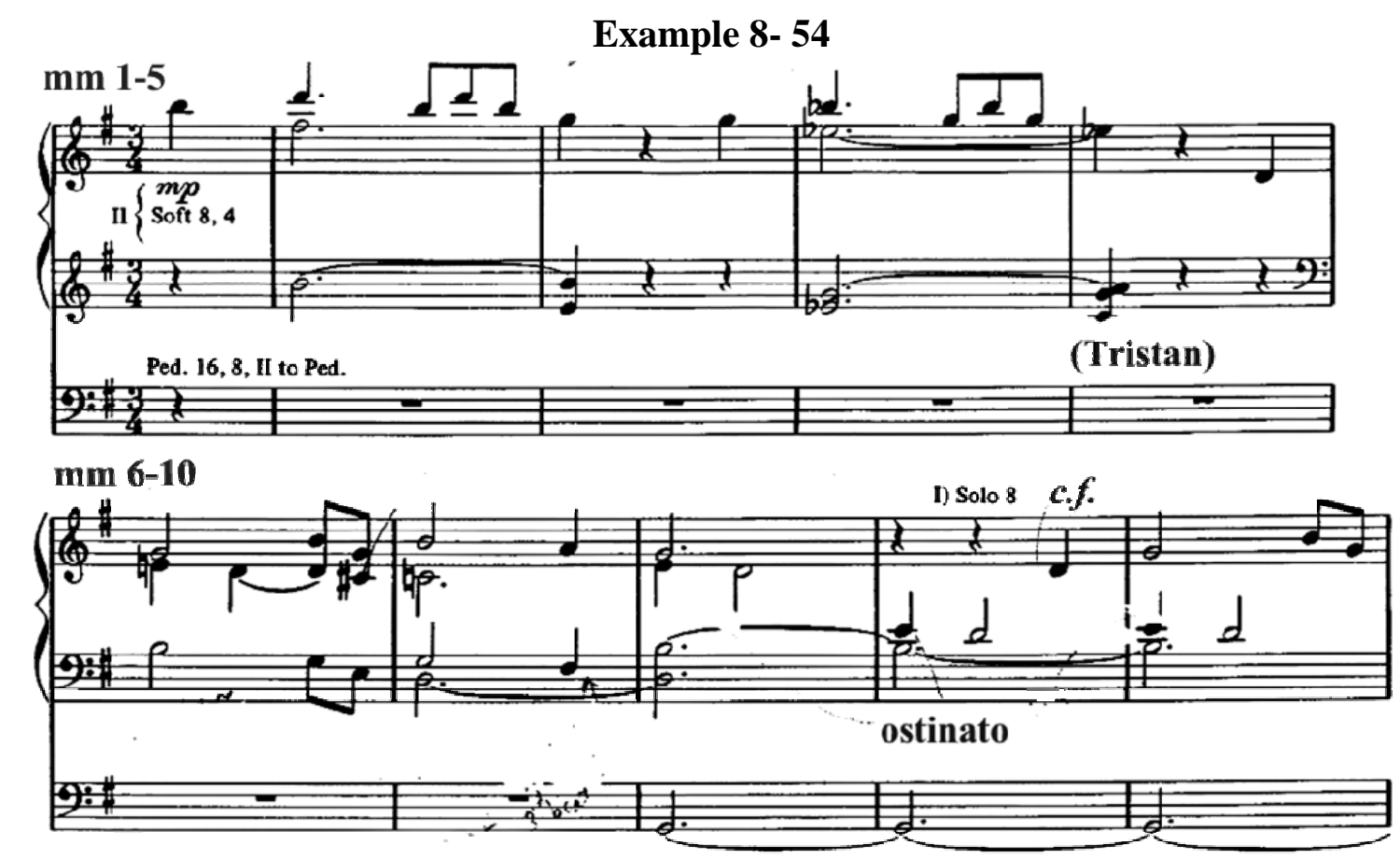

Chorale Cp118 Beneath the Cross of Jesus

Sacred Music Press KK427

Short Melody Chorale

$\mathrm{D}^{\mathrm{b}}$ major; $4 / 4$
Collection X; $(2 / 10[10])$

At Your Service (1989)

Three Manuals/Pedal

$22 \mathrm{~mm}$

A short melody chorale form, the c.f. enters on the fourth beat of the top voice, see

Ex. 8-55, which is in the tenor range, very reminiscent of the opening of the "Adagio"

movement from Saint-Saens' Symphony No. 3 for Organ. Each strophe is divided into

two phrases. At the third strophe Hebble puts the tune two octaves higher. The piece is

${ }^{189}$ Hebble, Florida tape one, side two. 
infused with blues harmony (mm. 4-6, 14-16, 18), passing chromaticism (mm. 5, 7, 11, 12, 15-18, 20) and gentle syncopation (mm. 1-2, 9-10, 11-12). The short coda (mm. 1822) contains a repeat of the second phrase of the last strophe in augmentation on a solo flute stop. Again Hebble employs text-painting on the word 'beneath': the c.f. is almost entirely below middle $\mathrm{C}$ while the chorale-free voices play in a high treble range.

\section{Example 8- 55}

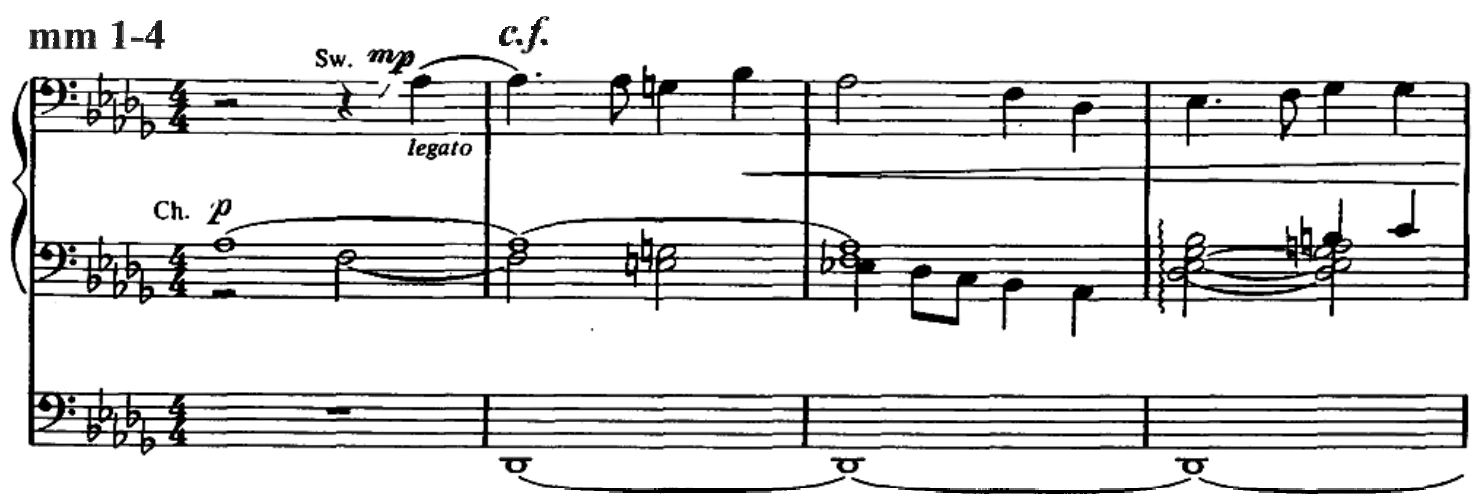

Chorale Cp119 Blessed Assurance Sacred Music Press KK427

Ritornello Chorale/paraphrase

D major; $9 / 8$ multiple meters
Collection X; (3/10[10])

At Your Service (1989)

Two/Three Manuals/Pedal

$55 \mathrm{~mm}$

This ritornello chorale directly parodies Bach’s “Jesu, Joy of Man’s Desiring” (from

Cantata 147), but instead uses the hymn tune Blessed Assurance in place of the Johann

Schop chorale. Hebble also changes the key from G major to D major, and the c.f. is in the soprano, see Ex. 8-56, m. 8. Note in the following outline how Hebble treats the c.f.. Most of the altered harmonies occur in the areas of c.f. treatment, and there is some rhythmic alteration of the Bach motifs (m. 1), see Ex. 8-56. Hebble builds C-minoreleventh and C\# -minor -eleventh chords (m. 39, beat 3) and G diminished chords over a dominant pedal (m. 46, beat 2). There is a preservation of the 'gospel' choral style of 
parallel 3rds and 6ths at the beginning of each ritornello (e.g. m. 1 and 2), which is the cultural background of this hymn. This piece also makes use of a new device on the organ called "MIDI" 190 which electronically adds in "a string orchestra". ${ }^{191}$ This is the only time in his complete works for organ that Hebble calls for MIDI. Polyrhythms in measures 37, 38 and 39 assist in preparing the expressivo usage of the fermatas.

\begin{tabular}{|c|c|c|c|c|c|c|}
\hline $\begin{array}{l}\text { Ritornello: } \\
\text { Quotes J.S. } \\
\text { Bach (147) } \\
\text { cantata }\end{array}$ & $\begin{array}{l}\quad \text { c.f. } \\
\text { Strophes } \\
\text { one and } \\
\text { two }\end{array}$ & $\begin{array}{l}\text { Ritornello: } \\
\text { Quotes } \\
\text { Bach }\end{array}$ & \begin{tabular}{l}
\multicolumn{1}{c}{ c.f. } \\
Refrain: \\
strophes \\
three and \\
four
\end{tabular} & $\begin{array}{l}\text { Ritornello: } \\
\text { Quotes } \\
\text { Bach in } \\
\text { (minor) }\end{array}$ & $\begin{array}{l}\text { c.f. } \\
\text { Refrain: } \\
\text { strophes } \\
\text { three and } \\
\text { four }\end{array}$ & $\begin{array}{l}\text { Ritornello: } \\
\text { Like } \\
\text { beginning: } \\
\text { quotes } \\
\text { Bach }\end{array}$ \\
\hline mm. 1-8 & $8-16$ & $16-23$ & $23-31$ & $31-36$ & $36-48$ & -55 \\
\hline
\end{tabular}

\section{Example 8- 56}

\section{mm 1-3}
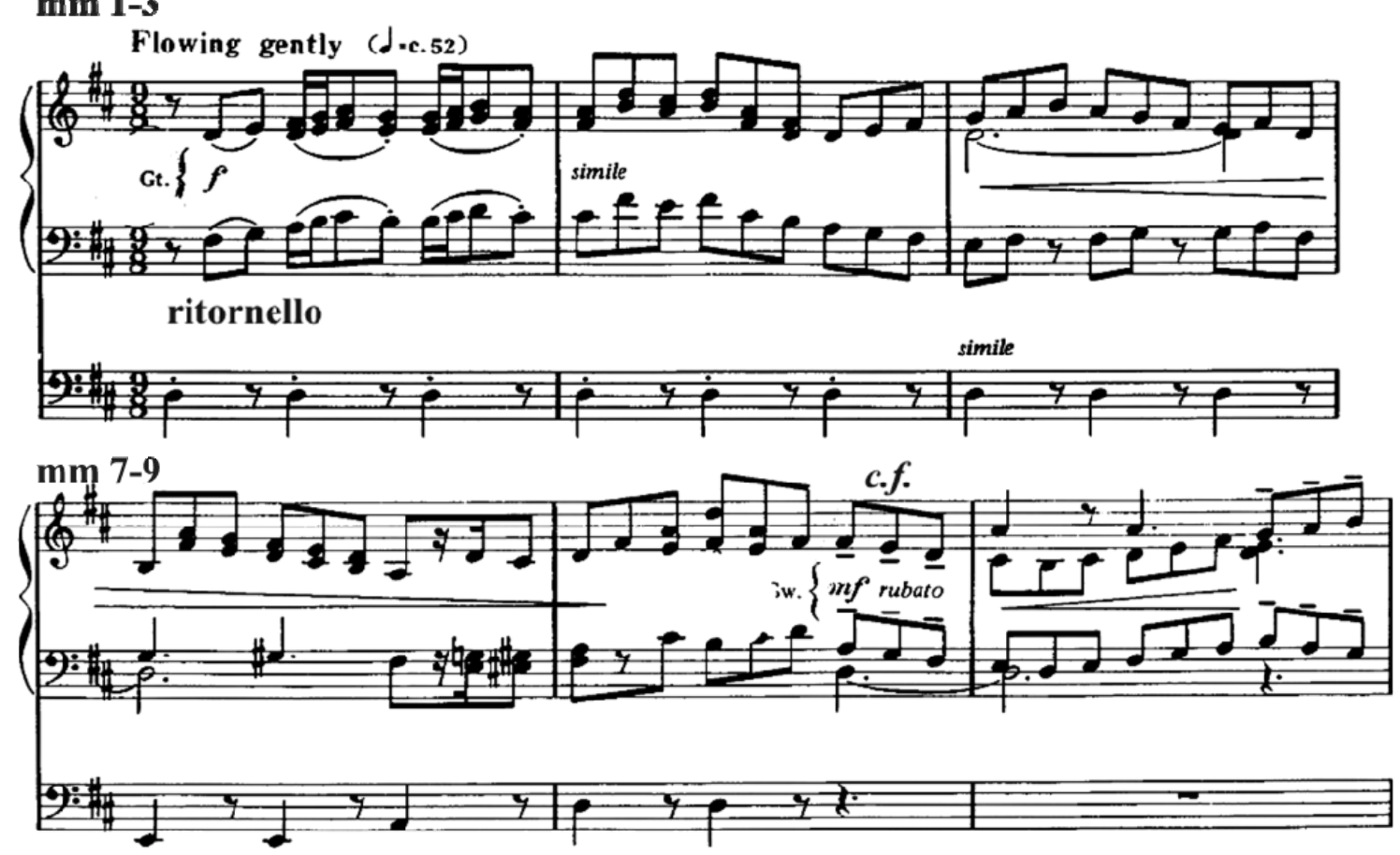

${ }^{190}$ This is an acronym for Multiple Instrument Digital Interface.

${ }^{191}$ See page 30 of the At Your Service collection. 
Chorale Cp120 Holy God, We Praise Your Name Collection X; (4/10[10])

Sacred Music Press KK427

At Your Service (1989)

Short Melody Chorale

F major; $3 / 4$ time

Two Manuals/Pedal

$41 \mathrm{~mm}$

Some balance is maintained between the eight measures of introduction and the nine measures of coda (the latter in which he repeats the last half of the last phrase of the c.f. in hemiola (mm. 33-37). Hebble treats the c.f. (m. 9 in the alto), see Ex. 8-57, quite simply throughout with a right-hand descant accompaniment of exactly twenty-four measures, which is exactly three times (Trinity) the length of the introduction or coda. He makes plentiful use of passing tones, but less so of chromatic harmonies of which the work is merely tinged. Parallel seventh chords accompany the third strophe (mm. 25-30). The brief Tristan harmony at $\mathrm{m} .33$ coordinates with the associated text "everlasting is Thy reign".

\begin{tabular}{|c|c|c|}
\hline Introduction & one verse of c.f. & Coda \\
\hline Hemiola; no pedal & Four successive strophes & Begins on Tristan m.33/3 \\
\hline
\end{tabular}

\section{Example 8- 57}

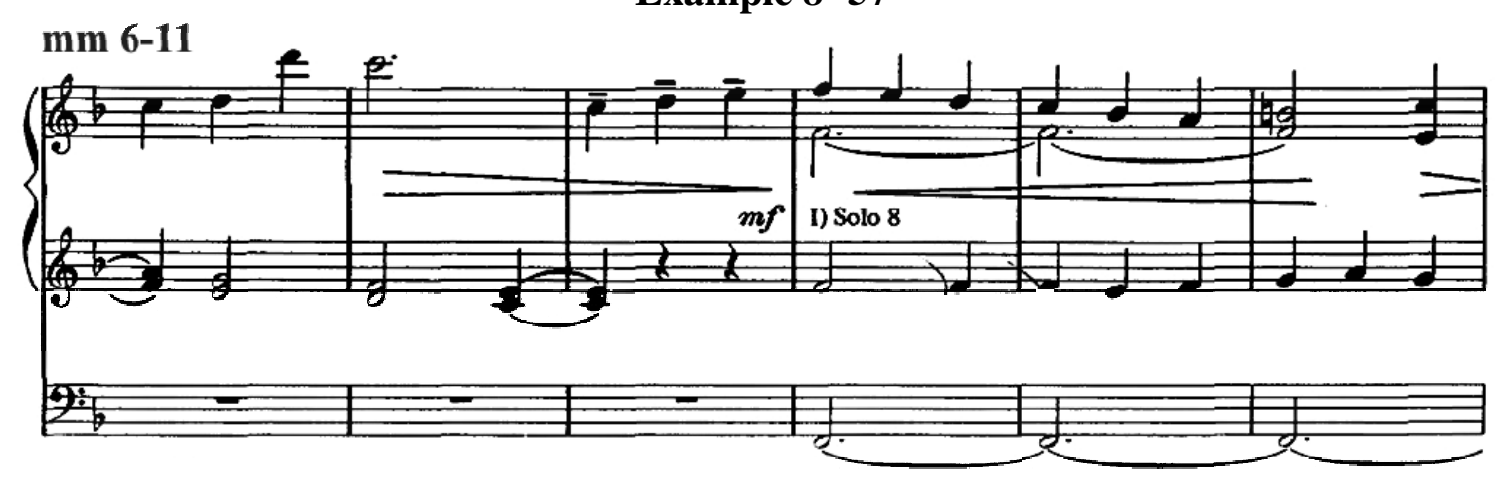


Chorale Cp121 Jesus Shall Reign

Sacred Music Press KK427

Long Chorale Fantasia

D major; $2 / 2$ time
Collection X; (5/10[10])

At Your Service (1989)

Three Manuals/Pedal

$108 \mathrm{~mm}$

There are three treatments of the c.f., as well as modulations and changing meters in a chorale fantasia form. The work has a highly extemporized style due to its similarity to the twentieth century French toccata with its fragmented quotes of the $c . f$. in the pedal (mm. 92-99, see Ex. 8-58, sy2 and 3 [36, 40, 51-52]), which is itself juxtaposed with the syncopated rhythmic treatment of the c.f. (mm. 33-36, see Ex. 8-58, sy1 [37-40, 41-44, 61-63]) throughout the work. The second verse of the $c . f$. is highlighted with great rhythmic variance of the normally square melody, which is coupled with quotes of the fragments of the $c . f$. in the pedal, which are in regular rhythm. The third verse features continued transformation of the theme rhythmically and harmonically and ends with a fortissimo reed quoting the last strophe against full organ accompanied by syncopated rhythms. This leads to a cyclic reprise of the rhythmic variety found in the second verse and also a cyclic return of the toccata figure of the first verse with the c.f. in the pedal. The work contains spicey harmonies and non-harmonic tones (2nds, 4ths, 6ths), as well as substitute dominants (mm. 44, 78). 


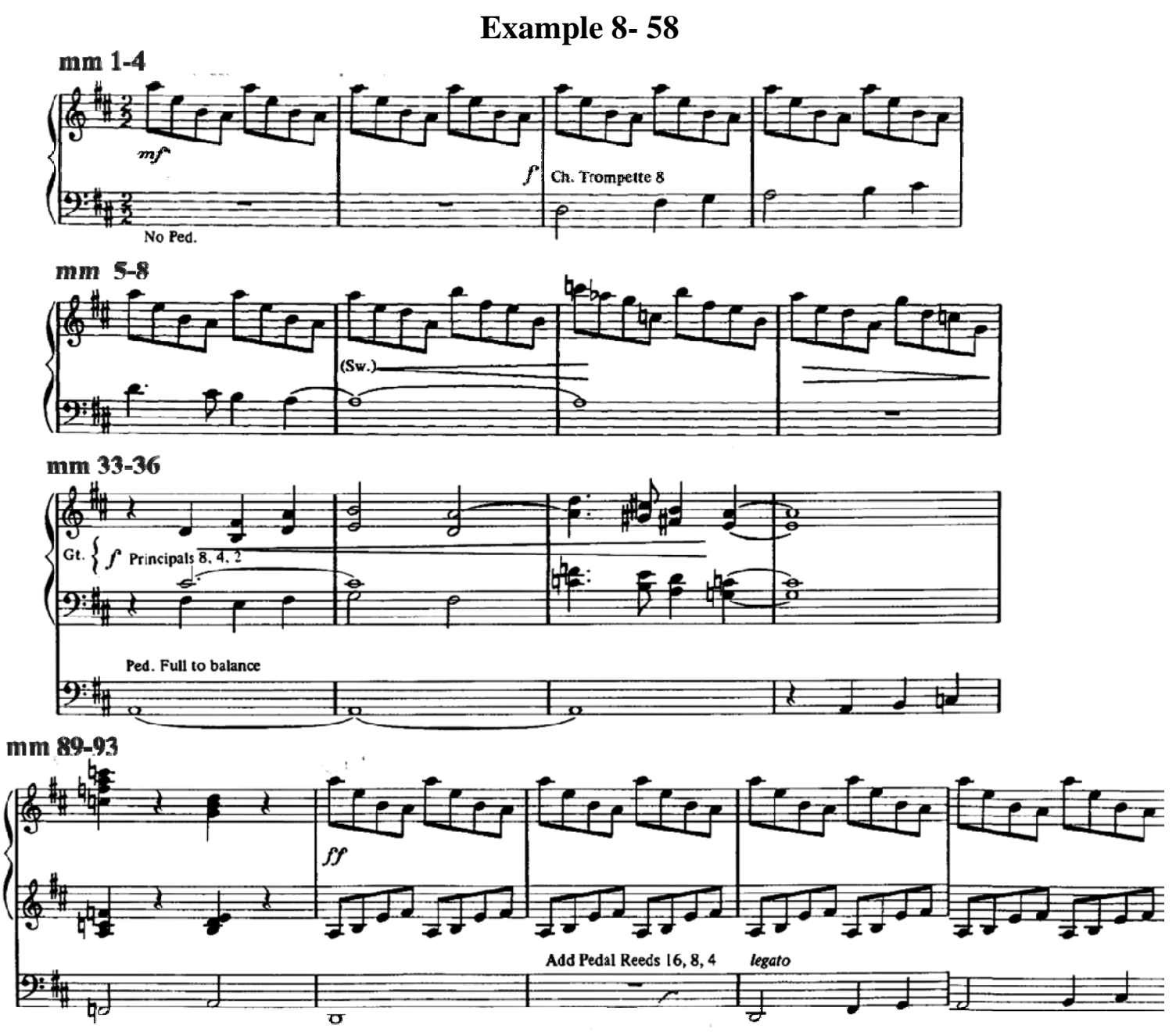

Chorale Cp122 Let All Mortal Flesh Keep Silence Collection X; (6/10[10])

Sacred Music Press KK427 At Your Service (1989)

Chorale Fantasia

Three Manuals/Pedal

Dorian mode $\left[\mathrm{B}^{\mathrm{b}}\right]$

$33 \mathrm{~mm}$

The opening accompaniment is a series of planing seventh chords, including the pedal,

while the c.f. is stated plainly on a solo stop in the right hand, see Ex. 8-58, sy1. The last four measures of the first verse of c.f. contain a subdominant pedal of fifths which "give the aura of a Medieval monastery". ${ }^{192}$ Verse two uses a different solo stop and reveals brief imitations. The coda quotes the first fragment of the c.f. in F, and before it is

${ }^{192}$ Hebble; Floria tape one, side two. 
finished, quotes the last fragment of the c.f. in D minor concurrently. There is another stretto treatment of the first fragments of the c.f. together, see Ex. 8-59, sy2, and then simultaneously with the last fragment of the c.f., along with Neapolitan harmony (m. 32), during the last four measures (30-33). The c.f. is called "Picardy", and Hebble appropriately ends the work using the 'picardy third' in D major. The planing found at the opening of the piece recurs in the final six measures.

Introduction
\begin{tabular}{|l|l|l|l|}
\hline tonic pedal on 5ths, & c.f. in d-minor with & c.f. in a-minor with & Stretto fragments: c.f. \\
1.h. on 3rds and 7ths & 5ths accompaniment & imitation at i and v & \begin{tabular}{l} 
elided cadence, m. 26 \\
\hline
\end{tabular} \\
\hline Measures 1-2 & $3-14$ & $15-26$ & $26-33$
\end{tabular}

\section{Example 8- 59}
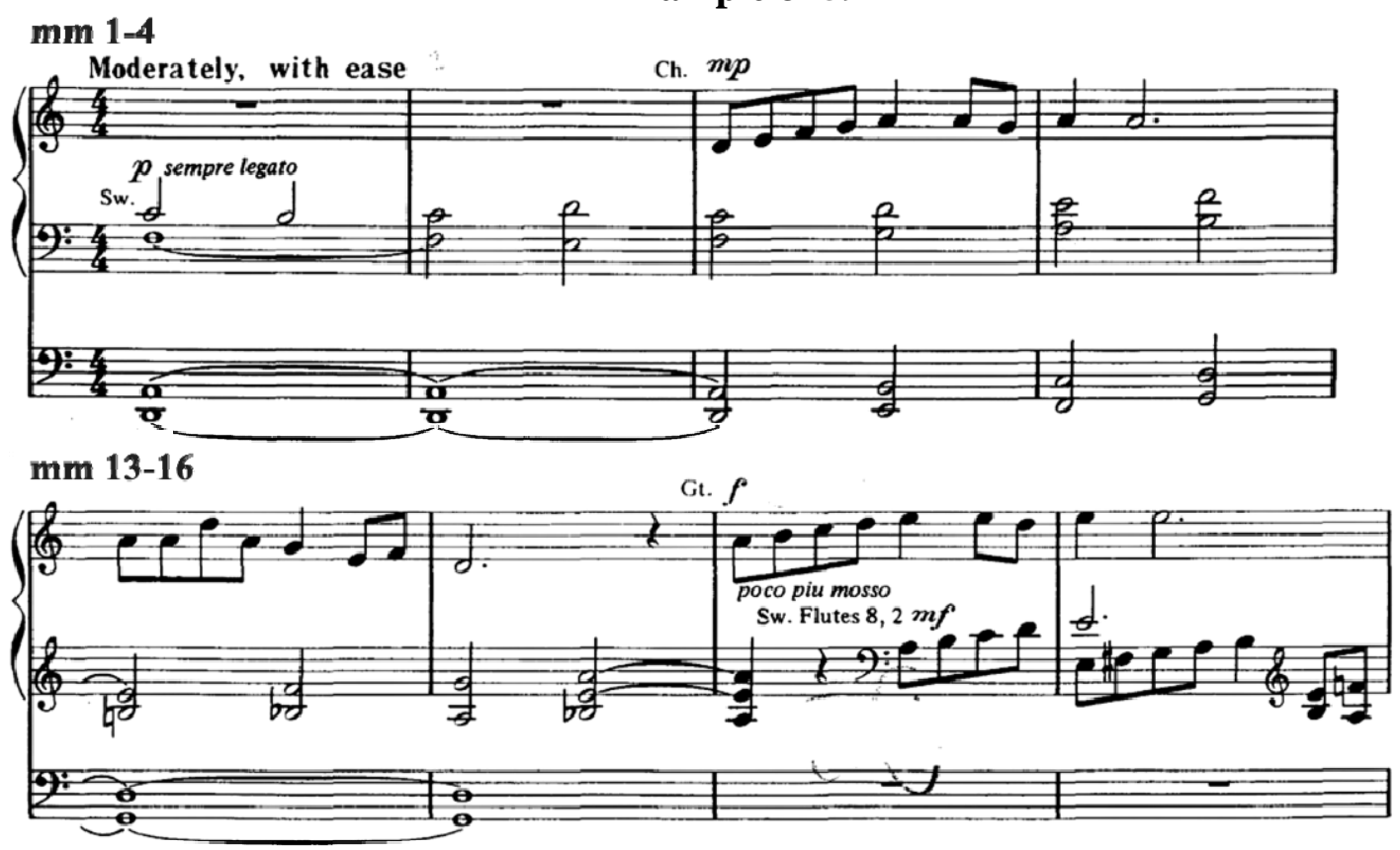

Chorale Cp123 Lo! He Comes with Clouds Descending Collection X (7/10[10])

Sacred Music Press KK427

Long Chorale Fantasia

$E^{b}$ major; 4/4 time At Your Service (1989) Three Manuals/Pedal $43 \mathrm{~mm}$

This is a good example of proportion in Hebble's organ music. See the bottom of the following chart. It is classified as a chorale fantasia because of its extended introduction, 
coda and interludes as well as its treatment of multiple verses. There is a five-measure introduction, then twelve measures of c.f. treatment (verse one) then fifteen measures of verse two (containing augmentation of the c.f.) and eleven measures of coda. Although the measures are not mathematically precise, the two verses are the same length with some augmentation in the second verse; the coda, which is improvisatory, is almost exactly as long as each verse and twice as long as the introduction. Of note is the preservation of the number (3): three phrases in the introduction, three different accompaniments to the c.f. in verses one and two and three phrases in the coda. The idea of three is also present in the tertian harmonies (see Ex. 8-60, sy1: beginning in an area of $\mathrm{C}$, three notes away from tonic $\mathrm{E}^{b^{193}}$ in measure one and in the first phrase of the c.f. in verse one, measures 6, 8 and 9). Three is also preserved in the three-note block chords (mm. 6-7, see Ex. 8-60, sy2; [13-14, 18-19, 27-28, 33-34, 35-36]). The expansion from three-notes to four-notes coordinates with the augmentation of the c.f. in verse two. ${ }^{194}$ The proportion here ${ }^{195}$ is worth noting, having 12 measures each exactly, which corresponds to the precise length of each verse in common time. Of harmonic interest is the use of the Neapolitan (m. 2, see Ex. 8-60, sy1; [17, 31, 32]), the arrival on Tristan harmonies (mm.4, see Ex. 8-60, sy1; [8]) and Hebble's typical deliberate avoidance of dominant-seventh harmonies, where they would otherwise normally occur. Hebble composes a harmonic pedal on the tonic (mm. 6-9; see Ex. 8-60, sy2); on the dominant (mm. 18-21, see Ex. 8-59, sy3; [14-15]); and on the subdominant (mm. 22-25, see

\footnotetext{
193 The key of $\mathrm{E}^{\mathrm{b}}$ also contains (3) flats.

${ }^{194}$ Hebble, Florida tape two, side one.

${ }^{195}$ Balance between the measures devoted to three-note chords and four-note chords parallels the size of the areas of c.f. treatment.
} 
Ex. 8-60, sy3). The entire work is infused with extended chords (mm.8-9, 12-13, 20-21,

37-43). Hebble also employs canon at three locations (mm. 27-31, 33-35, 37-41). ${ }^{196}$

\begin{tabular}{l|l|l|l|} 
Introduction & \multicolumn{1}{c}{ verse 1 } & verse 2 & coda \\
\hline \begin{tabular}{l|ll}
3 phrases \\
measures 1-2, 3-4, 4-5
\end{tabular} & 3 accompaniments of & 3 treatments of c.f. & 3 phrases \\
& c.f. & $18-21,22-26,27-32$ & $33-36,37-41,42-43$ \\
& $6-9,10-13,14-17$ & & \\
\hline $\begin{array}{llll}\text { five measures } & \text { twelve measures } & \text { fifteen measures } & \text { eleven measures } \\
1 \mathrm{x} & 2 \mathrm{x} & 3 \mathrm{x} & 2 \mathrm{x}\end{array}$
\end{tabular}
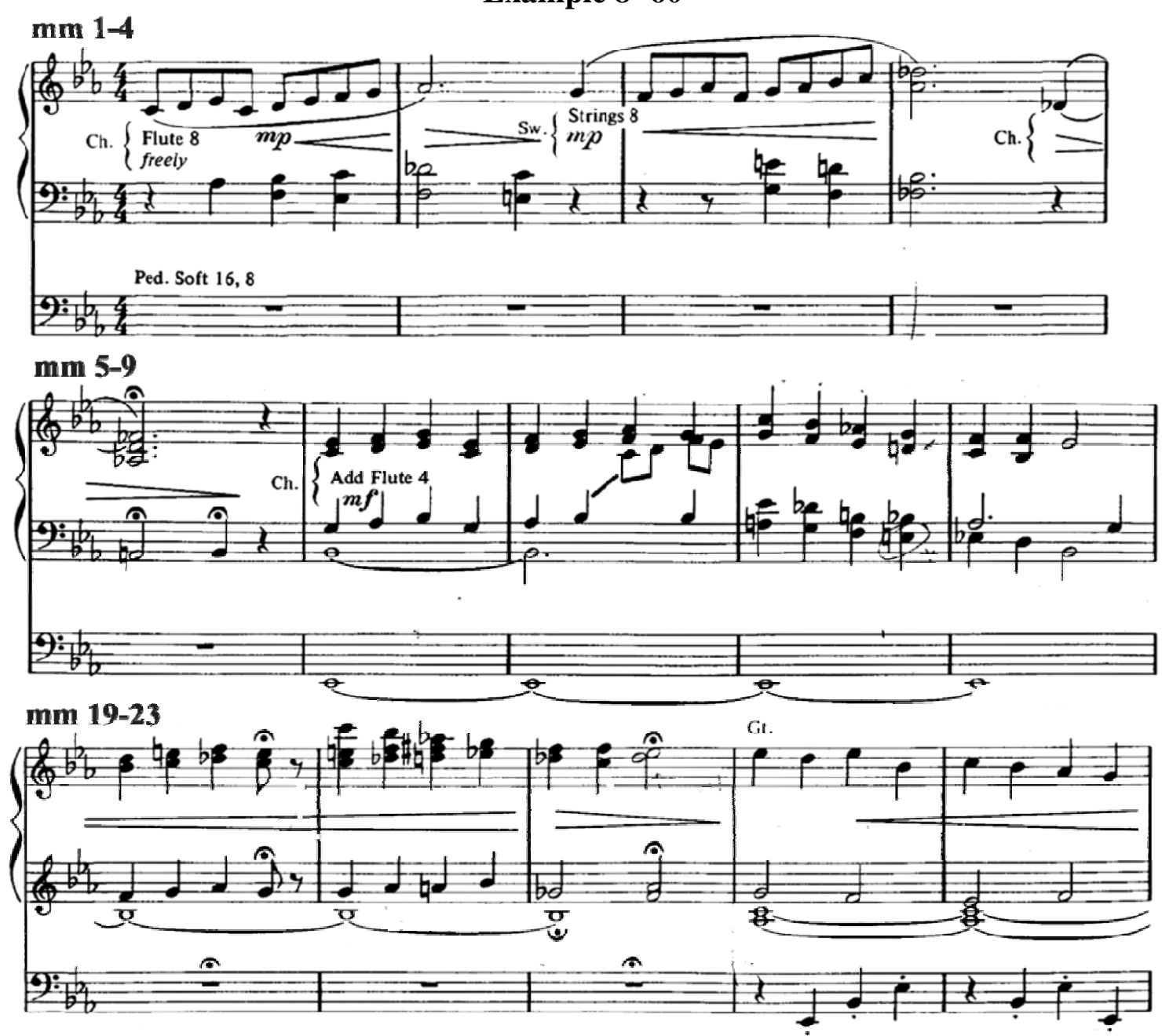

\footnotetext{
${ }^{196}$ Hebble continued commenting on what Boulanger told him: "if you buy a cheap chair, it will fall apart in a year; if you buy a well crafted chair, it should never fall apart", alluding to his crafting of this composition.
} 
Chorale Cp124 Most Perfect Is the Law of God

Sacred Music Press KK427

Long Trio Chorale

$E^{b}$ major; $3 / 4$ time
Collection X; $(8 / 10[10])$

At Your Service (1989)

Two manuals/Pedal

$48 \mathrm{~mm}$

Similar to a classical 'piano trio' (e.g., piano, violin, and cello), in which one of the instruments (e.g., the piano) can play more than one note simultaneously, the inner voice of this chorale occasionally contains two notes. The chorale preserves, however, three timbres: soft bass 8, flutes 8 and 2, plus the solo c.f., see Ex. 8-61, sy1. He combines the basic elements of two hymns: the jolting, dotted-rhythm of the tune "Glasgow" (which is the text most often used with this tune), ${ }^{197}$ and the melody of "Stracathro" as the c.f.. There are interludes, and an introduction and coda, making it a long form. After eight measures of introduction over a staccato pedal the c.f. enters in the right hand on a solo stop, and even the $c . f$. is occasionally influenced by the dotted-rhythm (mm. 11, 17, 26, 34-35). Marked Gracefully, with a bounce, the work is carefree in character, if not defiant, in its attitude towards the exhortation of the text with its jocular rhythm and jazzlike harmony (mm. 7-8, 11-12, 14-15, 17, 29-34, 37-49).

Most perfect is the law of God, Restoring those that stray; His testimony is most sure, Proclaiming wisdom's way. ${ }^{198}$

The work is off-handed as to which tune, which rhythm (the c.f. is occasionally ornamented) and which key to use (there is a modulation from $\mathrm{E}^{\mathrm{b}}$ to $\mathrm{E}$ before the third strophe at m. 22). The third and fourth strophes of the c.f. have an improvised character in the accompaniment (mm. 25-36). Here, the Tristan harmony $(\mathrm{mm} .15,39)$ is treated

\footnotetext{
${ }^{197}$ Ribble, John. The Hymnbook, Presbyterian Church in the U.S.A., NY, NY $\left(10^{\text {th }}\right.$ printing $), 1955$, p. 225. ${ }^{198}$ Ibid.
} 
metaphorically, depicting people's "endless lawlessness", ${ }^{199}$ the most telling example of which is the accompaniment of (m. 15). However, the 'Law of God' appears in all of the accompanying intervals of perfect-fourths, perfect-fifths or octaves supplied over the pizzicato bass throughout the composition. A pedal cadenza quotes a segment of $c . f$. and supplies a third melody lending strength to the bass line of this trio-like composition, see Ex. 8-61, sy2.

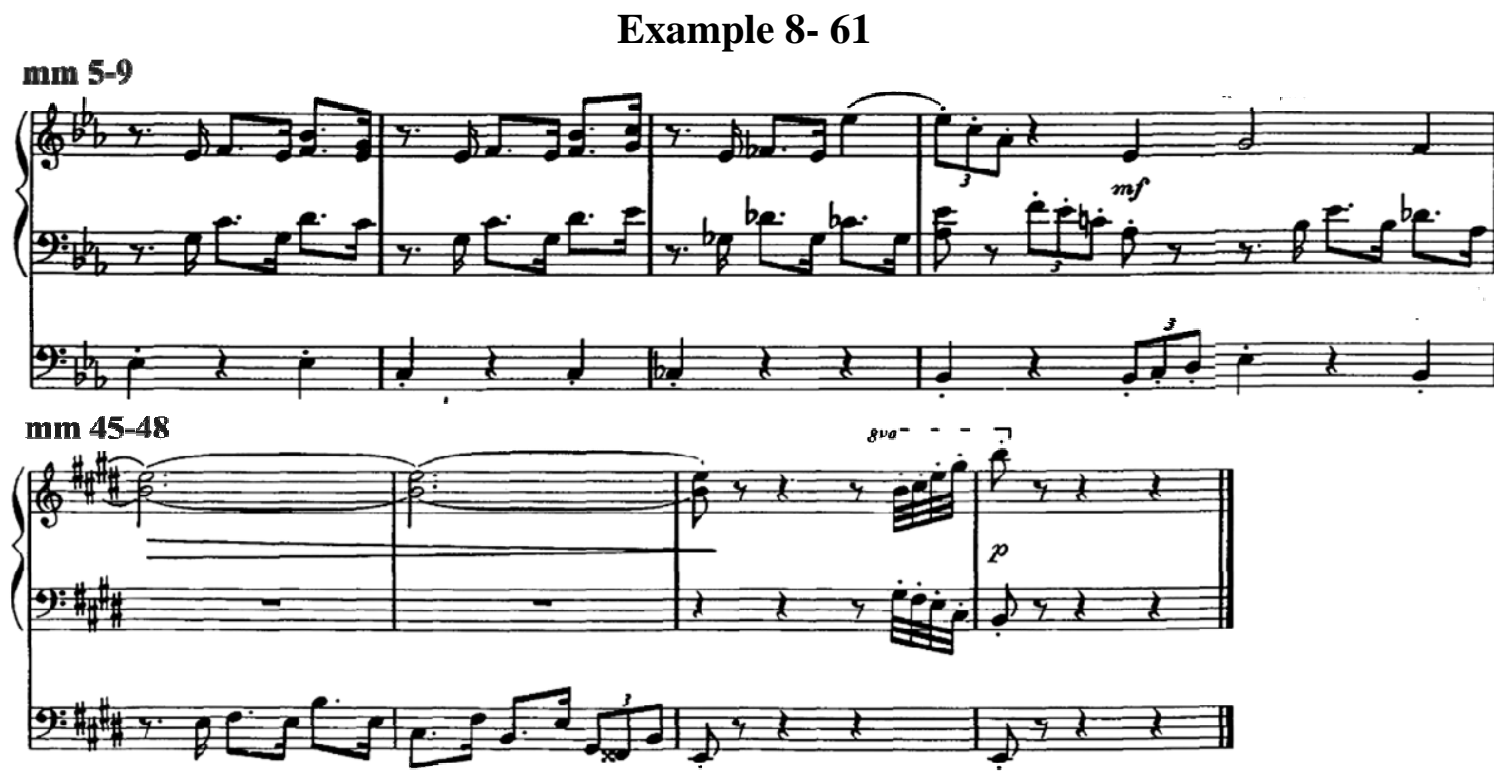

$\begin{array}{ll}\text { Chorale Cp125 Praise To the Lord } & \text { Collection X; }(9 / 10[10]) \\ \text { Sacred Music Press KK427 } & \text { At Your Service (1989) } \\ \text { Ritornello Chorale } & \text { Two manuals/Pedal } \\ \text { F major; } 3 / 4 \text { time } & 64 \mathrm{~mm}\end{array}$

This chorale has a re-occurring ritornello into which is woven the c.f. in successive strophes, see Ex. 8-62. Some ornamentation of the c.f. occurs in the second strophe (mm.23), the third strophe (m. 35) and the fourth strophe (m. 50) with imitation at

\begin{tabular}{|l|l|l|l|l|l|l|l|l|}
\hline Ritorn. & c.f. & Ritorn. & c.f. & Ritorn. & c.f. & Ritorn. & c.f. & Coda \\
\hline
\end{tabular}

\footnotetext{
${ }^{199}$ Hebble, FL interview.
} 


\begin{tabular}{|c|c|c|c|c|c|c|c|c|}
\hline $\begin{array}{l}2 \\
\text { phrases } \\
\text { mm.1-8 }\end{array}$ & $\begin{array}{l}\text { Strophe } \\
1 \\
12-15\end{array}$ & $\begin{array}{l}2 \\
\text { phrases } \\
15-22\end{array}$ & $\begin{array}{l}\text { Strophe } \\
2 \text {, orn. } \\
23-29\end{array}$ & $\begin{array}{l}\text { Smaller } \\
29-34\end{array}$ & $\begin{array}{l}\text { Strophe } \\
3 \text {, orn. } \\
35-39\end{array}$ & $\begin{array}{l}\text { Longer } \\
39-48\end{array}$ & $\begin{array}{l}\text { Strophe } \\
4, \text { orn. } \\
49-53\end{array}$ & $\begin{array}{l}\text { Ritorn. } \\
53-64\end{array}$ \\
\hline
\end{tabular}

(m.49). The coda, beginning at (m. 53) is reminiscent of Bach's treatment of the coda in Wehn wir in Höchsten Nöten Sein, BWV 668 by employing the iv over a tonic pedal to lend a slight 'ritardando' to the end. Hebble highlights this with descending fourths in syncopation in the left-hand. There is an ostinato in the pedal in the first four sections, see Ex. 8-62, which supplies structure for the various chromatic passing tones in the longer ritornello (mm. 39-48), as well as opportunity for harmony such as the Neapolitan (m. 59) and Tristan harmony (m. 22), the latter of which is not metaphorical. The ritornello proportions are well balanced with the coda being the longest ritornello section.

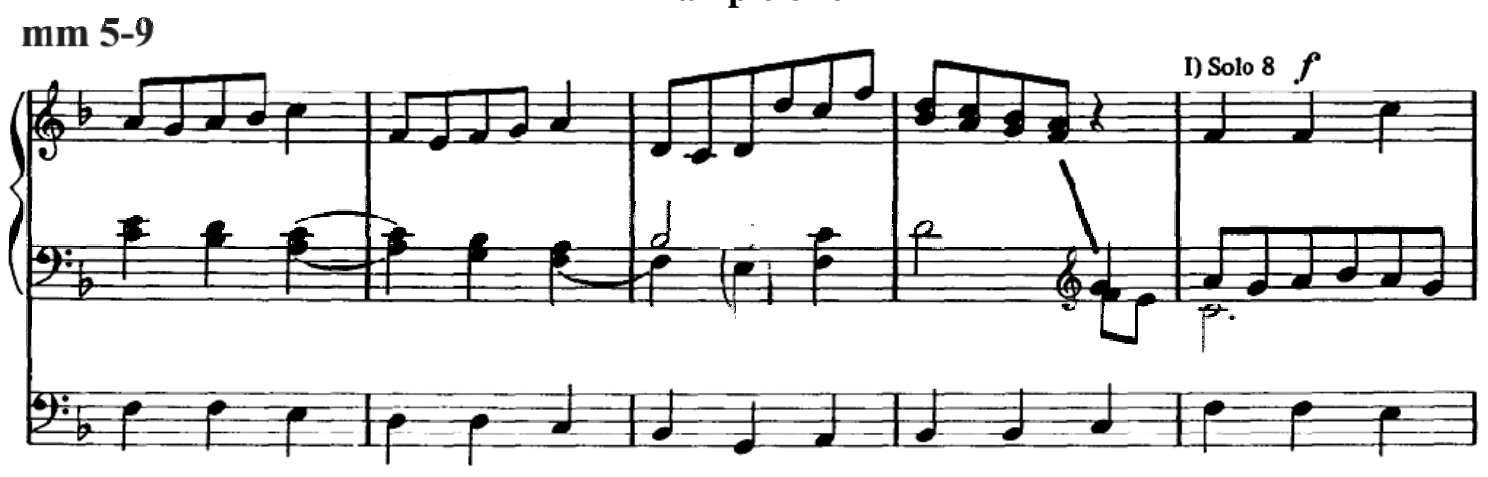

Chorale Cp126 Thee We Adore

Sacred Music Press KK427

Short Chorale Fantasia

$\mathrm{E}^{b}$ major; 2/4 time
Collection X; (10/10[10])

At Your Service (1989)

Three Manuals/Pedal

$51 \mathrm{~mm}$

Known also by its traditional tune title "Adoro Te Devote", it has one measure of fifths for an introduction, see Ex. 8-63, sy1, and two codettas (mm. 42-44 and 45-51). As a fantasia, it only quotes fragments of the c.f., the final phrase of which is highly disguised in the codas. This symbolizes that "adoration" is "never finished" and is "hard to 
distinguish". ${ }^{200}$ There is an infusion of mixolydian harmonies ${ }^{201}$ as well as a central section which suspends Tristan harmony ${ }^{202}$ (mm. 18-20) while the c.f. moves to B major, see Ex. 8-63, sy2, in measure 22-25. ${ }^{203}$ The many fourths and fifths imitate Medieval harmony in the writing (mm. 1-2, 5-6, 11, 15-18); the intervals later moving to parallel sixths (mm. 112-25, 31-34). These eventually change to parallel thirds, a move towards the Trinity ${ }^{204}$ (mm. 412-50). There is stretto between the pedal and manuals (mm. 3541), which also features a concurrent augmentation of the c.f. in the pedal line, see Ex. 863, sy3.

\footnotetext{
${ }^{200}$ Hebble interview; Florida tape one, side one.

${ }^{201}$ In the key of $\mathrm{E}^{b}$, this changes regular $\mathrm{D}^{\mathrm{b}} \mathrm{D}^{\mathrm{b}} \mathrm{b}$.

${ }^{202}$ Here it is $\mathrm{d} \#, \mathrm{f} \#, \mathrm{a}, \mathrm{c} \#$, but is spelled from the bass in the order of $\mathrm{d} \#-\mathrm{c} \#-\mathrm{a}-\mathrm{f} \#$.

${ }^{203}$ Here the c.f. moves from an F\# minor (v) chord, as Hebble avoids pure dominant-sevenths.

${ }^{204}$ Florida, tape one, side one.
} 


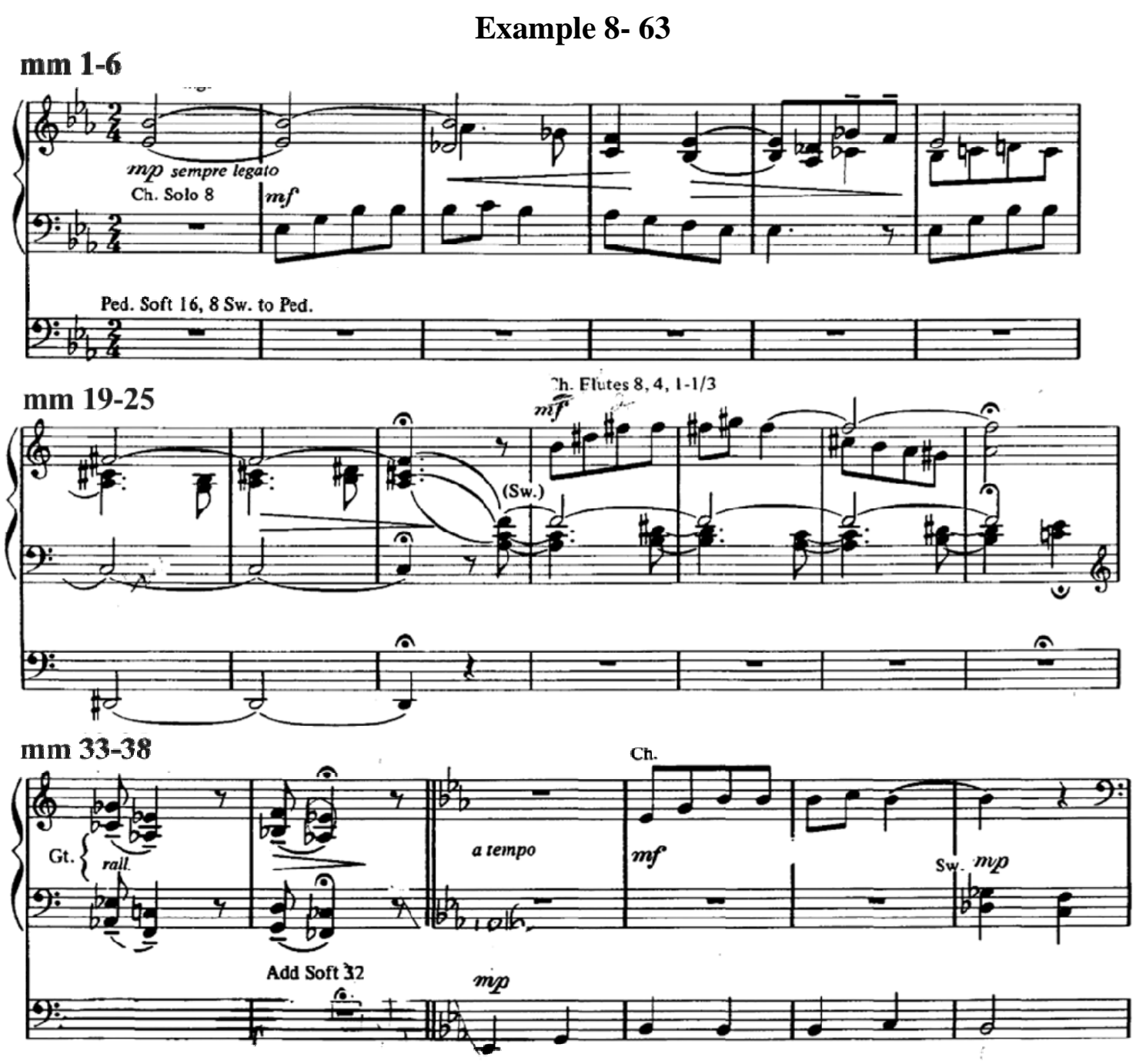

Chorale Cp132 Prelude on an American Folk Melody Collection XI; (1/1[10])

Sacred Music Press KK517-3

Long Melody Chorale

G major; multiple meters Designs for Organ (1992) Three Manuals/Pedal $52 \mathrm{~mm}$

It is a long form because of its multiple refrains, introduction and coda. It is based on the hymn-tune There Is a Balm in Gilead. It is a basic ABA treatment with A being the 'refrains' and B being the 'verse'. There is an extended improvisation in the B section. The twelve measure introduction, see Ex. 8-64, includes a complete statement of the refrain of the c.f., before Hebble treats the complete c.f. in the pedal (m. 12), while ninth 
and eleventh chords accompany in the manuals above. The B section expands the verse with a modulation from $\mathrm{F}$ major to A major (m. 27) and develops the motifs of the verse until it modulates back to F major (m. 37). At the return of the A section, Hebble "telescopes" 205 (ornaments) the c.f. with supporting jazz harmonies (mm. 39-40, 41-43). The coda repeats material from the introduction with altered harmony and syncopated rhythms and ends on a ninth chord with the added sixth.

Introduction
\begin{tabular}{|l|l|l|l|l|}
\hline $\begin{array}{l}\text { c.f. fragments in } \\
\text { soprano; c.f. solo } \\
\text { in tenor, no pedal }\end{array}$ & $\begin{array}{l}\text { c.f. in pedal solo, } \\
\text { altered chords, } \\
\text { changing meters }\end{array}$ & $\begin{array}{l}\text { c.f. in tenor solo, } \\
\text { r.h. in bass range } \\
\text { 'discouraged', } \\
\text { expands }\end{array}$ & $\begin{array}{l}\text { c.f. in soprano, I } \\
\text { and V pedals, } \\
\text { telescoping c.f. }\end{array}$ & $\begin{array}{l}\text { c.f. fragments } \\
\text { like introduction, } \\
\text { altered harmony }\end{array}$ \\
\hline mm. 1-12 & $21-36$ & $37-44$ & $44-52$ \\
\hline
\end{tabular}

\section{Example 8- 64}

\section{mm 1-3}
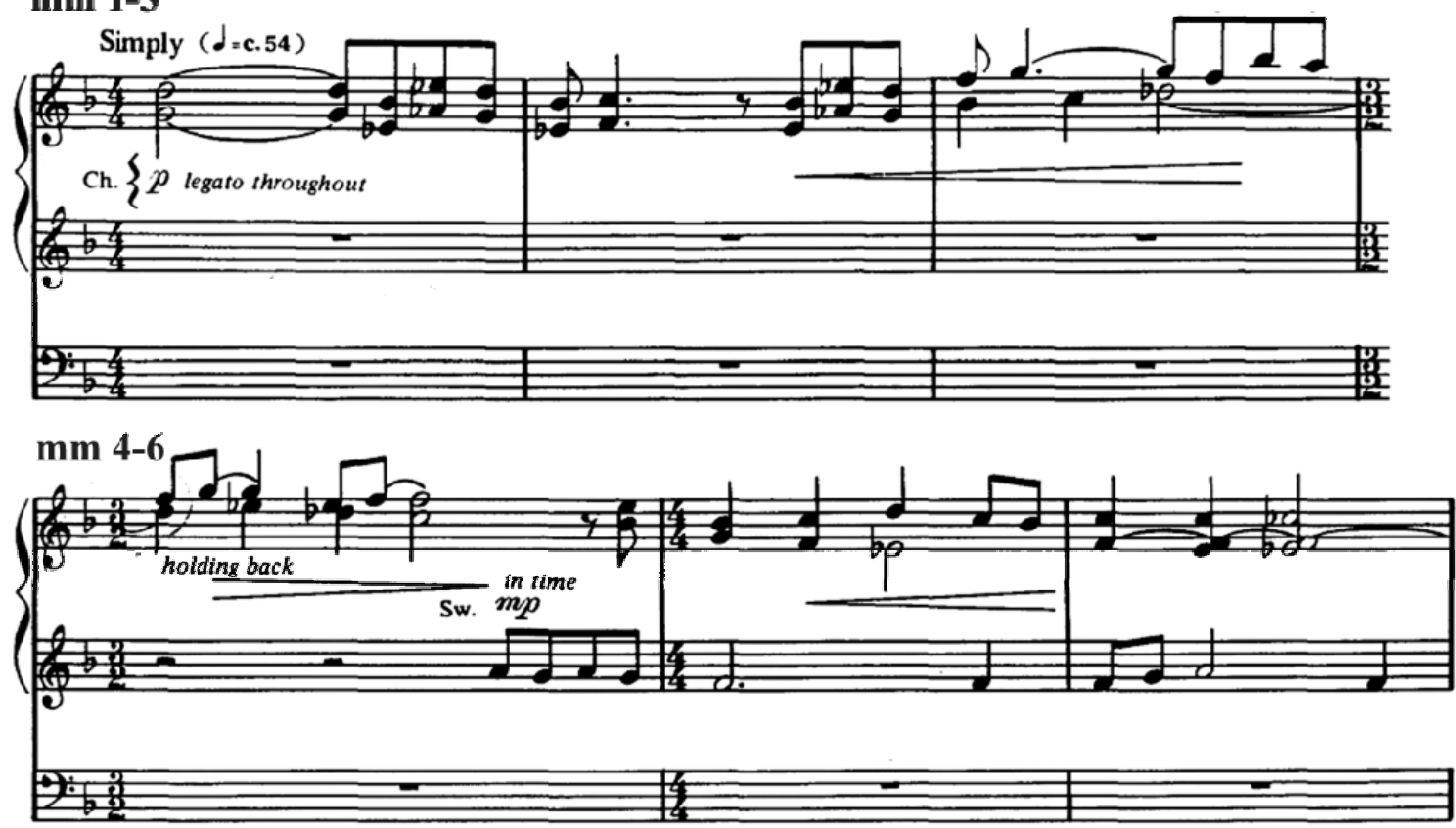

${ }^{205}$ Hebble's word for melodic extention by ornamentation. 
Chorale Cp137 Blessed Assurance

Belwin Mills EL03966

Long Melody Chorale

$A^{b}$ major; $9 / 8$ time
Collection XII; (1/2[8])

The Hebble Duet Collection (1994)

Two manuals/Pedal

$68 \mathrm{~mm}$

This is a duet for organ and piano and is in three large sections, hence the long form chorale: an introduction, a middle section that treats the c.f., and a coda. The introduction is in the dominant key $\left(\mathrm{E}^{\mathrm{b}}\right)$ and is a treatment of the triplet rhythm that outlines the words "bles-sed as-" and "Je-sus is". It is in a Gershwin-like jazz style, with altered harmony and unexpected harmonic progressions, when compared to its traditionally known harmony. The middle section treats the $c . f$. in the piano in augmentation with long, sustained chords in the organ part. He disguises the melody on the words "lost in His love" (mm. 32-33). He emphatically repeats the tune-fragment "this is my story" with fermatas and four octave, descending scales in the piano (mm. 47-49). This depicts Hebble himself saying "my story". Also, on the words "praising my Savior" (mm. 54-55) the piano plays hand-over-hand ascending scales through six octaves, a sign of "incompleteness". It depicts the "praising" of the "Savior" as "all the day long" and never complete. The coda repeats the harmonic and rhythmic material of the introduction with some alteration, see Ex. 8-65.

\begin{tabular}{|c|c|c|}
\hline Introduction & c.f. treatment & coda \\
\hline $\begin{array}{l}\text { Improvises on triplet } \\
\text { rhythm, dominant key }(\mathrm{V})\end{array}$ & $\begin{array}{l}\mathrm{A}^{b} \text { tonic, } \text { c.f. in piano in } \\
\text { augmentation, organ has } \\
\text { blues chords }\end{array}$ & $\begin{array}{l}\text { Revisits the introduction, } \\
\text { makes alterations }\end{array}$ \\
\hline mm. $1-10$ & $11-57$ & $57-65$ \\
\hline
\end{tabular}




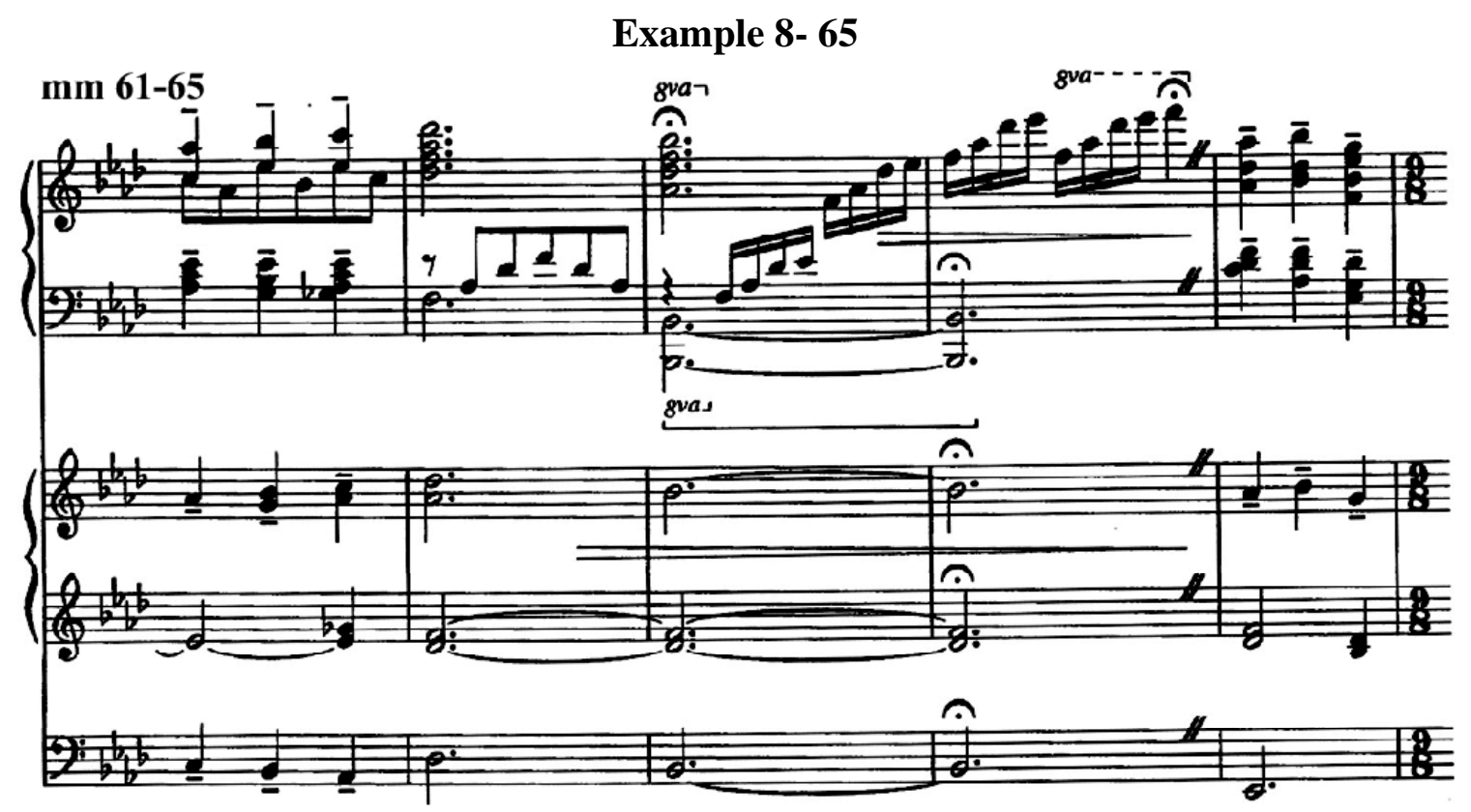

Chorale Cp139 Finlandia

Belwin Mills EL03966

Long Chorale Fantasia

F major; multiple meters
Collection XII; $(2 / 2[8])$

The Hebble Duet Collection (1994)

Three Manuals/Pedal

$77 \mathrm{~mm}$

This piece treats the hymn tune "Be Still, My Soul". It is a chorale fantasia long form with interludes, introduction and coda. It is a duet with organ and piano. It is in F major, but the middle section modulates to A major via a common-tone. It has a doubleintroduction, one part in F major (mm. 1-4) where the c.f. is in the piano in quintalquartal harmony, see Ex. 8-66; the other part is in A major (mm. 5-8). There are two larger middle sections: Section A is in A major and treats the c.f. beginning with the piano left-hand (mm. 8-16) and ending with the piano right-hand (mm. 17-31), while the organ plays altered harmony. Section $\mathrm{B}$, after a brief interlude, modulates back to $\mathrm{F}$ major and begins with the c.f. in the organ (mm. 33-36), then moves to the left-hand of the piano (mm. 37-40), then back to the organ (mm. 41-59) in hocket between the 
instruments. The extended coda (mm. 60-77) treats fragments of the c.f. on both instruments. The source material for this work is Sibelius' Finlandia Tone Poem.

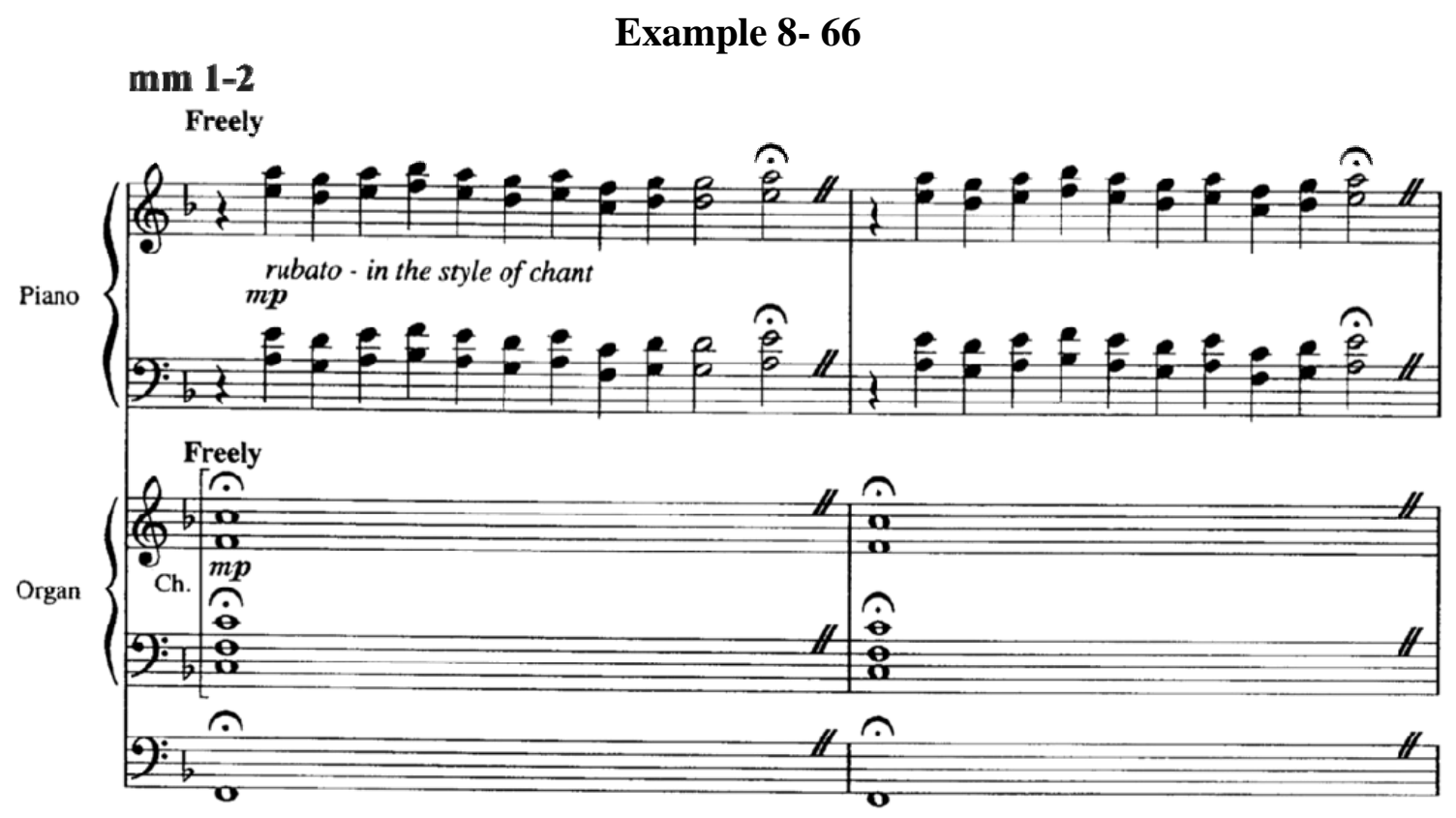

Chorale Cp150 O Perfect Love Belwin Mills GB9503 Long Melody Chorale $\mathrm{E}^{\mathrm{b}}$ major; $4 / 4$
Collection XIII; (1/1[15])

Wedding Music for Organists (1995)

Three Manuals/Pedal $32 \mathrm{~mm}$

Based on the song by Joseph Barnaby with one modulation, it is homophonic and hymn-

like in nature. Hebble keeps the arrangement simple, having only occasional passing dissonance and 'tightened up counterpoint'. ${ }^{206}$ Although there are no interludes, introductions, or codas, it is a long form because of its multiple verses. It contains a common-tone modulation from $\mathrm{E}^{\mathrm{b}}$ major down to $\mathrm{D}$ major in the second verse after the

${ }^{206}$ Hebble, phone conversation July 7, 2002. 
second strophe (m. 25). There Hebble makes use of a dominant pedal that leads instead to a plagal cadence, again avoiding the dominant-seventh chord.

\begin{tabular}{|c|c|}
\hline \multicolumn{2}{|c|}{ Verse Two } \\
\hline $\begin{array}{l}\text { Homophonic, c.f. in soprano, } \mathrm{E}^{b} \text { major, no } \\
\text { pedal on first two strophes }\end{array}$ & $\begin{array}{l}\text { First two strophes have no pedal in } \\
\text { modulates to D major and adds ped }\end{array}$ \\
\hline Measures $1-16$ & $17-32$ \\
\hline Chorale Cp169b "Playfully" & Single Work \\
\hline Hinshaw Music Incorporated HMO-150 & A Symphony of Light, II (1986) \\
\hline Long Chorale Fantasia & Three Manuals/Pedal \\
\hline C major; $4 / 4$ time & $109 \mathrm{~mm}$ \\
\hline
\end{tabular}

It treats the chorale How Brightly Shines the Morning Star within the larger work Symphony of Light Cp169. It is one of Hebble's largest chorale-preludes and is composed in an extemporized French paraphrase style like that of Pierre Cochereau. This work is teeming with musical devices. It grows in volume and textural complexity using a variety of organ registrations, then decrescendos to its simple origins in a quasi-ternary form with the c.f. as the principle theme with added introduction and coda. Perfect fourths form the introduction during which there are various metrical treatments of the c.f. fragments on different manuals (timbres). This coincides with the supplied text to the second movement of the Symphony of Light from Psalm 148:3 "Praise ye him, sun and moon; praise him all ye stars of light”, and depicts the c.f. as being created ex nihilo, from nothing as well as the many varieties of "praise". From measure forty, a small toccata develops out of block chords of the c.f. in the right-hand and no pedal. When this figure stops (m. 52) a repeat of the introductory material takes place in upside-down: the c.f. is in the tenor while seventh and ninth chords progress above it and in the pedal. This reversal is short and the c.f. moves to the right hand (m. 58) when the B section extemporizes upon the held notes of strophe three (mm. 62-66, 67-68, 77-82). During 
this, there is both canon (mm. 73-76) and stretto in bi-tonality: the treble c.f. (based on strophe one) is in F\# Lydian and the pedal c.f. (based on strophe three) is in C\# major (mm. 77-84). The C\# major is a brief misspelled incursion of Neapolitan harmony. The organ decrescendos and returns to section $\mathrm{A}(\mathrm{m} .87)$ this time in the relative minor (A minor). The coda reprises some of the introductory material (m. 93) along with echoes of the c.f. fragments across three manuals in a continual decrescendo. It ends on a tonic thirteenth chord.

\begin{tabular}{|c|c|c|c|c|}
\hline Introduction & $\mathrm{A}$ & $\mathrm{B}$ & $A^{\prime}$ & Coda \\
\hline $\begin{array}{l}\mathrm{V} / 9 ; \mathrm{V} / \mathrm{V} 9 ; \mathrm{I} 9 \\
c . f . \text { fragments, } \\
\text { metrical changes, } \\
\text { manual changes }\end{array}$ & $\begin{array}{l}\text { c.f. almost } \\
\text { complete quote, } \\
\text { toccata figure, }\end{array}$ & $\begin{array}{l}\text { Treatment of } c . f \text {. } \\
\text { strophe three, } \\
\text { modulation, } \\
\text { canon, stretto }\end{array}$ & $\begin{array}{l}\text { Return to section } \\
\text { A, altered } \\
\text { harmony, toccata } \\
\text { fragments }\end{array}$ & $\begin{array}{l}\mathrm{V} / 9 ; \mathrm{V} / \mathrm{V} 9 ; \mathrm{I} 9 \\
c . f . \text { fragments, } \\
\text { metrical changes, } \\
\text { manual changes }\end{array}$ \\
\hline mm. 1-39 & $40-57$ & $58-87$ & $87-92$ & 93-109 \\
\hline
\end{tabular}

$\begin{array}{ll}\text { Chorale Cp170 Lamentation on “Were You There?” } & \text { Single Work } \\ \text { Harold Flammer Publishing (HF5192) } & \text { (1997) } \\ \text { Long Melody Chorale } & \text { Two Manuals/Pedal } \\ \mathrm{E}^{\text {b }} \text { major in common time } & 41 \mathrm{~mm}\end{array}$

This work is temporarily out of print. It has a short introduction and coda and one treatment of the $c . f$. in the soprano. There are short interludes, hence the long form, that contain fragments of the $c . f$. with altered harmony and rhythms.

Chorale Cp171 Partita on Lobe Den Herren

Hinshaw Music Incorporated HMO-154

Chorale Partita

F major; multiple meters
Single Work. (1986)

Three (+) Manuals/Pedal $134 \mathrm{~mm}$

Like Bach, Hebble is didactic in his encyclopedic treatment of the c.f. motivically, texturally, harmonically and rhythmically. This work also demonstrates his ease with contrapuntal procedures. One can refer to the diagram of Lobe Den Herren provided by 
Hebble in the 'preface' for what specific notes of the c.f. are treated in the movements. ${ }^{207}$ The use of fragments of the c.f. is derived from the French Paraphrase technique of improvisation within the variations form, and the entire work is highly improvisatory in nature, see Ex. 8-67. Again, Neapolitan harmonies are frequent (mvmt. I, mm. 20, 22, 28). Tristan harmonies occur (mvmt. I, mm. 28, 43), and polytonality occurs (mvmt. I., mm. 59-72). There are key changes, modulation and jazz harmonies with lowered thirds and sixths (mvmt. I., mm. 53-58, 91-113). There is prevalent use of rhythmic devices such as syncopation (mvmt. I., mm. 8, 11, 13, 14, 30, 46-48, 93, 97, 99, 101, 111), ${ }^{208}$ metrical changes throughout all movements also occur, as well as polyrhythms (mvmt. II., mm. 1-4+, 13-17, 19-20, 27-31, 42-46), and hemiola (mvmt. I, mm. 46-48, 73-76, 85, 87, 102 and mvmt. II in the pedal). There is also extensive treatment of the c.f. including ornamentation (telescoping) ${ }^{209}$ (mvmt. I, mm. 60-63, 64-67, 68-72), and augmentation (mvmt I, mm. 53-58, 91-93; mvmt. III, mm. 23-25). There is diminution (mvmt. III, mm. 31, 33-36) and retrograde (mvmt. II, mm. 46, 49, 50, 52). Inversion (mvmt. III, mm. 21, $24-25,41)$ and various textural treatments occur including imitation, canon (mvmt I, mm. 59-60, mvmt. II, mm. 42-43, 45-46, 49-50), and ostinato (mvmt II, pedal).

\footnotetext{
${ }^{207}$ From the "Composer's Preface" to the Partita on 'Lobe Den Herren'.

${ }^{208}$ These are just some examples.

${ }^{209}$ Persichetti, Vincent. Twentieth Century Harmony, Norton and Norton Company, Inc., New York, 1961, p. 263. "Telescoping" for Hebble means 'stretching out a melodic line by adding notes to it'.
} 


\section{Example 8- 67}

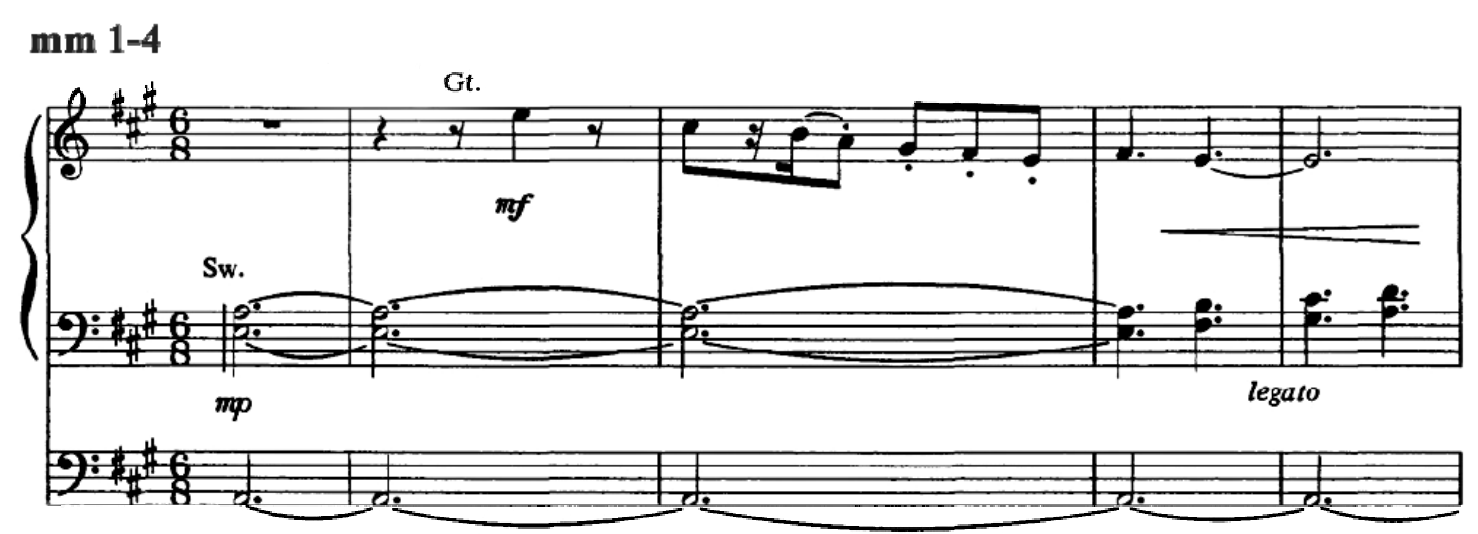

Chorale Cp172 Variations on an American Hymn Tune Single Work

Warner Brothers Publishing BHS9703

Chorale Variations

F major (multiple keys); multiple meters
(1997)

Three(+) Manuals/Pedal

$87 \mathrm{~mm}$

This work contains six variations plus an opening introductory section. Each variation could be played as a separate work. The American tune is "Nettleton", known in American church hymnody as "Come, Thou Fount of Every Blessing". The variations make exhaustive use of the resources of ACO registration, ranging from principal choruses to French and German Baroque stops to Romantic soft accompaniments with solo flutes and reeds, see Ex. 8-68, sy1. Variation III, Laid back - in a jazz style, see Ex. 8-67, sy5, uses a quasi-string-bass ostinato against the foreground of an ornamented c.f. and is quite jazzy in style. In addition to featuring forms idiomatic to the organ, such as the final Toccata with c.f. in the pedal in French Romantic style, see Ex. 8-68, sy8-9, which exploits other varied treatments of the c.f., these variations also stretch tonal daring, see Ex. 8-68, sy5. This includes the use of bi-tonality (var. II, mm. 34-36), polychordal writing (var. VI, mm. 21-26), Neapolitan harmonies (var. I, m. 17, 18; var. 
II, m. 34), Tristan harmonies (var. II, mm 26, 27), and jazz harmonies, all of which pervade the work. As well as ostinato (var. III), the texture is also organized by features of canon and imitation (var. I, mm. 8-13); the rhythm is also often syncopated (introduction, mm. 8,10-12, 16-18; var. II, mm. 4, 8, 19, 23; var. III, mm. 5, 19, 22, 27, 30, 47; var. IV, mm.3-4, 7-9; var. V, mm. 18, 20), see Ex. 8-68, sy6-7, and features frequent changes in meter (var. VI). 

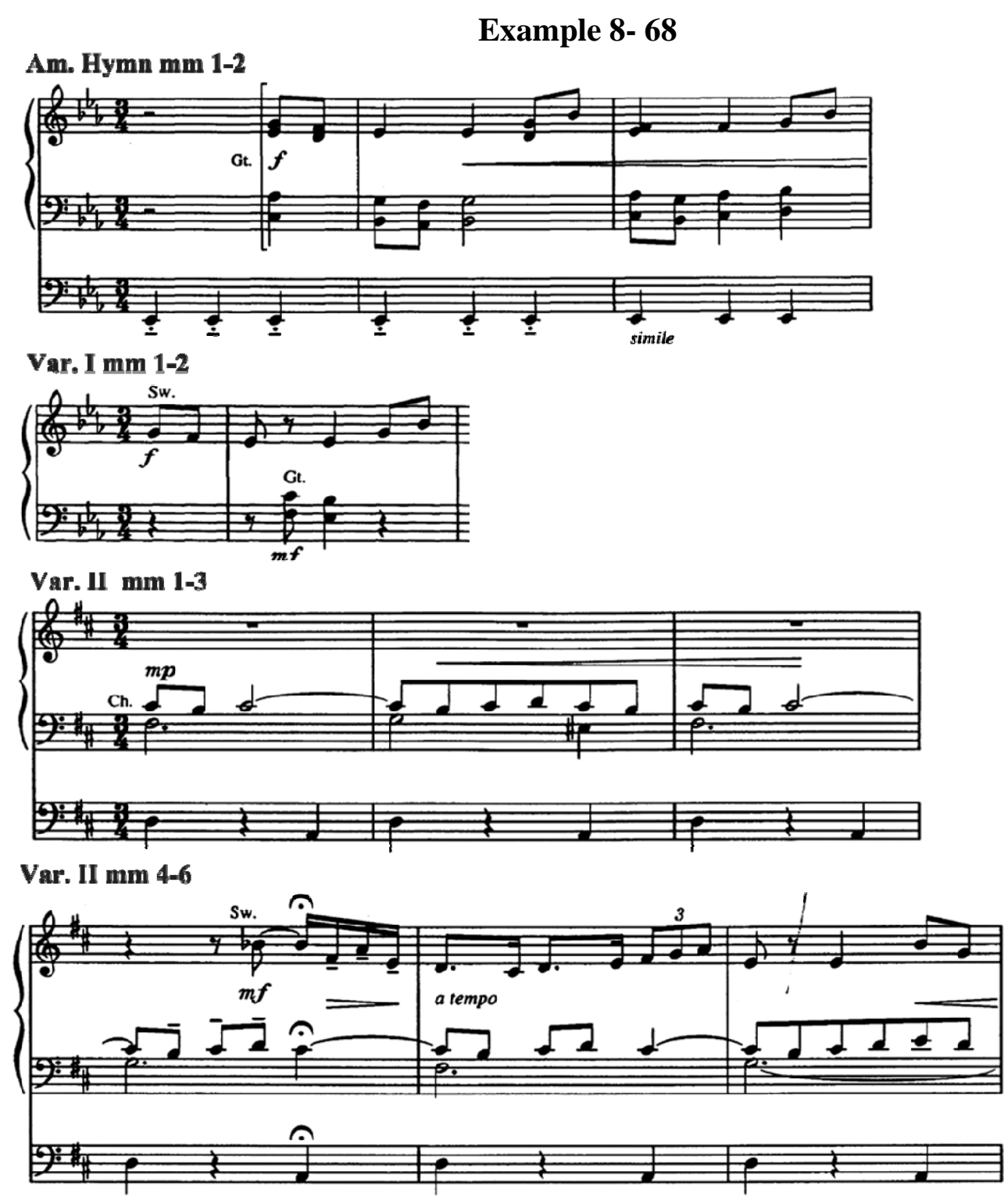

\section{Var. III mm 1-6}

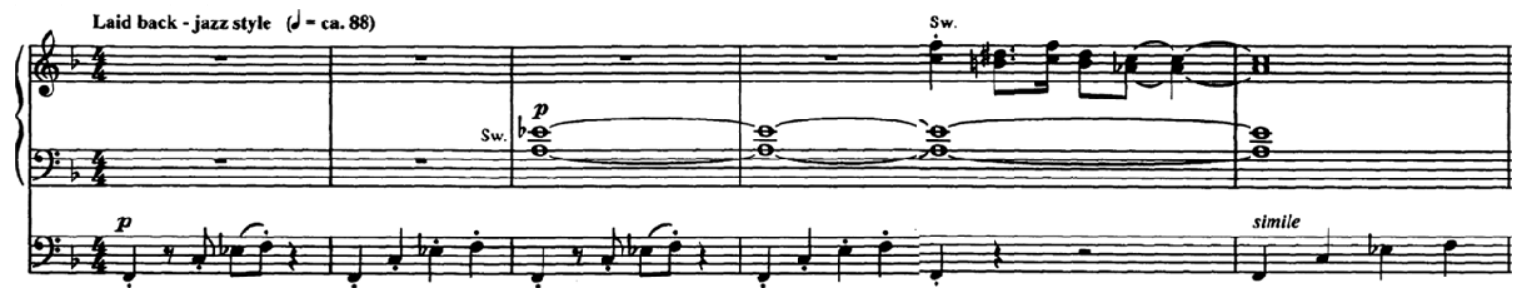

The published organ chorales of Robert Hebble offer the greater organ community a panorama of styles, whose music is so closely linked with the ACO. These include neo-classicism, jazz indebted styles, the American theater organ styles, 
interpretive elements, and hermeneutics. Hebble's organ chorale-preludes, while relying on past forms and techniques ${ }^{210}$, are modern testaments of church music steeped in Americana.

${ }^{210}$ Refer to "Use of the Organ", Chapter 5. 


\section{CHAPTER 9}

\section{The Free Works}

The free works of Hebble are those compositions for organ not based on a hymntune c.f. (or cantus prius factus), but are compositions based on original melodies as the principal theme and, as free works, take on an even greater improvisational nature. Although his free works adopt, for the most part, the arch form or ABA form, the most characteristic trait of his improvised compositions follow the so-called French Paraphrase technique. ${ }^{211}$ This was modeled by such twentieth century organists as Marcel Dupré (1886-1971), Maurice Duruflé (1902-1986) and Pierre Cochereau (1915-1981); all of whom Hebble personally heard improvise in this manner while he studied with Nadia Boulanger in Paris from 1955-1956. This technique can also be of a through-composed construction, although it mostly adopts an A-B-A approach. Hebble's free works in an improvisatory style are also based in such classic forms as ternary, sonata, rondo, free fantasia. ${ }^{212}$ This style incorporates some contrapuntal procedures in Hebble's music in a manner similar to the organ music of César Franck.

In short, the free works (as well as some of the chorale-based works) appear with two contrasting sections (sometimes more): one that is a more straight presentation of the principal theme and the other is quite improvisatory in style. The latter section offers suggestions and fragments of thematic ideas (like a chorale motet) or breaks away from the theme almost entirely (similar to a chorale fantasia). Both are part of the French

\footnotetext{
${ }^{211}$ Dupré, Marcel. Cours Complet d'Improvisation à l'Orgue. Paris: A.Leduc, 1962, p. 7. This style of improvisation was established and disseminated by Charles Tournemire and first used on the cover of his L'Orgue Mystique and in his "Notice of the Author".

${ }^{212}$ Bender, Jan. Organ Improvisation. St. Louis: Concordia Publishing House, 1975, pp. 112-21.
} 
Paraphrase technique. Hebble maintains a balance between sustaining musical interest with glimpses of 'familiar' harmonic or melodic material coupled with the interesting tonal resources of the ACO. Hebble employs these techniques in various ways, demonstrated by a perusal of his individual free works.

Freework Cp46 Brick Church Bradley Publications B22M24 G major; 3/4 time $38 \mathrm{~mm}$; binary
Collection V; $(1 / 5 /[12])$

The Robert Hebble Collection (1982)

Two Manuals/Pedal

Like the Flor Peeters' Aria for Organ, this piece is a pastoral with a repetitive left-hand accompaniment in quasi-binary form: the first half (mm. 1-16) moves away from tonic, the second half (mm. 17-38) moves towards tonic, see Ex. 9-1. The PT has a periodic structure of two four bar antecedent and consequence phrases, each extended. Substitute chords and altered chords abound when the theme re-appears in the second half ( $\mathrm{mm} .17-$ 28) as a 'solo' in the right-hand. Hebble says,

"I didn't mark a specific registration for this piece: I like to hear, instead, how different organists will register it. I'm always curious what they will use". ${ }^{213}$

It is designed as an interlude for a church service. Hebble received the idea for the theme when he passed a church called "Brick Church" in Brick, New Jersey, a suburb of Orange, New Jersey. The final phrase is a mixture of the antecedent and consequent phrases and the theme ends on the major-seventh over the tonic. 


\begin{tabular}{|c|c|c|c|c|}
\hline Introduction & Section One & Section Two & Codetta 1 & Codetta 2 \\
\hline $\begin{array}{l}\text { 6-4 inversion } \\
\text { chords over tonic } \\
\text { pedal }\end{array}$ & $\begin{array}{l}\text { Antecedent } 4 \mathrm{~m} \\
\text { consequent } 6 \mathrm{~m}\end{array}$ & $\begin{array}{l}\text { Antecedent } 4 \mathrm{~m} \\
\text { consequent } 8 \mathrm{~m}\end{array}$ & $\begin{array}{l}\text { Antecedent and } \\
\text { consequent } \\
\text { phrase combined }\end{array}$ & $\begin{array}{l}\text { Theme on M7 } \\
\text { substitute chords }\end{array}$ \\
\hline
\end{tabular}

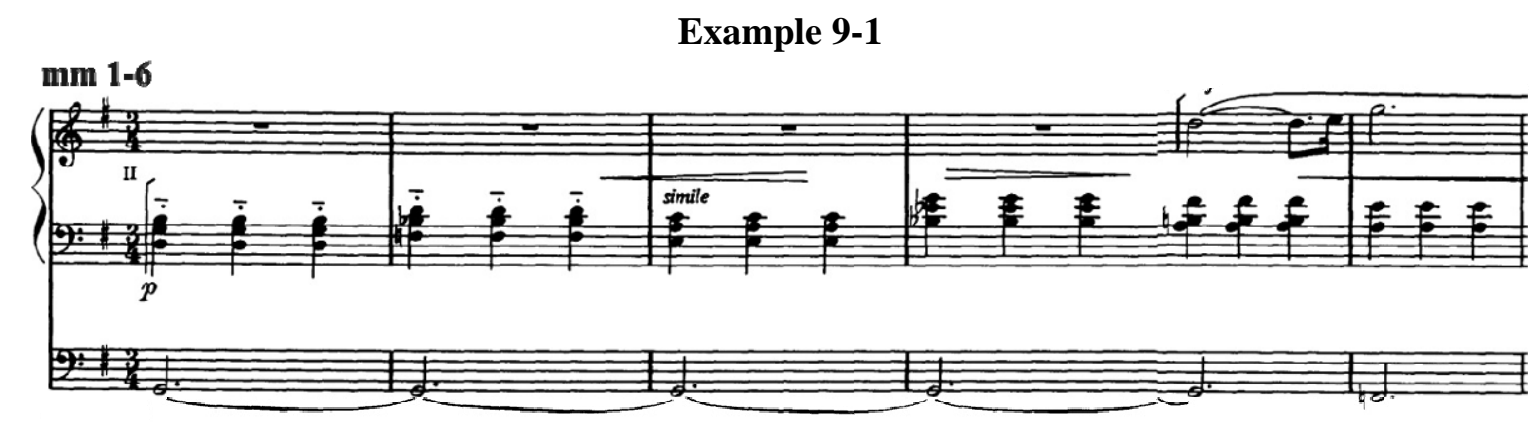

Freework Cp49 Day Star

Bradley Publications B22M24

E minor; $4 / 4$ time

$45 \mathrm{~mm}$; quasi-ritornello
Collection V; $(2 / 5 /[12])$

The Robert Hebble Collection (1982)

Three Manuals/Pedal

The score is subtitled from II Peter 1:19,

...you will do well to take heed, like a light that shines in a dark

place, until the day dawns, and the day star arises in your heart". ${ }^{214}$

It is similar to Cesár Franck's organ works in that it contains an interior second theme that is slower much like a chant seraphique, which Franck used in his chorales on an alternate registration $^{215}$, see Ex. 9-2, sy2. Composed in a quasi-ritornello form, the work pivots between episodes treating the PT and the ritornellos of the chant seraphique.

Although a free work, it is similar in formal design to Hebble's chorales. The 'star' is depicted in the main theme (mm. 2-9) on the Choir division's solo Flute 8 with tremolo, which 'twinkles' due to the tremolo and the high tessitura, see Ex. 9-2, sy1. The depiction

\footnotetext{
${ }^{213}$ Hebble, Florida tape two, side one.

214 ...The Holy Bible, Nashville, Tennessee, Thomas Nelson Publishers, (1976), p. 1787.

215 In this work Hebble employs the Swell Strings Celestè 8' (4' ad lib) for the chant seraphique.
} 
of "day" is achieved by the rising line of the chant seraphique (mm 9-12, 19-21, 41-42), and a climbing tessitura, alluding to the sun or stars. Proportion is demonstrated by the six measure antecedent phrase (mm. 2-6), the six measure consequent phrase (mm. 1318), and the final entrance of the PT of six measures (mm. 35-40).

Ritornello

Introduction

\begin{tabular}{|l|l|}
\hline $\begin{array}{l}\text { Ostinato on } \\
\text { chord cluster }\end{array}$ & $\begin{array}{l}\text { High tessitura, 2 } \\
\text { short phrases }\end{array}$ \\
\hline
\end{tabular}

Ritornello $3-8$ ascending line 9-12 chant seraphique

Swell Strings 8'

Ritornello

\begin{tabular}{|l|l|}
\hline theme consequent & chant seraphique \\
\hline $\begin{array}{l}\text { High tessitura, } 2 \\
\text { phrases reversed }\end{array}$ & $\begin{array}{l}\text { Ascending to } \mathrm{B}^{\mathrm{b}} \\
11^{\text {th }} \text { chord }\end{array}$ \\
\hline
\end{tabular}

13-18 19-21 mm 1-2

\section{Ritornello - -}

theme/antecedent theme/consequent

\begin{tabular}{|l|l|}
\hline $\begin{array}{l}\text { Mixolydian, built } \\
\text { off }{ }^{\natural} \mathrm{V}, 2 \text { phrases } \\
\text { polytonal }\end{array}$ & $\begin{array}{l}2 \text { longer phrases, } \\
\text { melodic } \\
\text { telescoping }\end{array}$ \\
\hline
\end{tabular}

$\mathrm{mm} 21-25$

26-32

\begin{tabular}{|l} 
theme/conse \\
$\begin{array}{l}\text { Augmented, } \\
\text { compound } \\
\text { rhythm }\end{array}$ \\
\hline
\end{tabular}

chant seraphique
$\begin{aligned} & \text { Ascending line, } \\ & \text { ends on a F11th } \\ & \text { chord }\end{aligned}$

coda Theme fragment, splits to 2 voices

$33-40$

$41-42$

$42-45$ 


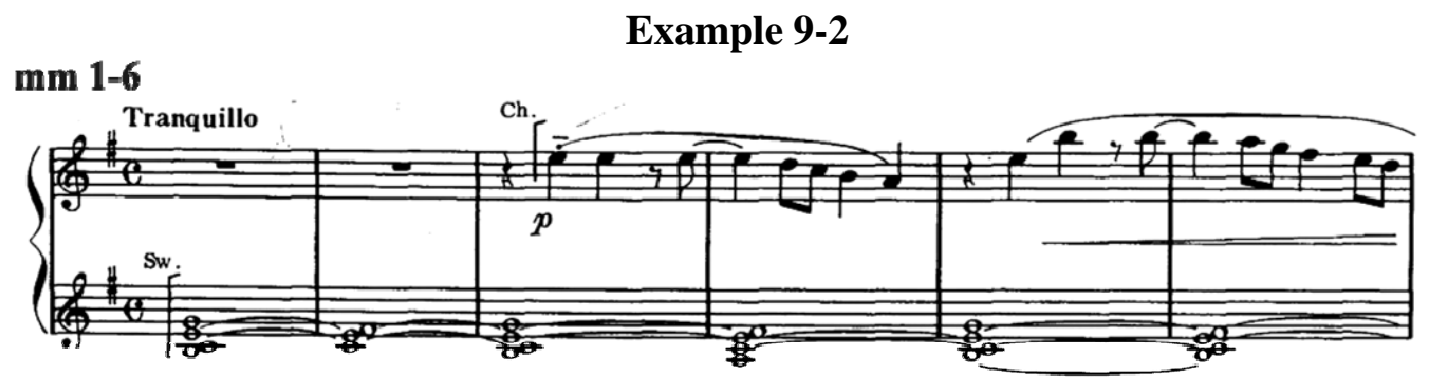

mm 19-24

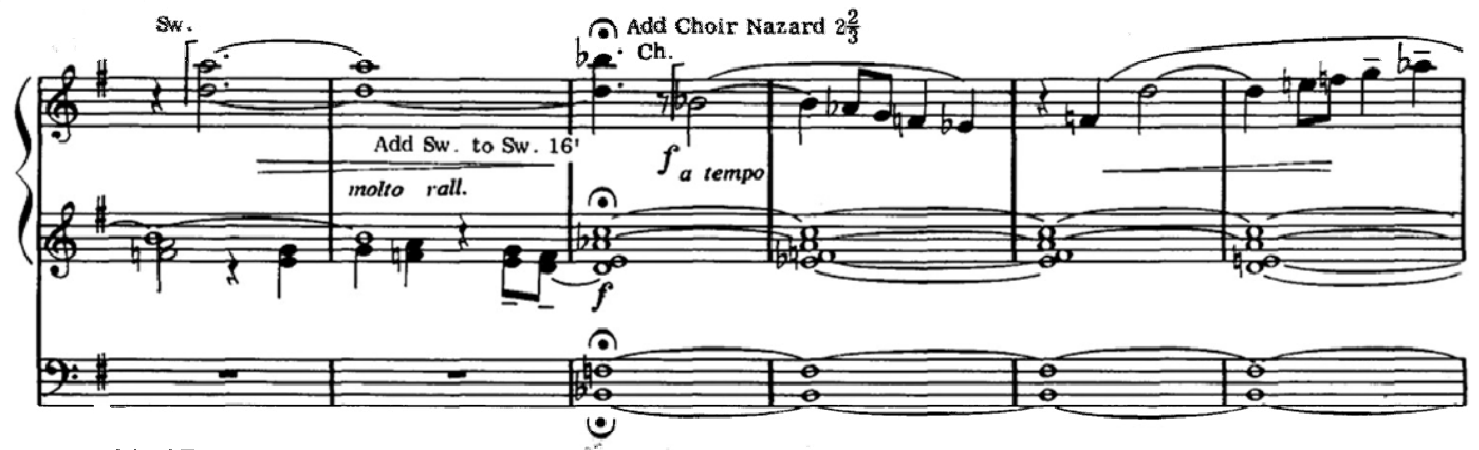

mm 41-45

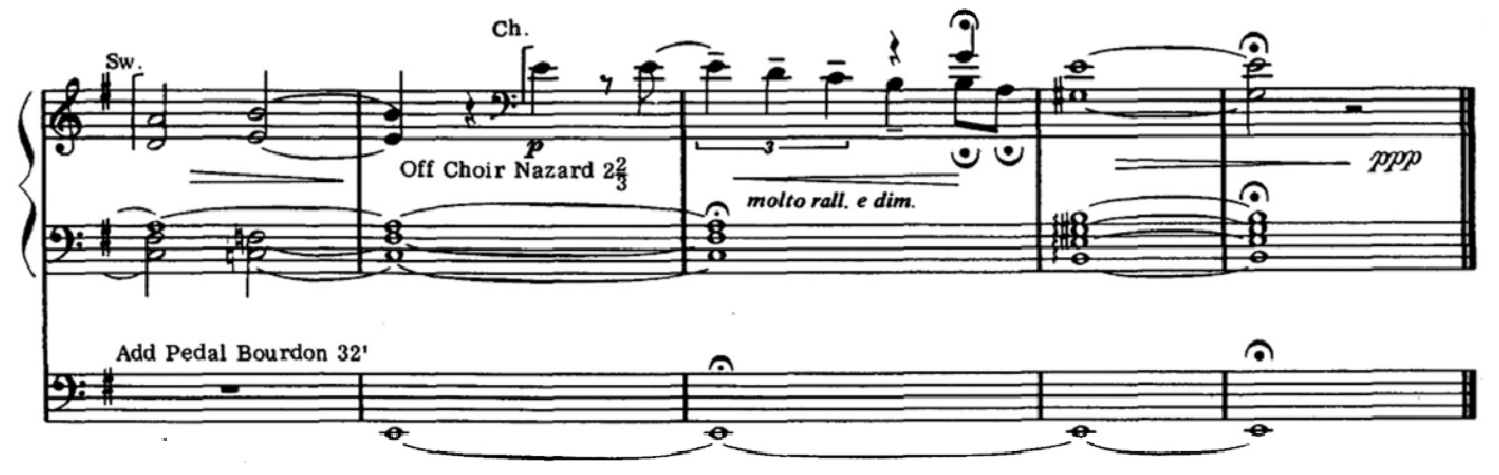

Freework Cp50 Exultate Deo

Bradley Publications B22M24

F major; 4/4 time

$73 \mathrm{~mm}$; ternary
Collection V; $(3 / 5 /[12])$

The Robert Hebble Collection (1982)

Three Manuals/Pedal

After a 14 bar introduction of small fanfare-like phrases, section A begins with with antecedent phrase of the PT (m. 15-18) then a consequent phrase (mm. 19-22), see Ex. 93. Section B has a soprano theme that is sequential (mm. 24-27, 28-31), which becomes more legato (mm. 32-37) and is echoed in the pedal (mm. 24-25). There are many intervallic references to intervals from the introduction. Section A returns in a new key 
(mm. 39-50) in $\mathrm{B}^{b}$ minor, the minor iv of $\mathrm{I}$, and is syncopated (mm. 45-46). The work ends palendromically with material from the introduction ( $\mathrm{mm} .47-60)$. The final section ends with diminished motifs (then augmented) from section A (mm. 64-70) and stretto occuring in the pedal. The work could be used for a postlude and it is marked Spiritoso and full organ.

\begin{tabular}{|c|c|c|c|c|}
\hline Intro & Section A & Section B & Section A & Final section \\
\hline $\begin{array}{l}\text { Little } \\
\text { fanfares }\end{array}$ & $\begin{array}{l}\text { Antecedent/con } \\
\text { sequent phrases }\end{array}$ & $\begin{array}{l}\text { Disjunct and } \\
\text { legato themes, } \\
\text { intro material }\end{array}$ & $\begin{array}{l}\text { Consequent and } \\
\text { antecedent phrases }\end{array}$ & $\begin{array}{l}\text { Diminution } \\
\text { stretto }\end{array}$ \\
\hline mm. 1- & $15-22$ & $23-50$ & $51-60$ & $61-73$ \\
\hline
\end{tabular}

\section{Example 9-3}

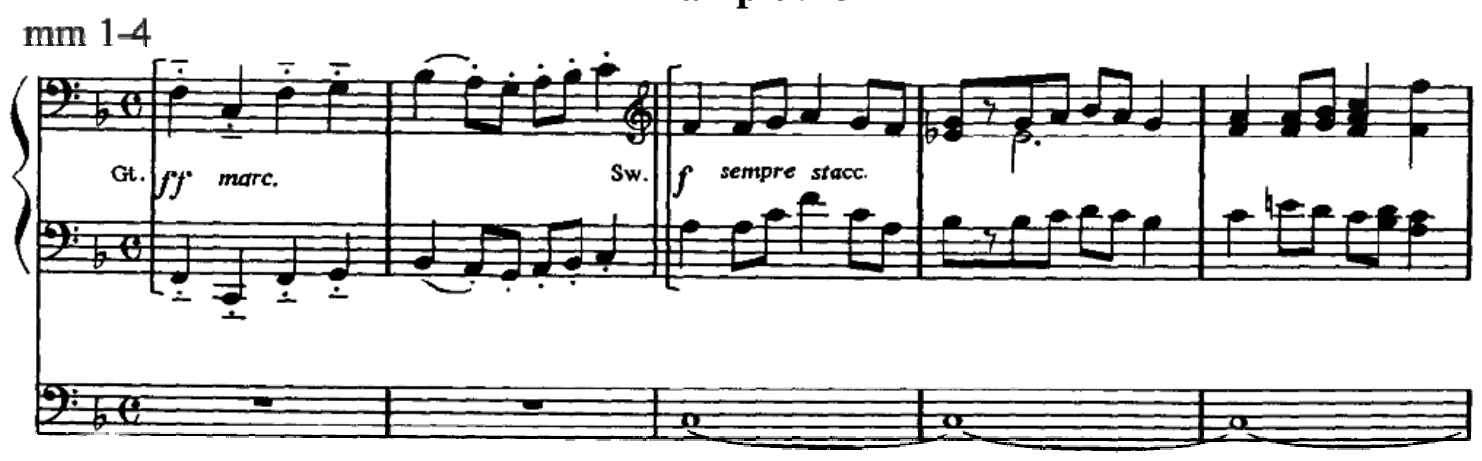

Freework Cp51 Pastorale

Bradley Publications B22M24

A minor; $3 / 4$ time

$72 \mathrm{~mm}$; ternary
Collection V; $(4 / 5 /[12])$

The Robert Hebble Collection (1982)

Two Manuals/Pedal

In ternary form, the PT contains periodic phrase structure of antecedent and consequent phrases (mm. 1-4, see Ex. 9-4, sy1; [5-8, 9-12, 13-16]) without pedal. Whereas the first and last sections begin with a pick-up before the accompaniment, the middle section has the accompaniment entering first ( $\mathrm{mm} \mathrm{21).} \mathrm{The} \mathrm{central} \mathrm{section} \mathrm{is} \mathrm{based} \mathrm{on} \mathrm{the} \mathrm{dominant}$ (V), see Ex. 9-4, sy2. When section A returns there are some alterations (m. 45) which 
result in fuller chords and the addition of pedal, see Ex. 9-4, sy3. There is a coda (mm.

60-72) featuring open spacing in the chords, altered harmony, syncopation and suspensions (mm. 65-70).

\begin{tabular}{|c|c|c|c|}
\hline Section A & Section B & Section A & Coda \\
\hline \begin{tabular}{|l|} 
Theme in \\
soprano \\
antecedent \\
consequent \\
phrasings
\end{tabular} & $\begin{array}{l}\text { Developed } \\
\text { thematic } \\
\text { material, } \\
\text { submediant pedal }\end{array}$ & $\begin{array}{l}\text { Return of } \\
\text { opening section } \\
\text { addition of pedal } \\
\text { and fuller chords }\end{array}$ & $\begin{array}{l}\text { Open position } \\
\text { altered chords, } \\
\text { suspensions, } \\
\text { tonic pedal }\end{array}$ \\
\hline
\end{tabular}

\section{Example 9-4}
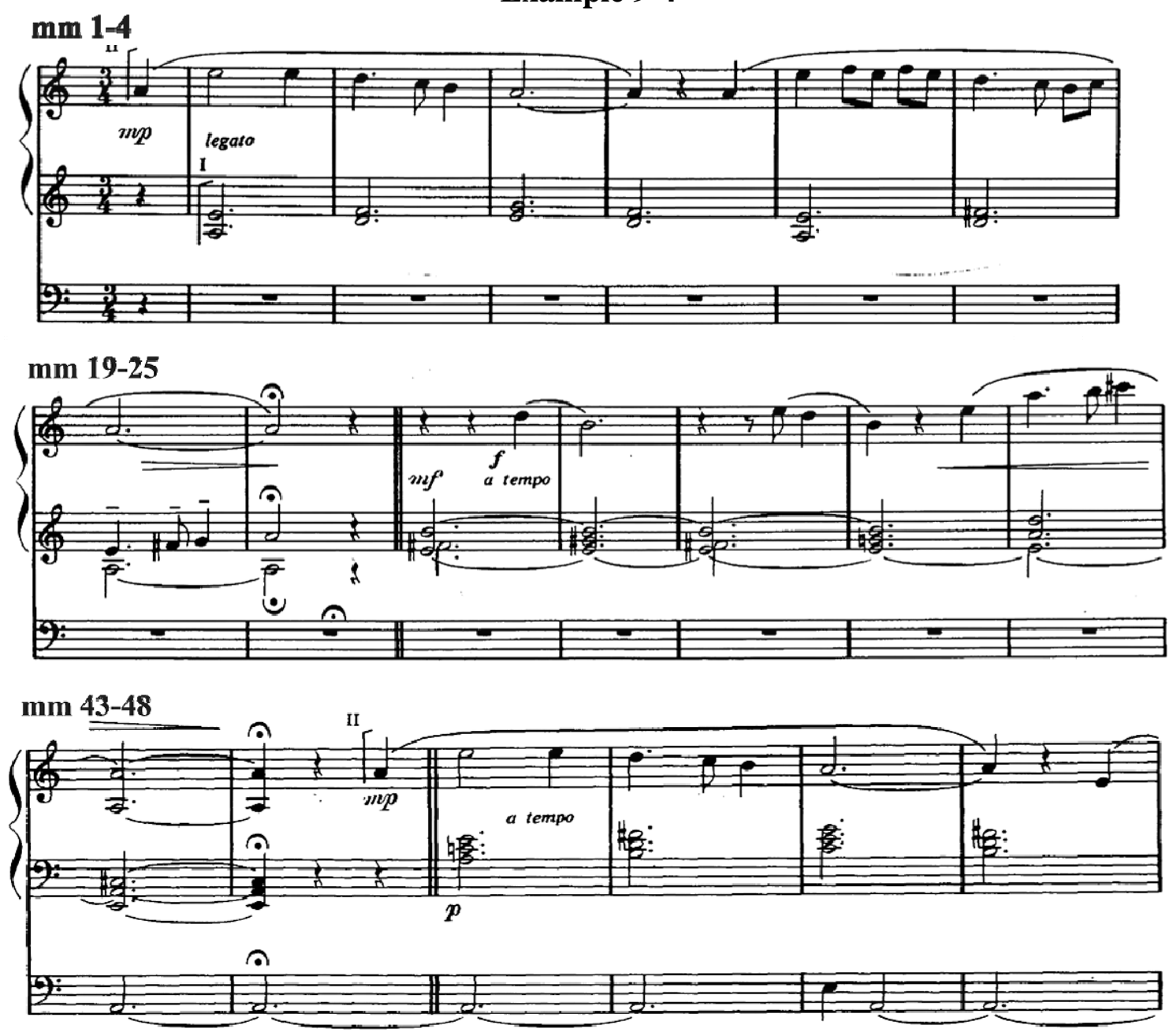
Freework Cp53 Stretch Forth Thy Hand to Heal Collection V; (5/5/[12])

Bradley Publications B22M24

F major; 3/4 time

The Robert Hebble Collection (1982)

$83 \mathrm{~mm}$; quasi-rondo form Three Manuals/Pedal chorale?

It was composed for Dr. William Armstrong who was Virgil Fox's physician during

Fox's bout with cancer. Hebble states that this piece is a Tone Poem based on the text from Acts 4:30:

By stretching forth thine hand to heal; and that signs and wonders may be done by the name of the holy child Jesus. ${ }^{216}$

The work employs thematic transformation as a means of expressing Hebble's (and Armstrong's) hope for a complete healing of Fox from his cancer. It is written in the manner of an improvisation, which is rondo-like in form. The introduction (mm. 1-9) quotes fragments of the theme, which evolves from F major to D minor, see Ex. 9-5, sy1. The opening section has two phrases: one phrase of six measures (mm. 10-15) (six being a sign of imperfection alluding to the medical malignancy of the cancer) and another phrase of seven measures (mm. 16-22) which is soaring and evokes the hope of what Fox wanted: to be transformed, healed. A sequence emerges, similar to a Franckian chant seraphique, of eight measures in three phrases (mm. 23-30, 31-38, 39-42) with the last abruptly foreshortened, alluding to Fox's life. This constitutes the middle portion of the work. The theme reappears (mm. 43-52), but is altered to ten measures (coordinating with the Ten Commandments) and is restated (mm. 53-58) in six measures (imperfect) in three-part canon. Another sequence of three phrases follows (mm. 60-62, 63-65, 66-68) and each is three measures long. Each time the theme is extended, or reharmonized, to allude to Fox's transformation to heaven (the number ten [commandments], the three-part

216 . - . . . The Holy Bible, New Standard Version, (1995), p. 1327. 
canon, and the three phrases of three measures [3x3]), which alludes to 'healing' or perfection. The final theme is presented in the standard musical proportion of eight measures (mm. 69-76) on one of Fox's favorite stops: the Vox Humana in the tenor range, see Ex. 9-5, sy2. The coda is the chant seraphique (mm. 77-84) which has modulated down a third to D major and is in the highest register while fragments of the theme play in the pedal on the Bourdon 32.

A B A

\begin{tabular}{|l|l|}
\hline Intro/fragments & $\begin{array}{l}\text { Sequence in } 3 \\
\text { Imperfect } 6 \text { meas.. } \\
\text { phrases; last one } \\
\text { cut-off early } 7 \text { meas. }\end{array}$ \\
\hline
\end{tabular}

mm. 1-9, 10-22

$23-42$

\section{Example 9-5}

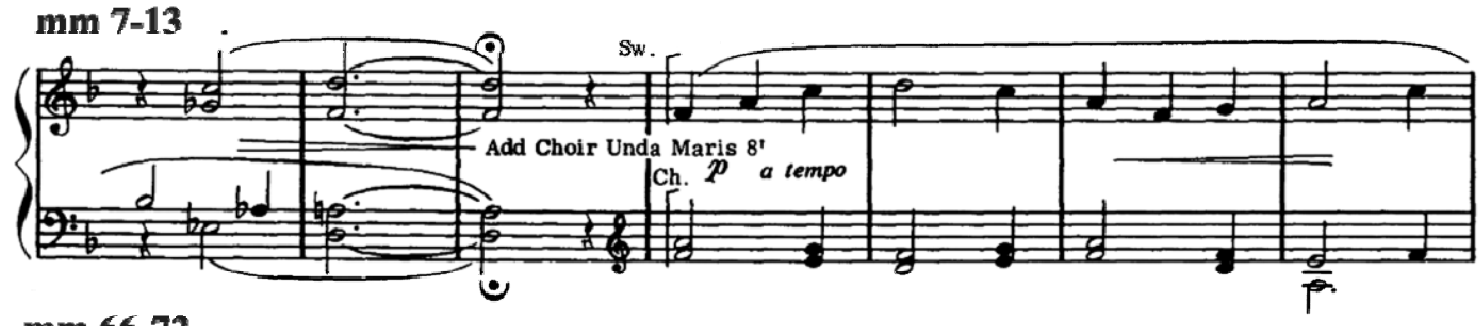

mm 66-72

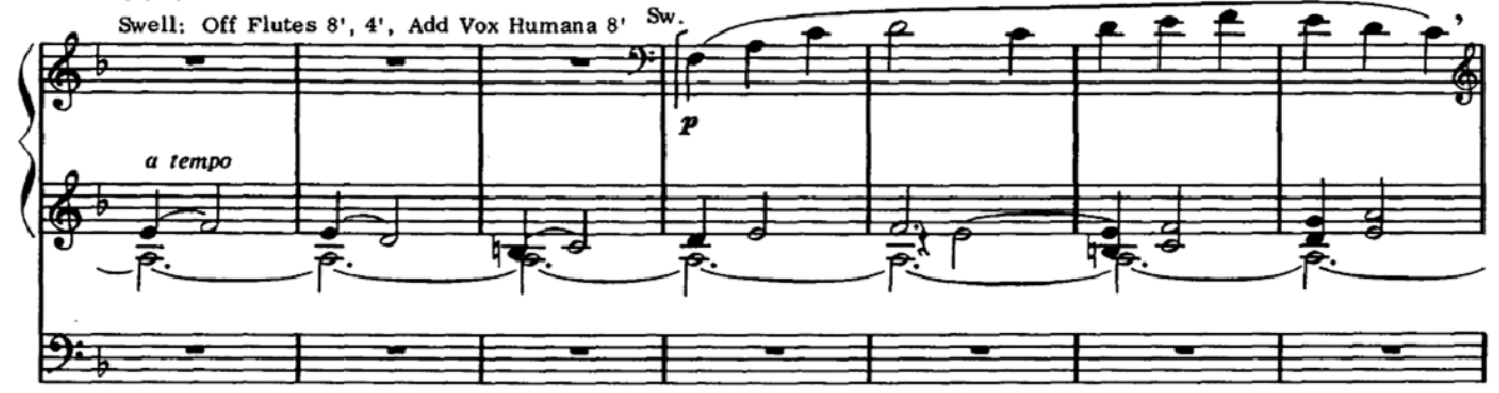


Free work Cp56 Celebration

Warner Brothers Pub. EL9508

C major; $3 / 4$ time

$126 \mathrm{~mm}$; ternary form
Collection VI; $(1 / 7 /[12])$

The Crystal Cathedral Collection (1982)

Three Manuals/Pedal

It features contrasting principal choruses and a solo fff reed in ternary form with slight alteration. After the introduction (mm. 1-9) section A contains four treatments of the PT (mm. 10-17, 18-25, 26-33, 34-41) each eight measures long, see Ex. 9-6. Although the harmony is altered with each repetition, the last phrase (mm. 34-41) modulates to $\mathrm{E}^{\text {b }}$ minor. Section B (mm. 42-49) is a series of runs over a dominant pedal with some syncopation and whole-note scales. Section C has a repeated phrase (mm. 49-57, 58-67) with the second phrase slightly reharmonized, but continuing with the dominant pedal. There is a reappearance of the introductory material $(\mathrm{mm} .68-76)$ for nine measures balancing with the initial introduction. There is then a $\mathrm{D}$ section of additional new material (mm. 77-96) which experiments with some of the ideas in Section B and C: of particular note is the flourish (mm. 93-96) that treats the music of section B (mm. 42-49). After the return of section A (mm. 97-104) is a coda (mm. 105-126) which prolongs a pedal tonic that is suspended in quarter-notes (mm. 105-112). There is then a brief return of section A where the PT is in canon (mm. 113-119) before a final flourish in the pedal and manuals, which, again, treats the music in Section B. The final phrase is whole-tone tinged and in polytonal harmony (mm. 123-126).

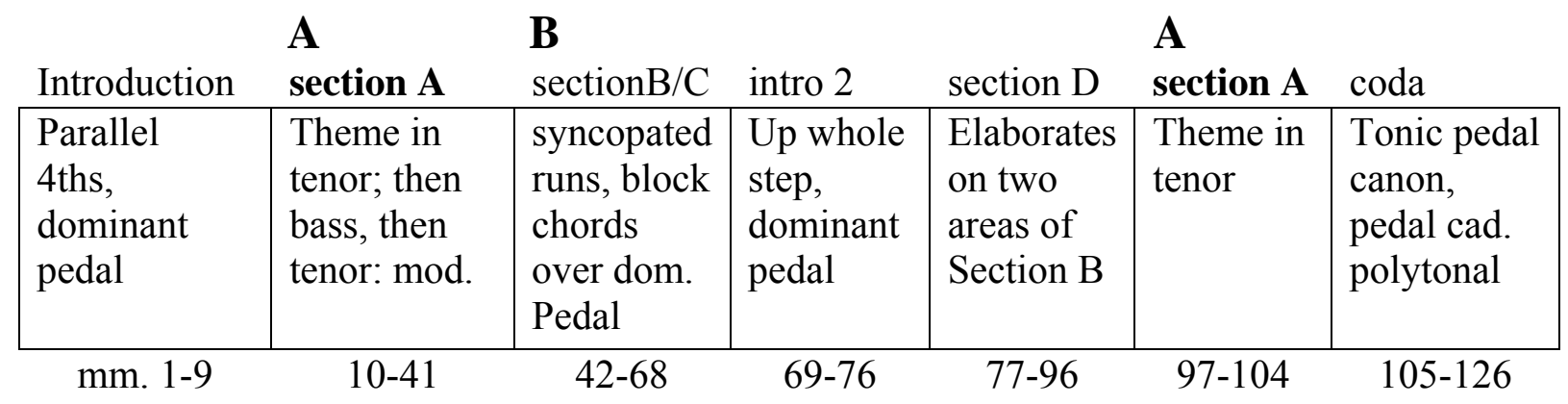




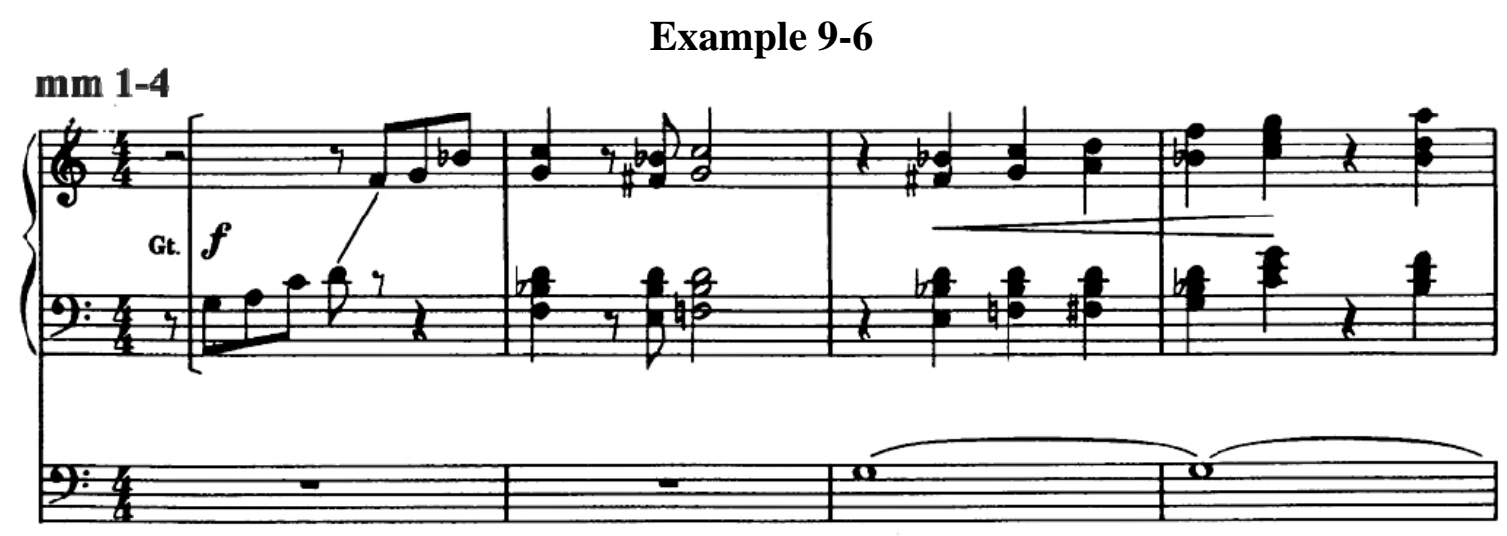

Freework Cp58 Heraldings

Warner Brothers Pub. EL9508

D major; $4 / 4$ time

$122 \mathrm{~mm}$; ternary form
Collection VI; (2/7/[12])

The Crystal Cathedral Collection (1982)

Five Manuals/Pedal

It is in ternary form, but similar to the rondo shape of the Trumpet Voluntary by Jeremiah Clarke (1673-1707). It was originally a large work for four divisions (main organ, gallery organ, antiphonal organ 1 and antiphonal organ 2), but is reduced in the Crystal Cathedral Collection for three manuals and pedal. It is in D major (the traditional key for the 'trumpet voluntaries') and has an extended introduction, see Ex. 9-7, sy1, in four sections: mm. 1-14 (fanfares), 15-22 (polytonal transitions), 23-30 (morphing theme), and 31-36 (fanfares). The PT appears in a double phrased A section in periodic structure (mm. 37-44, 45-52) with the second phrase more embellished than the first, see Ex. 9-7, sy2. This imitates the time-honored practice of 'improvising' the repeats, similar to a $d a$ capo aria form. Section B is also doubled: $\mathrm{mm}$. 55-65, 66-78. There is a section C that forms the central section of the work. It also contains double phrases, but then has a third 'tag' phrase based in the Neapolitan harmony. When section A returns it is not a direct quote of the previous section but is intensified with layered presentations of the PT of 
section A: twice in the hand and twice in the pedal, then fragmented and repeated. The coda (mm. 112-122) is one-third the size of the introduction but has four sections also.

\begin{tabular}{|c|c|c|c|c|c|}
\hline Introduction & section A & section $\mathrm{B}$ & section $\mathrm{C}$ & section A & Coda (intro) \\
\hline $\begin{array}{l}1 \text { - fanfares } \\
2 \text { - transition } \\
3 \text { - morphing } \\
4 \text { - fanfares }\end{array}$ & $\begin{array}{l}\text { Theme in } \\
\text { soprano, } \\
\text { repeats with } \\
\text { embellishments }\end{array}$ & $\begin{array}{l}\text { Theme in } \\
\text { soprano, } \\
\text { repeats, }\end{array}$ & $\begin{array}{l}\text { In } 3 \\
\text { sections, } \\
\text { third one in } \\
\text { Neapolitan } \\
\text { pedal }\end{array}$ & $\begin{array}{l}\text { Intensified, } \\
\text { layers of A } \\
\text { also in pedal } \\
\text { and fragments }\end{array}$ & $\begin{array}{l}1-3 \text { ideas } \\
2-2 \text { ideas } \\
3-\text { extended } \\
4-\text { final area }\end{array}$ \\
\hline
\end{tabular}

\section{Example 9-7}

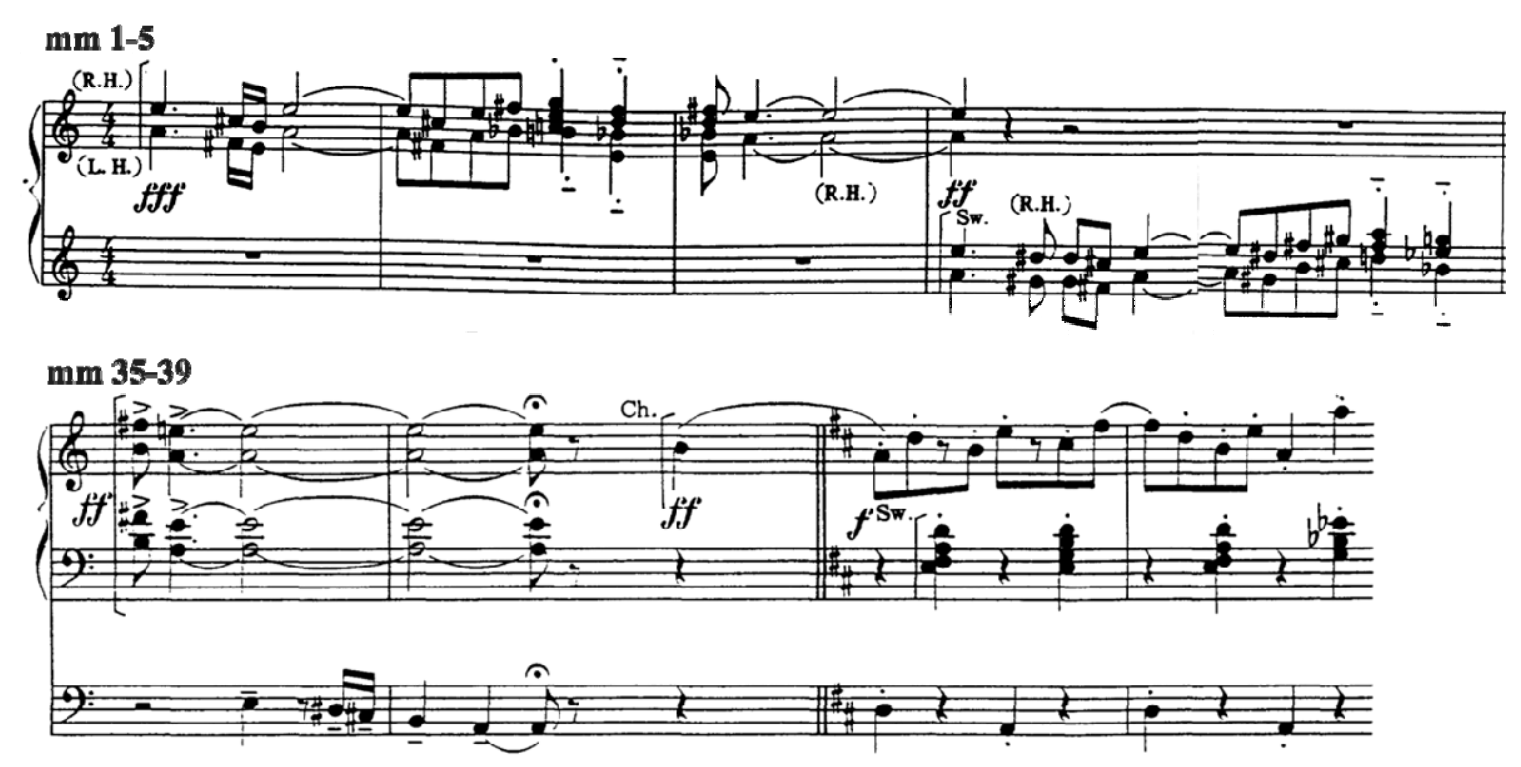

Freework Cp61 Pastel

Warner Brothers Pub. EL9508

$A^{b}$ major; $4 / 4$ time

$111 \mathrm{~mm}$; sonata form
Collection VI; (4/7/[12])

The Crystal Cathedral Collection (1982)

Three Manuals/Pedal

It is dedicated to Ted Alan Worth, who was Virgil Fox's protégé and friend to Hebble.

Worth performed many of Hebble's works in concert. ${ }^{217}$ This work is in sonata form.

After five measures of introduction of theme fragments, see Ex. 9-8, sy1, the exposition

${ }^{217}$ Torrence, p. 105. 
begins with the PT in periodic structure in the soprano (mm. 6-12). There is a short interlude (mm. 12-14), and the antecedent phrase of the PT is repeated (mm. 15-24). The development begins with the indication Tempo de Scherzo and the section commences rapidly on Flutes 8 and 1, see Ex. 9-8, sy2. The figura of this inner 'scherzo' contains thematic hints (motivically) and modulates to A minor (m. 47) where the PT enters augmented in the pedal (mm 47-73). The development continues by modulating back to $A^{b}$ while quoting fragments of the theme (mm. 77-99), with momentary pauses in $F$ minor and $\mathrm{D}^{b}$. After a brief interlude, the short recapitulation (mm. 100-105) returns in altered harmony, see Ex. 9-8, sy3. The coda (mm. 106-111) contains fragments of the theme and ends on an $\mathrm{A}^{\text {b }} 9^{\text {th }}$ chord with the added sixth. It is written with indications for two required preset combinations.

\begin{tabular}{|c|c|c|c|c|}
\hline Introduction & exposition & development & recapitulation & coda \\
\hline $\begin{array}{l}\text { Thematic } \\
\text { fragments, } \\
\text { begins on the } \mathrm{V}\end{array}$ & $\begin{array}{l}\text { Jazz harmonies, } \\
\text { chromaticism }\end{array}$ & $\begin{array}{l}\text { Scherzo; theme } \\
\text { fragments, full } \\
\text { theme in pedal }\end{array}$ & $\begin{array}{l}\text { Theme like } \\
\text { exposition, } \\
\text { altered harmony }\end{array}$ & $\begin{array}{l}\text { Similar to the } \\
\text { interlude before } \\
\text { development }\end{array}$ \\
\hline
\end{tabular}




\section{Example 9-8}
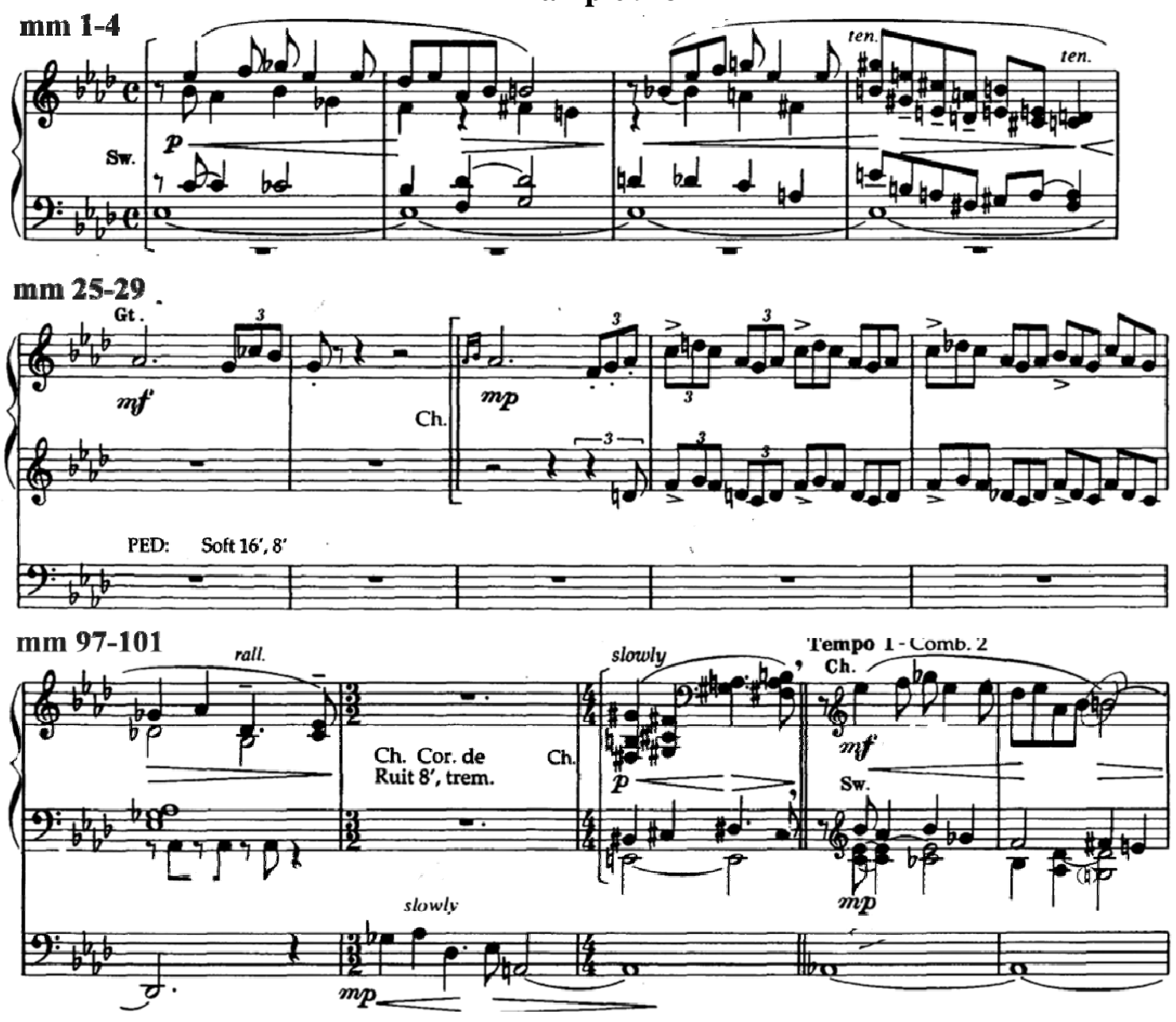

Free work Cp62 Psalm Prelude

Warner Brothers Pub. EL9508

F major; 4/4 time

$52 \mathrm{~mm}$; sonata form
Collection VI; $(5 / 7 /[12])$

The Crystal Cathedral Collection (1982)

Three Manuals/Pedal

It is in sonata form. The PT has periodic phrase structure and strongly resembles a hymn tune. One of the anomalies of this work is that the antecedent phrase (mm. 3-6) ends on tonic, rather than on the $\mathrm{V}$ (or a dissonance); similarly, the consequent phrase (mm. 7-10) ends on a dissonance, see Ex. 9-9, sy1. The key center changes from F major, where the PT is in the soprano, to $\mathrm{A}^{b}$ major (m. 11) where the PT is in the tenor, and the harmony slightly altered, see Ex. 9-9, sy2. There is a brief interlude (mm. 19-26), which treats 
fragments of the PT. After a pause (m. 26), a development commences on the $\mathrm{V}$ in $\mathrm{E}^{b}$ mixolydian where the PT is altered using the Oboe 8' stop against an ostinato in the pedal. There is another short interlude (mm. 35-38) before the recapitulation, which contains fragments of the theme and modulates back to $\mathrm{F}$ major. The recapitulation (mm. 39-46) is as the beginning, except that there is a canon two beats later in the pedal (m. 39). The theme is slightly altered in the soprano. The coda contains fragments of the theme treated as blue-notes.

\begin{tabular}{|c|c|c|c|c|}
\hline Introduction & exposition & development & recapitulation & coda \\
\hline $\begin{array}{l}\text { Theme fragments } \\
\text { D minor to } \\
\text { Neapolitan to V }\end{array}$ & $\begin{array}{l}\text { F theme in } \\
\text { soprano, } A^{b} \\
\text { theme in tenor }\end{array}$ & $\begin{array}{l}\mathrm{E}^{b} \text {, lowered } 7 \text { ths } \\
\text { mixolydian. theme } \\
\text { in soprano }\end{array}$ & $\begin{array}{l}\text { Theme in } \mathrm{F} \text {, } \\
\text { canon in pedal, } \\
\text { altered harmony }\end{array}$ & $\begin{array}{l}\text { Fragments of } \\
\text { theme }\end{array}$ \\
\hline $\mathrm{mm} \mathrm{1-2}$ & $3-26$ & $27-38$ & $39-46$ & $47-52$ \\
\hline
\end{tabular}

\section{Example 9-9}
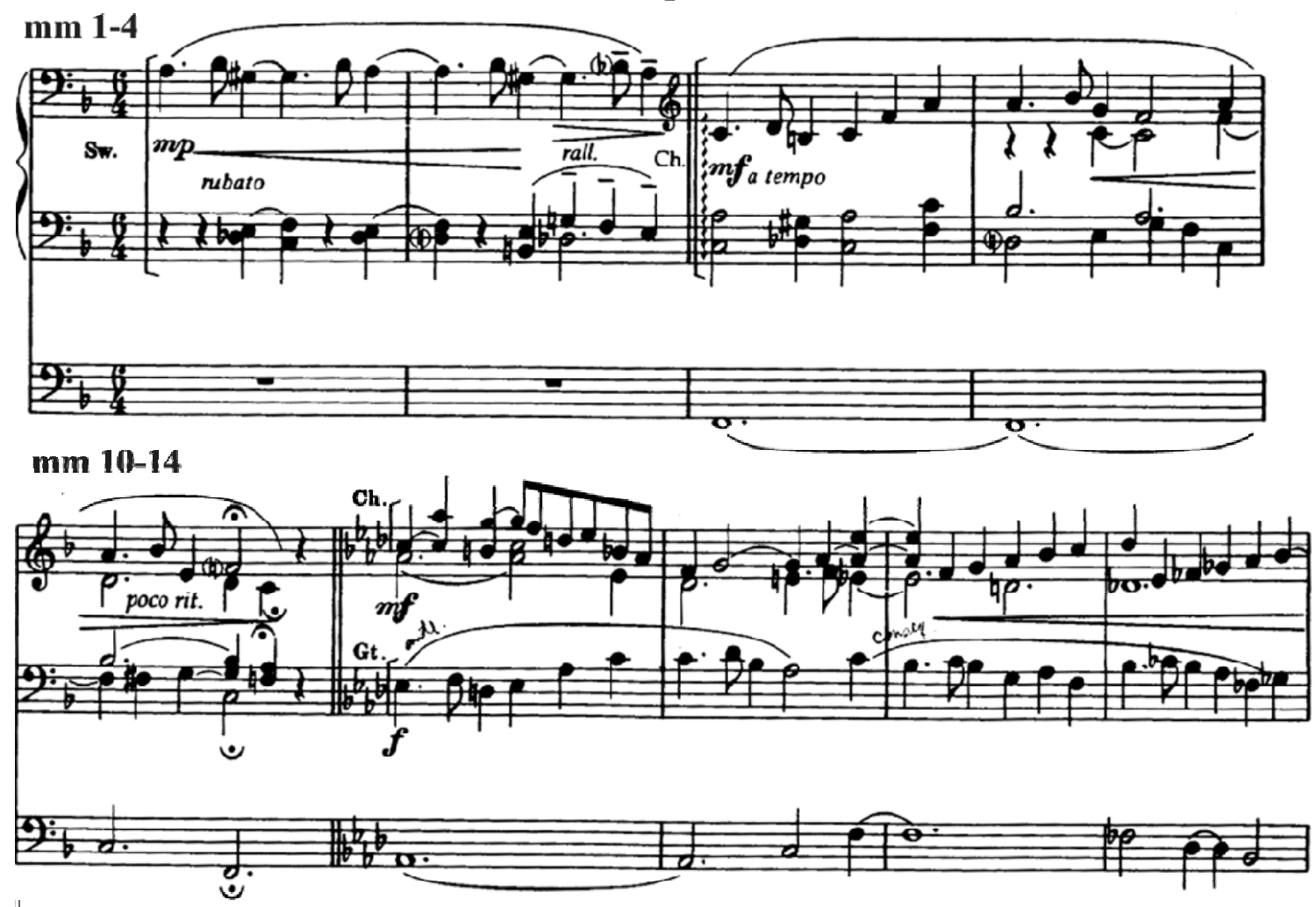
Free work Cp64 Rue des Saints-Pères Collection VI; (6/7/[12])

Warner Brothers Pub. EL9508

F major; $4 / 4$ time

The Crystal Cathedral Collection (1982)

$41 \mathrm{~mm}$; ternary form

This is a short sketch in ternary form and the first of the Palette Sketches. It begins with a short theme (mm. 1-3), which is interrupted by a brief interlude (mm. 3-6), see Ex. 9-10. The PT is repeated and embellished (mm. 7-17). A middle section treats unrelated musical material. The opening section returns (mm. 25) with a new stop and accompaniment (mm. 25-36). The short coda (mm. 37-41) is in three-part imitation, which resolves vii7 (diminished-seventh) to I, similar to some J. S. Bach choralepreludes. ${ }^{218}$

A
\begin{tabular}{|l|l|l|l|}
\hline $\begin{array}{l}\text { Solo theme in } \\
\text { tenor ambit }\end{array}$ & $\begin{array}{l}\text { Bi-tonal un- } \\
\text { related material }\end{array}$ & $\begin{array}{l}\text { Tenor theme w/ } \\
\text { accompaniment }\end{array}$ & $\begin{array}{l}\text { 3-part imitation } \\
\text { vi7 - I }\end{array}$ \\
\hline
\end{tabular}

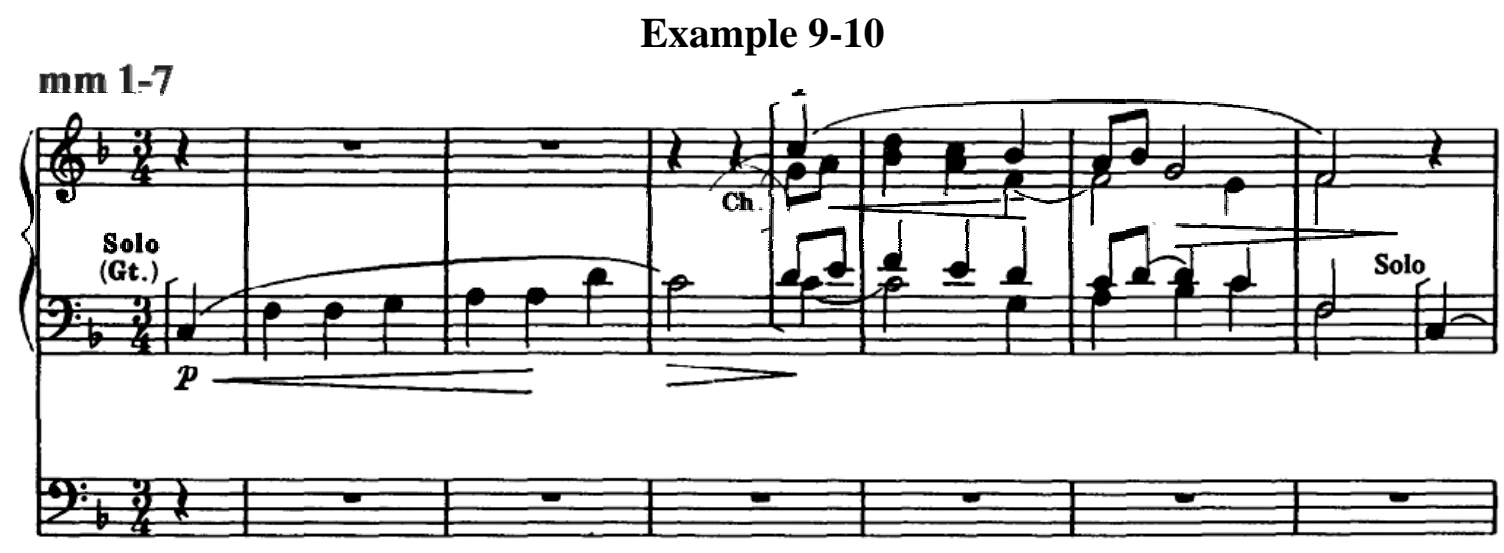

\footnotetext{
${ }^{218}$ Stinson, Russell. "Some Thoughts on Bach's Neumeister Chorales", The Journal of Musicology, Volume XI, no. 4, (1993), p. 464.
} 
Free work Cp65 Lapin agile sous la neige Collection VI; (6/7/[12])

Warner Brothers Pub. EL9508

E major; $4 / 4$ time

The Crystal Cathedral Collection (1982)

$42 \mathrm{~mm}$; binary form

Two Manuals - no pedal

It is in binary form, and is similar to the French Classic "duet", see Ex. 9-11. It is the second of the Palette Sketches. The anomaly here is the 'repeat' for the binary form is near the end of the work (on $\mathrm{V}$ ). The section after the repeat sign constitutes the coda and returns the composition to tonic. A middle section (mm. 13-31) treats the dominant (V). The coda creates imitation from the PT on the V leading to the tonic.

\begin{tabular}{|l|l|l|}
\multicolumn{1}{c}{ A } & \multicolumn{2}{c|}{ B } \\
\hline $\begin{array}{l}\text { Long theme in soprano, } \\
\text { accompaniment in the 1.h. }\end{array}$ & $\begin{array}{l}\text { Long theme in 1.h. then } \\
\text { imitated irregularly in r.h. }\end{array}$ & $\begin{array}{l}\text { Imitation of B section with } \\
\text { some new cadential material }\end{array}$ \\
\hline mm. 1-12 & $13-31$ & $32-42$ \\
\hline
\end{tabular}

\section{Example 9-11}

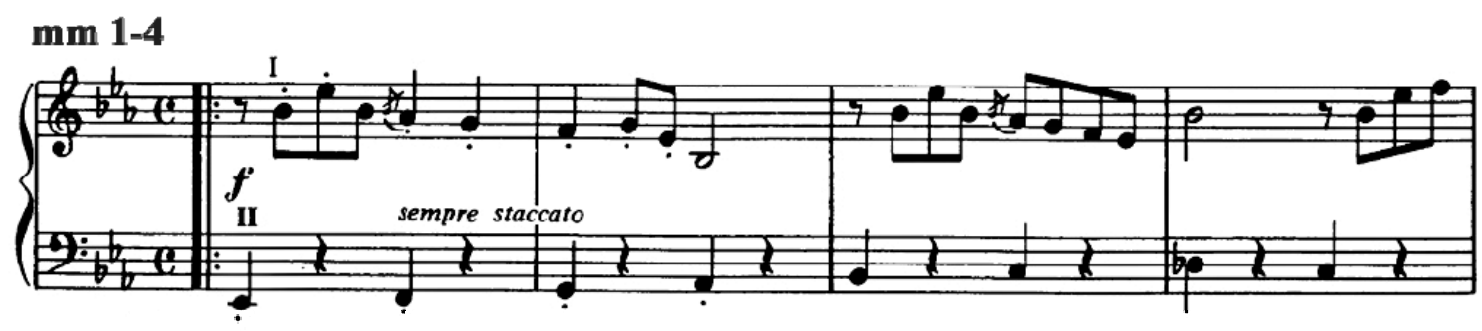

Free work Cp66 L'eglisse Saint-Sévern Collection VI; (6/7/[12])

Warner Brothers Pub. EL9508 The Crystal Cathedral Collection (1982)

E major; $3 / 4$ time

Three Manuals/Pedal

$25 \mathrm{~mm}$; ternary

In ternary form, it is a pictorial and atmospheric piece, the third of the Palette Sketches.

It is also a study in 3rds. After the opening section of foreshadowing the theme (mm. 1-

9), see Ex. 9-12, a middle section presents the theme in two phrases (m. 9-17). The

opening section returns (m. 18) but is altered from its previous entrance as a recollection 
of material from the PT (mm. 18-25). There is a "sigh" motif (m. 2) that permeates the composition. The work is filled with $9^{\text {th }}-11^{\text {th }}$ and $13^{\text {th }}$ chords.

\begin{tabular}{|c|c|c|}
\hline A & B & A \\
\hline foreshadowing; tonic to $\mathrm{V} / \mathrm{V}$; & $\begin{array}{l}\text { PT - G major, (dorian) to } \mathrm{E} \\
\text { minor, moments of } \mathrm{D} \text { major }\end{array}$ & $\begin{array}{l}\text { Recollection of A; Head } \\
\text { motif and tail-motif, } \\
\text { French } 6^{\text {th }} \text { to tonic }\end{array}$ \\
\hline
\end{tabular}
mm 1-9
9-17
$18-25$

\section{Example 9-12}

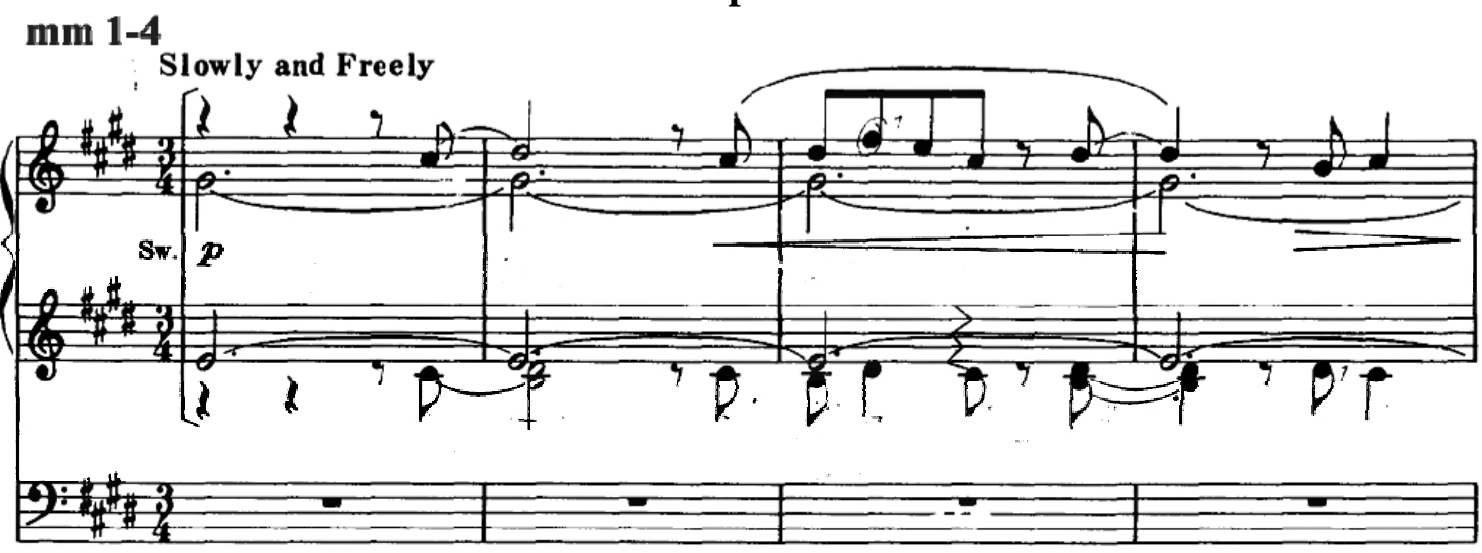

Free work Cp67 Paris, vu du Square Saint-Antoine Collection VI; (6/7/[12])

Warner Brothers Pub. EL9508

D major; $3 / 4$ time The Crystal Cathedral Collection (1982)

49mm; through-composed

Two Manuals/Pedal

A strict pedal ostinato is maintained throughout this fourth of the Palette Sketches. It is through-composed with a gradually evolving theme, see Ex. 9-13. The first section (mm. 4-21) has two partial statements of the PT (4-12, 13-21), but the second statement is harmonically, and melodically, altered. The third statement constitutes the middle portion of the work (mm. 22-31) and is more complete from the opening section and is harmonized by secondary dominance. Near the end is a short coda (m. 45). 


\begin{tabular}{l|l|l|l|l|}
\multicolumn{1}{l}{ Introduction } & A & B & C & \multicolumn{1}{c|}{ coda } \\
\hline $\begin{array}{l}\text { Pedal ostinato } \\
\text { and oscillating } \\
\text { accompaniment }\end{array}$ & $\begin{array}{l}\text { Theme in } \\
\text { soprano, repeated } \\
\text { with alteration }\end{array}$ & $\begin{array}{l}\text { Theme more } \\
\text { complete }\end{array}$ & $\begin{array}{l}\text { Theme even } \\
\text { more complete. }\end{array}$ & $\begin{array}{l}\text { Pedal ostinato } \\
\text { increases in } \\
\text { frequency. I9 }\end{array}$ \\
\hline \multicolumn{1}{c|}{ mm. 1-4 } & 5-21 & $33-44$ & $45-45$ \\
\hline
\end{tabular}

\section{Example 9-13}

\section{mm 1-6}

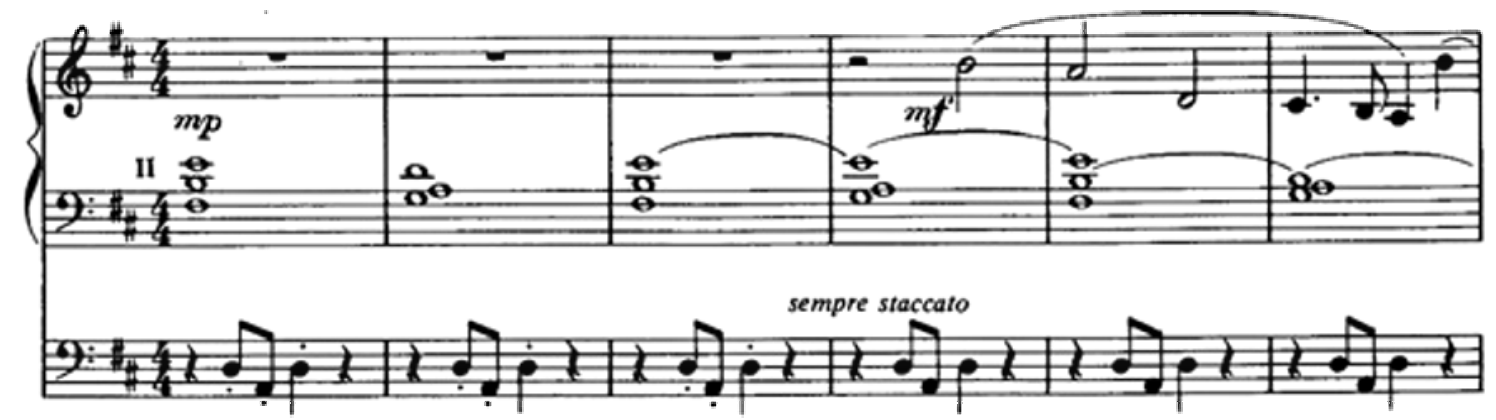

Free work Cp68 L'eglise Boissy-Saint-Antoine Collection VI; (6/7/[12]) Warner Brothers Pub. EL9508

F major; 4/4 time The Crystal Cathedral Collection (1982)

$34 \mathrm{~mm}$; song form

Three Manuals/Pedal

This work is the fifth of the Palette Sketches. It has an introduction (mm. 1-4) and an opening PT (mm. 5-12), section A, see Ex. 9-14. It has a similar theme (A') (mm. 13-20) that repeats as a bridge passage (mm. 21-24) and is repeated again (mm. 25-29). At this final repeat are concurrent fragments of the PT of section A. The coda revisits the introductory material with slight variation (mm. 30-34).

\begin{tabular}{l|l|l|l|r|}
\multicolumn{1}{l}{ Introduction } & \multicolumn{1}{l}{ A } & \multicolumn{1}{l}{ A'B } & \multicolumn{1}{c|}{ coda } \\
\hline $\begin{array}{l}\text { Two voices, } \\
\text { imitation in two } \\
\text { phrases to V }\end{array}$ & $\begin{array}{l}\text { PT in soprano } \\
\text { simple accomp. }\end{array}$ & $\begin{array}{l}\text { New melodic } \\
\text { idea. Consequent } \\
\text { theme, soprano }\end{array}$ & $\begin{array}{l}\text { repeated in } \\
\text { tenor }\end{array}$ & $\begin{array}{l}\text { Introductory } \\
\text { material revisited } \\
\text { leads to tonic }\end{array}$ \\
\hline \multicolumn{1}{|c|}{ mm. 1-4 } & $5-12$ & $13-20$ & $21-29$ & $30-34$ \\
\hline
\end{tabular}




\section{Example 9-14}

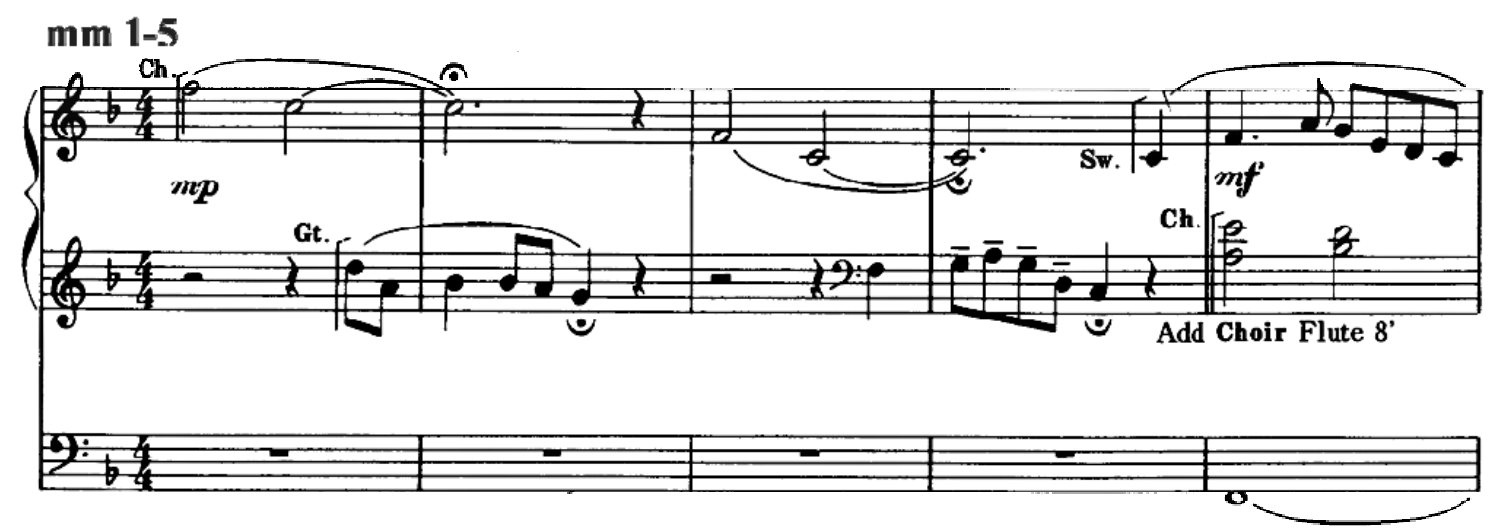

Free work Cp69 La Chapelle de Beaulieu Collection VI; (6/7/[12]) Warner Brothers Pub. EL9508 F minor; $4 / 4$ time The Crystal Cathedral Collection (1982) $20 \mathrm{~mm}$; ABA form

It is an $\mathrm{ABA}$ form in miniature with a small introduction and coda, the sixth of the Palette Sketches. The PT (in the baritone-tenor range) has an antecedent and consequent phrase each of four bars in F minor, see Ex. 9-15. The middle section modulates to A minor and no part of the theme repeats, except that there are remote fragments in the return at measure 16.

\begin{tabular}{|c|c|c|c|c|}
\hline Introduction & A & B & A & coda \\
\hline $\begin{array}{l}\text { Tonic pedal, } \\
\text { manual ostinato }\end{array}$ & $\begin{array}{l}\text { Theme in } \\
\text { baritone ambit, } \\
\text { not pedal }\end{array}$ & $\begin{array}{l}\text { Modulates to A } \\
\text { minor; preserves } \\
\text { accent on beat } 2\end{array}$ & $\begin{array}{l}\text { Theme returns in } \\
\text { fragments, return } \\
\text { pedal/ostinato }\end{array}$ & $\begin{array}{l}\text { Long hold, new } \\
\text { accompaniment } \\
\text { in ostinato }\end{array}$ \\
\hline
\end{tabular}




\section{Example 9-15}

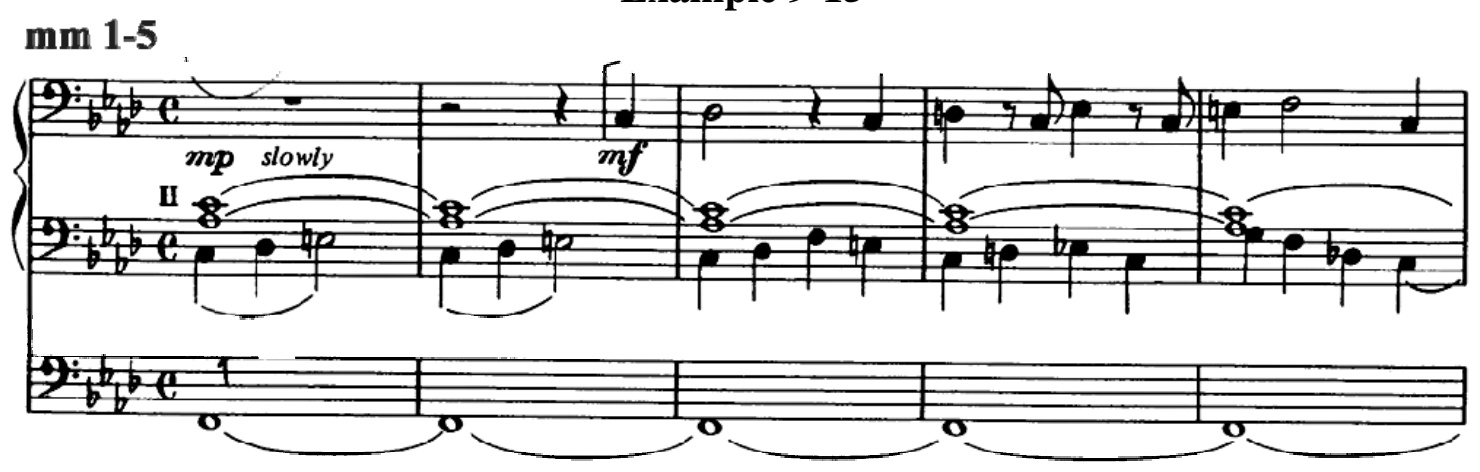

Free work Cp70 Crépscule. Golfe du Morbihan Collection VI; (6/7/[12])

Warner Brothers Pub. EL9508 The Crystal Cathedral Collection (1982)

C Phyrigian; 4/4 time

Three Manuals/Pedal

$56 \mathrm{~mm}$; sonata form

In C Phrygian (lowered second, third, sixth and seventh), it is the longest and last of the Palette Sketches, and employs thematic transformation in the 'develoment'. There are three statements of the PT in the 'exposition' (mm. 1-9, 10-17, 18-27), each one of which slightly transforms the melodic material, see Ex. 9-16. The statements begin with an upper pedal tonic in the right-hand, while the left-hand provides a head-motif (e.g., mm. 2-3) and a tail-motif (e.g., mm. 4-8). Each ends with a 'chant seraphique’ (e.g., mm. 79). The development (mm. 28-44) begins with a combination of an extended head-motif (becoming the basis for the accompanimental figura of the r.h. [mm. 32-35]). The r.h. figura morphs into a syncopated accompaniment (mm. 34-38) that fragments (mm. 3944) as it approaches the recapitulation. The 1.h. of the development is palendromic, beginning with an extended tail-motif (mm. 32-35), the head-motif (mm. 36-39; splitting the phrase in two parts at the crux of the palendrom), and then the tail-motif again (mm. 40-43). The recapitulation ( $\mathrm{mm} .46-51)$ reverses the tonic pedal to the $1 . \mathrm{h}$. and the PT to the r.h.. The coda (mm. 52-56) quotes fragments of the head and tail-motives. 


\begin{tabular}{|l|l|l|l|r|}
\multicolumn{1}{l|}{ Introduction } & \multicolumn{1}{l}{ Exposition } & Development & Recapitulation & Coda \\
\hline $\begin{array}{l}\text { Upper tonic } \\
\text { pedal, } \\
\text { minimalistic }\end{array}$ & $\begin{array}{l}\text { PT head and tail } \\
\text { motives, chant } \\
\text { seraphique }\end{array}$ & $\begin{array}{l}\text { Head-motif } \\
\text { accompanies } \\
\text { tail-motif = PT }\end{array}$ & $\begin{array}{l}\text { PT returns, l.h. } \\
\text { and r.h. reverse } \\
\text { roles, toccata }\end{array}$ & $\begin{array}{l}\text { Tonic pedal, } \\
\text { PT fragments }\end{array}$ \\
\hline \multicolumn{1}{|c|}{ mm. 1-2 } & $2-27$ & $28-45$ & $45-51$ & $52-56$ \\
\hline
\end{tabular}

\section{Example 9-16}

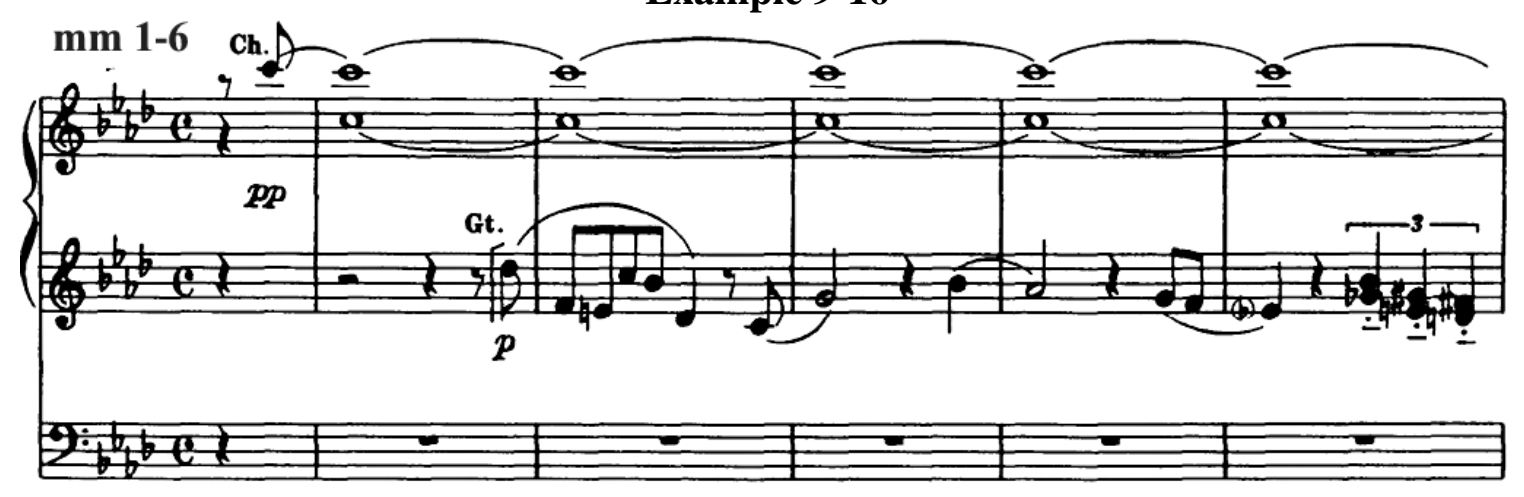

Free work Cp71 Soft Stillness and the Night Collection VI; (7/7/[12])

Warner Brothers Pub. EL9508

E minor; multiple meters

The Crystal Cathedral Collection (1982)

$63 \mathrm{~mm}$; sonata form

The inspiration for this work is both the German Expressionist style of the mid-twentieth century and an excerpt from William Shakespeare's Merchant of Venice:

"here we will sit and let the sounds of music creep in our ears - soft stillness and the night become the touches of sweet harmony."

Therein is contained the title of the work. It is one of Hebble's most highly chromatic, virtually dissonant works. The work also has the rare designation affettuoso. ${ }^{219}$ In sonata

\footnotetext{
${ }^{219}$ J. S. Bach was among the few that used the term in his Brandenburg Concerto No. 5, movement 2. The word in Italian means "affectionate", "loving".
} 
form, there is an introduction of seven bars where a trio suggests fragments of the pending theme on three separate textures (registrations) in a hocket-like style of writing, see Ex. 9-17, sy1. It is quasi-imitative here, the middle voice existing mostly to provide the greater 'dissonance'. At measure eight the PT begins in the soprano with a thickened texture in the accompaniment. The PT is presented with periodic phrasing of a four measure antecedent (mm. 8-11) and a four measure consequent phrase (mm. 12-18), the latter of which includes an extension. The exposition is also marked by a fragment of imitation in the pedal on a flute $4(\mathrm{~mm} .10-18)$ while the accompaniment (1.h.) is a slow moving series of quarter-notes, which are often in a planing motion. The development section (mm. 19-45) is marked poco animato and contains a new rhythmic motive of triplets improvising upon the PT, see Ex. 9-17, sy2. The key shifts from an area that began in $\mathrm{G}$ major to one of $\mathrm{E}$ minor in the development, then to B major (mm. 32-39). This section also exploits a counter-melody in the pedal, creating a false recapitulation in B major on organ foundations. At the tempo primo, mostly in $\mathrm{G}$ minor, the recapitulation is foreshortened, taking only excerpts from the exposition and condensing them closer together. The coda makes a general move away from the quasi-polyphony of the main portions of the work (those areas directly treating the PT), to homophony. These final phrases, marked by fermatas, are mostly an improvisation based on the main motif of the PT, ending the composition in E major. 


\begin{tabular}{|l|l|l|l|l|}
\hline Introduction & Exposition & Development & Recapitulation & Coda \\
\hline Quarter-notes & Quarter-notes & triplets & Quarter-notes & Quarter-notes \\
\hline $\begin{array}{l}\text { Trio writing, } \\
\text { hocket style }\end{array}$ & $\begin{array}{l}\text { PT four bar } \\
\text { periodic } \\
\text { structure; } \\
\text { counter-melody }\end{array}$ & $\begin{array}{l}\text { Improvise on } \\
\text { PT; counter- } \\
\text { melody in pedal }\end{array}$ & $\begin{array}{l}\text { PT excerpts } \\
\text { only; }\end{array}$ & $\begin{array}{l}\text { Homophony, } \\
\text { PT motif is } \\
\text { improvised } \\
\text { upon }\end{array}$ \\
\hline E minor & G major & Eminor/Bmajor & G minor & E major \\
\hline mm. 1-7 & $8-18$ & $19-45$ & $46-55$ & 56-63 \\
\hline
\end{tabular}
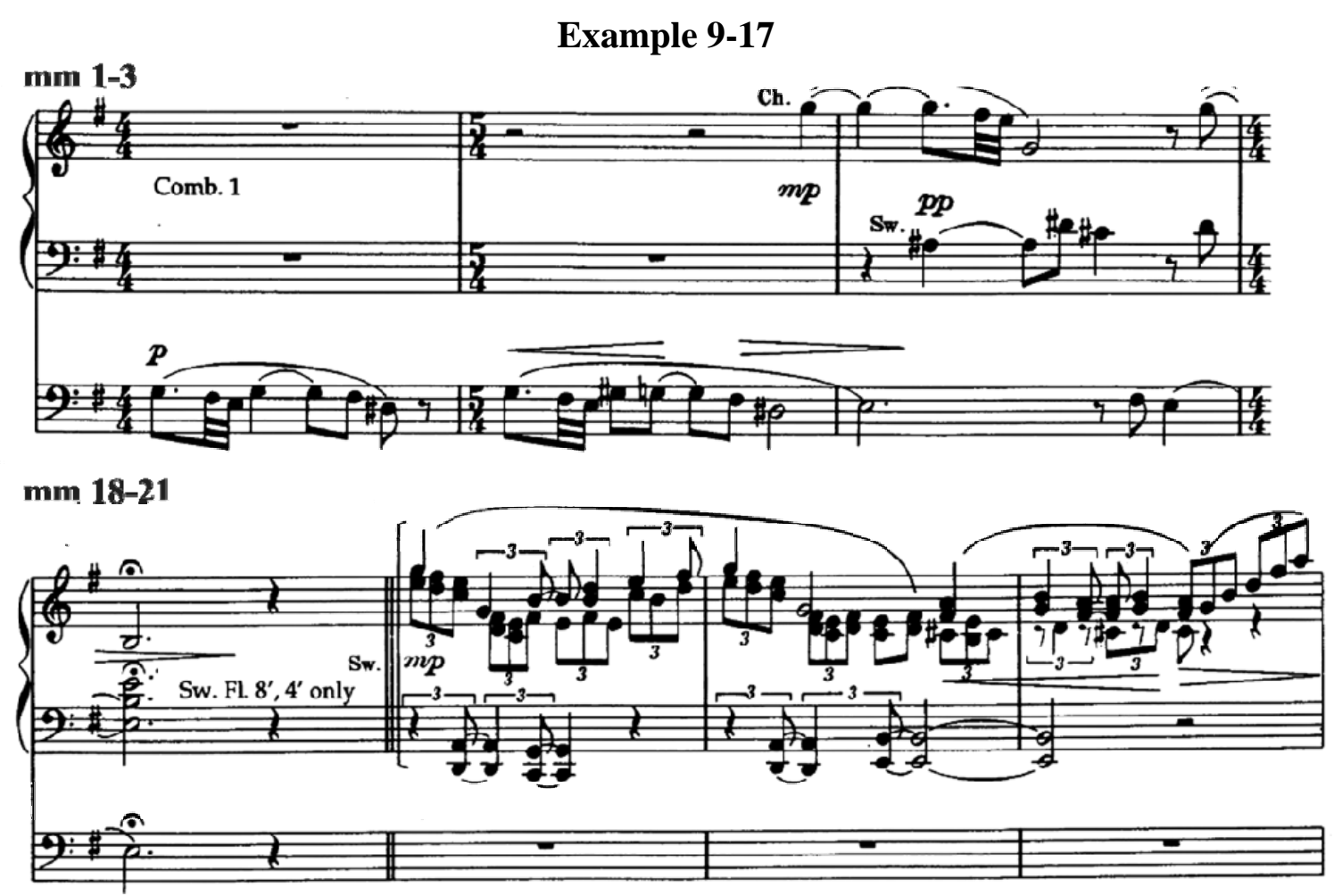

Free work Cp127 Cantilene

Sacred Music Press KK517-3

A major; $3 / 4$ time

$45 \mathrm{~mm}$; quasi-rondo
Collection XI; $(1 / 8 /[10])$

Designs for Organ (1992)

Two Manuals/Pedal

The word "cantilena" means "melody", and this work begins immediately with the melody without introduction. It is contains four-bar phrases, although occasionally Hebble adds a measure to ornament/extend the theme, see Ex. 9-18. The composition has two sections: A, which presents the PT on a solo stop, and B, which is more homophonic 
and does not feature a solo stop. They contrast each other. When Section A repeats (mm. 23-33) the PT is ornamented and there is imitation in the pedal (mm. 31-33). There is also an extension of the theme (mm. 31-33). The coda contrasts another solo stop, moving to a solo Flute 8 , which ends on the major $7^{\text {th }}$ of A major. A work titled cantilena, the melody permeates virtually the entire work in the A Sections, appearing in the soprano, tenor and pedal as well as in ornamentation and is only absent in Section B where a melody is tangentially present but slim.

\begin{tabular}{l|l|l|l|l|} 
Section A & \multicolumn{1}{l}{ Section B } & \multicolumn{1}{l}{ Section A } & \multicolumn{1}{l}{ Section B } & \multicolumn{1}{c|}{ Section A/Coda } \\
\hline $\begin{array}{l}\text { Theme in sop. } \\
\begin{array}{l}\text { Accomp. mimics } \\
\text { theme's rhythm }\end{array}\end{array}$ & $\begin{array}{l}\text { Homophonic, no } \\
\text { theme, contrast } \\
\text { of organ sounds }\end{array}$ & $\begin{array}{l}\text { Theme in Sop., } \\
\text { more ornamented } \\
\text { busier pedal, ext. }\end{array}$ & $\begin{array}{l}\text { Homophonic, no } \\
\text { theme contrast of } \\
\text { sound }\end{array}$ & $\begin{array}{l}\text { Theme in tenor } \\
\text { altered harm. } \\
\text { Coda ends on M7 }\end{array}$ \\
\hline \multicolumn{1}{c|}{ mm 1-10 } & $11-23$ & $23-33$ & $34-36$ & $37-40 / 41-45$ \\
\hline
\end{tabular}

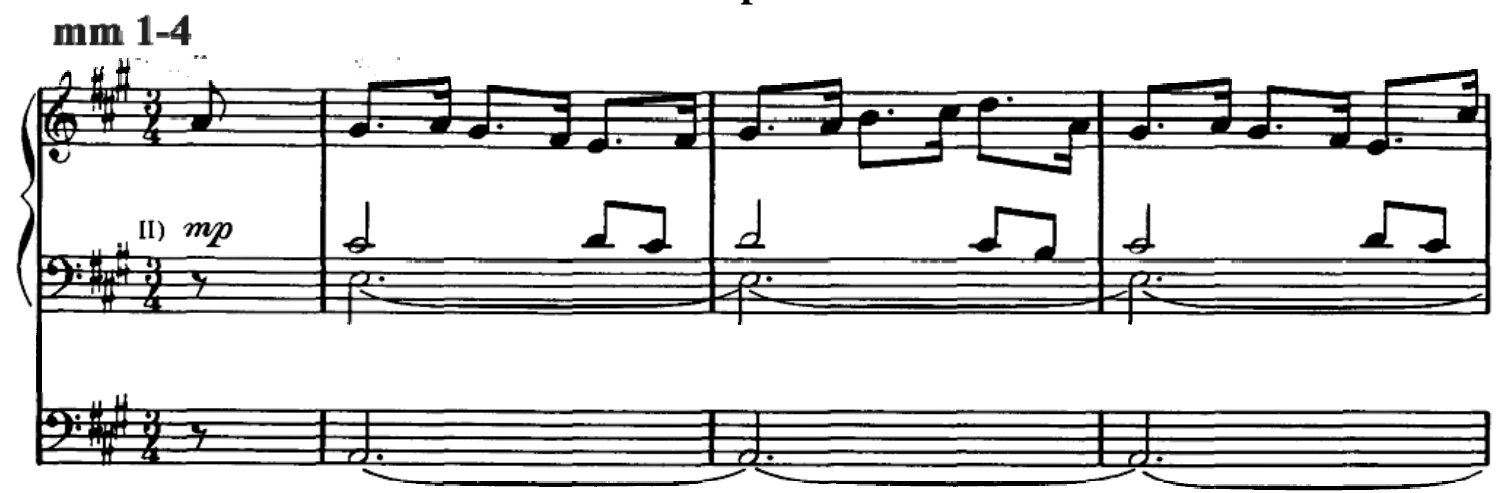

Free work Cp128 Chorale

Sacred Music Press KK517-3

F major; 4/4 time

$32 \mathrm{~mm}$; strophic
Collection XI; $(2 / 8 /[10])$

Designs for Organ (1992)

Two Manuals/Pedal

It is not based on a cantus prius factus, but on an original melody in a homophonic hymn-

like style. The work essentially pivots from Foundations on the Great to Antiphonal

Strings for the various strophes of the hymn-like tune. It is a short composition that can 
be played during an Offertory or as a Prelude and sounds like a regular church hymn, see Ex. 9-19. The antiphonal phrases use substitute chords and the overall harmonies here are blues-based and then altered or added to. The antiphonal phrases are without pedal and the phrases are all strophic in nature.

Strophe 1
\begin{tabular}{|l|l|l|l|l|}
\hline $\begin{array}{l}\text { Two 2-bar } \\
\text { phrases and a 2- } \\
\text { bar antiphon }\end{array}$ & $\begin{array}{l}\text { One long 4-bar } \\
\text { phrase and a 3- } \\
\text { bar antiphon }\end{array}$ & $\begin{array}{l}\text { One long 4-bar } \\
\text { phrase and a 3- } \\
\text { bar antiphon }\end{array}$ & $\begin{array}{l}\text { One long 4-bar } \\
\text { phrase and a 1- } \\
\text { bar antiphon }\end{array}$ & $\begin{array}{l}\text { A 2-bar phrase } \\
\text { and a 1-bar } \\
\text { antiphon, coda }\end{array}$ \\
\hline \multicolumn{1}{c|}{ mm 1-7 } & $7-14$ & $14-21$ & $21-26$ & $26-32$ \\
\hline
\end{tabular}

\section{Example 9-19}

\section{mm 1-5}

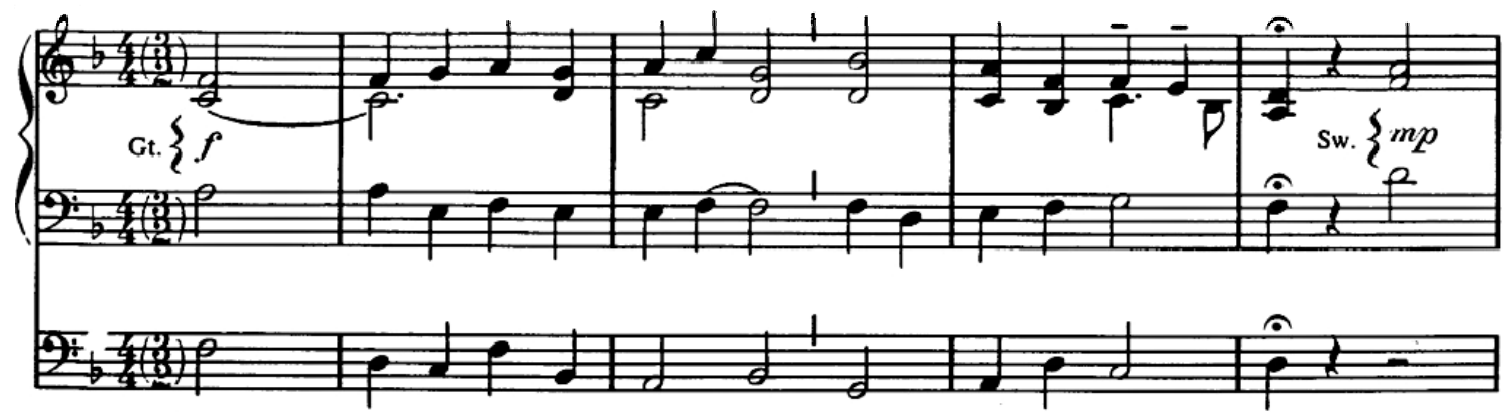

Free work Cp129 Divertimento

Sacred Music Press KK517-3

E minor; $6 / 8-5 / 8$ time

$36 \mathrm{~mm}$; palendrome/quasi-binary
Collection XI; $(3 / 8 /[10])$

Designs for Organ (1992)

Two Manuals - no pedal

A "divertimento" is "lighter entertainment music of an occasional nature from c. 17501780." ${ }^{, 20}$ Hebble states that "It is sort of a 'joke', like a Scherzo, but not in the form of one. It's very short, so I called it Divertimento. It's lighthearted."221 There are two taps

\footnotetext{
${ }^{220}$ Randel, p. 235.

${ }^{221}$ Hebble: Atlanta Interview, August 31, 2002.
} 
of the pedal at the end going from dominant to tonic (mm. 35-36). The work is a duet:

two independent melodic voices (mm. 1-2, 6, 7-10) and, particularly in the left-hand, as a bass-like support (mm. 4-8, 15). It is built upon nine four-bar phrases, which function as a quasi-palindrome, see Ex. 9-20. The palindrome is not literal but sectional, but it is doubled. While the previously mentioned palindrome occurs, also, at the mid-point, that which was in the left-hand (e.g. m. 15) is later in the right-hand (m. 19) and that which previously descended (e.g., m. 4) later ascends (m. 20) or (m. 15 to m. 27). Hebble's Cp129 Divertimento follows a quasi-binary outline.

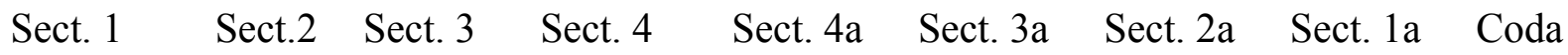

\begin{tabular}{|c|c|c|c|c|c|c|c|c|}
\hline $\begin{array}{l}\text { General } \\
\text { imita- } \\
\text { tion, l.h. } \\
\text { more } \\
\text { bass- } \\
\text { like }\end{array}$ & $\begin{array}{l}\text { Gener } \\
\text { al } \\
\text { imita- } \\
\text { tion, } \\
\text { l.h. } \\
\text { more } \\
\text { bass- } \\
\text { like }\end{array}$ & $\begin{array}{l}\text { Duet } \\
\text { betw.rh } \\
\text { and lh. } \\
5 / 8 \text { time } \\
\text { altered } \\
\text { 5ths }\end{array}$ & $\begin{array}{l}\text { Augment } \\
\text { ed } \\
\text { chords. } \\
\text { Lh bass- } \\
\text { like, lh } \\
\text { finishes }\end{array}$ & $\begin{array}{l}\text { Augmen } \\
\text { ted } \\
\text { chords. } \\
\text { lh bass- } \\
\text { like, rh } \\
\text { finishes }\end{array}$ & $\begin{array}{l}\text { Duet } \\
\text { betw. rh } \\
\text { and lh. } \\
5 / 8 \text { time } \\
\text { altered } \\
\text { 5ths }\end{array}$ & $\begin{array}{l}\text { General } \\
\text { imita- } \\
\text { tion, } \\
\text { contrary } \\
\text { motion, } \\
\text { lh more } \\
\text { forward }\end{array}$ & $\begin{array}{l}\text { General } \\
\text { imita- } \\
\text { tion, } \\
\text { duet, lh } \\
\text { more } \\
\text { forward }\end{array}$ & $\begin{array}{l}\text { Lh. } \\
\text { synco- } \\
\text { pations, } \\
\text { penulti- } \\
\text { mate = } \\
\text { Tristan } \\
\text { harmony }\end{array}$ \\
\hline $\mathrm{mm}$ & $5-8$ & $9-12$ & $13-16$ & $17-20$ & $1-24$ & 5-28 & $29-32$ & $33-36$ \\
\hline
\end{tabular}

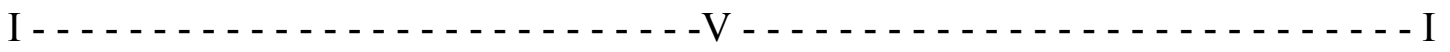

mm 1-5

Example 9-20

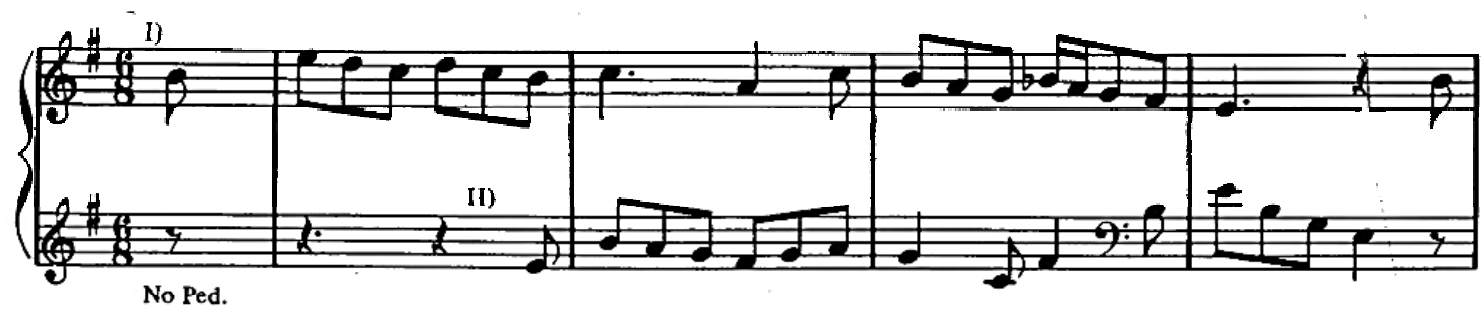

Free work Cp130 Litany of the Bells

Sacred Music Press KK517-3

$\mathrm{C}$ major; $3 / 4$ time

$82 \mathrm{~mm}$; through-composed
Collection XI; (4/8/[10])

Designs for Organ (1992)

Three Manuals/Pedal 
It features the "chimes" of the organ, which became prominent with the ACO and was borrowed from the cinema or theater organ. ${ }^{222}$ Hebble said that he wanted a "nice arrangement of a work for organ with chimes in their most resonant registers (alto or tenor), not the tacky arrangements organists so often use with it banging away in the soprano!"223 The word "litany" means "to repeat over and over". Hebble puts this concept to use in this composition by having the chime's melody (PT) repeat on another manual with a similar melodic contour, but a different register, see Ex. 9-21. It is then repeated on yet a third sound, hence the three manuals. The PT of the chimes is barely altered and, like a litanic prayer, repeats the same music over and over.

\begin{tabular}{|c|c|c|c|c|c|c|c|}
\hline Sect. 1 & Sect. 2 & Sect. 3 & Sect. 4 & Sect. 5 & Sect. 6 & Sect. 7 & Sect. 8 \\
\hline $\begin{array}{l}\text { Short } \\
\text { intro p.t. } \\
\text { in alto }\end{array}$ & $\begin{array}{l}\text { p.t., in } \\
\text { tenor, } \\
\text { repeated }\end{array}$ & $\begin{array}{l}\text { p.t. in alto } \\
\text { moves to } \\
\mathrm{V}\end{array}$ & $\begin{array}{l}\text { p.t. in alto } \\
\text { moves to } \\
\text { vi/V to } \mathrm{V}\end{array}$ & $\begin{array}{l}\text { p.t. - tenor } \\
\text { high } \\
\text { celestes }\end{array}$ & $\begin{array}{l}\text { p.t. in alto } \\
\text { moves to } \\
b_{\mathrm{Vi}}\end{array}$ & $\begin{array}{l}\text { No } \\
\text { chimes, } \\
\text { like intro }\end{array}$ & $\begin{array}{l}\text { p.t. in alto } \\
\text { plagal } \\
\text { cadence }\end{array}$ \\
\hline $\mathrm{mm} \mathrm{1-12}$ & $13-20$ & $21-32$ & $33-48$ & $49-56$ & $57-64$ & $65-72$ & $73-82$ \\
\hline
\end{tabular}

\section{Example 9-21}

\section{mm 1-6}

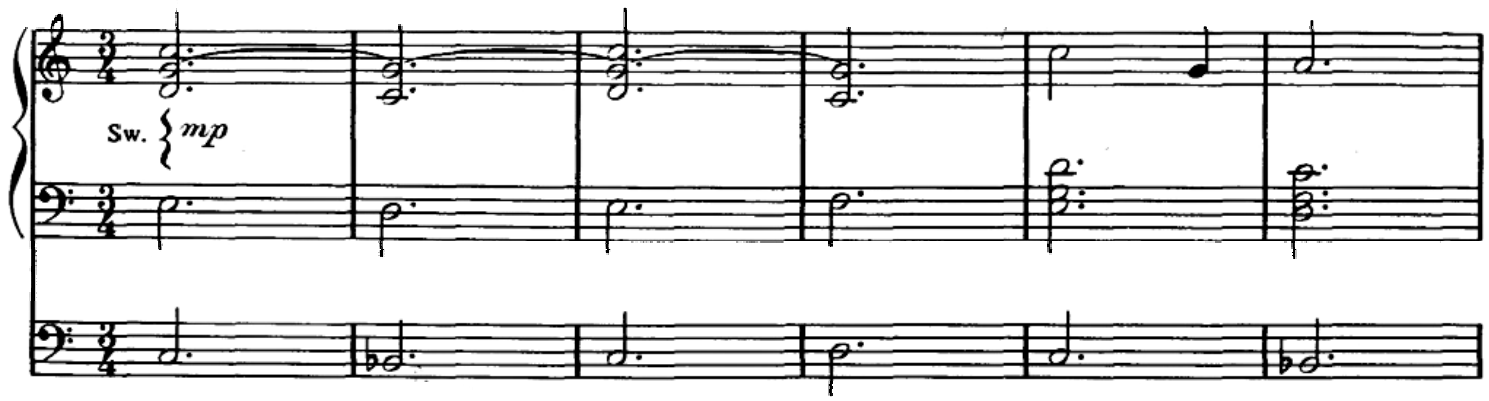

${ }^{222}$ Although "glockenspiels" and other "spieleren" were available in organs in the Baroque and Romantic periods, "church chimes" were specifically derived from the American theater organ as they portrayed bells of various kinds in films.

${ }^{223}$ Hebble; Florida Tape 2, side 2 
Free work Cp131 Night Communion

Sacred Music Press KK517-3

F minor; $4 / 4$ time

$52 \mathrm{~mm}$; ABA
Collection XI; (5/8/[10])

Designs for Organ (1992)

Three Manuals/Pedal

It is dedicated to Dr. William R. Ray "In appreciation of his leadership and inspiration in all the fine arts". Its principle theme remains mainly intact, even through the more improvised middle section, where the theme is only slightly modified. The work begins and ends with a quasi-passacaglia over a tonic manual pedal, while a descending tenor line precipitates four harmonic changes. In the first section of the piece there are four small passacaglia-like variations (mm. 1-16), see Ex. 9-22. Another repetitive figure in the pedal (mm. 16-18) at the key change (m. 16) presents a tonic pedal during harmonic changes occurring in the manuals, the PT sounding in the baritone ambit. Another shortlived repetitive figure (mm. 19-22) in the pedal forms a small ostinato over which small harmonic changes prepare the listener for the Middle Section. The Middle Section improvises upon the general directional gesture of the PT (mm. 23-33) and from it draws a rhythmic pattern. This pattern, originating at (mm. 23-25) is repeated at (mm. 27-28, 29-30, 31-33). There is a general lack of harmonic drive, depicting "night" and "rest". Overall, the only organizational material is "repetitive gestures" 224 , the ostinatos, the passacaglias, the rhythmic patterns, suggestive of the 'nightly routine' before bedtime" 225 . Before the coda is another brief section of passacaglia in F minor (mm. 3847), which contains two variations in which the end of the final variation is significantly altered and harmonically telescoped (mm. 45-47), implying an alteration to the "nightly routine'. The PT is slightly ornamented (mm. 40, 44, 46, 50) and the coda slows the

\footnotetext{
${ }^{224}$ Hebble: Atlanta Interview, August 31, 2002

${ }^{225}$ Ibid.
} 
general motion of the work to tonic via an augmented V chord (m. 49). Hebble states,

"It's a tone poem. It's pure color". ${ }^{226}$

\begin{tabular}{|c|c|c|c|c|}
\hline $\begin{array}{l}\text { A } \\
\text { Passacaglia }\end{array}$ & (transition) & $\begin{array}{l}\text { B } \\
\text { Middle Section }\end{array}$ & $\begin{array}{l}\text { A } \\
\text { Passacaglia }\end{array}$ & Coda \\
\hline $\begin{array}{l}\text { Four variations } \\
\text { exposing of } \\
\text { principle theme }\end{array}$ & $\begin{array}{l}\text { Short-lived } \\
\text { ostinatos in pedal } \\
\text { theme recurs }\end{array}$ & $\begin{array}{l}\text { Isorhythms, four } \\
\text { repetitions, } \\
\text { theme altered }\end{array}$ & $\begin{array}{l}\text { Two } \\
\text { variations, } \\
\text { ornamented } \\
\text { theme }\end{array}$ & $\begin{array}{l}\text { Change of } \\
\text { 'nightly routine' } \\
\text { augmented V }\end{array}$ \\
\hline $\begin{array}{l}\text { mm. 1-16 } \\
\text { F minor i }\end{array}$ & $\begin{array}{c}16-22 \\
\text { A minor \#iii }\end{array}$ & $\begin{array}{c}23-37 \\
\mathrm{D}^{\mathrm{b}} \text { major V1 }\end{array}$ & $\begin{array}{c}38-47 \\
\text { F minor i }\end{array}$ & $\begin{array}{c}48-52 \\
\text { F minor } \mathrm{i}\end{array}$ \\
\hline
\end{tabular}

\section{Example 9-22}

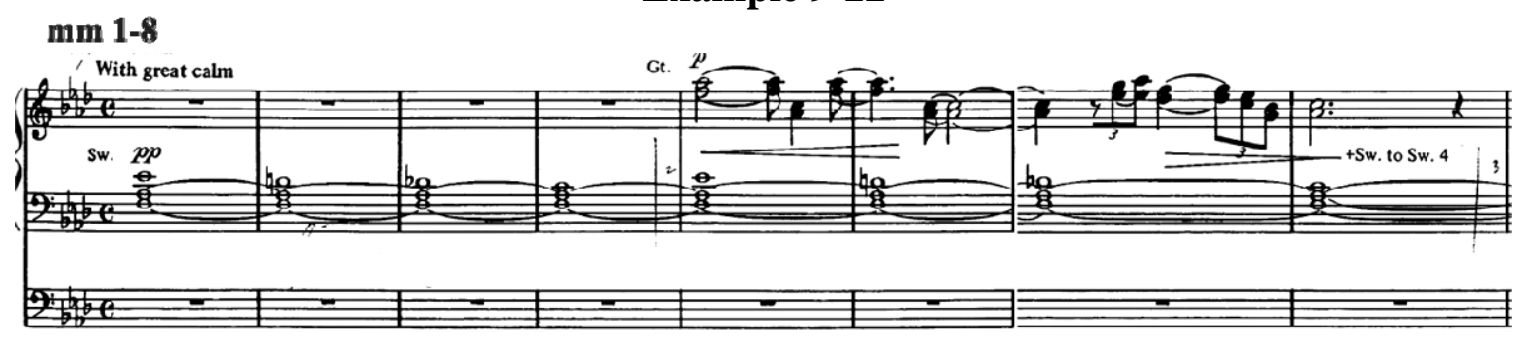

Free work Cp133 Supplication

Sacred Music Press KK517-3

C major; $4 / 4$ time

40mm; through-composed
Collection XI; (6/8/[10])

Designs for Organ (1992)

One Manual/Pedal

In the dictionary supplement for the World Library Encyclopedia 1974, the word "supplication" means "to plead humbly and earnestly, to address an entreaty". Hebble's comments provide clarification: "like a petition, we don't always ask the right questions when we pray. So this work guides the listener to "reconsider the question"”227 The "querry" or "object of desire" is the tone cluster in measure 1 that gets revisited at (mm. $7,13-19,20,28,30,32,34)$ that, when looked at individually, is revisited seven times, see Ex. 9-23, sy1. The first time is "measure 7" and the second one (mm. 13-19) has "seven"

${ }^{226}$ Ibid. 
measures. Seven is the numerological number for "perfection"; in this case, it means the "perfect querry". There are other hermeneutic ideas: one registration or stop means to be "focused" or "undistracted"; the 32' Bourdon is for "gravity" or "seriousness", and the pedal, always grouped in twos, refers to the duality of 'supplication' between God and the supplicant, between want and fulfillment, see Ex. 9-23, sy2. The tone-cluster depicts that the supplicant's 'want' is encumbered or may not be the 'perfect' and, even in the final chord (m. 40), may not get the answer for which he prayed. In the end, there are six sections to this work, and the number six refers to "incompleteness" or "imperfection". This implies that prayer is not perfect, but that its method is a means to fulfillment. The six measures of the first two sections imply that what the supplicant's desires may not be best. In the third section, the elongation of the theme to seven measures implies that through 'growth' (elongation) the supplicant approaches perfection. Up to this point there have been hints of octatonicism in the harmony, but in the fourth section the clusters are grouped in four-bar balanced musical phrases of "antecedent - consequent" in pure octatonic writing. This continues in the balance and unity of the fifth section with five two-bar phrases representing the "five wounds of Christ", where the inspiration of prayer is broken down to the realization that the supplicant's "woundedness" in his life sharpens the supplication to finer points. Its ten measures allude to the basics of the Ten Commandments. The sixth section is three measures, indicative of the Trinity, and implies that in the end God is there. The final tone cluster implies "incompleteness" or an "encumbered" outcome. In Hebble's own words he states, "It's a short tone poem about 'desire'. It's that simple", ${ }^{228}$ Source material would be Olivier Messiean's

\footnotetext{
${ }^{227}$ Ibid.

${ }^{228}$ Ibid.
} 
L'Ascension Suite pour L'Orgue (1949), fourth movement, or the Dupré Antiphons which use the same texture and pedal.

\begin{tabular}{|c|c|c|c|c|c|}
\hline Section 1 & Section 2 & Section 3 & Section 4 & Section 5 & Section 6 \\
\hline $\begin{array}{l}\text { Homophonic, } \\
\text { theme in } \\
\text { soprano, tone- } \\
\text { cluster, } 6 \\
\text { measures = } \\
\text { imperfect }\end{array}$ & $\begin{array}{l}\text { Homophonic, } \\
\text { theme in } \\
\text { soprano, } \\
\text { tone-cluster, } \\
6 \text { measures = } \\
\text { imperfect }\end{array}$ & $\begin{array}{l}\text { theme in } \\
\text { soprano, tone- } \\
\text { cluster, } 7 \\
\text { measures = } \\
\text { perfect, sign of } \\
\text { growth }\end{array}$ & $\begin{array}{l}\text { theme in } \\
\text { soprano, tone- } \\
\text { cluster, } 8 \\
\text { measures = } \\
\text { musical } \\
\text { balance, unity }\end{array}$ & $\begin{array}{l}\text { Five } 2 \\
\text { measure } \\
\text { phrases, ten } \\
\text { total measures } \\
= \\
\text { commandmts }\end{array}$ & $\begin{array}{l}3 \text { measures }= \\
\text { Trinity, ends } \\
\text { on a tone- } \\
\text { cluster like } \\
\text { beginning }\end{array}$ \\
\hline
\end{tabular}
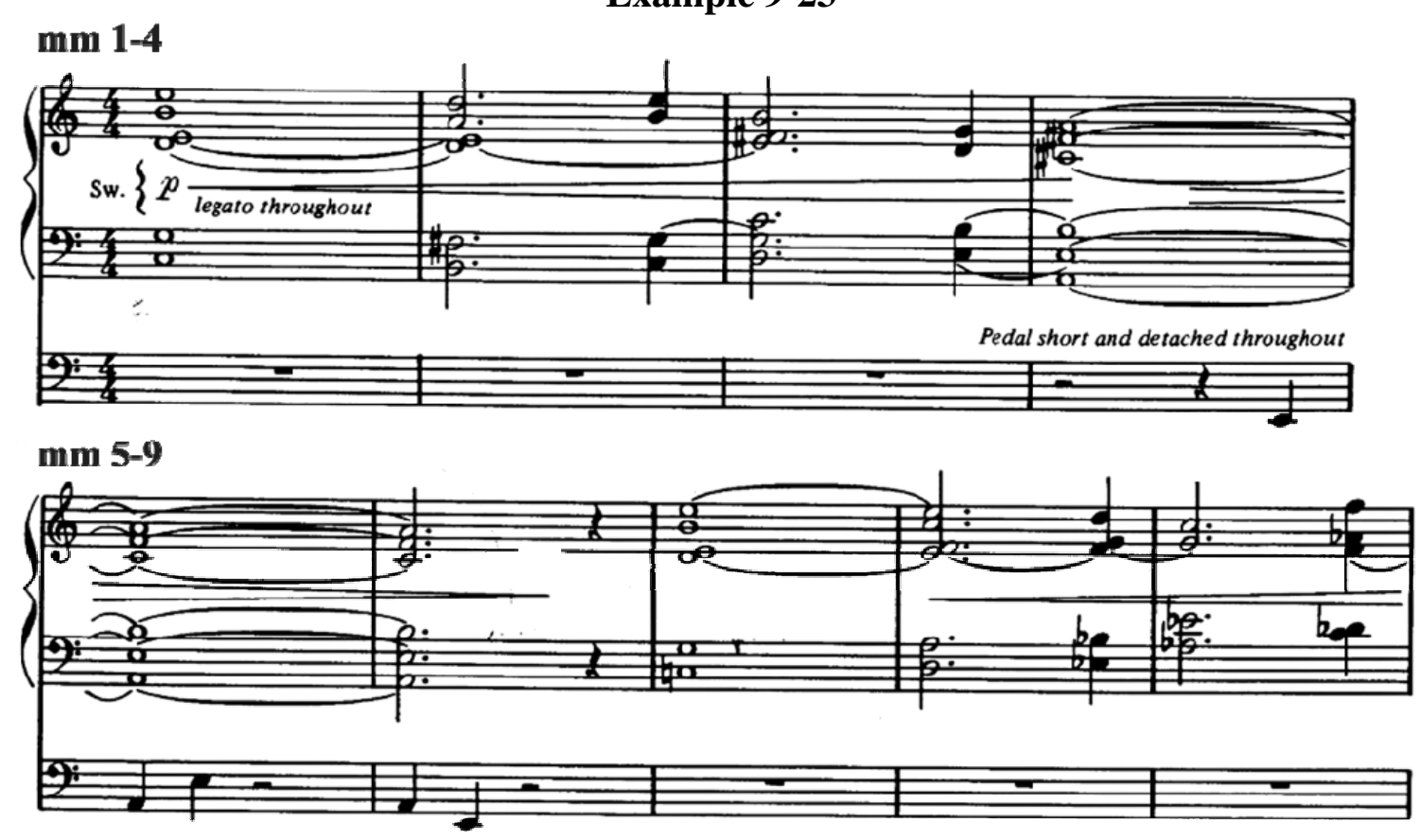

Free work Cp134 The Majestic Trumpet

Sacred Music Press KK517-3

G major; $4 / 4$ time

$35 \mathrm{~mm}$; quasi-rondo form
Collection XI; (7/8/[10])

Designs for Organ (1992)

Three Manuals/Pedal

It follows the traditional meter and architecture of similar source material (trumpet voluntaries) for the organ. Like Cp135 it features a very loud $\mathrm{ff}$ reed against almost full organ and has ornamental melodic extensions, without repeats, see Ex. 9-24. There is no 
introduction. The work begins with the loud trumpet stop. Since the accompaniment is so full, Hebble writes open spacing in the accompaniment to allow the solo trumpet stop to be heard clearly.

\begin{tabular}{|l|l|l|l|l|}
\hline Section A & Section B & Section C & Section A & Coda \\
\hline $\begin{array}{l}\text { Theme in sop. } \\
\text { Spacious accomp }\end{array}$ & $\begin{array}{l}\text { Phrases in 2-bar } \\
\text { groups, irregular }\end{array}$ & $\begin{array}{l}\text { Begins like A. } \\
\text { solo trot fanfares }\end{array}$ & $\begin{array}{l}\text { Theme in sop. } \\
\text { Altered harmony }\end{array}$ & $\begin{array}{l}\text { Full organ } \\
\text { fanfares }\end{array}$ \\
\hline mm. 1-8 & $12-15$ & $16-25$ & $26-33$ & $34-35$ \\
\hline
\end{tabular}

\section{Example 9-24}
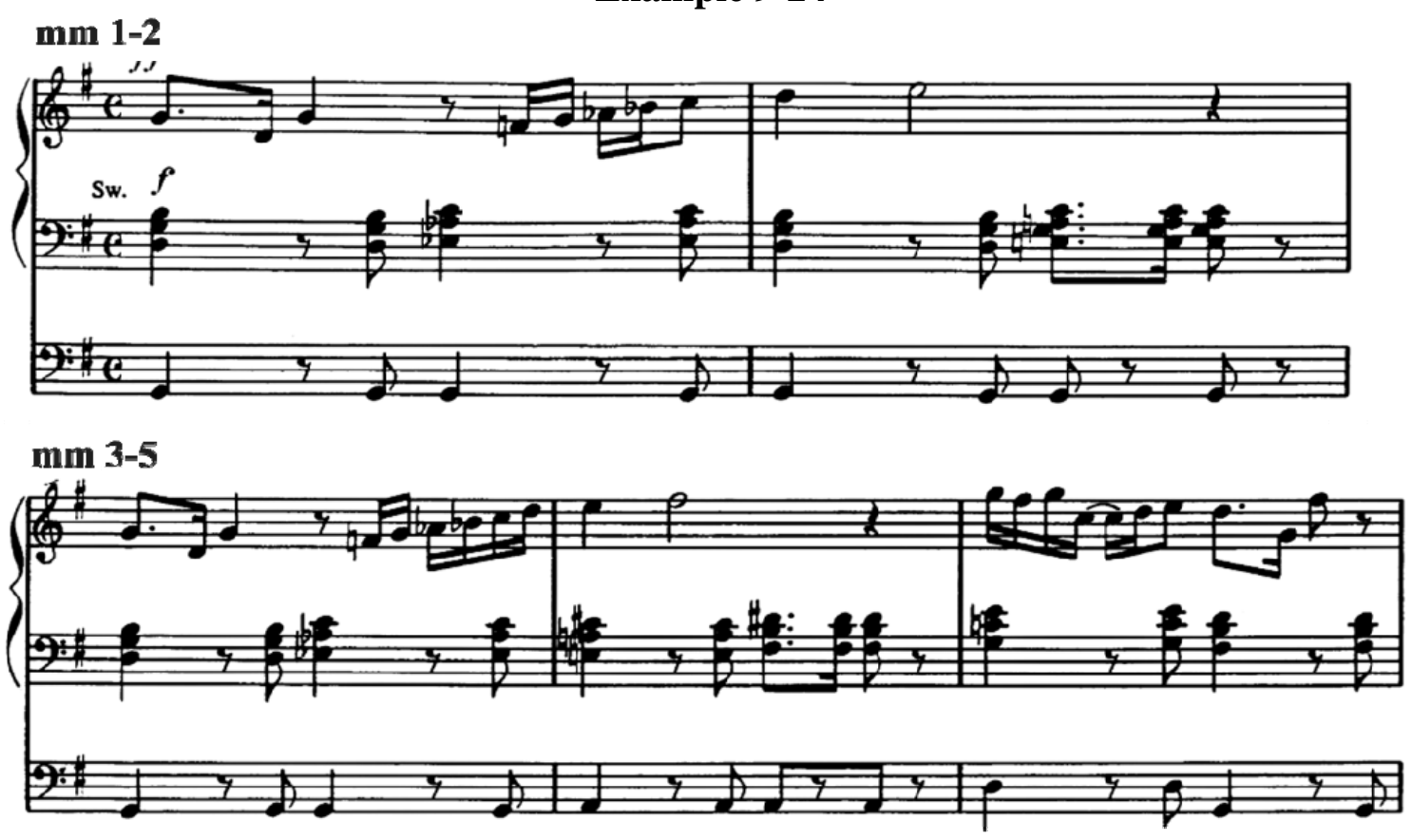

Free work Cp135 Trumpet Tune

Sacred Music Press KK517-3

A major; $3 / 4$ time

$54 \mathrm{~mm}$; ABA
Collection XI; $(8 / 8 /[10])$

Designs for Organ (1992)

Three Manuals/Pedal

It is a unique work in that while most "trumpet" pieces for organ are in common-time or march time. Cp135 is in 3/4; plus, it is in A major instead of the traditional D major, see Ex. 9-25. Its unique flourishes show off the ACO's State Trumpet or Trompette enChamade against the Principal Choruses of several divisions. Hebble structures this work within the traditional architectural framework of similar source material works for organ: 
A A'B B', C, A A', except that this work has no Section C. This composition also has a coda. Improvising in typical Baroque fashion, the second part of Section A, (the A'), is ornamented as per the performance practice of that day. In atypical fashion, in the second part of Section B, (the B'), the accompaniment is more ornamented than the PT; plus, this latter section is in the Neapolitan harmony of $\mathrm{B}^{b}$ major (mm. 25-27). When Section A returns, the PT is so disguised it is almost indistinguishable (mm. 34-49), and the accompanying harmonies are so altered that it seems quite unlike the first Section A.

\begin{tabular}{|c|c|c|c|}
\hline Section A A & Section B B' & Section A A & Coda \\
\hline $\begin{array}{l}\text { Theme in } 2 \text { parts: } \\
\text { A and A', second } \\
\text { part ornamented }\end{array}$ & $\begin{array}{l}\text { Theme in } 2 \text { parts: } \\
\text { B and B' second } \\
\text { part in Neapolitan }\end{array}$ & $\begin{array}{l}\text { Theme very } \\
\text { disguised, altered } \\
\text { harmony }\end{array}$ & $\begin{array}{l}\text { Fragments of both } \\
\text { themes, trpt } \\
\text { flourishes }\end{array}$ \\
\hline $\mathrm{mm} 1$ & $17-33$ & $34-49$ & $50-54$ \\
\hline
\end{tabular}

\section{Example 9-25}

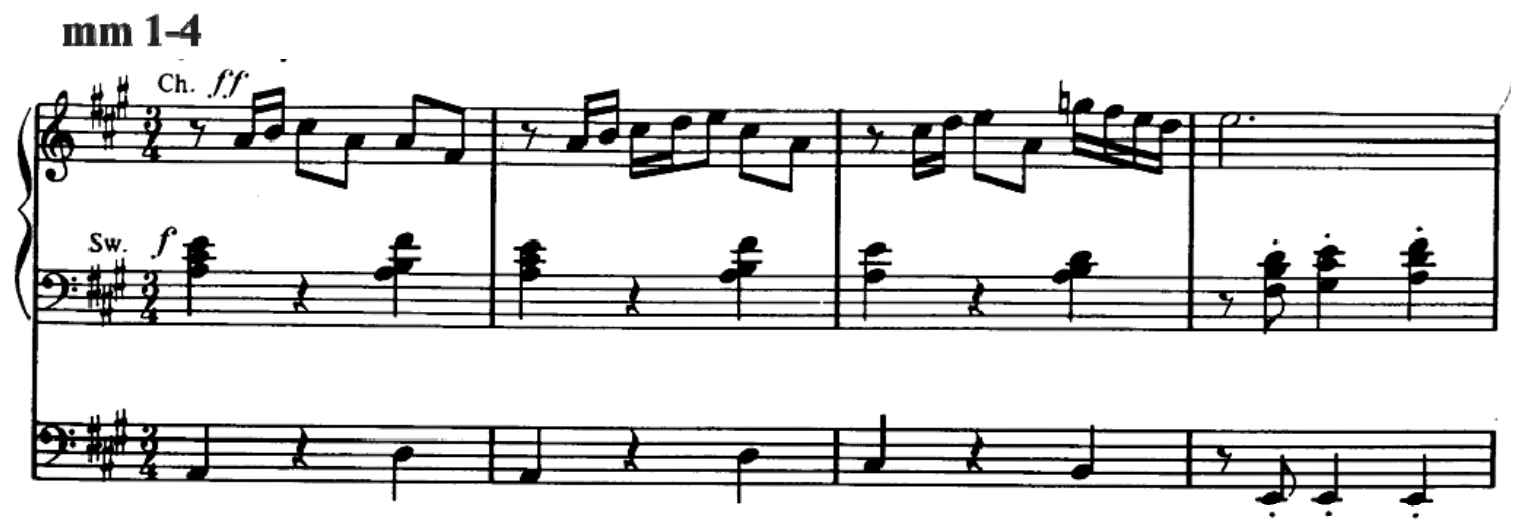

Free work Cp136 American Declaration Belwin Mills EL03966

$\mathrm{G}^{b}$ to $\mathrm{B}^{b}$ major; $4 / 4$ time $110 \mathrm{~mm} ;$ medley/through-composed
Collection XII; (1/2/[8]) The Hebble Duet Collection (1994).

Three Manuals/Pedal

This composition is a piano and organ duet medley based on three patriotic tunes:

"America the Beautiful", "Battle Hymn of the Republic" and "When Johnny Comes 
Marching Home." It is very virtuosic in nature with rapid toccata figures, see Ex. 9-26, sy1, and four octave scales for the piano and with great harmonic color and registration changes for the organ. In order to appreciate the composition, it is necessary to write out the texts of the three melodies and label them. In the meantime, the general outline of the work is as follows:

\begin{tabular}{|c|c|c|c|c|}
\hline Intro I and II & Section A & Section B & Section C & Coda \\
\hline $\begin{array}{l}\text { Piano toccata, } \\
\text { organ and piano } \\
\text { share fragments } \\
\text { of } 3 \text { themes }\end{array}$ & $\begin{array}{l}\text { Melody is } \\
\text { "When Johnny } \\
\text { Comes } \\
\text { Marching } \\
\text { Home" }\end{array}$ & $\begin{array}{l}\text { Melody is } \\
\text { "America, } \\
\text { the } \\
\text { Beautiful", } \\
\text { interlude }\end{array}$ & $\begin{array}{l}\text { Melody is } \\
\text { "Battle Hymn } \\
\text { of the } \\
\text { Republic," }\end{array}$ & $\begin{array}{l}\text { No thematic } \\
\text { frags. Explores } \\
\text { unrelated } \\
\text { harmonic areas }\end{array}$ \\
\hline $\mathrm{mm} .1-20,21-38$ & $39-67$ & $68-86$ & $87-103$ & $104-110$ \\
\hline
\end{tabular}

A fuller depiction of this work is rendered in the following chart, based on the labeled tunes in the order in which they appear in the score. The numbers in parenthesis represent which tune and the letters indicate the melodic differences within each strophe as Hebble uses them in this work.

1 - America The Beautiful

O beautiful for spacious skies. (1a) For amber waves of grain; For purple mountains, majesty (1a') Above the fruited plains. America, America! God sheds (1b) His grace on thee And crown thy good with brotherhood From sea to shining sea. (1c) (see Ex. 9-26, sy1, 2 and 4)
2 - Battle Hymn of the Republic

Mine eyes have seen the glory of the coming of the Lord, (2a) $\mathrm{He}$ is trampling out the vintage Where the grapes of wrath are stored (2a) He has loosed the fateful lightning Of his terrible, swift sword. (2a) His truth is marching on! Glory, glory, hallelujah! (2b1) Glory, glory, hallelujah! (2b2) Glory, glory, hallelujah! (2b1) His truth is marching on! (2b3) 
3 - When Johnny Comes Marching Home (see Ex. 9-26, sy3)

When Johnny comes marching home again: hurrah, hurrah! (3a)

We'll give him a hearty welcome then, hurrah, hurrah! (3a')

$\mathrm{O}$ the men will cheer, the boys will shout, the ladies they will all turn out, (3b)

And we'll all feel gay when Johnny comes marching home. (3c)

Introduction $\mathbf{I}$ :

\begin{tabular}{|c|c|c|c|c|}
\hline $\begin{array}{l}\text { Piano - toccata } \\
\text { Organ - frag. } \\
\text { 1a }\end{array}$ & $\begin{array}{l}\text { Piano - toccata } \\
\text { Organ - frag. } \\
\mathbf{1 a} 2\end{array}$ & $\begin{array}{l}\text { Piano - toccata } \\
\text { Organ - frag } \\
\text { 1a3 }\end{array}$ & $\begin{array}{l}\text { Piano-toccata } \\
\text { Organ - frag. } \\
\text { 1a4 }\end{array}$ & $\begin{array}{l}\text { Piano - toccata } \\
\text { Organ - frag. } \\
\text { 1a5 }\end{array}$ \\
\hline $\mathrm{mm} \mathrm{1-6}$ & $7-9$ & $9-12$ & $13-17$ & $17-20$ \\
\hline \multirow[t]{2}{*}{ Key $-G^{b} / E^{b} m$} & $\mathrm{~A}$ & $\mathrm{C}$ & $\mathrm{G}^{b} / \mathrm{E}^{b} \mathrm{~m} / \mathrm{C} 7$ & $\mathrm{~F}$ \\
\hline & & & VI & $\mathrm{V}$ \\
\hline Entrarmon.colth & ontorte $\mathrm{D}^{b} \rightarrow \mathrm{C}^{\#}$ & "e" & (N.) & \\
\hline
\end{tabular}

Introduction II:

\begin{tabular}{|c|c|c|c|c|}
\hline $\begin{array}{l}\text { Piano - V pedal } \\
\text { Organ - 2b-1 } \\
\text { Piano ends with } \\
\text { 3a in whole tone }\end{array}$ & $\begin{array}{l}\text { Piano - V pedal } \\
\text { Organ - 2b-2 } \\
\text { Piano ends with } \\
\text { 3b in whole-tone }\end{array}$ & $\begin{array}{l}\text { Piano - 3c-1 } \\
\text { Organ - 3c-2 in } \\
\text { whole tone V in } \\
\text { pedal }\end{array}$ & $\begin{array}{l}\text { Piano - 3c-3 } \\
\text { Organ - 3c-4 } \\
\text { altered. V in } \\
\text { pedal }\end{array}$ & $\begin{array}{l}\text { Interlude based } \\
\text { on } 3 c-5 \text { two } \\
\text { times }\end{array}$ \\
\hline
\end{tabular}

mm 21-22, 23-26 27-28, 29-31 32-33, 34-35 $35-36 \quad 37-38$

Key:- $\mathrm{B}^{b}$ minor / Whole-tone

Section A

\begin{tabular}{|c|c|c|c|c|}
\hline $\begin{array}{l}\text { Piano - quintal- } \\
\text { quartet ostinato } \\
\text { Organ - 3a and } \\
\text { 3a vi }\end{array}$ & $\begin{array}{l}\text { Piano - off-beat } \\
\text { syncopations 3c } \\
\text { Organ - 3b and } \\
\text { 3c interlude vi }\end{array}$ & $\begin{array}{l}\text { Piano - off-beat } \\
\text { syncopations } \\
\text { Organ - 3a and } \\
\text { 3b. } 3 \text { c canon \#v }\end{array}$ & $\begin{array}{l}\text { Interlude I- } \\
\text { piano moves } \\
\text { from B to E } \\
\# \mathrm{~V} \# \mathrm{I} \text { \#IV }\end{array}$ & $\begin{array}{l}\text { Interlude } 2- \\
\text { organ moves from } \\
\text { E to } D^{b} \# I V \text { BIII }\end{array}$ \\
\hline mm. 39-44 & $45-50$ & $51-58$ & $59-62$ & $63-67$ \\
\hline Key - gm & gm & $\mathrm{fHm}$ & $F \#-B-E$ & $E-D^{b}$ \\
\hline
\end{tabular}


Section B

\begin{tabular}{|c|c|c|c|c|}
\hline $\begin{array}{l}\text { Piano - 1a } \\
\text { Organ - } \\
\text { countermelody } \\
\text { b III IIth, } 13^{\text {th }}, 9 \text { th }\end{array}$ & $\begin{array}{l}\text { Piano - 1a } \\
\text { Organ - } \\
\text { countermelody } \\
\text { b III IIth, } 13^{\text {th }}, 9 \text { th }\end{array}$ & $\begin{array}{l}\text { Piano - 1b } \\
\text { Organ - } \\
\text { countermelody } \\
\text { b III } 7^{\text {th }}, 9^{\text {th }} 11^{\text {th }}\end{array}$ & $\begin{array}{l}\text { Piano - 1c } \\
\text { Organ - } \\
\text { countermelody } \\
\text { BIII } 7^{\text {th }}, 11^{\text {th, }} 13^{\text {th }}\end{array}$ & $\begin{array}{l}\text { Interlude - 1c in } \\
\text { imitation, } \\
\text { common-tone } \\
\text { modulation V - }\end{array}$ \\
\hline mm. 68-71 & $72-75$ & $76-79$ & $80-82$ & $83-86$ \\
\hline
\end{tabular}

Section C

\begin{tabular}{|c|c|c|c|c|}
\hline $\begin{array}{l}\text { Piano - major } \\
\text { sevenths } \\
\text { Organ - 2a } \\
I-B^{b} \text { major }\end{array}$ & $\begin{array}{l}\text { Piano - major } \\
\text { sevenths } \\
\text { Organ - 2a }\end{array}$ & $\begin{array}{l}\text { Piano - major } \\
\text { sevenths } \\
\text { Organ - 2a }\end{array}$ & $\begin{array}{l}\text { Piano - four } \\
\text { octave scales } \\
\text { Organ }-\mathbf{2 b} \\
\text { Altered harmony }\end{array}$ & $\begin{array}{l}\text { Coda - I to \#IV } \\
\text { then I to \#VI } \\
\text { then IV to II to I } \\
\text { unthematic }\end{array}$ \\
\hline $\mathrm{ml}^{2}$ & 0 & 91- & $95-103$ & $104-110$ \\
\hline
\end{tabular}


Example 9-26

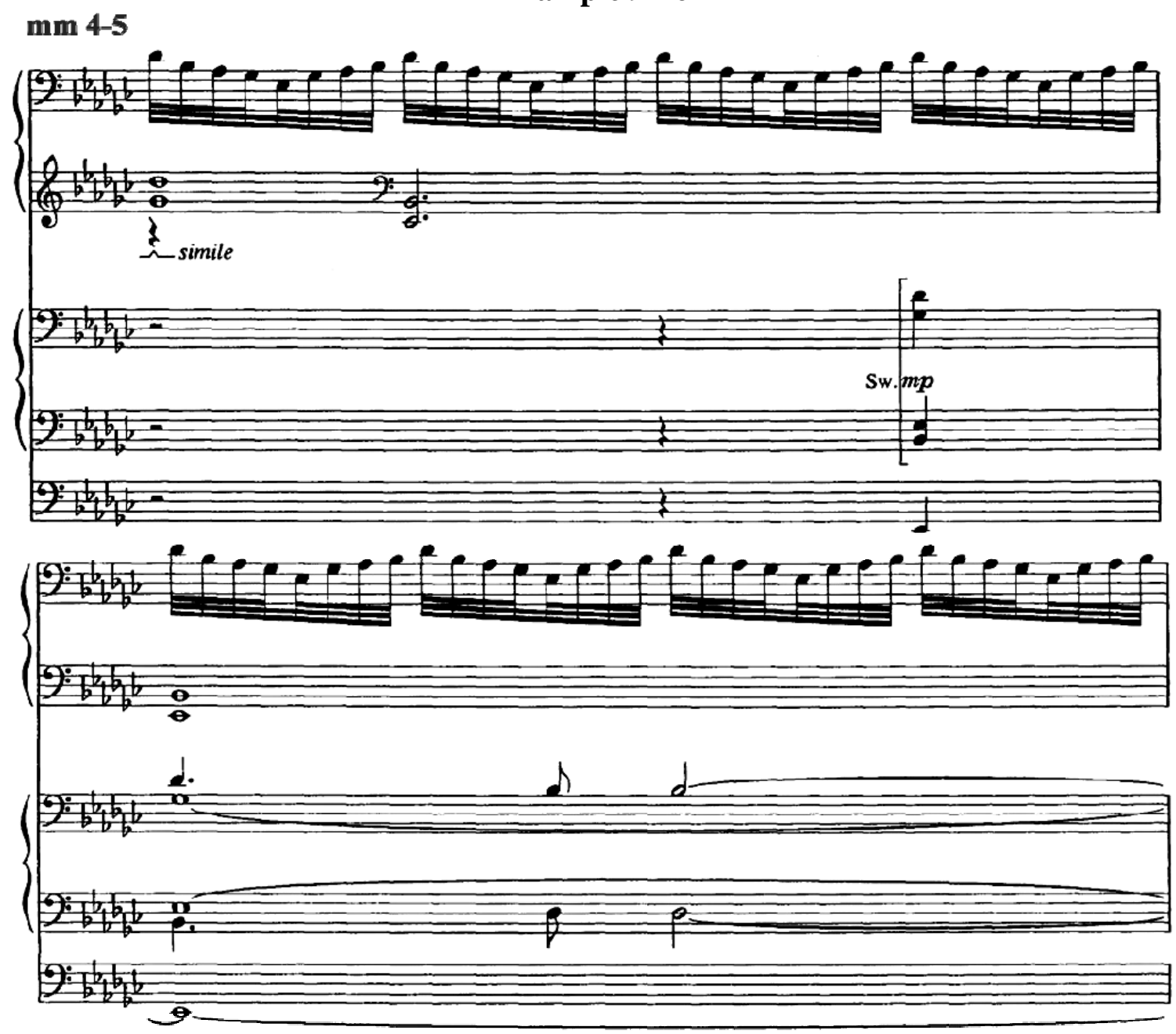




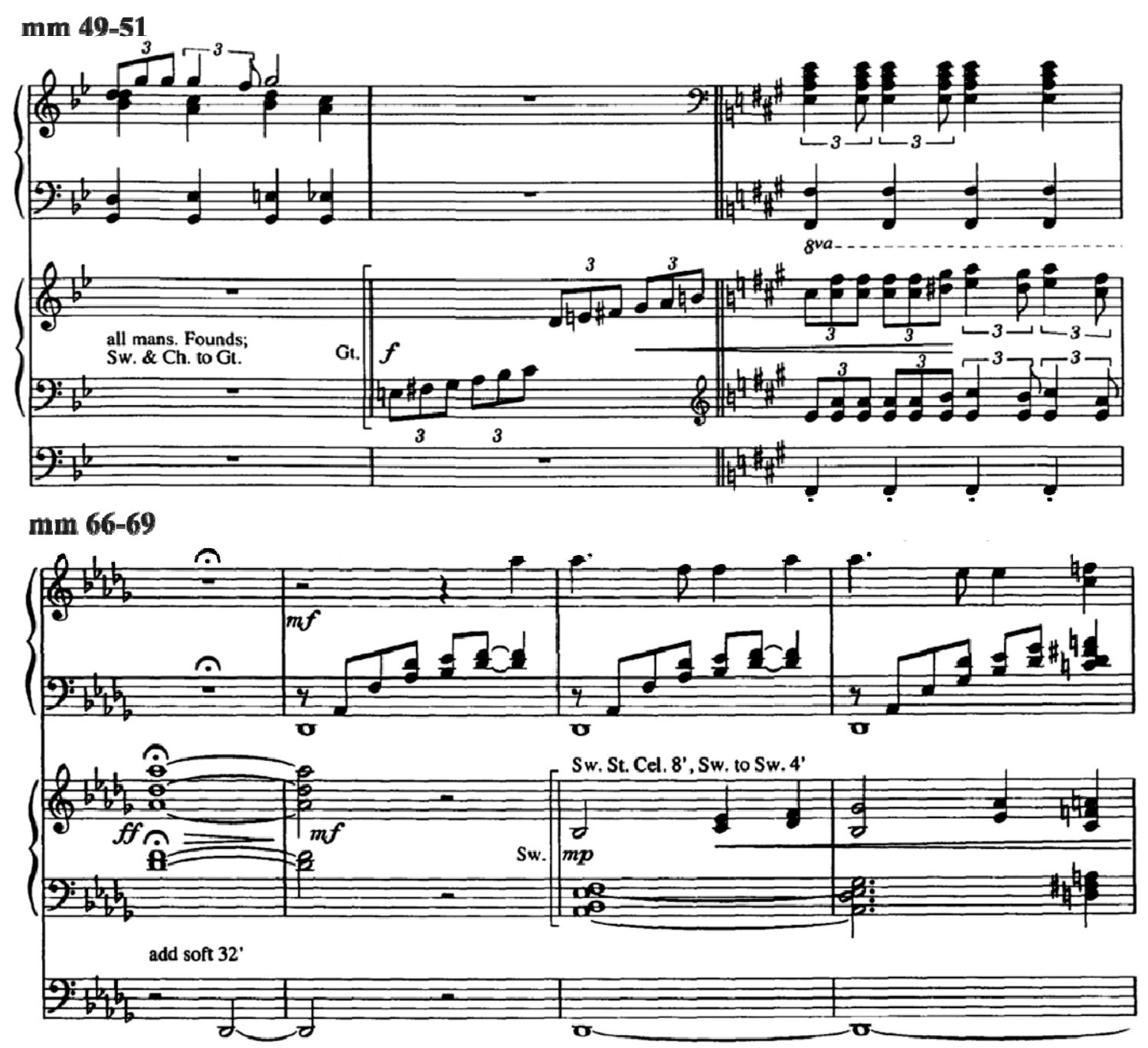

Free work Cp138 Chrysalis

Belwin Mills EL03966

Multiple keys; 4/4 time

$74 \mathrm{~mm}$; quasi-sonata form
Collection XII; (2/2/[8])

The Hebble Duet Collection (1994).

Three Manuals/Pedal

It is written as a duet with organ and piano. The work has two themes: one for the

butterfly and one for the caterpillar: and Hebble, here, composes with thematic

transformation, where each theme gradually takes on the characteristics of the other, see

Ex. 9-27. Underneath the title of the work in the collection are these words: 
"One of the most magical moments on earth is the moment that a caterpillar changes into a butterfly. In the cocoon there is a magical moment called chrysalis. It is the moment that the caterpillar has wings."

Hebble depicts the 'chrysalis' moment in the work. Of note is that the melody of the butterfly ascends (mm. 1-6) and the melody of the caterpillar descends (mm. 3-4, 6-7). However, the nature of "chrysalis" means that the caterpillar aspires to "ascend" (mm. 7$8,24-25)$, while the butterfly must descend to lay eggs, feed and rest (mm. 8-10, 12-13), and has within itself the very essence of 'caterpillar'. Thus, each melody takes on the characteristic of the other inasmuch as a butterfly is a caterpillar and a caterpillar is a butterfly (mm. 19, 47, 64-66). The caterpillar theme (m.3, (see Ex. 9-27, organ) develops in (mm.4, 10-11, 18-19, 22, 28-29, 40-43, 47, 49, 54-58). The butterfly theme (m.1, see Ex. 9-27, piano "flutterings") develops in (mm. 2,5-6, 8, 10-11, 13, 15-17, 24-27, 30-31, 60-63, 65-67). Each of these can show how the germ is transformed each time. The moment of chrysalis is when "change" no longer occurs (50-53) and something new happens: a new color feature on the organ (the Krummhorn). It is a unique work in thematic transformations, where not only do two themes transform, but take on each other's characteristics. The cycle is completed by the return to the original key, and that which was in the piano is now in the organ, and that which ascended now descends and vice-versa. The coda experiments with retrograde and inversion (mm. 63[65]-66, and 7274). 


\begin{tabular}{|c|c|c|c|c|}
\hline Introd & Exposition & Development & Result & Coda \\
\hline $\begin{array}{l}\text { General motive } \\
\text { outlines of } \\
\text { butterfly and } \\
\text { caterpillar, cycle } \\
\text { begins }\end{array}$ & $\begin{array}{l}\text { Exposing the } \\
\text { thematic material } \\
\text { as ascending or } \\
\text { descending }\end{array}$ & $\begin{array}{l}\text { Each theme } \\
\text { exchanges } \\
\text { direction, adopts } \\
\text { each other's } \\
\text { ideas and form }\end{array}$ & $\begin{array}{l}\text { Not a } \\
\text { recapitulation: } \\
\text { themes have } \\
\text { been transformed } \\
\text { then break down } \\
\text { motives }\end{array}$ & $\begin{array}{l}\text { retrograde } \\
\text { and } \\
\text { inversion of } \\
\text { introduction } \\
\text { cycle } \\
\text { repeats }\end{array}$ \\
\hline mm. $1-8$ & $12-23$ & $m_{24-53} \mathrm{D}$ & $54-64$ & $65-74$ \\
\hline
\end{tabular}

mm 1-3

Example 9-27

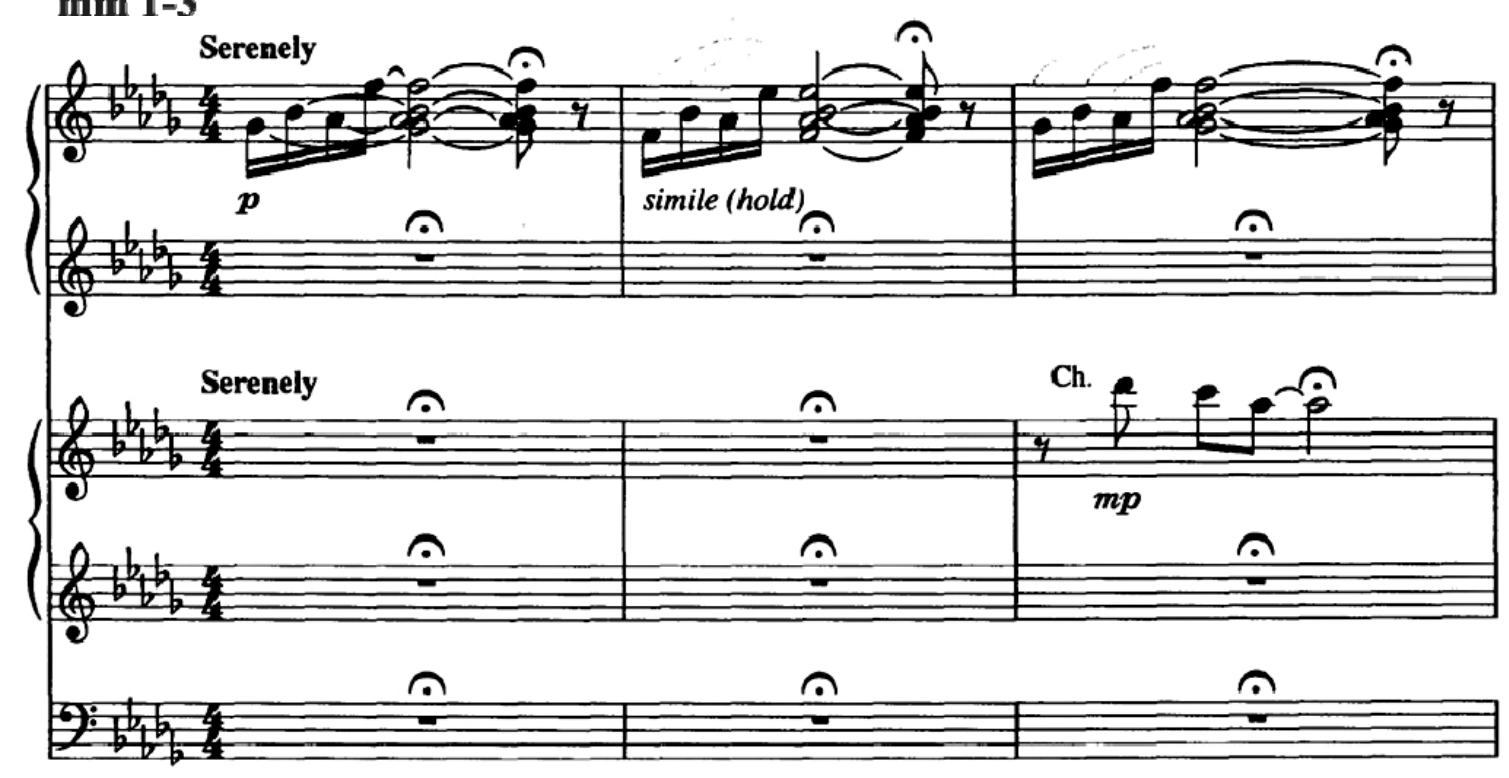

Free work Cp155 The Wedding at Cana Collection XIII; (1/3/[19])

Belwin Mills GB9503

G major; $4 / 4$ time

Wedding Music for Organists (1995)

$37 \mathrm{~mm}$; rondo form

Three Manuals/Pedal

It is in quasi-rondo form ( $\mathrm{AB}-\mathrm{AB}$ (with repeat)-A) with an added coda and introduction.

It was designed to replace the hackneyed "trumpet voluntaries" that dominate wedding organ processional music at the end of the twentieth century. After the introduction on full plenums, the trumpet tune is in the left hand, baritone ambit, see Ex. 9-28. This is different than the typical trumpet tunes, designed with the PT in the soprano, and offers a 
march-like, but less maestoso, less dramatic approach. The outline is as follows. The coda ends with two phrases of fanfares in the right-hand.

\begin{tabular}{|c|c|c|c|c|}
\hline Introduction & Section A & Section B (repeat) & Section A & Coda \\
\hline $\begin{array}{l}\text { Contains motives } \\
\text { of accomp. to PT } \\
\text { in } \mathrm{G} \text { major }\end{array}$ & $\begin{array}{l}\text { PT appears in } \\
\text { 1.h. while frag. } \\
\text { of intro. = r.h. }\end{array}$ & $\begin{array}{l}\text { Develops } \\
\text { motives from } \\
\text { intro. in } E^{b} m\end{array}$ & $\begin{array}{l}\text { PT recurs in 1.h. } \\
\text { in G major; } \\
\text { accomp. same }\end{array}$ & $\begin{array}{l}\text { Motives evolve } \\
\text { from B section } \\
\text { and intro. }\end{array}$ \\
\hline mm. 1-11 & $12-19 / 20-23$ & $24-27$ & $28-31$ & $32-37$ \\
\hline I & I & ${ }^{b} \mathrm{III}$ & I & IV - I \\
\hline
\end{tabular}

\section{Example 9-28}

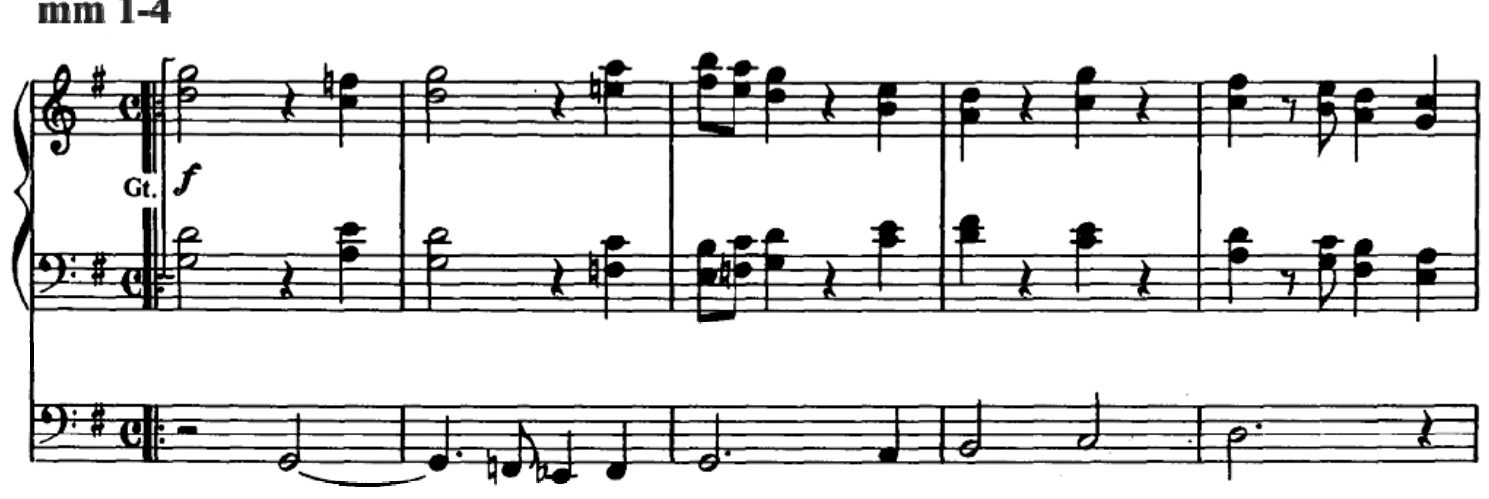

Free work Cp 169a,c,d Symphony of Light Hinshaw HMO-150

A major (multiple); 4/4 time (multiple) $37 \mathrm{~mm}$; sonata form, in movements
Single Work

(1986)

Five Manuals/Pedal

The second movement "Playfully" was already addressed in Chapter 5 under "Chorales". Movements I, III and IV will be discussed here. The entire work is for five manuals (Great, Swell, Choir, Solo and Antiphonal) and pedal. It is composed in the spirit of a Widor or Vierne organ symphony. Each movement has a subtitle that quotes Christian scripture. Movement I quotes St. John 5:35 "He was a burning and a shining light: and ye were willing for a season to rejoice in His light”, see Example 9-29a. 
Section A

Section B

Section A

PT (solo) homophonic
tertain from A to F majo

mm. 1-31

Frag. of PT, D minor to D

PT homophonic B major major to $\mathrm{B}$ minor, imitat.

$32-44$ (tertain to D) as V to $\mathrm{E}$.

45-54

Movement III quotes Isaiah 9:2 "The people that walked in darkness have seen a great light: they that dwell in the land of the shadow of death, upon them hath the light shined", see Example 9-30c. Movement IV quotes Isaiah also 60:1 "Arise, shine: for thy light is come, and the glory of the Lord is risen upon thee", see Example 9-31d. Each movement portrays the program set forth by the subtitle in organ improvisation. The PT, functioning as another "Fox theme", ${ }^{229}$ moves through the first movement via tertian (Trinitarian) relations: $\mathrm{A}$ to $\mathrm{F}$ to $\mathrm{Dm} / \mathrm{Dmaj}$ to $\mathrm{Bm} /$ major to $\mathrm{E}$. The third movement is a larger improvisation on its program and is a palindrome. The fourth movement is a large toccata form, see Ex. 9-31d.

\begin{tabular}{|c|c|c|c|c|}
\hline Introduction & Section A & Section B & Section A & Coda \\
\hline $\begin{array}{l}\text { Fragments of } \\
\text { PT }^{b} \text { minor } \\
{[\mathrm{V}]}\end{array}$ & $\begin{array}{l}\text { PT in pedal }-1 \\
\text { homoph. }-2 \\
\text { ornamented }-3\end{array}$ & $\begin{array}{l}\text { F\# pedal } \\
\left(\text { enharm } G^{b}\right) \\
\text { PT altered }\end{array}$ & $\begin{array}{l}\text { Part } 3 \text { toccata, } \\
\text { part } 2 \text { second, } \\
\text { part } 1 \text { last }\end{array}$ & $\begin{array}{l}\text { PT fragments } \\
\text { modulates to } \\
\mathrm{E}^{b} \text { minor [i] }\end{array}$ \\
\hline mm. $1-10$ & $11-56$ & $57-77$ & $78-132$ & $133-143$ \\
\hline
\end{tabular}

${ }^{229}$ This particular theme is also quoted in Cp91, m.11. 


\section{Example 9-29}

\section{mm 1-4}

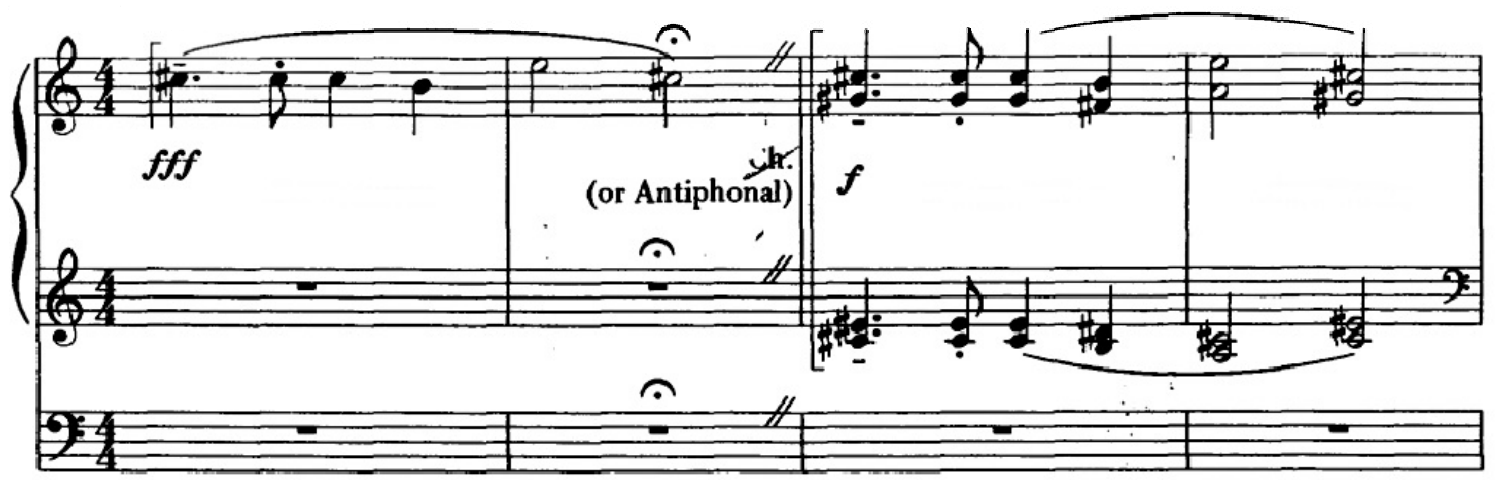

\section{mm 1-4}

\section{Example 9-30}
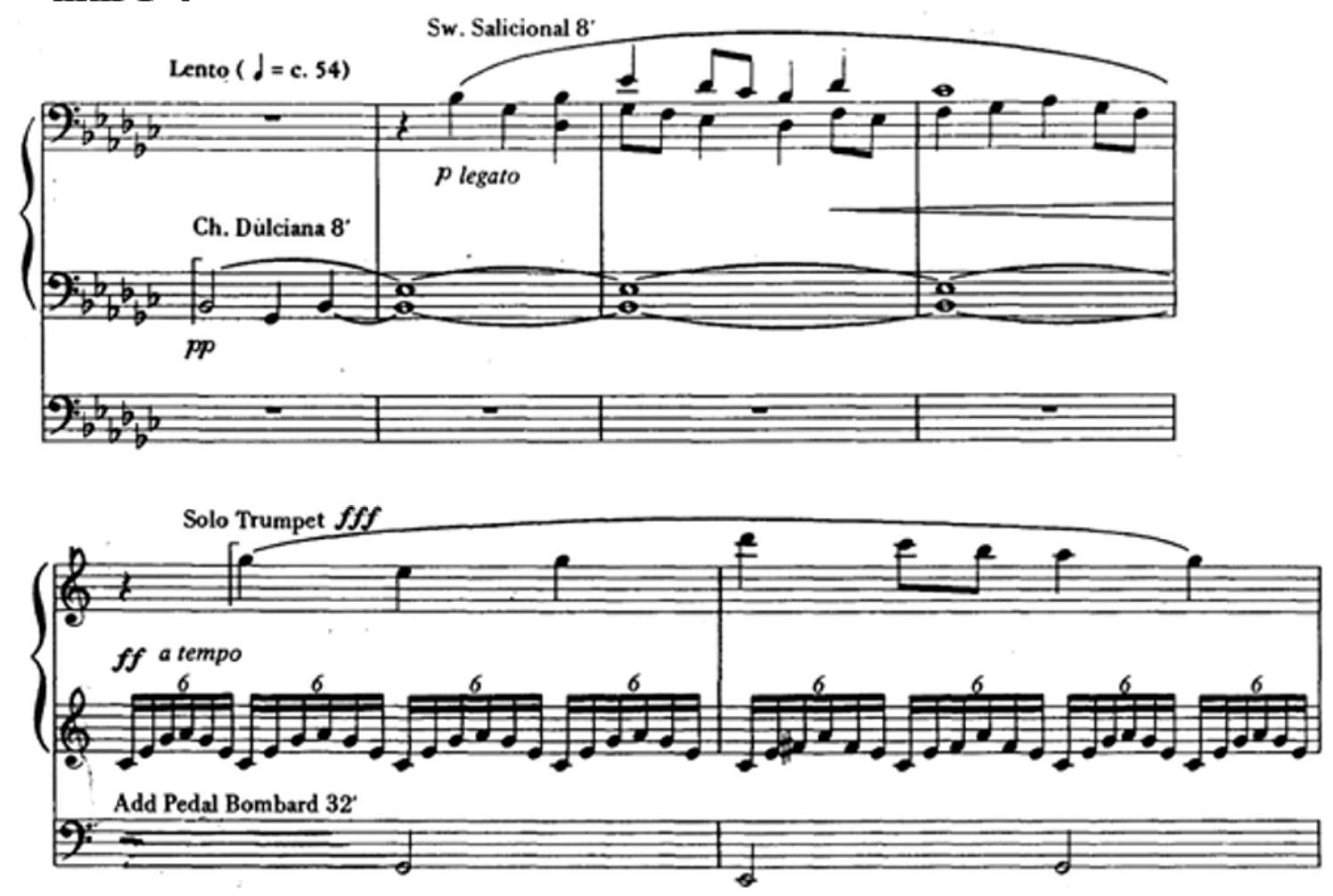


\section{Example 9- 31}

\section{mm 1-4}
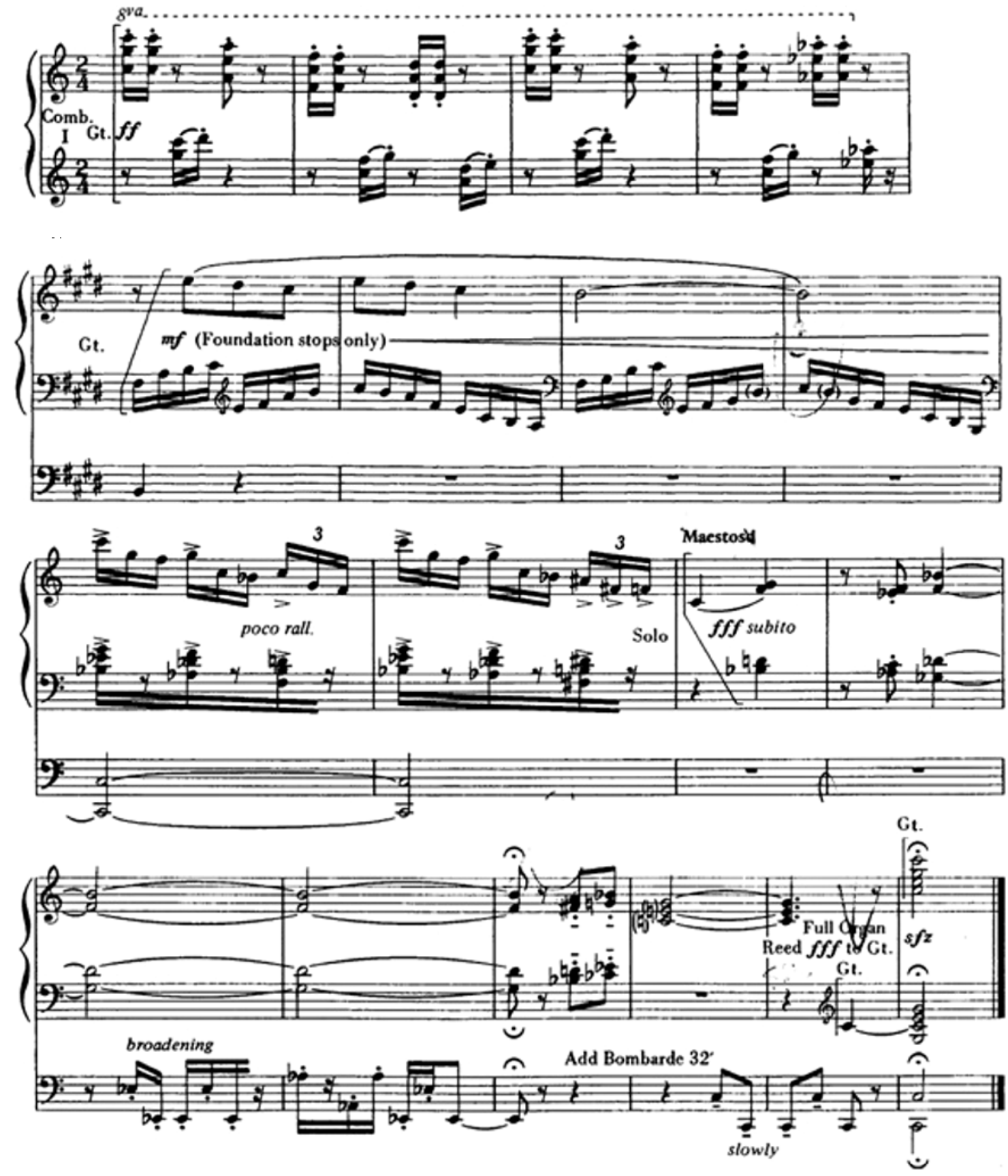

Hebble demonstrates his proficiency with larger, more complex forms in these free works. The compositions use his own themes, rather than a cantus prius factus. He borrows elements from his chorale compositions, such as affektenlehre and motif for 
articulation. From the theatre organ he borrows such concepts as 'program music' and thematic transformation. Now evidence may be drawn to decipher some conclusions. 


\section{Part IV}

CHAPTER 10

\section{Conclusion}

A summary of the information presented in parts I, II and III provides the foundation for the following conclusions in Part IV. These results illuminate the life and organ music of Robert Christian Hebble (b. 1934), and provide the basis for Hebble's place in the larger timeline of the organ in America in the twentieth century. They also suggest how Hebble's organ compositions reflect his compositional style.

From Part I, (Chapters 1, 2 and 3) the taped interview and oral history, are derived three characteristics regarding Hebble's life: 1) he came from a modest, if not enviable, musical background; meaning, Hebble had parents and grandparents who were musical and encouraged his interest in music. His skills developed and accrued at an early age. 2) From his youth Hebble had the fortune of meeting some of the most influential and colorful personalities of the day in organ music, namely, Ethel Smith, Virgil Fox, and Pierre Cochereau. ${ }^{230}$ 3) Hebble enjoyed a high level of education in music, beginning with the Juilliard Preparatory School, then Ivy League Yale University, study in Paris with Nadia Boulanger, then further Masters study at Juilliard. Some of his teachers included Vincent Persichetti, Paul Hindemith, Quincy Porter, Roger Sessions, Ralph Vaughan Williams and Nadia Boulanger, all of whom are discussed in chapters 2 and 3. The conclusions from part I is that Hebble had extensive musical experiences and education.

\footnotetext{
${ }^{230}$ Hebble also met Lee Liberace when he was 10 and had one piano lesson with Vladimir Horowitz.
} 
Early in his life he met and learned from influential twentieth century composers. He studied in Europe. He met some of the greatest performers of the day.

Part II discusses Hebble's approach to the organ: the ACO, his use of the organ, and the influences of this instrument in the development of his compositional style (Chapters 4, 5 and 6). The essential information of Chapter 4 discusses the ACO as a new style of organ building, steeped in the past, but created in the mid-twentieth century by American inventiveness and to enable performers to legitimately recreate earlier organ repertoires as well as the modern repertoire. The very nature of the ACO begged reconsideration of current compositional styles for the organ. ${ }^{231}$ This is due to its colorful and expansive capabilities: orchestral stops, console controls affecting timbre, and spatial placement of various divisions within a building. From Chapter 5, demonstrates that Hebble's registration of the organ is not only grounded in standard organ practices and techniques of the past, ${ }^{232}$ but is also mixed with his own colorful aesthetic drawn from the ASO and the ATO as well.

Chapter 6 reveals that some development of his compositional style was derived partly from his own ability to play the organ in conjunction with the compositional styles and forms required from him through time. The general trend of part II is 1) the ACO is a unique and colorful instrument capable of producing traditional as well as orchestral registrations. 2) Hebble creatively composed for this instrument, exploiting its traits and abilities. 3) Hebble's compositional style was forged both from his ability to play the organ and in conjunction with his compositional abilities. Thus, as his technical facility grew with the instrument, so did the complexity of his works.

\footnotetext{
${ }^{231}$ Hebble, it is postulated here, responded to this summons in his creative compositions for the ACO.

232 See the "Fesperman" list discussed in chapter 4.
} 
Part III explored Hebble's complete published organ music from 1958 to 1999, excluding his arrangements of classic repertoire. Chapter 7 discovered that his 16 published collections are framed by short periods of single published works, and that often each collection served a particular purpose (e.g., wedding music, chorales, and the Fox editions). ${ }^{233}$ Chapter 8 discussed Hebble's treatment of his chorales, classifying them into the standard repertoire types (e.g., chorale fantasias, melody chorales or ritornello chorales). Evidence cited in the particular entries, and in collaboration with the composer, reveals his fascination with improvisation, musical objects (discussed below) and the employment and manipulation of standard chorale archetypes. Chapter 9 examined the free works of Hebble's organ music, which indicated his high interest in improvisation in the French paraphrase style, as well as his maintenance of standard forms (e.g., rondo, sonata, ternary). ${ }^{234}$ The conclusions of Part III are 1) Hebble is a prolific composer for the organ near the end of the twentieth century. ${ }^{235}$ 2) His chorales employ standard types and combination forms, musical objects, jazz idioms and improvisation. And 3), his free works emphasize the twentieth century French organ improvisational style, jazz idioms, musical objects and eclecticism.

Taking each conclusion of the previous three parts collectively, one can further summarize this information into three groups: 1) he came from a substantial musical background, and was encouraged by his family and by famous, prismatic personalities.

2) A kaleidoscopic new instrument (ACO) commandeered more colorful registrations and

\footnotetext{
${ }^{233}$ Created to memorialize Virgil Fox and show his techniques to new generations of organists.

${ }^{234}$ Dupré, pp. 66-72, 118-137.

${ }^{235}$ There are 172 published organ works.
} 
pioneered possible developments into new forms ${ }^{236}$ through Hebble since this instrument had greater capabilities than organs of the past. 3) His published organ works reflect his interests in improvisation, jazz, musical objects and formal manipulation. Hebble is discussed in the modern organ world as a "colorist", much like his idol Maurice Ravel.

This leads to a brief discussion of his use of "musical objects", as this was also a propensity of Maurice Ravel. A quote from the entry on "Ravel, Maurice" by G. W. Hopkins in The New Grove Dictionary of Music and Musicians, (1980 edition) best serves to describe this phenomenon.

A musical object suggests a musical element considered in its own right as self-sufficient (an end in itself, as it were), hence free from the functional roles expected of musical subjects.... Since the object cannot actively participate in 'subjective' functions (those normally associated with musical exposition and development), its temporal extension must be constituted either of stasis or of some form of 'objective' (i.e. mechanical, automatic) movement. Examples would be, in the former case, an .... exceptionally isolated note or chord, and in the latter case...ostinato figures,... or a repetitive pedal point. ${ }^{237}$

Hebble's use of musical objects is derived from Ravel's. Hebble "collects pretty sounds"238 (such as the Tristan harmony, a Neapolitan chord, an octatonic scale or a mode) and weaves them into the fabric of his music, giving them no other function than to merely be present and offer an interesting sound. Further evidence of the non-function of some of Hebble's " $\$ 50$-chords"239 is through the misspellings that often occur (e.g., respelling a German augmented-sixth chord with the sharp sixth as a flat or natural), ${ }^{240}$

\footnotetext{
${ }^{236}$ The combination chorale form (see Chapter 8; e.g., Cp35, Cp47, Cp52, Cp59, etc.) and various free treatments derived from the French paraphrase technique (see Chapter 9; e.g., Cp64, Cp65, Cp68, Cp131) are examples. Also see Dupré, p. 61.

${ }^{237}$ Hopkins, G. W. "Maurice Ravel”, The New Groves Dictionary of Music and Musicians, (London), 15:615.

${ }^{238}$ Hebble, FL interview, 2001.

${ }^{239}$ Ibid. (a term invented by Hebble regarding his lavish, extended chords)

${ }^{240}$ See Heraldings Cp58, mm. 56-57; or mm. 94-95.
} 
while still preserving the 'sound' of the progression. In other words, Hebble feels that the "sound of the overall harmonic progression" 241 with the French augmented-sixth is beautiful, but it does not result in a move to the dominant according to the rule. Instead, the F6 is isolated as an interesting sound and the remaining harmony has an unorthodox resolution. Hebble often furthers his use of such chords and progressions by incorporating non-harmonic tones to augmented-sixth chords, such as an added second or an added fourth. ${ }^{242}$

His use of the Tristan harmony, particularly in the chorales, is another example of a musical object. Hebble enjoys the sound of the Tristan chord saying, "it is a sonority I have always enjoyed working with." ${ }^{243}$ Rarely does he quote the actual Tristan chord ${ }^{244}$ (f, b, d\# and g\#), ${ }^{245}$ and instead respells it, or transposes it, but he is usually careful to preserve Wagner's original spacing. He extends his use of this harmony by having it act as a metaphor for non-resolution ${ }^{246}$ super-imposing the harmony over an associated hymn text. The difference between the Tristan chord and a half-diminished-seventh chord borrowed from jazz harmony in Hebble's organ music is 1) Hebble preserves the traditional spacing of the Tristan chord, isolates it and uses it only in chorales, while the half-diminished-seventh chord may have any spacing. And, 2) if a Tristan-like sonority occurs in the free works, it is often the half-diminished-seventh chord, as there are no associated hymn texts for the metaphor. In collaboration with the concept of 'nonresolution' in the chorales, the Tristan chord usually occurs in conjunction with the

\footnotetext{
${ }^{241}$ Hebble, FL interview, 2001.

${ }^{242}$ See Heraldings Cp58, m. 94.

243 Ibid.

${ }^{244}$ Hebble uses the actual Tristan chord in Nave Cp1 (m.12) and in Heraldings Cp58 (m.105), for example.

245 Plantinga, pp. 287, 289.

${ }^{246}$ Magee, Bryan. The Tristan Chord, New York, Metropolitan Books/Henry Holt and Company (2000), p. 208.
} 
associated texts of the c.f. that mention such church tenets as the fairness of Jesus (see Fairest Lord, Jesus Cp97) or simplicity (see Simple Gifts Cp20).

Musical objectification of the Neapolitan chord is more easily heard in Hebble's organ music than seen in the score, often due to respellings. Again, this chord does not function in the orthodox manner (spelled as $a^{b} I I$ in first inversion and leading to a dominant), but usually tinges an area of tonic or dominant with the 'sounds' of Neapolitan harmony. Once more, Hebble enjoys the beautiful sound of a Neapolitan chord, ${ }^{247}$ and weaves it into the fabric of his music, but only as a musical object: nonfunctioning, respelled, isolated. (See Heraldings Cp 58, mm. 95-98, for example).

The elements of jazz are also stylistic features of Hebble's organ music (syncopation, blue harmony and improvisation) and contribute to his collection of "pretty sounds." ${ }^{248}$ The employment of jazz elements in his music can be traced back to his experiences with the theatre organ. The ATO (American Theatre Organ) was not designed to recreate standard organ repertoire like the ACO, but was designed to accompany silent films in place of a pit orchestra and as such was a more orchestrally conceived instrument. Hebble's grandmother, Nellie Edwards (see Chapter 1), played the theatre organ in the Roxy Theatre of Orange, New Jersey. It is evidence of its direct influence on him. This instrument (due to its situation) played more popular repertoire (containing jazz elements) during Hebble's lifetime, a style he then imitated on the piano. Hebble also spent many years accompanying and rehearsing Broadway singers and participated in high school musicals both as a student and a teacher. Jazz is part of his

\footnotetext{
${ }^{247}$ Hebble often joked during interviews with the author that he and Virgil Fox called these "metropolitan chords", instead of Neapolitan chords, since they offer only the 'sound', not the function, of a harmonic progression.

${ }^{248}$ Hebble, FL interview, 2001.
} 
life. The combination of jazz elements into classic music styles is considered "Third Stream." ${ }^{249}$ Perhaps the most important attraction of jazz for Hebble is its improvisational nature.

Improvisation, virtually unpracticed by classical musicians, ${ }^{250}$ is at the heart of twentieth century French organ music ${ }^{251}$ and the centerpiece of Hebble's organ music. Dupré was renown for his improvisations on his American tours. ${ }^{252}$ For some organists it is still the ultimate measure of skill. Hebble's improvisations go a step further than the French paraphrase style (one of paraphrasing a theme in the context of heightened chromaticism, polytonalism to the point of perceived dissonance) $)^{253}$ and take on the syncopation and blue elements characteristic of American jazz. This synthesis is essential to Hebble's own voice and understanding his organ style.

What stylistic approaches are evident in Hebble's compositions for organ? His style is an eclectic mixture of American and French orchestral organ styles. The synthesis of the twentieth century French paraphrase improvisational organ style with American jazz elements (ATO) constitutes the nucleus of Hebble's approach to composing for the organ, and is its most distinctive feature.

Hebble's place in American organ music near the end of the twentieth century puts him among the most prolific of composers with a synthesized (eclectic) style like other mid-century composers (e.g. Benjamin Britten and Leonard Bernstein). Although most of Hebble's organ works were published in a period of post-modernism (post 1972),

\footnotetext{
${ }^{249}$ Shipton, Alyn. A New History of Jazz, New York, Continuum Publishing, (2001), p. 350.

${ }^{250}$ Whitney, p. 257.

${ }^{251}$ Hebble has spent much time in Paris, and heard organists such as Marcel Dupré and Pierre Cochereau improvise.

${ }^{252}$ Ochse, p. 324.

${ }^{253}$ Schloesser, Stephen. Jazz Age Catholicism, Mystic Modernism in Postwar Paris 1919-1933, Toronto, University of Toronto Press (2005), p. 283.
} 
many of his borrowed ideas (the French paraphrase and jazz) come from musical ideas generated mid-century. When one considers the influence of the ATO on Hebble, the tendency is to date his organ style more towards mid-century. Many of the musical styles of the middle twentieth century involved serialism and abstraction, ${ }^{254}$ and other styles which gave way to increasing dissonance. While the latter style arguably prevailed for a time, Hebble maintained a neo-classic tonal center in much of his organ works, involving a more "known," relaxed, traditional, even entertaining, style. ${ }^{255}$

While many modern composers for the organ have seen a tremendous distance between their compositions and their audiences, Hebble is more accepted and understood than many. Perhaps this is due to Hebble's composing in other mediums (piano, choral), whereas some of his collegues compose exclusively for the organ. Comparisons with them become a challenge. Again, the combination of jazz elements and the French paraphrase improvisational techniques makes Hebble unique. Neither of these characteristics was popular in church music, where the organ is most used, but gradually these elements have made their way into modern worship. Hebble's organ music is enjoying some popularity evidenced in the amount of his music currently in print, as well as its continued prominence at AGO conventions (e.g. Bethlehem, PA 2001, Denver, CO 2002, Philadelphia, PA 2003 and Los Angeles, CA 2004) where it was featured in concerts.

Although the French paraphrase technique has had a small influence on other post-modern American composers of organ music (e.g., Gordon Young, Robert Hilf,

\footnotetext{
${ }^{254}$ Simms, Bryan R. Music of the Twentieth Century; Style and Structure (second edition), New York, Schirmer Books (1996), p. 403.

${ }^{255}$ Ibid., pp. 403, 410-411.
} 
William Albright) Hebble has also had a quiet influence on other composers of organ music. His incorporation of jazz elements and unique registrations (not excluding his penchant for fiery toccatas in the French style) have influenced such current composers for the organ as Mark Thewes, James Biery, Diane Bish, Charles Callahan and William Haller and Kevin Sadowski.

Finally, the philosophy of church music (and thus organ music) changed drastically in the twentieth century, particularly in the 1960s with the advent of Vatican II, at a juncture when Hebble was most thinking "outside of the box." The Vatican promulgated the document Gaudete et Spes ${ }^{256}$ 1962, (Pastoral Constitution of the Church in the Modern World) which brought the faith of the church into the common marketplace of ideas, to "embrace modernity" rather than be "reactive" to it. ${ }^{257}$ This document was meant to reach people where they are with education, with the arts/music in the work and labor centers. Its theology was designed to make the church an outward, joyous and powerful church as cultivators of the modern. Part II, article 55 of this document states

From day to day, in every group or nation, there is an increase in the number of men and women who are conscious that they themselves are the authors and artisans of the culture of their community...despite the complexity of knowledge and art today, it remains each man's duty to retain an understanding (61)... and to harmonize culture with Christian teaching (62). ${ }^{258}$

${ }^{256}$ Translated as "Joy and Hope" and later promulgated by Pope Paul VI in 1965.

${ }^{257}$ Article 3, Gaudete et Spes.

${ }^{258}$ Ibid., Articles 55, 61 and 62. 
This has come to mean that the church's theologies may be articulated in the various types of modern arts. Over time this has come to be understood by artisans and composers as bringing through art the theology of the church to the common people, to be where the people are. This was realized by composers of church music (including organ music) as inclusive of elements of modern music, such as jazz and popular music. In some respects the Protestant church was already promoting this philosophy in their worship services with Gospel music, and felt that Vatican II was the church's real and final response to the Reformation: reframing the faith and theology. Hebble was part of a larger movement of a mid-twentieth century dynamic that harmonized the new with tradition, and synthesized the arts while preserving wisdom in a more commonplace cultural context. The openness of worship to modernity thus affected the organ music of Robert Hebble.

Hebble's organ music is also arguably among the composers of "third stream" music: Gunther Schuller (b. 1925) wrote Conversations (1959) and Concerto for Orchestra (1966) where jazz and concert music are combined. ${ }^{259}$ This is not unlike Hebble's employment of jazz in the French paraphrase or in organ chorales. Similarly, composers of jazz music incorporated aspects of art music into their compositions. Hebble's idol George Gershwin also combined popular music with art music. ${ }^{260}$ Also the musical group Emerson, Lake and Palmer pioneered attempts to avail themselves of the classics. The Beatles also incorporated elements of classical music into their rock. Penny Lane and For No One are songs they wrote which use obbligato solos by orchestral instruments (the piccolo trumpet and French horn, respectively), lending to

\footnotetext{
${ }^{259}$ Simms, p. 420.

${ }^{260} \mathrm{Ibid}$.
} 
their music a flavor of the Baroque. ${ }^{261}$ Robert Hebble's organ compositions are part of this age of pluralism.

${ }^{261}$ Ibid. 


\section{Appendix A}

The Complete Published Works List

The Music of Robert Hebble (b. 1934)

\#s - for the Organ Works are chronological for Collections, contents alphabetical. ( )s - indicate "arrangements"

* - Re-released from an earlier publication. $\quad * *$ - Labled as such in the collection.

ORGAN: SINGLE WORKS，PART I (1958-1967)

$\mathrm{Cp}$

$1 \quad$ Nave (single) - 1958 (H. W. Gray 859 )

(2) Now Thank We All Our God (Fox, Bach) 1959

(3) Ye Sweet Retreat (Boyce, Fox, Hebble) H.W. Gray 901

(4) Rigaudon (Fox, Campra) 1962

(5) Adagio in D Minor (Fox, Vivaldi) 1967

\section{DESCRIPTION}

chorale

arrangement

arrangement

arrangement

arrangement

\section{ORGAN: COLLECTIONS}

I Ted Alan Worth In Concert (4) - 1971, Sacred Music Press KK246

6

(7)

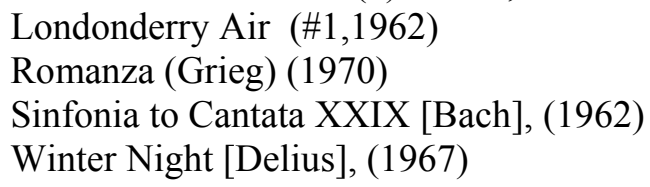

(II and III are under "Arrangements") $=\mathrm{Cp} 10$ to $\mathrm{Cp} 30$

IV Hymn Tunes, Preludes and Improvisations (13) - 1981, Bradley Publications 24M22 [These works were composed in the 1960s and 1970s]

Amazing Grace $(\# 2,1972)$

chorale

Bread of Life

Chorale-Prelude on "Beatitudo"

Chorale-Prelude on "Lead, Kindly Light"

chorale

Chorale-Prelude on "Spohr"

chorale

Cwm Rhondda

chorale

Haec Dies Resurgam

chorale

Herzliebster Jesu

chorale

Hyfrydol

Londonderry Air $(\# 2,1974)$

Simple Gifts (\#2)

Toccata Brevis (1970)

Where Christmas Dwells

chorale

chorale

chorale

chorale

chorale

chorale

chorale

V The Robert Hebble Collection (12) - 1982, Bradley Publications B22M24

Ave Verum (Mozart)

Bell Symphony (Purcell)

Brick Church

Chorale-Prelude on "Ellers" arrangement

arrangement

free work

chorale 
Chorale-Prelude on "Land of Rest"

Day Star

Exultate Deo

Pastorale

Postlude on "Nicea"

Stretch Forth Thy Hand To Heal

The Heavens Declare the Glory of God (Marcello)

Trumpet Tune (Handel) chorale

free work

free work

free work

chorale

free work

arrangement

arrangement

VI The Crystal Cathedral Collection (12) - 1995, Warner Bros. Pub EL9508

Celebration

Diptych on "Orientis Partibus"

free work

Heraldings

"I Wonder As I Wander"

chorale

free work

Meditation on "My Shepherd Will Supply"

chorale

Nave (repeat from H.W. Gray Pub. 859)

chorale

Pastel

Psalm-Prelude

Schematics (based on Ton y botel and Ebenezer)

chorale

free work

free work

Seven Palette Sketches of Utrillo (7)

chorale

Soft Stillness and the Night

free works

Toccata on "Old Hundredth"

free work

chorale

VII The Hymnal Companion-Free Accompaniments (18) - 1983, Bradley Publications B23M27

Amazing Grace (\#1, 1962: composed, not published order)reharmonization

Aurelia

The Battle Hymn of the Republic

reharmonization

Beatitudo

Cwm Rhondda

Darwall

Diademata

Ellecombe

Ellers

Forest Green

Herzliebster Jesu

Lasst Uns Erfreuen

Lob Den Herren

Lyons

Miles Lane

Nicaea

Pilgrims

St. Anne

reharmonization

reharmonization

reharmonization

reharmonization

reharmonization

reharmonization

reharmonization

reharmonization

reharmonization

reharmonization

reharmonization

reharmonization

reharmonization

reharmonization

reharmonization

reharmonization

VIII Rejoice (14) - 1984, Bradley Publications B23M28

Abide with $\mathrm{Me}$

chorale

Antiphonia on Aberstwyth

chorale

Balocco on Martyn

Chorale-Prelude on St. Columba

chorale

Chorale-Improvisation on St. Margaret

chorale

chorale

Chorale-Prelude on Slane

chorale 
Fairest Lord Jesus

Festive Piece on "A Mighty Fortress"

Paraphrase on "Jesus Loves Me"

Reflection on "In the Cross of Christ I Glory"

Ring Out, Wild Bells

Scherzo on "Joyful, Joyful"

Toccatino Con Rico Tino

Variations on Medieval Carol chorale

chorale

chorale

chorale

chorale

chorale

chorale

chorale

chorale

chorale

chorale

chorale

chorale

chorale

chorale

chorale

chorale

chorale

chorale

chorale

chorale

chorale

chorale

chorale

chorale

chorale

chorale

chorale

chorale

chorale

chorale

XI Designs for Organ (10) - 1992 Sacred Music Press KK517-3

Cantilene

free work

Chorale

Divertimento

Litany of the Bells

Night Communion

Prelude on an American Folk Melody

free work

free work

free work

free work

Romanza

chorale

Supplication

arrangement

The Majestic Trumpet

free work

Trumpet Tune

free work

free work

XII The Hebble Duet Collection (8) - 1994 Belwin Mills EL03966

American Declaration

Blessed Assurance (Knapp/Hebble)

free work

chorale

Chrysalis

free work 
139

(140)

151
Finlandia

In Thee Is Joy (Bach)

Parlez-Moi d'Amour (Lenoir)

The Sunken Cathedral (Debussy)

Take Us, Lord, Into Thy Keeping (Bach) chorale

arrangement arrangement arrangement arrangement

XIII Wedding Music for Organists (19) - 1995 Belwin Mills GB9503

Andante Cantabile (Widor)

Aria (Handel)

Bell Symphony (Purcell)

arrangement

arrangement

Bist Du Bei Mir (Bach)

Celebration

A Dream (Grieg)

The Heavens Declare the Glory of God (Marcello)

arrangement

arrangement

free work

arrangement

Largo (Handel)

My Dearest Love (Giordani) "Caro Mi'a Bene"

arrangement

arrangement

O Perfect Love

arrangement

Reverie (1983) "Wedding Day"

chorale

Rondeau (Moret)

free work

To a Wild Rose (MacDowell)

arrangement

Trumpet Tune (Handel)

arrangement

Trumpet Tune (Stanley)

arrangement

arrangement

The Wedding at Cana

free work

Wedding Day (Grieg)

arrangement

Wedding March (Mendelssohn)

arrangement

Wedding March (Wagner)

arrangement

XIV Festive Hymns and Pieces (10) - 1995, Warner Bros. Publications GB9502

Amazing Grace (\#2)

chorale

Celebration

free work

Exultate Deo

Festive Piece on "A Mighty Fortress"

free work

Haec Dies Resurgam

chorale

Rondeau (Moret)

Toccata Brevis

chorale

Toccata on "Festal Song" (Rico Tino)

arrangement

chorale

Trumpet Tune (Handel)

chorale

arrangement

XV Favorite Hymns for Organ (15) - 1981 Belwin/1995 Warner Bros. Pub. BHS 9501

Abide with Me

chorale

Be Thou My Vision

Chorale Prelude on "Spohr"

chorale

Fairest Lord, Jesus

chorale

Herzliebster Jesu

chorale

Land of Rest

Lead, Kindly Light (1970)

O Love That Will Not Let Me Go

chorale

chorale

Postlude on Holy Holy Holy

Savior, Again to Thy Dear Name

chorale

chorale

chorale

Scherzo on Joyful Joyful

chorale

Simple Gifts

chorale

chorale 
$53^{*}$

94*

$104 *$
Stretch Forth Thy Hand to Heal

The King of Love

Variations on a Medieval Carol chorale

chorale

chorale

ORGAN: COLLECTIONS/ARRANGEMENTS - (In Collaboration with Virgil Fox)

II Virgil Fox - The Organist (12) [arr. Hebble] - 1980, Bradley Publications 24M21 Adagio Cantabile (Bach) arrangement Arioso (Bach) arrangement Cantabile-Symphonique (Saint-Seans) arrangement Fanfares, From "Parsival" (Wagner) arrangement In Dulci Jubilo (Liszt) arrangement Libera Me (Faure) arrangement Nocturne (Faure) arrangement Schmücke dich, o liebe Seele (Bach) arrangement Schmücke dich, o liebe Seele (Brahms) arrangement Sheep May Safely Graze (Bach) arrangement Simple Gifts (Hebble) (\#1) The Star Spangled Banner (Key) chorale arrangement

III Virgil Fox - The Christmas Album (9) [arr. Hebble] - 1980, Bradley Pub. 24M20 Echo Noel (D’Aquin) Good King Wenceslas (Hebble)

arrangement Hallelujah Chorus (Handel) In Dulci Jubilo (Fox, Bach) Joy To the World (Hebble) Noel Sur Les Flutes (D’Aquin) O Little Town of Bethlehem (Hebble) Pastoral Symphony (Handel) Silent Night (Hebble) chorale arrangement arrangement chorale arrangement chorale arrangement chorale

XVI The Virgil Fox Legacy (9) - 1999, Sacred Music Press KK276

Air for the G String (Bach) arrangement Chorale from Cantata XXII (Bach) Chorale "Rejoice, Beloved Christians"(Bach) arrangement Erbarm Dich Mein, O Herr Gott (Bach) arrangement Fantasy and Fugue in G Minor (Bach) Fugue á la Gigue (Bach) Jesu, Joy of Man's Desiring (Bach) Toccata and Fugue in D Minor (Bach) Wachet Auf, Ruft Uns Die Stimme (Bach) arrangement arrangement arrangement arrangement arrangement arrangement

ORGAN: SINGLE WORKS, PART II (1972-1997)

(168) We Thank Thee, God (Bach), (1972) Sacred Music Press SM60 31* Amazing Grace (single) 1974, H. W. Gray Publishing

37* Haec Dies Resurgam (single) 1980, H. W. Gray

169 A Symphony of Light (4) - 1986, Hinshaw HMO-150

arrangement chorale chorale free work 


\begin{tabular}{|c|c|c|}
\hline a & I Maestoso & free work \\
\hline b & II Playfully & chorale \\
\hline $\mathrm{c}$ & III Lento & free work \\
\hline $\mathrm{d}$ & IV Final & free work \\
\hline 170 & \multicolumn{2}{|c|}{ Lamentation on “Were You There?” 1997, Harold Flammer HF5192 chorale } \\
\hline $104 *$ & Variations on a Medieval Carol (7) & chorale \\
\hline a & Moderato & chorale \\
\hline $\mathrm{b}$ & I. Spirited & chorale \\
\hline $\mathrm{c}$ & II. Allegro & chorale \\
\hline $\mathrm{d}$ & III. Andante sostenuto & chorale \\
\hline e & IV. Lively & chorale \\
\hline $\mathrm{f}$ & V. Adagio Cantabile & chorale \\
\hline $\mathrm{g}$ & VI. Allegro & chorale \\
\hline $57^{*}$ & Variations on "Orientus Partibus" (3 & chorale \\
\hline $\mathrm{a}$ & I. Ostinato & chorale \\
\hline $\mathrm{b}$ & II. Moderato & chorale \\
\hline $\mathrm{c}$ & III. Ritornello & chorale \\
\hline
\end{tabular}

171 Partita on Lobe Den Herren (3) - 1986, Hinshaw Music Inc. HMO-154

a I. Praeludium chorale

b II. Sicilienne chorale

c III. Finale chorale

172 Variations on an American Hymn (7) - 1997, Warner Bros. Pub. BHS9703

a Theme chorale

b I. Gently chorale

c II. Cantabile chorale

d III. Laid back-- jazz style chorale

e IV. Spirited chorale

f V. Serene chorale

g VI. Allegro di bravura (Toccata) chorale

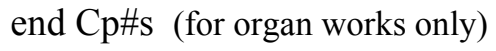

PIANO (Unpublished piano works not included; no chronological or alphabetical ordering)

Space Voyage (Collection) - (1982) Bradley Publications B13M24

Mission Control

Astronauts

Launch Pad in the Moonlight

Countdown

Calibrate the Computer

Pick Up the Count

T Minus Nine

Go Ahead

Lift Off 
Zero Gravity

Orbit

Smooth Landing

Cityscape (Contemporary Level Book 5) Bradley Publications

Fifth Movement (Contemporary Level Book 5) Bradley Publications

Right Lane Must Exit (Contemporary Level Book 6) Bradley Publications

Hanon Companion (Volume One) (1981) Bradley Publications B13M20

Brightly in Three-Four

Fugue

Notturno

Out Front!

Prelude

The Foggiest Notion

Hanon Companion (Volume Two) (1981) Bradley Publications B13M21

First Light

Period Piece

Purdy Lane

Staffordshire Blues

The Choo Palace in Ancient Peking

ANTHEMS AND CHORAL WORKS (S.A.T.B) (unpublished choral works not included)

A Child (Polistina) Bradley Publications

A Goodly Time To Be Dancing (Handel) Bradley Pub.

And Rejoice! (Polistina) Heritage Music Press

Ah, Holy Jesus (Herzliebster Jesu) Bradley Pub.

Arise, Shine for Thy Light Is Come Bradley Pub.

Bow Down Thine Ear, O Lord Bradley Pub.

Celebration of Unity (A Choral Mass) GIA Pub.\#

Kyrie

Gloria

Credo

Sanctus

Agnus Dei

Come, Let Us Sing a Song of Joy / Bradley Pub.

Here Lies a Rose (Burns) Bradley Pub.

Incline Thy Ear, O Lord (Bach) Harold Flammer

Jesus, Lord, We Look To Thee / Harold Flammer

Jesus Shall Reign / Hinshaw Music

Lonesome Valley / Heritage Music Press

Lord of Our Life and God of Our Salvation / Bradley Pub

Moses in the Cradle (Polistina) Bradley Publications

My Spirit Longeth for Thee / H.W. Gray

Praise to the Lord, The Almighty / Sacred Music Press

Praise Ye the Lord / Bradley Publications

Prayer (Polistina) Bradley Publications

Prayer (Polistina)[re-released] Hinshaw Music Inc.

Safe in Thy Grace / Bradley Publications

Salvation! O The Joyful Sound / Bradley Publications
Arrangement

Arrangement

Arrangement

Free work

Free work

Free work

Free work
Free work

Arrangement
Arrangement
Free-work
Free-work
Free-work
Free-work
Arrangement
Free-work
Free-work
Free-work
Arrangement
Arrangement
Free-work
Free-work 
Savior, Again to Thy Dear Name / Hinshaw Music Inc.

See the Child (Polistina) Bradley Publications

Sheep May Safely Graze (Bach) Bradley Publications

There Is a Child (Polistina) Shawnee Press

To God Be the Glory / Hinshaw Music Inc.

Whither Shall I Go From Thy Spirit / Bradley Pub.

Sing His Praises (Collection) (d.?) Bradley Publications \#?

Amen

Breathe on Me, Breath of God

Create in Me a Clean Heart

Day By Day

Enter Into His Gates

For in Him We Live

For With Thee Is the Fountain of Life

I Was Glad

Lord, Hear Our Prayer

Now Enter In

O Come, Let Us Sing to Our God

O Sing to the Lord a New Song

Sing to the Lord
Arrangement Arrangement Arrangement Arrangement Arrangement Free-work

\section{SECULAR CHORAL WORKS (S.A.T.B.)}

A Charles Dickens Christmas (Polistina) Mc Afee

A Little Christmas Music (Polistina) Bradley Publications

A Little Christmas Music / [re-released] Hinshaw Music Inc A Stephen Foster Trilogy / Bradley Publications

Encore (Polistina) Bradley Publications

For Now (Pachelbel/Polistina) Bradley Publications

For Now (Pachelbel Canon)[re-released] Hinshaw Music

Masters in the Hall / Bradley Publications

Midnight Sleigh Bells (Prokofieff/Polistina) Shawnee Press

Moonlight (Debussy) Bradley Publications

To a Wild Rose (MacDowell) Bradley Publications
Arrangement

Arrangement

Arrangement Free-work Arrangement Arrangement Arrangement Free-work Arrangement Arrangement Arrangement

\section{CHORAL WORKS - MEN'S VOICES (T.T.B.B.)}

Drink To Me Only With Thine Eyes / Shawnee Press Eternal Father, Strong To Save / Bradley Publications A Little Christmas Music (Polistina)

Praise To the Lord / Bradley Publications
Free-work?

chorale-arrangement chorale-arrangement Free-work? 
Appendix B

Unpublished Organ Works by Robert Hebble (b. 1934)

1955 Free-work, Chanson for Organ (worked on this with Nadia Boulanger).

1956 Free-work, Pière (atmospheric).

1956 Chorale, Chorale on "Ton y botel" (worked on this with Nadia Boulanger).

1961 Chorale, Prelude on "Wessex".

1961 Pastorale (dedicated to Richard Purvis, based on his original tune like a tone poem).

1962 Chorale, Break Thou the Bread of Life.

1964 Free-work, Chanson for Organ (tone poem).

1964 Chorale, Chorale Prelude on "Beatitudo"

1964 Transcription, “Andante” from Symphony for Strings by Jean Francis.

? Free-work, Resoundings (an extended toccata).

1970 Transcription, Tuba Tune by C. S. Lang.

1970 Transcription, Nocturne by Gabriel Fauré, Shylock, Opus 57.

? Free-work, "Jeweled Light" - Fantasy in Stained Glass (extended tone-poem, commissioned and recorded by Fred Swann)

1975 Transcription, Edward Elgar, Opus 70.

1978 Free-work, Pastorale (unfinished).

? Free-work, Prisms (four movement suite in Jazz-style).

1983 Free-work, Acclamations (for 2 organs, premiered at the Crystal Cathedral).

1986 Transcription, The Walk to Paradise Garden, by Delius (Commissioned by the Fredrick Delius Society).

1987 Chorale, Chorale Fantasia on "Easter Awakenings" (medley based on Easter Hymn, Victory, and St, Kevin)

1989 Chorale, As the Dew from Heaven Distilling (Morman Alma Mater)

1998 Chorale, With Thee Shall End the Day (based on "Ellers", chorale-improvisation).

2001 Free-work, Litany of St. Marks; (tone poem, Canton, Ohio; June 17, 2001).

2001 Chorale, Meditation on "Veni Creator" (dedicated to Mary Jane Wolfe)

2002 Free-work, Cathedral Tapestry (new Crystal Cathedral Commission, for 2 organs and carillon)

2002 Free-work, Litany, Denver AGO Commission (in Memory of Virgil Fox)

2004 Free-work, Cathedral of Commerce, New Wannamaker Commission; Lord and taylor, Philadelphia. 
? Chorale, Improvisation on "Duke Street”, (extended variations).

? Chorale, Joyful and Triumphant, (Prelude and Fugue on "Adeste Fidelis").

? Chorale, Nunc Coelis (based on "land of rest").

? Chorale, What a Friend We Have in Jesus.

? Chorale, Festival Piece on "St. George's Windsor”.

? Chorale, Toccata on a Moravian Hymn (based on "Bechler").

? Transcription, Prince of Denmark's March (Clarke).

? Transcription, Adagio in G Minor (Albinoni).

? Transcription, Tristan und Isolde (Prelude to Act III; Richard Wagner).

? Transcription, Lament of Dido, (Purcell).

? Transcription, Pavane, (from "Ma Mere L'oye” by Ravel).

? Transcription, Intermezzo (from "Fennimore and Gerda", by Delius).

? Transcription, Songs My Mother Taught Me (Dvorak).

? Transcription, The Lost Chord (Sullivan).

? Book: Getting There is Half the Fun (a textbook with musical examples on modulation). 
Appendix C

The Organ Music of Robert Hebble (b. 1934)

Discography $^{262}$

Christmas Carols on the Organ (Virgil Fox)

RCA Victor LM-145

Christmas in St. Paul's (Virgil Fox)

Heldon HCR 3762

Gloria (The Shawnee Choir)

Shawnee P-587

Hark! The Herald Angels (Virgil Fox)

Capitol P8531

$\underline{\text { Lead, Kindly Light (Robert Hebble) }}$

Organ Arts

Organ Reveries (Virgil Fox)

Columbia ML 4401

Praise To the Lord (Ted Alan Worth)

Organ Arts

Silhouettes (Virgil Fox)

Capitol SP8509

$\underline{\text { Swann and Ruffatti Over Orlando }}$

Orlando

$\underline{\text { Ted Alan Worth in Concert }}$

Organ Arts

Ted Alan Worth Plays the Organ

Heldon HCR-871-

$1 \mathrm{SD}$

$\underline{\text { Ted Alan Worth Performs }}$

Centerline CPI 8004/5

The Cathedral Sings

Cathedral MA-1448

$\underline{\text { The Christmas Album (Virgil Fox) }}$

Command CC 11032

SD

The Sound of Ruffatti (Ted Alan Worth)

Ruffatti

Vale of Dreams (Virgil Fox)

Capitol SP 8557

\footnotetext{
${ }^{262}$ Rowell, Lois Irene. American Organ Music on Records, Organ Literature Foundation, Braintree, Massachusetts, (1976). This resource offered partial assistance, the remainder is either from Hebble's personal collection or from various websites.
} 
$\underline{\text { Virgil Fox Encores }}$

$\underline{\text { Virgil Fox in Celebration of Fifty Years }}$

$\underline{\text { Virgil Fox Plays the John Wannamaker Organ }}$

Pipe Organ of the Mormon Tabernacle (Clay Christianen)

O Magnify the Lord (Crystal Cathedral -Fred Swann)

Love Is Come Again (Cathedral of the Sacred Heart, Newark, NJ)

Bach to Sousa (James Dale)

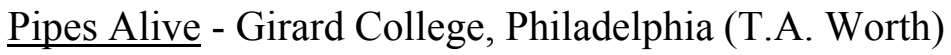

Heavenly Hebble (Robert Hebble)

$\underline{\text { Sorties, Preludes and Pavanes }}$

(Riverside 2001)
RCA Victor LSC-

2268

Heldon HCR 1SD577

Command

CC11025SD

Klavier Records

International, Inc.

Gothic Records, Inc.

Pro Organo

Pines Recordings

Direct-to-Tape

Recording Co

First Congregational

Church, Lake Worth, Florida

Pro Organo

CD 7146 
Appendix D

THE SPECIFICATION OF THE RIVERSIDE CHURCH ORGAN

(Aeolian-Skinner, 1953-1954: Five manuals, 12 divisions, 203 ranks)

CHANCEL ORGAN

Great Manual (II)

Manual (IV)

stops

Untersatz $\quad 32^{\prime}$

Brumm Bass 16'

Violone $\quad 16^{\prime}$

Diapason $\quad 8^{\prime}$

Prinzipal $\quad 8^{\prime}$

Holz Gedackt $\quad 8^{\prime}$

Flute Oktaviante $8^{\prime}$

Gemshorn $\quad 8^{\prime}$

Quinte

Octave

Spitz Prinzipal 4'

Flute Couverte $4^{\prime}$

Octave Quinte 2 2/3'

Super Octave 2'

Blockflöte 2'

Tierce

$13 / 5$

Kleine Mixture IV

Fourniture VII $11 / 3$,

Scharff IV

Posaune

Trompete

$1 / 2$

16

Klarine

8 '

4 '

Grand Chorus VII 8'

(Gallery)

Tremulant

Chimes

Harp

Celesta

Chancel Pedal

Contre Basse 32' $\underline{\text { Swell Manual (III) } \quad \text { Choir Manual (I) }}$

$\underline{\text { Solo }}$

\begin{tabular}{|c|c|c|c|c|}
\hline Contra Gamba 3 & $32^{\prime}$ & Quintaton & $16^{\prime}$ & Gambe \\
\hline Gambe & $16^{\prime}$ & Viola Pomposa & $8^{\prime}$ & Gambe Celeste $8^{\prime}$ \\
\hline Flûte & $16^{\prime}$ & Viola Celeste & $8^{\prime}$ & Doppelflöte \\
\hline Rohr Bordun & $16^{\prime}$ & Erzähler & $8^{\prime}$ & Orchestral Flute4' \\
\hline Montre & $8^{\prime}$ & ErzählerCeleste & $8^{\prime}$ & Quinte Flute2 2/3' \\
\hline Rohrflöte & $8^{\prime}$ & Dulcett II & $8^{\prime}$ & Fife \\
\hline Viole de Gambe & e $8^{\prime}$ & Concert Flute & $8^{\prime}$ & Corno di Bassetto $16^{\prime}$ \\
\hline Viole Céleste & $8^{\prime}$ & Cor de Nuit & $8^{\prime}$ & English Horn $\quad 8^{\prime}$ \\
\hline Salicional & $8^{\prime}$ & Prinzipal & $4^{\prime}$ & French Horn \\
\hline Voix Céleste & $8^{\prime}$ & Koppelflöte & $4^{\prime}$ & Orchestral Oboe8' \\
\hline Flauto Dolce & $8^{\prime}$ & Rohr Nasat & $22 / 3^{\prime}$ & Trompette Harm. $8^{\prime}$ \\
\hline Flûte Céleste & $8^{\prime}$ & Zauberflöte & $2^{\prime}$ & Clairon Harm. $4^{\prime}$ \\
\hline Prestant & $4^{\prime}$ & Tierce & $13 / 5^{\prime}$ & Mounted Cornet $8^{\prime}$ \\
\hline \multicolumn{2}{|c|}{ Flûte Harmonique 4' } & Larigot & $11 / 3^{\prime}$ & Chimes \\
\hline Unda Maris II & 4 & Sifflöte & $1^{\prime}$ & Celesta \\
\hline Nazard & $22 / 3$ & Jeu de Clochette & e II 2 & Zimbelsterr \\
\hline Dolce Cornet III & I $22 / 3$ & Mixture III-IV & 1 ' & Tremulant \\
\hline
\end{tabular}

Doublette 2' Zimbel III 3/4,

Spillflöte 2' $\quad$ Serpent

Tierce $13 / 5^{\prime}$, Petite Trompette 8'

Plein Jeu IV $11 / 3^{\prime}$ Krumhorn 8 '

Cymbale IV 2/3' Rohr Schalmei 4'

Positiv Manual (IV)

Prinzipal $8^{\prime}$

Singend Gedeckt 8 '

Oktav $\quad 4^{\prime}$

Contre Trompette 16' Cornet (collective) 8' Rohrflöte 4'

Trompette $\quad 8^{\prime} \quad$ Festival Trumpet $8^{\prime} \quad$ Superoktav 2'

Hautbois $\quad 8^{\prime} \quad$ (Bombarde) Larigot $11 / 3^{\prime}$

Oboe d' Amore 8' Tremulant Mixture V $11{ }^{\prime} \quad 3^{\prime}$

Clarinet $\quad 8^{\prime}$

Menschenstimme $8^{\prime}$

Harp

Terzzymbel III $1 / 3^{\prime}$

Trompeta Majestatis $8^{\prime}$

Celesta Trichter Regal $8^{\prime}$

Nachtigall Tremulant
Clairon $\quad 4^{\prime}$

Octave Trumpet $4^{\prime}$ 


\begin{tabular}{|c|c|c|c|c|c|c|c|}
\hline \multicolumn{2}{|c|}{ Contra Bourdon 32' } & \multicolumn{2}{|c|}{ Cornet (Collective) $8^{\prime}$} & \multicolumn{4}{|c|}{ GALLERY ORGAN } \\
\hline Contre Gambe & $32^{\prime}$ & \multirow{2}{*}{\multicolumn{2}{|c|}{ Tremulant }} & & & & \\
\hline Contre Basse & $16^{\prime}$ & & & \multicolumn{2}{|c|}{ Gallery Great (II) } & \multicolumn{2}{|c|}{$\underline{\text { Gallery Swell (III) }}$} \\
\hline Prinzipal & 16 & \multicolumn{2}{|c|}{ Chancel Bombarde (V) } & Quintade & $16^{\prime}$ & Bourdon & $16^{\prime}$ \\
\hline Bourdon & 16 & \multicolumn{2}{|c|}{ Mounted Cornet8' } & Prinzipal & $8^{\prime}$ & Gedeckt & $8^{\prime}$ \\
\hline Violone (Gt) & $16^{\prime}$ & \multicolumn{2}{|c|}{ Festival Trumpet } & \multicolumn{2}{|c|}{ Flûte Harmonique8' } & Salicional & 8 \\
\hline Gambe (Sw) & $16^{\prime}$ & \multicolumn{2}{|c|}{ Festival Trumpet } & Octave & $4^{\prime}$ & Voix Céleste & $8^{\prime}$ \\
\hline \multicolumn{2}{|c|}{ Flûte Conique (Sw)16' } & \multicolumn{2}{|c|}{ Festival Trumpet } & \multicolumn{2}{|c|}{ Flûte à Chemineé $4^{\prime}$} & Aeoline & $8^{\prime}$ \\
\hline \multicolumn{2}{|c|}{ Rohr Bourdon (“) 16' } & \multicolumn{2}{|c|}{ Trompeta Majestatis } & Fifteenth & $2^{\prime}$ & Vox Angel. & $8^{\prime}$ \\
\hline \multicolumn{2}{|c|}{ Quintaton $(\mathrm{CH}) 16^{\prime}$} & \multicolumn{2}{|l|}{ Tuba Mirabilis } & Fourniture IV & $11 / 3$ & Octave Geig. & $4^{\prime}$ \\
\hline Prinzipal & $8^{\prime}$ & \multicolumn{2}{|c|}{ Bombarde Ventil } & \multicolumn{2}{|c|}{ Trompeta Majestatis 8} & Flûte Oct. & $4^{\prime}$ \\
\hline Spitz Principal & $8^{\prime}$ & & & Trompette & $8^{\prime}$ & Sesquialtera II & \\
\hline Bourdon & $8^{\prime}$ & & & \multicolumn{2}{|l|}{ Chimes } & Doublette & $2^{\prime}$ \\
\hline Cello & $8^{\prime}$ & \multicolumn{2}{|c|}{ Gallery Grand Chorus (II } & \multirow{2}{*}{\multicolumn{2}{|c|}{ Tremulant }} & Plein Jeu IV & \\
\hline Rohrflöte (Sw) & $8^{\prime}$ & Diapason & $8^{\prime}$ & & & Fagotto & $16^{\prime}$ \\
\hline \multicolumn{2}{|c|}{ Flute Octaviante4' } & Major Octave & $4^{\prime}$ & \multicolumn{2}{|c|}{ Gallery Celestial (V) } & Trompette & $8^{\prime}$ \\
\hline Quinte & $51 / 3^{\prime}$ & Plein Jeu V & $2^{\prime}$ & Viole Aetheria & $8^{\prime}$ & Hautbois & $4^{\prime}$ \\
\hline Choral Bass & $4^{\prime}$ & & & Viole Céleste & $8^{\prime}$ & Tremulant & \\
\hline Nachthorn & $4^{\prime}$ & \multicolumn{2}{|l|}{ Gallery Pedal } & Cor de Nuit & $8^{\prime}$ & & \\
\hline Flöte (Gt) & $4^{\prime}$ & Grand Cornet & $32^{\prime}$ & \multicolumn{2}{|c|}{ Flûte Celeste II $8^{\prime}$} & & \\
\hline Rohrflöte (Sw) & $4^{\prime}$ & Open Wood & $16^{\prime}$ & Flûte Traversiè & re $4^{\prime}$ & & \\
\hline Blockflöte (Gt) & $2^{\prime}$ & Prinzipal & $16^{\prime}$ & Nasat & $22 / 3^{\prime}$ & & \\
\hline Mixture III & $2^{\prime}$ & Lieblich (Sw) & $16^{\prime}$ & Cor d' Amore 8 & & & \\
\hline Cymbel III & $11 / 3^{\prime}$ & Quintade (Gt) & $16^{\prime}$ & Cromorne & $8^{\prime}$ & & \\
\hline Grand Harmonic & $\operatorname{cs} 32^{\prime}$ & Octave & $8^{\prime}$ & Vox Humana & $8^{\prime}$ & & \\
\hline Contre Bombarc & de $32^{\prime}$ & Pommer & $8^{\prime}$ & Tremulant & & & \\
\hline Bombarde & $16^{\prime}$ & Super Octave & $4^{\prime}$ & & & & \\
\hline Rankett & $16^{\prime}$ & Mixture III & $2^{\prime}$ & & & & \\
\hline Contre Trpt. (Sy & N) $16^{\prime}$ & Bombarde & $16^{\prime}$ & & & & \\
\hline Serpent (Ch) & $16^{\prime}$ & Fagotto (Sw) & $16^{\prime}$ & & & & \\
\hline Trumpet & $8^{\prime}$ & Trompette & $8^{\prime}$ & & & & \\
\hline Rankett & $8^{\prime}$ & & & & & & \\
\hline Clairon & $4^{\prime}$ & & & & & & \\
\hline Trompette (Solo & $4^{\prime}$ & & & & & & \\
\hline Rankett & $4^{\prime}$ & & & & & & \\
\hline $\begin{array}{r}\text { Trompeta Majes } \\
\text { Chimes } \\
\text { Pedal D }\end{array}$ & statis $8^{\prime}$ & & & & & & \\
\hline
\end{tabular}




\section{Appendix E}

\section{SPECIFICATION OF THE CRYSTAL CATHEDRAL ORGAN}

(The 'Hazel Wright Organ' was inaugurated May 7, 1982)

[Five manuals, 287+ ranks, 13 divisions, and the largest drawknob console ever built]

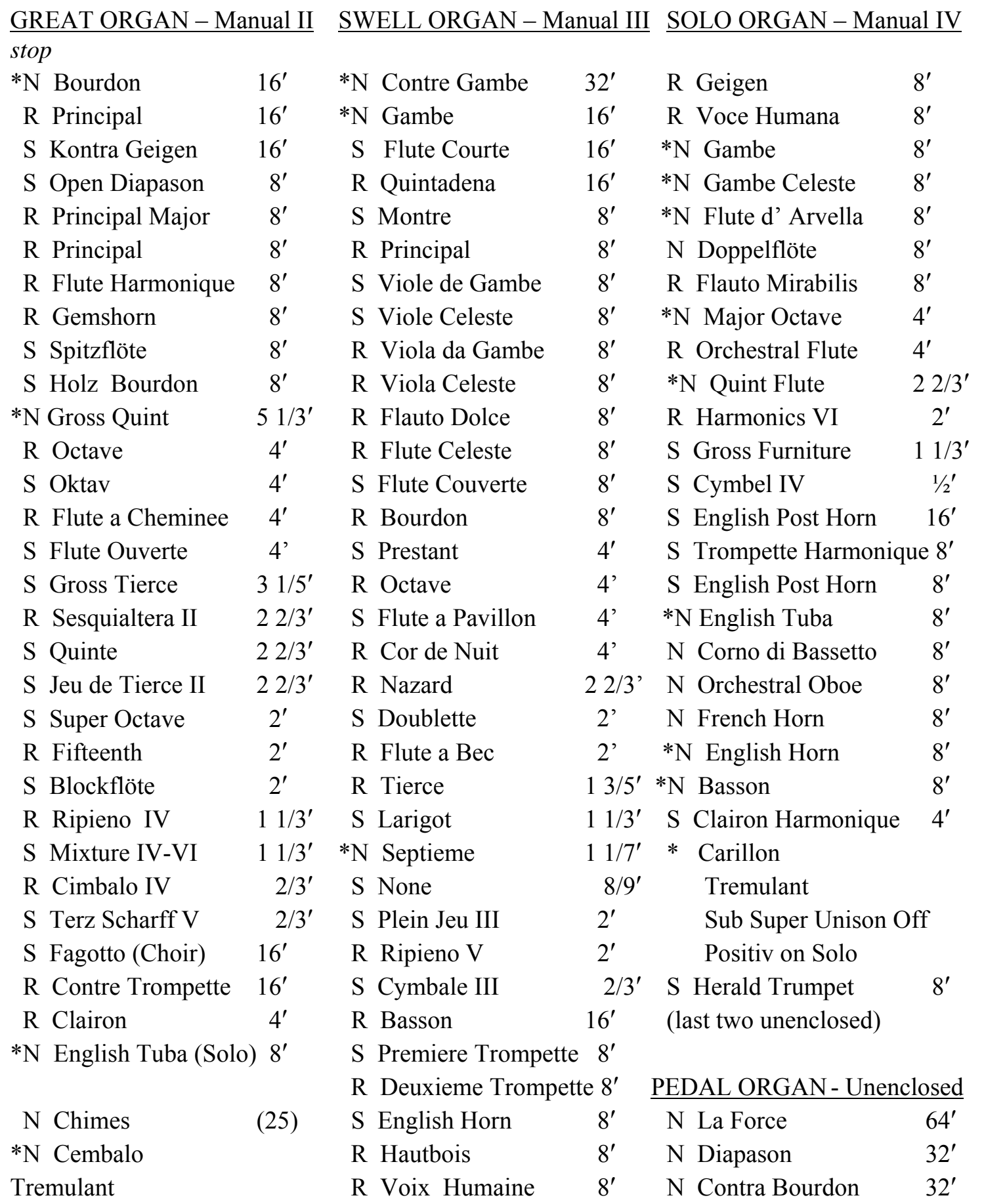




\begin{tabular}{|c|c|c|c|c|c|c|c|}
\hline \multirow{3}{*}{\multicolumn{3}{|c|}{ at }} & \multicolumn{2}{|c|}{ S Premiere Clairon } & $4^{\prime}$ & S Contra Geigen & $32^{\prime}$ \\
\hline & & & \multicolumn{3}{|c|}{ R Deuxieme Clairon 4' } & N Contre Gambe(Swell) & $32^{\prime}$ \\
\hline & & & \multicolumn{3}{|c|}{ R Cornet V (collective) 8 ' } & N Diapason & $16^{\prime}$ \\
\hline \multicolumn{3}{|c|}{ POSITIV ORGAN - floating } & \multicolumn{3}{|c|}{ Tremulant } & S Contre Basse & $16^{\prime}$ \\
\hline \multicolumn{3}{|c|}{ S Holzquintade } & $16^{\prime}$ & \multicolumn{2}{|c|}{ Sub Super Unison Off } & R Contrabasso & $16^{\prime}$ \\
\hline & Holzquintade & & 8 & \multicolumn{2}{|l|}{ Positiv on Swell } & S Geigen (Great) & $16^{\prime}$ \\
\hline & Rohrflöte & & 8 & \multicolumn{2}{|c|}{ S Expression to Solo } & R Principal (Great) & $16^{\prime}$ \\
\hline & Principal & & 4 & \multicolumn{2}{|c|}{ R Expression to Solo } & S Principal & $16^{\prime}$ \\
\hline & Oktav & & \multicolumn{3}{|l|}{2 ' } & S Bourdon & $16^{\prime}$ \\
\hline & Larigot & $11 / 3^{\prime}$ & \multicolumn{3}{|c|}{ CHOIR ORGAN - Manual I } & R Subbasso & $16^{\prime}$ \\
\hline & Sifflöte & $1 '$ & \multicolumn{2}{|c|}{ S Gemshorn } & $16^{\prime}$ & N Gambe (Swell) & $16^{\prime}$ \\
\hline & Scharff IV & $2 / 3$ & \multicolumn{2}{|c|}{ S Viola Pomposa } & $8^{\prime}$ & S Gemshorn (Choir) & $16^{\prime}$ \\
\hline & Terz Zimbel III & $1 / 4$ & \multicolumn{2}{|c|}{ S Viola Celeste } & $8^{\prime}$ & R Quintadena (Swell) & $16^{\prime}$ \\
\hline & Krummhorn & $8^{\prime}$ & \multicolumn{2}{|c|}{ S Cor de Nuit } & $8^{\prime}$ & S Flute Courte (Swell) & $16^{\prime}$ \\
\hline \multicolumn{3}{|c|}{ S Rohr Schalmei } & \multicolumn{2}{|c|}{ S Flauto Dolce } & $8^{\prime}$ & \multicolumn{2}{|c|}{ S Holzquintade (Positiv) 16' } \\
\hline & Tremulant & & & Flute Celeste & $8^{\prime}$ & N Quinte & $102 / 3$, \\
\hline \multirow{2}{*}{\multicolumn{3}{|c|}{ Sub Unison Off }} & & Prinzipal & $4^{\prime}$ & S Octave & $8^{\prime}$ \\
\hline & & & S K & Koppelflöte & $4^{\prime}$ & R Principal & $8^{\prime}$ \\
\hline GOS & SPEL ORGAN - F & oating & S R & Rohr nasat & $22 / 3^{\prime}$ & $\mathrm{N}$ Geigen & $8^{\prime}$ \\
\hline (abo & ove the East end) & & $* \mathrm{~S} P$ & Prinzipal & $2^{\prime}$ & S Geigen (Great) & $8^{\prime}$ \\
\hline & Trompette-en-Cha & made 16 ' & & Zauberflöte & $2^{\prime}$ & S Spitzflöte & $8^{\prime}$ \\
\hline & Trompette-en-Cha & made 8 & $\mathrm{~S} \mathrm{~T}$ & Tierce & $13 / 5^{\prime}$ & S Quintade (Positiv) & $8^{\prime}$ \\
\hline $\mathrm{N}$ & Trompette-en-Cha & nade 4 ' & S L & Larigot & $11 / 3^{\prime}$ & $\mathrm{R}$ Bordone & $8^{\prime}$ \\
\hline & Sub Octave Cc & upler & S S & Scharff IV & $2 / 3^{\prime}$ & $\mathrm{S}$ Bou & $8^{\prime}$ \\
\hline & Gospel on Ma & ual $\mathrm{V}$ & & Fagotto & $16^{\prime}$ & S Gemshorn (Choir) & $8^{\prime}$ \\
\hline & Gospel on Ma & ual IV & S P & Petite Trompette & $8^{\prime}$ & S Flute Courte (Swell) & $8^{\prime}$ \\
\hline & Gospel on Ma & ual III & & Clarinet & $8^{\prime}$ & *N Octave Quinte & $51 / 3^{\prime}$ \\
\hline & Gospel on Ma & ual II & & Fagotto & $8^{\prime}$ & S Choralbass & $4^{\prime}$ \\
\hline & Gospel on Ma1 & ual I & R $\mathrm{I}$ & Millenial Tpt (Galler & ry) 8 & R Octave & $4^{\prime}$ \\
\hline & & & & Harp & 8 & S Spillflöte & $4^{\prime}$ \\
\hline EPIS & ISTLE ORGAN - F & loating & $\mathrm{N} \mathrm{I}$ & Harp & $4^{\prime}$ & R Spitzflöte & $4^{\prime}$ \\
\hline (abo & ove the West end) & & & Tremulant & & R Octave & $2^{\prime}$ \\
\hline & Trompette-en-Cha & made $16^{\prime}$ & & Sub Super Unis & on Off & S Spillflöte & $2^{\prime}$ \\
\hline & Trompette-en-Cha & nade $8^{\prime}$ & & Positiv on Choir & & S Fourniture IV & $51 / 3^{\prime}$ \\
\hline & Trompette-en-Cha & made $4^{\prime}$ & & & & R Ripieno VI & $22 / 3^{\prime}$ \\
\hline $\mathrm{N}$ & Trompette-en-Cha & made $2^{\prime}$ & $\underline{\mathrm{ECH}}$ & IO ORGAN - Floati & & S Acuta II & $11 / 3^{\prime}$ \\
\hline $\mathrm{N} \mathrm{I}$ & Mounted Cornet V & (TC) $8^{\prime}$ & $\mathrm{N} \mathrm{H}$ & Fern Flute & $8^{\prime}$ & N Grand Cornet IV & $32^{\prime}$ \\
\hline & Sub Octave Cc & upler & $\mathrm{N}$ & Vox Amorosa II & $8^{\prime}$ & S Contre Bombarde & $32^{\prime}$ \\
\hline & Epistle on Ma1 & ual V & $\mathrm{N}$ & Voix Seraphique II & $8^{\prime}$ & S Posaune & $16^{\prime}$ \\
\hline & Epistle on Ma1 & ual IV & $\mathrm{N}$ & Choeur des Violes II & II $8^{\prime}$ & S Bombarde (Swelll) & $16^{\prime}$ \\
\hline & Epistle on Ma1 & ual III & $\mathrm{N} \mathrm{I}$ & Divinare & $4^{\prime}$ & S English Post Horn (So & olo) $16^{\prime}$ \\
\hline & Epistle on Ma1 & ual II & $\mathrm{N} \mathrm{I}$ & Rohr Nasat & $22 / 3$ & $\mathrm{R}$ Contre Trompette $(\mathrm{Gr}$ & reat) $16^{\prime}$ \\
\hline & Epistle on Ma1 & ual I & $\mathrm{N}$ & Anthropoglossa & $8^{\prime}$ & S Fagotto (Choir) & $16^{\prime}$ \\
\hline & & & $\mathrm{N}$ & Oboe d' Amore & $8^{\prime}$ & R Basson (Swell) & $16^{\prime}$ \\
\hline
\end{tabular}




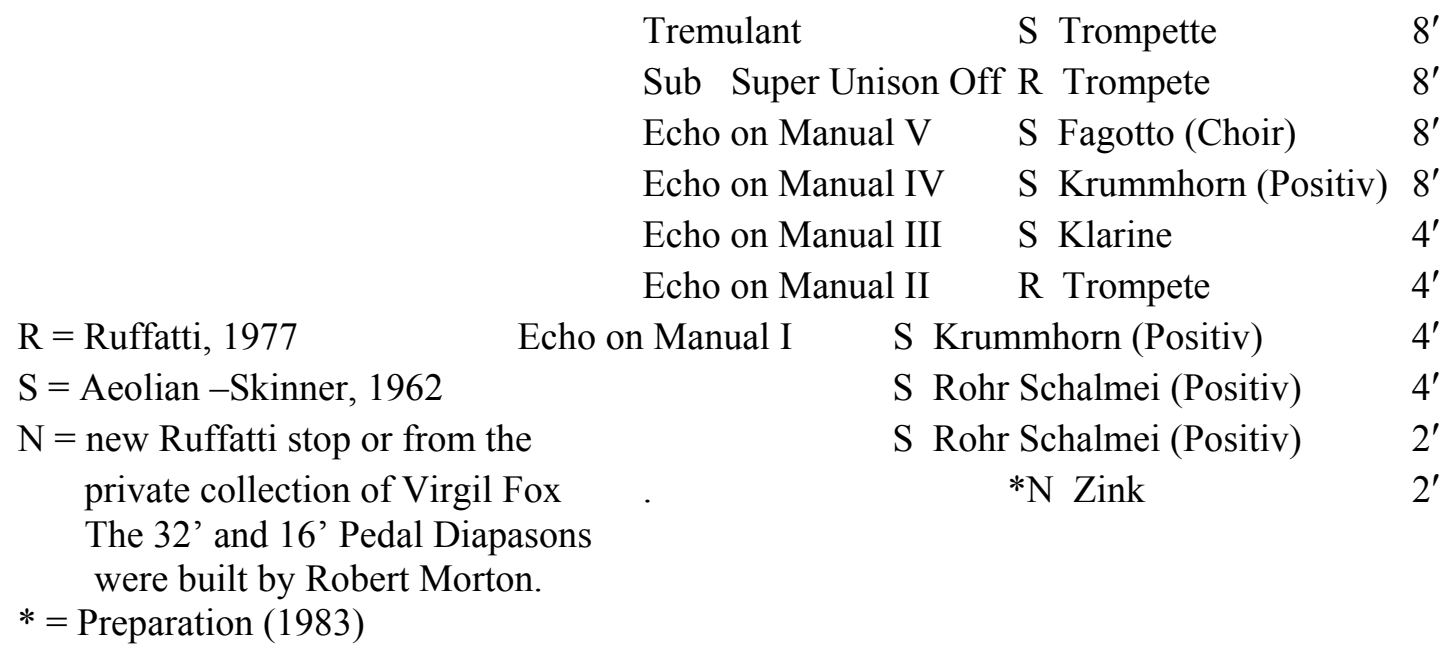

SOUTH GALLERY ORGAN

\begin{tabular}{|c|c|c|c|c|}
\hline & T ORGAN - Floating & CELES & TIAL ORGAN - Manu & $\mathrm{ll} \mathrm{V}$ \\
\hline & $\mathrm{R}$ Principale & 8 & R Erzahler & $16^{\prime}$ \\
\hline & R Holzgedeckt & 8 & R Bourdon & $16^{\prime}$ \\
\hline & R Ottava & 4 ' & $* \mathrm{~N}$ Principal & $8^{\prime}$ \\
\hline & R Koppelflöte & 4 ' & R Viola Pomposa & $8^{\prime}$ \\
\hline & R Fifteenth & 2 ' & $\mathrm{R}$ Viola Celeste & $8^{\prime}$ \\
\hline & $\mathrm{R}$ Ninteenth & $11 / 3$ & R Erzahler & $8^{\prime}$ \\
\hline CONSOLE CONTROLS & $\mathrm{R}$ Twenty-second & 1 ' & R Erzahler Celeste & 8 \\
\hline Great to Pedal Reversible & $\begin{array}{l}* \mathrm{~N} \text { Fourniture IV } \\
* \mathrm{~N} \text { Flute d' Argent II }\end{array}$ & $\begin{array}{c}11 / 3^{\prime} \\
8^{\prime}\end{array}$ & & \\
\hline Swell to Pedal “ & R Zimbel IV & $1 / 2$ & $\mathrm{R}$ Flute a Cheminee & $8^{\prime}$ \\
\hline Choir to Pedal “ & $\mathrm{R}$ Millenial Trumpet & $8^{\prime}$ & ${ }^{*} \mathrm{~N}$ Principal & $4^{\prime}$ \\
\hline Solo to Pedal “ & (En Chamade) & & $\mathrm{R}$ Principalino & $4^{\prime}$ \\
\hline Celestial to Pedal “ & Tremulant & & R Flute Veneziano & $4^{\prime}$ \\
\hline Positiv to Pedal “ & Sub Super Unison Off & & ${ }^{*} \mathrm{~N}$ Sesquialtera II & $22 / 3^{\prime}$ \\
\hline Gallery Great to Pedal “ & Gallery Great on V & & $* \mathrm{~N}$ Octave & 2 \\
\hline String to Pedal “ & Gallery Great on IV & & $\mathrm{R}$ Octavin & 2 ' \\
\hline Gospel to Pedal “ & Gallery Great on III & & *N Mixture VI & $11 / 3^{\prime}$ \\
\hline Epistle to Pedal “ & Gallery Great on II & & *N Scharff III & $2 / 3^{\prime}$ \\
\hline Echo to Pedal “ & Gallery Great on I & & *N Jeu de Clochette I & I 4/5' \\
\hline Swell to Great “ & S Herald Trumpet (Mai & in Solo) & R Bombarde & $16^{\prime}$ \\
\hline $\begin{array}{l}\text { Solo to Great " } \\
\text { Positiv on Choir “ }\end{array}$ & & & R Dulzian & $16^{\prime}$ \\
\hline Positiv on Great “ & $\underline{\text { STRING ORGA }}$ & $\mathrm{AN}-\mathrm{Flo}$ & ating $\mathrm{R}$ Trompette & $8^{\prime}$ \\
\hline Gallery Great on Great “ & $\mathrm{N}$ Viola & 16 & R English Horn & $8^{\prime}$ \\
\hline String on Great " & N Viola Celest & te $16^{\prime}$ & $\mathrm{R}$ Cromorne & $8^{\prime}$ \\
\hline String on Choir " & $\mathrm{N}$ Dulciana & $8^{\prime}$ & S Vox Humana & $8^{\prime}$ \\
\hline String on Swell “ & N Unda Maris & $8^{\prime}$ & R Cor de Schuller & $4^{\prime}$ \\
\hline Echo on Swell “ & $\begin{array}{l}\text { N Salicional } \\
\text { N Voix Celest }\end{array}$ & $\begin{array}{r}8^{\prime} \\
8^{\prime}\end{array}$ & $\begin{array}{l}\text { R Chalumeau } \\
\text { * Harp }\end{array}$ & $4^{\prime}$ \\
\hline
\end{tabular}




Gallery Great on Choir
String on Solo “
Positiv on Solo “
Gallery Great on Solo “
Great/Choir Transfer
Main Organ Silent
Gallery Organ Silent
32' Diapason (toe stud)
32' Contre Bourdon “
32' Contre Gambe “
32' Kontra Geigen “
32' Contre Bombarde “
All Mixtures Silent “
All Reeds Silent “
16' Manual Stops Silent
32' Pedal stops Silent
Reed Tutti I and II (Celestial)
Reed Tutti I and II (Solo)
Reed Tutti I and II (Great)
Silencer Cancel
General Cancel
All Swells to Swell
Orchestral Crescendo
Grand Crescendo
Zimbelstern
Pedal FFF
Tutti (Full Organ)
Main Console Off
Gallery Console Off
Microprocessor Reset

* Glockenspiel

N Dulcett Celeste $\quad 8^{\prime} \quad *$ Etoile de Grand Matin

$\mathrm{N}$ Muted Viole I $\quad 8^{\prime} \quad *$ Rossignol

$\mathrm{N}$ Viole I Celeste $\quad 8^{\prime} \quad$ Tremulant

N Muted Viole II $\quad 8^{\prime} \quad$ Sub Super Unison Off

$\mathrm{N}$ Viole II Celeste $\quad 8^{\prime} \quad$ Positiv on Celestial

$\mathrm{N}$ Violincello $\quad 8^{\prime}$

$\mathrm{N}$ Violincello Celeste $8^{\prime}$

Tremulant

Sub Super Unison Off

String on Manual V

String on Manual IV

String on Manual III

String on Manual II

String on Manual I
GALLERY PEDAL ORGAN

N Contra Bourdon (Main) 32'

$\mathrm{N}$ Open Wood 16'

N Viola (String) 16'

N Viola Celeste (String) 16'

R Bourdon (Celestial) 16'

N Principal (Celestial) $\quad 8^{\prime}$

$\mathrm{N}$ Viola (String) $\quad 8^{\prime}$

$\mathrm{N}$ Viola Celeste (String) $8^{\prime}$

N Prinzipal (Celestial) $4^{\prime}$

$\mathrm{N}$ Mixture IV 2'

R Contra Posaune $\quad 32^{\prime}$

R Posaune 16'

R Bombarde (Celestial) 16'

N Grand Harmonics 32'

R Millenial Tpt (Great) $8^{\prime}$ 


\section{Appendix F \\ Music Examples}

\section{CHAPTER 8}

EXAMPLE 8- 1

EXAMPLE 8- 2

EXAMPLE 8- 3

EXAMPLE 8- 4

EXAMPLE 8- 5

EXAMPLE 8- 6

EXAMPLE 8- 7

EXAMPLE 8- 8

EXAMPLE 8- 9

EXAMPLE 8- 10

EXAMPLE 8- 11

EXAMPLE 8- 12

EXAMPLE 8- 13

EXAMPLE 8- 14

EXAMPLE 8- 15

EXAMPLE 8- 16

EXAMPLE 8- 17

EXAMPLE 8- 18

EXAMPLE 8- 19

EXAMPLE 8- 20

EXAMPLE 8- 21

EXAMPLE 8- 22

EXAMPLE 8- 23

EXAMPLE 8- 24

EXAMPLE 8- 25

EXAMPLE 8- 26

EXAMPLE 8- 27

EXAMPLE 8- 28

EXAMPLE 8- 29

EXAMPLE 8- 30

EXAMPLE 8- 31

EXAMPLE 8- 32

EXAMPLE 8- 33

EXAMPLE 8- 34

EXAMPLE 8- 35

EXAMPLE 8- 36

EXAMPLE 8- 37

EXAMPLE 8- 38a

EXAMPLE 8- 38b

EXAMPLE 8- 39

EXAMPLE 8- 40
Cp1 Nave................................................................... 95

Cp6 Londonderry Air....................................................... 96

Cp20 Simple Gifts............................................................. 97

Cp23 Good King Wenceslaus ............................................ 98

Cp26 Joy to the World ....................................................... 100

Cp28 O Little Town of Bethlehem....................................p. 102

Cp30 Silent Night.............................................................. 103

Cp31 Amazing Grace...................................................... 105

Cp32 Bread of Life ………………………………............. 107

Cp33 Beatitudo ……………………………………......... 109

Cp34 Lead Kindly Light .................................................... 110

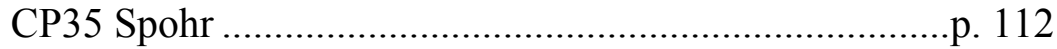

Cp36 Cwm Rhondda .......................................................... 114

Cp37 Haec Dies Resurgam ................................................. 116

Cp38 Herzliebster Jesu........................................................ 118

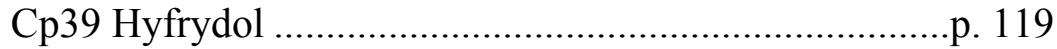

Cp40 Londonderry Air....................................................p. 121

Cp41 Simple Gifts............................................................. 122

Cp42 Toccata Brevis ........................................................ 124

Cp43 Where Christmas Dwells.......................................... 126

Cp47 Ellers.................................................................... 127

Cp48 Land of Rest ........................................................ 128

Cp52 Postlude Nicea ......................................................... 129

Cp57 Diptych "Orientus Partibus"......................................p. 130

Cp59 I Wonder as I Wander..............................................p. 133

Cp60 My Shepherd Will Supply ......................................... 135

Cp63 Shematics................................................................... 137

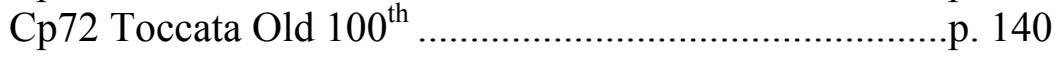

Cp91 Abide With Me ......................................................... 142

Cp92 Antiphonia ................................................................. 143

Cp93 Balocco on Martin ...................................................p. 145

Cp94 St. Columba ………………………………............ 146

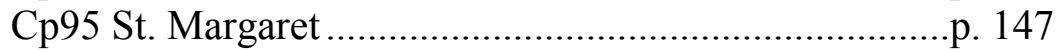

Cp97 Fairest Lord Jesus ..................................................... 150

Cp98 A Mighty Fortress ................................................... 151

Cp99 Jesus Loves Me .....................................................p. 153

Cp100 In the Cross.......................................................p. 154

Cp101 Ring Out Bells .....................................................p. 155

Cp102 Scherzo Joyful Joyful ............................................. 157

Cp103 Toccatino Rico Tino .................................................. 159

Cp104 Variation Medieval Carol ........................................ 161 
EXAMPLE 8- 41

EXAMPLE 8- 42

EXAMPLE 8- 43

EXAMPLE 8- 44

EXAMPLE 8- 45

EXAMPLE 8- 46

EXAMPLE 8- 47

EXAMPLE 8- 48

EXAMPLE 8- 49

EXAMPLE 8- 50

EXAMPLE 8- 51

EXAMPLE 8- 52

EXAMPLE 8- 53

EXAMPLE 8- 54

EXAMPLE 8- 55

EXAMPLE 8- 56

EXAMPLE 8- 57

EXAMPLE 8- 58

EXAMPLE 8- 59

EXAMPLE 8- 60

EXAMPLE 8- 61

EXAMPLE 8- 62

EXAMPLE 8- 63

EXAMPLE 8- 64

EXAMPLE 8- 65

EXAMPLE 8- 66

EXAMPLE 8- 67

EXAMPLE 8- 68
Cp205 Attende Domine

.p. 163

Cp106 At the Cross

p. 165

Cp107 Cleanse Me...

p. 166

Cp108 Come Holy Ghost

p. 168

Cp109 Dear Maker.

p. 170

Cp110 Hail Holy Queen.

p. 171

Cp111 Immaculate Mary.

p. 172

Cp112a O Saving Victim

p. 173

Cp112b O Saving Victim.

p. 174

Cp113 Sing of Mary.

p. 175

Cp114 Improv Salve Regina

p. 176

Cp115 Veni Creator Spiritus

p. 177

Cp116 Victimae Paschali

p. 179

Cp117 Amazing Grace

p. 180

Cp118 Beneath the Cross

p. 181

Cp119 Blessed Assurance

p. 182

Cp120 Holy God we Praise

p. 183

Cp121 Jesus Shall Reign

p. 185

Cp122 Let All Mortal Flesh.....

p. 186

Cp123 Lo He Comes

p. 188

Cp124 Most Perfect

p. 190

Cp125 Praise to the Lord.

p. 191

Cp126 Thee We Adore.

p. 193

Cp132 Prelude American Folk.

p. 194

Cp137 Blessed Assurance

p. 196

Cp139 Finlandia....

p. 197

Cp171 Partita Lobe den Herren.

p. 201

Cp173 Variation American Hymn

.p. 203

\section{CHAPTER 9}

EXAMPLE 9- 1

EXAMPLE 9- 2

EXAMPLE 9- 3

EXAMPLE 9- 4

EXAMPLE 9- 5

EXAMPLE 9- 6

EXAMPLE 9- 7

EXAMPLE 9- 8

EXAMPLE 9- 9

EXAMPLE 9- 10

EXAMPLE 9- 11

EXAMPLE 9- 12

EXAMPLE 9- 13
Cp46 Brick Church

p. 207

Cp59 Day Star

p. 209

Cp50 Exultate Deo

p. 210

CP51 Pastorale...

p. 211

Cp53 Stretch Forth Thy Hand

p. 213

Cp56 Celebration

p. 215

Cp58 Heraldings

p. 216

Cp61 Pastel

p. 218

Cp62 Psalm Prelude

p. 219

Cp64 Rue de Saints Pere

p. 220

Cp65 Lapin Agile

p. 221

Cp66 L'eglisse Saint Severn

p. 222

Cp67 Vu du Square Saint Antoine ..p. 223 
EXAMPLE 9- 14

EXAMPLE 9- 15

EXAMPLE 9- 16

EXAMPLE 9- 17

EXAMPLE 9- 18

EXAMPLE 9- 19

EXAMPLE 9- 20

EXAMPLE 9- 21

EXAMPLE 9- 22

EXAMPLE 9- 23

EXAMPLE 9- 24

EXAMPLE 9- 25

EXAMPLE 9- 26

EXAMPLE 9- 27

EXAMPLE 9- 28

EXAMPLE 9- 29

EXAMPLE 9- 30

EXAMPLE 9- 31
Cp68 L'eglisse Boissy Saint Antoine

Cp69 La Chapelle de Beaulieu.

p. 224

Cp70 Crepsule Golfe de Morbihan

p. 225

Cp71 Soft Stillness and the Night.....

p. 226

Cp127 Cantilene.

p. 228

Cp128 Chorale

p. 229

Cp129 Divertimento

p. 230

Cp130 Litany of the Bells

p. 231

Cp131 Night Communion

p. 232

Cp133 Supplication

p. 234

Cp134 Majestic Trumpet.

p. 236

Cp135 Trumpet Tune

p. 237

Cp136 American Declaration

p. 238

Cp138 Chrysalie....

p. 242

Cp155 Wedding at Cana

p. 246

Cp169a Symphony of Light

p. 247

Cp169c Symphony of Light

p. 248

Cp169d Symphony of Light

p. 249 


\section{BIBLIOGRAPHY}

\section{Books:}

Audsley, George Ashdown. The Art of Organ Building, Dover Publications, NewYork (1965).

Barnes, William Harrison. The Contemporary American Organ, J. Fischer Publishing, Glen Rock, New Jersey (1971).

Bender, Jan. Organ Improvisation. St. Louis: Concordia Publishing House, 1975.

Boretz, Benjamin. Perspectives on American Composers, W. W. Norton, NewYork, (1971).

Callahan, Charles. The American Classic Organ: A History in Letters, The Organ Historical Society, Richmond, Virginia (1990).

Daugherty, F. Mark. Organ Music in Print, 1990 Supplement, Musicdata, Philadelphia (1990).

Dupré, Marcel. Cours Complet d'Improvisation à l'Orgue. Paris: A. Leduc, (1962).

Fesperman, John. Two Essays on Organ Design. Raleigh, NC, Sunbury Press (1975).

Frankel, Walter A. Organ Music in Print, 1997 Master Index, Musicdata, Philadelphia (1997).

Geer, E. Harold. Organ Registration in Theory and Practice. J. Fischer Publishing, Glen Rock, New Jersey (1957).

Goode, Jack C. Pipe Organ Registration, Abingdon Press, New York, (1964).

Harrison, F.L. "Cantus Firmus", New College Encyclopedia of Music. W.W. Norton Company, New York (1976).

Hettinger, Sharon L. American Organ Music of the 20 $0^{\text {th }}$ Century: An Annotated Bibliography of Composers, Harmonie Park Press, Warren Michigan (1997).

Locher, Carl. An Explanation of Organ Stops with Hints for Effective Registrations, (translated by Agnes Schauenburg), K. Paul, Trench and Company, London, (1888).

Magee, Bryan. The Tristan Chord, Wagner and Philosophy, Metropolitan Books, Henry Holt and Company, New York (2001). 
Ochse, Orpha. The History of the Organ in the United States, Indiana University Press, Bloomington, Indiana, (1975).

Owens, Barbara. The Registration of Baroque Organ Music. Indiana University Press Bloomington, (1997).

Owen, Barbara and Williams, Peter. The Organ: The New Groves Musical Instrument Series. London: W. W. Norton, (1988).

Pape, Uwe. Die Orgelbewegung in Amerika. Berlin, Pape Verlag (1980).

Plantinga, Leon. Romantic Music, A History of Musical Style in Nineteenth Century Europe, W.W. Norton, New York (1984).

Randel, Don Michael. "Chorale", The New Harvard Dictionary of Music, The Belknap Press of Harvard University Press, Cambridge Massachusetts (1986).

Ribble, John. The Hymnbook The Presbyterian Church in America, New York (1955).

Ranger, Richard. "Electric Music as New Supplement to Tone of Organ Pipes", The Diapason. Vol. 23, No. 12, November (1932).

Rowell, Lois Irene. American Organ Music on Records, Organ Literature Foundation, Braintree, Massachusetts (1976).

Shipton, Alyn. A New History of Jazz, New York, Continuum Publishing, (2001).

Simms, Bryan. Music of the Twentieth Century, Style and Structure, Second Edition. New York, Schirmer Books (1996).

Skinner, Ernest M. The Modern Organ. New York: H.W. Gray (1917).

Schloesser, Stephen. Jazz Age Catholicism, Mystic Modernism in Postwar Paris 19191933, Toronto, University of Toronto Press (2005).

Sumner, William Leslie. The Organ: Its Evolution, Principles of Construction and Use. MacDonald and Company, $3^{\text {rd }}$ edition, London, (1962).

Torrence, Richard, et al. Virgil Fox “The Dish”. Circles International, New York, (2001).

Whitney, Craig. All the Stops; The Glorious Pipe Organ and Its American Masters. Public Affairs, New York (2003).

Williams, Peter. The Organ Music of J. S. Bach, (III Background), Cambridge 
University Press, Cambridge (1984).

.....The Holy Bible (New International Version), Nashville, Tennessee, Thomas Nelson Publishers (1976).

\section{Articles:}

Hopkins, G. W. "Maurice Ravel", The New Groves Dictionary of Music and Musicians, (London, 1980), 15:.

Mardirosian, Haig. "Reviews", The American Organist, March 2002, volume 36, no. 3, pp. 88-89.

Nye, E. M. "Walter Holtkamp - A Master Organ Builder", The Diapason, No. 202: Vol. LI, October (1971).

Phelps, Lawrence. "A Short History of the Organ Revival”, Church Music, no. 1 (1967).

Widor, Charles-Marie. L'Orgue Moderne, Leduc, Paris (1932).

Yaeger, Marshall. "Review: The Virgil Fox Memorial Recital - October 8, 2000", The Clarion, Virgil Fox Society, NewYork (Number 51, January, 2001), pp. 4-5.

-----. The Cathedral Organs (pamphlet), Cathedral Church of Saint John the Divine, New York City, (1992).

-----. The Organs and Organists of The Riverside Church - a History, 120 Riverside Drive, New York, New York (1978).

\section{Dissertations:}

Hill, Gregory Edwin. The $20^{\text {th }}$ Century Revival of the Organ Chorale, PhD Musicology, University of California at Santa Barbara (1992) DDM Code: 71keHilG

Kasouf, Edward Joseph. Louis Vierne and His Six Organ Symphonies, PhD Musicology, Catholic University of America (1970), iii, 208p. DDM Code: 71keKasE; DA\#: 31/05:2422; RILM\#: 70:597dd; UM\#: 70-22,717.

Minter, William John. "Church Music in the American Baptist Union of the San Francisco Bay Cities", thesis, Union Theological Seminary, (1960). 


\section{Scores:}

The Complete Organ Works of Robert Hebble (Belwin-Mills and Warner Brothers Music) [with permission/ Joe (copyrights department), 5/2002].

Smith, Ethel. Ethel Smith's Favorite Hymns for Hammond Organ. New York: Charles H. Hanson Music Company (1948). qM14.8.S5 F35x

\section{Cassette Tapes:}

A group of six 90 minute high quality cassette tapes were used to make an oral history with the composer in an interview style recording. The author asks questions to which the composer offers answers that he expands upon and extends. Many notes have been taken from these tapes regarding his biography, style of composing, meaning in his compositions, reasons for registrations, unique use of the organ. The tapes, which are in the possession of the author, can be made available. 